\title{
The Forest Inventory and Analysis Database: Database Description and Users Manual Version 4.0 for Phase 2
}

Sharon W. Woudenberg, Barbara L. Conkling, Barbara M. O'Connell, Elizabeth B. LaPoint, Jeffery A. Turner, Karen L. Waddell

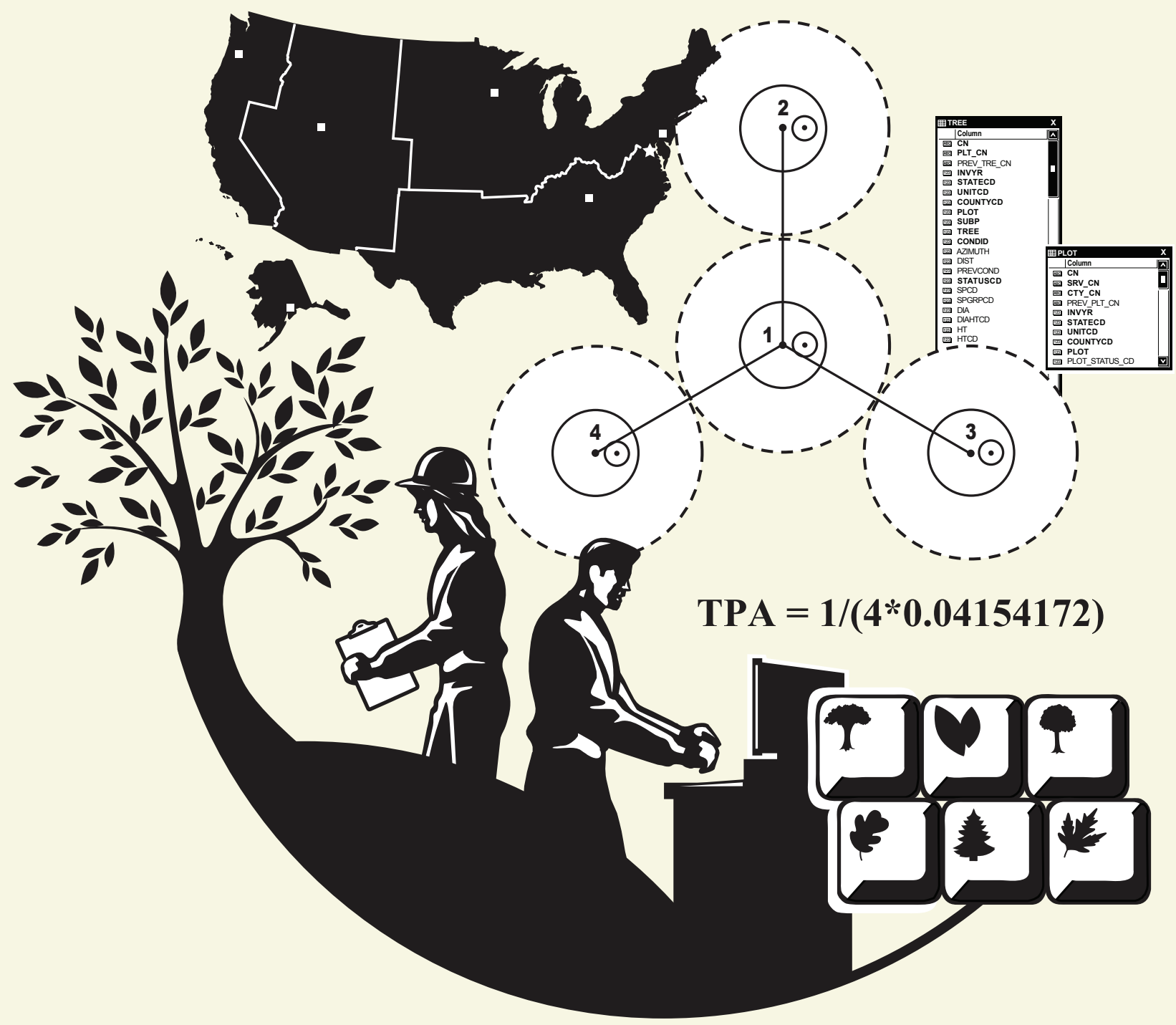

USDA United States Department of Agriculture

Forest Service

Rocky Mountain Research Station

ForET SERVICE General Technical Report RMRS-GTR-245

December 2010 
Woudenberg, Sharon W.; Conkling, Barbara L.; O’Connell, Barbara M.; LaPoint, Elizabeth B.; Turner, Jeffery A.; Waddell, Karen L. 2010. The Forest Inventory and Analysis Database: Database description and users manual version 4.0 for Phase 2. Gen. Tech. Rep. RMRSGTR-245. Fort Collins, CO: U.S. Department of Agriculture, Forest Service, Rocky Mountain Research Station. 336 p.

\section{Abstract}

This document is based on previous documentation of the nationally standardized Forest Inventory and Analysis database (Hansen and others 1992; Woudenberg and Farrenkopf 1995; Miles and others 2001). Documentation of the structure of the Forest Inventory and Analysis database (FIADB) for Phase 2 data, as well as codes and definitions, is provided. Examples for producing population level estimates are also presented. This database provides a consistent framework for storing forest inventory data across all ownerships for the entire United States. These data are available to the public.

Keywords: Forest Inventory and Analysis, inventory database, users manual, monitoring

\section{Authors}

Sharon W. Woudenberg is a Supervisory Forester with the Inventory and Monitoring Program, USDA Forest Service, Rocky Mountain Research Station, Ogden, Utah.

Barbara L. Conkling is a Research Assistant Professor in the Department of Forestry and Environmental Resources, North Carolina State University, Raleigh, North Carolina.

Barbara M. O'Connell is a Forester with the Forest Inventory and Analysis Program, USDA Forest Service, Northern Research Station, Newtown Square, Pennsylvania.

Elizabeth B. LaPoint is a Forester with the Natural Resources Inventory, Monitoring and Assessment Program, Northern Research Station, Durham, New Hampshire.

Jeffery A. Turner is a Forester with the Forest Inventory and Analysis Program, USDA Forest Service, Southern Research Station, Knoxville, Tennessee.

Karen L. Waddell is a Forester with the Resource Monitoring and Assessment Program, USDA Forest Service, Pacific Northwest Research Station, Portland, Oregon.

You may order additional copies of this publication by sending your mailing information in label form through one of the following media. Please specify the publication title and number.

\section{Publishing Services}

Telephone (970) 498-1392

FAX (970) 498-1122

E-mail rschneider@fs.fed.us

Web site http://www.fs.fed.us/rmrs

Mailing Address Publications Distribution

Rocky Mountain Research Station

240 West Prospect Road

Fort Collins, CO 80526 


\section{Preface}

Forest Inventory and Analysis (FIA) is a continuing endeavor mandated by Congress in the Forest and Rangeland Renewable Resources Planning Act of 1974 and the McSweeney-McNary Forest Research Act of 1928. FIA's primary objective is to determine the extent, condition, volume, growth, and depletion of timber on the Nation's forest land. Before 1999, all inventories were conducted on a periodic basis. The passage of the 1998 Farm Bill requires FIA to collect data annually on plots within each State. This kind of up-to-date information is essential to frame realistic forest policies and programs. USDA Forest Service regional research stations are responsible for conducting these inventories and publishing summary reports for individual States.

In addition to published reports, the Forest Service provides data collected in each inventory to those interested in further analysis. This report describes a standard format in which data can be obtained. This standard format, referred to as the Forest Inventory and Analysis Database (FIADB) structure, was developed to provide users with as much data as possible in a consistent manner among States. A number of inventories conducted prior to the implementation of the annual inventory are available in the FIADB. However, various data attributes may be empty or the items may have been collected or computed differently. Annual inventories use a common plot design and common data collection procedures nationwide, resulting in greater consistency among FIA work units than earlier inventories. Data field definitions note inconsistencies caused by different sampling designs and processing methods.

\section{Acknowledgments}

In addition to those listed as authors, the following people provided additional contributions to this document:

George Breazeale, Computer Specialist, USDA Forest Service, Pacific Northwest Research Station, Portland, Oregon. Brian Cordova, Computer Programmer/Analyst, Harry Reid Center for Environmental Studies, University of Nevada-Las Vegas, Las Vegas, Nevada. Joseph Donnegan, Supervisory Biological Scientist, USDA Forest Service, Pacific Northwest Research Station, Portland, Oregon. Mark Hansen, Research Forester (retired), Forest Inventory and Analysis Program, USDA Forest Service, Northern Research Station, Saint Paul, Minnesota (currently Research Associate, Department of Forest Resources, University of Minnesota, Saint Paul, Minnesota). Jason R. Meade, Forester, USDA Forest Service, Southern Research Station, Knoxville, Tennessee. James Menlove, Ecologist, USDA Forest Service, Rocky Mountain Research Station, Ogden, Utah. Patrick Miles, Research Forester, USDA Forest Service, Northern Research Station, Saint Paul, Minnesota. Scott A. Pugh, Forester, USDA Forest Service, Northern Research Station, Houghton, Michigan. Ted Ridley, IT Specialist, USDA Forest Service, Southern Research Station, Knoxville, Tennessee. John D. Shaw, Biological Scientist, USDA Forest Service, Rocky Mountain Research Station, Inventory and Monitoring Program, Ogden, Utah.

Research support was provided by the USDAForest Service Research Stations listed above and in part through the Research Joint Venture Agreements and 07-JV-11330146-134, 08-JV-11330146-078, and 09-JV-11330146-087 between the U.S. Department of Agriculture, Forest Service, Southern Research Station, and North Carolina State University.

The use of trade or firm names in this publication is for reader information and does not imply endorsement by the U.S. Department of Agriculture of any product or service. 


\section{Contents}

Preface

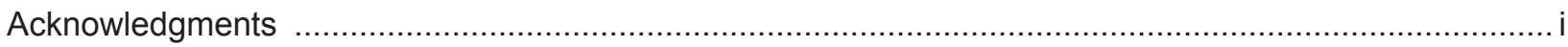

Chapter 1 Introduction

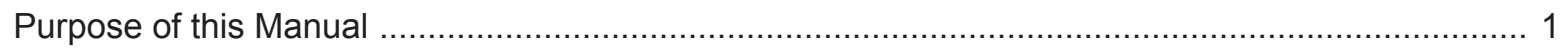

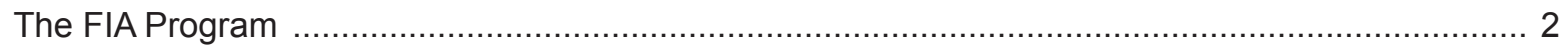

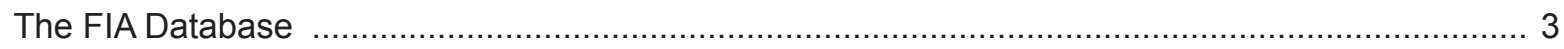

Changes From the Previous Database Version ......................................................................... 4

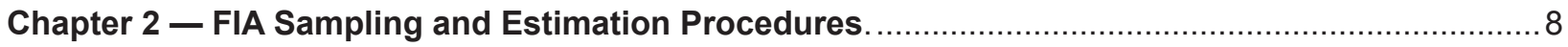

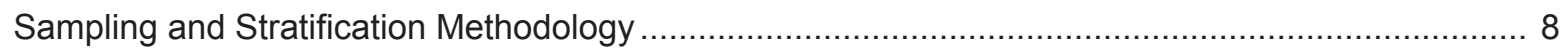

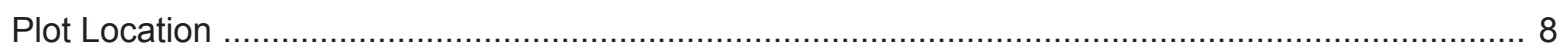

Plot Design, Condition Delineation, and Types of Data Attributes............................................. 10

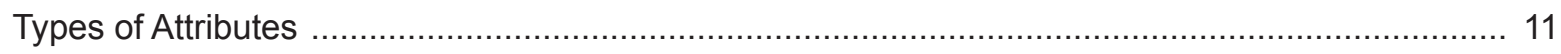

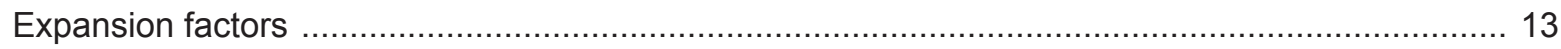

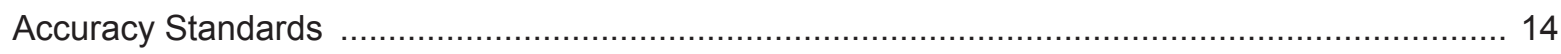

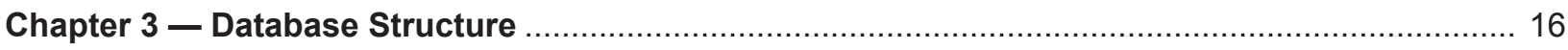

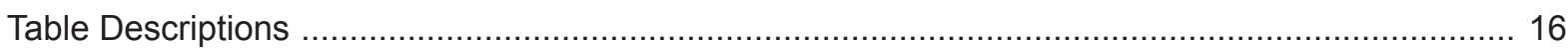

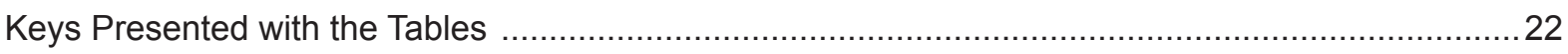

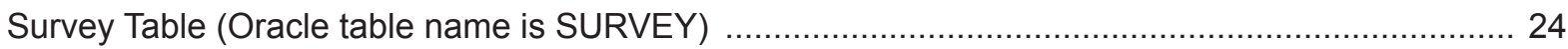

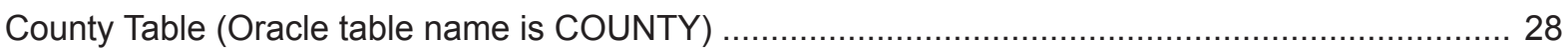

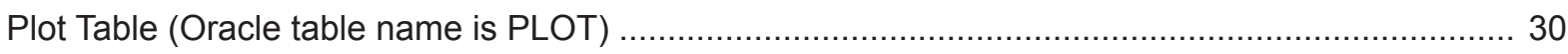

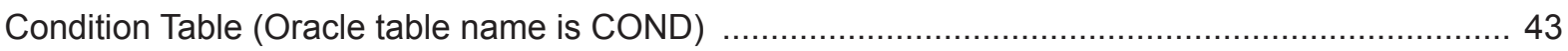

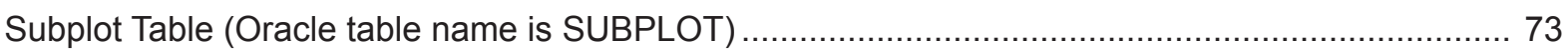

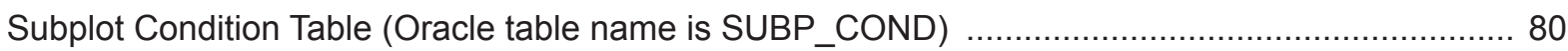

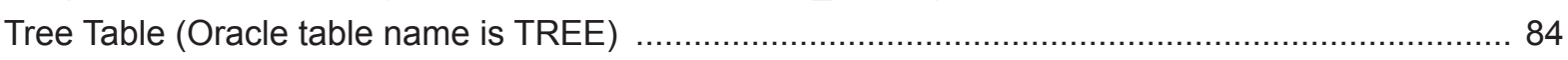

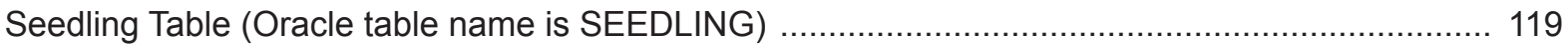

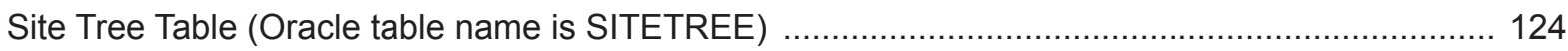

Boundary Table (Oracle table name is BOUNDARY) ............................................................... 130

Subplot Condition Change Matrix (Oracle table name is SUBP_COND_CHNG_MTRX) ............... 135

Tree Regional Biomass Table (Oracle table name is TREE_REGIONAL_BIOMASS) ................... 139

Population Estimation Unit Table (Oracle table name is POP_ESTN_UNIT) ............................... 141

Population Evaluation Table (Oracle table name is POP_EVAL) .................................................. 144

Population Evaluation Attribute Table (Oracle table name is POP_EVAL_ATTRIBUTE) ................ 147

Population Evaluation Group Table (Oracle table name is POP_EVAL_GRP) ............................... 149

Population Evaluation Type Table (Oracle table name is POP_EVAL_TYP) .................................153

Population Plot Stratum Assignment Table (Oracle table name is

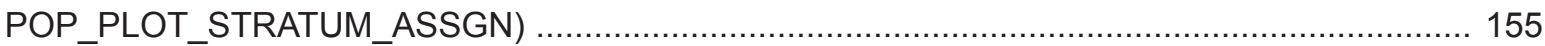

Population Stratum Table (Oracle table name is POP_STRATUM) …....................................... 159

Reference Population Attribute Table (Oracle table name is REF_POP_ATTRIBUTE) .................. 163 
Reference Population Evaluation Type Description Table (Oracle table name is

REF_POP_EVAL_TYP_DESCR) 165

Reference Forest Type Table (Oracle table name is REF_FOREST_TYPE) …........................... 167

Reference Species Table (Oracle table name is REF_SPECIES) ............................................ 169

Reference Species Group Table (Oracle table name is REF_SPECIES_GROUP) ....................... 184

Reference Habitat Type Description Table (Oracle table name is REF_HABTYP_DESCRIPTION) 186

Reference Habitat Type Publication Table (Oracle table name is REF_HABTYP_PUBLICATION) 188

Reference Citation Table (Oracle table name is REF_CITATION) .......................................... 190

Reference Forest Inventory and Analysis Database Version Table (Oracle table name is

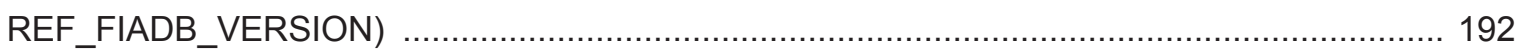

Reference State Elevation Table (Oracle table name is REF_STATE_ELEV) ............................... 194

Reference Unit Table (Oracle table name is REF_UNIT) …................................................. 196

Chapter 4 - Calculating Population Estimates and Their Associated Sampling Errors ............. 198

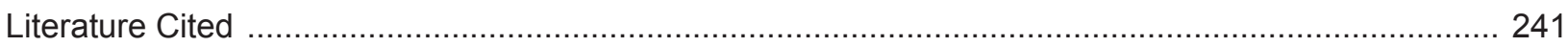

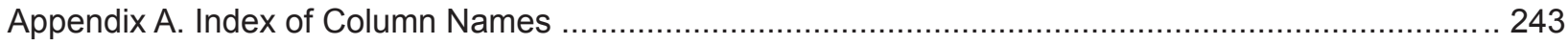

Appendix B. Forest Inventory and Analysis (FIA) Plot Design Codes and Definitions by

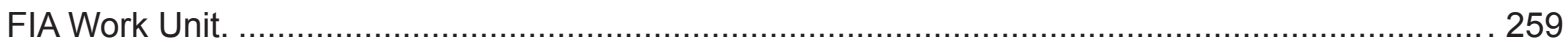

Appendix C. State, Survey Unit, and County Codes …............................................................ 264

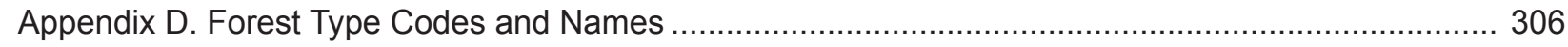

Appendix E. Administrative National Forest Codes and Names .................................................... 310

Appendix F. Tree Species Codes, Names, and Occurrences.............................................................. 313

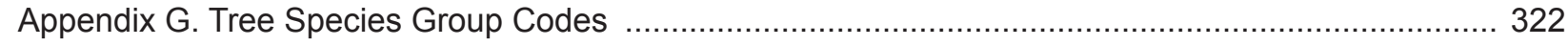

Appendix H. Damage Agent codes for PNW ........................................................................ 323

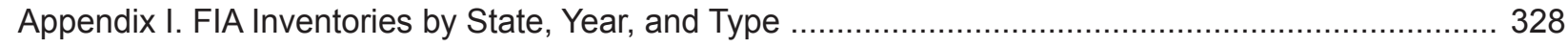

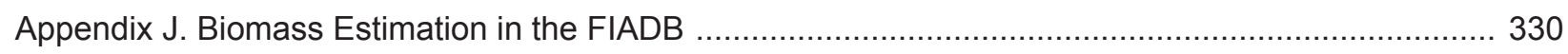




\section{Chapter 1 -- Introduction}

\section{Purpose of This Manual}

This manual is the definitive guide to the Forest Inventory and Analysis database (FIADB). This document replaces General Technical Report NC-218 (Miles and others 2001), which covered version 1.0 of the FIADB, and subsequent updates that appeared as online documentation to the FIADB through version 3.0. Although it is used widely within the Forest Inventory and Analysis (FIA) program, a substantial part, if not the majority, of the intended audience includes those outside FIA who are interested in using FIA data for their own analyses. Awareness of the potential uses of FIA data by users outside the FIA community is growing, and the data become increasingly useful as additional attributes are collected. However, as is the case with any data source, it is incumbent upon the user to understand not only the data definitions and acquisition methods, but also the context in which the data were collected. This manual is intended to help current and potential users understand the necessary details of the FIADB.

This manual has four chapters. The remainder of chapter 1 includes general introductions to the FIA program and the FIA database, including brief histories of both. It provides a convenient overview for those who have an interest in using FIA data, but have not yet become familiar with the FIA program. Chapter 2 provides descriptions of FIA sampling methods, including plot location and design, data measurement and computation, and general estimation procedures. Chapter 3 describes the tables that comprise the database, the attributes stored in each table, and the linkages between tables. Descriptions of the attributes, their data format, valid values, and other important details are given, but the appropriate field manuals should be consulted for exact specifications regarding data collection methods. Users with a good understanding of chapter 3 and fundamental database management skills should be able to conduct a wide range of analyses. Chapter 4 explains the standard methods used to compile population-level estimates from FIADB, and applies the new estimation procedures documented by Bechtold and Patterson (2005). These procedures are based on adoption of the annual inventory system and the mapped plot design, and constitute a major change when compared to previous compilation procedures. However, the new compilation procedures should allow more flexible analyses, especially as additional panels are completed under the annual inventory system.

There are several conventions used in this manual. The names of attributes (i.e., columns within tables) and table names appear in capital letters (e.g., PLOT table). Some attribute names appear in two or more tables. In most cases, such as the State code (STATECD), the attribute has the same definition in all tables. However, there are situations where attributes with the same name are defined differently in each table. One such example is the VALUE attribute in the REF_FOREST_TYPE table, which is used to identify the forest type and refers to appendix D. However, the VALUE attribute in the REF_UNIT table is used to indicate the FIA survey unit identification number from appendix C. In most cases, such as in the table descriptions in chapter 3, the attribute name will be used alone and the affiliation with a particular table is implied by the context. In cases where an attribute name has a different meaning in two or more tables, a compound naming convention, using the table name followed by the attribute name, will be used. In the VALUE attribute example, the name REF_FOREST_TYPE.VALUE refers to the VALUE 
attribute in the REF_FOREST_TYPE table, while REF_UNIT.VALUE refers to the VALUE attribute in the REF_UNIT table.

\section{The FIA Program}

The FIA program is mandated by Congress in the Forest and Rangeland Renewable Resources Planning Act of 1974 and the McSweeney-McNary Forest Research Act of 1928. The mission of FIA is to determine the extent, condition, volume, growth, and depletions of timber on the Nation's forest land. FIA is the only program that collects, publishes, and analyzes data from all ownerships of forest land in the United States (Smith 2002). Throughout the 80-year history of the program, inventories have been conducted by a number of geographically dispersed FIA work units.

Currently, the national FIA program is implemented by four regionally distributed work units that are coordinated by a National Office in Washington, DC (see figure 1). The four FIA work units are named by the Research Station in which they reside. Station abbreviations are used within this document and they are defined as Pacific Northwest Research Station (PNWRS), Northern Research Station (NRS), Rocky Mountain Research Station (RMRS), and Southern Research Station (SRS). NRS was recently formed from the merger of North Central Research Station (NCRS) and Northeastern Research Station (NERS). Some data items still retain these designations.

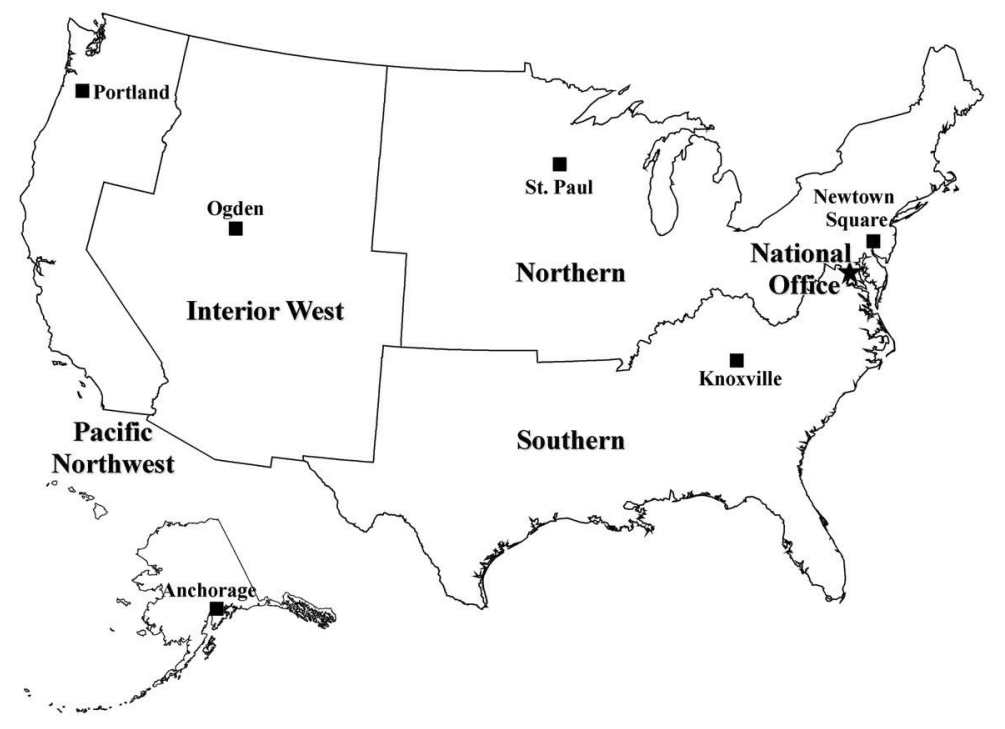

Figure 1. Boundaries of the four regionally distributed FIA work units and locations of program offices.

Starting in 1929, FIA accomplished its mission by conducting periodic forest inventories on a Stateby-State basis. With the completion of Arizona, New Mexico, and Nevada in 1962, all 48 coterminous States had at least one periodic inventory (Van Hooser and others 1993). Repeat intervals for inventorying individual States have varied widely. By the late 1990s, most States had been inventoried more than once under the periodic inventory system; however, not all periodic data are available in electronic form (appendix I lists all periodic data available in the FIADB and the year in which annual inventory began). 
With the passage of the 1998 Farm Bill, the FIA program was required to move from a periodic inventory to an annualized system, with a portion of all plots within a State measured each year (Gillespie 1999). Starting in 1999, States were phased into the annual inventory system (appendix I). At the time of publication of this document, annual inventory has not yet been started in Wyoming and Interior Alaska. Although the 1998 Farm Bill specified that 20 percent of the plots within each State would be visited annually, funding limitations have resulted in the actual portion of plots measured annually ranging between 10 and 20 percent, depending on the State.

Periodic and annual data are analyzed to produce reports at State, regional, and national levels. In addition to published reports, data are made available to the public for those who are interested in conducting their own analyses. Downloadable data, available online at http://fia.fs.fed.us/toolsdata/, follow the format described in this document. Also available at this site are tools to make population estimates. The web-based EVALIDator tool or the Forest Inventory Data Online (FIDO) tool provide interactive access to the FIADB.

\section{The FIA Database}

The Forest Inventory and Analysis Database (FIADB) was developed to provide users with data in a consistent format, spanning all States and inventories. The first version of FIADB replaced two FIA regional databases; the Eastern States (Eastwide database) documented by Hansen and others (1992), and Western States (Westwide database) documented by Woudenberg and Farrenkopf (1995). A new national plot design (see chapter 2) provided the impetus for replacing these two databases, and FIA work units adopted the new design in all State inventories initiated after 1998. The FIADB table structure is currently derived from the National Information Management System (NIMS), which was designed to process and store annual inventory data. This is the fourth version of the single national FIA database to be released. A number of changes in the FIADB structure have been made to accommodate the data processing and storage requirements of NIMS. As a result, data from periodic inventories are stored in a format consistent with annual inventory data.

FIADB files are available for periodic inventory data collected as early as 1977 (see appendix I). A wide variety of plot designs and regionally defined attributes were used in periodic inventories, often differing by State. Because of this, some data attributes may not be populated or certain data may have been collected or computed differently. During some periodic inventories, ground plot data were collected on nonreserved timberland only. Low productivity forest land, reserved (areas reserved from timber harvesting), and nonforested areas usually were not ground sampled. To account for the total area of a State, "place holder" plots were created to represent these nonsampled areas, which are identified by plot design code 999 in FIADB (PLOT.DESIGNCD =999). For these plots, many attributes that are normally populated for forested plots will be blank. Users should be aware that while place holder plots account for the area of nonsampled forest land, they do not account for the corresponding forest attributes (such as volume, growth, or mortality) that may exist in those areas.

Annual inventories, initiated sometime after 1999 depending on the State, use a nationally standardized plot design and common data collection procedures resulting in greater consistency among FIA work units than earlier inventories. However, as part of a continuing effort to improve the inventory, some changes in methodology and attribute definitions have been implemented after the new design was put into practice. Beginning in 1998, FIA started using a National Field Guide referenced as Field Guide 1.0. The database contains an attribute labeled MANUAL that stores the 
version number of the field guide under which the data were collected. When both the plot design is coded as being the national design (PLOT.DESIGNCD =1) and the field guide is coded with a number greater than or equal to 1, certain attributes are defined as being "core" while others are allowed to be "core optional." Core attributes must be collected by every FIA work unit, using the same definition and set of codes. In contrast, collection of core optional attributes are decided upon by individual FIA work units, using the same national protocol, predefined definition, and set of codes. Many attributes, regardless of whether or not they are core or core optional, are only populated for forested conditions, and are blank for other conditions (such as nonforest or water). Attributes described in chapter 3 are noted if they are core optional.

Users who wish to analyze data using aggregations of multiple State inventories or multiple inventories within States should become familiar with changes in methodology and attribute definitions (see chapters 2 and 3). For each attribute in the current version of FIADB, an effort has been made to provide the current definition of the attribute, as well as any variations in definition that may have been used among various FIA work units. In other words, although inventory data have been made available in a common data format, users should be aware of differences that might affect their analyses.

\section{Changes From the Previous Database Version}

Database users should also be aware that changes are made for each version of FIADB. Sometimes the changes are minimal, such as simply rewriting explanatory text for clarification or adding new codes to a particular attribute. Database tables and/or attributes may be added or removed. In this release (4.0), a number of reference tables have been added. Also, two tables were added to modify the way population estimates are handled. Another important table addition is the Subplot Condition Change Matrix table that tracks changes in any condition class attribute between two visits to a plot. In appendix F, several changes were made in the SPGRPCD column. Tables 1-5 summarize the major modifications to FIADB Version 4.0.

Table 1. Database entire tables added in FIADB V4.0

\begin{tabular}{|l|l|}
\hline Name of table added & Table description \\
\hline SUBP_COND_CHNG_MTRX & Subplot Condition Change Matrix \\
\hline TREE_REGIONAL_BIOMASS & Tree Regional Biomass \\
\hline POP_EVAL_TYP & Population Evaluation Type \\
\hline REF_POP_EVAL_TYP_DESCR & Reference Population Evaluation Type Description \\
\hline REF_FOREST_TYPE & Reference Forest Type \\
\hline REF_SPECIES & Reference Species \\
\hline REF_SPECIES_GROUP & Reference Species Group \\
\hline REF_HABTYP_DESCRIPTION & Reference Habitat Type Description \\
\hline REF_HABTYP_PUBLICATION & Reference Habitat Type Publication \\
\hline REF_CITATION & Reference Citation \\
\hline REF_FIADB_VERSION & Reference Forest Inventory and Analysis Database Version \\
\hline REF_STATE_ELEV & Reference State Elevation \\
\hline REF_UNIT & Reference Unit \\
\hline
\end{tabular}


Table 2. Database table attribute additions in FIADB V4.0

\begin{tabular}{|c|c|}
\hline Name of table affected & Name of column added to table \\
\hline SURVEY & RSCD \\
\hline SURVEY & ANN_INVENTORY \\
\hline PLOT & INTENSITY \\
\hline PLOT & NF_SAMPLING_STATUS_CD \\
\hline PLOT & NF_PLOT_STATUS_CD \\
\hline PLOT & NF_PLOT_NONSAMPLE_REASN_CD \\
\hline PLOT & P2VEG_SAMPLING_STATUS_CD \\
\hline PLOT & P2VEG_SAMPLING_LEVEL_DETAIL_CD \\
\hline PLOT & INVASIVE_SAMPLING_STATUS_CD \\
\hline PLOT & INVASIVE_SPECIMEN_RULE_CD \\
\hline COND & CARBON_DOWN_DEAD \\
\hline COND & CARBON_LITTER \\
\hline COND & CARBON_SOIL_ORG \\
\hline COND & CARBON_STANDING_DEAD \\
\hline COND & CARBON_UNDERSTORY_AG \\
\hline COND & CARBON_UNDERSTORY_BG \\
\hline COND & HARVEST_TYPE1_SRS \\
\hline COND & HARVEST_TYPE2_SRS \\
\hline COND & HARVEST_TYPE3_SRS \\
\hline COND & NF_COND_STATUS_CD \\
\hline COND & NF_COND_NONSAMPLE_REASN_CD \\
\hline COND & CANOPY_CVR_SAMPLE_METHOD_CD \\
\hline COND & LIVE_CANOPY_CVR_PCT \\
\hline COND & LIVE_MISSING_CANOPY_CVR_PCT \\
\hline COND & NBR_LIVE_STEMS \\
\hline SUBPLOT & NF_SUBP_STATUS_CD \\
\hline SUBPLOT & NF_SUBP_NONSAMPLE_REASN_CD \\
\hline SUBPLOT & P2VEG_SUBP_STATUS_CD \\
\hline SUBPLOT & P2VEG_SUBP_NONSAMPLE_REASN_CD \\
\hline SUBPLOT & INVASIVE_SUBP_STATUS_CD \\
\hline SUBPLOT & INVASIVE_NONSAMPLE_REASN_CD \\
\hline TREE & DRYBIO_BOLE \\
\hline TREE & DRYBIO_TOP \\
\hline TREE & DRYBIO_STUMP \\
\hline TREE & DRYBIO_SAPLING \\
\hline TREE & DRYBIO_WDLD_SPP \\
\hline TREE & DRYBIO_BG \\
\hline TREE & CARBON_AG \\
\hline TREE & CARBON_BG \\
\hline TREE & PREV_PNTN_SRS \\
\hline POP_ESTN_UNIT & P1SOURCE \\
\hline
\end{tabular}




\begin{tabular}{|l|l|}
\hline Name of table affected & Name of column added to table \\
\hline POP_EVAL & START_INVYR \\
\hline POP_EVAL & END_INVYR \\
\hline POP_EVAL_ATTRIBUTE & CN \\
\hline POP_EVAL_ATTRIBUTE & STATECD \\
\hline POP_EVAL_GRP & NOTES \\
\hline REF_POP_ATTRIBUTE & CN \\
\hline REF_POP_ATTRIBUTE & FOOTNOTE \\
\hline
\end{tabular}

Table 3. Database table attribute deletions in FIADB V4.0

\begin{tabular}{|l|l|}
\hline Name of table affected & Name of column deleted \\
\hline PLOT & CREW_TYPE \\
\hline PLOT & MANUAL_DB \\
\hline PLOT & REPLACED_PLOT_NBR \\
\hline PLOT & LAST_INVYR_MEASURED \\
\hline COND & TRTOPCD \\
\hline COND & PASTNFCD \\
\hline COND & DISTANCE_WATER_SRS \\
\hline TREE & PREVSUBC \\
\hline SITETREE & SITREE_EQU_NO_PNWRS \\
\hline
\end{tabular}

Table 4. Database table attributes renamed in FIADB V4.0

\begin{tabular}{|l|l|l|}
\hline Name of table affected & Old attribute name & New attribute name \\
\hline PLOT & GROWCD & GROW_TYP_CD \\
\hline PLOT & MORTCD & MORT_TYP_CD \\
\hline COND & TRTCD1_SRS & HARVEST_TYPE1_SRS \\
\hline COND & TRTCD2_SRS & HARVEST_TYPE2_SRS \\
\hline COND & TRTCD3_SRS & HARVEST_TYPE3_SRS \\
\hline SUBPLOT & STATUSCD & SUBP_STATUS_CD \\
\hline SITETREE & COND_CLASS_LIST & CONDLIST \\
\hline
\end{tabular}

Table 5. Database table attributes moved to another table in FIADB V4.0

\begin{tabular}{|l|l|l|}
\hline Original table & New table & Column moved and renamed \\
\hline TREE & TREE_REGIONAL_BIOMASS & REGIONAL_DRYBIOT \\
\hline TREE & TREE_REGIONAL_BIOMASS & REGIONAL_DRYBIOM \\
\hline
\end{tabular}

A change was made in the stocking equation assignment for various tree species and was applied to all annual inventory plot data. This change can result in a different computed forest type for a given plot. Several new forest types have been added and some changes were made in the way forest types are grouped. 
Another significant change relates to biomass and carbon. FIA adopted a standard methodology to compute biomass of various tree components, which are used to convert biomass to carbon estimates. Previous biomass estimates, which were derived using a variety of equations, have been moved to a new table called TREE_REGIONAL_BIOMASS. Users can choose which attribute to summarize and can make comparisons between the estimates derived from the different methodologies.

Modeled condition level carbon attributes have been added to the FIADB and can be used to obtain results similar to those found in the U.S. Environmental Protection Agency's (EPA's) Greenhouse Gas Inventory (http://epa.gov/climatechange/emissions/). 


\section{Chapter 2 -- FIA Sampling and Estimation Procedures}

To use the FIADB effectively, users should acquire a basic understanding of FIA sampling and estimation procedures. Generally described, FIA uses what may be characterized as a three-phase sampling scheme. Phase $1(\mathrm{P} 1)$ is used for stratification, while Phase 2 (P2) consists of plots that are visited or photo-interpreted. A subset of Phase 2 plots are designated as Phase 3 (P3) plots (formerly known as Forest Health Monitoring (FHM) plots) where additional health indicator attributes are collected. Phases 1 and 2 are described in this chapter, but Phase 3 is described in a separate user's manual (Woodall and others 2010). The exception is P3 crown attributes, which are described in the TREE table of this document.

\section{Sampling and Stratification Methodology}

\section{Remote Sensing (P1)}

The basic level of inventory in the FIA program is the State, which begins with the interpretation of a remotely sensed sample, referred to as Phase $1(\mathrm{P} 1)$. The intent of $\mathrm{P} 1$ is to classify the land into various remote sensing classes for the purpose of developing meaningful strata. A stratum is a group of plots that have the same or similar remote sensing classifications. Stratification is a statistical technique used by FIA to aggregate Phase 2 ground samples into groups to reduce variance when stratified estimation methods are used. The total area of the estimation unit is assumed to be known.

Each Phase 2 ground plot is assigned to a stratum and the weight of the stratum is based on the proportion of the stratum within the estimation unit. Estimates of population totals are then based on the sum of the product of the known total area, the stratum weight, and the mean of the plot level attribute of interest for each stratum. The expansion factor for each stratum within the estimation unit is the product of the known total area and the stratum weight divided by the number of Phase 2 plots in the stratum.

Selection criteria for remote sensing classes and computation of area expansion factors differ from State to State. Users interested in the details of how these expansion factors are assigned to ground plots for a particular State should contact the appropriate FIA work unit (see table 6).

Ground Sampling (P2)

FIA ground plots, or Phase 2 plots, are designed to cover a 1-acre sample area; however, not all trees on the acre are measured. Ground plots may be new plots that have never been measured, or re-measurement plots that were measured during one or more previous inventories. Recent inventories use a nationally standard, fixed-radius plot layout for sample tree selection (see figure 2). Various arrangements of fixed-radius and variable-radius (prism) subplots were used to select sample trees in older inventories.

\section{Plot Location}

The FIADB includes coordinates for every plot location in the database, whether it is forested or not, but these are not the precise locations of the plot centers. In an amendment to the Food Security Act of 1985 (reference 7 USC $2276 \S 1770$ ), Congress directed FIA to ensure the privacy of private landowners. Exact plot coordinates could be used in conjunction with other publicly available data to link plot data to specific landowners, in violation of requirements set by Congress. In addition to 
the issue of private landowner privacy, the FIA program had concerns about plot integrity and vandalism of plot locations on public lands. A revised policy has been implemented and methods for making approximate coordinates available for all plots have been developed. These methods are collectively known as "fuzzing and swapping" (Lister and others 2005).

In the past, FIA provided approximate coordinates for its periodic data in the FIADB. These coordinates were within 1.0 mile of the exact plot location (this is called fuzzing). However, because some private individuals own extensive amounts of land in certain counties, the data could still be linked to these owners. In order to maintain the privacy requirements specified in the amendments to the Food Security Act of 1985, up to 20 percent of the private plot coordinates are swapped with another similar private plot within the same county (this is called swapping). This method creates sufficient uncertainty at the scale of the individual landowner such that privacy requirements are met. It also ensures that county summaries and any breakdowns by categories, such as ownership class, will be the same as when using the true plot locations. This is because only the coordinates of the plot are swapped - all the other plot characteristics remain the same. The only difference will occur when users want to subdivide a county using a polygon. Even then, results will be similar because swapped plots are chosen to be similar based on attributes such as forest type, stand-size class, latitude, and longitude (each FIA work unit has chosen its own attributes for defining similarity).

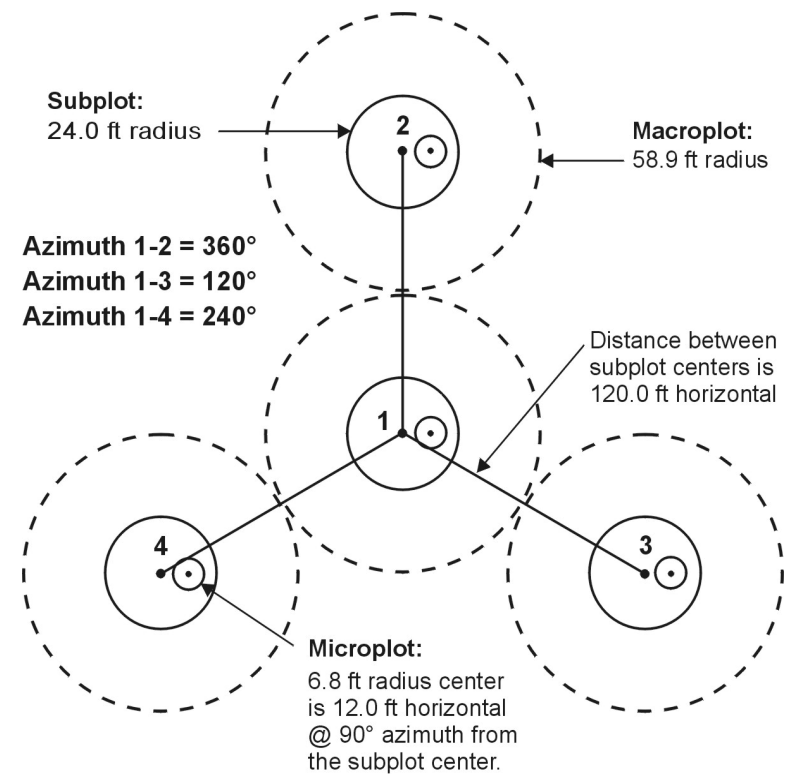

Figure 2. The FIA mapped plot design. Subplot 1 is the center of the cluster with subplots 2, 3, and 4 located 120 feet away at azimuths of $360^{\circ}, 120^{\circ}$, and $240^{\circ}$, respectively.

For plot data collected under the current plot design, plot numbers are reassigned to sever the link to other coordinates stored in the FIADB prior to the change in the law. Private plots are also swapped using the method described above; remeasured plots are swapped independent of the periodic data. All plot coordinates are fuzzed, but less than before - within 0.5 mile for most plots and up to 1.0 mile on a small subset of them. This was done to make it difficult to locate the plot on the ground, while maintaining a good correlation between the plot data and map-based characteristics. 
For most user applications, such as woodbasket analyses and estimates of other large areas, fuzzed and swapped coordinates provide a sufficient level of accuracy. However, some FIA customers require more precision of plot locations in order to perform analyses by user-defined polygons and for relating FIA plot data to other map-based information, such as soils maps and satellite imagery. In order to accommodate this need, FIA provides spatial data services that allow most of the desired analyses while meeting privacy requirements. The possibilities and limitations for these types of analyses are case-specific, so interested users should contact their local FIA work unit for more information.

\section{Plot Design, Condition Delineation, and Types of Data Attributes}

\section{Plot Designs}

The current national standard FIA plot design was originally developed for the Forest Health Monitoring program (Scott and others 1993). It was adopted by FIA in the mid-1990s and used for the last few periodic inventories and all annual inventories. The standard plot consists of four 24.0foot radius subplots (approximately 0.0415 or 1/24 acre) (see figure 2), on which trees 5.0 inches and greater in diameter are measured. Within each of these subplots is nested a 6.8 -foot radius microplot (approximately 1/300th acre) on which trees smaller than 5.0 inches in diameter are measured. A core optional variant of the standard design includes four "macroplots," each with a radius of 58.9 feet (approximately $1 / 4$ acre) that originate at the centers of the 24.0 -foot radius subplots. Breakpoint diameters between the 24-foot radius subplots and the macroplots vary and are specified in the macroplot breakpoint diameter attribute (PLOT.MACRO_BREAKPOINT_DIA).

Prior to adoption of the current plot design, a wide variety of plot designs were used. Periodic inventories might include a mixture of designs, based on forest type, ownership, or time of plot measurement. In addition, similar plot designs (e.g., 20 BAF variable-radius plots) might have been used with different minimum diameter specifications (e.g., 1-inch versus 5-inch). Details on these designs are included in appendix B (plot design codes).

\section{Conditions}

An important distinguishing feature between the current plot design and previous designs is that different conditions are "mapped" on the current design (see figure 3). In older plot designs, adjustments were made to the location of the plot center or the subplots were rearranged such that the entire plot sampled a single condition. In the new design, the plot location and orientation remains fixed, but boundaries between conditions are mapped and recorded. Conditions are defined by changes in land use or changes in vegetation that occur along more-or-less distinct boundaries. Reserved status, owner group, forest type, stand-size class, regeneration status, and stand density are used to define forest conditions. For example, the subplots may cover forest and nonforest areas, or it may cover a single forested area that can be partitioned into two or more distinct stands.

Although mapping is used to separate forest and nonforest conditions, different nonforest conditions occurring on a plot are not mapped during initial plot establishment. Each condition occurring on the plot is assigned a condition proportion, and all conditions on a plot add up to 1.0. For plot designs other than the mapped design, condition proportion is always equal to 1.0 in FIADB. 


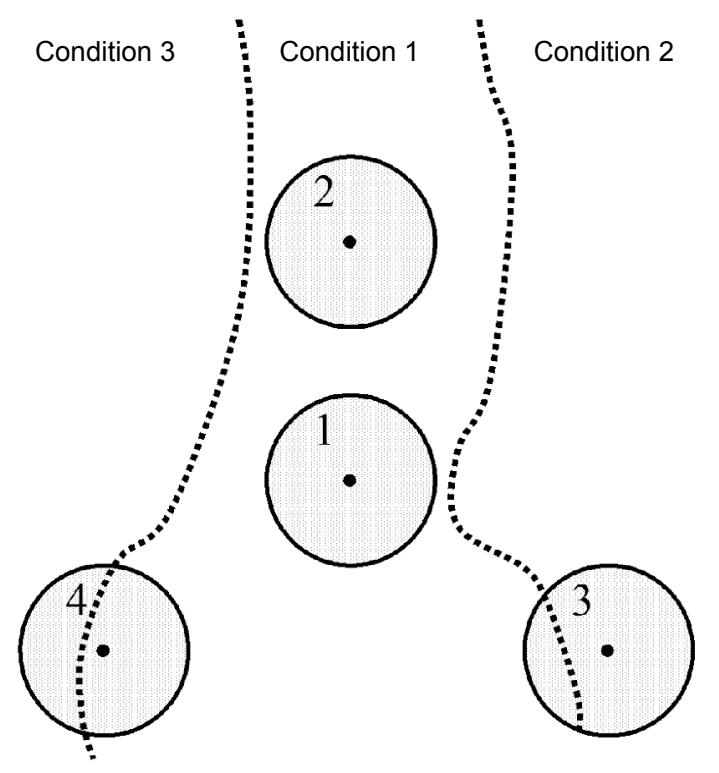

Figure 3. The FIA mapped plot design. Subplot 1 is the center of the cluster with subplots 2,3 , and 4 located 120 feet away at azimuths of $360^{\circ}, 120^{\circ}$, and $240^{\circ}$, respectively. When a plot straddles two or more conditions, the plot area is divided by condition.

\section{Types of Attributes}

\section{Measured, Assigned, and Computed Attributes}

In addition to attributes that are collected in the field, FIADB includes attributes that are populated in the office. Examples of field attributes include tree diameter and height, and slope and aspect of the plot and subplot. Attributes that are populated in the office include assigned attributes, such as county and owner group codes, or computed attributes, such as tree and area expansion factors, and tree volumes.

For measured attributes, this document provides only basic information on the methodology used in the field. The authoritative source for methodology is the Forest Inventory and Analysis National Core Field Guide used during the inventory in which the data were collected (see http://www.fia.fs.fed.us/library/field-guides-methods-proc/). The MANUAL attribute in the PLOT table documents the version number where data collection protocols can be found.

Values of attributes that are assigned in the office are determined in several ways, depending on the attribute. For example, ownership may be determined using geographic data or local government records. Other attributes, such as Congressional District and Ecological Subsection are assigned values based on data management needs.

Some computed attributes in the database are derived using other attributes in the database. Ordinarily, such attributes would not be included in a database table because they could be 
computed using the supplied attributes. However, some data compilation routines are complex or vary within or among FIA work units, so these computed attributes are populated for the convenience of database users.

One example of a computed attribute is site index, which is computed at the condition level. Site index is generally a function of height and age, although other attributes may be used in conjunction. In addition, several different site index equations may be available for a species within its range. Height and age data are included in the TREE table, but only certain trees (see SITETREE table) are included in the site index attribute that is reported for the condition. As a result, it would be time-consuming for users to replicate the process required to calculate site index at the condition level. For convenience, the condition (COND) table includes site index (SICOND), the species for which it is calculated (SISP), and the site index base age (SIBASE).

In most cases computed attributes should be sufficient for users' needs, because the equations and algorithms used to compute them have been determined by the FIA program to be the best available for the plot location. However, for most computed attributes the relevant tree and plot level attributes used to compute them are included in the database, so users may do their own calculations if desired.

\section{Regional Attributes}

A number of regionally specific attributes are available in FIADB. These regional attributes are identified by FIA work unit, both in the table structure description (e.g., the attribute is named with an extension such as NERS) and in the attribute description (e.g., the attribute description text contains the phrase "Only collected by..."). For specific questions about the data from a particular FIA work unit, please contact the individuals listed in table 6.

Table 6. Contacts at individual FIA work units

\begin{tabular}{|l|l|l|l|l|l|l|}
\hline FIA Work Unit & RSCD & States & $\begin{array}{l}\text { Database } \\
\text { Contact }\end{array}$ & Phone & $\begin{array}{l}\text { Analyst } \\
\text { Contact }\end{array}$ & Phone \\
\hline $\begin{array}{l}\text { Rocky Mountain } \\
\text { (RMRS) }\end{array}$ & 22 & $\begin{array}{l}\text { AZ,CO,ID,MT,NV, } \\
\text { NM,UT,WY }\end{array}$ & Mark Rubey & $801-625-5647$ & John Shaw & $801-625-5673$ \\
\hline $\begin{array}{l}\text { North Central } \\
\text { (NCRS)* }\end{array}$ & 23 & $\begin{array}{l}\text { IL,IN,IA,KS,MI,MN, } \\
\text { MO,NE,ND,SD,WI }\end{array}$ & Carol Alerich & $610-557-4068$ & $\begin{array}{l}\text { Will } \\
\text { McWilliams }\end{array}$ & $610-557-4050$ \\
\hline $\begin{array}{l}\text { Northeastern } \\
\text { (NERS)* }\end{array}$ & 24 & $\begin{array}{l}\text { CT,DE,ME,MD,MA, } \\
\text { NH,NJ,NY,OH,PA, } \\
\text { RI, VT,WV }\end{array}$ & Carol Alerich & $610-557-4068$ & $\begin{array}{l}\text { Will } \\
\text { McWilliams }\end{array}$ & $610-557-4050$ \\
\hline $\begin{array}{l}\text { Pacific Northwest } \\
\text { (PNWRS) }\end{array}$ & 26,27 & AK,CA,HI,OR,WA & Ron Wanek & $503-808-2048$ & $\begin{array}{l}\text { Karen } \\
\text { Waddell }\end{array}$ & $503-808-2046$ \\
\hline & & $\begin{array}{l}\text { AL,AR,FL,GA,KY, } \\
\text { LA,MS,NC,OK,SC, } \\
\text { SN,TX,VA, PR, VI }\end{array}$ & Jeff Turner & $865-862-2053$ & Tom Brandeis & $865-862-2030$ \\
\hline
\end{tabular}

*The North Central Research Station (NCRS) and the Northeastern Research Station (NERS) have merged to become one research station, the Northern Research Station. The former regional designations are kept to accommodate the data.

More information on attribute types is included in chapter 3. 


\section{Expansion Factors}

\section{Tree Expansion Factors}

The expansion factor(s) used to scale each tree on a plot to a per-acre basis is dependent on the plot design. For fixed-plot designs, scaling is straightforward, with the number of trees per acre (TPA) represented by one tree equal to the inverse of the plot area in acres. The general formula is shown by equation [1]:

$$
\mathrm{TPA}=1 /\left(\mathrm{N}^{*} \mathrm{~A}\right)
$$

Where $\mathrm{N}$ is the number of subplots, and

A is the area of each subplot.

For example, the TPA of each tree $\geq 5.0$ inches in diameter occurring on the current plot design would be calculated using equation [2]:

$$
\mathrm{TPA}=1 /(4 * 0.04154172)=6.018046
$$

This expansion factor can be found in the TPA_UNADJ attribute in the TREE table (see chapter 3) for plots measured with the annual plot design. In variable-radius plot designs, the per-acre expansion factor is determined by the diameter of the tree, the basal area factor (BAF), and the number of subplots used in the plot design. The general formula is shown by equation [3]:

$$
\begin{aligned}
\mathrm{TPA}= & \left(\mathrm{BAF} / 0.005454 * \mathrm{DIA}^{2}\right) / \mathrm{N} \\
& \text { Where BAF is the variable-radius basal area factor in square feet, } \\
& \text { DIA is diameter of the tally tree in inches, and } \\
& \mathrm{N} \text { is the number of subplots in the plot design. }
\end{aligned}
$$

For example, if a 11.5-inch tree is tallied using a $10 \mathrm{BAF}$ prism on a variable-radius design plot that uses five subplots, the calculation is:

$$
\mathrm{TPA}=\left(10 / 0.005454 * 11.5^{2}\right) / 5=2.773
$$

A 5.2-inch tree will have a greater expansion factor:

$$
\mathrm{TPA}=\left(10 / 0.005454 * 5.2^{2}\right) / 5=13.562
$$

Although it is not necessary to calculate expansion factors for different plot designs because they are stored in TPA_UNADJ, information on plot design can be found by using the code from the DESIGNCD attribute in the PLOT table to look up the plot design specifications in appendix B.

\section{Plot Area Expansion Factors}

Some previous versions of FIADB have included area expansion factors in the PLOT table that were used to scale plot-level data to population-level estimates (see EXPCURR and related attributes in Miles and others 2001). In this version of FIADB, area expansion factors have been removed from the PLOT table. Instead, there is one area expansion factor (EXPNS) stored in the POP_STRATUM table. This change is needed because of the way annual inventory data are compiled. Under the annual inventory system, new plots are added each year. Adjustment factors that are used to compensate for denied access, inaccessible, and other reasons for not sampling may 
differ each time new data replaces older data. Both the number of acres each plot represents and the adjustments for the proportion of plots not sampled may change each year. In order to allow users to obtain population estimates for any grouping of data, an adjustment factor has been calculated and stored for each set of data being compiled. There is a separate adjustment factor for each fixed plot size: microplot, subplot, and macroplot. These attributes are also stored in the POP_STRATUM table. Each time the data are stratified differently, the adjustments and expansion factor may change. Therefore, FIA provides a different expansion factor every time the data are restratified.

FIA has chosen the term 'evaluation' to describe this process of storing different stratifications of data either for an individual set of data or for the changing sets of data through time. Each aggregation of data is given an evaluation identifier (EVALID). The user can select population estimates for the most current set of data or for previous sets of data. In addition to being able to calculate population estimates, users can now calculate sampling error information because FIA is storing all of the Phase 1 information used for the stratification. That information is stored for each estimation unit, which is usually a geographic subset of the State (see the POP_ESTN_UNIT table). For more information about evaluations and calculation of area expansion factors, see chapter 4.

A different method of population estimation is being implemented in this version of FIADB. In FIADB 3.0, users would select the appropriate evaluation sequence number (EVAL_CN_FOR_xxx) from the POP_EVAL_GRP table. This evaluation sequence number allowed them to select the appropriate plots and associated expansions. The newly added POP_EVAL_TYP table allows users to perform the similar queries, retrieving the same information, and will allow for a variety of evaluations to be added in the future. The previous method will continue to work in version 4.0.

\section{Accuracy Standards}

Forest inventory plans are designed to meet sampling error standards for area, volume, growth, and removals provided in the Forest Service directive (FSH 4809.11) known as the Forest Survey Handbook (U.S. Department of Agriculture 2008). These standards, along with other guidelines, are aimed at obtaining comprehensive and comparable information on timber resources for all parts of the country. FIA inventories are commonly designed to meet the specified sampling errors at the State level at the 67 percent confidence limit (one standard error). The Forest Survey Handbook mandates that the sampling error for area cannot exceed 3 percent error per 1 million acres of timberland. A 5 percent (Eastern United States) or 10 percent (Western United States) error per 1 billion cubic feet of growing-stock on timberland is applied to volume, removals, and net annual growth. Unlike the mandated sampling error for area, sampling errors for volume, removals, and growth are only targets.

FIA inventories are extensive inventories that provide reliable estimates for large areas. As data are subdivided into smaller and smaller areas, such as a geographic unit or a county, the sampling errors increase and the reliability of the estimates goes down.

- A State with 5 million acres of timberland would have a maximum allowable sampling error of 1.3 percent $\left(3 \% \times(1,000,000)^{0.5} /(5,000,000)^{0.5}\right)$.

- A geographic unit within that State with 1 million acres of timberland would have a 3.0 percent maximum allowable sampling error $\left(3 \% \mathrm{x}(1,000,000)^{0.5} /(1,000,000)^{0.5}\right)$.

- A county within that State with 100 thousand acres would have a 9.5 percent maximum allowable sampling error $\left(3 \% \mathrm{x}(1,000,000)^{0.5} /(100,000)^{0.5}\right)$ at the 67 percent confidence level. 
The greater allowance for sampling error in smaller areas reflects the decrease in sample size as estimation area decreases.

Estimation procedures and the calculation of confidence intervals for typical FIA tables are discussed in chapter 4. Additional information on estimation and confidence intervals can be found in Bechtold and Patterson (2005). 


\section{Chapter 3 -- Database Structure}

This chapter provides information about the database tables, including detailed descriptions of all attributes within the tables. Each column or attribute in a table is listed with its unabbreviated name, followed by a description of the attribute. Attributes that are coded include a list of the codes and their meanings. Appendix A is an index of the attributes, sorted alphabetically by column name, showing the table where the column is found including the attribute number in the table. Some overview information is presented below, followed by a section with complete information about all tables and attributes.

\section{Table Descriptions}

There are nineteen data tables and eleven reference tables in the Phase 1 and Phase 2 portions of the FIA Database.

- SURVEY table - Contains one record for each year an inventory is conducted in a State for annual inventory or one record for each periodic inventory.

- SURVEY.CN = PLOT.SRV_CN links the unique inventory record for a State and year to the plot records.

- COUNTY table - Reference table for the county codes and names. This table also includes survey unit codes.

- COUNTY.CN = PLOT.CTY_CN links the unique county record to the plot record.

- PLOT table - Provides information relevant to the entire 1-acre field plot. This table links to most other tables, and the linkage is made using PLOT.CN $=$ TABLE_NAME.PLT_CN (TABLE_NAME is the name of any table containing the column name PLT_CN). Below are some examples of linking PLOT to other tables.

$\circ$ PLOT.CN $=$ COND.PLT_CN links the unique plot record to the condition class $\operatorname{record}(\mathrm{s})$.

- $\quad$ PLOT.CN $=$ SUBPLOT.PLT_CN links the unique plot record to the subplot records.

○ PLOT.CN $=$ TREE.PLT_CN links the unique plot record to the tree records.

- PLOT.CN = SEEDLING.PLT_CN links the unique plot record to the seedling records.

- COND table - Provides information on the discrete combination of landscape attributes that define the condition (a condition will have the same land class, reserved status, owner group, forest type, stand-size class, regeneration status, and stand density).

O PLOT.CN = COND.PLT_CN links the condition class record (s) to the plot table.

- COND.PLT_CN $=$ SITETREE.PLT_CN and COND.CONDID $=$ SITETREE.CONDID links the condition class record to the site tree data.

$\circ$ COND.PLT_CN $=$ TREE.PLT_CN and COND.CONDID $=$ TREE.CONDID links the condition class record to the tree data.

- SUBPLOT table - Describes the features of a single subplot. There are multiple subplots per 1-acre field plot and there can be multiple conditions sampled on each subplot.

- PLOT.CN $=$ SUBPLOT.PLT_CN links the unique plot record to the subplot records.

○ SUBPLOT.PLT_CN = COND.PLT_CN and SUBPLOT.MACRCOND = COND.CONDID links the macroplot conditions to the condition class record.

- SUBPLOT.PLT CN = COND.PLT CN and SUBPLOT.SUBPCOND = COND.CONDID links the subplot conditions to the condition class record.

- SUBPLOT.PLT_CN = COND.PLT_CN and SUBPLOT.MICRCOND = COND.CONDID links the microplot conditions to the condition class record. 
- SUBP_COND table - Contains information about the proportion of a subplot in a condition. - PLOT.CN $=$ SUBP_COND.PLT_CN links the subplot condition class record to the plot table.

- SUBP_COND.PLT_CN $=$ COND.PLT_CN and SUBP_COND.CONDID $=$ COND.CONDID links the condition class records found on the four subplots to the subplot description.

- TREE table - Provides information for each tree 1 inch in diameter and larger found on a microplot, subplot, or core optional macroplot.

- PLOT.CN $=$ TREE.PLT_CN links the tree records to the unique plot record.

○ COND.PLT_CN $=$ TREE.PLT_CN and COND.CONDID $=$ TREE.CONDID links the tree records to the unique condition record.

- SEEDLING table - Provides a count of the number of live trees of a species found on a microplot that are less than 1 inch in diameter but at least 6 inches in length for conifer species or at least 12 inches in length for hardwood species.

○ PLOT.CN = SEEDLING.PLT_CN links the seedling records to the unique plot record.

- SITETREE table - Provides information on the site tree(s) collected in order to calculate site index and/or site productivity information for a condition.

○ PLOT.CN = SITETREE.PLT_CN links the site tree records to the unique plot record.

- SITETREE.PLT_CN $=$ COND.PLT_CN and SITETREE.CONDID $=$ COND.CONDID links the site tree record(s)to the unique condition class record.

- BOUNDARY table - Provides a description of the demarcation line between two conditions that occur on a single subplot.

○ PLOT.CN = BOUNDARY.PLT_CN links the boundary records to the unique plot record.

- SUBP_COND_CHNG_MTRX table - Contains information about the mix of current and previous conditions that occupy the same area on the subplot.

○ PLOT.CN $=$ SUBP_COND_CHNG_MTRX.PLT_CN links the subplot condition change matrix records to the unique plot record.

○ PLOT.PREV_PLOT_CN $=$ SUBP_COND_CHNG_MTRX.PREV_PLT_CN links the subplot condition change matrix records to the unique previous plot record.

- TREE_REGIONAL_BIOMASS table - Contains biomass estimates computed using equations and methodology that varies by FIA work unit. This table retains valuable information for generating biomass estimates that match earlier published reports.

○ TREE.CN $=$ TREE_REGIONAL_BIOMASS.TRE_CN links a tree regional biomass record to the corresponding unique tree.

- POP_ESTN_UNIT table - An estimation unit is a geographic area that can be drawn on a map. It has known area and the sampling intensity must be the same within a stratum within an estimation unit. Generally estimation units are contiguous areas, but exceptions are made when certain ownerships, usually National Forests, are sampled at different intensities. One record in the POP_ESTN_UNIT table corresponds to a single estimation unit.

- POP_ESTN_UNNIT.CN $=$ POP_STRATUM.ESTN_UNIT_CN links the unique stratified geographical area (ESTN_UNIT) to the strata (STRATUMCD) that are assigned to each ESTN_UNIT.

- POP_EVAL table - An evaluation is the combination of a set of plots (the sample) and a set of Phase 1 data (obtained through remote sensing, called a stratification) that can be used to produce population estimates for a State (an evaluation may be created to produce population estimates for a region other than a State, such as the Black Hills National Forest). 
A record in the POP_EVAL table identifies one evaluation and provides some descriptive information about how the evaluation may be used.

○ POP_ESTN_UNIT.EVAL_CN = POP_EVAL.CN links the unique evaluation identifier (EVĀLID) in the POP_EVAL table to the unique geographical areas (ESTN_UNIT) that are stratified. Within a population evaluation (EVALID) there can be multiple population estimation units, or geographic areas across which there are a number of values being estimated (e.g., estimation of volume across counties for a given State.)

- POP_EVAL_ATTRIBUTE table - Provides information as to which population estimates can be provided by an evaluation. If an evaluation can produce 22 of the 92 currently supported population estimates, there will be 22 records in the POP_EVAL_ATTRIBUTE table (one per population estimate) for that evaluation.

○ POP_EVAL.CN = POP_EVAL_ATTRIBUTE.EVAL_CN links the unique evaluation identifier to the list of population estimates that can be derived for that evaluation.

- POP_EVAL_GRP table - Provides information on the suite of evaluations that were used to generate a complete set of reports for an inventory. In a typical State inventory report, one evaluation is used to generate an estimate of the total land area; a second evaluation is used to generate current estimates of volume, numbers of trees and biomass; and a third evaluation is used for estimating growth, removals and mortality. One record in the POP_EVAL_GRP record identifies all the evaluations that were used in generating estimates for a State inventory report. Each record in the POP_EVAL table corresponds to an EVAL_CN_FOR_XX column in the POP_EVAL_GRP table, (XX is one of the following: Expall, Expcurr, Expvol, Expgrow, Expmort, or Expremv). Similar information is contained in the POP_EVAL_TYP table, which has been added to this version of the database.

○ POP_EVAL_TYP.EVAL_GRP_CN $=$ POP_EVAL_GRP.CN links the evaluation type record to the evaluation group record.

○ POP_EVAL.CN $=$ POP_EVAL_GRP.EVAL_CN_FOR_EXPALL links the evaluation for all land to the evaluation identifier that includes all plots used to make the estimate.

○ POP_EVAL.CN = POP_EVAL_GRP.EVAL_CN_FOR_EXPCURR links the evaluation for sampled land to the evaluation identifier that includes all sampled plots used to make the estimate.

○ POP_EVAL.CN $=$ POP_EVAL_GRP.EVAL_CN_FOR_EXPVOL links the evaluation for tree volume, biomass, or number of trees to the evaluation identifier that includes all plots used to make these estimates.

○ POP_EVAL.CN = POP_EVAL_GRP.EVAL_CN_FOR_EXPGROW links the evaluation for average annual tree growth to the evaluation identifier that includes all remeasured plots used to make the estimate.

○ POP_EVAL.CN $=$ POP_EVAL_GRP.EVAL_CN_FOR_EXPMORT links the evaluation for average annual tree mortality to the evaluation identifier that includes all remeasured plots used to make the estimate.

○ POP_EVAL.CN = POP_EVAL_GRP.EVAL_CN_FOR_EXPREMV links the evaluation for average annual tree removals to the evaluation identifier that includes all remeasured plots used to make the estimate.

- POP_EVAL_TYP table - Provides information on the type of evaluations that were used to generate a set of tables for an inventory report. In a typical State inventory report, one evaluation is used to generate an estimate of the total land area; a second evaluation is used to generate current estimates of volume, numbers of trees and biomass; and a third evaluation is used for estimating growth, removals and mortality. 
○ POP_EVAL_TYP.EVAL_CN $=$ POP_EVAL.CN links the evaluation type record to the evaluation record.

○ POP_EVAL_TYP.EVAL_GRP_CN $=$ POP_EVAL_GRP.CN links the evaluation type record to the evaluation group record.

○ POP_EVAL_TYP.EVAL_TYP $=$ REF_POP_EVAL_TYP_DESCR.EVAL_TYP links an evaluation type record to an evaluation type description reference record.

- POP_PLOT_STRATUM_ASSGN table - Stratum information is assigned to a plot by overlaying the plot's location on the Phase 1 imagery. Plots are linked to their appropriate stratum for an evaluation via the POP_PLOT_STRATUM_ASSGN table.

○ POP_PLOT_STRATUM_ASSGN.PLT_ $\bar{C} N=$ PLOT. $\bar{C} N$ links the stratum assigned to the plot record.

- POP_STRATUM table - The area within an estimation unit is divided into strata. The area for each stratum can be calculated by determining the proportion of Phase 1 pixels/plots in each stratum and multiplying that proportion by the total area in the estimation unit. Information for a single stratum is stored in a single record of the POP_STRATUM table. ○ POP_STRATUM.CN = POP_PLOT_STRATUM_ASSGN.STRATUMM_CN links the defined stratum to each plot.

- REF_CITATION table - Identifies the published source for information on specific gravities, moisture content, and bark as a percent of wood volume that is provided in the REF_SPECIES table.

○ REF_SPECIES.WOOD_SPGR_GREENVOL_DRYWT_CIT = REF_CITATION.CITATTION_NBR

○ REF_SPECIES.BARK_SPGR_GREENVOL_DRYWT_CIT $=$ REF_CITATION.CITATTION_NBR

○ REF_SPECIES.MC_PCT_GREEN_WOOD_CIT $=$ REF CITATION.CITATION NBR

- REF_SPECIES.MC_PCT_GREEN_BARK_CIT $=$ REF_CITATION.CITATIÖN_NBR

○ REF_SPECIES.WOOD_SPGR_MC12VOL_DRYWT_CIT $=$ REF_CITATION.CITATTION_N̄BR

- REF_SPECIES.BARK_VOL_PCT_CIT $=$ REF_CITATION.CITATION_NBR

- REF_FIADB_VERSION table - Contains information identifying the format of the currently available FIADB.

- REF_FOREST_TYPE table - A reference table containing forest type codes, descriptive names, forest type group codes and other information. Data users should link codes as shown below and then obtain the information stored in MEANING to convert the code to a name.

○ REF_FOREST_TYPE.VALUE $=$ COND.FORTYPCD links the forest type reference record to the condition forest code used for reporting and analysis purposes.

○ REF_FOREST_TYPE.VALUE = COND.FLDTYPCD links the forest type reference record to the condition forest type code recorded by field crews.

- REF_FOREST_TYPE.VALUE = COND.FORTYPCDCALC links the forest type reference record to the condition forest type code calculated by an algorithm.

- REF_POP_ATTRIBUTE table - Identifies all of the population estimates that are currently supported, and provides information useful to the estimation procedure. There are currently 92 records in the REF_POP_ATTRIBUTE table providing information ranging from how to calculate forest area to average annual net growth on forestland. 
○ REF POP ATTRIBUTE.ATTRIBUTE NBR = POP_EVAL_ATTRIBUTE.ATTRIBUTE_NBR links the description of the unique population estimate to the records of evaluations that can be used to make those estimates.

- REF_POP_EVAL_TYP_DESCR table - A reference table containing the description for each evaluation type.

○ REF_POP_EVAL_TYP_DESCR.EVAL_TYP $=$ POP_EVAL_TYP.EVAL_TYP links an evaluation type description reference record to an evaluation type record.

- REF_SPECIES table - A reference table containing the species code, descriptive common name, scientific name, and many other attributes for each species. For example, data users who want to convert the species code to the associated common name should link codes as shown below and then obtain the information stored in COMMON_NAME.

○ REF_SPECIES.SPCD = TREE.SPCD links the species reference table record to the tree species code.

- REF_SPECIES.SPCD $=$ SEEDLING.SPCD links the species reference table record to the seedling species code.

○ REF_SPECIES.SPCD $=$ SITETREE.SPCD links the species reference table record to the site tree species code.

- REF_SPECIES_GROUP table - A reference table containing the species group code, descriptive name, and several other attributes for each species group. Data users should link codes as shown below and then obtain the information stored in NAME to convert the code to a descriptive name.

○ REF_SPECIES_GROUP.SPGRPCD = TREE.SPGRPCD links the species group reference table to the tree species group code.

○ REF_SPECIES_GROUP.SPGRPCD = SEEDLING.SPGRPCD links the species reference table record to the seedling species group code.

○ REF_SPECIES_GROUP.SPGRPCD = SITETREE.SPGRPCD links the species reference table record to the site tree species group code.

- REF_STATE_ELEV - Reference table containing information about minimum and maximum elevation found within a State.

- REF_STATE_ELEV.STATECD = SURVEY.STATECD links the State elevation reference record to the survey record.

- REF_UNIT table - The description for each survey unit in a State.

○ REF_UNIT.STATECD $=$ PLOT.STATECD and REF_UNIT.VALUE $=$ PLOT.UNITCD links the survey unit description (MEANING) to the PLOT record.

Figure 4 helps to illustrate how the Phase 1 and other population estimation tables relate to one another and to the PLOT table. 


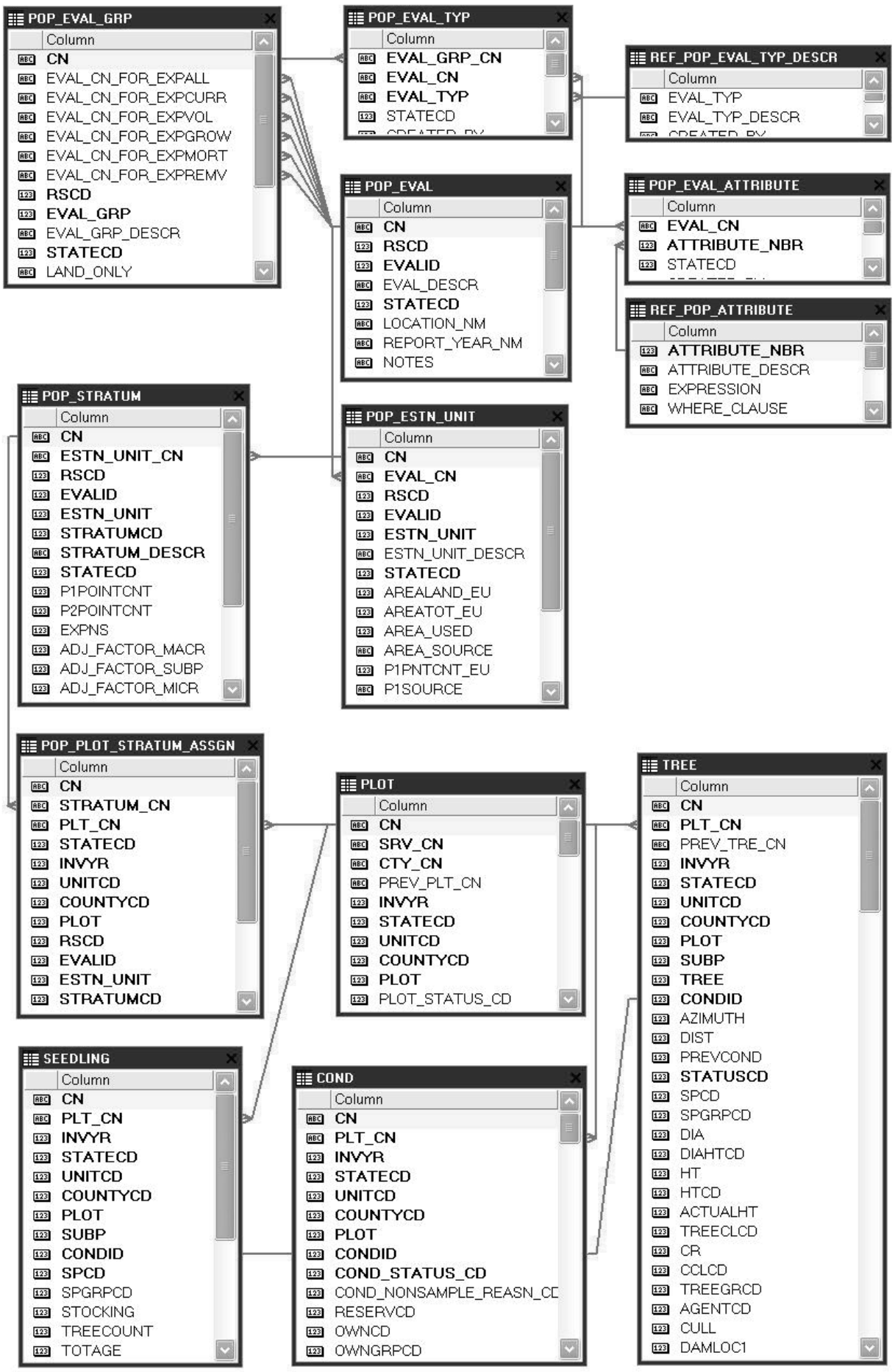

Figure 4. Relationships among Phase 1 and population estimation tables to the Phase 2 plot and other frequently used tables. 


\section{Keys Presented with the Tables}

Each summarized table in chapter 3 has a list of keys just below the bottom of the table. These keys are used to join data from different tables. The following provides a general definition of each kind of key.

\section{Primary key}

A single column in a table whose values uniquely identify each row in an Oracle table. The primary key in each FIADB 4.0 table is the CN column.

The name of the primary key for each table is listed in the table description. It follows the nomenclature of 'TABLEABBREVIATION'_PK. The table abbreviations are:

\begin{tabular}{|c|c|}
\hline Table name & Table abbreviation \\
\hline SURVEY & SRV \\
\hline COUNTY & CTY \\
\hline PLOT & PLT \\
\hline COND & CND \\
\hline SUBPLOT & SBP \\
\hline SUBP_COND & SCD \\
\hline $\mathrm{TREE}^{-}$ & TRE \\
\hline SEEDLING & SDL \\
\hline SITETREE & SIT \\
\hline BOUNDARY & BND \\
\hline SUBP_COND_CHNG_MTRX & CMX \\
\hline TREE_REGIONAL_BIOMASS & TRB \\
\hline POP_ESTN_UNIT & PEU \\
\hline $\mathrm{POP}_{-}^{-} \mathrm{EVAL}^{-}$ & PEV \\
\hline POP_EVAL_ATTRIBUTE & PEA \\
\hline POP_EVAL_GRP & PEG \\
\hline POP_EVAL_TYP & PET \\
\hline POP_PLOT_STRATUM_ASSGN & PPSA \\
\hline POP_STRAT̄UM & PSM \\
\hline REF_POP_ATTRIBUTE & PAE \\
\hline REF_POP_EVAL_TYP_DESCR & PED \\
\hline REF_FORĒET_TȲPE & RFT \\
\hline REF_SPECIES & SPC \\
\hline REF_SPECIES_GROUP & SPG \\
\hline REF_HABTYP_DESCRIPTION & RHN \\
\hline REF_HABTYP_PUBLICATION & $\mathrm{RPN}$ \\
\hline REF_CITATION & CIT \\
\hline REF_FIADB_VERSION & RFN \\
\hline REF_STATE_ELEV & RSE \\
\hline REF_UNIT & UNT \\
\hline
\end{tabular}

\footnotetext{
1 The use of trade or firm names in this publication is for reader information only and does not imply endorsement by the U.S. Department of Agriculture of any product or service.
} 


\section{Unique key}

Multiple columns in a table whose values uniquely identify each row in an Oracle table. There can be one and only one row for each unique key value.

The unique key varies for each FIADB 4.0 table. The unique key for the PLOT table is STATECD, INVYR, UNITCD, COUNTYCD, and PLOT. The unique key for the COND table is PLT_CN and CONDID.

The name of the unique key for each table is listed in the table description. It follows the nomenclature of 'TABLEABBREVIATION'_UK.

\section{Natural key}

A type of unique key made from existing attributes in the table. It is stored as an index in this database.

Not all FIADB 4.0 tables have a natural key. For example, there is no natural key in the PLOT table, rather the natural key and the unique key are the same. The natural key for the COND table is STATECD, INVYR, UNITCD, COUNTYCD, PLOT, and CONDID.

The name of the natural key for each table is listed in the table description. It follows the nomenclature of 'TABLEABBREVIATION'_NAT_I.

\section{Foreign key}

A column in a table that is used as a link to a matching column in another Oracle table.

A foreign key connects a record in one table to one and only one record in another table. Foreign keys are used both to link records between data tables and as a check (or constraint) to prevent "unrepresented data." For example, if there are rows of data in the TREE table for a specific plot, there needs to be a corresponding data row for that same plot in the PLOT table. The foreign key in the TREE table is the attribute PLT_CN, which links specific rows in the TREE table to one record in the PLOT table using the plot attribute CN.

The foreign key for the COND table is PLT_CN. There is always a match of the PLT_CN value to the $\mathrm{CN}$ value in the PLOT table.

The name of the foreign key for each table is listed in the table description. It follows the nomenclature of 'SOURCETABLEABBREVIATION' 'MATCHINGTABLEABBREVIATION'_FK, where the source table is the table containing the foreign key and the matching table is the table the foreign key matches. The foreign key usually matches the $\mathrm{CN}$ column of the matching table. Most tables in FIADB 4.0 have only one foreign key, but tables can have multiple foreign keys. 
Survey Table (Oracle table name is SURVEY)

\begin{tabular}{|c|c|c|c|}
\hline & Column name & Descriptive name & Oracle data type \\
\hline 1 & $\mathrm{CN}$ & Sequence number & VARCHAR2(34) \\
\hline 2 & INVYR & Inventory year & NUMBER(4) \\
\hline 3 & P3_OZONE_IND & Phase 3 ozone indicator & VARCHAR2(1) \\
\hline 4 & STATECD & State code & NUMBER(4) \\
\hline 5 & STATEAB & State abbreviation & VARCHAR2(2) \\
\hline 6 & STATENM & State name & VARCHAR2(28) \\
\hline 7 & RSCD & Region or station code & $\operatorname{NUMBER}(2)$ \\
\hline 8 & ANN_INVENTORY & Annual inventory & VARCHAR2(1) \\
\hline 9 & NOTES & Notes & VARCHAR2(2000) \\
\hline 10 & CREATED_BY & Created by & VARCHAR2(30) \\
\hline 11 & CREATED_DATE & Created date & DATE \\
\hline 12 & CREATED_IN_INSTANCE & Created in instance & VARCHAR2(6) \\
\hline 13 & MODIFIED_BY & Modified by & VARCHAR2(30) \\
\hline 14 & MODIFIED_DATE & Modified date & DATE \\
\hline 15 & MODIFIED_IN_INSTANCE & Modified in instance & VARCHAR2(6) \\
\hline 16 & CYCLE & Inventory cycle number & NUMBER(2) \\
\hline 17 & SUBCYCLE & Inventory subcycle number & NUMBER(2) \\
\hline
\end{tabular}

\begin{tabular}{|l|l|l|l|}
\hline Type of Key & Column(s) order & Tables to link & Abbreviated notation \\
\hline Primary & (CN) & N/A & SRV_PK \\
\hline Unique & $\begin{array}{l}\text { (STATECD, INVYR, } \\
\text { P3_OZONE_IND, CYCLE) }\end{array}$ & N/A & SRV_UK \\
\hline
\end{tabular}

1. $\mathrm{CN}$

2. INVYR
Sequence number. A unique sequence number used to identify a survey record.

Inventory year. The year that best represents when the inventory data were collected. Under the annual inventory system, a group of plots is selected each year for sampling. The selection is based on a panel system. INVYR is the year in which the majority of plots in that group were collected (plots in the group have the same panel and, if applicable, subpanel). Under periodic inventory, a reporting inventory year was selected, usually based on the year in which the majority of the plots were collected or the mid-point of the years over which the inventory spanned. For either annual or periodic inventory, INVYR is not necessarily the same as MEASYEAR.

Exceptions:

INVYR $=9999$. INVYR is set to 9999 to distinguish Phase 3 plots taken by the western FIA work units that are "off subpanel." This is due to differences in measurement intervals between Phase 3 (measurement interval $=5$ years) and Phase 2 (measurement interval $=10$ years) plots. Only users interested in performing certain Phase 3 data analyses should access plots with this anomalous value in INVYR. 
INVYR $<100$. INVYR $<100$ indicates that population estimates were derived from a pre-NIMS regional processing system and the same plot either has been or may soon be re-processed in NIMS as part of a separate evaluation. The NIMS processed copy of the plot follows the standard INVYR format. This only applies to plots collected in the South (SURVEY.RSCD $=33$ ) with the national design or a similar regional design (PLOT.DESIGNCD $=1$ or 220-233) that were collected when the inventory year was 1998 through 2005.

INVYR $=98$ is equivalent to 1998 but processed through regional system INVYR $=99$ is equivalent to 1999 but processed through regional system INVYR $=0$ is equivalent to 2000 but processed through regional system $\mathrm{INVYR}=1$ is equivalent to 2001 but processed through regional system INVYR $=2$ is equivalent to 2002 but processed through regional system $\mathrm{INVYR}=3$ is equivalent to 2003 but processed through regional system INVYR $=4$ is equivalent to 2004 but processed through regional system $\mathrm{INVYR}=5$ is equivalent to 2005 but processed through regional system

3. P3_OZONE_IND

Phase 3 ozone indicator. Values are Y (yes) and N (no). If Y, then the Survey is for a P3 ozone inventory. If N, then the Survey is not for a P3 ozone inventory. Note that P3_OZONE_IND is part of the unique key because ozone data are stored as a separate inventory (survey); therefore, combinations of STATECD and INVYR may occur more than one time.

4. STATECD State code. Bureau of the Census Federal Information Processing Standards (FIPS) two-digit code for each State. Refer to appendix C.

5. STATEAB State abbreviation. The two-character State abbreviation. Refer to appendix C.

6. STATENM State name. Refer to appendix C.

7. RSCD Region or Station Code. Identification number of the Forest Service National Forest System Region or Station (FIA work unit) that provided the inventory data (see appendix $\mathrm{C}$ for more information).

$\begin{array}{ll}\text { Code } & \text { Description } \\ 22 & \text { Rocky Mountain Research Station (RMRS) } \\ 23 & \text { North Central Research Station (NCRS) } \\ 24 & \text { Northeastern Research Station (NERS) } \\ 26 & \text { Pacific Northwest Research Station (PNWRS) } \\ 27 & \text { Pacific Northwest Research Station (PNWRS)-Alaska } \\ 33 & \text { Southern Research Station (SRS) }\end{array}$




\section{ANN_INVENTORY}

Annual Inventory. An indicator to show if a particular inventory was collected as an annual inventory or a periodic inventory. Values are $\mathrm{Y}$ or $\mathrm{N}$, and $\mathrm{Y}$ means that the inventory is annual.

9. NOTES Notes. An optional item where notes about the inventory may be stored.

10. CREATED_BY Created by. The employee who created the record. This attribute is intentionally left blank in download files.

11. CREATED_DATE

Created date. The date the record was created. Date will be in the form DDMON-YYYY.

12. CREATED_IN_INSTANCE

Created in instance. The database instance in which the record was created. Each computer system has a unique database instance code and this attribute stores that information to determine on which computer the record was created.

13. MODIFIED_BY

Modified by. The employee who modified the record. This field will be blank (null) if the data have not been modified since initial creation. This attribute is intentionally left blank in download files.

14. MODIFIED_DATE

Modified date. The date the record was last modified. This field will be blank (null) if the data have not been modified since initial creation. Date will be in the form DD-MON-YYYY.

\section{MODIFIED_IN_INSTANCE}

Modified in instance. The database instance in which the record was modified. This field will be blank (null) if the data have not been modified since initial creation.

16. CYCLE Inventory cycle number. A number assigned to a set of plots, measured over a particular period of time from which a State estimate using all possible plots is obtained. A cycle number $>1$ does not necessarily mean that information for previous cycles resides in the database. A cycle is relevant for periodic and annual inventories.

17. SUBCYCLE Inventory subcycle number. For an annual inventory that takes n years to measure all plots, subcycle shows in which of the n years of the cycle the 
FIA Database Description and Users Manual for Phase 2, version 4.0

Chapter 3. Survey Table

data were measured. Subcycle is 0 for a periodic inventory. Subcycle 99 may be used for plots that are not included in the estimation process. 
County Table (Oracle table name is COUNTY)

\begin{tabular}{|l|l|l|l|}
\hline & Column name & Descriptive name & Oracle data type \\
\hline 1 & STATECD & State code & NUMBER(4) \\
\hline 2 & UNITCD & Survey unit code & NUMBER(2) \\
\hline 3 & COUNTYCD & County code & NUMBER(3) \\
\hline 4 & COUNTYNM & County name & VARCHAR2(50) \\
\hline 5 & CN & Sequence number & VARCHAR2(34) \\
\hline 6 & CREATED_BY & Created by & VARCHAR2(30) \\
\hline 7 & CREATED_DATE & Created date & DATE \\
\hline 8 & CREATED_IN_INSTANCE & Created in instance & VARCHAR2(6) \\
\hline 9 & MODIFIED_BY & Modified by & VARCHAR2(30) \\
\hline 10 & MODIFIED_DATE & Modified date & DATE \\
\hline 11 & MODIFIED_IN_INSTANCE & Modified in instance & VARCHAR2(6) \\
\hline
\end{tabular}

\begin{tabular}{|l|l|l|l|}
\hline Type of key & Column(s) order & Tables to link & Abbreviated notation \\
\hline Primary & $(\mathrm{CN})$ & N/A & CTY_PK \\
\hline Unique & (STATECD, UNITCD, COUNTYCD) & N/A & CTY_UK \\
\hline
\end{tabular}

1. STATECD State code. Bureau of the Census Federal Information Processing Standards (FIPS) two-digit code for each State. Refer to appendix C.

2. UNITCD Survey unit code. Forest Inventory and Analysis survey unit identification number. Survey units are usually groups of counties within each State. For periodic inventories, Survey units may be made up of lands of particular owners. Refer to appendix C for codes.

3. COUNTYCD County code. The identification number for a county, parish, watershed, borough, or similar governmental unit in a State. FIPS codes from the Bureau of the Census are used. Refer to appendix $\mathrm{C}$ for codes.

4. COUNTYNM County name. County name as recorded by the Bureau of the Census for individual counties, or the name given to a similar governmental unit by the FIA program. Only the first 50 characters of the name are used. Refer to appendix $\mathrm{C}$ for names.

5. CN Sequence number. A unique sequence number used to identify a county record.

6. CREATED_BY Created by. The employee who created the record. This attribute is intentionally left blank in download files.

7. CREATED_DATE

Created date. The date the record was created. Date will be in the form DDMON-YYYY. 


\section{CREATED_IN_INSTANCE}

Created in instance. The database instance in which the record was created. Each computer system has a unique database instance code and this attribute stores that information to determine on which computer the record was created.

9. MODIFIED_BY

Modified by. The employee who modified the record. This field will be blank (null) if the data have not been modified since initial creation. This attribute is intentionally left blank in download files.

10. MODIFIED_DATE

Modified date. The date the record was last modified. This field will be blank (null) if the data have not been modified since initial creation. Date will be in the form DD-MON-YYYY.

\section{MODIFIED_IN_INSTANCE}

Modified in instance. The database instance in which the record was modified. This field will be blank (null) if the data have not been modified since initial creation. 
Plot Table (Oracle table name is PLOT)

\begin{tabular}{|c|c|c|c|}
\hline & Column name & Descriptive name & Oracle data type \\
\hline 1 & $\mathrm{CN}$ & Sequence number & VARCHAR2(34) \\
\hline 2 & SRV_CN & Survey sequence number & VARCHAR2(34) \\
\hline 3 & CTY_CN & County sequence number & VARCHAR2(34) \\
\hline 4 & PREV_PLT_CN & Previous plot sequence number & VARCHAR2(34) \\
\hline 5 & INVYR & Inventory year & NUMBER(4) \\
\hline 6 & STATECD & State code & NUMBER(4) \\
\hline 7 & UNITCD & Survey unit code & NUMBER(2) \\
\hline 8 & COUNTYCD & County code & NUMBER(3) \\
\hline 9 & PLOT & Phase 2 plot number & NUMBER(5) \\
\hline 10 & PLOT_STATUS_CD & Plot status code & NUMBER(1) \\
\hline 11 & PLOT_NONSAMPLE_REASN_CD & Plot nonsampled reason code & NUMBER(2) \\
\hline 12 & MEASYEAR & Measurement year & NUMBER(4) \\
\hline 13 & MEASMON & Measurement month & NUMBER(2) \\
\hline 14 & MEASDAY & Measurement day & NUMBER(2) \\
\hline 15 & REMPER & Remeasurement period & $\operatorname{NUMBER}(3,1)$ \\
\hline 16 & KINDCD & Sample kind code & NUMBER(2) \\
\hline 17 & DESIGNCD & Plot design code & NUMBER(4) \\
\hline 18 & RDDISTCD & Horizontal distance to improved road code & NUMBER(2) \\
\hline 19 & WATERCD & Water on plot code & NUMBER(2) \\
\hline 20 & LAT & Latitude & $\operatorname{NUMBER}(8,6)$ \\
\hline 21 & LON & Longitude & $\operatorname{NUMBER}(9,6)$ \\
\hline 22 & ELEV & Elevation & NUMBER(5) \\
\hline 23 & GROW_TYP_CD & Type of annual volume growth code & NUMBER(2) \\
\hline 24 & MORT_TYP_CD & Type of annual mortality volume code & NUMBER(2) \\
\hline 25 & P2PANEL & Phase 2 panel number & NUMBER(2) \\
\hline 26 & P3PANEL & Phase 3 panel number & NUMBER(2) \\
\hline 27 & ECOSUBCD & Ecological subsection code & VARCHAR2(7) \\
\hline 28 & CONGCD & Congressional district code & NUMBER(4) \\
\hline 29 & MANUAL & Manual (field guide) version number & $\operatorname{NUMBER}(3,1)$ \\
\hline 30 & SUBPANEL & Subpanel & NUMBER(2) \\
\hline 31 & KINDCD_NC & Sample kind code, North Central & $\operatorname{NUMBER}(2)$ \\
\hline 32 & QA_STATUS & Quality assurance status & NUMBER(1) \\
\hline 33 & CREATED_BY & Created by & VARCHAR2(30) \\
\hline 34 & CREATED_DATE & Created date & DATE \\
\hline 35 & CREATED_IN_INSTANCE & Created in instance & VARCHAR2(6) \\
\hline 36 & MODIFIED_BY & Modified by & VARCHAR2(30) \\
\hline
\end{tabular}


FIA Database Description and Users Manual for Phase 2, version 4.0 Chapter 3. Plot Table

\begin{tabular}{|l|l|l|l|}
\hline & Column name & Descriptive name & Oracle data type \\
\hline 37 & MODIFIED_DATE & Modified date & DATE \\
\hline 38 & MODIFIED_IN_INSTANCE & Modified in instance & VARCHAR2(6) \\
\hline 39 & MICROPLOT_LOC & Microplot location & VARCHAR2(12) \\
\hline 40 & DECLINATION & Declination & NUMBER(4,1) \\
\hline 41 & EMAP_HEX & EMAP hexagon & NUMBER(7) \\
\hline 42 & SAMP_METHOD_CD & Sample method code & NUMBER(1) \\
\hline 43 & SUBP_EXAMINE_CD & Subplots examined code & NUMBER(1) \\
\hline 44 & MACRO_BREAKPOINT_DIA & Macroplot breakpoint diameter & NUMBER(2) \\
\hline 45 & INTENSITY & Intensity & VARCHAR2(2) \\
\hline 46 & CYCLE & Inventory cycle number & NUMBER(2) \\
\hline 47 & SUBCYCLE & Inventory subcycle number & NUMBER(2) \\
\hline 48 & ECO_UNIT_PNW & $\begin{array}{l}\text { Ecological unit, Pacific Northwest } \\
\text { Research Station }\end{array}$ & VARCHAR2(10) \\
\hline 49 & TOPO_POSITION_PNW & $\begin{array}{l}\text { Topographic position, Pacific Northwest } \\
\text { Research Station }\end{array}$ & VARCHAR2(2) \\
\hline 50 & NF_SAMPLING_STATUS_CD & Nonforest sampling status code & NUMBER(1) \\
\hline 51 & NF_PLOT_STATUS_CD & Nonforest plot status cd & NUMBER(1) \\
\hline 52 & $\begin{array}{l}\text { NF_PLOT_NONSAMPLE_REASN_- } \\
\text { CD }\end{array}$ & Nonforest plot nonsampled reason code & NUMBER(2) \\
\hline 53 & P2VEG_SAMPLING_STATUS_CD & P2 vegetation sampling status code & NUMBER(1) \\
\hline 54 & $\begin{array}{l}\text { P2VEG_SAMPLING_LEVEL_ } \\
\text { DETAIL_CD }\end{array}$ & P2 vegetation sampling level detail code & NUMBER(1) \\
\hline 55 & $\begin{array}{l}\text { INVASIVE_SAMPLING_STATUS_ } \\
\text { CD }\end{array}$ & Invasive sampling status code & NUMBER(1) \\
\hline 56 & $\begin{array}{l}\text { INVASIVE_SPECIMEN_RULE_ } \\
\text { CD }\end{array}$ & Invasive specimen rule code & NUMBER(1) \\
\hline
\end{tabular}

\begin{tabular}{|l|l|l|l|}
\hline Type of Key & Column(s) order & Tables to link & Abbreviated notation \\
\hline Primary & (CN) & N/A & PLT_PK \\
\hline Unique & $\begin{array}{l}\text { (STATECD, INVYR, UNITCD, } \\
\text { COUNTYCD, PLOT) }\end{array}$ & N/A & PLT_UK \\
\hline Foreign & (CTY_CN) & PLOT to COUNTY & PLT_CTY_FK \\
\hline & (SRV_CN) & PLOT to SURVEY & PLT_SRV_FK \\
\hline
\end{tabular}

1. $\mathrm{CN}$

2. SRV_CN

3. CTY_CN
Sequence number. A unique sequence number used to identify a plot record. Survey sequence number. Foreign key linking the plot record to the survey record.

County sequence number. Foreign key linking the plot record to the county record. 


\section{PREV_PLT_CN}

Previous plot sequence number. Foreign key linking the plot record to the previous inventory's plot record for this location. Only populated on remeasurement plots.

5. INVYR

Inventory year. The year that best represents when the inventory data were collected. Under the annual inventory system, a group of plots is selected each year for sampling. The selection is based on a panel system. INVYR is the year in which the majority of plots in that group were collected (plots in the group have the same panel and, if applicable, subpanel). Under periodic inventory, a reporting inventory year was selected, usually based on the year in which the majority of the plots were collected or the mid-point of the years over which the inventory spanned. For either annual or periodic inventory, INVYR is not necessarily the same as MEASYEAR.

Exceptions:

INVYR $=9999$. INVYR is set to 9999 to distinguish Phase 3 plots taken by the western FIA work units that are "off subpanel." This is due to differences in measurement intervals between Phase 3 (measurement interval $=5$ years) and Phase 2 (measurement interval $=10$ years) plots. Only users interested in performing certain Phase 3 data analyses should access plots with this anomalous value in INVYR.

INVYR $<100$. INVYR $<100$ indicates that population estimates were derived from a pre-NIMS regional processing system and the same plot either has been or may soon be re-processed in NIMS as part of a separate evaluation. The NIMS processed copy of the plot follows the standard INVYR format. This only applies to plots collected in the South (SURVEY.RSCD $=33$ ) with the national design or a similar regional design (DESIGNCD $=1$ or 220-233) that were collected when the inventory year was 1998 through 2005.

INVYR $=98$ is equivalent to 1998 but processed through regional system $\mathrm{INVYR}=99$ is equivalent to 1999 but processed through regional system INVYR $=0$ is equivalent to 2000 but processed through regional system $\mathrm{INVYR}=1$ is equivalent to 2001 but processed through regional system $\mathrm{INVYR}=2$ is equivalent to 2002 but processed through regional system $\mathrm{INVYR}=3$ is equivalent to 2003 but processed through regional system $\mathrm{INVYR}=4$ is equivalent to 2004 but processed through regional system $\mathrm{INVYR}=5$ is equivalent to 2005 but processed through regional system

6. STATECD State code. Bureau of the Census Federal Information Processing Standards (FIPS) two-digit code for each State. Refer to appendix C.

7. UNITCD Survey unit code. Forest Inventory and Analysis survey unit identification number. Survey units are usually groups of counties within each State. For periodic inventories, Survey units may be made up of lands of particular owners. Refer to appendix $\mathrm{C}$ for codes. 
8. COUNTYCD County code. The identification number for a county, parish, watershed, borough, or similar governmental unit in a State. FIPS codes from the Bureau of the Census are used. Refer to appendix $\mathrm{C}$ for codes.

9. PLOT

Phase 2 plot number. An identifier for a plot. Along with STATECD, INVYR, UNITCD, COUNTYCD and/or some other combinations of variables, PLOT may be used to uniquely identify a plot.

10. PLOT_STATUS_CD

Plot status code. A code that describes the sampling status of the plot. Blank (null) values may be present for periodic inventories.

$\begin{array}{ll}\text { Code } & \text { Description } \\ 1 & \text { Sampled }- \text { at least one accessible forest land condition present on plot } \\ 2 & \text { Sampled }- \text { no accessible forest land condition present on plot } \\ 3 & \text { Nonsampled }\end{array}$

\section{PLOT_NONSAMPLE_REASN_CD}

Plot nonsampled reason code. For entire plots that cannot be sampled, one of the following reasons is recorded.

\section{Code Description}

01 Outside U.S. boundary - Entire plot is outside of the U.S. border.

02 Denied access area - Access to the entire plot is denied by the legal owner, or by the owner of the only reasonable route to the plot.

03 Hazardous - Entire plot cannot be accessed because of a hazard or danger, for example cliffs, quarries, strip mines, illegal substance plantations, high water, etc.

05 Lost data - Plot data file was discovered to be corrupt after a panel was completed and submitted for processing.

$06 \quad$ Lost plot - Entire plot cannot be found.

07 Wrong location - Previous plot can be found, but its placement is beyond the tolerance limits for plot location.

08 Skipped visit - Entire plot skipped. Used for plots that are not completed prior to the time a panel is finished and submitted for processing. This code is for office use only.

09 Dropped intensified plot - Intensified plot dropped due to a change in grid density. This code used only by units engaged in intensification. This code is for office use only.

10 Other - Entire plot not sampled due to a reason other than one of the specific reasons already listed.

11 Ocean - Plot falls in ocean water below mean high tide line.

12. MEASYEAR Measurement year. The year in which the plot was completed. MEASYEAR may differ from INVYR. 
13. MEASMON Measurement month. The month in which the plot was completed. May be blank (null) for periodic inventory.

$\begin{array}{llll}\text { Code } & \text { Description } & \text { Code } & \text { Description } \\ 01 & \text { January } & 07 & \text { July } \\ 02 & \text { February } & 08 & \text { August } \\ 03 & \text { March } & 09 & \text { September } \\ 04 & \text { April } & 10 & \text { October } \\ 05 & \text { May } & 11 & \text { November } \\ 06 & \text { June } & 12 & \text { December }\end{array}$

14. MEASDAY Measurement day. The day of the month in which the plot was completed. May be blank (null) for periodic inventory.

15. REMPER Remeasurement period. The number of years between measurements for remeasured plots. This attribute is null (blank) for new plots or remeasured plots that are not used for growth, removals, or mortality estimates. For data processed with NIMS, REMPER is the number of years between measurements (to the nearest 0.1 year). For data processed with systems other than NIMS, remeasurement period is based on the number of growing seasons between measurements. Allocation of parts of the growing season by month is different for each FIA work unit. Contact the appropriate FIA work unit for information on how this is done for a particular State. NOTE: it is not valid to use REMPER to estimate periodic change.

16. KINDCD Sample kind code. A code indicating the type of plot installation. Database users may also want to examine DESIGNCD to obtain additional information about the kind of plot being selected.

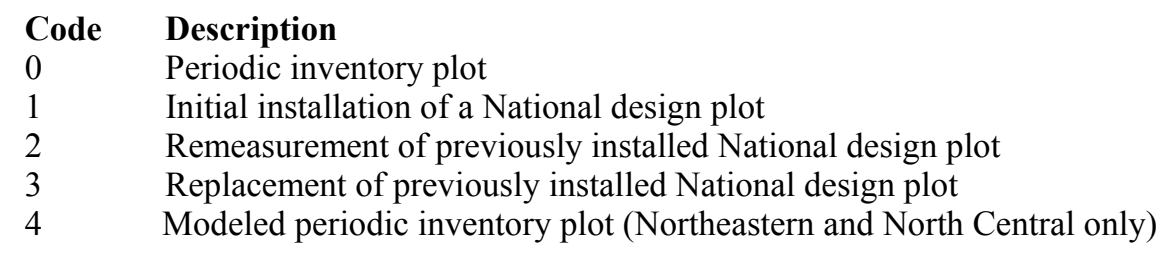

17. DESIGNCD Plot design code. A code indicating the type of plot design used to collect the data. Refer to appendix B for a list of codes and descriptions.

18. RDDISTCD Horizontal distance to improved road code. The straight-line distance from plot center to the nearest improved road, which is a road of any width that is maintained as evidenced by pavement, gravel, grading, ditching, and/or other improvements. Populated for all forested plots using the National Field Guide protocols (MANUAL $\geq 1.0$ ) and populated by some FIA work units for inventory plots collected where MANUAL $<1.0$. 


$\begin{array}{ll}\text { Code } & \text { Description } \\ 1 & 100 \mathrm{ft} \text { or less } \\ 2 & 101 \mathrm{ft} \text { to } 300 \mathrm{ft} \\ 3 & 301 \mathrm{ft} \text { to } 500 \mathrm{ft} \\ 4 & 501 \mathrm{ft} \text { to } 1000 \mathrm{ft} \\ 5 & 1001 \mathrm{ft} \text { to } 1 / 2 \mathrm{mile} \\ 6 & 1 / 2 \text { to } 1 \text { mile } \\ 7 & 1 \text { to } 3 \text { miles } \\ 8 & 3 \text { to } 5 \text { miles } \\ 9 & \text { Greater than } 5 \text { miles }\end{array}$

19. WATERCD Water on plot code. Water body $<1$ acre in size or a stream $<30$ feet wide that has the greatest impact on the area within the forest land portion of the four subplots. The coding hierarchy is listed in order from large permanent water to temporary water. Populated for all forested plots using the National Field Guide protocols (MANUAL $\geq 1.0$ ) and populated by some FIA work units for inventory plots collected where MANUAL $<1.0$.

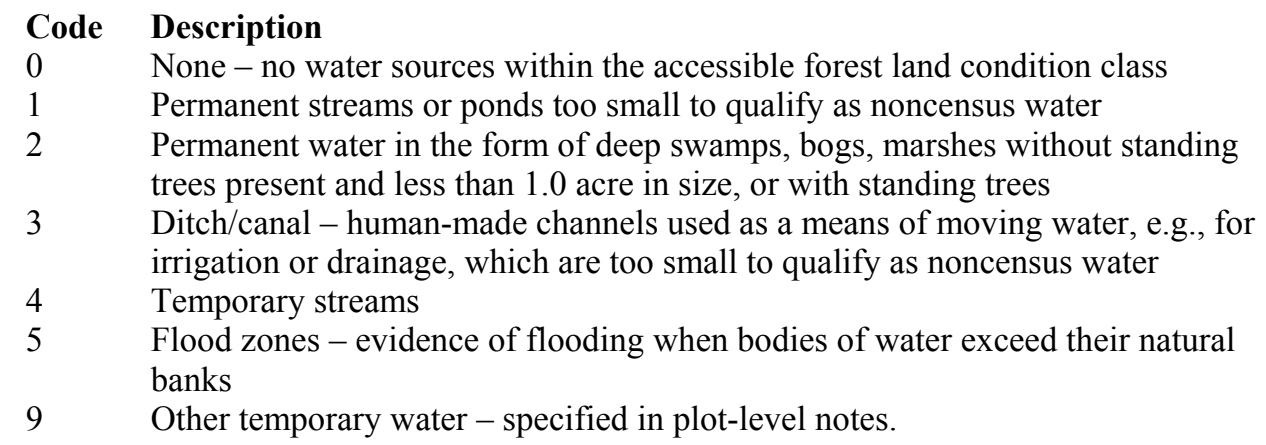

20. LAT

21. $\mathrm{LON}$

22. ELEV
Latitude. The approximate latitude of the plot in decimal degrees using NAD 83 datum. Actual plot coordinates cannot be released because of a Privacy provision enacted by Congress in the Food Security Act of 1985. Therefore, this attribute is approximately $+/-1$ mile and, for annual inventory data, most plots are within $+/-1 / 2$ mile. Annual data have additional uncertainty for private plots caused by swapping plot coordinates for up to 20 percent of the plots. In some cases, the county centroid is used when the actual coordinate is not available.

Longitude. The approximate longitude of the plot in decimal degrees using NAD 83 datum. Actual plot coordinates cannot be released because of a Privacy provision enacted by Congress in the Food Security Act of 1985. Therefore, this attribute is approximately $+/-1$ mile and, for annual inventory data, most plots are within $+/-1 / 2$ mile. Annual data have additional uncertainty for private plots caused by swapping plot coordinates for up to 20 percent of the plots. In some cases, the county centroid is used when the actual coordinate is not available.

Elevation. The distance the plot is located above sea level, recorded in feet (NAD 83 datum). Negative values indicate distance below sea level. 
23. GROW_TYP_CD

Type of annual volume growth code. A code indicating how volume growth is estimated. Current annual growth is an estimate of the amount of volume that was added to a tree in the year before the tree was sampled, and is based on the measured diameter increment recorded when the tree was sampled or on a modeled diameter for the previous year. Periodic annual growth is an estimate of the average annual change in volume occurring between two measurements, usually the current inventory and the previous inventory, where the same plot is evaluated twice. Periodic annual growth is the increase in volume between inventories divided by the number of years between each inventory. This attribute is blank (null) if the plot does not contribute to the growth estimate.

$\begin{array}{ll}\text { Code } & \text { Description } \\ 1 & \text { Current annual } \\ 2 & \text { Periodic annual }\end{array}$

24. MORT_TYP_CD

Type of annual mortality volume code. A code indicating how mortality volume is estimated. Current annual mortality is an estimate of the volume of trees dying in the year before the plot was measured, and is based on the year of death or on a modeled estimate. Periodic annual mortality is an estimate of the average annual volume of trees dying between two measurements, usually the current inventory and previous inventory, where the same plot is evaluated twice. Periodic annual mortality is the loss of volume between inventories divided by the number of years between each inventory. Periodic average annual mortality is the most common type of annual mortality estimated. This attribute is blank (null) if the plot does not contribute to the mortality estimate.

$\begin{array}{ll}\text { Code } & \text { Description } \\ 1 & \text { Current annual } \\ 2 & \text { Periodic annual }\end{array}$

25. P2PANEL Phase 2 panel number. The value for P2PANEL ranges from 1 to 7 for annual inventories and is blank (null) for periodic inventories. A panel is a sample in which the same elements are measured on two or more occasions. FIA divides the plots in each State into 5 or 7 panels that can be used to independently sample the population.

26. P3PANEL Phase 3 panel number. A panel is a sample in which the same elements are measured on two or more occasions. FIA divides the plots in each State into 5 or 7 panels that can be used to independently sample the population. The value for P3PANEL ranges from 1 to 7 for those plots where Phase 3 data were collected. If the plot is not a Phase 3 plot, then this attribute is left blank (null). 
27. ECOSUBCD Ecological subsection code. An area of similar surficial geology, lithology, geomorphic process, soil groups, subregional climate, and potential natural communities. Subsection boundaries usually correspond with discrete changes in geomorphology. Subsection information is used for broad planning and assessment. Subsection codes for the coterminous United States were developed as part of the "Forest Service Map of Provinces, Sections, and Subsections of the United States (Cleland and others 2007) (visit http://fsgeodata.fs.fed.us/other_resources/ecosubregions.html). For southeast and south coastal Alaska, the subsection codes are based on the ecological sections as designated in the "Ecoregions and Subregions of Alaska, EcoMap version 2.0" (Nowacki and Brock 1995) (visit http://agdcftp1.wr.usgs.gov/pub/projects/fhm/ecomap.gif). The ECOSUBCD is based on fuzzed and swapped plot coordinates. This attribute is coded for the coterminous United States, southeast and south coastal Alaska, and is left blank (null) in all other instances.

28. CONGCD Congressional district code. A territorial division of a State from which a member of the U.S. House of Representatives is elected. The congressional district code assigned to a plot (regardless of when it was measured) is for the current Congress; the assignment is made based on the plot's approximate coordinates. CONGCD is a four-digit number. The first two digits are the State FIPS code and the last two digits are the congressional district number. If a State has only one congressional district, the congressional district number is 00. If a plot's congressional district assignment falls in a State other than the plot's actual State due to using the approximate coordinates, the congressional district code will be for the nearest congressional district in the correct State. This attribute is coded for the coterminous States and Alaska, and is left blank (null) in all other instances. For more information about the coverage used to assign this attribute, see National Atlas of the United States (2007).

29. MANUAL Manual (field guide) version number. Version number of the Field Guide used to describe procedures for collecting data on the plot. The National FIA Field Guide began with version 1.0; therefore data taken using the National Field procedures will have PLOT.MANUAL $\geq 1.0$. Data taken according to field instructions prior to the use of the National Field Guide have PLOT.MANUAL $<1.0$.

30. SUBPANEL Subpanel. Subpanel assignment for the plot for those FIA work units using subpaneling. FIA uses a 5-panel system (see P2PANEL) to divide plot sampling over a 5-year period. Funding for western FIA work units is only sufficient to allow plot sampling over a 10-year period. Therefore, panels are further divided into subpanels. This attribute is left blank (null) if subpaneling is not used. In some States, seven panels are used and SUBPANEL is blank (null). 
31. KINDCD_NC Sample kind code, North Central. This attribute is populated through 2005 for the former North Central work unit (SURVEY.RSCD = 23) and is blank (null) for all other FIA work units.

$\begin{array}{ll}\text { Code } & \text { Description } \\ 0 & \text { New/lost } \\ 6 & \text { Remeasured } \\ 8 & \text { Old location but not remeasured } \\ 20 & \text { Skipped } \\ 33 & \text { Replacement of lost plot }\end{array}$

32. QA_STATUS Quality assurance status. A code indicating the type of plot data collected. Populated for all forested subplots using the National Field Guide protocols (MANUAL $\geq 1.0$ ).

$\begin{array}{ll}\text { Code } & \text { Description } \\ 1 & \text { Standard production plot } \\ 2 & \text { Cold check } \\ 3 & \text { Reference plot (off grid) } \\ 4 & \text { Training/practice plot (off grid) } \\ 5 & \text { Botched plot file (disregard during data processing) } \\ 6 & \text { Blind check } \\ 7 & \text { Production plot (hot check) }\end{array}$

33. CREATED_BY Created by. The employee who created the record. This attribute is intentionally left blank in download files.

34. CREATED_DATE

Created date. The date the record was created. Date will be in the form DDMON-YYYY.

35. CREATED_IN_INSTANCE

Created in instance. The database instance in which the record was created. Each computer system has a unique database instance code and this attribute stores that information to determine on which computer the record was created.

36. MODIFIED_BY

Modified by. The employee who modified the record. This field will be blank (null) if the data have not been modified since initial creation. This attribute is intentionally left blank in download files.

37. MODIFIED DATE

Modified date. The date the record was last modified. This field will be blank (null) if the data have not been modified since initial creation. Date will be in the form DD-MON-YYYY. 


\section{MODIFIED IN INSTANCE}

Modified in instance. The database instance in which the record was modified. This field will be blank (null) if the data have not been modified since initial creation.

39. MICROPLOT_LOC

Microplot location. Values are 'OFFSET' or 'CENTER.' The offset microplot center is located 12 feet due east (90 degrees) of subplot center. The current standard is that the microplot is located in the 'OFFSET' location, but some earlier inventories, including some early panels of the annual inventory, may contain data where the microplot was located at the 'CENTER' location. Populated for annual inventory and may be populated for periodic inventory.

40. DECLINATION

Declination. (Core optional.) The azimuth correction used to adjust magnetic north to true north. All azimuths are assumed to be magnetic azimuths unless otherwise designated. The Portland FIA work unit historically has corrected all compass readings for true north. This field is to be used only in cases where FIA work units are adjusting azimuths to correspond to true north; for FIA work units using magnetic azimuths, this field will always be set $=0$ in the office. This field carries a decimal place because the USGS corrections are provided to the nearest half degree. DECLINATION is defined as:

\section{DECLINATION $=($ TRUE NORTH - MAGNETIC NORTH $)$}

41. EMAP_HEX EMAP hexagon. The identifier for the approximately 160,000 acre Environmental Monitoring and Assessment Program (EMAP) hexagon in which the plot is located. EMAP hexagons are available to the public, cover the coterminous United States, and have been used in summarizing and aggregating data about numerous natural resources. Populated for annual inventory and may be populated for periodic inventory.

\section{SAMP_METHOD_CD}

Sample method code. A code indicating if the plot was observed in the field or remotely sensed in the office.

Code Description

1 Field visited, meaning a field crew physically examined the plot and recorded information at least about subplot 1 center condition (see SUBP_EXAMINE_CD below).

2 Remotely sensed, meaning a determination was made using some type of imagery that a field visit was not necessary. When the plot is sampled remotely, the number of subplots examined (SUBP_EXAMINE_CD) usually equals 1. 
43. SUBP_EXAMINE_CD

Subplots examined code. A code indicating the number of subplots examined. By default, PLOT_STATUS_CD $=1$ plots have all 4 subplots examined.

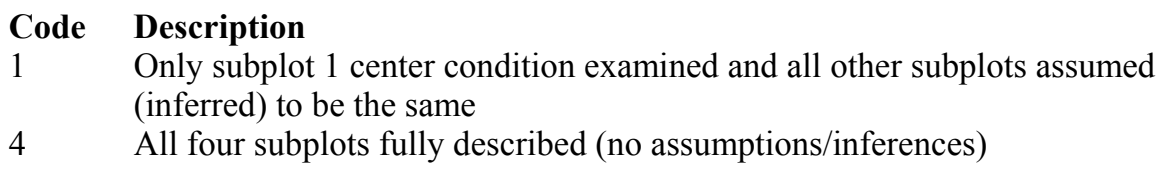

\section{MACRO_BREAKPOINT_DIA}

Macroplot breakpoint diameter. (Core optional.) A macroplot breakpoint diameter is the diameter (either DBH or DRC) above which trees are measured on the plot extending from 0.01 to 58.9 feet horizontal distance from the center of each subplot. Examples of different breakpoint diameters used by western FIA work units are 24 inches or 30 inches (Pacific Northwest), or 21 inches (Interior West). Installation of macroplots is core optional and is used to have a larger plot size in order to more adequately sample large trees. If macroplots are not being installed, this item will be left blank (null).

45. INTENSITY Intensity. A code used to identify federal base grid annual inventory plots and plots that have been added to intensify a particular sample. Under the federal base grid, one plot is collected in each theoretical hexagonal polygon, which is slightly more than 5,900 acres in size. Plots with INTENSITY $=1$ are part of the federal base grid. In some instances, States and/or agencies have provided additional support to increase the sampling intensity for an area. Supplemental plots have INTENSITY set to higher numbers depending on the amount of plot intensification chosen for the particular estimation unit. Populated for annual inventory data only.

46. CYCLE Inventory cycle number. A number assigned to a set of plots, measured over a particular period of time from which a State estimate using all possible plots is obtained. A cycle number $>1$ does not necessarily mean that information for previous cycles resides in the database. A cycle is relevant for periodic and annual inventories.

47. SUBCYCLE Inventory subcycle number. For an annual inventory that takes $\mathrm{n}$ years to measure all plots, subcycle shows in which of the $n$ years of the cycle the data were measured. Subcycle is 0 for a periodic inventory. Subcycle 99 may be used for plots that are not included in the estimation process.

\section{ECO_UNIT_PNW}

Ecological unit, Pacific Northwest Research Station. Plots taken by PNW FIA are assigned to the ecological unit in which they are located. Certain units have stocking adjustments made to the plots that occur on very low productivity lands, which thereby reduces the estimated potential 
productivity of the plot. More information can be found in MacLean (1973). Only collected by certain FIA work units (SURVEY.RSCD $=26$ or 27).

49. TOPO_POSITION_PNW

Topographic position, Pacific Northwest Research Station. The topographic position that describes the plot area. Illustrations available in Plot section of PNW field guide located at:

http//www.fs.fed.us/pnw/fia/publications/fieldmanuals.shtml. Adapted from information found in Wilson (1900). Only collected by certain FIA work units (SURVEY.RSCD = 26).

Code
1
2
3
4
5
6
7
8
9

Topographic position
Ridge top or mountain peak over 130 feet
Narrow ridge top or mountain peak over 130 feet wide
Side hill - upper $1 / 3$
Side hill - middle $1 / 3$
Side hill - lower $1 / 3$
Canyon bottom less than 660 feet wide
Bench, terrace or dry flat
Broad alluvial flat over 660 feet wide
Swamp or wet flat

Common shape of slope
Flat
Convex
Convex
No rounding
Concave
Concave
Flat
Flat
Flat

50. NF_SAMPLING_STATUS_CD

Nonforest sampling status code. Intentionally left blank. Will be populated in version 5.0.

\section{NF_PLOT_STATUS_CD}

Nonforest plot status code. Intentionally left blank. Will be populated in version 5.0.

\section{NF_PLOT_NONSAMPLE_REASN_CD}

Nonforest plot nonsampled reason code. Intentionally left blank. Will be populated in version 5.0.

53. P2VEG_SAMPLING_STATUS_CD

P2 vegetation sampling status code. Intentionally left blank. Will be populated in version 5.0.

54. P2VEG_SAMPLING_LEVEL_DETAIL_CD

P2 vegetation sampling level detail code. Intentionally left blank. Will be populated in version 5.0.

\section{INVASIVE_SAMPLING_STATUS_CD}

Invasive sampling status code. Intentionally left blank. Will be populated in version 5.0. 
56. INVASIVE_SPECIMEN_RULE_CD

Invasive specimen rule code. Intentionally left blank. Will be populated in version 5.0. 
FIA Database Description and Users Manual for Phase 2, version 4.0

Chapter 3. Condition Table

Condition Table (Oracle table name is COND)

\begin{tabular}{|c|c|c|c|}
\hline & Column name & Descriptive name & Oracle data type \\
\hline 1 & $\mathrm{CN}$ & Sequence number & VARCHAR2(34) \\
\hline 2 & PLT_CN & Plot sequence number & VARCHAR2(34) \\
\hline 3 & INVYR & Inventory year & NUMBER(4) \\
\hline 4 & STATECD & State code & NUMBER(4) \\
\hline 5 & UNITCD & Survey unit code & NUMBER(2) \\
\hline 6 & COUNTYCD & County code & NUMBER(3) \\
\hline 7 & PLOT & Phase 2 plot number & NUMBER(5) \\
\hline 8 & CONDID & Condition class number & NUMBER(1) \\
\hline 9 & COND_STATUS_CD & Condition status code & NUMBER(1) \\
\hline 10 & $\begin{array}{l}\text { COND_NONSAMPLE_ } \\
\text { REASN_CD }\end{array}$ & Condition nonsampled reason code & NUMBER(2) \\
\hline 11 & RESERVCD & Reserved status code & NUMBER(2) \\
\hline 12 & OWNCD & Owner class code & NUMBER(2) \\
\hline 13 & OWNGRPCD & Owner group code & NUMBER(2) \\
\hline 14 & FORINDCD & Private owner industrial status code & NUMBER(2) \\
\hline 15 & ADFORCD & Administrative forest code & NUMBER(4) \\
\hline 16 & FORTYPCD & Forest type code, derived by algorithm & NUMBER(3) \\
\hline 17 & FLDTYPCD & Field forest type code & NUMBER(3) \\
\hline 18 & MAPDEN & Mapping density & NUMBER(1) \\
\hline 19 & STDAGE & Stand age & NUMBER(4) \\
\hline 20 & STDSZCD & Stand-size class code derived by algorithm & NUMBER(2) \\
\hline 21 & FLDSZCD & Field stand-size class code & NUMBER(2) \\
\hline 22 & SITECLCD & Site productivity class code & NUMBER(2) \\
\hline 23 & SICOND & Site index for the condition & NUMBER(3) \\
\hline 24 & SIBASE & Site index base age & NUMBER(3) \\
\hline 25 & SISP & Site index species code & NUMBER(4) \\
\hline 26 & STDORGCD & Stand origin code & NUMBER(2) \\
\hline 27 & STDORGSP & Stand origin species code & NUMBER \\
\hline 28 & PROP_BASIS & Proportion basis & VARCHAR2(12) \\
\hline 29 & CONDPROP_UNADJ & Condition proportion unadjusted & $\operatorname{NUMBER}(5,4)$ \\
\hline 30 & MICRPROP_UNADJ & Microplot proportion unadjusted & $\operatorname{NUMBER}(5,4)$ \\
\hline 31 & SUBPPROP_UNADJ & Subplot proportion unadjusted & $\operatorname{NUMBER}(5,4)$ \\
\hline 32 & MACRPROP_UNADJ & Macroplot proportion unadjusted & $\operatorname{NUMBER}(5,4)$ \\
\hline 33 & SLOPE & Slope & NUMBER(3) \\
\hline 34 & ASPECT & Aspect & NUMBER(3) \\
\hline 35 & PHYSCLCD & Physiographic class code & NUMBER(2) \\
\hline 36 & GSSTKCD & Growing-stock stocking code & NUMBER(2) \\
\hline 37 & ALSTKCD & All live stocking code & NUMBER(2) \\
\hline 38 & DSTRBCD1 & Disturbance 1 code & $\operatorname{NUMBER}(2)$ \\
\hline
\end{tabular}




\begin{tabular}{|c|c|c|c|}
\hline & Column name & Descriptive name & Oracle data type \\
\hline 39 & DSTRBYR1 & Disturbance year 1 & NUMBER(4) \\
\hline 40 & DSTRBCD2 & Disturbance 2 code & $\operatorname{NUMBER}(2)$ \\
\hline 41 & DSTRBYR2 & Disturbance year 2 & NUMBER(4) \\
\hline 42 & DSTRBCD3 & Disturbance 3 code & NUMBER(2) \\
\hline 43 & DSTRBYR3 & Disturbance year 3 & NUMBER(4) \\
\hline 44 & TRTCD1 & Stand treatment 1 code & NUMBER(2) \\
\hline 45 & TRTYR1 & Treatment year 1 & NUMBER(4) \\
\hline 46 & TRTCD2 & Stand treatment 2 code & NUMBER(2) \\
\hline 47 & TRTYR2 & Treatment year 2 & NUMBER(4) \\
\hline 48 & TRTCD3 & Stand treatment 3 code & NUMBER(2) \\
\hline 49 & TRTYR3 & Treatment year 3 & NUMBER(4) \\
\hline 50 & PRESNFCD & Present nonforest code & NUMBER(2) \\
\hline 51 & BALIVE & Basal area of live trees & $\operatorname{NUMBER}(9,4)$ \\
\hline 52 & FLDAGE & Field-recorded stand age & NUMBER(4) \\
\hline 53 & ALSTK & All-live-tree stocking percent & $\operatorname{NUMBER}(7,4)$ \\
\hline 54 & GSSTK & Growing-stock stocking percent & $\operatorname{NUMBER}(7,4)$ \\
\hline 55 & FORTYPCDCALC & Forest type code calculated & NUMBER(3) \\
\hline 56 & HABTYPCD1 & Habitat type code 1 & VARCHAR2(10) \\
\hline 57 & HABTYPCD1_PUB_CD & Habitat type code 1 publication code & VARCHAR2(10) \\
\hline 58 & $\begin{array}{l}\text { HABTYPCD1_DESCR_ } \\
\text { PUB_CD }\end{array}$ & $\begin{array}{l}\text { Habitat type code } 1 \text { description publication } \\
\text { code }\end{array}$ & VARCHAR2(10) \\
\hline 59 & HABTYPCD2 & Habitat type code 2 & VARCHAR2(10) \\
\hline 60 & HABTYPCD2_PUB_CD & Habitat type code 2 publication code & VARCHAR2(10) \\
\hline 61 & $\begin{array}{l}\text { HABTYPCD2_DESCR_ } \\
\text { PUB_CD }\end{array}$ & $\begin{array}{l}\text { Habitat type code } 2 \text { description publication } \\
\text { code }\end{array}$ & VARCHAR2(10) \\
\hline 62 & MIXEDCONFCD & Mixed conifer code & VARCHAR2(1) \\
\hline 63 & VOL_LOC_GRP & Volume location group & VARCHAR2(200) \\
\hline 64 & SITECLCDEST & Site productivity class code estimated & NUMBER(2) \\
\hline 65 & SITETREE_TREE & Site tree tree number & NUMBER(4) \\
\hline 66 & SITECL_METHOD & Site class method & NUMBER(2) \\
\hline 67 & CARBON_DOWN_DEAD & Carbon in down dead & $\operatorname{NUMBER}(13,6)$ \\
\hline 68 & CARBON_LITTER & Carbon in litter & $\operatorname{NUMBER}(13,6)$ \\
\hline 69 & CARBON_SOIL_ORG & Carbon in soil organic material & $\operatorname{NUMBER}(13,6)$ \\
\hline 70 & CARBON_STANDING_DEAD & Carbon in standing dead trees & $\operatorname{NUMBER}(13,6)$ \\
\hline 71 & CARBON_UNDERSTORY_AG & Carbon in the understory aboveground & $\operatorname{NUMBER}(13,6)$ \\
\hline 72 & CARBON_UNDERSTORY_BG & Carbon in the understory belowground & $\operatorname{NUMBER}(13,6)$ \\
\hline 73 & CREATED_BY & Created by & VARCHAR2(30) \\
\hline 74 & CREATED_DATE & Created date & DATE \\
\hline 75 & CREATED_IN_INSTANCE & Created in instance & VARCHAR2(6) \\
\hline 76 & MODIFIED_BY & Modified by & VARCHAR2(30) \\
\hline
\end{tabular}


FIA Database Description and Users Manual for Phase 2, version 4.0 Chapter 3. Condition Table

\begin{tabular}{|c|c|c|c|}
\hline & Column name & Descriptive name & Oracle data type \\
\hline 77 & MODIFIED_DATE & Modified date & DATE \\
\hline 78 & MODIFIED_IN_INSTANCE & Modified in instance & VARCHAR2(6) \\
\hline 79 & CYCLE & Inventory cycle number & NUMBER(2) \\
\hline 80 & SUBCYCLE & Inventory subcycle number & NUMBER(2) \\
\hline 81 & $\begin{array}{l}\begin{array}{l}\text { SOIL_ROOTING_DEPTH_ } \\
\text { PNW }\end{array} \\
\end{array}$ & $\begin{array}{l}\text { Soil rooting depth, Pacific Northwest } \\
\text { Research Station }\end{array}$ & VARCHAR2(1) \\
\hline 82 & $\begin{array}{l}\text { GROUND_LAND_CLASS_ } \\
\text { PNW }\end{array}$ & $\begin{array}{l}\text { Present ground land class, Pacific } \\
\text { Northwest Research Station }\end{array}$ & VARCHAR2(3) \\
\hline 83 & $\begin{array}{l}\text { PLANT_STOCKABILITY_ } \\
\text { FACTOR PNW }\end{array}$ & $\begin{array}{l}\text { Plant stockability factor, Pacific Northwest } \\
\text { Research Station }\end{array}$ & NUMBER \\
\hline 84 & STND_COND_CD_PNWRS & $\begin{array}{l}\text { Stand condition code, Pacific Northwest } \\
\text { Research Station }\end{array}$ & NUMBER(1) \\
\hline 85 & $\begin{array}{l}\text { STND_STRUC_CD_ } \\
\text { PNWRS }\end{array}$ & $\begin{array}{l}\text { Stand structure code, Pacific Northwest } \\
\text { Research Station }\end{array}$ & NUMBER(1) \\
\hline 86 & STUMP_CD_PNWRS & $\begin{array}{l}\text { Stump code, Pacific Northwest Research } \\
\text { Station }\end{array}$ & VARCHAR2(1) \\
\hline 87 & FIRE_SRS & Fire, Southern Research Station & NUMBER(1) \\
\hline 88 & GRAZING_SRS & Grazing, Southern Research Station & NUMBER(1) \\
\hline 89 & HARVEST_TYPE1_SRS & $\begin{array}{l}\text { Harvest type code } 1 \text {, Southern Research } \\
\text { Station }\end{array}$ & $\operatorname{NUMBER}(2)$ \\
\hline 90 & HARVEST_TYPE2_SRS & $\begin{array}{l}\text { Harvest type code 2, Southern Research } \\
\text { Station }\end{array}$ & NUMBER(2) \\
\hline 91 & HARVEST_TYPE3_SRS & $\begin{array}{l}\text { Harvest type code } 3 \text {, Southern Research } \\
\text { Station }\end{array}$ & NUMBER(2) \\
\hline 92 & LAND_USE_SRS & Land use, Southern Research Station & NUMBER(2) \\
\hline 93 & OPERABILITY_SRS & Operability, Southern Research Station & $\operatorname{NUMBER}(2)$ \\
\hline 94 & STAND_STRUCTURE_SRS & Stand structure, Southern Research Station & NUMBER(2) \\
\hline 95 & NF_COND_STATUS_CD & Nonforest condition status code & NUMBER(1) \\
\hline 96 & $\begin{array}{l}\text { NF_COND_NONSAMPLE_ } \\
\text { REASN_CD }\end{array}$ & $\begin{array}{l}\text { Nonforest condition nonsampled reason } \\
\text { code }\end{array}$ & NUMBER(2) \\
\hline 97 & $\begin{array}{l}\text { CANOPY_CVR_SAMPLE_ } \\
\text { METHOD_CD }\end{array}$ & Canopy cover sample method code & NUMBER(2) \\
\hline 98 & $\begin{array}{l}\text { LIVE_CANOPY_CVR_ } \\
\text { PCT }\end{array}$ & Live canopy cover percent & $\operatorname{NUMBER}(3)$ \\
\hline 99 & $\begin{array}{l}\text { LIVE_MISSING_CANOPY_ } \\
\text { CVR_PCT }\end{array}$ & Live plus missing canopy cover percent & NUMBER(3) \\
\hline 100 & NBR_LIVE_STEMS & Number of live stems & NUMBER(5) \\
\hline
\end{tabular}

\begin{tabular}{|l|l|l|l|}
\hline Type of key & Column(s) order & Tables to link & Abbreviated notation \\
\hline Primary & (CN) & N/A & CND_PK \\
\hline Unique & (PLT_CN, CONDID) & N/A & CND_UK \\
\hline Natural & $\begin{array}{l}\text { (STATECD, INVYR, UNITCD, } \\
\text { COUNTYCD, PLOT, CONDID) }\end{array}$ & N/A & CND_NAT_I \\
\hline Foreign & (PLT_CN) & CONDITION to PLOT & CND_PLT_FK \\
\hline
\end{tabular}

1. $\mathrm{CN}$

Sequence number. A unique sequence number used to identify a condition record. 


\section{PLT_CN}

3. INVYR

Plot sequence number. Foreign key linking the condition record to the plot record.

Inventory year. The year that best represents when the inventory data were collected. Under the annual inventory system, a group of plots is selected each year for sampling. The selection is based on a panel system. INVYR is the year in which the majority of plots in that group were collected (plots in the group have the same panel and, if applicable, subpanel). Under periodic inventory, a reporting inventory year was selected, usually based on the year in which the majority of the plots were collected or the mid-point of the years over which the inventory spanned. For either annual or periodic inventory, INVYR is not necessarily the same as MEASYEAR.

Exceptions:

INVYR $=9999$. INVYR is set to 9999 to distinguish Phase 3 plots taken by the western FIA work units that are "off subpanel." This is due to differences in measurement intervals between Phase 3 (measurement interval $=5$ years) and Phase 2 (measurement interval $=10$ years) plots. Only users interested in performing certain Phase 3 data analyses should access plots with this anomalous value in INVYR.

INVYR $<100$. INVYR $<100$ indicates that population estimates were derived from a pre-NIMS regional processing system and the same plot either has been or may soon be re-processed in NIMS as part of a separate evaluation. The NIMS processed copy of the plot follows the standard INVYR format. This only applies to plots collected in the South (SURVEY.RSCD = 33) with the national design or a similar regional design (PLOT.DESIGNCD $=1$ or 220-233) that were collected when the inventory year was 1998 through 2005.

INVYR $=98$ is equivalent to 1998 but processed through regional system $\mathrm{INVYR}=99$ is equivalent to 1999 but processed through regional system INVYR $=0$ is equivalent to 2000 but processed through regional system $\mathrm{INVYR}=1$ is equivalent to 2001 but processed through regional system $\mathrm{INVYR}=2$ is equivalent to 2002 but processed through regional system $\mathrm{INVYR}=3$ is equivalent to 2003 but processed through regional system INVYR $=4$ is equivalent to 2004 but processed through regional system INVYR $=5$ is equivalent to 2005 but processed through regional system

4. STATECD State code. Bureau of the Census Federal Information Processing Standards (FIPS) two-digit code for each State. Refer to appendix C.

5. UNITCD Survey unit code. Forest Inventory and Analysis survey unit identification number. Survey units are usually groups of counties within each State. For periodic inventories, survey units may be made up of lands of particular owners. Refer to appendix C for codes. 
6. COUNTYCD County code. The identification number for a county, parish, watershed, borough, or similar governmental unit in a State. FIPS codes from the Bureau of the Census are used. Refer to appendix $\mathrm{C}$ for codes.

7. PLOT

Phase 2 plot number. An identifier for a plot. Along with STATECD, INVYR, UNITCD, COUNTYCD and/or some other combination of variables, PLOT may be used to uniquely identify a plot.

8. CONDID

Condition class number. Unique identifying number assigned to each condition on a plot. A condition is initially defined by condition class status. Differences in reserved status, owner group, forest type, stand-size class, regeneration status, and stand density further define condition for forest land. Mapped nonforest conditions are also assigned numbers. At the time of the plot establishment, the condition class at plot center (the center of subplot 1) is usually designated as condition class 1 . Other condition classes are assigned numbers sequentially at the time each condition class is delineated. On a plot, each sampled condition class must have a unique number that can change at remeasurement to reflect new conditions on the plot.

\section{COND_STATUS_CD}

Condition status code. A code indicating the basic land cover.

\section{Code Description}

1 Forest land - Land with at least 10 percent cover (or equivalent stocking) by live trees of any size, including land that formerly had such tree cover and that will be naturally or artificially regenerated. To qualify, the area must be at least 1.0 acre in size and 120.0 feet wide. Forest land includes transition zones, such as areas between forest and nonforest lands that have at least 10 percent cover (or equivalent stocking) with live trees and forest areas adjacent to urban and built-up lands. Roadside, streamside, and shelterbelt strips of trees must have a width of at least 120 feet and continuous length of at least 363 feet to qualify as forest land. Unimproved roads and trails, streams, and clearings in forest areas are classified as forest if they are $<120$ feet wide or an acre in size. Treecovered areas in agricultural production settings, such as fruit orchards, or treecovered areas in urban settings, such as city parks, are not considered forest land. For data collected prior to annual inventory (PLOT.MANUAL $<1.0$ ), the definition for forest land may have been slightly different (for example, in the past some FIA work units used 5 percent cover rather than 10 percent.) Nonforest land - Any land within the sample that does not meet the definition of accessible forest land or any of the other types of basic land covers. To qualify, the area must be at least 1.0 acre in size and 120.0 feet wide, with some exceptions that are described in the document "Forest inventory and analysis national core field guide, volume 1: field data collection procedures for Phase 2 plots, version 4.0.” (http://www.fia.fs.fed.us/library/field-guides-methodsproc/.) Evidence of "possible" or future development or conversion is not considered. A nonforest land condition will remain in the sample and will be examined at the next occasion to see if it has become forest land.

3 Noncensus water - Lakes, reservoirs, ponds, and similar bodies of water 1.0 acre to 4.5 acre in size. Rivers, streams, canals, etc., 30.0 feet to 200 feet wide (1990 U.S. Census definition - U.S. Census Bureau 1994). This definition was used in the 1990 census and applied when the data became available. Earlier inventories defined noncensus water differently. 


\section{Code Description}

$4 \quad$ Census water - Lakes, reservoirs, ponds, and similar bodies of water 4.5 acre in size and larger; and rivers, streams, canals, etc., more than 200 feet wide (1990 U.S. Census definition; U.S. Census Bureau 1994).

5 Nonsampled - Any portion of a plot within accessible forest land that cannot be sampled is delineated as a separate condition. There is no minimum size requirement. The reason the condition was not sampled is provided in COND_NONSAMPLE_REASN_CD.

\section{COND_NONSAMPLE_REASN_CD}

Condition nonsampled reason code. For condition classes that cannot be sampled, one of the following reasons is recorded.

\section{Code Description}

01 Outside U.S. boundary - Condition class is outside the U.S. border.

02 Denied access area - Access to the condition class is denied by the legal owner, or by the owner of the only reasonable route to the condition class.

03 Hazardous situation - Condition class cannot be accessed because of a hazard or danger, for example cliffs, quarries, strip mines, illegal substance plantations, temporary high water, etc.

05 Lost data - The data file was discovered to be corrupt after a panel was completed and submitted for processing. Used for the single condition that is required for this plot. This code is for office use only.

06 Lost plot - Entire plot cannot be found. Used for the single condition that is required for this plot.

07 Wrong location - Previous plot can be found, but its placement is beyond the tolerance limits for plot location. Used for the single condition that is required for this plot.

08 Skipped visit - Entire plot skipped. Used for plots that are not completed prior to the time a panel is finished and submitted for processing. Used for the single condition that is required for this plot. This code is for office use only.

09 Dropped intensified plot - Intensified plot dropped due to a change in grid density. Used for the single condition that is required for this plot. This code used only by units engaged in intensification. This code is for office use only.

10 Other - Condition class not sampled due to a reason other than one of the specific reasons listed.

11 Ocean - Condition falls in ocean water below mean high tide line.

11. RESERVCD Reserved status code. (Core for accessible forestland; Core optional for other sampled land.) Reserved land is land that is withdrawn by law(s) prohibiting the management of the land for the production of wood products.

\section{Code Description \\ $0 \quad$ Not reserved \\ 1 Reserved}

12. OWNCD Owner class code. (Core for all accessible forestland; Core optional for other sampled land.) A code indicating the class in which the landowner (at the time of the inventory) belongs. When PLOT.DESIGNCD $=999$, OWNCD may be blank (null). 


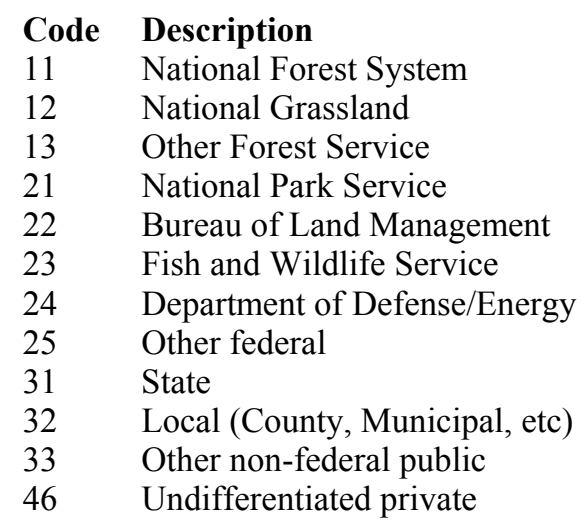

The following detailed private owner land codes are not available in this database because of the FIA data confidentiality policy. Users needing this type of information should contact the FIA Spatial Data Services (SDS) group by following the instructions provided at: http://www.fia.fs.fed.us/toolsdata/spatial/.

$\begin{array}{ll}\text { Code } & \text { Description } \\ 41 & \text { Corporate } \\ 42 & \text { Non-governmental conservation/natural resources organization } \\ 43 & \text { Unincorporated local partnership/association/club } \\ 44 & \text { Native American (Indian) } \\ 45 & \text { Individual }\end{array}$

13. OWNGRPCD Owner group code. (Core for all accessible forestland; Core optional for other sampled land.) A broader group of landowner classes. When PLOT.DESIGNCD = 999, OWNGRPCD may be blank (null).

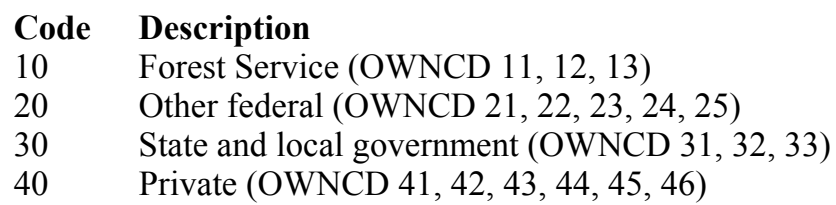

14. FORINDCD Private owner industrial status code. (Core for all accessible forestland where owner group is private; Core optional for other sampled land where owner group is private.) A code indicating whether the landowner owns and operates a primary wood processing plant. A primary wood processing plant is any commercial operation that originates the primary processing of wood on a regular and continuing basis. Examples include: pulp or paper mill, sawmill, panel board mill, post or pole mill.

This attribute is retained in this database for informational purposes but is intentionally left blank (null) because of the FIA data confidentiality policy. Users needing this type of information should contact the FIA Spatial Data Services (SDS) group by following the instructions provided at: http://www.fia.fs.fed.us/tools-data/spatial/. 


\section{Code Description}

$0 \quad$ Land is not owned by industrial owner with wood processing plant

1 Land is owned by industrial owner with wood processing plant

15. ADFORCD

16. FORTYPCD
Administrative forest code. Identifies the administrative unit (Forest Service Region and National Forest) in which the condition is located. The first two digits of the four digit code are for the region number and the last two digits are for the Administrative National Forest number. Refer to appendix E for codes. Populated only for U.S. Forest Service lands OWNGRPCD = 10 and blank (null) for all other owners.

Forest type code. This is the forest type used for reporting purposes. It is primarily derived using a computer algorithm, except when less than 25 percent of the plot samples a particular forest condition.

Usually, FORTYPCD equals FORTYPCDCALC. In certain situations, however, the result from the algorithm (FORTYPCDCALC) is overridden by the field call. The field-recorded forest type code (FLDTYPCD) is stored in this attribute when less than 25 percent of the plot samples the forested condition (CONDPROP_UNADJ $<0.25$ ).

In most cases, FORTYPCD is the same as the field-recorded forest type (FLDTYPCD). However, situations of under sampling may cause this attribute to differ from FLDTYPCD.

Nonstocked forest land is land that currently has less than 10 percent stocking but formerly met the definition of forest land. Forest conditions meeting this definition have few, if any, trees sampled. In these instances, the algorithm cannot assign a specific forest type and the resulting forest type code is 999 , meaning nonstocked.

Refer to appendix D for the complete list of forest type codes and names.

17. FLDTYPCD Field forest type code. Forest type, assigned by the field crew, based on the tree species or species groups forming a plurality of all live stocking. The field crew assesses the forest type based on the acre of forestland around the plot, in addition to the species sampled on the condition. Refer to appendix D for a detailed list of forest type codes and names. Nonstocked forest land is land that currently has less than 10 percent stocking but formerly met the definition of forest land. When PLOT.MANUAL $<2.0$, forest conditions that do not meet this stocking level were coded FLDTYPCD $=999$. Beginning with manual version 2.0, the crew no longer recorded nonstocked as 999. Instead, they recorded FLDSZCD $=0$ to identify nonstocked conditions and entered an estimated forest type for the condition. The crew determined the estimated forest type by either recording the previous forest type on remeasured plots or, on all other plots, the most appropriate forest type to the condition based on the seedlings present or the forest type of the adjacent forest stands. Periodic inventories will differ in the way FLDTYPCD was recorded - it is best to check with individual FIA work units for details. In general, when FLDTYPCD is used for analysis, it is necessary to examine the 
18. MAPDEN

19. STDAGE

20. STDSZCD values of both FLDTYPCD and FLDSZCD to identify nonstocked forest land.

Mapping density. A code indicating the relative tree density of the condition. Codes other than 1 are used as an indication that a significant difference in tree density is the only factor causing another condition to be recognized and mapped on the plot. May be blank (null) for periodic inventories.

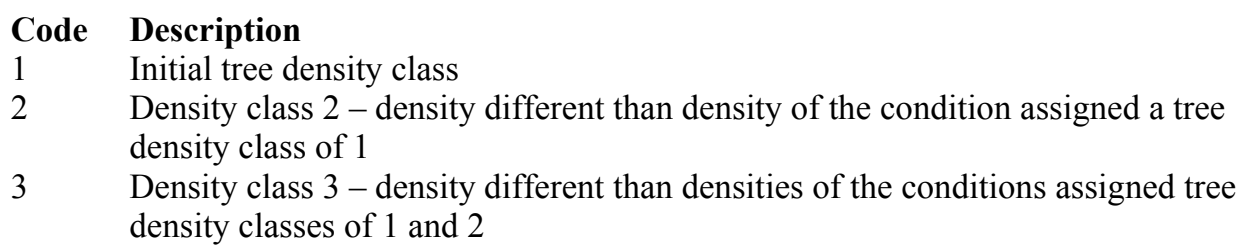

Stand age. For annual inventories (PLOT.MANUAL $\geq 1.0$ ), stand age is equal to the field-recorded stand age (FLDAGE) with some exceptions. One exception is if FLDAGE $=999$, then stand age is computed. When FLDAGE $=998$, STDAGE is blank (null) because no trees were cored in the field. Another exception is that RMRS always computes stand age using fieldrecorded tree ages from trees in the calculated stand-size class. If no tree ages are available, then RMRS sets this attribute equal to FLDAGE. For all inventories, nonstocked stands have STDAGE set to 0. In periodic inventories, stand age is determined using local procedures. Annual inventory data will contain stand ages assigned to the nearest year. For some older inventories, stand age was set to 10 -year classes for stands $<100$ years old, 20 -year age classes for stands between 100 and 200 years, and 100-year age classes if older than 200 years. These classes were converted to store the midpoint of the age class in years. Blank (null) values in the periodic data (PLOT.MANUAL $<1.0$ ) indicate that the stand was recorded as mixed age on forested condition classes. Age is difficult to measure and therefore STDAGE may have large measurement errors.

Stand-size class code. A classification of the predominant (based on stocking) diameter class of live trees within the condition assigned using an algorithm. Large diameter trees are at least 11.0 inches diameter for hardwoods and at least 9.0 inches diameter for softwoods. Medium diameter trees are at least 5.0 inches diameter and smaller than large diameter trees. Small diameter trees are $<5.0$ inches diameter. When $<25$ percent of the plot samples the forested condition (CONDPROP_UNADJ $<0.25)$, this attribute is set to the equivalent field-recorded stand-size class (FLDSZCD). Populated for all forest annual plots, all forest periodic plots, and all NCRS periodic plots that were measured as "nonforest with trees" (e.g., wooded pasture, windbreaks). 


\section{Code Description}

1 Large diameter - Stands with an all live stocking of at least 10 (base 100); with more than 50 percent of the stocking in medium and large diameter trees; and with the stocking of large diameter trees equal to or greater than the stocking of medium diameter trees

2 Medium diameter - Stands with an all live stocking of at least 10 (base 100); with more than 50 percent of the stocking in medium and large diameter trees; and with the stocking of large diameter trees less than the stocking of medium diameter trees

3 Small diameter - Stands with an all live stocking value of at least 10 (base 100 ) on which at least 50 percent of the stocking is in small diameter trees

$5 \quad$ Nonstocked - Forest land with all live stocking $<10$

21. FLDSZCD Field stand-size class code. Field-assigned classification of the predominant (based on stocking) diameter class of live trees within the condition. Blank (null) values may be present for periodic inventories.

\section{Code Description}

$0 \quad$ Nonstocked - Meeting the definition of accessible land and one of the following applies (1) $<10$ percent stocked by trees of any size, and not classified as cover trees (see code 6), or (2) for several western woodland species where stocking standards are not available, $<5$ percent crown cover of trees of any size.

$1 \leq 4.9$ inches (seedlings / saplings). At least 10 percent stocking (or 5 percent crown cover if stocking standards are not available) in trees of any size; and at least $2 / 3$ of the crown cover is in trees $<5.0$ inches DBH/DRC.

$25.0-8.9$ inches (softwoods)/ $5.0-10.9$ inches (hardwoods). At least 10 percent stocking (or 5 percent crown cover if stocking standards are not available) in trees of any size; and at least one-third of the crown cover is in trees $\geq 5.0$ inches DBH/DRC and the plurality of the crown cover is in softwoods $5.0-8.9$ inches diameter and/or hardwoods 5.0 - 10.9 inches $\mathrm{DBH}$, and/or for western woodland trees $5.0-8.9$ inches DRC.

$39.0-19.9$ inches (softwoods)/ $11.0-19.9$ inches (hardwoods). At least 10 percent stocking (or 5 percent crown cover if stocking standards are not available) in trees of any size; and at least one-third of the crown cover is in trees $\geq 5.0$ inches DBH/DRC and the plurality of the crown cover is in softwoods 9.0 - 19.9 inches diameter and/or hardwoods between $11.0-19.9$ inches DBH, and for western woodland trees $9.0-19.9$ inches DRC.

$4 \quad 20.0-39.9$ inches. At least 10 percent stocking (or 5 percent crown cover if stocking standards are not available) in trees of any size; and at least onethird of the crown cover is in trees $\geq 5.0$ inches DBH/DRC and the plurality of the crown cover is in trees $20.0-39.9$ inches DBH.

$540.0+$ inches. At least 10 percent stocking (or 5 percent crown cover if stocking standards are not available) in trees of any size; and at least onethird of the crown cover is in trees $\geq 5.0$ inches DBH/DRC and the plurality of the crown cover is in trees $\geq 40.0$ inches DBH.

6 Cover trees (trees not on species list, used for plots classified as nonforest): $<10$ percent stocking by trees of any size, and $>5$ percent crown cover of species that comprise cover trees.

\section{SITECLCD}

Site productivity class code. A classification of forest land in terms of inherent capacity to grow crops of industrial wood. Identifies the potential growth in cubic feet/acre/year and is based on the culmination of mean annual increment of fully stocked natural stands. For data stored in the database that were processed outside of NIMS, this variable may be assigned 
based on the site productivity determined with the site trees, or from some other source, but the actual source of the site productivity class code is not known. For data processed with NIMS, this variable may either be assigned based on the site trees available for the plot, or, if no valid site trees are available, this variable is set equal to SITECLCDEST, a default value that is either an estimated or predicted site productivity class. If SITECLCDEST is used to populate SITECLCD, the variable SITECL_METHOD is set to 6.

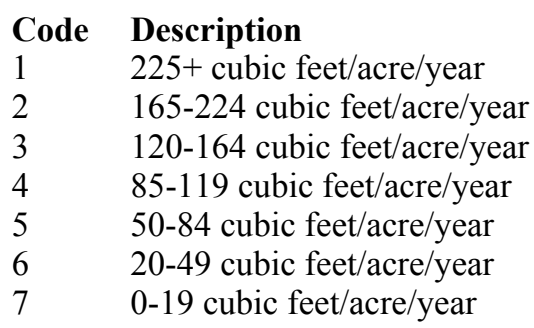

23. SICOND Site index for the condition. This represents the average total length in feet that dominant and co-dominant trees are expected to attain in well-stocked, even-aged stands at the specified base age (SIBASE). Site index is estimated for the condition by either using an individual tree or by averaging site index values that have been calculated for individual site trees (see SITETREE.SITREE) of the same species (SISP). As a result, it may be possible to find additional site index values that are not used in the calculation of SICOND in the SITETREE tables when site index has been calculated for more than one species in a condition. This attribute is blank (null) when no site index data are available.

24. SIBASE

Site index base age. The base age (sometimes called reference age), in years, of the site index curve used to derive site index. Base age may be breast height age or total age, depending on the specifications of the site index curves being used. This attribute is blank (null) when no site tree data are available.

25. SISP

Site index species code. The species upon which the site index is based. In most cases, the site index species will be one of the species that define the forest type of the condition (FORTYPCD). In cases where there are no suitable site trees of the type species, other suitable species may be used. This attribute is blank (null) when no site tree data are available.

26. STDORGCD Stand origin code. Method of stand regeneration for the trees in the condition. An artificially regenerated stand is established by planting or artificial seeding. Populated for all forest annual plots, all forest periodic plots, and all NCRS periodic plots that were measured as "nonforest with trees" (e.g., wooded pasture, windbreaks).

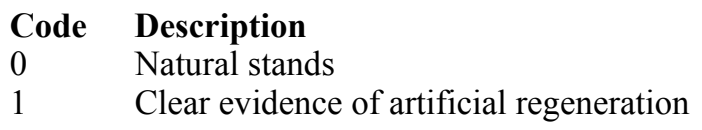


27. STDORGSP Stand origin species code. The species code for the predominant artificially regenerated species (only when STDORGCD $=1$ ). See appendix F. May not be populated for some FIA work units when PLOT.MANUAL $<1.0$.

28. PROP_BASIS Proportion basis. A value indicating what type of fixed-size subplots were installed when this plot was sampled. This information is needed to use the proper adjustment factor for the stratum in which the plot occurs (see POP_STRATUM.ADJ_FACTOR_SUBP and POP_STRATUM.ADJ_FACTOR_MACR.) Usually 24-foot radius subplots are installed and in this case, the value for PROP_BASIS is "SUBP." However, when 58.9-foot radius macroplots are installed, the value is "MACR." This attribute is blank (null) for periodic inventories.

29. CONDPROP_UNADJ

Condition proportion unadjusted. The unadjusted proportion of the plot that is in the condition. This variable is retained for ease of area calculations. It is equal to either SUBPPROP_UNADJ or MACRPROP_UNADJ, depending on the value of PROP_BASIS. The sum of all condition proportions for a plot equals 1 . When generating population area estimates, this proportion is adjusted by either the POP_STRATUM.ADJ_FACTOR_MACR or the POP_STRATUM.ADJ_FACTOR_SUBP to account for partially nonsampled plots (access denied or hazardous portions).

30. MICRPROP_UNADJ

Microplot proportion unadjusted. The unadjusted proportion of the microplots that are in the condition. The sum of all microplot condition proportions for a plot equals 1 .

\section{SUBPPROP UNADJ}

Subplot proportion unadjusted. The unadjusted proportion of the subplots that are in the condition. The sum of all subplot condition proportions for a plot equals 1.

\section{MACRPROP_UNADJ}

Macroplot proportion unadjusted. The unadjusted proportion of the macroplots that are in the condition. When macroplots are installed, the sum of all macroplot condition proportions for a plot equals 1; otherwise this attribute is left blank (null).

33. SLOPE

Slope. The angle of slope, in percent, of the condition. Valid values are 000 through 155 for data collected when PLOT.MANUAL $\geq 1.0$, and 000 through 200 on data collected when PLOT.MANUAL $<1.0$. When PLOT.MANUAL $<1.0$, the field crew measured condition slope by sighting along the average incline or decline of the condition. When PLOT.MANUAL $\geq 1.0$, slope is collected on subplots but no longer collected for conditions. When PLOT.MANUAL $\geq 1.0$, the slope from the subplot representing the greatest 
34. ASPECT

35. PHYSCLCD percentage of the condition is assigned as a surrogate. In the event that two or more subplots represent the same amount of area in the condition, the slope from the lower numbered subplot is used. Populated for all forest annual plots, all forest periodic plots, and all NCRS periodic plots that were measured as "nonforest with trees" (e.g., wooded pasture, windbreaks).

Aspect. The direction of slope, to the nearest degree, for most of the condition. North is recorded as 360 . When slope is $<5$ percent, there is no aspect and this item is set to zero. When PLOT.MANUAL $<1.0$, the field crew measured condition aspect. When PLOT.MANUAL $\geq 1.0$, aspect is collected on subplots but no longer collected for conditions. NOTE: for plots measured when PLOT.MANUAL $\geq 1.0$, the aspect from the subplot representing the greatest percentage of the condition is assigned as a surrogate. In the event that two or more subplots represent the same percentage of area in the condition, the slope from the lower numbered subplot is used. Populated for all forest annual plots, all forest periodic plots, and all NCRS periodic plots that were measured as "nonforest with trees" (e.g., wooded pasture, windbreaks).

Physiographic class code. The general effect of land form, topographical position, and soil on moisture available to trees. These codes are new in annual inventory; older inventories have been updated to these codes when possible. Also populated for the NCRS periodic plots that were measured as "nonforest with trees" (e.g., wooded pasture, windbreaks).

\section{Code Description}

Xeric sites (normally low or deficient in available moisture)

11 Dry Tops - Ridge tops with thin rock outcrops and considerable exposure to sun and wind.

12 Dry Slopes - Slopes with thin rock outcrops and considerable exposure to sun and wind. Includes most mountain/steep slopes with a southern or western exposure.

13 Deep Sands - Sites with a deep, sandy surface subject to rapid loss of moisture following precipitation. Typical examples include sand hills, ridges, and flats in the South, sites along the beach and shores of lakes and streams.

19 Other Xeric - All dry physiographic sites not described above.

Mesic sites (normally moderate but adequate available moisture)

21 Flatwoods - Flat or fairly level sites outside of flood plains. Excludes deep sands and wet, swampy sites.

22 Rolling Uplands - Hills and gently rolling, undulating terrain and associated small streams. Excludes deep sands, all hydric sites, and streams with associated flood plains.

23 Moist Slopes and Coves - Moist slopes and coves with relatively deep, fertile soils. Often these sites have a northern or eastern exposure and are partially shielded from wind and sun. Includes moist mountain tops and saddles.

24 Narrow flood plains/Bottomlands - Flood plains and bottomlands less than 1/4-mile in width along rivers and streams. These sites are normally well drained but are subjected to occasional flooding during periods of heavy or extended precipitation. Includes associated levees, benches, and terraces within a 1/4 mile limit. Excludes swamps, sloughs, and bogs. 


\section{Code Description}

25 Broad Floodplains/Bottomlands - Floodplains and bottomlands $1 / 4$ mile or wider along rivers and streams. These sites are normally well drained but are subjected to occasional flooding during periods of heavy or extended precipitation. Includes associated levees, benches, and terraces. Excludes swamps, sloughs, and bogs with year-round water problems.

29 Other Mesic - All moderately moist physiographic sites not described above.

Hydric sites (normally abundant or overabundant moisture all year)

31 Swamps/Bogs - Low, wet, flat, forested areas usually quite extensive that are flooded for long periods except during periods of extreme drought. Excludes cypress ponds and small drains.

32 Small Drains - Narrow, stream-like, wet strands of forest land often without a well-defined stream channel. These areas are poorly drained or flooded throughout most of the year and drain the adjacent higher ground.

33 Bays and wet pocosins - Low, wet, boggy sites characterized by peaty or organic soils. May be somewhat dry during periods of extended drought. Examples include sites in the Carolina bays in the Southeast United States.

34 Beaver ponds.

35 Cypress ponds.

39 Other hydric - All other hydric physiographic sites.

36. GSSTKCD

37. ALSTKCD

38. DSTRBCD1
Growing-stock stocking code. A code indicating the stocking of the condition by growing-stock trees, including seedlings. Growing-stock trees are those where tree class (TREE.TREECLCD) equals 2 or, for seedlings that do not have tree class assigned where species group (TREE.SPGRPCD) is not equal to 23 (western woodland softwoods), 43 (eastern noncommercial hardwoods), and 48 (western woodland hardwoods). Populated for all forest annual plots, all forest periodic plots, and all NCRS periodic plots that were measured as "nonforest with trees" (e.g., wooded pasture, windbreaks).

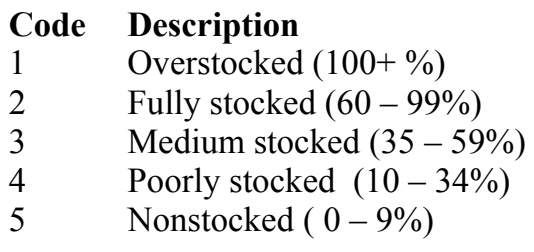

All live stocking code. A code indicating the stocking of the condition by live trees, including seedlings. Data are in classes as listed for GSSTKCD above. May not be populated for some FIA work units when PLOT.MANUAL $<1.0$. Populated for all forest annual plots, all forest periodic plots, and all NCRS periodic plots that were measured as "nonforest with trees" (e.g., wooded pasture, windbreaks).

Disturbance 1 code. A code indicating the kind of disturbance occurring since the last measurement or within the last 5 years for new plots. The area affected by the disturbance must be at least 1 acre in size. A significant level of disturbance (mortality or damage to 25 percent of the trees in the condition) is required. Populated for all forested conditions using the National Field Guide protocols (PLOT.MANUAL $\geq 1.0$ ) and populated by some FIA work units where PLOT.MANUAL $<1.0$. Codes 11, 12, 21, and 22 are valid where PLOT. MANUAL $\geq 2.0$. 


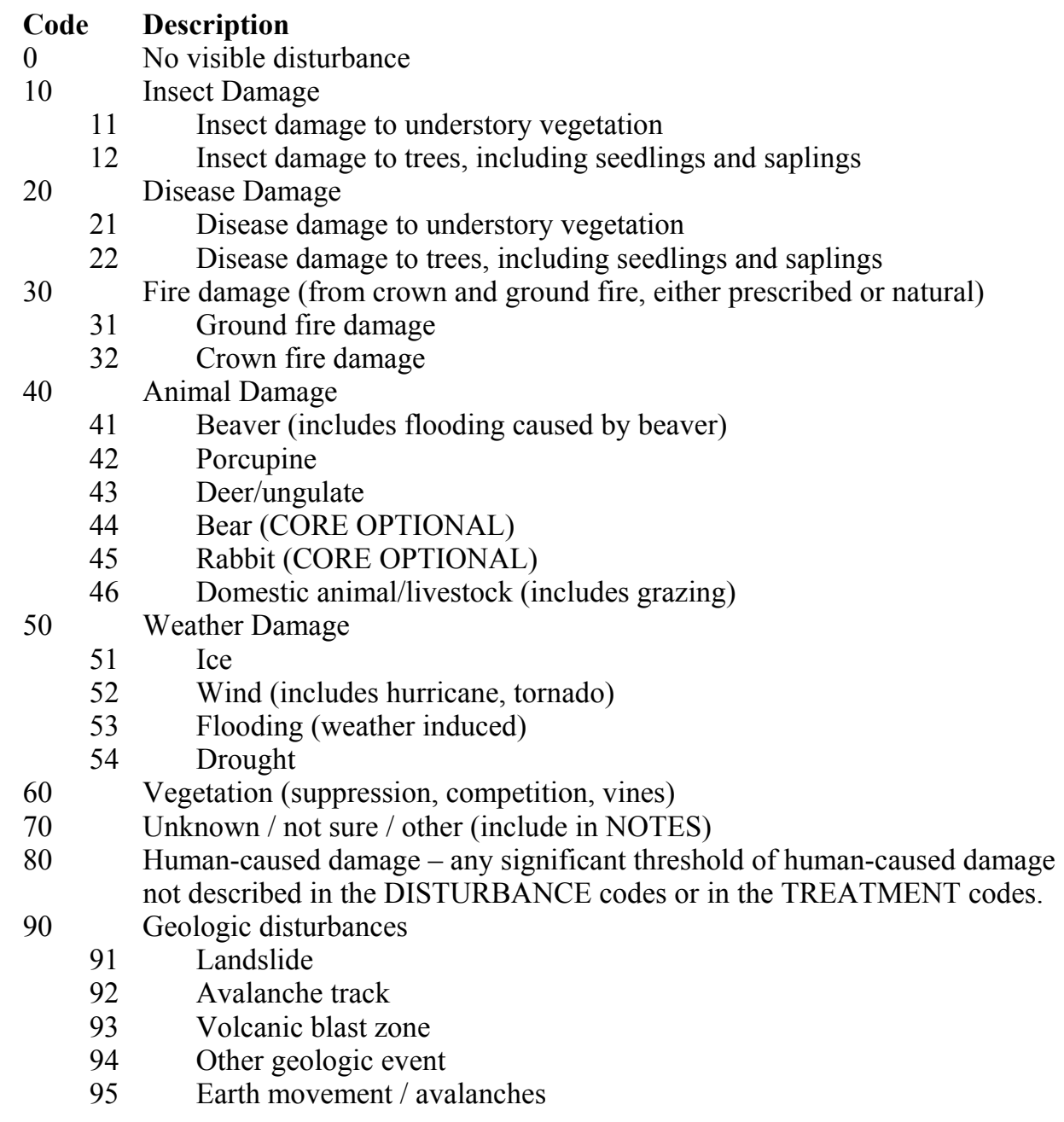

39. DSTRBYR1 Disturbance year 1. Year in which Disturbance 1 is estimated to have occurred. If the disturbance occurs continuously over a period of time, the value 9999 is used. Populated for all forested conditions that have some disturbance using the National Field Guide protocols (PLOT.MANUAL $\geq 1.0$ ) and populated by some FIA work units where PLOT.MANUAL $<1.0$. If DISTRBCD1 $=0$ then DSTRBYR1 = blank (null) or 0.

40. DSTRBCD2 Disturbance 2 code. The second disturbance code, if the stand has experienced more than one disturbance. See DSTRBCD1 for more information. This attribute is new in annual inventory.

41. DSTRBYR2 Disturbance year 2. The year in which Disturbance 2 occurred. See DSTRBYR1 for more information. This attribute is new in annual inventory.

42. DSTRBCD3 Disturbance 3 code. The third disturbance code, if the stand has experienced more than two disturbances. See DSTRBCD1 for more information. This attribute is new in annual inventory.

43. DSTRBYR3 Disturbance year 3. The year in which Disturbance 3 occurred. See DSTRBYR1 for more information. This attribute is new in annual inventory. 


\section{TRTCD1}

45. TRTYR1

46. TRTCD2

47. TRTYR2

48. TRTCD3

49. TRTYR3

50. PRESNFCD
Treatment code 1. A code indicating the type of stand treatment that has occurred since the last measurement or within the last 5 years for new plots. The area affected by the treatment must be at least 1 acre in size. Populated for all forested conditions using the National Field Guide protocols (PLOT.MANUAL $\geq 1.0$ ) and populated by some FIA work units where PLOT.MANUAL $<1.0$. When PLOT.MANUAL $<1.0$, inventories may record treatments occurring within the last 20 years for new plots.

\section{Code Description}

$00 \quad$ No observable treatment.

10 Cutting - The removal of one or more trees from a stand.

20 Site preparation - Clearing, slash burning, chopping, disking, bedding, or other practices clearly intended to prepare a site for either natural or artificial regeneration.

30 Artificial regeneration - Following a disturbance or treatment (usually cutting), a new stand where at least 50 percent of the live trees present resulted from planting or direct seeding.

40 Natural regeneration - Following a disturbance or treatment (usually cutting), a new stand where at least 50 percent of the live trees present (of any size) were established through the growth of existing trees and/or natural seeding or sprouting.

50 Other silvicultural treatment - The use of fertilizers, herbicides, girdling, pruning, or other activities (not covered by codes 10-40) designed to improve the commercial value of the residual stand, or chaining, which is a practice used on western woodlands to encourage wildlife forage.

Treatment year 1. Year in which Stand Treatment 1 is estimated to have occurred. Populated for all forested conditions that have some treatment using the National Field Guide protocols (PLOT.MANUAL $\geq 1.0$ ) and populated by some FIA work units where PLOT.MANUAL $<1.0$. If TRTCD $1=00$ then TRTYR $1=$ blank (null) or 0 .

Treatment code 2. A code indicating the type of stand treatment that has occurred since the last measurement or within the last 5 years for new plots. See TRTCD1 for more information.

Treatment year 2. Year in which Stand Treatment 2 is estimated to have occurred. See TRTYR1 for more information.

Treatment code 3 . A code indicating the type of stand treatment that has occurred since the last measurement or within the last 5 years for new plots. See TRTCD1 for more information.

Treatment year 3. Year in which Stand Treatment 3 is estimated to have occurred. See TRTYR1 for more information.

Present nonforest code. (Core for remeasured conditions that were forest before and are now nonforest; Core optional for all conditions where current condition class status is nonforest, regardless of the previous condition.) A code indicating the current nonforest land use for conditions that were previously classified as forest but are now classified as nonforest. This attribute can be optionally recorded for all nonforest conditions, regardless of 
either past land status or whether the condition has a previous measurement. May be populated when PLOT.MANUAL $<1.0$.

Code Description

10 Agricultural land

11 Cropland

12 Pasture (improved through cultural practices)

13 Idle farmland

14 Orchard

15 Christmas tree plantation

16 Maintained wildlife opening*

17 Windbreak/Shelterbelt*

20 Rangeland

30 Developed

31 Cultural (business, residential, other intense human activity)

32 Rights-of-way (improved road, railway, power line)

33 Recreation (park, golf course, ski run)

34 Mining*

40 Other (undeveloped beach, marsh, bog, snow, ice)

$41 \quad$ Nonvegetated*

42 Wetland*

43 Beach*

45 Nonforest-Chaparral*

*These codes are currently regional. They will become national in PLOT.MANUAL = 5.0.

51. BALIVE

52. FLDAGE

Basal area of live trees. Basal area in square feet per acre of all live trees over 1 inch DBH/DRC sampled in the condition.

Field-recorded stand age. The stand age as assigned by the field crew. Based on the average total age, to the nearest year, of the trees in the field-recorded stand-size class of the condition, determined using local procedures. For nonstocked stands, 0 is stored. If all of the trees in a condition class are of a species that by regional standards cannot be bored for age (e.g., mountain mahogany, tupelo), 998 is recorded. If tree cores are not counted in the field, but are collected and sent to the office for the counting of rings, 999 is recorded.

53. ALSTK

All-live-tree stocking percent. The sum of stocking percent values of all live trees on the condition. The percent is then assigned to a stocking class, which is found in ALSTKCD. May not be populated for some FIA work units when PLOT.MANUAL $<1.0$.

54. GSSTK Growing-stock stocking percent. The sum of stocking percent values of all growing-stock trees on the condition. The percent is then assigned to a stocking class, which is found in GSSTKCD. May not be populated for some FIA work units when PLOT.MANUAL $<1.0$.

\section{FORTYPCDCALC}

Forest type code calculated. Forest type is always calculated based on the tree species sampled on the condition. The forest typing algorithm is a hierarchical procedure applied to the tree species sampled on the condition. The algorithm begins by comparing the live tree stocking of softwoods and 
hardwoods and continues in a stepwise fashion comparing successively smaller subgroups of the preceding aggregation of initial type groups, selecting the group with the largest aggregate stocking value. The comparison proceeds in most cases until a plurality of a forest type is identified.

Nonstocked forest land is land that currently has less than 10 percent stocking but formerly met the definition of forest land. Forest conditions meeting this definition have few, if any, trees sampled. In these instances, the algorithm cannot assign a specific forest type and the resulting forest type code is 999, meaning nonstocked. See also FORTYPCD and FLDTYPCD for other forest type attributes. Refer to appendix D for a complete list of forest type codes and names.

56. HABTYPCD1 Habitat type code 1. A code indicating the primary habitat type (or community type) for this condition. Unique codes are determined by combining both habitat type code and publication code (HABTYPCD1 and HABTYPCD1_PUB_CD). Habitat type captures information about both the overstory and understory vegetation and usually describes the vegetation that is predicted to become established after all successional stages of the ecosystem are completed without any disturbance. This code can be translated using the publication in which it was named and described (see HABTYPCD1_PUB_CD and HABTYPCD1_DESCR_PUB_CD). Only collected by certain FIA work units (SURVEY $\overline{R S C D}=22, \overline{2} 3$, or 26 ).

\section{HABTYPCD1_PUB_CD}

Habitat type code 1 publication code. A code indicating the publication that lists the name for the habitat type code (HABTYPCD1). Publication information is documented in the REF_HABTYP_PUBLICATION table. Only used by certain FIA work units ( $\overline{\mathrm{S} U R V E Y . \overline{R S C D}}=22,23$, or 26).

\section{HABTYPCD1_DESCR_PUB_CD}

Habitat type code 1 description publication code. A code indicating the publication that gives a description for habitat type code 1 (HABTYPCD1). This publication may or may not be the same publication that lists the name of the habitat type (HABTYPCD1_PUB_CD). Publication information is documented in REF_HABTYP_PUBBLICATION table. Only used by certain FIA work units (SURVEY.RSCD $=22,23$, or 26).

59. HABTYPCD2 Habitat type code 2. A code indicating the secondary habitat type (or community type) for this condition. Unique codes are determined by combining both habitat type code and publication code (HABTYPCD2 and HABTYPCD2_PUB_CD). Habitat type captures information about both the overstory and understory vegetation and usually describes the vegetation that is predicted to become established after all successional stages of the ecosystem are completed without any disturbance. This code can be translated using the publication in which it was named and described (see 
60. HABTYPCD2_PUB_CD

Habitat type code 2 publication code. A code indicating the publication that lists the name for the habitat type code (HABTYPCD2). Publication information is documented in REF_HABTYP_PUBLICATION table. Only used by certain FIA work units (SURVEY.R $\overline{S C D}=22,23$, or 26).

\section{HABTYPCD2_DESCR_PUB_CD}

Habitat type code 2 description publication code. A code indicating the publication that gives a description for habitat type code 2 (HABTYPCD2). This publication may or may not be the same publication that lists the name of the habitat type (HABTYPCD2_PUB_CD). Publication information is documented in REF_HABTYP_PUBLICATION table. Only used by certain FIA work units (SURVEY.RSCD $=22,23$, or 26).

\section{MIXEDCONFCD}

Mixed conifer site code. An indicator to show that the forest condition is a mixed conifer site in California. These sites are a complex association of ponderosa pine, sugar pine, Douglas-fir, white fir, red fir, and/or incensecedar. Mixed conifer sites use a specific site index equation. This is a yes/no attribute. This attribute is left blank (null) for all other States. Only collected by certain FIA work units (SURVEY.RSCD = 26).

\section{Code Description}

$\mathrm{Y} \quad$ Yes, the condition is a mixed conifer site in California

$\mathrm{N} \quad$ No, the condition is not a mixed conifer site in California

\section{VOL_LOC_GRP}

Volume location group. An identifier indicating what equations are used for volume, biomass, site index, etc. A volume group is usually designated for a geographic area, such as a State, multiple States, a group of counties, or an ecoregion.

\begin{tabular}{|l|l|}
\hline Code & Description \\
\hline S22LAZN & Northern Arizona Ecosections \\
\hline S22LAZS & Southern Arizona Ecosections \\
\hline S22LCOE & Eastern Colorado Ecosections \\
\hline S22LCOW & Western Colorado Ecosections \\
\hline S22LID & Idaho Ecosections \\
\hline S22LMTE & Eastern Montana Ecosections \\
\hline S22LMTW & Western Montana Ecosections \\
\hline S22LNV & Nevada Ecosections \\
\hline S22LNMN & Northern New Mexico Ecosections \\
\hline S22 LNMS & Southern New Mexico Ecosections \\
\hline
\end{tabular}




\begin{tabular}{|l|l|}
\hline Code & Description \\
\hline S22LUTNE & Northern \& Eastern Utah Ecosections \\
\hline S22LUTSW & Southern \& Western Utah Ecosections \\
\hline S22LWYE & Eastern Wyoming Ecosections \\
\hline S22LWYW & Western Wyoming Ecosections \\
\hline S23LCS & Central States (IL, IN, IW, MO) \\
\hline S23LLS & Lake States (MI, MN, WI) \\
\hline S23LPS & Plains States (KS, NE, ND, SD) \\
\hline S24 & Northeastern States (CT, DE, ME, MD, MA, NH, NJ, NY, OH, PA, RI, VT, WV) \\
\hline S26LCA & California other than mixed conifer forest type \\
\hline S26LCAMIX & California mixed conifer forest type \\
\hline S26LEOR & Eastern Oregon \\
\hline S26LEWA & Eastern Washington \\
\hline S26LORJJ & Oregon Jackson and Josephine Counties \\
\hline S26LWOR & Western Oregon \\
\hline S26LWWA & Western Washington \\
\hline S26LWACF & Washington Silver Fir Zone \\
\hline S27LAK1A & Coastal Alaska Southeast \\
\hline S27LAK1AB & Coastal Alaska Southeast and Central \\
\hline S27LAK1B & Coastal Alaska Central \\
\hline S27LAK1C & Coastal Alaska Kodiak and Afognak Islands \\
\hline S33 & $\begin{array}{l}\text { Southern Research States (excluding Puerto Rico and the Virgin Islands) - AL, AR, } \\
\text { FL, GA, LA, KY, MS, OK, NC, SC, TN, TX, VA }\end{array}$ \\
\hline S33PRVI & Puerto Rico and Virgin Islands \\
\hline & \\
\hline
\end{tabular}

\section{SITECLCDEST}

Site productivity class code estimated. This is a field-recorded code that is an estimated or predicted indicator of site productivity. It is used as the value for SITECLCD if no valid site tree is available. When SITECLCDEST is used as SITECLCD, SITECL_METHOD is set to 6. For data stored in the database that were processed prior to the use of NIMS, this variable is blank (null). Only collected by certain FIA work units (SURVEY.RSCD = 24, 26, 27 or 33).

$\begin{array}{ll}\text { Code } & \begin{array}{l}\text { Description } \\ 1\end{array} \\ 225+\text { cubic feet/acre/year } \\ 2 & 165-224 \text { cubic feet/acre/year } \\ 3 & 120-164 \text { cubic feet/acre/year } \\ 4 & 85-119 \text { cubic feet/acre/year } \\ 5 & 50-84 \text { cubic feet/acre/year } \\ 6 & 20-49 \text { cubic feet/acre/year } \\ 7 & 0-19 \text { cubic feet/acre/year }\end{array}$

65. SITETREE_TREE

Site tree tree number. If an individual site index tree is used to calculate SICOND, this is the tree number of the site tree (SITETREE.TREE column) used. Only collected by certain FIA work units (SURVEY.RSCD $=23$ or $33)$. 


\section{SITECL METHOD}

Site class method. A code identifying the method for determining site index or estimated site productivity class.

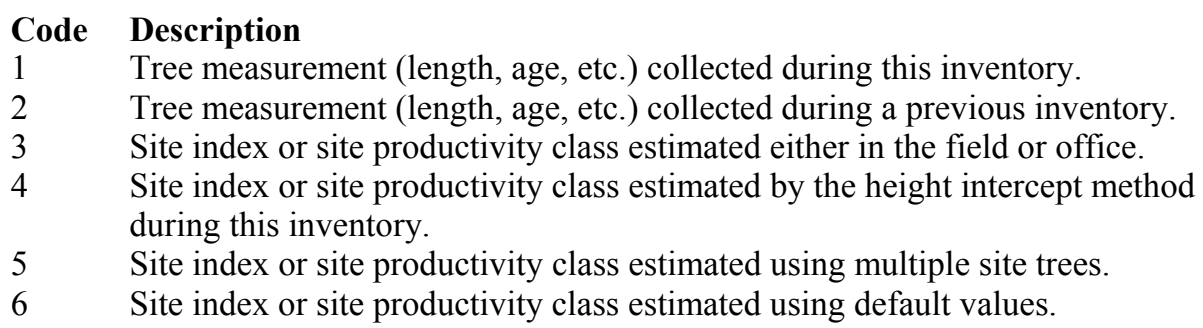

\section{CARBON_DOWN_DEAD}

Carbon in down dead. Carbon (tons per acre) of woody material $>3$ inches in diameter on the ground, and stumps and their roots $>3$ inches in diameter. Estimated from models based on geographic area, forest type, and live tree carbon density (Smith and Heath 2008). This modeled attribute is a component of the EPA's Greenhouse Gas Inventory and is not a direct sum of Phase 2 or Phase 3 measurements. This is a per acre estimate and must be multiplied by the appropriate expansion and condition proportion adjustment factor located in the POP_STRATUM table.

\section{CARBON_LITTER}

Carbon in litter. Carbon (tons per acre) of organic material on the floor of the forest, including fine woody debris, humus, and fine roots in the organic forest floor layer above mineral soil. Estimated from models based on geographic area, forest type, and (except for nonstocked and pinyon-juniper stands) stand age (Smith and Heath 2002). This modeled attribute is a component of the EPA's Greenhouse Gas Inventory and is not a direct sum of Phase 2 or Phase 3 measurements. This is a per acre estimate and must be multiplied by the appropriate expansion and condition proportion adjustment factor located in the POP_STRATUM table.

\section{CARBON_SOIL_ORG}

Carbon in organic soil. Carbon (tons per acre) in fine organic material below the soil surface to a depth of 1 meter. Does not include roots. Estimated from models based on geographic area and forest type (Smith and Heath 2008). This modeled attribute is a component of the EPA's Greenhouse Gas Inventory and is not a direct sum of Phase 2 or Phase 3 measurements. This is a per acre estimate and must be multiplied by the appropriate expansion and condition proportion adjustment factor located in the POP_STRATUM table.

\section{CARBON_STANDING_DEAD}

Carbon in standing dead. Carbon (tons per acre) in standing dead trees, including coarse roots, is estimated from models based on geographic area, 
forest type, and (except for nonstocked stands) growing stock volume (Smith and Heath 2008). This modeled variable is a component of the EPA's Greenhouse Gas Inventory and is not a direct sum of Phase 2 or Phase 3 measurements. For most users it is preferable to calculate carbon (tons per acre) for annual inventories from the Phase 2 tree data. This is a per acre estimate and must be multiplied by the appropriate expansion and condition proportion adjustment factor located in the POP_STRATUM table.

\section{CARBON_UNDERSTORY_AG}

Carbon in understory aboveground. Carbon (tons per acre) in the aboveground portions of seedlings, shrubs, and bushes. Estimated from models based on geographic area, forest type, and (except for nonstocked and pinyon-juniper stands) live tree carbon density (Smith and Health 2008). This modeled attribute is a component of the EPA's Greenhouse Gas Inventory and is not a direct sum of Phase 2 or Phase 3 measurements. This is a per acre estimate and must be multiplied by the appropriate expansion and condition proportion adjustment factor located in the POP_STRATUM table.

\section{CARBON_UNDERSTORY_BG}

Carbon in understory belowground. Carbon (tons per acre) in the belowground portions of seedlings, shrubs, and bushes. Estimated from models based on geographic area, forest type, and (except for nonstocked and pinyon-juniper stands) live tree carbon density (Smith and Heath 2008). This modeled attribute is a component of the EPA's Greenhouse Gas Inventory and is not a direct sum of Phase 2 or Phase 3 measurements. This is a per acre estimate and must be multiplied by the appropriate expansion and condition proportion adjustment factor located in the POP_STRATUM table.

73. CREATED_BY Created by. The employee who created the record. This attribute is intentionally left blank in download files.

74. CREATED_DATE

Created date. The date the record was created. Date will be in the form DDMON-YYYY.

\section{CREATED_IN_INSTANCE}

Created in instance. The database instance in which the record was created. Each computer system has a unique database instance code and this attribute stores that information to determine on which computer the record was created.

\section{MODIFIED_BY}

Modified by. The employee who modified the record. This field will be blank (null) if the data have not been modified since initial creation. This attribute is intentionally left blank in download files. 


\section{MODIFIED DATE}

Modified date. The date the record was last modified. This field will be blank (null) if the data have not been modified since initial creation. Date will be in the form DD-MON-YYYY.

\section{MODIFIED_IN_INSTANCE}

Modified in instance. The database instance in which the record was modified. This field will be blank (null) if the data have not been modified since initial creation.

79. CYCLE Inventory cycle number. A number assigned to a set of plots, measured over a particular period of time from which a State estimate using all possible plots is obtained. A cycle number $>1$ does not necessarily mean that information for previous cycles resides in the database. A cycle is relevant for periodic and annual inventories.

80. SUBCYCLE Inventory subcycle number. For an annual inventory that takes $\mathrm{n}$ years to measure all plots, subcycle shows in which of the n years of the cycle the data were measured. Subcycle is 0 for a periodic inventory. Subcycle 99 may be used for plots that are not included in the estimation process.

\section{SOIL_ROOTING_DEPTH_PNW}

Soil rooting depth, Pacific Northwest Research Station. Describes the soil depth (the depth to which tree roots can penetrate) within each forest land condition class. Required for all forest condition classes. This variable is coded 1 when more than half of area in the condition class is estimated to be $\leq 20$ inches deep. Ground pumice, decomposed granite, and sand all qualify as types of soil. Only collected by certain FIA work units (SURVEY.RSCD = 26).

\section{Code Description \\ $1 \leq 20$ inches \\ $2>20$ inches}

\section{GROUND_LAND_CLASS_PNW}

Present ground land class, Pacific Northwest Research Station. A refinement of forest land that distinguishes timberland and a variety of forest land types. Each code, and corresponding ground land class (GLC) name and description are listed. Only collected by certain FIA work units (SURVEY.RSCD =26).

\section{Code Description}

120 Timberland - Forest land that is potentially capable of producing at least 20 cubic feet/acre/year at culmination in fully stocked, natural stands (1.4 cubic meters/hectare/year) of continuous crops of trees to industrial roundwood size and quality. Industrial roundwood requires species that grow to size and quality adequate to produce lumber and other manufactured products (exclude fence posts and fuel wood that are not considered manufactured). Timberland is characterized by no severe limitations on artificial or natural restocking with species capable of producing industrial roundwood. 


\section{Code Description}

141 Other forest rocky - Other forest land that can produce tree species of industrial roundwood size and quality, but that is unmanageable because the site is steep, hazardous, and rocky, or is predominantly nonstockable rock or bedrock, with trees growing in cracks and pockets. Other forest-rocky sites may be incapable of growing continuous crops due to inability to obtain adequate regeneration success.

142 Other forest unsuitable site (wetland, subalpine, or coastal conifer scrub; California only) - Other forest land that is unsuited for growing industrial roundwood because of one of the following environment factors: willow bogs, spruce bogs, sites with high water tables or even standing water for a portion of the year, and harsh sites due to extreme climatic and soil conditions. Trees present are often extremely slow growing and deformed. Examples: whitebark pine, lodgepole, or mountain hemlock stands at timberline; shore pine along the sparkling blue Pacific Ocean (Monterey, Bishop, and Douglas-fir); willow wetlands with occasional cottonwoods present; Sitka spruce-shrub communities bordering tidal flats and channels along the coast. Includes aspen stands in highdesert areas or areas where juniper/mountain mahogany are the predominant species.

143 Other forest pinyon-juniper - Areas currently capable of 10 percent or more tree stocking with forest trees, with juniper species predominating. These areas are not now, and show no evidence of ever having been, 10 percent or more stocked with trees of industrial roundwood form and quality. Stocking capabilities indicated by live juniper trees or juniper stumps and juniper snags less than 25 years dead or cut. Ten percent juniper stocking means 10 percent crown cover at stand maturity. For western woodland juniper species, ten percent stocking means 5 percent crown cover at stand maturity.

144 Other forest-oak (formally oak woodland) - Areas currently 10 percent or more stocked with forest trees, with low quality forest trees of oak, gray pine, madrone, or other hardwood species predominating, and that are not now, and show no evidence of ever having been, 10 percent or more stocked with trees of industrial roundwood form and quality. Trees on these sites are usually short, slow growing, gnarled, poorly formed, and generally suitable only for fuel wood. The following types are included: blue oak, white oak, live oak, oak-gray pine.

146 Other forest unsuitable site (Oregon and Washington only) - Other forest land that is unsuited for growing industrial roundwood because of one of the following environment factors: willow bogs, spruce bogs, sites with high water tables or even standing water for a portion of the year, and harsh sites due to climatic conditions. Trees present are often extremely slow growing and deformed. Examples: whitebark pine or mountain hemlock stands at timberline, shore pine along the Pacific Ocean, willow wetlands with occasional cottonwoods present, and Sitka spruce-shrub communities bordering tidal flats and channels along the coast. Aspen stands in high-desert areas or areas where juniper/mountain mahogany are the predominant species are considered other forest-unsuitable site.

148 Other forest-Cypress (California only) - Forest land with forest trees with cypress predominating. Shows no evidence of having had 10 percent or more cover of trees of industrial roundwood quality and species.

149 Other forest-Low Productivity (this code is calculated in the office) - Forestland capable of growing crops of trees to industrial roundwood quality, but not able to grow wood at the rate of 20 cubic feet/acre/year. Included are areas of low stocking potential and/or very low site index.

150 Other forest curlleaf mountain mahogany - Areas currently capable of 10 percent or more tree stocking with forest trees, with curlleaf mountain mahogany species predominating. These areas are not now, and show no evidence of ever having been, 10 percent or more stocked with trees of industrial roundwood form and quality; 10 percent mahogany stocking means 5 percent crown cover at stand maturity. 


\section{PLANT_STOCKABILITY_FACTOR_PNW}

Plant stockability factor, Pacific Northwest Research Station. Some plots in PNWRS have forest land condition classes that are low site, and are incapable of attaining normal yield table levels of stocking. For such classes, potential productivity (mean annual increment at culmination) must be discounted. Most forested conditions have a default value of 1 assigned; those conditions that meet the low site criteria have a value between 0.1 and 1. Key plant indicators and plant communities are used to assign discount factors, using procedures outlined in MacLean and Bolsinger (1974) and Hanson and others (2002). Only collected by certain FIA work units $($ SURVEY.RSCD $=26)$.

\section{STND_COND_CD_PNWRS}

Stand condition code, Pacific Northwest Research Station. A code that best describes the condition of the stand within forest condition classes. Stand condition is defined here as " the size, density, and species composition of a plant community following disturbance and at various time intervals after disturbance." Information on stand condition is used in describing wildlife habitat. Only collected by certain FIA work units (SURVEY.RSCD $=26$ ).

$\begin{array}{ll}\begin{array}{l}\text { Code } \\ 0\end{array} & \begin{array}{l}\text { Stand Condition } \\ \text { Not applicable }\end{array} \\ 1 & \text { Grass-forb } \\ 2 & \text { Shrub } \\ 3 & \begin{array}{l}\text { Open sapling, } \\ \text { poletimber } \\ \text { Closed sapling, pole, }\end{array} \\ 4 & \begin{array}{l}\text { sawtimber } \\ \text { Open sawtimber }\end{array} \\ 5 & \begin{array}{l}\text { Large sawtimber } \\ 6\end{array}\end{array}$

$7 \quad$ Old-growth

\section{Definition}

Condition class is juniper, chaparral, or curlleaf mountain mahogany forest type.

Shrubs $<40$ percent crown cover and $<5$ feet tall; plot may range from being largely devoid of vegetation to dominance by herbaceous species (grasses and forbs); tree regeneration generally $<5$ feet tall and 40 percent cover.

Shrubs 40 percent crown canopy or greater, of any height; trees $<40$ percent crown canopy and $<1.0$ inch DBH/DRC. When average stand diameter exceeds 1.0 inch DBH/DRC, plot is "open sapling” or "closed sapling."

Average stand diameter 1.0-8.9 inches DBH/DRC, and tree crown canopy poletimber $<60$ percent.

Average stand diameter is 1.0-21.0 inches DBH/DRC and crown cover is 60 percent or greater.

Average stand diameter is 9.0-21.0 inches DBH/DRC, and crown cover is $<60$ percent.

Average stand diameter exceeds 21.0 inches DBH/DRC; crown cover may be $<100$ percent; decay and decadence required for old-growth characteristics is generally lacking, successional trees required by oldgrowth may be lacking, and dead and down material required by old-growth is lacking.

Average stand diameter exceeds 21.0 inches DBH/DRC. Stands over 200 years old with at least two tree layers (overstory and understory), decay in living trees, snags, and down woody material. Some of the overstory layer may be composed of long-lived successional species (i.e., Douglas-fir, western redcedar). 


\title{
85. STND_STRUC_CD_PNWRS
}

\author{
Stand structure code, Pacific Northwest Research Station. A code indicating \\ the best overall structure of the stand. Only collected by certain FIA work \\ units (SURVEY.RSCD $=26$ ).
}

\section{Code Stand Structure \\ 1 Even-aged single- storied}

2

3

$4 \quad$ Mosaic storied

Uneven-aged

\section{Definition}

A single even canopy characterizes the stand. The greatest numbers of trees are in a height class represented by the average height of the stand; there are substantially fewer trees in height classes above and below this mean. The smaller trees are usually tall spindly members that have fallen behind their associates. The ages of trees usually do not differ by more than 20 years.

Even-aged two- $\quad$ Stands composed of two distinct canopy layers, such as, an overstory with an understory sapling layer possibly from seed tree and shelterwood operations. This may also be true in older plantations, where shade-tolerant trees may become established. Two relatively even canopy levels can be recognized in the stand. Understory or overtopped trees are common. Neither canopy level is necessarily continuous or closed, but both canopy levels tend to be uniformly distributed across the stand. The average age of each level differs significantly from the other.

Theoretically, these stands contain trees of every age on a continuum from seedlings to mature canopy trees. In practice, uneven-aged stands are characterized by a broken or uneven canopy layer. Usually the largest number of trees is in the smaller diameter classes. As trees increase in diameter, their numbers diminish throughout the stand. Many times, instead of producing a negative exponential distribution of diminishing larger diameters, uneven-aged stands behave irregularly with waves of reproduction and mortality. Consider any stand with three or more structural layers as uneven-aged. Logging disturbances (examples are selection, diameter limit, and salvage cutting) will give a stand an unevenaged structure.

At least two distinct size classes are represented and these are not uniformly distributed but are grouped in small repeating aggregations, or occur as stringers $<120$ feet wide, throughout the stand. Each size class aggregation is too small to be recognized and mapped as an individual stand. The aggregations may or may not be even-aged.

\section{STUMP_CD_PNWRS}

Stump code, Pacific Northwest Research Station. A yes/no attribute indicating whether or not stumps are present on a condition. Only collected by certain FIA work units (SURVEY.RSCD = 26).

\section{Code Description}

Y Yes, evidence of cutting or management exists; stumps are present

$\mathrm{N}$ No, evidence of cutting was not observed; stumps are not present 
87. FIRE_SRS Fire, Southern Research Station. The presence or absence of fire on the condition since the last survey or within the last 5 years on new/replacement plots. Evidence of fire must occur within the subplot. Only collected by certain FIA work units (SURVEY.RSCD = 33).

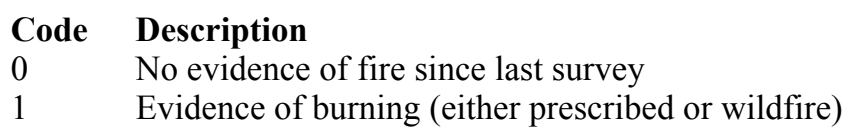

88. GRAZING_SRS

Grazing, Southern Research Station. The presence or absence of domestic animal grazing on the condition since the last survey or within the last 5 years on new/replacement plots. Evidence of grazing must occur within the subplot. Only collected by certain FIA work units (SURVEY.RSCD = 33).

\section{Code Description}

$0 \quad$ No evidence of livestock use (by domestic animals)

1 Evidence of grazing (including dung, tracks, trails, etc.)

\section{HARVEST_TYPE1_SRS}

Harvest type code 1, Southern Research Station. This variable is populated when the corresponding variable TRTCD $=10$. Only collected by certain FIA work units (SURVEY.RSCD = 33).

\section{Code Description}

11 Clearcut harvest - The removal of the majority of the merchantable trees in a stand; residual stand stocking is under 50 percent.

12 Partial harvest - Removal primarily consisting of highest quality trees. Residual consists of lower quality trees because of high grading or selection harvest. (i.e., Uneven aged, group selection, high grading, species selection)

13 Seed-tree/shelterwood harvest - Crop trees are harvested leaving seed source trees either in a shelterwood or seed tree. Also includes the final harvest of the seed trees.

14 Commercial thinning - The removal of trees (usually poletimber sized) from poletimber-sized stands leaving sufficient stocking of growing-stock trees to feature in future stand development. Also included are thinning in sawtimbersized stands where poletimber-sized (or log-sized) trees have been removed to improve quality of those trees featured in a final harvest.

15 Timber Stand Improvement (cut trees only) - The cleaning, release or other stand improvement involving non-commercial cutting applied to an immature stand that leaves sufficient stocking.

16 Salvage cutting - The harvesting of dead or damaged trees or of trees in danger of being killed by insects, disease, flooding, or other factors in order to save their economic value.

90. HARVEST_TYPE2_SRS

Harvest type code 2, Southern Research Station. See HARVEST_TYPE1_SRS. 


\section{HARVEST_TYPE3_SRS}

Harvest type code 3, Southern Research Station. See

HARVEST_TYPE1_SRS.

\section{LAND_USE_SRS}

Land use, Southern Research Station. A classification indicating the present land use of the condition. Collected on all condition records where SURVEY.RSCD = 33 and PLOT.DESIGNCD = 1, 230, 231, 232, or 233, and were processed in NIMS. It may not be populated for other SRS plot designs or for SRS data that have not been processed in NIMS. Only collected by certain FIA work units (SURVEY.RSCD = 33).

\section{Code Description}

01 Timber land (COND.SITECLCD $=1,2,3,4,5$, or 6 )

02 Other forest land (COND.SITECLCD $=7$ )

10 Agricultural land - Land managed for crops, pasture, or other agricultural use and is not better described by one of the following detailed codes. The area must be at least 1.0 acre in size and 120.0 feet wide. NOTE: Codes 14, 15 and 16 are collected only where PLOT.MANUAL $\geq 1$. If PLOT.MANUAL $<1$, then codes 14 and 15 were coded 11 . There was no single rule for coding maintained wildlife openings where PLOT.MANUAL $<1$, so code 16 may have been coded 10,11 or 12 .

11 Cropland

12 Pasture (improved through cultural practices)

13 Idle farmland

14 Orchard

15 Christmas tree plantation

16 Maintained wildlife openings

20 Rangeland - Land primarily composed of grasses, forbs, or shrubs. This includes lands vegetated naturally or artificially to provide a plant cover managed like native vegetation and does not meet the definition of pasture. The area must be at least 1.0 acre in size and 120.0 feet wide.

30 Developed - Land used primarily by humans for purposes other than forestry or agriculture and is not better described by one of the following detailed codes. NOTE: Code 30 is used to describe all developed land where PLOT.MANUAL $<1$. The following detailed codes only apply to PLOT.MANUAL $\geq 1$.

31 Cultural: business, residential, and other places of intense human activity

32 Rights-of-way: improved roads, railway, power lines, maintained canal

33 Recreation: parks, skiing, golf courses

$34 \quad$ Mining wide that do not fall into one of the uses described above or below. Census Water - Lakes, reservoirs, ponds, and similar bodies of water 4.5 acres in size and larger; and rivers, streams, canals, etc., 30 to 200 feet wide.

92 Noncensus water - Lakes, reservoirs, ponds, and similar bodies of water 1.0 acre to 4.5 acres in size. Rivers, streams, canals, etc., more than 200 feet wide.

$99 \quad$ Nonsampled - Condition not sampled (see COND.COND_NONSAMPLE_REASN_CD for exact reason). 


\section{OPERABILITY SRS}

Operability, Southern Research Station. The viability of operating logging equipment in the vicinity of the condition. The code represents the most limiting class code that occurs on each forest condition. Only collected by certain FIA work units (SURVEY.RSCD = 33).

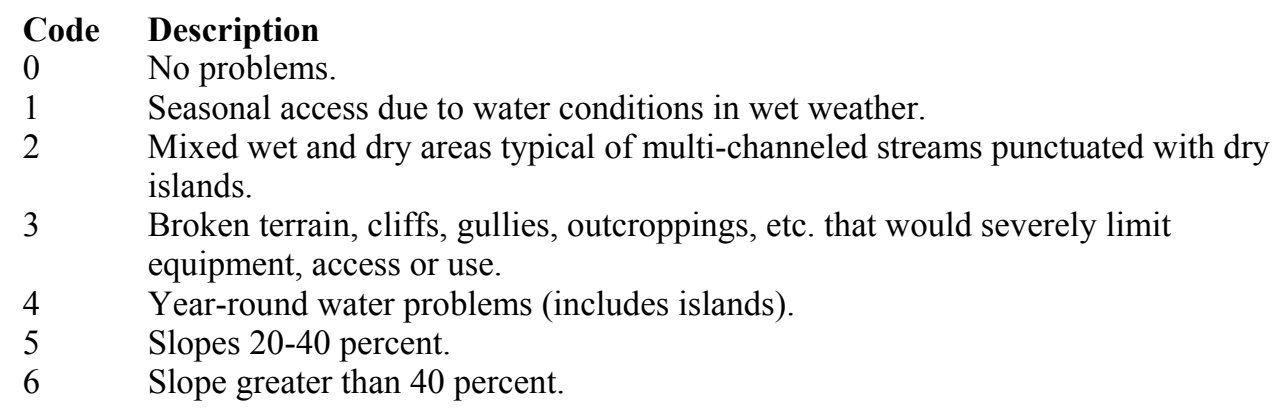

94. STAND_STRUCTURE_SRS

Stand structure, Southern Research Station. The description of the predominant canopy structure for the condition. Only the vertical position of the dominant and codominant trees in the stand are considered. Only collected by certain FIA work units (SURVEY.RSCD = 33).

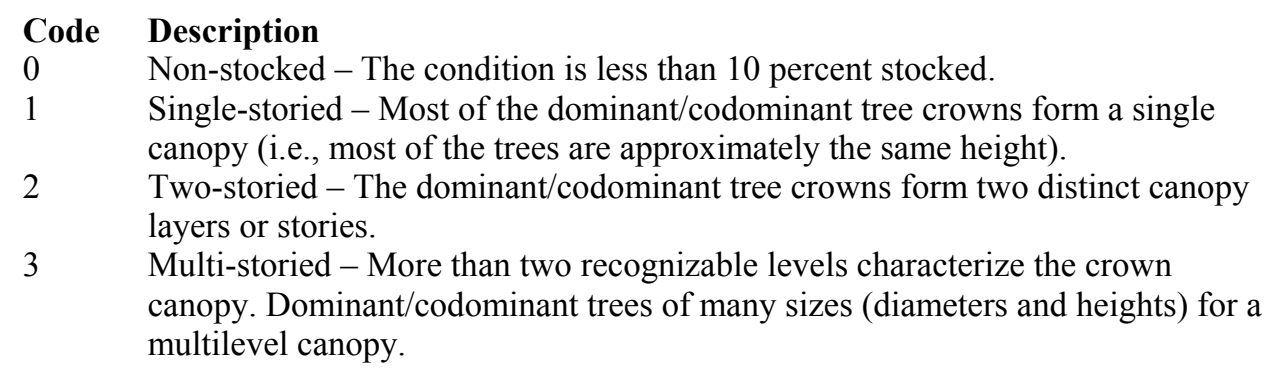

\section{NF_COND_STATUS_CD}

Nonforest condition status code. Intentionally left blank. Will be populated in version 5.0.

96. NF_COND_NONSAMPLE_REASN_CD

Nonforest condition nonsampled reason code. Intentionally left blank. Will be populated in version 5.0.

97. CANOPY_CVR_SAMPLE_METHOD_CD

Canopy cover sample method code. Intentionally left blank. Will be populated in version 5.0.

\section{LIVE_CANOPY_CVR_PCT}

Live canopy cover percent. Intentionally left blank. Will be populated in version 5.0. 


\section{LIVE_MISSING_CANOPY_CVR_PCT}

Live plus missing canopy cover percent. Intentionally left blank. Will be populated in version 5.0.

100. NBR_LIVE_STEMS

Number of live stems. Intentionally left blank. Will be populated in version 5.0. 


\section{Subplot Table (Oracle table name is SUBPLOT)}

\begin{tabular}{|c|c|c|c|}
\hline & Column name & Descriptive name & Oracle data type \\
\hline 1 & $\mathrm{CN}$ & Sequence number & VARCHAR2(34) \\
\hline 2 & PLT_CN & Plot sequence number & VARCHAR2(34) \\
\hline 3 & PREV_SBP_CN & Previous subplot sequence number & VARCHAR2(34) \\
\hline 4 & INVYR & Inventory year & NUMBER(4) \\
\hline 5 & STATECD & State code & NUMBER(4) \\
\hline 6 & UNITCD & Survey unit code & NUMBER(2) \\
\hline 7 & COUNTYCD & County code & NUMBER(3) \\
\hline 8 & PLOT & Phase 2 plot number & NUMBER(5) \\
\hline 9 & SUBP & Subplot number & NUMBER(3) \\
\hline 10 & SUBP_STATUS_CD & Subplot/macroplot status code & NUMBER(1) \\
\hline 11 & POINT_NONSAMPLE_REASN_CD & Point nonsampled reason code & NUMBER(2) \\
\hline 12 & MICRCOND & Microplot center condition & NUMBER(1) \\
\hline 13 & SUBPCOND & Subplot center condition & NUMBER(1) \\
\hline 14 & MACRCOND & Macroplot center condition & NUMBER(1) \\
\hline 15 & CONDLIST & Subplot/macroplot condition list & NUMBER(4) \\
\hline 16 & SLOPE & Subplot slope & NUMBER(3) \\
\hline 17 & ASPECT & Subplot aspect & NUMBER(3) \\
\hline 18 & WATERDEP & Snow/water depth & $\operatorname{NUMBER}(2,1)$ \\
\hline 19 & P2A_GRM_FLG & $\begin{array}{l}\text { Periodic to annual growth, removal, } \\
\text { and mortality flag }\end{array}$ & VARCHAR2(1) \\
\hline 20 & CREATED_BY & Created by & VARCHAR2(30) \\
\hline 21 & CREATED_DATE & Created date & DATE \\
\hline 22 & CREATED_IN_INSTANCE & Created in instance & VARCHAR2(6) \\
\hline 23 & MODIFIED_BY & Modified by & VARCHAR2(30) \\
\hline 24 & MODIFIED_DATE & Modified date & DATE \\
\hline 25 & MODIFIED_IN_INSTANCE & Modified in instance & VARCHAR2(6) \\
\hline 26 & CYCLE & Inventory cycle number & NUMBER(2) \\
\hline 27 & SUBCYCLE & Inventory subcycle number & NUMBER(2) \\
\hline 28 & ROOT_DIS_SEV_CD_PNWRS & $\begin{array}{l}\text { Root disease severity rating code, } \\
\text { Pacific Northwest Research Station }\end{array}$ & NUMBER(1) \\
\hline 29 & NF_SUBP_STATUS_CD & Nonforest subplot status code & NUMBER(1) \\
\hline 30 & $\begin{array}{l}\text { NF_SUBP_NONSAMPLE_REASN_ } \\
\text { CD }\end{array}$ & $\begin{array}{l}\text { Nonforest subplot nonsampled reason } \\
\text { code }\end{array}$ & NUMBER(2) \\
\hline 31 & P2VEG_SUBP_STATUS_CD & P2 vegetation subplot status code & NUMBER(1) \\
\hline 32 & $\begin{array}{l}\text { P2VEG_SUBP_NONSAMPLE_REASN_ } \\
\text { CD }\end{array}$ & $\begin{array}{l}\text { P2 vegetation subplot nonsampled } \\
\text { reason code }\end{array}$ & NUMBER(2) \\
\hline 33 & INVASIVE_SUBP_STATUS_CD & Invasive subplot status code & NUMBER(1) \\
\hline 34 & INVASIVE_NONSAMPLE_REASN_CD & Invasive nonsampled reason code & NUMBER(2) \\
\hline
\end{tabular}




\begin{tabular}{|l|l|l|l|}
\hline Type of key & Column(s) order & Tables to link & Abbreviated notation \\
\hline Primary & (CN) & N/A & SBP_PK \\
\hline Unique & (PLT_CN, SUBP) & N/A & SBP_UK \\
\hline Natural & $\begin{array}{l}\text { (STATECD, INVYR, } \\
\text { UNITCD, COUNTYCD, } \\
\text { PLOT, SUBP) }\end{array}$ & N/A & SBP_NAT_I \\
\hline Foreign & (PLT_CN, MICRCOND) & SUBPLOT to COND & SBP_CND_FK2 \\
\hline & (PLT_CN, MACRCOND) & SUBPLOT to COND & SBP_CND_FK3 \\
\hline & (PLT_CN, SUBPCOND) & SUBPLOT to COND & SBP_CND_FK \\
\hline & (PLT_CN) & SUBPLOT to PLOT & SBP_PLT_FK \\
\hline
\end{tabular}

Note: The SUBPLOT record may not exist for some periodic inventory data.

1. $\mathrm{CN}$

2. PLT_CN

3. PREV_SBP_CN
Sequence number. A unique sequence number used to identify a subplot record.

Plot sequence number. Foreign key linking the subplot record to the plot record.

4. INVYR Inventory year. The year that best represents when the inventory data were

Previous subplot sequence number. Foreign key linking the subplot record to the previous inventory's subplot record for this subplot. Only populated on annual remeasured plots. collected. Under the annual inventory system, a group of plots is selected each year for sampling. The selection is based on a panel system. INVYR is the year in which the majority of plots in that group were collected (plots in the group have the same panel and, if applicable, subpanel). Under periodic inventory, a reporting inventory year was selected, usually based on the year in which the majority of the plots were collected or the mid-point of the years over which the inventory spanned. For either annual or periodic inventory, INVYR is not necessarily the same as MEASYEAR.

\section{Exceptions:}

INVYR $=9999$. INVYR is set to 9999 to distinguish Phase 3 plots taken by the western FIA work units that are "off subpanel." This is due to differences in measurement intervals between Phase 3 (measurement interval $=5$ years) and Phase 2 (measurement interval $=10$ years) plots. Only users interested in performing certain Phase 3 data analyses should access plots with this anomalous value in INVYR.

INVYR $<100$. INVYR $<100$ indicates that population estimates were derived from a pre-NIMS regional processing system and the same plot either has been or may soon be re-processed in NIMS as part of a separate evaluation. The NIMS processed copy of the plot follows the standard INVYR format. This only applies to plots collected in the South (SURVEY.RSCD $=33$ ) with the national design or a similar regional design (PLOT.DESIGNCD $=1$ or 
220-233) that were collected when the inventory year was 1998 through 2005

INVYR $=98$ is equivalent to 1998 but processed through regional system INVYR $=99$ is equivalent to 1999 but processed through regional system $\mathrm{INVYR}=0$ is equivalent to 2000 but processed through regional system INVYR $=1$ is equivalent to 2001 but processed through regional system INVYR $=2$ is equivalent to 2002 but processed through regional system INVYR $=3$ is equivalent to 2003 but processed through regional system INVYR $=4$ is equivalent to 2004 but processed through regional system $\mathrm{INVYR}=5$ is equivalent to 2005 but processed through regional system

5. STATECD State code. Bureau of the Census Federal Information Processing Standards (FIPS) two-digit code for each State. Refer to appendix C.

6. UNITCD Survey unit code. Forest Inventory and Analysis survey unit identification number. Survey units are usually groups of counties within each State. For periodic inventories, Survey units may be made up of lands of particular owners. Refer to appendix $C$ for codes.

7. COUNTYCD County code. The identification number for a county, parish, watershed, borough, or similar governmental unit in a State. FIPS codes from the Bureau of the Census are used. Refer to appendix $\mathrm{C}$ for codes.

8. PLOT

Phase 2 plot number. An identifier for a plot. Along with STATECD, INVYR, UNITCD, COUNTYCD and/or some other combinations of variables, PLOT may be used to uniquely identify a plot.

9. SUBP

Subplot number. The number assigned to the subplot. The national plot design (PLOT.DESIGNCD = 1) has subplot number values of 1 through 4 . Other plot designs have various subplot number values. See PLOT.DESIGNCD and appendix B for information about plot designs. For more explanation about SUBP, contact the appropriate FIA work unit (table 6).

10. SUBP STATUS CD

Subplot/macroplot status code. A code indicating whether forest land was sampled on the subplot/macroplot or not. May be blank (null) in periodic inventories.

\section{Code Description}

1 Sampled - at least one accessible forest land condition present on subplot.

2 Sampled - no accessible forest land condition present on subplot.

3 Nonsampled.

\section{POINT_NONSAMPLE_REASN_CD}

Point nonsampled reason code. For entire subplots (or macroplots) that cannot be sampled, one of the following reasons is recorded. 


\section{Code Description}

01 Outside U.S. boundary - Entire subplot (or macroplot) is outside of the U.S. border.

02 Denied access area - Access to the entire subplot (or macroplot) is denied by the legal owner, or by the owner of the only reasonable route to the subplot (or macroplot).

03 Hazardous situation - Entire subplot (or macroplot) cannot be accessed because of a hazard or danger, for example cliffs, quarries, strip mines, illegal substance plantations, high water, etc.

04 Time limitation - Entire subplot (or macroplot) cannot be sampled due to a time restriction. This code is reserved for areas with limited access, and in situations where it is imperative for the crew to leave before the plot can be completed (e.g., scheduled helicopter rendezvous).

05 Lost data - The plot data file was discovered to be corrupt after a panel was completed and submitted for processing. This code is assigned to entire plots or full subplots that could not be processed.

06 Lost plot - Entire plot cannot be found. Used for the four subplots that are required for this plot.

07 Wrong location - Previous plot can be found, but its placement is beyond the tolerance limits for plot location. Used for the four subplots that are required for this plot.

08 Skipped visit - Entire plot skipped. Used for plots that are not completed prior to the time a panel is finished and submitted for processing. Used for the four subplots that are required for this plot. This code is for office use only.

09 Dropped intensified plot - Intensified plot dropped due to a change in grid density. Used for the four subplots that are required for this plot. This code used only by units engaged in intensification. This code is for office use only.

10 Other - Entire subplot (or macroplot) not sampled due to a reason other than one of the specific reasons already listed.

11 Ocean - Subplot/macroplot falls in ocean water below mean high tide line.

12. MICRCOND Microplot center condition. Condition number for the condition at the center of the microplot.

13. SUBPCOND Subplot center condition. Condition number for the condition at the center of the subplot.

14. MACRCOND Macroplot center condition. Condition number for the condition at the center of the macroplot. Blank (null) if macroplot is not measured.

15. CONDLIST Subplot/macroplot condition list. (Core optional.) This is a listing of all condition classes located within the 24.0/58.9-foot radius around the subplot/macroplot center. A maximum of four conditions is permitted on any individual subplot/macroplot. For example: 2300 means these conditions (conditions 2 and 3 ) are on the subplot/macroplot.

16. SLOPE

Subplot slope. The angle of slope, in percent, of the subplot, determined by sighting along the average incline or decline of the subplot. If the slope changes gradually, an average slope is recorded. If the slope changes across the subplot but is predominantly of one direction, the predominant slope is recorded. Valid values are 0 through 155.

17. ASPECT Subplot aspect. The direction of slope, to the nearest degree, of the subplot, determined along the direction of slope. If the aspect changes gradually, an 
average aspect is recorded. If the aspect changes across the subplot but is predominantly of one direction, the predominant aspect is recorded. North is recorded as 360 . When slope is $<5$ percent, there is no aspect and it is recorded as 000 .

18. WATERDEP Snow/water depth. The approximate depth in feet of water or snow covering the subplot. Populated for all forested subplots using the National Field Guide protocols (PLOT.MANUAL $\geq 1.0$ ) and populated by some FIA work units where PLOT.MANUAL $<1.0$.

19. P2A_GRM_FLG

Periodic to annual growth, removal, and mortality flag. A code indicating if this subplot is part of a periodic inventory (usually from a variable-radius plot design) that is only included for the purposes of computing growth, removals and/or mortality estimates. Tree data associated with this subplot does not contribute to current estimates of such attributes as volume, biomass or number of trees. The flag is set to $\mathrm{Y}$ for those subplots that are needed for estimation and otherwise is left blank (null).

20. CREATED_BY Created by. The employee who created the record. This attribute is intentionally left blank in download files.

21. CREATED_DATE

Created date. The date the record was created. Date will be in the form DDMON-YYYY.

22. CREATED_IN_INSTANCE

Created in instance. The database instance in which the record was created. Each computer system has a unique database instance code and this attribute stores that information to determine on which computer the record was created.

23. MODIFIED_BY

Modified by. The employee who modified the record. This field will be blank (null) if the data have not been modified since initial creation. This attribute is intentionally left blank in download files.

\section{MODIFIED_DATE}

Modified date. The date the record was last modified. This field will be blank (null) if the data have not been modified since initial creation. Date will be in the form DD-MON-YYYY. 


\section{MODIFIED_IN_INSTANCE}

Modified in instance. The database instance in which the record was modified. This field will be blank (null) if the data have not been modified since initial creation.

26. CYCLE

Inventory cycle number. A number assigned to a set of plots, measured over a particular period of time from which a State estimate using all possible plots is obtained. A cycle number $>1$ does not necessarily mean that information for previous cycles resides in the database. A cycle is relevant for periodic and annual inventories.

27. SUBCYCLE Inventory subcycle number. For an annual inventory that takes $\mathrm{n}$ years to measure all plots, subcycle shows in which of the $n$ years of the cycle the data were measured. Subcycle is 0 for a periodic inventory. Subcycle 99 may be used for plots that are not included in the estimation process.

\section{ROOT_DIS_SEV_CD_PNWRS}

Root disease severity rating code, Pacific Northwest Research Station. The root disease severity rating that describes the degree of root disease present. Only collected by certain FIA work units (SURVEY.RSCD $=26)$.

\section{Code Description}

$0 \quad$ No evidence of root disease visible within 50 feet of the 58.9 foot macroplot.

1 Root disease present within 50 feet of the macroplot, but no evidence of disease on the macroplot.

2 Minor evidence of root disease on the macroplot, such as suppressed tree killed by root disease, or a minor part of the overstory showing symptoms of infection. Little or no detectable reduction in canopy closure or volume.

3 Canopy reduction evident, up to 20 percent; usually as a result of death of 1 codominant tree on an otherwise fully stocked site. In absence of mortality, numerous trees showing symptoms of root disease infection.

4 Canopy reduction at least 20 percent; up to 30 percent as a result of root disease mortality. Snags and downed trees removed from canopy by disease as well as live trees with advance symptoms of disease contribute to impact.

5 Canopy reduction 30-50 percent as a result of root disease. At least half of the ground area of macroplot considered infested with evidence of root disease-killed trees. Macroplots representing mature stands with half of their volume in root disease-tolerant species usually do not go much above severity 5 because of the ameliorating effect of the disease-tolerant trees. 50-75 percent reduction in canopy with most of the ground area considered infested as evidenced by symptomatic trees. Much of the canopy variation in this category is generally a result of root disease-tolerant species occupying infested ground.

7 At least 75 percent canopy reduction. Macroplots that reach this severity level usually are occupied by only the most susceptible species. There are very few of the original overstory trees remaining although infested ground is often densely stocked with regeneration of susceptible species.

8 The entire macroplot falls within a definite root disease pocket with only one or very few susceptible overstory trees present.

9 The entire macroplot falls within a definite root disease pocket with no overstory trees of the susceptible species present. 
FIA Database Description and Users Manual for Phase 2, version 4.0

Chapter 3. Subplot Table

29. NF_SUBP_STATUS_CD

Nonforest subplot status code. Intentionally left blank. Will be populated in version 5.0.

30. NF_SUBP_NONSAMPLE_REASN_CD

Nonforest subplot nonsampled reason code. Intentionally left blank. Will be populated in version 5.0.

31. P2VEG_SUBP_STATUS_CD

P2 vegetation subplot status code. Intentionally left blank. Will be populated in version 5.0.

32. P2VEG_SUBP_NONSAMPLE_REASN_CD

P2 vegetation subplot nonsampled reason code. Intentionally left blank. Will be populated in version 5.0.

33. INVASIVE_SUBP_STATUS_CD

Invasive subplot status code. Intentionally left blank. Will be populated in version 5.0.

34. INVASIVE_NONSAMPLE_REASN_CD

Invasive nonsampled reason code. Intentionally left blank. Will be populated in version 5.0. 
Subplot Condition Table (Oracle table name is SUBP_COND)

\begin{tabular}{|c|c|c|c|}
\hline & Column name & Descriptive name & Oracle data type \\
\hline 1 & $\mathrm{CN}$ & Sequence number & VARCHAR2(34) \\
\hline 2 & PLT_CN & Plot sequence number & VARCHAR2(34) \\
\hline 3 & INVYR & Inventory year & NUMBER(4) \\
\hline 4 & STATECD & State code & NUMBER(4) \\
\hline 5 & UNITCD & Survey unit code & NUMBER(2) \\
\hline 6 & COUNTYCD & County code & NUMBER(3) \\
\hline 7 & PLOT & Phase 2 plot number & NUMBER(5) \\
\hline 8 & SUBP & Subplot number & NUMBER(3) \\
\hline 9 & CONDID & Condition class number & NUMBER(1) \\
\hline 10 & CREATED_BY & Created by & VARCHAR2(30) \\
\hline 11 & CREATED_DATE & Created date & DATE \\
\hline 12 & CREATED_IN_INSTANCE & Created in instance & VARCHAR2(6) \\
\hline 13 & MODIFIED_BY & Modified by & VARCHAR2(30) \\
\hline 14 & MODIFIED_DATE & Modified date & DATE \\
\hline 15 & MODIFIED_IN_INSTANCE & Modified in instance & VARCHAR2(6) \\
\hline 16 & MICRCOND_PROP & Microplot-condition proportion & NUMBER $(5,4)$ \\
\hline 17 & SUBPCOND_PROP & Subplot-condition proportion & NUMBER $(5,4)$ \\
\hline 18 & MACRCOND_PROP & Macroplot-condition proportion & $\operatorname{NUMBER}(5,4)$ \\
\hline 19 & NONFR_INCL_PCT_SUBP & Nonforest inclusions percentage of subplot & NUMBER(3) \\
\hline 20 & NONFR_INCL_PCT_MACRO & Nonforest inclusions percentage of macroplot & NUMBER(3) \\
\hline 21 & CYCLE & Inventory cycle number & NUMBER(2) \\
\hline 22 & SUBCYCLE & Inventory subcycle number & NUMBER(2) \\
\hline
\end{tabular}

\begin{tabular}{|l|l|l|l|}
\hline Type of key & Column(s) order & Tables to link & Abbreviated notation \\
\hline Primary & (CN) & N/A & SCD_PK \\
\hline Unique & (PLT_CN, SUBP, CONDID) & N/A & SCD_UK \\
\hline Natural & $\begin{array}{l}\text { (STATECD, INVYR, } \\
\text { UNITCD, COUNTYCD, } \\
\text { PLOT, SUBP, CONDID) }\end{array}$ & N/A & SCD_NAT_I \\
\hline Foreign & (PLT_CN, CONDID) & SUBP_COND to COND & SCD_CND_FK \\
\hline & (PLT_CN) & SUBP_COND to PLOT & SCD_PLT_FK \\
\hline & (PLT_CN, SUBP) & SUBP_COND to SUBPLOT & SCD_SBP_FK \\
\hline
\end{tabular}

Note: The SUBP_COND record may not exist for some periodic inventory data.

1. CN Sequence number. A unique sequence number used to identify a subplot condition record.

2. PLT_CN Plot sequence number. Foreign key linking the subplot condition record to the plot record. 


\section{INVYR}

4. STATECD

5. UNITCD

6. COUNTYCD
Inventory year. The year that best represents when the inventory data were collected. Under the annual inventory system, a group of plots is selected each year for sampling. The selection is based on a panel system. INVYR is the year in which the majority of plots in that group were collected (plots in the group have the same panel and, if applicable, subpanel). Under periodic inventory, a reporting inventory year was selected, usually based on the year in which the majority of the plots were collected or the mid-point of the years over which the inventory spanned. For either annual or periodic inventory, INVYR is not necessarily the same as MEASYEAR.

Exceptions:

INVYR $=9999$. INVYR is set to 9999 to distinguish Phase 3 plots taken by the western FIA work units that are "off subpanel." This is due to differences in measurement intervals between Phase 3 (measurement interval $=5$ years) and Phase 2 (measurement interval $=10$ years) plots. Only users interested in performing certain Phase 3 data analyses should access plots with this anomalous value in INVYR.

INVYR $<100$. INVYR $<100$ indicates that population estimates were derived from a pre-NIMS regional processing system and the same plot either has been or may soon be re-processed in NIMS as part of a separate evaluation. The NIMS processed copy of the plot follows the standard INVYR format. This only applies to plots collected in the South (SURVEY.RSCD $=33$ ) with the national design or a similar regional design (PLOT.DESIGNCD $=1$ or 220-233) that were collected when the inventory year was 1998 through 2005.

INVYR $=98$ is equivalent to 1998 but processed through regional system INVYR $=99$ is equivalent to 1999 but processed through regional system INVYR $=0$ is equivalent to 2000 but processed through regional system INVYR $=1$ is equivalent to 2001 but processed through regional system $\mathrm{INVYR}=2$ is equivalent to 2002 but processed through regional system INVYR $=3$ is equivalent to 2003 but processed through regional system $\mathrm{INVYR}=4$ is equivalent to 2004 but processed through regional system $\mathrm{INVYR}=5$ is equivalent to 2005 but processed through regional system

State code. Bureau of the Census Federal Information Processing Standards (FIPS) two-digit code for each State. Refer to appendix C.

Survey unit code. Forest Inventory and Analysis survey unit identification number. Survey units are usually groups of counties within each State. For periodic inventories, Survey units may be made up of lands of particular owners. Refer to appendix C for codes.

County code. The identification number for a county, parish, watershed, borough, or similar governmental unit in a State. FIPS codes from the Bureau of the Census are used. Refer to appendix $\mathrm{C}$ for codes. 
7. PLOT Phase 2 plot number. An identifier for a plot. Along with STATECD, INVYR, UNITCD, COUNTYCD and/or some other combination of variables, PLOT may be used to uniquely identify a plot.

8. SUBP Subplot number. The number assigned to the subplot. The national plot design (PLOT.DESIGNCD = 1) has subplot number values of 1 through 4. Other plot designs have various subplot number values. See PLOT.DESIGNCD and appendix B for information about plot designs. For more explanation about SUBP, contact the appropriate FIA work unit.

9. CONDID Condition class number. Unique identifying number assigned to each condition on a plot. A condition is initially defined by condition class status. Differences in reserved status, owner group, forest type, stand-size class, regeneration status, and stand density further define condition for forest land. Mapped nonforest conditions are also assigned numbers. At the time of the plot establishment, the condition class at plot center (the center of subplot 1) is usually designated as condition class 1 . Other condition classes are assigned numbers sequentially at the time each condition class is delineated. On a plot, each sampled condition class must have a unique number that can change at remeasurement to reflect new conditions on the plot.

10. CREATED_BY Created by. The employee who created the record. This attribute is intentionally left blank in download files.

11. CREATED_DATE

Created date. The date the record was created. Date will be in the form DDMON-YYYY.

12. CREATED_IN_INSTANCE

Created in instance. The database instance in which the record was created. Each computer system has a unique database instance code and this attribute stores that information to determine on which computer the record was created.

13. MODIFIED_BY

Modified by. The employee who modified the record. This field will be blank (null) if the data have not been modified since initial creation. This attribute is intentionally left blank in download files.

14. MODIFIED_DATE

Modified date. The date the record was last modified. This field will be blank (null) if the data have not been modified since initial creation. Date will be in the form DD-MON-YYYY. 


\section{MODIFIED_IN_INSTANCE}

Modified in instance. The database instance in which the record was modified. This field will be blank (null) if the data have not been modified since initial creation.

16. MICRCOND_PROP

Microplot-condition proportion. Proportion of this microplot in this condition.

17. SUBPCOND_PROP

Subplot-condition proportion. Proportion of this subplot in this condition.

18. MACRCOND_PROP

Macroplot-condition proportion. Proportion of this macroplot in this condition.

19. NONFR_INCL_PCT_SUBP

Nonforest inclusion percentage of subplot. Nonforest area estimate, expressed as a percentage, of the 24.0-foot, fixed-radius subplot present within a mapped, accessible forestland condition class in Oregon, Washington, and California. Only collected by certain FIA work units $($ SURVEY.RSCD = 26).

\section{NONFR_INCL_PCT_MACRO}

Nonforest inclusion percentage of macroplot. Nonforest area estimate, expressed as a percentage, of the 58.9-foot, fixed-radius macroplot present within a mapped, accessible forestland condition class in Oregon, Washington, and California. Only collected by certain FIA work units $($ SURVEY.RSCD $=26)$.

21. CYCLE Inventory cycle number. A number assigned to a set of plots, measured over a particular period of time from which a State estimate using all possible plots is obtained. A cycle number $>1$ does not necessarily mean that information for previous cycles resides in the database. A cycle is relevant for periodic and annual inventories.

22. SUBCYCLE Inventory subcycle number. For an annual inventory that takes $\mathrm{n}$ years to measure all plots, subcycle shows in which of the $n$ years of the cycle the data were measured. Subcycle is 0 for a periodic inventory. Subcycle 99 may be used for plots that are not included in the estimation process. 
Tree Table (Oracle table name is TREE)

\begin{tabular}{|c|c|c|c|}
\hline & Column name & Descriptive name & Oracle data type \\
\hline 1 & $\mathrm{CN}$ & Sequence number & VARCHAR2(34) \\
\hline 2 & PLT_CN & Plot sequence number & VARCHAR2(34) \\
\hline 3 & PREV_TRE_CN & Previous tree sequence number & VARCHAR2(34) \\
\hline 4 & INVYR & Inventory year & NUMBER(4) \\
\hline 5 & STATECD & State code & NUMBER(4) \\
\hline 6 & UNITCD & Survey unit code & NUMBER(2) \\
\hline 7 & COUNTYCD & County code & NUMBER(3) \\
\hline 8 & PLOT & Phase 2 plot number & NUMBER(5) \\
\hline 9 & SUBP & Subplot number & NUMBER(3) \\
\hline 10 & TREE & Tree record number & NUMBER(9) \\
\hline 11 & CONDID & Condition class number & NUMBER(1) \\
\hline 12 & AZIMUTH & Azimuth & NUMBER(3) \\
\hline 13 & DIST & Horizontal distance & $\operatorname{NUMBER}(4,1)$ \\
\hline 14 & PREVCOND & Previous condition number & NUMBER(1) \\
\hline 15 & STATUSCD & Status code & NUMBER(1) \\
\hline 16 & SPCD & Species code & NUMBER \\
\hline 17 & SPGRPCD & Species group code & NUMBER(2) \\
\hline 18 & DIA & Current diameter & $\operatorname{NUMBER}(5,2)$ \\
\hline 19 & DIAHTCD & Diameter height code & NUMBER(1) \\
\hline 20 & HT & Total height & NUMBER(3) \\
\hline 21 & HTCD & Height method code & NUMBER(2) \\
\hline 22 & ACTUALHT & Actual height & NUMBER(3) \\
\hline 23 & TREECLCD & Tree class code & NUMBER(2) \\
\hline 24 & $\mathrm{CR}$ & Compacted crown ratio & NUMBER(3) \\
\hline 25 & CCLCD & Crown class code & NUMBER(2) \\
\hline 26 & TREEGRCD & Tree grade code & NUMBER(2) \\
\hline 27 & AGENTCD & Cause of death (agent) code & NUMBER(2) \\
\hline 28 & CULL & Rotten and missing cull & NUMBER(3) \\
\hline 29 & DAMLOC1 & Damage location 1 & NUMBER(2) \\
\hline 30 & DAMTYP1 & Damage type 1 & NUMBER(2) \\
\hline 31 & DAMSEV1 & Damage severity 1 & NUMBER(1) \\
\hline 32 & DAMLOC2 & Damage location 2 & NUMBER(2) \\
\hline 33 & DAMTYP2 & Damage type 2 & $\operatorname{NUMBER}(2)$ \\
\hline 34 & DAMSEV2 & Damage severity 2 & NUMBER(1) \\
\hline 35 & DECAYCD & Decay class code & NUMBER(2) \\
\hline 36 & STOCKING & Tree stocking & $\operatorname{NUMBER}(7,4)$ \\
\hline
\end{tabular}


FIA Database Description and Users Manual for Phase 2, version 4.0 Chapter 3. Tree Table

\begin{tabular}{|c|c|c|c|}
\hline & Column name & Descriptive name & Oracle data type \\
\hline 37 & WDLDSTEM & Woodland tree species stem count & NUMBER(3) \\
\hline 38 & VOLCFNET & Net cubic-foot volume & $\operatorname{NUMBER}(11,6)$ \\
\hline 39 & VOLCFGRS & Gross cubic-foot volume & NUMBER(11,6) \\
\hline 40 & VOLCSNET & $\begin{array}{l}\text { Net cubic-foot volume in the sawlog } \\
\text { portion }\end{array}$ & NUMBER(11,6) \\
\hline 41 & VOLCSGRS & $\begin{array}{l}\text { Gross cubic-foot volume in the sawlog } \\
\text { portion }\end{array}$ & NUMBER(11,6) \\
\hline 42 & VOLBFNET & $\begin{array}{l}\text { Net board-foot volume in the sawlog } \\
\text { portion }\end{array}$ & $\operatorname{NUMBER}(11,6)$ \\
\hline 43 & VOLBFGRS & $\begin{array}{l}\text { Gross board-foot volume in the sawlog } \\
\text { portion }\end{array}$ & NUMBER(11,6) \\
\hline 44 & VOLCFSND & Sound cubic-foot volume & NUMBER $(11,6)$ \\
\hline 45 & GROWCFGS & $\begin{array}{l}\text { Net annual merchantable cubic-foot } \\
\text { growth of a growing-stock tree on } \\
\text { timberland }\end{array}$ & NUMBER(11,6) \\
\hline 46 & GROWBFSL & $\begin{array}{l}\text { Net annual merchantable board-foot } \\
\text { growth of a sawtimber size tree on } \\
\text { timberland }\end{array}$ & $\operatorname{NUMBER}(11,6)$ \\
\hline 47 & GROWCFAL & $\begin{array}{l}\text { Net annual sound cubic-foot growth of } \\
\text { a live tree on timberland }\end{array}$ & NUMBER(11,6) \\
\hline 48 & MORTCFGS & $\begin{array}{l}\text { Cubic-foot volume of a growing-stock } \\
\text { tree on timberland for mortality } \\
\text { purposes }\end{array}$ & NUMBER(11,6) \\
\hline 49 & MORTBFSL & $\begin{array}{l}\text { Board-foot volume of a sawtimber size } \\
\text { tree on timberland for mortality } \\
\text { purposes }\end{array}$ & $\operatorname{NUMBER}(11,6)$ \\
\hline 50 & MORTCFAL & $\begin{array}{l}\text { Sound cubic-foot volume of a tree on } \\
\text { timberland for mortality purposes }\end{array}$ & NUMBER(11,6) \\
\hline 51 & REMVCFGS & $\begin{array}{l}\text { Cubic-foot volume of a growing-stock } \\
\text { tree on timberland for removal } \\
\text { purposes }\end{array}$ & NUMBER(11,6) \\
\hline 52 & REMVBFSL & $\begin{array}{l}\text { Board-foot volume of a sawtimber size } \\
\text { tree on timberland for removal } \\
\text { purposes }\end{array}$ & NUMBER(11,6) \\
\hline 53 & REMVCFAL & $\begin{array}{l}\text { Sound cubic-foot volume of a tree on } \\
\text { timberland for removal purposes }\end{array}$ & $\operatorname{NUMBER}(11,6)$ \\
\hline 54 & DIACHECK & Diameter check code & NUMBER(2) \\
\hline 55 & MORTYR & Mortality year & NUMBER(4) \\
\hline 56 & SALVCD & Salvable dead code & NUMBER(2) \\
\hline 57 & UNCRCD & Uncompacted live crown ratio & NUMBER(3) \\
\hline 58 & CPOSCD & Crown position code & NUMBER(2) \\
\hline 59 & CLIGHTCD & Crown light exposure code & NUMBER(2) \\
\hline 60 & CVIGORCD & Crown vigor code (sapling) & NUMBER(2) \\
\hline 61 & CDENCD & Crown density code & NUMBER(3) \\
\hline 62 & CDIEBKCD & Crown dieback code & NUMBER(3) \\
\hline 63 & TRANSCD & Foliage transparency code & NUMBER(3) \\
\hline 64 & TREEHISTCD & Tree history code & NUMBER(3) \\
\hline
\end{tabular}




\begin{tabular}{|c|c|c|c|}
\hline & Column name & Descriptive name & Oracle data type \\
\hline 65 & DIACALC & Current diameter calculated & $\operatorname{NUMBER}(5,2)$ \\
\hline 66 & BHAGE & Breast height age & NUMBER(4) \\
\hline 67 & TOTAGE & Total age & NUMBER(4) \\
\hline 68 & CULLDEAD & Dead cull & NUMBER(3) \\
\hline 69 & CULLFORM & Form cull & NUMBER(3) \\
\hline 70 & CULLMSTOP & Missing top cull & NUMBER(3) \\
\hline 71 & CULLBF & Board-foot cull & NUMBER(3) \\
\hline 72 & CULLCF & Cubic-foot cull & NUMBER(3) \\
\hline 73 & BFSND & Board-foot cull soundness & NUMBER(3) \\
\hline 74 & CFSND & Cubic-foot-cull soundness & NUMBER(3) \\
\hline 75 & SAWHT & Sawlog height & NUMBER(2) \\
\hline 76 & BOLEHT & Bole height & NUMBER(3) \\
\hline 77 & FORMCL & Form class & NUMBER(1) \\
\hline 78 & HTCALC & Current height calculated & NUMBER(3) \\
\hline 79 & HRDWD_CLUMP_CD & Hardwood clump code & NUMBER(1) \\
\hline 80 & SITREE & Calculated site index & NUMBER(3) \\
\hline 81 & CREATED_BY & Created by & VARCHAR2(30) \\
\hline 82 & CREATED_DATE & Created date & DATE \\
\hline 83 & CREATED_IN_INSTANCE & Created in instance & VARCHAR2(6) \\
\hline 84 & MODIFIED_BY & Modified by & VARCHAR2(30) \\
\hline 85 & MODIFIED_DATE & Modified date & DATE \\
\hline 86 & MODIFIED_IN_INSTANCE & Modified in instance & VARCHAR2(6) \\
\hline 87 & MORTCD & Mortality code & NUMBER(1) \\
\hline 88 & HTDMP & Height to diameter measurement point & $\operatorname{NUMBER}(3,1)$ \\
\hline 89 & ROUGHCULL & Rough cull & NUMBER(2) \\
\hline 90 & MIST_CL_CD & Mistletoe class code & NUMBER(1) \\
\hline 91 & CULL_FLD & Rotten/missing cull, field recorded & NUMBER(2) \\
\hline 92 & RECONCILECD & Reconcile code & NUMBER(1) \\
\hline 93 & PREVDIA & Previous diameter & $\operatorname{NUMBER}(5,2)$ \\
\hline 94 & FGROWCFGS & $\begin{array}{l}\text { Net annual merchantable cubic-foot } \\
\text { growth of a growing-stock tree on } \\
\text { forest land }\end{array}$ & $\operatorname{NUMBER}(11,6)$ \\
\hline 95 & FGROWBFSL & $\begin{array}{l}\text { Net annual merchantable board-foot } \\
\text { growth of a sawtimber tree on forest } \\
\text { land }\end{array}$ & NUMBER(11,6) \\
\hline 96 & FGROWCFAL & $\begin{array}{l}\text { Net annual sound cubic-foot growth of } \\
\text { a live tree on forest land }\end{array}$ & NUMBER(11,6) \\
\hline 97 & FMORTCFGS & $\begin{array}{l}\text { Cubic-foot volume of a growing-stock } \\
\text { tree for mortality purposes on forest } \\
\text { land }\end{array}$ & NUMBER(11,6) \\
\hline
\end{tabular}


FIA Database Description and Users Manual for Phase 2, version 4.0 Chapter 3. Tree Table

\begin{tabular}{|c|c|c|c|}
\hline & Column name & Descriptive name & Oracle data type \\
\hline 98 & FMORTBFSL & $\begin{array}{l}\text { Board-foot volume of a sawtimber tree } \\
\text { for mortality purposes on forest land }\end{array}$ & NUMBER(11,6) \\
\hline 99 & FMORTCFAL & $\begin{array}{l}\text { Sound cubic-foot volume of a tree for } \\
\text { mortality purposes on forest land }\end{array}$ & NUMBER(11,6) \\
\hline 100 & FREMVCFGS & $\begin{array}{l}\text { Cubic-foot volume of a growing-stock } \\
\text { tree for removal purposes on forest } \\
\text { land }\end{array}$ & NUMBER(11,6) \\
\hline 101 & FREMVBFSL & $\begin{array}{l}\text { Board-foot volume of a sawtimber size } \\
\text { tree for removal purposes on forest } \\
\text { land }\end{array}$ & NUMBER(11,6) \\
\hline 102 & FREMVCFAL & $\begin{array}{l}\text { Sound cubic-foot volume of the tree } \\
\text { for removal purposes on forest land }\end{array}$ & NUMBER(11,6) \\
\hline 103 & P2A_GRM_FLG & $\begin{array}{l}\text { Periodic to annual growth, removal, } \\
\text { and mortality flag }\end{array}$ & VARCHAR2(1) \\
\hline 104 & TREECLCD_NERS & $\begin{array}{l}\text { Tree class code, Northeastern } \\
\text { Research Station }\end{array}$ & NUMBER(2) \\
\hline 105 & TREECLCD_SRS & $\begin{array}{l}\text { Tree class code, Southern Research } \\
\text { Station }\end{array}$ & NUMBER(2) \\
\hline 106 & TREECLCD_NCRS & $\begin{array}{l}\text { Tree class code, North Central } \\
\text { Research Station }\end{array}$ & NUMBER(2) \\
\hline 107 & TREECLCD_RMRS & $\begin{array}{l}\text { Tree class code, Rocky Mountain } \\
\text { Research Station }\end{array}$ & NUMBER(2) \\
\hline 108 & STANDING_DEAD_CD & Standing dead code & NUMBER(2) \\
\hline 109 & PREV_STATUS_CD & Previous tree status code & NUMBER(1) \\
\hline 110 & PREV_WDLDSTEM & Previous woodland stem count & NUMBER(3) \\
\hline 111 & TPA_UNADJ & Trees per acre unadjusted & NUMBER(11,6) \\
\hline 112 & TPAMORT_UNADJ & Mortality trees per acre unadjusted & NUMBER(11,6) \\
\hline 113 & TPAREMV_UNADJ & Removal trees per acre unadjusted & NUMBER(11,6) \\
\hline 114 & TPAGROW_UNADJ & Growth trees per acre unadjusted & NUMBER(11,6) \\
\hline 115 & DRYBIO_BOLE & Dry biomass in the merchantable bole & $\operatorname{NUMBER}(13,6)$ \\
\hline 116 & DRYBIO_TOP & Dry biomass in the top of the tree & $\operatorname{NUMBER}(13,6)$ \\
\hline 117 & DRYBIO_STUMP & Dry biomass in the tree stump & $\operatorname{NUMBER}(13,6)$ \\
\hline 118 & DRYBIO_SAPLING & Dry biomass of saplings & $\operatorname{NUMBER}(13,6)$ \\
\hline 119 & DRYBIO_WDLD_SPP & Dry biomass of woodland tree species & NUMBER(13,6) \\
\hline 120 & DRYBIO_BG & Dry biomass of the roots & $\operatorname{NUMBER}(13,6)$ \\
\hline 121 & CARBON_AG & $\begin{array}{l}\text { Carbon in the aboveground portion of } \\
\text { the tree }\end{array}$ & NUMBER(13,6) \\
\hline 122 & CARBON_BG & $\begin{array}{l}\text { Carbon in the belowground portion of } \\
\text { the tree }\end{array}$ & NUMBER(13,6) \\
\hline 123 & CYCLE & Inventory cycle number & NUMBER(2) \\
\hline 124 & SUBCYCLE & Inventory subcycle number & NUMBER(2) \\
\hline 125 & BORED_CD_PNWRS & $\begin{array}{l}\text { Tree bored code, Pacific Northwest } \\
\text { Research Station }\end{array}$ & NUMBER(1) \\
\hline 126 & DAMLOC1_PNWRS & $\begin{array}{l}\text { Damage location 1, Pacific Northwest } \\
\text { Research Station }\end{array}$ & NUMBER(2) \\
\hline 127 & DAMLOC2_PNWRS & $\begin{array}{l}\text { Damage location 2, Pacific Northwest } \\
\text { Research Station }\end{array}$ & NUMBER(2) \\
\hline
\end{tabular}




\begin{tabular}{|c|c|c|c|}
\hline & Column name & Descriptive name & Oracle data type \\
\hline 128 & DIACHECK_PNWRS & $\begin{array}{l}\text { Diameter check, Pacific Northwest } \\
\text { Research Station }\end{array}$ & NUMBER(1) \\
\hline 129 & DMG_AGENT1_CD_PNWRS & $\begin{array}{l}\text { Damage agent 1, Pacific Northwest } \\
\text { Research Station }\end{array}$ & NUMBER(2) \\
\hline 130 & DMG_AGENT2_CD_PNWRS & $\begin{array}{l}\text { Damage agent 2, Pacific Northwest } \\
\text { Research Station }\end{array}$ & NUMBER(2) \\
\hline 131 & DMG_AGENT3_CD_PNWRS & $\begin{array}{l}\text { Damage agent 3, Pacific Northwest } \\
\text { Research Station }\end{array}$ & NUMBER(2) \\
\hline 132 & MIST_CL_CD_PNWRS & $\begin{array}{l}\text { Leafy mistletoe class code, Pacific } \\
\text { Northwest Research Station }\end{array}$ & NUMBER(1) \\
\hline 133 & SEVERITY1_CD_PNWRS & $\begin{array}{l}\text { Damage severity 1, Pacific Northwest } \\
\text { Research Station for years 2001-2004 }\end{array}$ & NUMBER(1) \\
\hline 134 & SEVERITY1A_CD_PNWRS & $\begin{array}{l}\text { Damage severity 1A, Pacific } \\
\text { Northwest Research Station } \\
\end{array}$ & NUMBER(2) \\
\hline 135 & SEVERITY1B_CD_PNWRS & \begin{tabular}{|l} 
Damage severity 1B, Pacific \\
Northwest Research Station \\
\end{tabular} & NUMBER(1) \\
\hline 136 & SEVERITY2_CD_PNWRS & $\begin{array}{l}\text { Damage severity 2, Pacific Northwest } \\
\text { Research Station for years 2001-2004 }\end{array}$ & NUMBER(1) \\
\hline 137 & SEVERITY2A_CD_PNWRS & $\begin{array}{l}\text { Damage severity 2A, Pacific } \\
\text { Northwest Research Station starting in } \\
2005\end{array}$ & NUMBER(2) \\
\hline 138 & SEVERITY2B_CD_PNWRS & \begin{tabular}{|l|} 
Damage severity 2B, Pacific \\
Northwest Research Station starting in \\
2005
\end{tabular} & NUMBER(1) \\
\hline 139 & SEVERITY3_CD_PNWRS & $\begin{array}{l}\text { Damage severity 3, Pacific Northwest } \\
\text { Research Station for years 2001-2004 } \\
\end{array}$ & NUMBER(1) \\
\hline 140 & UNKNOWN_DAMTYP1_PNWRS & $\begin{array}{l}\text { Unknown damage type 1, Pacific } \\
\text { Northwest Research Station }\end{array}$ & NUMBER(1) \\
\hline 141 & UNKNOWN_DAMTYP2_PNWRS & $\begin{array}{l}\text { Unknown damage type 2, Pacific } \\
\text { Northwest Research Station }\end{array}$ & NUMBER(1) \\
\hline 142 & PREV_PNTN_SRS & $\begin{array}{l}\text { Previous periodic prism point, tree } \\
\text { number, Southern Research Station }\end{array}$ & NUMBER(4) \\
\hline
\end{tabular}

\begin{tabular}{|l|l|l|l|}
\hline Type of key & Column(s) & Tables to link & Abbreviated notation \\
\hline Primary & (CN) & N/A & TRE_PK \\
\hline Unique & (PLT_CN, SUBP, TREE) & N/A & TRE_UK \\
\hline Natural & $\begin{array}{l}\text { (STATECD, INVYR, UNITCD, } \\
\text { COUNTYCD, PLOT, SUBP, TREE) }\end{array}$ & N/A & TRE_NAT_I \\
\hline Foreign & $($ PLT_CN $)$ & TREE to PLOT & TRE_PLT_FK \\
\hline
\end{tabular}

1. CN Sequence number. A unique sequence number used to identify a tree record.

2. PLT_CN Plot sequence number. Foreign key linking the tree record to the plot record.

\section{PREV_TRE_CN}

Previous tree sequence number. Foreign key linking the tree to the previous inventory's tree record for this tree. Only populated on trees remeasured from a previous annual inventory.

4. INVYR Inventory year. The year that best represents when the inventory data were collected. Under the annual inventory system, a group of plots is selected 
each year for sampling. The selection is based on a panel system. INVYR is the year in which the majority of plots in that group were collected (plots in the group have the same panel and, if applicable, subpanel). Under periodic inventory, a reporting inventory year was selected, usually based on the year in which the majority of the plots were collected or the mid-point of the years over which the inventory spanned. For either annual or periodic inventory, INVYR is not necessarily the same as MEASYEAR.

\section{Exceptions:}

INVYR $=9999$. INVYR is set to 9999 to distinguish Phase 3 plots taken by the western FIA work units that are "off subpanel." This is due to differences in measurement intervals between Phase 3 (measurement interval $=5$ years) and Phase 2 (measurement interval $=10$ years) plots. Only users interested in performing certain Phase 3 data analyses should access plots with this anomalous value in INVYR.

INVYR $<100$. INVYR $<100$ indicates that population estimates were derived from a pre-NIMS regional processing system and the same plot either has been or may soon be re-processed in NIMS as part of a separate evaluation. The NIMS processed copy of the plot follows the standard INVYR format. This only applies to plots collected in the South $($ SURVEY.RSCD $=33$ ) with the national design or a similar regional design (PLOT.DESIGNCD $=1$ or 220-233) that were collected when the inventory year was 1998 through 2005.

$\mathrm{INVYR}=98$ is equivalent to 1998 but processed through regional system $\mathrm{INVYR}=99$ is equivalent to 1999 but processed through regional system INVYR $=0$ is equivalent to 2000 but processed through regional system $\mathrm{INVYR}=1$ is equivalent to 2001 but processed through regional system $\mathrm{INVYR}=2$ is equivalent to 2002 but processed through regional system $\mathrm{INVYR}=3$ is equivalent to 2003 but processed through regional system $\mathrm{INVYR}=4$ is equivalent to 2004 but processed through regional system $\mathrm{INVYR}=5$ is equivalent to 2005 but processed through regional system

5. STATECD State code. Bureau of the Census Federal Information Processing Standards (FIPS) two-digit code for each State. Refer to appendix C.

6. UNITCD Survey unit code. Forest Inventory and Analysis survey unit identification number. Survey units are usually groups of counties within each State. For periodic inventories, Survey units may be made up of lands of particular owners. Refer to appendix $\mathrm{C}$ for codes.

7. COUNTYCD County code. The identification number for a county, parish, watershed, borough, or similar governmental unit in a State. FIPS codes from the Bureau of the Census are used. Refer to appendix $\mathrm{C}$ for codes.

8. PLOT

Phase 2 plot number. An identifier for a plot. Along with STATECD, INVYR, UNITCD, COUNTYCD and/or some other combinations of variables, PLOT may be used to uniquely identify a plot. 
9. SUBP Subplot number. The number assigned to the subplot. The national plot design (PLOT.DESIGNCD $=1$ ) has subplot number values of 1 through 4 . Other plot designs have various subplot number values. See PLOT.DESIGNCD and appendix B for information about plot designs. For more explanation about SUBP, contact the appropriate FIA work unit.

10. TREE

Tree record number. A number used to uniquely identify a tree on a subplot. Tree numbers can be used to track trees when PLOT.DESIGNCD is the same between inventories.

11. CONDID Condition class number. Unique identifying number assigned to each condition on a plot. A condition is initially defined by condition class status. Differences in reserved status, owner group, forest type, stand-size class, regeneration status, and stand density further define condition for forest land. Mapped nonforest conditions are also assigned numbers. At the time of the plot establishment, the condition class at plot center (the center of subplot 1) is usually designated as condition class 1 . Other condition classes are assigned numbers sequentially at the time each condition class is delineated. On a plot, each sampled condition class must have a unique number that can change at remeasurement to reflect new conditions on the plot.

12. AZIMUTH Azimuth. The direction, to the nearest degree, from subplot center (microplot center for saplings) to the center of the base of the tree (geographic center for multi-stemmed woodland species). Due north is represented by 360 degrees. This attribute is populated for live and standing dead trees in a forest condition that were measured on any of the four subplots of the national plot design. It may be populated for other tree records.

13. DIST

Horizontal distance. The horizontal distance in feet from subplot center (microplot center for saplings) to the center of the base of the tree (geographic center for multi-stemmed woodland species). This attribute is populated for live and standing dead trees in a forest condition that were measured on any of the four subplots of the national plot design. It may be populated for other tree records.

14. PREVCOND Previous condition number. Identifies the condition within the plot on which the tree occurred at the previous inventory.

15. STATUSCD Status code. A code indicating whether the sample tree is live, cut, or dead at the time of measurement. Includes dead and cut trees, which are required to estimate aboveground biomass and net annual volume for growth, mortality, and removals. This code is not used when querying data for change estimates. Note: New and replacement plots use only codes 1 and 2. 


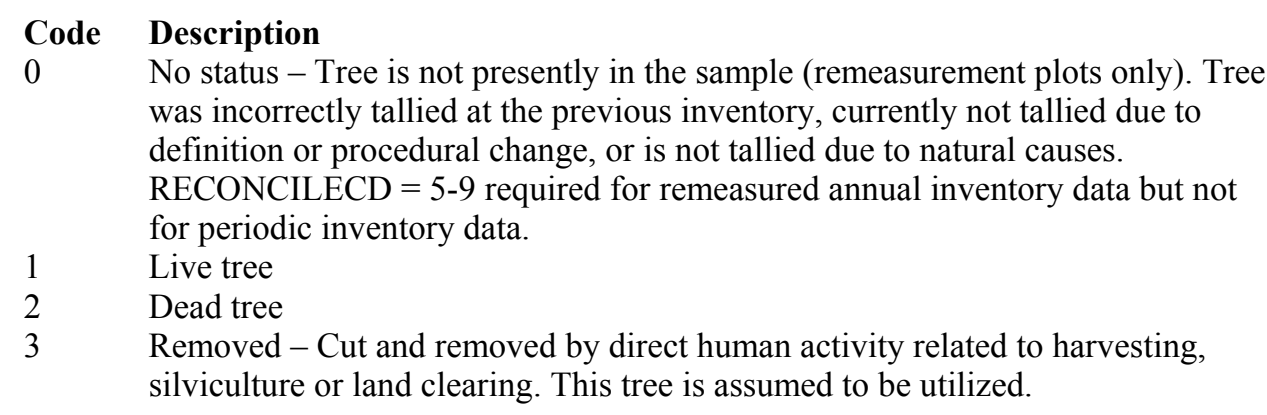

16. SPCD

17. SPGRPCD

18. DIA

19. DIAHTCD

20. HT

21. HTCD
Species code. An FIA tree species code. Refer to appendix F for codes.

Species group code. A code assigned to each tree species in order to group them for reporting purposes on presentation tables. Codes and their associated names (see REF_SPECIES_GROUP.NAME) are shown in appendix G. Individual tree species and corresponding species group codes are shown in appendix F.

Current diameter. The current diameter (in inches) of the sample tree at the point of diameter measurement. For additional information about where the tree diameter is measured, see DIAHTCD or HTDMP. DIA for live trees contains the measured value. DIA for cut and dead trees presents problems associated with uncertainty of when the tree was cut or died as well as structural deterioration of dead trees. Consult individual FIA work units for explanations of how DIA is collected for dead and cut trees.

Diameter height code. A code indicating the location at which diameter was measured. For trees with code 1 (DBH), the actual measurement point may be found in HTDMP.

\section{Code Description \\ 1 Breast height (DBH) \\ 2 Root collar (DRC)}

Total height. (Core Phase 2: $\geq 5$.0-inch DBH/DRC live trees; Core optional Phase 2: 1.0-4.9-inch DBH/DRC live trees and $\geq 5$.0-inch DBH/DRC standing dead trees. Core Phase 3: $\geq 1$.0-inch DBH/DRC live trees; Core optional Phase 3: $\geq 5.0$ inch DBH/DRC standing dead trees.) The total length (height) of a sample tree (in feet) from the ground to the tip of the apical meristem. The total length of a tree is not always its actual length. If the main stem is broken, the actual length is measured or estimated and the missing piece is added to the actual length to estimate total length. The amount added is determined by measuring the broken piece if it can be located on the ground; otherwise it is estimated. The minimum height for timber species is 5 feet and for woodland species is 1 foot.

Height method code. (Core Phase 2: $\geq 5$.0-inch DBH/DRC live trees; Core optional Phase 2: 1.0-4.9-inch DBH/DRC live trees and $\geq 5$.0-inch DBH/DRC standing dead trees. Core Phase 3: $\geq 1$.0-inch DBH/DRC live trees; Core 
optional Phase 3: $\geq 5$.0-inch DBH/DRC standing dead trees.) A code indicating how length (height) was determined.

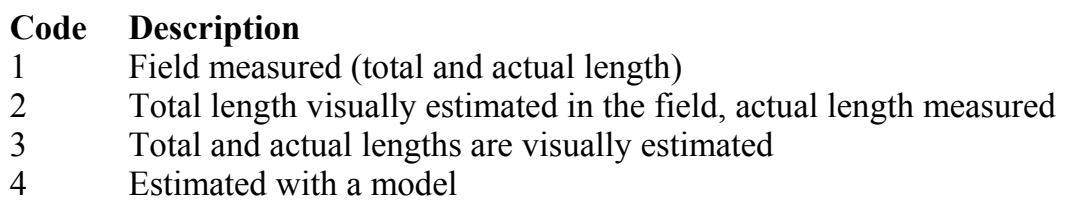

22. ACTUALHT Actual height. (Core Phase 2: live and standing dead trees with broken or missing tops, $\geq 5$.0-inch DBH/DRC; Core optional Phase 2: live trees 1.0-4.9-inch DBH/DRC with broken or missing tops; Core Phase 3: live trees $\geq 1.0$-inch $D B H / D R C$ (with broken or missing tops and standing dead trees $\geq 5.0$-inch $D B H / D R C$ [with broken or missing tops]) The length (height) of the tree to the nearest foot from ground level to the highest remaining portion of the tree still present and attached to the bole. If ACTUALHT $=$ HT, then the tree does not have a broken top. If ACTUALHT $<$ HT, then the tree does have a broken or missing top. The minimum height for timber species is 5 feet and for woodland species is 1 foot.

23. TREECLCD Tree class code. A code indicating the general quality of the tree. In annual inventory, this is the tree class for both live and dead trees at the time of current measurement. In periodic inventory, for cut and dead trees, this is the tree class of the tree at the time it died or was cut. Therefore, cut and dead trees collected in periodic inventory can be coded as growing-stock.

\section{Code Description}

2 Growing-stock - All live trees of commercial species that meet minimum merchantability standards. In general, these trees have at least one solid 8-foot section, are reasonably free of form defect on the merchantable bole, and at least 34 percent or more of the volume is merchantable. For the California, Oregon, and Washington inventories, a 26 percent or more merchantable volume standard is applied, rather than 34 percent or more. Excludes rough or rotten cull trees.

3 Rough cull - All live trees that do not now, or prospectively, have at least one solid 8-foot section, reasonably free of form defect on the merchantable bole, or have 67 percent or more of the merchantable volume cull; and more than half of this cull is due to sound dead wood cubic-foot loss or severe form defect volume loss. For the California, Oregon, and Washington inventories, 75 percent or more cull, rather than 67 percent or more cull, applies. This class also contains all trees of noncommercial species, or those species where SPGRPCD equals 23 (western woodland softwoods), 43 (eastern noncommercial hardwoods), or 48 (western woodland hardwoods). Refer to appendix F to find the species that have these SPGRPCD codes. For dead trees, this code indicates that the tree is salvable (sound).

4 Rotten cull - All live trees with 67 percent or more of the merchantable volume cull, and more than half of this cull is due to rotten or missing cubic-foot volume loss. California, Oregon, and Washington inventories use a 75 percent cutoff. For dead trees, this code indicates that the tree is nonsalvable (not sound).

24. $\mathrm{CR}$

Compacted crown ratio. The percent of the tree bole supporting live, healthy foliage (the crown is ocularly compacted to fill in gaps) when compared to actual length (ACTUALHT). When PLOT.MANUAL $<1.0$ the variable may 
25. CCLCD

26. TREEGRCD

27. AGENTCD have been a code, which was converted to the midpoint of the ranges represented by the codes, and is stored as a percentage.

Crown class code. A code indicating the amount of sunlight received and the crown position within the canopy.

Code Description

1 Open grown - Trees with crowns that have received full light from above and from all sides throughout all or most of their life, particularly during early development.

2 Dominant - Trees with crowns extending above the general level of the canopy and receiving full light from above and partly from the sides; larger than the average trees in the stand, and with crowns well developed, but possibly somewhat crowded on the sides.

3 Codominant - Trees with crowns forming part of the general level of the crown cover and receiving full light from above, but comparatively little from the side. Usually with medium crowns more or less crowded on the sides.

4 Intermediate - Trees shorter than those in the preceding two classes, with crowns either below or extending into the canopy formed by the dominant and codominant trees, receiving little direct light from above, and none from the sides; usually with small crowns very crowded on the sides.

$5 \quad$ Overtopped - Trees with crowns entirely below the general canopy level and receiving no direct light either from above or the sides.

Tree grade code. A code indicating the quality of sawtimber-sized trees. This attribute is populated for live, growing-stock, sawtimber size trees on subplots 1-4 on national manual plots that are in a forest condition class. This attribute may be populated for other tree records that do not meet the above criteria. For example, it may be populated with the previous tree grade on dead and cut trees. Standards for tree grading are specific to species and differ slightly by research station. Only collected by certain FIA work units (SURVEY.RSCD = 23, 24, or 33). Tree grade codes range from 1 to 5 .

Cause of death (agent) code. (Core: all remeasured plots when the tree was alive at the previous visit and at revisit is dead or removed OR the tree is standing dead in the current inventory and the tree is ingrowth, through growth, or a missed live tree; Core optional: all initial plot visits when tree qualifies as a mortality tree.) When PLOT.MANUAL $\geq 1.0$, this variable was collected on only dead and cut trees. When PLOT.MANUAL $<1.0$, this variable was collected on all trees (live, dead, and cut). Cause of damage was recorded for live trees if the presence of damage or pathogen activity was serious enough to reduce the quality or vigor of the tree. When a tree was damaged by more than one agent, the most severe damage was coded. When no damage was observed on a live tree, 00 was recorded. Damage recorded for dead trees was the cause of death. When the cause of death could not be determined for a tree, 99 was recorded. Each FIA program records specific codes that may differ from one State to the next. These codes fall within the ranges listed below. For the specific codes used in a particular State, contact the FIA work unit responsible for that State (table 6). 


\section{Code Description}

$00 \quad$ No agent recorded (only allowed on live trees in data prior to 1999)

10 Insect

20 Disease

30 Fire

$40 \quad$ Animal

$50 \quad$ Weather

60 Vegetation (e.g., suppression, competition, vines/kudzu)

70 Unknown/not sure/other - includes death from human activity not related to silvicultural or landclearing activity (accidental, random, etc.) TREE NOTES required.

80 Silvicultural or landclearing activity (death caused by harvesting or other silvicultural activity, including girdling, chaining, etc., or to landclearing activity).

28. CULL

Rotten and missing cull. The percent of the cubic-foot volume in a live or dead tally tree that is rotten or missing. This is a calculated value that includes field-recorded cull (CULL_FLD) and any additional cull due to broken top.

\section{DAMLOC1}

Damage location 1. (Core where PLOT.MANUAL = 1.0 through 1.6; Core optional beginning with PLOT.MANUAL = 1.7.) A code indicating where damage (meeting or exceeding a severity threshold, as defined in the field guide) is present on the tree.

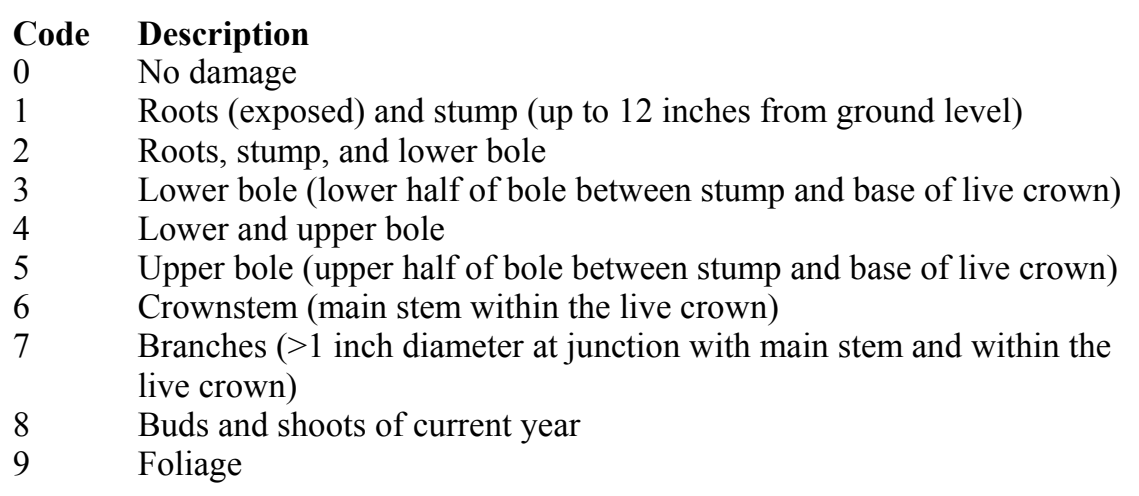

30. DAMTYP1 Damage type 1. (Core where PLOT.MANUAL =1.0 through 1.6; Core optional beginning with PLOT.MANUAL = 1.7.) A code indicating the kind of damage (meeting or exceeding a severity threshold, as defined in the field guide) present. If DAMLOC1 $=0$, then DAMTYP1 = blank (null).

$\begin{array}{ll}\text { Code } & \text { Description } \\ 01 & \text { Canker, gall } \\ 02 & \text { Conk, fruiting body, or sign of advanced decay } \\ 03 & \text { Open wound } \\ 04 & \text { Resinosis or gumosis } \\ 05 & \text { Crack or seam } \\ 11 & \text { Broken bole or broken root within } 3 \text { feet of bole } \\ 12 & \text { Broom on root or bole } \\ 13 & \text { Broken or dead root further than } 3 \text { feet from bole } \\ 20 & \text { Vines in the crown } \\ 21 & \text { Loss of apical dominance, dead terminal } \\ 22 & \text { Broken or dead branches }\end{array}$


FIA Database Description and Users Manual for Phase 2, version 4.0

Chapter 3. Tree Table

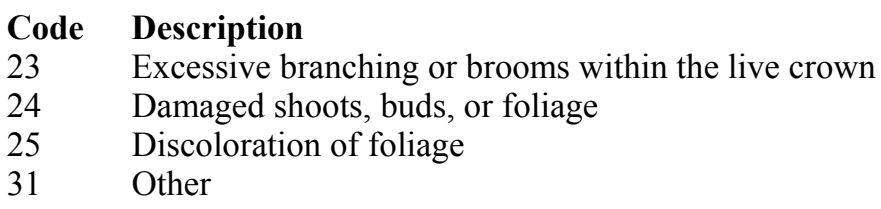

31. DAMSEV1 Damage severity 1. (Core where PLOT.MANUAL $=1.0$ through 1.6; Core optional beginning with PLOT.MANUAL = 1.7.) A code indicating how much of the tree is affected. Valid severity codes vary by damage type and damage location and must exceed a threshold value, as defined in the field guide. If DAMLOC1 $=0$, then DAMSEV1 = blank (null).

$\begin{array}{ll}\text { Code } & \text { Description } \\ 0 & \text { 01 to } 09 \% \text { of location affected } \\ 1 & 10 \text { to } 19 \% \text { of location affected } \\ 2 & 20 \text { to } 29 \% \text { of location affected } \\ 3 & 30 \text { to } 39 \% \text { of location affected } \\ 4 & 40 \text { to } 49 \% \text { of location affected } \\ 5 & 50 \text { to } 59 \% \text { of location affected } \\ 6 & 60 \text { to } 69 \% \text { of location affected } \\ 7 & 70 \text { to } 79 \% \text { of location affected } \\ 8 & 80 \text { to } 89 \% \text { of location affected } \\ 9 & 90 \text { to } 99 \% \text { of location affected }\end{array}$

32. DAMLOC2 Damage location 2. (Core where PLOT.MANUAL $=1.0$ through 1.6; Core optional beginning with PLOT.MANUAL = 1.7.) A code indicating where secondary damage (meeting or exceeding a severity threshold, as defined in the field guide) is present. Use same codes as DAMLOC1. If DAMLOCl $=0$, then DAMLOC2 = blank (null) or 0 .

33. DAMTYP2 Damage type 2. (Core where PLOT.MANUAL $=1.0$ through 1.6; Core optional beginning with PLOT.MANUAL = 1.7.) A code indicating the kind of secondary damage (meeting or exceeding a severity threshold, as defined in the field guide) present. Use same codes as DAMTYP1. If DAMLOCl $=0$, then DAMTYP2 = blank (null).

34. DAMSEV2 Damage severity 2. (Core where PLOT.MANUAL $=1.0$ through 1.6; Core optional beginning with PLOT.MANUAL = 1.7.) A code indicating how much of the tree is affected by the secondary damage. Valid severity codes vary by damage type and damage location and must exceed a threshold value, as defined in the field guide. Use same codes as DAMSEV1. If DAMLOCl $=0$, then DAMSEV2 = blank (null).

35. DECAYCD Decay class code. A code indicating the stage of decay in a standing dead tree. Populated where PLOT.MANUAL $\geq 1.0$ 


\section{Code Description}

$1 \quad$ All limbs and branches are present; the top of the crown is still present; all bark remains; sapwood is intact, with minimal decay; heartwood is sound and hard

2 There are few limbs and no fine branches; the top may be broken; a variable amount of bark remains; sapwood is sloughing with advanced decay; heartwood is sound at base but beginning to decay in the outer part of the upper bole

3 Only limb stubs exist; the top is broken; a variable amount of bark remains; sapwood is sloughing; heartwood has advanced decay in upper bole and is beginning at the base

$4 \quad$ Few or no limb stubs remain; the top is broken; a variable amount of bark remains; sapwood is sloughing; heartwood has advanced decay at the base and is sloughing in the upper bole

$5 \quad$ No evidence of branches remains; the top is broken; $<20$ percent of the bark remains; sapwood is gone; heartwood is sloughing throughout

36. STOCKING Tree stocking. The stocking value computed for each live tree. Stocking values are computed using several specific species equations that were developed from normal yield tables and stocking charts. Resultant values are a function of diameter. The stocking of individual trees is used to calculate COND.GSSTK, COND.GSSTKCD, COND.ALSTK, and COND.ALSTKCD.

37. WDLDSTEM Woodland tree species stem count. The number of live and dead stems used to calculate diameter on a woodland tree. Used for tree species where diameter is measured at the root collar. For a stem to be counted, it must have a minimum stem size of 1 inch in diameter and 1 foot in length. Blank (null) if not a woodland species.

38. VOLCFNET

Net cubic-foot volume. For timber species (trees where the diameter is measured at breast height $[\mathrm{DBH}]$ ), this is the net volume of wood in the central stem of a sample tree $\geq 5$.0 inches in diameter, from a 1-foot stump to a minimum 4-inch top diameter, or to where the central stem breaks into limbs all of which are $<4.0$ inches in diameter. For woodland species (trees where the diameter is measured at root collar [DRC]), VOLCFNET is the net volume of wood and bark from the DRC measurement point(s) to a $1 \frac{1}{2}$-inch top diameter; includes branches that are at least $1 \frac{1}{2}$ inches in diameter along the length of the branch. This is a per tree value and must be multiplied by TPA_UNADJ to obtain per acre information. This attribute is blank (null) for trees with DIA $<5.0$ inches. All trees measured after 1998 with DIA $\geq 5.0$ inches (including dead and cut trees) will have entries in this field. Does not include rotten, missing, and form cull (volume loss due to rotten, missing, and form cull defect has been deducted).

39. VOLCFGRS Gross cubic-foot volume. For timber species (trees where the diameter is measured at breast height [DBH]), this is the total volume of wood in the central stem of sample trees $\geq 5.0$ inches in diameter, from a 1-foot stump to a minimum 4-inch top diameter, or to where the central stem breaks into limbs all of which are $<4.0$ inches in diameter. For woodland species (trees where the diameter is measured at root collar [DRC]), VOLCFGRS is the total 
volume of wood and bark from the DRC measurement point(s) to a $1 \frac{1}{2}$-inch top diameter; includes branches that are at least $1 \frac{1}{2}$ inches in diameter along the length of the branch. This is a per tree value and must be multiplied by TPA_UNADJ to obtain per acre information. This attribute is blank (null) for trees with DIA $<5.0$ inches. All trees measured after 1998 with DIA $\geq 5.0$ inches (including dead and cut trees) have entries in this field. Includes rotten, missing and form cull (volume loss due to rotten, missing, and form cull defect has not been deducted).

40. VOLCSNET

Net cubic-foot volume in the sawlog portion. The net volume of wood in the central stem of a timber species tree of sawtimber size (9.0 inches DIA minimum for softwoods, 11.0 inches DIA minimum for hardwoods), from a 1 -foot stump to a minimum top diameter, $(7.0$ inches for softwoods, 9.0 inches for hardwoods) or to where the central stem breaks into limbs, all of which are less than the minimum top diameter. This is a per tree value and must be multiplied by TPA_UNADJ to obtain per acre information. This attribute is blank (null) for softwood trees with DIA $<9.0$ inches (11.0 inches for hardwoods). All larger trees have entries in this field if they are growingstock trees $($ TREECLCD $=2$ and STATUSCD $=1)$. All rough and rotten trees $($ TREECLCD $=3$ or 4$)$ and dead and cut trees $($ STATUSCD $=2$ or 3 ) are blank (null) in this field.

41. VOLCSGRS Gross cubic-foot volume in the sawlog portion. This is the total volume of wood in the central stem of a timber species tree of sawtimber size (9.0 inches DIA minimum for softwoods, 11.0 inches DIA minimum for hardwoods), from a 1-foot stump to a minimum top diameter (7.0 inches for softwoods, 9.0 inches for hardwoods), or to where the central stem breaks into limbs, all of which are less than the minimum top diameter. This is a per tree value and must be multiplied by TPA_UNADJ to obtain per acre information. This attribute is blank (null) for softwood trees with DIA $<9.0$ inches (11.0 inches for hardwoods). All larger trees have entries in this field if they are growing-stock trees (TREECLCD $=2$ and STATUSCD $=1)$. All rough and rotten trees $($ TREECLCD $=3$ or 4$)$ and dead and cut trees (STATUSCD $=2$ or 3 ) are blank (null) in this field.

42. VOLBFNET Net board-foot volume in the sawlog portion. This is the net volume (International $1 / 4$-inch rule) of wood in the central stem of a timber species tree of sawtimber size (9.0 inches DIA minimum for softwoods, 11.0 inches DIA minimum for hardwoods), from a 1-foot stump to a minimum top diameter (7.0 inches for softwoods, 9.0 inches for hardwoods), or to where the central stem breaks into limbs all of which are less than the minimum top diameter. This is a per tree value and must be multiplied by TPA_UNADJ to obtain per unit area information. This attribute is blank (null) for softwood trees with DIA $<9.0$ inches (11.0 inches for hardwoods). All larger trees should have entries in this field if they are growing-stock trees (TREECLCD $=2$ and $\mathrm{STATUSCD}=1)$. All rough and rotten trees $(\mathrm{TREECLCD}=3$ or 4$)$ and dead and cut trees (STATUSCD $=2$ or 3 ) are blank (null) in this field. 
43. VOLBFGRS Gross board-foot volume in the sawlog portion. This is the total volume (International $1 / 4$-inch rule) of wood in the central stem of a timber species tree of sawtimber size (9.0 inches DIA minimum for softwoods, 11.0 inches DIA minimum for hardwoods), from a 1-foot stump to a minimum top diameter (7.0 inches for softwoods, 9.0 inches for hardwoods), or to where the central stem breaks into limbs all of which are less than the minimum top DIA. This is a per tree value and must be multiplied by TPA_UNADJ to obtain per unit area information. This attribute is blank (null) for softwood trees with DIA $<9.0$ inches (11.0 inches for hardwoods). All larger trees should have entries in this field if they are growing-stock trees (TREECLCD $=2$ and STATUSCD $=1)$. All rough and rotten trees $($ TREECLCD $=3$ or 4$)$ and dead and cut trees (STATUSCD $=2$ or 3 ) are blank (null) in this field.

44. VOLCFSND Sound cubic-foot volume. For timber species (trees where the diameter is measured at breast height $[\mathrm{DBH}])$, the volume of sound wood in the central stem of a sample tree $\geq 5.0$ inches in diameter from a 1-foot stump to a minimum 4-inch top diameter or to where the central stem breaks into limbs all of which are $<4.0$ inches in diameter. For woodland species (trees where the diameter is measured at root collar [DRC]), VOLCFSND is the net volume of wood and bark from the DRC measurement point(s) to a minimum $1 \frac{1}{2}$-inch top diameter; includes branches that are at least $1 \frac{1 / 2}{2}$ inches in diameter along the length of the branch. This is a per tree value and must be multiplied by TPA_UNADJ to obtain per acre information. This attribute is blank (null) for trees with DIA $<5.0$ inches. All trees with DIA $\geq 5.0$ inches (including dead trees) have entries in this field. Does not include rotten and missing cull (volume loss due to rotten and missing cull defect has been deducted).

45. GROWCFGS Net annual merchantable cubic-foot growth of a growing-stock tree on timberland. This is the net change in cubic-foot volume per year of this tree (for remeasured plots, $\left(\mathrm{V}_{2}-\mathrm{V}_{1}\right) /\left(\mathrm{t}_{2}-\mathrm{t}_{1}\right)$; where 1 and 2 denote the past and current measurement, respectively, $\mathrm{V}$ is volume, and $\mathrm{t}$ indicates year of measurement). Because this value is net growth, it may be a negative number. Negative growth values are usually due to mortality $\left(\mathrm{V}_{2}=0\right)$ but can also occur on live trees that have a net loss in volume because of damage, rot, broken top, or other causes. To expand to a per acre value, multiply by TPAGROW_UNADJ.

46. GROWBFSL Net annual merchantable board-foot growth of a sawtimber size tree on timberland. This is the net change in board-foot (International 1/4-inch rule) volume per year of this tree (for remeasured plots $\left(\mathrm{V}_{2}-\mathrm{V}_{1}\right) /\left(\mathrm{t}_{2}-\mathrm{t}_{1}\right)$ ). Because this value is net growth, it may be a negative number. Negative growth values are usually due to mortality $\left(\mathrm{V}_{2}=0\right)$ but can also occur on live trees that have a net loss in volume because of damage, rot, broken top, or other causes. To expand to a per acre value, multiply by TPAGROW_UNADJ.

47. GROWCFAL Net annual sound cubic-foot growth of a live tree on timberland. The net change in cubic-foot volume per year of this tree (for remeasured plots 
$\left.\left(\mathrm{V}_{2}-\mathrm{V}_{1}\right) /\left(\mathrm{t}_{2}-\mathrm{t}_{1}\right)\right)$. Because this value is net growth, it may be a negative number. Negative growth values are usually due to mortality $\left(\mathrm{V}_{2}=0\right)$ but can also occur on live trees that have a net loss in volume because of damage, rot, broken top, or other causes. To expand to a per acre value, multiply by TPAGROW_UNADJ. GROWCFAL differs from GROWCFGS by including all trees, regardless of tree class.

48. MORTCFGS Cubic-foot volume of a growing-stock tree on timberland for mortality purposes. Represents the cubic-foot volume of a growing-stock tree at time of death. To obtain estimates of annual per acre mortality, multiply by TPAMORT_UNADJ.

49. MORTBFSL Board-foot volume of a sawtimber size tree on timberland for mortality purposes. Represents the board-foot (International 1/4-inch rule) volume of a sawtimber tree at time of mortality. To obtain estimates of annual per acre mortality, multiply by TPAMORT_UNADJ.

50. MORTCFAL Sound cubic-foot volume of a tree on timberland for mortality purposes. Represents the cubic-foot volume of the tree at time of mortality. To obtain estimates of annual per acre mortality, multiply by TPAMORT_UNADJ. MORTCFAL differs from MORTCFGS by including all trees, regardless of tree class.

51. REMVCFGS Cubic-foot volume of a growing-stock tree on timberland for removal purposes. Represents the cubic-foot volume of the tree at time of removal. To obtain estimates of annual per acre removals, multiply by TPAREMV_UNADJ.

52. REMVBFSL Board-foot volume of a sawtimber size tree on timberland for removal purposes. Represents the board-foot (International 1/4-inch rule) volume of the tree at time of removal. To obtain estimates of annual per acre removals, multiply by TPAREMV_UNADJ.

53. REMVCFAL Sound cubic-foot volume of a tree on timberland for removal purposes. Represents the cubic-foot volume of the tree at time of removal. To obtain estimates of annual per acre removals, multiply by TPAREMV_UNADJ. REMVCFAL differs from REMVCFGS by including all trees, regardless of tree class.

54. DIACHECK Diameter check code. A code indicating the reliability of the diameter measurement.

\section{Code Description}

0 Diameter accurately measured

1 Diameter estimated

2 Diameter measured at different location than previous measurement (remeasurement trees only)

5 Diameter modeled in the office (used with periodic inventories)

Note: If both codes 1 and 2 apply, code 2 is used. 
55. MORTYR Mortality year. (Core optional.) The estimated year in which a remeasured tree died or was cut. Populated where PLOT.MANUAL $\geq 1.0$ and populated by some FIA work units where PLOT.MANUAL $<1.0$.

56. SALVCD Salvable dead code. A standing or down dead tree considered merchantable by regional standards. Contact the appropriate FIA work unit for information on how this code is assigned for a particular State (table 6).

$\begin{array}{ll}\text { Code } & \text { Description } \\ 0 & \text { Dead not salvable } \\ 1 & \text { Dead salvable }\end{array}$

57. UNCRCD Uncompacted live crown ratio. (Core optional Phase 2: $\geq 5$.0-inch live trees; Core Phase 3: $\geq 1$.0-inch live trees.) Percentage determined by dividing the live crown length by the actual tree length. When PLOT.MANUAL $<3.0$ the variable was a code, which was converted to the midpoint of the ranges represented by the codes, and is stored as a percentage.

58. CPOSCD Crown position code. (Core on Phase 3 plots only.) The relative position of each tree in relation to the overstory canopy.

$\begin{array}{ll}\text { Code } & \text { Description } \\ 1 & \text { Superstory } \\ 2 & \text { Overstory } \\ 3 & \text { Understory } \\ 4 & \text { Open canopy }\end{array}$

59. CLIGHTCD Crown light exposure code. (Core optional on Phase 2 plots; Core on Phase 3 plots only.) A code indicating the amount of light being received by the tree crown. Collected for all live trees at least 5 inches DBH/DRC. Trees with UNCRCD $<35$ have a maximum CLIGHTCD of 1 .

$\begin{array}{ll}\begin{array}{l}\text { Code } \\ 0\end{array} & \begin{array}{l}\text { Description } \\ \text { The tree receives no direct sunlight because it is shaded by adjacent trees or } \\ \text { other vegetation }\end{array} \\ 1 & \begin{array}{l}\text { Receives full light from the top or } 1 \text { side } \\ 2\end{array} \\ \text { Receives full light from the top and } 1 \text { side (or } 2 \text { sides without the top) } \\ 4 & \text { Receives full light from the top and } 2 \text { sides (or } 3 \text { sides without the top) } \\ 5 & \text { Receives full light from the top and } 3 \text { sides }\end{array}$

60. CVIGORCD Crown vigor code. (Core optional on Phase 2 plots; Core on Phase 3 plots only.) A code indicating the vigor of sapling crowns. Collected for live trees between 1 and 4.9 inches DBH/DRC. 


\section{Code Description}

1 Saplings must have an uncompacted live crown ratio of 35 or higher, have $<5$ percent dieback (deer/rabbit browse is not considered as dieback but is considered missing foliage) and 80 percent or more of the foliage present is normal or at least 50 percent of each leaf is not damaged or missing. Twigs and branches that are dead because of normal shading are not included.

2 Saplings do not meet class 1 or 3 criteria. They may have any uncompacted live crown ratio, may or may not have dieback and may have between 21 and 100 percent of the foliage classified as normal.

3 Saplings may have any uncompacted live crown ratio and have 1 to 20 percent normal foliage or the percent of foliage missing combined with the percent of leaves that are over 50 percent damaged or missing should equal 80 percent or more of the live crown. Twigs and branches that are dead because of normal shading are not included. Code is also used for saplings that have no crown by definition

61. CDENCD Crown density code. (Core optional on Phase 2 plots; Core on Phase 3 plots only.) A code indicating how dense the tree crown is, estimated in percent classes. Collected for all live trees at least 5 inches DBH/DRC. Crown density is the amount of crown branches, foliage and reproductive structures that blocks light visibility through the crown.

$\begin{array}{ll}\text { Code } & \text { Description } \\ 00 & 0 \% \\ 05 & 1-5 \% \\ 10 & 6-10 \% \\ 15 & 11-15 \% \\ \cdot & \cdot \\ \cdot & \cdot \\ . & \cdot \\ 95 & 91-95 \% \\ 99 & 96-100 \%\end{array}$

62. CDIEBKCD Crown dieback code. (Core optional on Phase 2 plots; Core on Phase 3 plots only.) A code indicating the amount of recent dead material in the upper and outer portion of the crown, estimated in percent classes. Collected for all live trees at least 5 inches $\mathrm{DBH} / \mathrm{DRC}$.

$\begin{array}{ll}\text { Code } & \text { Description } \\ 00 & 0 \% \\ 05 & 1-5 \% \\ 10 & 6-10 \% \\ 15 & 11-15 \% \\ \cdot & \cdot \\ \cdot & \cdot \\ . & \cdot \\ 95 & 91-95 \% \\ 99 & 96-100 \%\end{array}$

63. TRANSCD Foliage transparency code. (Core optional on Phase 2 plots; Core on Phase 3 plots only.) A code indicating the amount of light penetrating the foliated portion of the crown, estimated in percent classes. Collected for all live trees at least 5 inches $\mathrm{DBH} / \mathrm{DRC}$. 


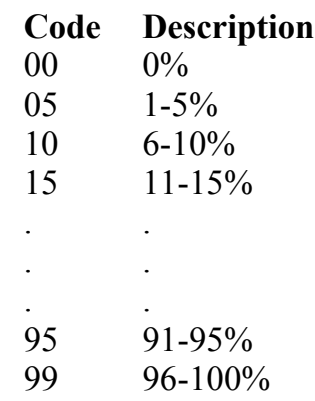

64. TREEHISTCD Tree history code. Identifies the tree with detailed information as to whether the tree is live, dead, cut, removed due to land use change, etc. Contact the appropriate FIA work unit for the definitions (table 6). Only collected by certain FIA units (SURVEY.RSCD $=23,24$, or 33).

65. DIACALC Current diameter calculated. If the diameter is unmeasurable (i.e., the tree is cut or dead), the diameter is calculated (in inches) and stored in this variable. Only collected by certain FIA work units (SURVEY.RSCD $=23$ or 33).

66. BHAGE

67. TOTAGE

Breast height age. The age of a live tree derived from counting tree rings from an increment core sample extracted at a height of 4.5 feet above ground. Breast height age is collected for a subset of trees and only for trees that the diameter is measured at breast height (DBH). This data item is used to calculate classification variables such as stand age. For PNWRS, one tree is sampled for BHAGE for each species, within each crown class, and for each condition class present on a plot. Age of saplings $(<5.0$ inches DBH $)$ may be aged by counting branch whorls above 4.5 feet. No timber hardwood species other than red alder are bored for age. For RMRS, one tree is sampled for each species and broad diameter class present on a plot. Only collected by certain FIA work units (SURVEY.RSCD $=22$ or 26) and is left blank (null) when it is not collected.

Total age. The age of a live tree derived either from counting tree rings from an increment core sample extracted at the base of a tree where diameter is measured at root collar (DRC), or for small saplings (1.0 to 2.9 inches DBH) by counting all branch whorls, or by adding a species-dependent number of years to breast height age. Total age is collected for a subset of trees and is used to calculate classification variables such as stand age. Only collected by certain FIA work units (SURVEY.RSCD $=22$ or 26) and is left blank (null) when it is not collected.

68. CULLDEAD Dead cull. The percent of the gross cubic-foot volume that is cull due to sound dead material. Recorded for all trees that are at least 5.0 inches in diameter. Only collected by certain FIA work units (SURVEY.RSCD $=22$ ). This attribute is blank (null) for trees smaller than 5 inches and is always null for the other FIA work units.

69. CULLFORM Form cull. The percent of the gross cubic-foot volume that is cull due to form defect. Recorded for live trees that are at least 5.0 inches DBH. Only 
collected by certain FIA work units (SURVEY.RSCD = 22). This attribute is blank (null) for dead trees, trees smaller than 5 inches $\mathrm{DBH}$, for all trees where the diameter is measured at root collar (DRC), and is always null for the other FIA work units.

70. CULLMSTOP Missing top cull. The percent of the gross cubic-foot volume that is cull due to a missing (broken) merchantable top. Recorded for trees that are at least 5.0 inches in diameter. The volume estimate does not include any portion of the missing top that is $<4.0$ inches DOB (diameter outside bark). Many broken top trees may have $0 \%$ missing top cull because no merchantable volume was lost. Only collected by certain FIA work units (SURVEY.RSCD $=22$ ). This attribute is blank (null) for trees smaller than 5 inches diameter and is always null for the other FIA work units.

71. CULLBF Board-foot cull. The percent of the gross board-foot volume that is cull due to rot or form. Only collected by certain FIA work units (SURVEY.RSCD = 24).

72. CULLCF Cubic-foot cull. The percent of the gross cubic-foot volume that is cull due to rot or form. Only collected by certain FIA work units (SURVEY.RSCD = 24).

73. BFSND

Board-foot-cull soundness. The percent of the board-foot cull that is sound (due to form). Only collected by certain FIA work units (SURVEY.RSCD=24).

74. CFSND

Cubic-foot-cull soundness. The percent of the cubic-foot cull that is sound (due to form). Only collected by certain FIA work units (SURVEY.RSCD=24).

75. SAWHT

Sawlog height. The length (height) of a tree, recorded to a 7-inch top (9-inch for hardwoods), where at least one 8-foot log, merchantable or not, is present. On broken topped trees, sawlog length is recorded to the point of the break. Only collected by certain FIA work units (SURVEY.RSCD $=24)$.

76. BOLEHT Bole height. The length (height) of a tree, recorded to a 4-inch top, where at least one 4-foot section is present. Only collected by certain FIA work units $($ SURVEY.RSCD = 24).

77. FORMCL Form class. A code used in calculating merchantable bole net volume. Recorded for all live hardwood trees tallied that are $\geq 5.0$ inch DBH/DRC. Also recorded for conifers $\geq 5.0$ inch DBH in Region 5 National Forests. Only collected by certain FIA work units (SURVEY.RSCD = 26).

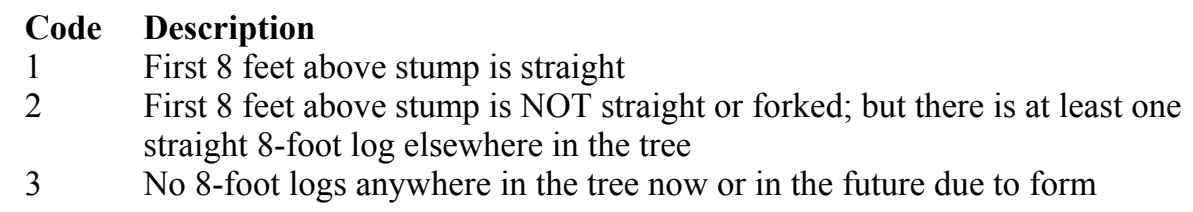

78. HTCALC Current height calculated. If the height is unmeasurable (i.e., the tree is cut or dead), the height is calculated (in feet) and stored in this variable. Only collected by certain FIA work units (SURVEY.RSCD = 33). 
79. HRDWD_CLUMP_CD

Hardwood clump code. A code sequentially assigned to each hardwood clump within each species as they are found on a subplot. Up to 9 hardwood clumps can be identified and coded within each species on each subplot. A clump is defined as having 3 or more live stems originating from a common point on the root system. Western woodland hardwood species are not evaluated for clump code. Clump code data are used to adjust stocking estimates since trees growing in clumps contribute less to stocking than do individual trees. Only collected by certain FIA work units (SURVEY.RSCD $=26$ ).

80. SITREE Calculated site index. Computed for every tree. The site index represents the average total length (in feet) that dominant and co-dominant trees in fullystocked, even-aged stands (of the same species as this tree) will obtain at key ages (usually 25 or 50 years). Only collected by certain FIA work units (SURVEY.RSCD $=23$ ).

81. CREATED_BY Created by. The employee who created the record. This attribute is intentionally left blank in download files.

82. CREATED_DATE

Created date. The date the record was created. Date will be in the form DDMON-YYYY.

83. CREATED_IN_INSTANCE

Created in instance. The database instance in which the record was created. Each computer system has a unique database instance code and this attribute stores that information to determine on which computer the record was created.

84. MODIFIED_BY

Modified by. The employee who modified the record. This field will be blank (null) if the data have not been modified since initial creation. This attribute is intentionally left blank in download files.

85. MODIFIED_DATE

Modified date. The date the record was last modified. This field will be blank (null) if the data have not been modified since initial creation. Date will be in the form DD-MON-YYYY. 


\section{MODIFIED IN INSTANCE}

Modified in instance. The database instance in which the record was modified. This field will be blank (null) if the data have not been modified since initial creation.

87. MORTCD Mortality code. (Core optional.) Used for a tree that was alive within past 5 years, but has died.

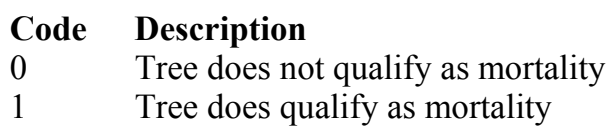

88. HTDMP Height to diameter measurement point. (Core optional.) For trees measured directly at 4.5 feet above ground, this item is blank (null). If the diameter is not measured at 4.5 feet, the actual length from the ground, to the nearest 0.1 foot, at which the diameter was measured for each tally tree, 1.0-inch $\mathrm{DBH}$ and larger.

89. ROUGHCULL Rough cull. (Core optional.) Percentage of sound dead cull, as a percent of the merchantable bole/portion of the tree.

90. MIST_CL_CD Mistletoe class code. (Core optional.) A rating of dwarf mistletoe infection. Recorded on all live conifer species except juniper. Using the Hawksworth (1979) six-class rating system, the live crown is divided into thirds, and each third is rated using the following scale: 0 is for no visible infection, 1 for $<50$ percent of branches infected, 2 for $>50$ percent of branches infected. The ratings for each third are summed together to yield the Hawksworth rating.

$\begin{array}{ll}\text { Code } & \text { Description } \\ 0 & \text { Hawksworth tree DMR rating of 0, no infection } \\ 1 & \text { Hawksworth tree DMR rating of 1, light infection } \\ 2 & \text { Hawksworth tree DMR rating of 2, light infection } \\ 3 & \text { Hawksworth tree DMR rating of 3, medium infection } \\ 4 & \text { Hawksworth tree DMR rating of 4, medium infection } \\ 5 & \text { Hawksworth tree DMR rating of 5, heavy infection } \\ 6 & \text { Hawksworth tree DMR rating of } 6, \text { heavy infection }\end{array}$

91. CULL_FLD Rotten/missing cull, field -recorded. (Core: $\geq 5$.0-inch live trees; Core optional: $\geq 5$.0-inch standing dead trees.) The percentage rotten or missing cubic-foot cull volume, estimated to the nearest 1 percent. This estimate does not include any cull estimate above actual length; therefore volume lost from a broken top is not included (see CULL for percent cull including cull from broken top). When field crews estimate volume loss (tree cull), they only consider the cull on the merchantable bole/portion of the tree, from a 1-foot stump to a 4-inch top diameter outside bark (DOB). For western woodland species, the merchantable portion is between the point of DRC measurement to a 1.5 -inch top DOB. 


\section{RECONCILECD}

Reconcile code. Recorded for remeasurement locations only. A code indicating the reason a tree either enters or is no longer a part of the inventory.

\section{Code Description}

1 Ingrowth or reversions - either a new tally tree not qualifying as through growth or a new tree on land that was formerly nonforest and now qualifies as forest land (includes reversion or encroachments).

2 Through growth - new tally tree 5 inches DBH/DRC and larger, within the microplot, which was not missed at the previous inventory.

3 Missed live - a live tree missed at previous inventory and that is live, dead, or removed now.

$4 \quad$ Missed dead - a dead tree missed at previous inventory and that is dead or removed now.

5 Shrank - live tree that shrunk below threshold diameter on microplot/subplot/macroplot plot.

6 Missing (moved) - tree was correctly tallied in previous inventory, but has now moved beyond the radius of the plot due to natural causes (i.e., small earth movement, hurricane). Tree must be either live before and still alive now or dead before and dead now. If tree was live before and now dead, this is a mortality tree and should have STATUSCD $=2($ not 0$)$.

$7 \quad$ Cruiser error - erroneously tallied at previous inventory

8 Procedural change - tree was tallied at the previous inventory, but is no longer tallied due to a definition or procedural change.

9 Tree was sampled before, but now the area where the tree was located is nonsampled. All trees on the nonsampled area have RECONCILECD $=9$.

93. PREVDIA Previous diameter. The previous diameter (in inches) of the sample tree at the point of diameter measurement. Populated for remeasured trees.

94. FGROWCFGS Net annual merchantable cubic-foot growth of a growing-stock tree on forest land. This is the net change in cubic-foot volume per year of this tree (for remeasured plots, $\left(\mathrm{V}_{2}-\mathrm{V}_{1}\right) /\left(\mathrm{t}_{2}-\mathrm{t}_{1}\right)$; where 1 and 2 denote the past and current measurement, respectively, $\mathrm{V}$ is volume, $\mathrm{t}$ indicates date of measurement, and $\mathrm{t}_{2}-\mathrm{t}_{1}=$ PLOT.REMPER). Because this value is net growth, it may be $\mathrm{a}$ negative number. Negative growth values are usually due to mortality $\left(\mathrm{V}_{2}=0\right)$ but can also occur on live trees that have a net loss in volume because of damage, rot, broken top, or other causes. To expand to a per acre value, multiply by TPAGROW_UNADJ.

95. FGROWBFSL Net annual merchantable board-foot growth of a sawtimber tree on forest land. This is the net change in board-foot (International $1 / 4$-inch rule) volume per year of this tree (for remeasured plots $\left(\mathrm{V}_{2}-\mathrm{V}_{1}\right) /\left(\mathrm{t}_{2}-\mathrm{t}_{1}\right)$ ). Because this value is net growth, it may be a negative number. Negative growth values are usually due to mortality $\left(\mathrm{V}_{2}=0\right)$ but can also occur on live trees that have a net loss in volume because of damage, rot, broken top, or other causes. To expand to a per acre value, multiply by TPAGROW_UNADJ.

96. FGROWCFAL Net annual sound cubic-foot growth of a live tree on forest land. The net change in cubic-foot volume per year of this tree (for remeasured plots 
$\left.\left(\mathrm{V}_{2}-\mathrm{V}_{1}\right) /\left(\mathrm{t}_{2}-\mathrm{t}_{1}\right)\right)$. Because this value is net growth, it may be a negative number. Negative growth values are usually due to mortality $\left(\mathrm{V}_{2}=0\right)$ but can also occur on live trees that have a net loss in volume because of damage, rot, broken top, or other causes. To expand to a per acre value, multiply by TPAGROW_UNADJ. FGROWCFAL differs from FGROWCFGS by including all trees, regardless of tree class.

97. FMORTCFGS Cubic-foot volume of a growing-stock tree for mortality purposes on forest land. Represents the cubic-foot volume of a growing-stock tree at time of mortality. To obtain estimates of annual per acre mortality, multiply by TPAMORT_UNADJ.

98. FMORTBFSL Board-foot volume of a sawtimber tree for mortality purposes on forest land. Represents the board-foot (International 1/4-rule) volume of a sawtimber tree at time of mortality. To obtain estimates of annual per acre mortality, multiply by TPAMORT_UNADJ.

99. FMORTCFAL Sound cubic-foot volume of a tree for mortality purposes on forest land. Represents the cubic-foot volume of the tree at time of mortality. To obtain estimates of annual per acre mortality, multiply by TPAMORT_UNADJ. FMORTCFAL differs from FMORTCFGS by including all trees, regardless of tree class.

100. FREMVCFGS Cubic-foot volume of a growing-stock tree for removal purposes on forest land. Represents the cubic-foot volume of the tree at time of removal. To obtain estimates of annual per acre removals, multiply by TPAREMV_UNADJ.

101. FREMVBFSL Board-foot volume of a sawtimber size tree for removal purposes on forest land. Represents the board-foot (International 1/4-rule) volume of the tree at time of removal. To obtain estimates of annual per acre removals, multiply by TPAREMV_UNADJ.

102. FREMVCFAL Sound cubic-foot volume of the tree for removal purposes on forest land. Represents the cubic-foot volume of the tree at time of removal. To obtain estimates of annual per acre removals, multiply by TPAREMV_UNADJ. FREMVCFAL differs from FREMVCFGS by including all trees, regardless of tree class.

103. P2A_GRM_FLG

Periodic to annual growth, removal, and mortality flag. A code indicating if this tree is part of a periodic inventory (usually from a variable-radius plot design) that is only included for the purposes of computing growth, removals and/or mortality estimates. This tree does not contribute to current estimates of such attributes as volume, biomass or number of trees. The flag is set to $\mathrm{Y}$ for those trees that are needed for estimation and otherwise is left blank (null). 
Tree class code, Northeastern Research Station. In annual inventory, this code represents a classification of the overall quality of a tree that is 5.0 inches DBH and larger. It classifies the quality of a sawtimber tree based on the present condition, or it classifies the quality of a poletimber tree as a prospective determination (i.e., a forecast of potential quality when and if the tree becomes sawtimber size). For more detailed description, see the regional field guide. Only collected by certain FIA work units (SURVEY.RSCD = 24).

\section{Code Description}

1 Preferred - Live tree that would be favored in cultural operations. Mature tree, that is older than the rest of the stand; has less than 20 percent total board foot cull; is expected to live for 5 more years: and is a low risk tree. In general, the tree has the following qualifications:

- must be free from "general" damage (i.e., damages that would now or prospectively cause a reduction of tree class, significantly deter growth, or prevent it from producing marketable products in the next 5 years).

- should have no more than 10 percent board-foot cull due to form defect.

- should have good vigor, usually indicated by a crown ratio of 30 percent or more and dominant or co-dominant.

- usually has a grade 1 butt log.

2 Acceptable - This class includes:

- live sawtimber tree that does not qualify as a preferred tree but is not a cull tree (see Rough and Rotten Cull).

- live poletimber tree that prospectively will not qualify as a preferred tree, but is not now or prospectively a cull tree (see Rough and Rotten Cull). Rough Cull - This class includes:

- live sawtimber tree that currently has 67 percent or more predominantly sound board-foot cull; or does not contain one merchantable 12-foot sawlog or two non-contiguous merchantable 8-foot sawlogs.

- live poletimber tree that currently has 67 percent or more predominantly sound cubic-foot cull; or prospectively will have 67 percent or more predominantly sound board-foot cull; or will not contain one merchantable 12-foot sawlog or two noncontiguous merchantable 8-foot sawlogs. Rotten Cull - This class includes:

- live sawtimber tree that currently has 67 percent or more predominantly unsound board-foot cull.

- live poletimber tree that currently has 67 percent or more predominantly unsound cubic-foot cull; or prospectively will have 67 percent or more predominantly unsound board-foot cull.

5 Dead - Tree that has recently died (within the last several years); but still retains many branches (including some small branches and possibly some fine twigs); and has bark that is generally tight and hard to remove from the tree.

6 Snag - Dead tree, or what remains of a dead tree, that is at least 4.5 feet tall and is missing most of its bark. This category includes a tree covered with bark that is very loose. This bark can usually be removed, often times in big strips, with very little effort. A snag is not a recently dead tree. Most often, it has been dead for several years - sometimes, for more than a decade.

\section{TREECLCD_SRS}

Tree class code, Southern Research Station. A code indicating the general quality of the tree. Prior to the merger of the Southern and Southeastern Research Stations (INVYR $\leq 1997$ ), growing-stock (code 2) was only 
assigned to species that were considered to have commercial value. Since the merger (INVYR >1997), code 2 has been applied to all tree species meeting the growing-stock form, grade, size and soundness requirements, regardless of commercial value. Only collected by certain FIA work units $($ SURVEY.RSCD = 33).
Code Description
2 Growing-stock - All trees that have at least one 12-foot log or two 8-foot logs that meet grade and size requirements and at least $1 / 3$ of the total board foot volume is merchantable. Poletimber-sized trees are evaluated based on their potential.
3 Rough cull - Trees that do not contain at least one 12-foot log or two 8 -foot logs, or more than $1 / 3$ of the total board foot volume is not merchantable, primarily due to roughness or poor form.
4 Rotten cull: Trees that do not contain at least one 12-foot log or two 8 -foot logs, or more than $1 / 3$ of the total board foot volume is not merchantable, primarily due to rotten, unsound wood.

106. TREECLCD_NCRS

Tree class code, North Central Research Station. In annual inventory, a code indicating tree suitability for timber products, or the extent of decay in the butt section of down-dead trees. It is recorded on live standing, standingdead, and down dead trees that are 1.0 inches DBH and larger. Tree class is basically a check for the straightness and soundness of the sawlog portion on a sawtimber tree or the potential sawlog portion on a poletimber tree or sapling. "Sawlog portion" is defined as the length between the 1-foot stump and the 9.0-inch top diameter of outside bark, DOB, for hardwoods, or the 7.0-inch top DOB for softwoods. For more detailed description, see the regional field guide http://www.nrs.fs.fed.us/fia/data-collection/. Only collected by certain FIA work units (SURVEY.RSCD = 23). 


\section{Code Description}

20 Growing-stock - Any live tree of commercial species that is saw-timber size and has at least one merchantable 12-foot sawlog or two merchantable 8 -foot sawlogs meeting minimum log-grade requirements. At least onethird of the gross board-foot volume of the sawlog portion must be merchantable material. A merchantable sawlog must be at least 50 percent sound at any point. Any pole timber size tree that has the potential to meet the above specifications.

30 Rough Cull, Salvable, and Salvable-down - Includes any tree of noncommercial species, or any tree that is saw-timber size and has no merchantable sawlog. Over one-half of the volume in the sawlog portion does not meet minimum log-grade specifications due to roughness, excessive sweep or crook, splits, cracks, limbs, or forks. Rough cull polesize trees do not have the potential to meet the specifications for growingstock because of forks, limb stoppers, or excessive sweep or crook. A down-dead tree $\geq 5$. 0 -inch DBH that meets these standards is given a tree/decay code of 30 .

31 Short-log Cull - Any live saw-timber-size tree of commercial species that has at least one 8-foot sawlog, but less than a 12-foot sawlog, meeting minimum log-grade specifications. Any live saw-timber-size tree of commercial species that has less than one-third of the volume of the sawlog portion in merchantable logs, but has at least one 8-foot or longer sawlog meeting minimum log-grade specifications. A short sawlog must be 50 percent sound at any point. Pole-size trees never receive a tree class code 31 .

40 Rotten Cull - Any live tree of commercial species that is saw-timber size and has no merchantable sawlog. Over one-half of the volume in the sawlog portion does not meet minimum log-grade specifications primarily because of rot, missing sections, or deadwood. Classify any pole-size tree that does not have the potential to meet the specifications for growingstock because of rot as rotten cull. Assume that all live trees will eventually attain sawlog size at DBH. Predicted death, tree vigor, and plot site index are not considered in determining tree class. A standing-dead tree without an 8 -foot or longer section that is at least 50 percent sound has a tree class of 40. On remeasurement of a sapling, if it has died and is still standing it is given a tree class of 40 .

\section{TREECLCD RMRS}

Tree class code, Rocky Mountain Research Station. A code indicating the general quality of the tree. Only collected by certain FIA work units (SURVEY.RSCD = 22).

\section{Code Description}

1 Sound-live timber species - All live timber trees (species with diameter measured at breast height) that meet minimum merchantability standards. In general, these trees have at least one solid 8-foot section, are reasonably free of form defect on the merchantable bole, and at least 34 percent or more of the volume is merchantable. Excludes rough or rotten cull timber trees.

2 All live woodland species - All live woodland trees (species with diameter measured at root collar). All trees assigned to species groups 23 and 48 belong in this category (see appendix $\mathrm{G}$ ). 


\section{Code Description}

3 Rough-live timber species - All live trees that do not now, or prospectively, have at least one solid 8-foot section, reasonably free of form defect on the merchantable bole, or have 67 percent or more of the merchantable volume cull; and more than half of this cull is due to sound dead wood cubic-foot loss or severe form defect volume loss.

$4 \quad$ Rotten-live timber species - All live trees with 67 percent or more of the merchantable volume cull, and more than half of this cull is due to rotten or missing cubic-foot volume loss.

$5 \quad$ Hard (salvable) dead - dead trees that have less than 67 percent of the volume cull due to rotten or missing cubic-foot volume loss.

6 Soft (nonsalvable) dead - dead trees that have 67 percent or more of the volume cull due to rotten or missing cubic-foot volume loss.

\section{STANDING_DEAD_CD}

Standing dead code. A code indicating if a tree qualifies as standing dead. To qualify as a standing dead tally tree, the dead tree must be at least 5.0 inches in diameter, have a bole that has an unbroken actual length of at least 4.5 feet, and lean less than 45 degrees from vertical as measured from the base of the tree to 4.5 feet. Populated where PLOT.MANUAL $\geq 2.0$; may be populated using information collected on dead trees in earlier inventories for dead trees.

For western woodland species with multiple stems, a tree is considered down if more than $2 / 3$ of the volume is no longer attached or upright; cut and removed volume is not considered. For western woodland species with single stems to qualify as a standing dead tally tree, dead trees must be at least 5.0 inches in diameter, be at least 1.0 foot in unbroken ACTUAL LENGTH, and lean less than 45 degrees from vertical.

\section{Code Description}

$0 \quad$ No - tree does not qualify as standing dead

$1 \quad$ Yes - tree does qualify as standing dead

\section{PREV_STATUS_CD}

Previous tree status code. Tree status that was recorded at the previous inventory on all tally trees $\geq 1.0$ inch in diameter.

\section{Code Description}

1 Live tree - live tree at the previous inventory

2 Dead tree - standing dead at the previous inventory

\section{PREV_WDLDSTEM}

Previous woodland stem count. Woodland tree species stem count that was recorded at the previous inventory.

111. TPA_UNADJ Trees per acre unadjusted. The number of trees per acre that the sample tree theoretically represents based on the sample design. For fixed radius plots taken with the mapped plot design (PLOT.DESIGNCD = 1), TPA_UNADJ is set to a constant derived from the plot size and equals 6.018046 for trees sampled on subplots, 74.965282 for trees sampled on microplots, and 
0.999188 for trees sampled on macroplots. Variable radius plots were often used in earlier inventories, so the value in TPA_UNADJ decreases as the tree diameter increases. Based on the procedures described in Bechtold and Patterson (2005), this attribute can be adjusted using factors stored on the POP_STRATUM table to derive population estimates. Examples of estimating population totals are shown in chapter 4 .

112. TPAMORT_UNADJ

Mortality trees per acre unadjusted. The number of mortality trees per acre per year that the sample tree theoretically represents based on the sample design. For fixed radius plots taken with the mapped plot design (PLOT.DESIGNCD =1), TPAMORT_UNADJ is set to a constant derived from the plot size divided by PLOT.REMPER. Variable radius plots were often used in earlier inventories, so the value in TPAMORT_UNADJ decreases as the tree diameter increases. This attribute will be blank (null) if the tree does not contribute to mortality estimates. Based on the procedures described in Bechtold and Patterson (2005), this attribute can be adjusted using factors stored on the POP_STRATUM table to derive population estimates. Examples of estimating population totals are shown in chapter 4.

\section{TPAREMV_UNADJ}

Removal trees per acre unadjusted. The number of removal trees per acre per year that the sample tree theoretically represents based on the sample design. For fixed radius plots taken with the mapped plot design (PLOT.DESIGNCD $=1$ ), TPAREMV_UNADJ is set to a constant derived from the plot size divided by PLOT.REMPER. Variable radius plots were often used in earlier inventories, so the value in TPAREMV_UNADJ decreases as the tree diameter increases. This attribute will be blank (null) if the tree does not contribute to removals estimates. Based on the procedures described in Bechtold and Patterson (2005), this attribute can be adjusted using factors stored on the POP_STRATUM table to derive population estimates. Examples of estimating population totals are shown in chapter 4.

\section{TPAGROW_UNADJ}

Growth trees per acre unadjusted. The number of growth trees per acre that the sample tree theoretically represents based on the sample design. For fixed radius plots taken with the mapped plot design (PLOT.DESIGNCD $=1$ ), TPAGROW_UNADJ is set to a constant derived from the plot size. Variable radius plots were often used in earlier inventories, so the value in TPAGROW_UNADJ decreases as the tree diameter increases. This attribute will be blank (null) if the tree does not contribute to growth estimates. Based on the procedures described in Bechtold and Patterson (2005), this attribute can be adjusted using factors stored on the POP_STRATUM table to derive population estimates. Examples of estimating population totals are shown in chapter 4. 


\section{DRYBIO_BOLE}

Dry biomass in the merchantable bole. The oven-dry biomass (pounds) in the merchantable bole of timber species [trees where diameter is measured at breast height $(\mathrm{DBH})] \geq 5$ inches in diameter. This is the biomass of sound wood in live and dead trees, including bark, from a 1-foot stump to a minimum 4-inch top diameter of the central stem. This is a per tree value and must be multiplied by TPA_UNADJ to obtain per acre information. This attribute is blank (null) for timber species with DIA $<5.0$ inches and for woodland species. See DRYBIO_WDLD_SPP for biomass of woodland species and DRYBIO_SAPLING for biomass of timber species with DIA $<5$ inches. For dead or cut timber trees, this number represents the biomass at the time of death or last measurement. DRYBIO_BOLE is based on VOLCFSND and specific gravity information derived by the Forest Products Lab and others (values stored in the REF_SPECIES table). If VOLCFSND is not available, then either VOLCFGRS * Percent Sound or VOLCFNET * (average ratio of cubic foot sound to cubic foot net volume, calculated as national averages by species group and diameter) is used. The source of specific gravity information for each species can be found by linking the REF_SPECIES table to the REF_CITATION table. Appendix J contains equations used to estimate biomass components in the FIADB.

116. DRYBIO_TOP Dry biomass in the top of the tree. The oven-dry biomass (pounds) in the top and branches (combined) of timber species [trees where diameter is measured at breast height $(\mathrm{DBH})] \geq 5$ inches in diameter. DRYBIO_TOP includes the tip, the portion of the stem above the merchantable bole (i.e., above the 4-inch top diameter), and all branches; excludes foliage. Estimated for live and dead trees. This is a per tree value and must be multiplied by TPA_UNADJ to obtain per acre information. For dead or cut trees, this number represents the biomass at the time of death or last measurement. This attribute is blank (null) for timber species with DIA $<5.0$ inches and for woodland species. See DRYBIO_WDLD_SPP for biomass of woodland species, and DRYBIO_SAPLING $\bar{G}$ for biomass of timber species with DIA $<5.0$ inches. Appendix $\mathrm{J}$ contains equations used to estimate biomass components in the FIADB.

\section{DRYBIO_STUMP}

Dry biomass in the tree stump. The oven-dry biomass (pounds) in the stump of timber species [trees where diameter is measured at breast height (DBH)] $\geq 5$ inches in diameter. The stump is that portion of the tree from the ground to the bottom of the merchantable bole (i.e., below 1 foot). This is a per tree value and must be multiplied by TPA_UNADJ to obtain per acre information. Estimated for live and dead trees. For dead or cut trees, this number represents the biomass at the time of death or last measurement. This attribute is blank (null) for timber species with DIA $<5.0$ inches and for woodland species. See DRYBIO_WDLD_SPP for biomass of woodland species, and DRYBIO_SAPLING for biomass of timber species with 
DIA $<5.0$ inches. Appendix J contains equations used to estimate biomass components in the FIADB.

\section{DRYBIO SAPLING}

Dry biomass of saplings. The oven-dry biomass (pounds) of the aboveground portion, excluding foliage, of live trees with a diameter from 1 to 4.9 inches. Calculated for timber species only. The biomass of saplings is based on biomass computed from Jenkins and others (2003), using the observed diameter and an adjustment factor. This is a per tree value and must be multiplied by TPA_UNADJ to obtain per acre information. Appendix J contains equations used to estimate biomass components in the FIADB.

\section{DRYBIO_WDLD_SPP}

Dry biomass of woodland tree species. The oven-dry biomass (pounds) of the aboveground portion of a live or dead tree, excluding foliage, the tree tip (top of the tree above $1 \frac{1}{2}$ inches in diameter), and a portion of the stump from ground to diameter at root collar (DRC). Calculated for woodland species (trees where diameter is measured at DRC) with a diameter $\geq 1$ inch. This is a per tree value and must be multiplied by TPA_UNADJ to obtain per acre information. This attribute is blank (null) for woodland species with DIA $<1.0$ inch and for all timber species. Appendix J contains equations used to estimate biomass components in the FIADB.

120. DRYBIO_BG Dry biomass of the roots. The oven-dry biomass (pounds) of the belowground portion of a tree, includes coarse roots with a root diameter $\geq 0.1 \mathrm{inch}$. This is a modeled estimate, calculated on live trees with a diameter of $\geq 1$ inch and dead trees with a diameter of $\geq 5$ inches, for both timber and woodland. This is a per tree value and must be multiplied by TPA_UNADJ to obtain per acre information. Appendix J contains equations used to estimate biomass components in the FIADB.

121. CARBON_AG Carbon in the aboveground portion of the tree. The carbon (pounds) in the aboveground portion, excluding foliage, of live trees with a diameter $\geq 1$ inch, and dead trees with a diameter $\geq 5$ inches. Calculated for both timber and woodland species. This is a per tree value and must be multiplied by TPA_UNADJ to obtain per acre information. Carbon is assumed to be onehalf the value of biomass and is derived by summing the aboveground biomass estimates and multiplying by 0.5 as follows:

$$
\begin{aligned}
& \text { CARBON_AG }=0.5 *(\text { DRYBIO_BOLE }+ \text { DRYBIO_STUMP }+ \\
& \text { DRYBIO_TOP }+ \text { DRYBIO_SAPLING }+ \text { DRYBIO_WDLD_SPP })
\end{aligned}
$$

122. CARBON_BG Carbon in the belowground portion of the tree. The carbon (pounds) of coarse roots $>0.1$ inch in root diameter. Calculated for live trees with a diameter $\geq 1$ inch, and dead trees with a diameter $\geq 5$ inches, for both timber and woodland species. This is a per tree value and must be multiplied by 
TPA_UNADJ to obtain per acre information. Carbon is assumed to be onehalf the value of belowground biomass as follows:

CARBON_BG $=0.5 *$ DRYBIO_BG

123. CYCLE Inventory cycle number. A number assigned to a set of plots, measured over a particular period of time from which a State estimate using all possible plots is obtained. A cycle number $>1$ does not necessarily mean that information for previous cycles resides in the database. A cycle is relevant for periodic and annual inventories.

124. SUBCYCLE Inventory subcycle number. For an annual inventory that takes $n$ years to measure all plots, subcycle shows in which of the $\mathrm{n}$ years of the cycle the data were measured. Subcycle is 0 for a periodic inventory. Subcycle 99 may be used for plots that are not included in the estimation process.

125. BORED_CD_PNWRS

Tree bored code, Pacific Northwest Research Station. Used in conjunction with tree age (BHAGE and TOTAGE). Only collected by certain FIA work units (SURVEY.RSCD = 26).

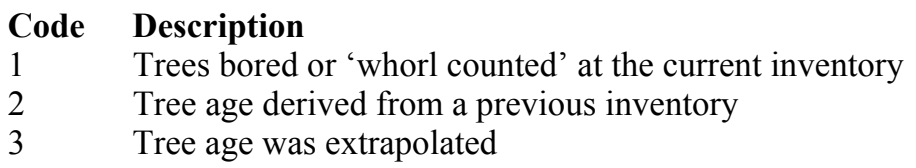

\section{DAMLOC1_PNWRS}

Damage location 1, Pacific Northwest Research Station. The location on the tree where Damage Agent 1 is found. Only collected by certain FIA work units (SURVEY.RSCD = 26).

\begin{tabular}{|c|c|c|}
\hline Code & Location & Definition \\
\hline 0 & & No damage found. \\
\hline 1 & Roots & Above ground up to 12 inches on bole. \\
\hline 2 & Bole & $\begin{array}{l}\text { Main stem(s) starting at } 12 \text { inches above the ground, including } \\
\text { forks up to a } 4 \text { inch top. (A fork is at least equal to } 1 / 3 \text { diameter } \\
\text { of the bole, and occurs at an angle }<45 \text { degrees in relation to } \\
\text { the bole.) This is not a valid location code for woodland } \\
\text { species; use only locations } 1,3 \text {, and } 4 \text {. }\end{array}$ \\
\hline 3 & Branch & $\begin{array}{l}\text { All other woody material. Primary branch(s) occur at an angle } \\
\geq 45^{\circ} \text { in relation to the bole. }\end{array}$ \\
\hline 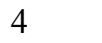 & Foliage & All leaves, buds, and shoots. \\
\hline
\end{tabular}

\section{DAMLOC2_PNWRS}

Damage location 2, Pacific Northwest Research Station. See

DAMLOC1_PNWRS. Only collected by certain FIA work units $($ SURVEY.RSCD $=26)$. 
128. DIACHECK_PNWRS

Diameter check, Pacific Northwest Research Station. A separate estimate of the diameter without the obstruction if the diameter was estimated because of moss/vine/obstruction, etc. Only collected by certain FIA work units $($ SURVEY.RSCD $=26)$.

\section{Code Description}

$5 \quad$ Diameter estimated because of moss.

$6 \quad$ Diameter estimated because of vines.

7 Diameter estimated (double nail diameter).

129. DMG_AGENT1_CD_PNWRS

Damage agent 1, Pacific Northwest Research Station. Primary damage agent code in PNW. Up to three damaging agents can be coded in PNW as DMG_AGENT1_CD_PNWRS, DMG_AGENT2_CD_PNWRS, and DMG_AGENT3_CD_PNWRS. A code indicating the tree damaging agent that is considered to be of greatest importance to predict tree growth, survival, and forest composition and structure. Additionally, there are two classes of damaging agents. Class I damage agents are considered more important than class II agents and are thus coded as a primary agent before the class II agents. For more information, see appendix H. Only collected by certain FIA work units (SURVEY.RSCD $=26$ ).

130. DMG_AGENT2_CD_PNWRS

Damage agent 2, Pacific Northwest Research Station. See

DAM_AGENT1_CD_PNWRS. Only collected by certain FIA work units $(\mathrm{SUR} \overline{\mathrm{V}} \mathrm{EY} \cdot \mathrm{RSCD}=\overline{\mathrm{2}}$ ).

131. DMG_AGENT3_CD_PNWRS

Damage agent 3, Pacific Northwest Research Station. Damage Agent is a 2digit code with values 01 to 91 . Only collected by certain FIA work units $($ SURVEY.RSCD $=26)$.

132. MIST_CL_CD_PNWRS

Leafy mistletoe class code, Pacific Northwest Research Station. All juniper species, incense cedars, white fir (CA only) and oak trees are rated for leafy mistletoe infection. This item is used to describe the extent and severity of leafy mistletoe infection (see MIST_CL_CD for dwarf mistletoe information). Only collected by certain FIA work units (SURVEYRSCD=26).

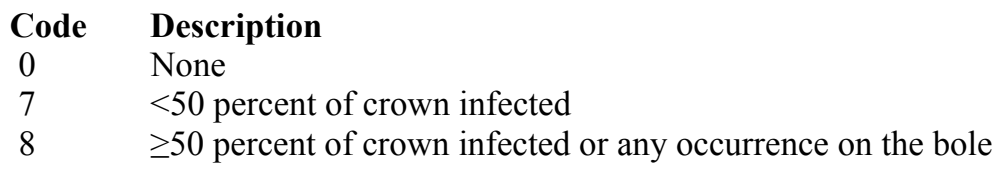




\section{SEVERITY1_CD_PNWRS}

Damage severity 1, Pacific Northwest Research Station for years 2001-2004. Damage severity depends on the damage agent coded (see appendix $\mathrm{H}$ for codes). This is a 2-digit code that indicates either percent of location damaged (01-99), or the appropriate class of damage (values vary from 0-9 depending on the specific Damage Agent). Only collected by certain FIA work units (SURVEY.RSCD $=26$ ).

\section{SEVERITY1A_CD_PNWRS}

Damage severity 1A, Pacific Northwest Research Station. Damage severity depends on the damage agent coded (see appendix $\mathrm{H}$ for codes). This is a 2-digit code indicating either percent of location damaged (01-99), or the appropriate class of damage (values vary from 0-4 depending on the specific Damage Agent). Only collected by certain FIA work units (SURVEY.RSCD $=26)$.

\section{SEVERITY1B_CD_PNWRS}

Damage severity 1B, Pacific Northwest Research Station. Damage severity B is only coded when the Damage Agent is white pine blister rust (36). Only collected by certain FIA work units (SURVEY.RSCD = 26).

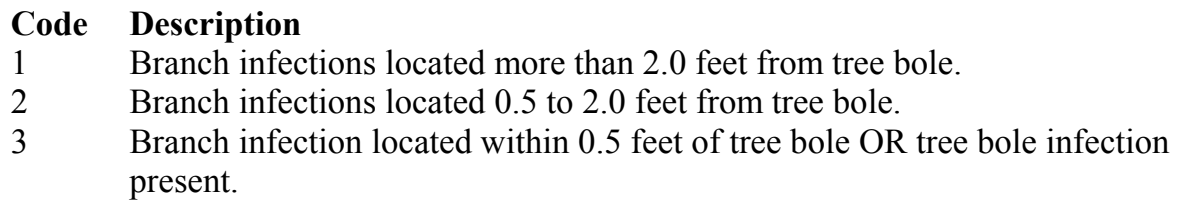

136. SEVERITY2_CD_PNWRS

Damage severity 2, Pacific Northwest Research Station for years 2001-2004. Damage severity depends on the damage agent coded (see appendix $\mathrm{H}$ for codes). This is a 2-digit code indicating either percent of location damaged (01-99), or the appropriate class of damage (values vary from 0-9 depending on the specific Damage Agent). Only collected by certain FIA work units $($ SURVEY.RSCD $=26)$.

\section{SEVERITY2A_CD_PNWRS}

Damage severity 2A, Pacific Northwest Research Station starting in 2005. See SEVERITY1A_CD_PNWRS. Only collected by certain FIA work units $($ SURVEY.RSCD $=26)$.

\section{SEVERITY2B_CD_PNWRS}

Damage severity 2B, Pacific Northwest Research Station starting in 2005. See SEVERITY1B_CD_PNWRS. Only collected by certain FIA work units $($ SURVEY.RSCD $=26$ ). 
139. SEVERITY3_CD_PNWRS

Damage severity 3, Pacific Northwest Research Station for years 2001-2004. Damage severity depends on the damage agent coded (see appendix $\mathrm{H}$ for codes). This is a 2-digit code indicating either percent of location damaged (01-99), or the appropriate class of damage (values vary from 0-9 depending on the specific Damage Agent). Only collected by certain FIA work units (SURVEY.RSCD $=26$ ).

140. UNKNOWN_DAMTYP1_PNWRS

Unknown damage type 1, Pacific Northwest Research Station. A code indicating the sign or symptom recorded when UNKNOWN damage code 90 is used. Only collected by certain FIA work units (SURVEY.RSCD = 26).

$\begin{array}{ll}\text { Code } & \text { Description } \\ 1 & \text { canker/gall } \\ 2 & \text { open wound } \\ 3 & \text { resinosis } \\ 4 & \text { broken } \\ 5 & \text { damaged or discolored foliage } \\ 6 & \text { other }\end{array}$

141. UNKNOWN_DAMTYP2_PNWRS

Unknown damage type 2, Pacific Northwest Research Station. See UNKNOWN_DAMTYP1_PNWRS. Only collected by certain FIA work units (SURVEY $\bar{E} \cdot \mathrm{RSCD}=\overline{2} 6$ ).

142. PREV_PNTN_SRS

Previous periodic prism number, tree number, Southern Research Station. In some older Southeast Experiment Station states, the prism point, tree number (PNTN) of the current cycle did not match the previous cycle's prism point, tree number. PREV_PNTN_SRS is used to join the current and the previous prism plot trees. 
FIA Database Description and Users Manual for Phase 2, version 4.0

Chapter 3. Seedling Table

Seedling Table (Oracle table name is SEEDLING)

\begin{tabular}{|l|l|l|l|}
\hline & Column name & Descriptive name & Oracle data type \\
\hline 1 & CN & Sequence number & VARCHAR2(34) \\
\hline 2 & PLT_CN & Plot sequence number & VARCHAR2(34) \\
\hline 3 & INVYR & Inventory year & NUMBER(4) \\
\hline 4 & STATECD & State code & NUMBER(4) \\
\hline 5 & UNITCD & Unit code & NUMBER(2) \\
\hline 6 & COUNTYCD & County code & NUMBER(3) \\
\hline 7 & PLOT & Phase 2 plot number & NUMBER(5) \\
\hline 8 & SUBP & Subplot number & NUMBER(3) \\
\hline 9 & CONDID & Condition class number & NUMBER(1) \\
\hline 10 & SPCD & Species code & NUMBER \\
\hline 11 & SPGRPCD & Species group code & NUMBER(2) \\
\hline 12 & STOCKING & Tree stocking & NUMBER(7,4) \\
\hline 13 & TREECOUNT & Tree count for seedlings & NUMBER(3) \\
\hline 14 & TOTAGE & Total age & NUMBER(3) \\
\hline 15 & CREATED_BY & Created by & VARCHAR2(30) \\
\hline 16 & CREATED_DATE & Created date & DATE \\
\hline 17 & CREATED_IN_INSTANCE & Created in instance & VARCHAR2(6) \\
\hline 18 & MODIFIED_BY & Modified by & VARCHAR2(30) \\
\hline 19 & MODIFIED_DATE & Modified date & DATE \\
\hline 20 & MODIFIED_IN_INSTANCE & Modified in instance & VARCHAR2(6) \\
\hline 21 & TREECOUNT_CALC & Tree count used in calculations & NUMBER \\
\hline 22 & TPA_UNADJ & Trees per acre unadjusted & NUMBER(11,6) \\
\hline 23 & CYCLE & Inventory cycle number & NUMBER(2) \\
\hline 24 & SUBCYCLE & Inventory subcycle number & NUMBER(2) \\
\hline & & & \\
\hline
\end{tabular}

\begin{tabular}{|l|l|l|l|}
\hline Type of key & Column(s) & Tables to link & Abbreviated notation \\
\hline Primary & (CN) & N/A & SDL_PK \\
\hline Unique & (PLT_CN, SUBP, CONDID, SPCD) & N/A & SDL_UK \\
\hline Natural & $\begin{array}{l}\text { (STATECD, INVYR, UNITCD, } \\
\text { COUNTYCD, PLOT, SUBP, } \\
\text { CONDID, SPCD) }\end{array}$ & N/A & SDL_NAT_I \\
\hline Foreign & (PLT_CN) & SEEDLING to PLOT & SDL_PLT_FK \\
\hline
\end{tabular}

Seedling data collection overview - When PLOT.MANUAL $<2.0$, the national core procedure was to record the actual seedling count up to six seedlings and then record $6+$ if at least six seedlings were present. However, the following regions collected the actual seedling count when PLOT.MANUAL <2.0: Rocky Mountain Research Station (RMRS) and North Central Research Station (NCRS). If PLOT.MANUAL $<2.0$ and TREECOUNT is blank (null), then a value of 6 in TREECOUNT_CALC represents 6 or more seedlings. In the past, seedlings were often tallied in FIA inventories only to the extent necessary to determine if some minimum number were present, 
which means that seedlings were often under-reported. Note: The SEEDLING record may not exist for some periodic inventories.

1. $\mathrm{CN}$

2. PLT_CN

3. INVYR
Sequence number. A unique index used to easily identify a seedling.

Plot sequence number. Foreign key linking the seedling record to the plot record.

Inventory year. The year that best represents when the inventory data were collected. Under the annual inventory system, a group of plots is selected each year for sampling. The selection is based on a panel system. INVYR is the year in which the majority of plots in that group were collected (plots in the group have the same panel and, if applicable, subpanel). Under periodic inventory, a reporting inventory year was selected, usually based on the year in which the majority of the plots were collected or the mid-point of the years over which the inventory spanned. For either annual or periodic inventory, INVYR is not necessarily the same as MEASYEAR.

Exceptions:

INVYR $=9999$. INVYR is set to 9999 to distinguish Phase 3 plots taken by the western FIA work units that are "off subpanel." This is due to differences in measurement intervals between Phase 3 (measurement interval $=5$ years) and Phase 2 (measurement interval $=10$ years) plots. Only users interested in performing certain Phase 3 data analyses should access plots with this anomalous value in INVYR.

INVYR $<100$. INVYR $<100$ indicates that population estimates were derived from a pre-NIMS regional processing system and the same plot either has been or may soon be re-processed in NIMS as part of a separate evaluation. The NIMS processed copy of the plot follows the standard INVYR format. This only applies to plots collected in the South (SURVEY.RSCD $=33$ ) with the national design or a similar regional design (PLOT.DESIGNCD $=1$ or 220-233) that were collected when the inventory year was 1998 through 2005.

INVYR $=98$ is equivalent to 1998 but processed through regional system $\mathrm{INVYR}=99$ is equivalent to 1999 but processed through regional system INVYR $=0$ is equivalent to 2000 but processed through regional system $\mathrm{INVYR}=1$ is equivalent to 2001 but processed through regional system $\mathrm{INVYR}=2$ is equivalent to 2002 but processed through regional system $\mathrm{INVYR}=3$ is equivalent to 2003 but processed through regional system $\mathrm{INVYR}=4$ is equivalent to 2004 but processed through regional system $\mathrm{INVYR}=5$ is equivalent to 2005 but processed through regional system

4. STATECD State code. Bureau of the Census Federal Information Processing Standards (FIPS) two-digit code for each State. Refer to appendix C. 
5. UNITCD

6. COUNTYCD

7. PLOT

8. SUBP

9. CONDID

10. SPCD

11. SPGRPCD

12. STOCKING
Survey unit number. Forest Inventory and Analysis survey unit identification number. Survey units are usually groups of counties within each State. For periodic inventories, Survey units may be made up of lands of particular owners. Refer to appendix C for codes.

County code. The identification number for a county, parish, watershed, borough, or similar governmental unit in a State. FIPS codes from the Bureau of the Census are used. Refer to appendix $\mathrm{C}$ for codes.

Phase 2 plot number. An identifier for a plot. Along with STATECD, INVYR, UNITCD, COUNTYCD and/or some other combinations of variables, PLOT may be used to uniquely identify a plot.

Subplot number. The number assigned to the subplot. The national plot design (PLOT.DESIGNCD = 1) has subplot number values of 1 through 4 . Other plot designs have various subplot number values. See PLOT.DESIGNCD and appendix B for information about plot designs. For more explanation about SUBP, contact the appropriate FIA work unit (table $6)$.

Condition class number. Unique identifying number assigned to each condition on a plot. A condition is initially defined by condition class status. Differences in reserved status, owner group, forest type, stand-size class, regeneration status, and stand density further define condition for forest land. Mapped nonforest conditions are also assigned numbers. At the time of the plot establishment, the condition class at plot center (the center of subplot 1) is usually designated as condition class 1 . Other condition classes are assigned numbers sequentially at the time each condition class is delineated. On a plot, each sampled condition class must have a unique number that can change at remeasurement to reflect new conditions on the plot.

Species code. An FIA species code. Refer to appendix F for codes.

Species group code. A code assigned to each tree species in order to group them for reporting purposes on presentation tables. Codes and their associated names (see REF_SPECIES_GROUP.NAME) are shown in appendix G. Individual tree species and corresponding species group codes are shown in appendix F.

Tree stocking. The stocking value assigned to each count of seedlings, by species. Stocking is a relative term used to describe (in percent) the adequacy of a given stand density in meeting a specific management objective. Species or forest type stocking functions were used to assess the stocking contribution of seedling records. These functions, which were developed using stocking guides, relate the area occupied by an individual tree to the area occupied by a tree of the same size growing in a fully stocked stand of like trees. The stocking of seedling count records is used in the calculation of COND.GSSTKCD and COND.ALSTKCD on the condition record. 
13. TREECOUNT Tree count (for seedlings). Indicates the number of seedlings (DIA $<1.0$ inch) present on the microplot. Conifer seedlings are at least 6 inches tall and hardwood seedlings are at least 12 inches tall. When PLOT.MANUAL $<2.0$, the national core procedure was to record the actual seedling count up to six seedlings and then record $6+$ if at least six seedlings were present. However, the following regions collected the actual seedling count when PLOT.MANUAL <2.0: Rocky Mountain Research Station (RMRS) and North Central Research Station (NCRS). If PLOT.MANUAL $<2.0$ and TREECOUNT is blank (null), then a value of 6 in TREECOUNT_CALC represents 6 or more seedlings.

14. TOTAGE Total age. The seedling's total age. Total age is collected for a subset of seedling count records, using one representative seedling for the species. The age is obtained by counting the terminal bud scars or the whorls of branches and may be used in the stand age calculation. Only collected by certain FIA work units (SURVEY.RSCD = 22). This attribute may be blank (null) for SURVEY.RSCD $=22$ and is always null for the other FIA work units.

15. CREATED_BY Created by. The employee who created the record. This attribute is intentionally left blank in download files.

16. CREATED_DATE

Created date. The date the record was created. Date will be in the form DDMON-YYYY.

17. CREATED_IN_INSTANCE

Created in instance. The database instance in which the record was created. Each computer system has a unique database instance code and this attribute stores that information to determine on which computer the record was created.

18. MODIFIED_BY

Modified by. The employee who modified the record. This field will be blank (null) if the data have not been modified since initial creation. This attribute is intentionally left blank in download files.

19. MODIFIED_DATE

Modified date. The date the record was last modified. This field will be blank (null) if the data have not been modified since initial creation. Date will be in the form DD-MON-YYYY.

20. MODIFIED_IN_INSTANCE

Modified in instance. The database instance in which the record was modified. This field will be blank (null) if the data have not been modified since initial creation. 


\section{TREECOUNT CALC}

Tree count used in calculations. This attribute is set either to COUNTCD, which was dropped in FIADB version 2.1, or TREECOUNT. When PLOT.MANUAL $<2.0$, the national core procedure was to record the actual seedling count up to six seedlings and then record $6+$ if at least six seedlings were present. However, the following regions collected the actual seedling count when PLOT.MANUAL <2.0: Rocky Mountain Research Station (RMRS) and North Central Research Station (NCRS). If

PLOT.MANUAL $<2.0$ and TREECOUNT is blank (null), then a value of 6 in TREECOUNT_CALC represents 6 or more seedlings.

22. TPA_UNADJ Trees per acre unadjusted. The number of seedlings per acre that the seedling count theoretically represents based on the sample design. For fixed radius plots taken with the mapped plot design (PLOT.DESIGNCD =1), TPA_UNADJ equals 74.965282 times the number of seedlings counted. For plots taken with other sample designs, this attribute may be blank (null). Based on the procedures described in Bechtold and Patterson (2005), this attribute can be adjusted using factors stored on the POP_STRATUM table to derive population estimates. Examples of estimating population totals are shown in chapter 4 .

23. CYCLE Inventory cycle number. A number assigned to a set of plots, measured over a particular period of time from which a State estimate using all possible plots is obtained. A cycle number $>1$ does not necessarily mean that information for previous cycles resides in the database. A cycle is relevant for periodic and annual inventories.

24. SUBCYCLE Inventory subcycle number. For an annual inventory that takes n years to measure all plots, subcycle shows in which of the $n$ years of the cycle the data were measured. Subcycle is 0 for a periodic inventory. Subcycle 99 may be used for plots that are not included in the estimation process. 
Site Tree Table (Oracle table name is SITETREE)

\begin{tabular}{|c|c|c|c|}
\hline & Column name & Descriptive name & Oracle data type \\
\hline 1 & $\mathrm{CN}$ & Sequence number & VARCHAR2(34) \\
\hline 2 & PLT_CN & Plot sequence number & VARCHAR2(34) \\
\hline 3 & PREV_SIT_CN & Previous site tree sequence number & VARCHAR2(34) \\
\hline 4 & INVYR & Inventory year & NUMBER(4) \\
\hline 5 & STATECD & State code & NUMBER(4) \\
\hline 6 & UNITCD & Survey unit code & NUMBER(2) \\
\hline 7 & COUNTYCD & County code & NUMBER(3) \\
\hline 8 & PLOT & Phase 2 plot number & NUMBER(5) \\
\hline 9 & CONDID & Condition class number & NUMBER(1) \\
\hline 10 & TREE & Tree number & NUMBER(9) \\
\hline 11 & SPCD & Species code & NUMBER \\
\hline 12 & DIA & Diameter & $\operatorname{NUMBER}(5,2)$ \\
\hline 13 & HT & Total height & NUMBER(3) \\
\hline 14 & AGEDIA & Tree age at diameter & NUMBER(3) \\
\hline 15 & SPGRPCD & Species group code & NUMBER(2) \\
\hline 16 & SITREE & Site index for the tree & NUMBER(3) \\
\hline 17 & SIBASE & Site index base age & NUMBER(3) \\
\hline 18 & SUBP & Subplot number & NUMBER(3) \\
\hline 19 & AZIMUTH & Azimuth & NUMBER(3) \\
\hline 20 & DIST & Horizontal distance & $\operatorname{NUMBER}(4,1)$ \\
\hline 21 & METHOD & Site tree method code & NUMBER(2) \\
\hline 22 & SITREE_EST & Estimated site index for the tree & NUMBER(3) \\
\hline 23 & VALIDCD & Validity code & NUMBER(1) \\
\hline 24 & CONDLIST & Condition class list & NUMBER(4) \\
\hline 25 & CREATED_BY & Created by & VARCHAR2(30) \\
\hline 26 & CREATED_DATE & Created date & DATE \\
\hline 27 & CREATED_IN_INSTANCE & Created in instance & VARCHAR2(6) \\
\hline 28 & MODIFIED_BY & Modified by & VARCHAR2(30) \\
\hline 29 & MODIFIED_DATE & Modified date & DATE \\
\hline 30 & MODIFIED_IN_INSTANCE & Modified in instance & VARCHAR2(6) \\
\hline 31 & CYCLE & Inventory cycle number & NUMBER(2) \\
\hline 32 & SUBCYCLE & Inventory subcycle number & NUMBER(2) \\
\hline
\end{tabular}

\begin{tabular}{|l|l|l|l|}
\hline Type of key & Column(s) order & Tables to link & Abbreviated notation \\
\hline Primary & (CN) & N/A & SIT_PK \\
\hline Unique & (PLT_CN, CONDID, TREE) & N/A & SIT_UK \\
\hline Natural & $\begin{array}{l}\text { (STATECD, INVYR, } \\
\text { UNITCD, COUNTYCD, } \\
\text { PLOT, CONDID, TREE) }\end{array}$ & N/A & SIT_NAT_I \\
& & \\
\hline
\end{tabular}




\begin{tabular}{|l|l|l|l|}
\hline Type of key & Column(s) order & Tables to link & Abbreviated notation \\
\hline Foreign & (PLT_CN, CONDID) & SITETREE to COND & SIT_CND_FK \\
\hline & (PLT_CN) & SITETREE to PLOT & SIT_PLT_FK \\
\hline
\end{tabular}

Note: The SITETREE record may not exist for some periodic inventory data.

1. $\mathrm{CN}$

2. PLT_CN
Sequence number. A unique sequence number used to identify a site tree record.

Plot sequence number. Foreign key linking the site tree record to the plot record.

3. PREV_SIT_CN Previous site tree sequence number. Foreign key linking the site tree to the previous inventory's site tree record for this tree. Only populated for site trees from previous annual inventories.

4. INVYR

Inventory year. The year that best represents when the inventory data were collected. Under the annual inventory system, a group of plots is selected each year for sampling. The selection is based on a panel system. INVYR is the year in which the majority of plots in that group were collected (plots in the group have the same panel and, if applicable, subpanel). Under periodic inventory, a reporting inventory year was selected, usually based on the year in which the majority of the plots were collected or the mid-point of the years over which the inventory spanned. For either annual or periodic inventory, INVYR is not necessarily the same as MEASYEAR.

Exceptions:

INVYR $=9999$. INVYR is set to 9999 to distinguish Phase 3 plots taken by the western FIA work units that are "off subpanel." This is due to differences in measurement intervals between Phase 3 (measurement interval $=5$ years) and Phase 2 (measurement interval $=10$ years) plots. Only users interested in performing certain Phase 3 data analyses should access plots with this anomalous value in INVYR.

INVYR $<100$. INVYR $<100$ indicates that population estimates were derived from a pre-NIMS regional processing system and the same plot either has been or may soon be re-processed in NIMS as part of a separate evaluation. The NIMS processed copy of the plot follows the standard INVYR format. This only applies to plots collected in the South $($ SURVEY.RSCD $=33$ ) with the national design or a similar regional design (PLOT.DESIGNCD $=1$ or 220-233) that were collected when the inventory year was 1998 through 2005.

INVYR $=98$ is equivalent to 1998 but processed through regional system INVYR $=99$ is equivalent to 1999 but processed through regional system $\mathrm{INVYR}=0$ is equivalent to 2000 but processed through regional system $\mathrm{INVYR}=1$ is equivalent to 2001 but processed through regional system 
INVYR $=2$ is equivalent to 2002 but processed through regional system INVYR $=3$ is equivalent to 2003 but processed through regional system $\mathrm{INVYR}=4$ is equivalent to 2004 but processed through regional system $\mathrm{INVYR}=5$ is equivalent to 2005 but processed through regional system

5. STATECD State code. Bureau of the Census Federal Information Processing Standards (FIPS) two-digit code for each State. Refer to appendix C.

6. UNITCD Survey unit code. Forest Inventory and Analysis survey unit identification number. Survey units are usually groups of counties within each State. For periodic inventories, survey units may be made up of lands of particular owners. Refer to appendix C for codes.

7. COUNTYCD County code. The identification number for a county, parish, watershed, borough, or similar governmental unit in a State. FIPS codes from the Bureau of the Census are used. Refer to appendix $\mathrm{C}$ for codes.

8. PLOT

9. CONDID

10. TREE

11. SPCD

12. DIA

13. HT

14. AGEDIA

15. SPGRPCD
Phase 2 plot number. An identifier for a plot. Along with STATECD, INVYR, UNITCD, COUNTYCD and/or some other combinations of variables, PLOT may be used to uniquely identify a plot.

Condition class number. Unique identifying number assigned to each condition on a plot. A condition is initially defined by condition class status. Differences in reserved status, owner group, forest type, stand-size class, regeneration status, and stand density further define condition for forest land. Mapped nonforest conditions are also assigned numbers. At the time of the plot establishment, the condition class at plot center (the center of subplot 1) is usually designated as condition class 1 . Other condition classes are assigned numbers sequentially at the time each condition class is delineated. On a plot, each sampled condition class must have a unique number that can change at remeasurement to reflect new conditions on the plot.

Tree number. A number used to uniquely identify a site tree on a condition.

Species code. A standard tree species code. Refer to appendix F for codes.

Diameter. The current diameter (in inches) of the tree at the point of diameter measurement (DBH/DRC).

Total height. The total length (height) of a sample tree (in feet) from the ground to the top of the main stem.

Tree age at diameter. Age (in years) of tree at the point of diameter measurement (DBH/DRC). Age is determined by an increment sample.

Species group code. A code assigned to each tree species in order to group them for reporting purposes on presentation tables. Codes and their associated names (see REF_SPECIES_GROUP.NAME) are shown in appendix G. Individual tree species and corresponding species group codes are shown in appendix F. 
16. SITREE

17. SIBASE

18. SUBP

19. AZIMUTH

20. DIST

21. METHOD

22. SITREE_EST

23. VALIDCD
Site index for the tree. Site index is calculated for dominant and co-dominant trees using one of several methods (see METHOD). It is expressed as height in feet that the tree is expected to attain at a base- or reference age (see SIBASE). Most commonly, site index is calculated using a family of curves that show site index as a function of total length and either breast-height age or total age. The height-intercept (or growth-intercept) method is commonly used for young trees or species that produce conspicuous annual branch whorls; using this method, site index is calculated with the height growth attained for a short period (usually 3 to 5 years) after the tree has reached breast height. Neither age nor total length determination are necessary when using the height-intercept method, so one or more of those variables may be null for a site tree on which the height-intercept method was used.

Site index base age. The base age (sometimes called reference age), in years, of the site index curves used to derive site index. Base age is specific to a given family of site index curves, and is usually set close to the common rotation age or the age of culmination of mean annual increment for a species. The most commonly used base ages are $25,50,80$, and 100 years. It is possible for a given species to have different sets of site index curves in different geographic regions, and each set of curves may use a different base age.

Subplot number. (Core optional.) The number assigned to the subplot. The national plot design (PLOT.DESIGNCD $=1$ ) has subplot number values of 1 through 4. Other plot designs have various subplot number values. See PLOT.DESIGNCD and appendix B for information about plot designs. For more explanation about SUBP, contact the appropriate FIA work unit (table $6)$.

Azimuth. (Core optional.) The direction, to the nearest degree, from subplot center to the center of the base of the tree (geographic center for multistemmed woodland species). Due north is represented by 360 degrees.

Horizontal distance. (Core optional.) The horizontal distance in feet from subplot center (microplot center for saplings) to the pith at the base of the tree (geographic center for multi-stemmed woodland species).

Site tree method code. The method for determining the site index. $\begin{array}{ll}\text { Code } & \text { Description } \\ 1 & \text { Tree measurements (length, age, etc.) collected during this inventory. } \\ 2 & \text { Tree measurements (length, age, etc.) collected during a previous inventory. } \\ 3 & \text { Site index estimated either in the field or office. } \\ 4 & \text { Site index determined by the height intercept method during this inventory. }\end{array}$

Estimated site index for the tree. The estimated site index or the site index determined by the height intercept method.

Validity code. A code indicating if this site tree provided a valid result from the site index computation. Some trees collected by the field crew yield a 
negative value from the equation due to their age, height or diameter being outside the range of values for which the equation was developed.

Computational results for trees that fail are not used to estimate the site index or site productivity class for the condition. If the site calculation for this tree was successful, this attribute is set to 1.

\section{Code Description}

$0 \quad$ Tree failed in site index calculations.

1 Tree was successful in site index calculations.

24. CONDLIST Condition class list. A list of numbers indicating all of the condition classes for which the site index data for this tree can be used.

25. CREATED_BY Created by. The employee who created the record. This attribute is intentionally left blank in download files.

26. CREATED_DATE

Created date. The date the record was created. Date will be in the form DDMON-YYYY.

\section{CREATED_IN_INSTANCE}

Created in instance. The database instance in which the record was created. Each computer system has a unique database instance code and this attribute stores that information to determine on which computer the record was created.

28. MODIFIED_BY

Modified by. The employee who modified the record. This field will be blank (null) if the data have not been modified since initial creation. This attribute is intentionally left blank in download files.

29. MODIFIED_DATE

Modified date. The date the record was last modified. This field will be blank (null) if the data have not been modified since initial creation. Date will be in the form DD-MON-YYYY.

30. MODIFIED_IN_INSTANCE

Modified in instance. The database instance in which the record was modified. This field will be blank (null) if the data have not been modified since initial creation.

31. CYCLE Inventory cycle number. A number assigned to a set of plots, measured over a particular period of time from which a State estimate using all possible plots is obtained. A cycle number $>1$ does not necessarily mean that 
FIA Database Description and Users Manual for Phase 2, version 4.0

Chapter 3. Site Tree Table

information for previous cycles resides in the database. A cycle is relevant for periodic and annual inventories.

32. SUBCYCLE Inventory subcycle number. For an annual inventory that takes $n$ years to measure all plots, subcycle shows in which of the $n$ years of the cycle the data were measured. Subcycle is 0 for a periodic inventory. Subcycle 99 may be used for plots that are not included in the estimation process. 
Boundary Table (Oracle table name is BOUNDARY)

\begin{tabular}{|c|c|c|c|}
\hline & Column name & Descriptive name & Oracle data type \\
\hline 1 & $\mathrm{CN}$ & Sequence number & VARCHAR2(34) \\
\hline 2 & PLT_CN & Plot sequence number & VARCHAR2(34) \\
\hline 3 & INVYR & Inventory year & NUMBER(4) \\
\hline 4 & STATECD & State code & NUMBER(4) \\
\hline 5 & UNITCD & Survey unit code & NUMBER(2) \\
\hline 6 & COUNTYCD & County code & NUMBER(3) \\
\hline 7 & PLOT & Phase 2 plot number & NUMBER(5) \\
\hline 8 & SUBP & Subplot number & NUMBER(3) \\
\hline 9 & SUBPTYP & Plot type code & NUMBER(1) \\
\hline 10 & BNDCHG & Boundary change code & NUMBER(1) \\
\hline 11 & CONTRAST & Contrasting condition & NUMBER(1) \\
\hline 12 & AZMLEFT & Left azimuth & NUMBER(3) \\
\hline 13 & AZMCORN & Corner azimuth & NUMBER(3) \\
\hline 14 & DISTCORN & Corner distance & NUMBER(3) \\
\hline 15 & AZMRIGHT & Right azimuth & NUMBER(3) \\
\hline 16 & CYCLE & Inventory cycle number & NUMBER(2) \\
\hline 17 & SUBCYCLE & Inventory subcycle number & NUMBER(2) \\
\hline 18 & CREATED_BY & Created by & VARCHAR2(30) \\
\hline 19 & CREATED_DATE & Created date & DATE \\
\hline 20 & CREATED_IN_INSTANCE & Created in instance & VARCHAR2(6) \\
\hline 21 & MODIFIED_BY & Modified by & VARCHAR2(30) \\
\hline 22 & MODIFIED_DATE & Modified date & DATE \\
\hline 23 & MODIFIED_IN_INSTANCE & Modified in instance & VARCHAR2(6) \\
\hline
\end{tabular}

\begin{tabular}{|l|l|l|l|}
\hline Type of key & Column(s) order & Tables to link & Abbreviated notation \\
\hline Primary & (CN) & N/A & BND_PK \\
\hline Unique & $\begin{array}{l}\text { (PLT_CN, SUBP, } \\
\text { SUBPTYP, AZMLEFT, } \\
\text { AZMRIGHT) }\end{array}$ & N/A & BND_UK \\
\hline Natural & $\begin{array}{l}\text { (STATECD, INVYR, } \\
\text { UNITCD, COUNTYCD, } \\
\text { PLOT, SUBP, SUBPTYP, } \\
\text { AZMLEFT, AZMRIGHT) }\end{array}$ & N/A & BND_NAT_I \\
\hline Foreign & (PLT_CN) & BOUNDARY to PLOT & BND_PLT_FK \\
\hline
\end{tabular}

Note: The BOUNDARY record may not exist for some periodic inventory data.

1. CN Sequence number. A unique sequence number used to identify a boundary record. 


\section{PLT_CN}

3. INVYR
Plot sequence number. Foreign key linking the boundary record to the plot record.

Inventory year. The year that best represents when the inventory data were collected. Under the annual inventory system, a group of plots is selected each year for sampling. The selection is based on a panel system. INVYR is the year in which the majority of plots in that group were collected (plots in the group have the same panel and, if applicable, subpanel). Under periodic inventory, a reporting inventory year was selected, usually based on the year in which the majority of the plots were collected or the mid-point of the years over which the inventory spanned. For either annual or periodic inventory, INVYR is not necessarily the same as MEASYEAR.

Exceptions:

INVYR $=9999$. INVYR is set to 9999 to distinguish Phase 3 plots taken by the western FIA work units that are "off subpanel." This is due to differences in measurement intervals between Phase 3 (measurement interval $=5$ years) and Phase 2 (measurement interval $=10$ years) plots. Only users interested in performing certain Phase 3 data analyses should access plots with this anomalous value in INVYR.

INVYR $<100$. INVYR $<100$ indicates that population estimates were derived from a pre-NIMS regional processing system and the same plot either has been or may soon be re-processed in NIMS as part of a separate evaluation. The NIMS processed copy of the plot follows the standard INVYR format. This only applies to plots collected in the South (SURVEY.RSCD = 33) with the national design or a similar regional design (PLOT.DESIGNCD $=1$ or 220-233) that were collected when the inventory year was 1998 through 2005 .

$\mathrm{INVYR}=98$ is equivalent to 1998 but processed through regional system INVYR $=99$ is equivalent to 1999 but processed through regional system INVYR $=0$ is equivalent to 2000 but processed through regional system $\mathrm{INVYR}=1$ is equivalent to 2001 but processed through regional system $\mathrm{INVYR}=2$ is equivalent to 2002 but processed through regional system INVYR $=3$ is equivalent to 2003 but processed through regional system INVYR $=4$ is equivalent to 2004 but processed through regional system INVYR $=5$ is equivalent to 2005 but processed through regional system

4. STATECD State code. Bureau of the Census Federal Information Processing Standards (FIPS) two-digit code for each State. Refer to appendix C.

5. UNITCD Survey unit code. Forest Inventory and Analysis survey unit identification number. Survey units are usually groups of counties within each State. For periodic inventories, survey units may be made up of lands of particular owners. Refer to appendix $\mathrm{C}$ for codes. 
6. COUNTYCD County code. The identification number for a county, parish, watershed, borough, or similar governmental unit in a State. FIPS codes from the Bureau of the Census are used. Refer to appendix $\mathrm{C}$ for codes.

7. PLOT

8. SUBP

9. SUBPTYP

10. BNDCHG

11. CONTRAST

12. AZMLEFT

13. AZMCORN

14. DISTCORN
Phase 2 plot number. An identifier for a plot. Along with STATECD, UNITCD, INVYR, COUNTYCD and/or some other combinations of variables, PLOT may be used to uniquely identify a plot.

Subplot number. The number assigned to the subplot. The national plot design (PLOT.DESIGNCD = 1) has subplot number values of 1 through 4 . Other plot designs have various subplot number values. See PLOT.DESIGNCD and appendix B for information about plot designs. For more explanation about SUBP, contact the appropriate FIA work unit.

Plot type code. Specifies whether the boundary data are for a subplot, microplot, or macroplot.

\section{Code Description \\ $1 \quad$ Subplot boundary \\ $2 \quad$ Microplot boundary \\ 3 Macroplot boundary}

Boundary change code. A code indicating the relationship between previously recorded and current boundary information. Set to blank (null) for new plots (PLOT.KINDCD $=1$ or 3 ).

\footnotetext{
Code Description

$0 \quad$ No change - boundary is the same as indicated on plot map by previous crew.

1 New boundary, or boundary data have been changed to reflect an actual on-the-

ground physical change resulting in a difference from the boundaries recorded.

2 Boundary has been changed to correct an error from a previous crew.

3 Boundary has been changed to reflect a change in variable definition.
}

Contrasting condition. The condition class number of the condition class that contrasts with the condition class located at the subplot center (for boundaries on the subplot or macroplot) or at the microplot center (for boundaries on the microplot), e.g., the condition class present on the other side of the boundary.

Left azimuth. The azimuth, to the nearest degree, from the subplot, microplot, or macroplot plot center to the farthest left point (facing the contrasting condition class) where the boundary intersects the subplot, microplot, or macroplot plot circumference.

Corner azimuth. The azimuth, to the nearest degree, from the subplot, microplot, or macroplot plot center to a corner or curve in a boundary. If a boundary is best described by a straight line between the two circumference points, then 000 is recorded for AZMCORN.

Corner distance. The horizontal distance, to the nearest 1 foot, from the subplot, microplot, or macroplot plot center to the boundary corner point. 
Blank (null) when AZMCORN = 000; populated when BOUNDARY.AZMCORN $>000$.

15. AZMRIGHT Right azimuth. The azimuth, to the nearest degree, from subplot, microplot, or macroplot plot center to the farthest right point (facing the contrasting condition) where the boundary intersects the subplot, microplot, or macroplot plot circumference.

16. CYCLE Inventory cycle number. A number assigned to a set of plots, measured over a particular period of time from which a State estimate using all possible plots is obtained. A cycle number $>1$ does not necessarily mean that information for previous cycles resides in the database. A cycle is relevant for periodic and annual inventories.

17. SUBCYCLE Inventory subcycle number. For an annual inventory that takes $\mathrm{n}$ years to measure all plots, subcycle shows in which of the $n$ years of the cycle the data were measured. Subcycle is 0 for a periodic inventory. Subcycle 99 may be used for plots that are not included in the estimation process.

18. CREATED_BY Created by. The employee who created the record. This attribute is intentionally left blank in download files.

19. CREATED_DATE

Created date. The date the record was created. Date will be in the form DDMON-YYYY.

20. CREATED_IN_INSTANCE

Created in instance. The database instance in which the record was created. Each computer system has a unique database instance code and this attribute stores that information to determine on which computer the record was created.

21. MODIFIED_BY

Modified by. The employee who modified the record. This field will be blank (null) if the data have not been modified since initial creation. This attribute is intentionally left blank in download files.

22. MODIFIED_DATE

Modified date. The date the record was last modified. This field will be blank (null) if the data have not been modified since initial creation. Date will be in the form DD-MON-YYYY. 


\section{MODIFIED IN INSTANCE}

Modified in instance. The database instance in which the record was modified. This field will be blank (null) if the data have not been modified since initial creation. 
FIA Database Description and Users Manual for Phase 2, version 4.0

Chapter 3. Subplot Condition Change Matrix Table

Subplot Condition Change Matrix (Oracle table name is SUBP_COND_CHNG_MTRX)

\begin{tabular}{|l|l|l|l|}
\hline & Column name & Descriptive name & Oracle data type \\
\hline 1 & CN & Sequence number & VARCHAR2(34) \\
\hline 2 & STATECD & State code & NUMBER(4) \\
\hline 3 & SUBP & Subplot number & NUMBER(1) \\
\hline 4 & SUBPTYP & Subplot type & NUMBER(1) \\
\hline 5 & PLT_CN & Plot sequence number & VARCHAR2(34) \\
\hline 6 & CONDID & Condition class number & NUMBER(1) \\
\hline 7 & PREV_PLT_CN & Previous plot sequence number & VARCHAR2(34) \\
\hline 8 & PREVCOND & Previous condition class number & NUMBER(1) \\
\hline 9 & SUBPTYP_PROP_CHNG & $\begin{array}{l}\text { Percent change of subplot condition } \\
\text { between previous to current inventory }\end{array}$ & NUMBER(5,4) \\
\hline 10 & CREATED_BY & Created by & VARCHAR2(30) \\
\hline 11 & CREATED_DATE & Created date & DATE \\
\hline 12 & CREATED_IN_INSTANCE & Created in instance & VARCHAR2(6) \\
\hline 13 & MODIFIED_BY & Modified by & VARCHAR2(30) \\
\hline 14 & MODIFIED_DATE & Modified date & DATE \\
\hline 15 & MODIFIED_IN_INSTANCE & Modified in instance & VARCHAR2(6) \\
\hline
\end{tabular}

\begin{tabular}{|l|l|l|l|}
\hline Type of key & Column(s) order & Tables to link & Abbreviated notation \\
\hline Primary & (CN) & N/A & CMX_PK \\
\hline Unique & $\begin{array}{l}\text { (PLT_CN, PREV_PLT_CN, } \\
\text { SUBP, SUBPTYP, } \\
\text { CONDID, PREVCOND) }\end{array}$ & CMX_UK \\
\hline Foreign & (PREV_PLT_CN) & $\begin{array}{l}\text { SUBP_COND_CHNG_MTRX } \\
\text { to PLOT }\end{array}$ & CMX_PLT_FK \\
\cline { 2 - 4 } & (PLT_CN) & $\begin{array}{l}\text { SUBP_COND_CHNG_MTRX } \\
\text { to PLOT }\end{array}$ & CMX_PLT_FK2 \\
\hline
\end{tabular}

This table contains information about the mix of current and previous conditions that occupy the same area on the subplot. Figure 5 provides an illustration of how the information in this table is derived using data from two points in time that is stored in the BOUNDARY and COND tables. 

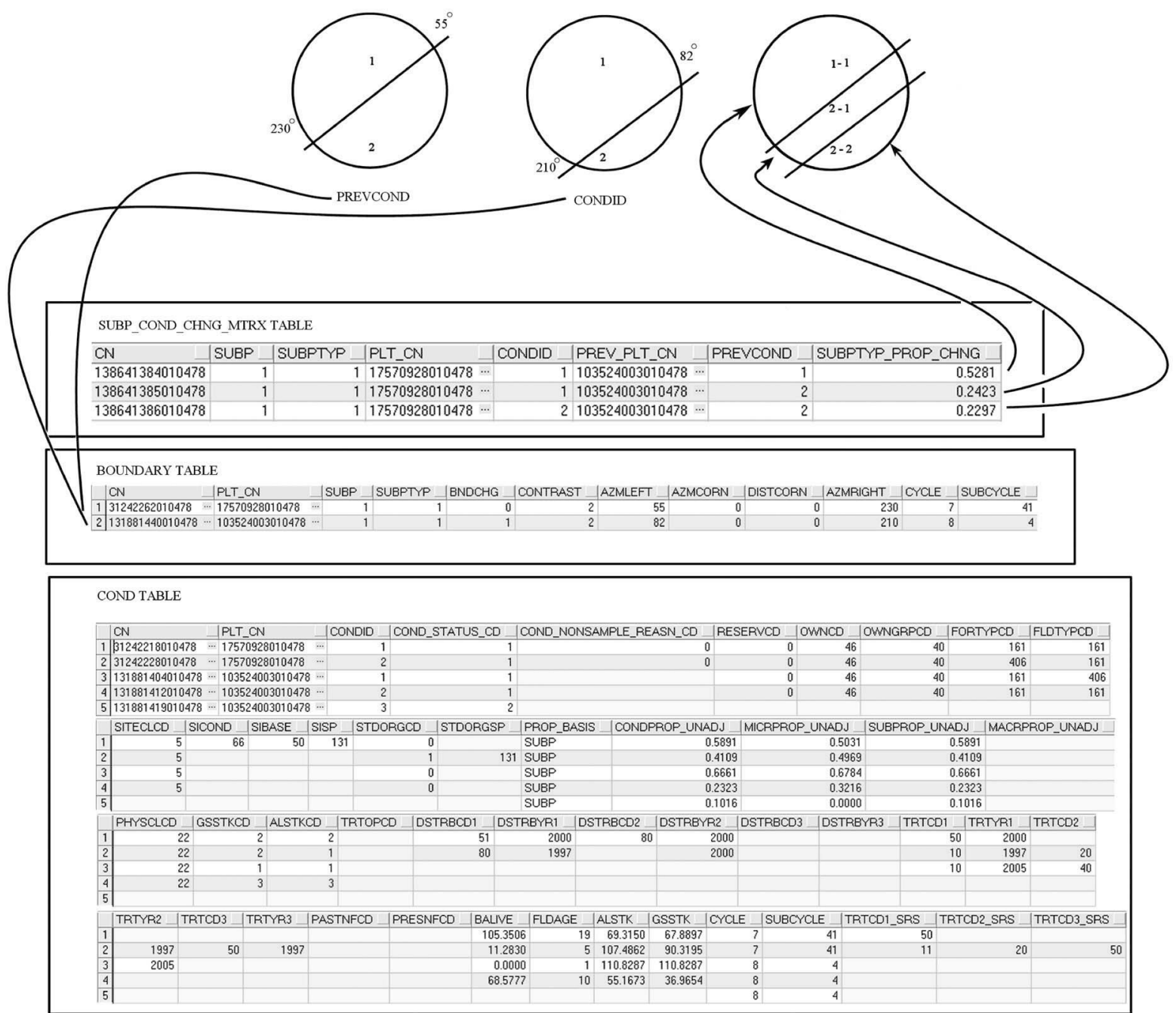

Figure 5. Illustration of the SUBP_COND_CHNG_MTRX table function

1. CN Sequence number. A unique sequence number used to identify a change matrix table record.

2. STATECD States code. Bureau of the Census Federal Information Processing Standards (FIPS) two-digit code for each State. Refer to appendix C.

3. SUBP Subplot number. The number assigned to the subplot. The national plot design (PLOT.DESIGNCD = 1) has subplot number values of 1 through 4. Other plot designs have various subplot number values. 
FIA Database Description and Users Manual for Phase 2, version 4.0

Chapter 3. Subplot Condition Change Matrix Table

4. SUBPTYP Plot type code. Specifies whether the record is for a subplot, microplot, or macroplot.

$\begin{array}{ll}\text { Code } & \begin{array}{l}\text { Description } \\ 1\end{array} \\ \text { Subplot } \\ 2 & \text { Microplot } \\ 3 & \text { Macroplot }\end{array}$

5. PLT_CN Plot sequence number. The foreign key linking the SUBP_COND_CHNG_MTRX record to the PLOT record for the current inventory.

6. CONDID Condition class number. Unique identifying number assigned to each condition on a plot.

7. PREV_PLT_CN

Previous plot sequence number. The foreign key linking the SUBP_COND_CHNG_MTRX record to the PLOT record from the previous inventory.

8. PREVCOND Previous condition class number. Identifies the condition class number from the previous inventory.

9. SUBPTYP_PROP_CHNG

Subplot type proportion change. The unadjusted proportion of the subplot that is in the same geographic area condition for both the previous and current inventory. The sum of all subplot type change proportions for an individual plot equals 4 for each plot type (microplot, subplot, and/or macroplot). Divide the result by 4 to obtain change at the plot level.

10. CREATED_BY Created by. The employee who created the record. This attribute is intentionally left blank in download files.

11. CREATED_DATE

Created date. The date the record was created. Date will be in the form DDMON-YYYY.

\section{CREATED_IN_INSTANCE}

Created in instance. The database instance in which the record was created. Each computer system has a unique database instance code and this attribute stores that information to determine on which computer the record was created. 
13. MODIFIED_BY

Modified by. The employee who modified the record. This field will be blank (null) if the data have not been modified since initial creation. This attribute is intentionally left blank in download files.

14. MODIFIED_DATE

Modified date. The date the record was last modified. This field will be blank (null) if the data have not been modified since initial creation. Date will be in the form DD-MON-YYYY.

\section{MODIFIED IN INSTANCE}

Modified in instance. The database instance in which the record was modified. This field will be blank (null) if the data have not been modified since initial creation. 
Tree Regional Biomass Table (Oracle table name is TREE_REGIONAL_BIOMASS)

\begin{tabular}{|l|l|l|l|}
\hline & Column name & Descriptive name & Oracle data type \\
\hline 1 & TRE_CN & Tree sequence number & VARCHAR2(34) \\
\hline 2 & STATECD & State code & NUMBER(4) \\
\hline 3 & REGIONAL_DRYBIOT & $\begin{array}{l}\text { Regional total tree biomass oven-dry } \\
\text { weight }\end{array}$ & NUMBER(13,6) \\
\hline 4 & REGIONAL_DRYBIOM & $\begin{array}{l}\text { Regional merchantable stem biomass } \\
\text { oven-dry weight }\end{array}$ & NUMBER(13,6) \\
\hline 5 & CREATED_BY & Created by & VARCHAR2(30) \\
\hline 6 & CREATED_DATE & Created date & DATE \\
\hline 7 & CREATED_IN_INSTANCE & Created in instance & VARCHAR2(6) \\
\hline 8 & MODIFIED_BY & Modified by & VARCHAR2(30) \\
\hline 9 & MODIFIED_DATE & Modified date & DATE \\
\hline 10 & MODIFIED_IN_INSTANCE & Modified in instance & VARCHAR2(6) \\
\hline
\end{tabular}

\begin{tabular}{|l|l|l|l|}
\hline Type of key & Column(s) order & Tables to link & Abbreviated notation \\
\hline Primary & (TRE_CN) & N/A & TRB_PK \\
\hline Foreign & (TRE_CN) & $\begin{array}{l}\text { TREE_REGIONAL_BIOMASS to } \\
\text { TREE }\end{array}$ & TRB_TRE_FK \\
\hline
\end{tabular}

This table provides biomass estimates of live and dead trees 1 inch in diameter and larger using equations and methods that vary by FIA work unit. Both REGIONAL_DRYBIOT and REGIONAL_DRYBIOM preserve the original data and computation procedures used by FIA work units to calculate DRYBIOT and DRYBIOM in previous versions of FIADB. Users should be aware that for some FIA work units, these biomass estimates may not include bark. Biomass estimates in this table will differ from biomass estimates found on the TREE table records because components such as bark, stump, and top (with branches) are now being stored on the TREE table are derived by applying ratios to stem biomass. The TREE table will be the source of biomass data used in official reporting. However, the TREE_REGIONAL_BIOMASS table contains valuable information for generating biomass estimates that match earlier published reports.

1. TRE_CN Tree sequence number. Foreign key linking the tree regional biomass record to the tree record.

2. STATECD States code. Bureau of the Census Federal Information Processing Standards (FIPS) two-digit code for each State. Refer to appendix C.

\section{REGIONAL_DRYBIOT}

Regional dry total biomass (pounds). The total aboveground biomass of a sample tree 1.0 inch diameter or larger, including all tops and limbs (but excluding foliage). This is a per tree value and must be multiplied by TPA_UNADJ to obtain per acre information. Calculated in oven-dry pounds per tree. This field should have an entry if DIA is 1.0 inch or larger, regardless of STATUSCD or TREECLCD; zero otherwise. For dead or cut trees, this number represents the biomass at the time of death or last 
measurement. Because total biomass has been calculated differently among FIA work units, contact the appropriate FIA work units (see table 6) for information on how biomass was estimated and whether bark was included.

\section{REGIONAL_DRYBIOM}

Regional dry merchantable stem biomass (pounds). The total gross biomass (including bark) of a tree 5.0 inches DBH or larger from a 1-foot stump to a minimum 4-inch top diameter of the central stem. This is a per tree value and must be multiplied by TPA_UNADJ to obtain per acre information. Calculated in oven-dry pounds per tree. This field should have an entry if DIA is 5.0 inches or larger, regardless of STATUSCD or TREECLCD; zero otherwise. For dead or cut trees, this number represents the biomass at the time of death or last measurement. Because total biomass has been calculated differently among FIA work units, contact the appropriate FIA work unit (see table 6) for information on how biomass was estimated and whether bark was actually included.

5. CREATED_BY Created by. The employee who created the record. This attribute is intentionally left blank in download files.

6. CREATED_DATE

Created date. The date the record was created. Date will be in the form DDMON-YYYY.

\section{CREATED_IN_INSTANCE}

Created in instance. The database instance in which the record was created. Each computer system has a unique database instance code and this attribute stores that information to determine on which computer the record was created.

8. MODIFIED_BY

Modified by. The employee who modified the record. This field will be blank (null) if the data have not been modified since initial creation. This attribute is intentionally left blank in download files.

9. MODIFIED_DATE

Modified date. The date the record was last modified. This field will be blank (null) if the data have not been modified since initial creation. Date will be in the form DD-MON-YYYY.

\section{MODIFIED_IN_INSTANCE}

Modified in instance. The database instance in which the record was modified. This field will be blank (null) if the data have not been modified since initial creation. 
FIA Database Description and Users Manual for Phase 2, version 4.0

Chapter 3. Population Estimation Unit Table

Population Estimation Unit Table (Oracle table name is POP_ESTN_UNIT)

\begin{tabular}{|c|c|c|c|}
\hline & Column name & Descriptive name & Oracle data type \\
\hline 1 & $\mathrm{CN}$ & Sequence number & VARCHAR2(34) \\
\hline 2 & EVAL_CN & Evaluation sequence number & VARCHAR2(34) \\
\hline 3 & RSCD & Region or station code & NUMBER(2) \\
\hline 4 & EVALID & Evaluation identifier & NUMBER(6) \\
\hline 5 & ESTN_UNIT & Estimation unit & NUMBER(6) \\
\hline 6 & ESTN_UNIT_DESCR & Estimation unit description & VARCHAR2(255) \\
\hline 7 & STATECD & State code & NUMBER(4) \\
\hline 8 & AREALAND_EU & Land area within the estimation unit & NUMBER(12,2) \\
\hline 9 & AREATOT_EU & Total area within the estimation unit & NUMBER(12,2) \\
\hline 10 & AREA_USED & Area used to calculate all expansion factors & NUMBER(12,2) \\
\hline 11 & AREA_SOURCE & Area source & VARCHAR2(50) \\
\hline 12 & P1PNTCNT_EU & Phase 1 point count for the estimation unit & NUMBER(12) \\
\hline 13 & P1SOURCE & Phase 1 source & VARCHAR2(30) \\
\hline 14 & CREATED_BY & Created by & VARCHAR2(30) \\
\hline 15 & CREATED_DATE & Created date & DATE \\
\hline 16 & CREATED_IN_INSTANCE & Created in instance & VARCHAR2(6) \\
\hline 17 & MODIFIED_BY & Modified by & VARCHAR2(30) \\
\hline 18 & MODIFIED_DATE & Modified date & DATE \\
\hline 19 & MODIFIED IN INSTANCE & Modified in instance & VARCHAR2(6) \\
\hline
\end{tabular}

\begin{tabular}{|l|l|l|l|}
\hline Type of key & Column(s) order & Tables to link & Abbreviated notation \\
\hline Primary & (CN) & N/A & PEU_PK \\
\hline Unique & $\begin{array}{l}\text { (RSCD, EVALID }, \\
\text { ESTN_UNIT) }\end{array}$ & N/A & PEU_UK \\
\hline Foreign & (EVAL_CN) & POP_ESTN_UNIT to POP_EVAL & PEU_PEV_FK \\
\hline
\end{tabular}

1. $\mathrm{CN}$

2. EVAL_CN

3. RSCD
Sequence number. A unique sequence number used to identify an estimation unit record.

Evaluation sequence number. Foreign key linking the estimation unit record to the evaluation record.

Region or Station Code. Identification number of the Forest Service National Forest System Region or Station (FIA work unit) that provided the inventory data (see appendix $\mathrm{C}$ for more information).

\footnotetext{
Code Description

$22 \quad$ Rocky Mountain Research Station (RMRS)

23 North Central Research Station (NCRS)

24 Northeastern Research Station (NERS)

26 Pacific Northwest Research Station (PNWRS)

27 Pacific Northwest Research Station (PNWRS)-Alaska

33 Southern Research Station (SRS)
} 
4. EVALID Evaluation identifier. The EVALID code and the RSCD code together uniquely identify a set of field plots and associated Phase 1 summary data used to make population estimates.

5. ESTN_UNIT Estimation unit. The specific geographic area that is stratified. Estimation units are often determined by a combination of geographical boundaries, sampling intensity and ownership.

6. ESTN_UNIT_DESCR

Estimation unit description. A description of the estimation unit (e.g., name of the county).

7. STATECD State code. Bureau of the Census Federal Information Processing Standards (FIPS) two-digit code for each State. Refer to appendix C. For evaluations that do not conform to the boundaries of a single State the value of

STATECD should be set to 99 .

8. AREALAND_EU

Land area within the estimation unit. The area of land in acres enclosed by the estimation unit. Census water is excluded.

9. AREATOT_EU

Total area within the estimation unit. This includes land and census water enclosed by the estimation unit.

10. AREA_USED Area used to calculate all expansion factors. Is equivalent to AREATOT_EU if a station estimates all area, including census water; and to AREALAND_EU if a station estimates land area only.

11. AREA_SOURCE

Area Source. Identifies the source of the area numbers. Usually the area source is either the U.S. Census Bureau or area estimates based on pixel counts. Example values are "US CENSUS 2000" or "PIXEL COUNT."

12. P1PNTCNT_EU

Phase 1 point count for the estimation unit. For remotely sensed data this will be the total number of pixels in the estimation unit.

13. P1SOURCE Phase 1 source. Identifies the Phase 1 data source used for this stratification. Examples are NLCD and AERIAL PHOTOS.

14. CREATED_BY Created by. The employee who created the record. This attribute is intentionally left blank in download files. 
FIA Database Description and Users Manual for Phase 2, version 4.0

Chapter 3. Population Estimation Unit Table

\section{CREATED DATE}

Created date. The date the record was created. Date will be in the form DDMON-YYYY.

16. CREATED_IN_INSTANCE

Created in instance. The database instance in which the record was created. Each computer system has a unique database instance code and this attribute stores that information to determine on which computer the record was created.

17. MODIFIED_BY

Modified by. The employee who modified the record. This field will be blank (null) if the data have not been modified since initial creation. This attribute is intentionally left blank in download files.

18. MODIFIED_DATE

Modified date. The date the record was last modified. This field will be blank (null) if the data have not been modified since initial creation. Date will be in the form DD-MON-YYYY

\section{MODIFIED_IN_INSTANCE}

Modified in instance. The database instance in which the record was modified. This field will be blank (null) if the data have not been modified since initial creation. 
Population Evaluation Table (Oracle table name is POP EVAL)

\begin{tabular}{|l|l|l|l|}
\hline & Column name & Descriptive name & Oracle data type \\
\hline 1 & CN & Sequence number & VARCHAR2(34) \\
\hline 2 & RSCD & Region or Station code & NUMBER(2) \\
\hline 4 & EVALID & Evaluation identifier & NUMBER(6) \\
\hline 5 & STATECD & Evaluation description & VARCHAR2(255) \\
\hline 6 & LOCATION_NM & State code & NUMBER(4) \\
\hline 7 & REPORT_YEAR_NM & Location name & Report year name \\
\hline 8 & NOTES & Notes & VARCHAR2(255) \\
\hline 9 & CREATED_BY & Created by & VARCHAR2(2000) \\
\hline 10 & CREATED_DATE & Created date & VARCHAR2(30) \\
\hline 11 & CREATED_IN_INSTANCE & Created in instance & DATE \\
\hline 12 & MODIFIED_BY & Modified by & VARCHAR2(6) \\
\hline 13 & MODIFIED_DATE & Modified date & VARCHAR2(30) \\
\hline 14 & MODIFIED_IN_INSTANCE & Modified in instance & DATE \\
\hline 15 & START_INVYR & Start inventory year & NARCHAR2(6) \\
\hline 16 & END_INVYR & End inventory year & NUMBER(4) \\
\hline
\end{tabular}

\begin{tabular}{|l|l|l|l|}
\hline Type of key & Column(s) order & Tables to link & Abbreviated notation \\
\hline Primary & $(\mathrm{CN})$ & N/A & PEV_PK \\
\hline Unique & (RSCD, EVALID) & N/A & PEV_UK \\
\hline
\end{tabular}

1. CN Sequence number. A unique sequence number used to identify an evaluation record.

2. RSCD Region or Station Code. Identification number of the Forest Service National Forest System Region or Station (FIA work unit) that provided the inventory data (see appendix C for more information).

$\begin{array}{ll}\text { Code } & \text { Description } \\ 22 & \text { Rocky Mountain Research Station (RMRS) } \\ 23 & \text { North Central Research Station (NCRS) } \\ 24 & \text { Northeastern Research Station (NERS) } \\ 26 & \text { Pacific Northwest Research Station (PNWRS) } \\ 27 & \text { Pacific Northwest Research Station (PNWRS)-Alaska } \\ 33 & \text { Southern Research Station (SRS) }\end{array}$

3. EVALID Evaluation identifier. The EVALID code and the RSCD code together uniquely identify a set of field plots and associated Phase 1 summary data used to make population estimates.

4. EVAL_DESCR Evaluation description. A description of the area being evaluated (often a State), the time period of the evaluation, and the type of estimates the 
FIA Database Description and Users Manual for Phase 2, version 4.0

Chapter 3. Population Evaluation Table

evaluation can be used to compute (i.e., all lands, area, volume, growth, removals, and mortality).

5. STATECD State code. Bureau of the Census Federal Information Processing Standards (FIPS) two-digit code for each State. Refer to appendix C.

6. LOCATION_NM

Location name. Geographic area as it would appear in the title of a report.

7. REPORT_YEAR_NM

Report year name. The data collection years that would appear in the title of a report.

8. NOTES Notes. Notes should include information about the stratification method. May include citation for any publications that used the evaluation.

9. CREATED_BY Created by. The employee who created the record. This attribute is intentionally left blank in download files.

10. CREATED_DATE

Created date. The date the record was created. Date will be in the form DDMON-YYYY.

\section{CREATED_IN_INSTANCE}

Created in instance. The database instance in which the record was created. Each computer system has a unique database instance code and this attribute stores that information to determine on which computer the record was created.

12. MODIFIED_BY

Modified by. The employee who modified the record. This field will be blank (null) if the data have not been modified since initial creation. This attribute is intentionally left blank in download files.

13. MODIFIED_DATE

Modified date The date the record was last modified. This field will be blank (null) if the data have not been modified since initial creation. Date will be in the form DD-MON-YYYY.

\section{MODIFIED_IN_INSTANCE}

Modified in instance. The database instance in which the record was modified. This field will be blank (null) if the data have not been modified since initial creation. 


\section{START_INVYR}

Start inventory year. The starting year for the data included in the evaluation.

16. END_INVYR End inventory year. The ending year for the data included in the evaluation. 
FIA Database Description and Users Manual for Phase 2, version 4.0

Chapter 3. Population Evaluation Attribute Table

Population Evaluation Attribute Table (Oracle table name is POP_EVAL_ATTRIBUTE)

\begin{tabular}{|l|l|l|l|}
\hline & Column name & Descriptive name & Oracle data type \\
\hline 1 & CN & Sequence number & VARCHAR2(34) \\
\hline 2 & EVAL_CN & Evaluation sequence number & VARCHAR2(34) \\
\hline 3 & ATTRIBUTE_NBR & Attribute number & NUMBER(3) \\
\hline 4 & STATECD & State code & NUMBER(4) \\
\hline 5 & CREATED_BY & Created by & VARCHAR2(30) \\
\hline 6 & CREATED_DATE & Created date & DATE \\
\hline 7 & CREATED_IN_INSTANCE & Created in instance & VARCHAR2(6) \\
\hline 8 & MODIFIED_BY & Modified by & VARCHAR2(30) \\
\hline 9 & MODIFIED_DATE & Modified date & DATE \\
\hline 10 & MODIFIED_IN_INSTANCE & Modified in instance & VARCHAR2(6) \\
\hline
\end{tabular}

\begin{tabular}{|l|l|l|l|}
\hline Type of key & Column(s) order & Tables to link & Abbreviated notation \\
\hline Unique & $\begin{array}{l}\text { (EVAL_CN, } \\
\text { ATTRIBUTE_NBR) }\end{array}$ & N/A & PEA_UK \\
\hline Foreign & $\begin{array}{l}\text { (ATTRIBUTE_NBR) } \\
\text { POP_EVAL_ATTRIBUTE to } \\
\text { REF_POP_ATTRIBUTE }\end{array}$ & PEA_PAE_FK \\
\hline & $\begin{array}{l}\text { (EVAL_CN) } \\
\text { POP_EVAL_ATTRIBUTE to }\end{array}$ & PEA_PEV_FK \\
\hline
\end{tabular}

1. $\mathrm{CN}$

Sequence number. A unique sequence number used to identify an evaluation attribute record.

2. EVAL_CN Evaluation sequence number. Foreign key linking the population evaluation attribute record to the population evaluation record.

3. ATTRIBUTE_NBR

Attribute number. Foreign key linking the population evaluation attribute record to the reference population attribute record.

4. STATECD State code. Bureau of the Census Federal Information Processing Standards (FIPS) two-digit code for each State. Refer to appendix C.

5. CREATED_BY Created by. The employee who created the record. This attribute is intentionally left blank in download files.

6. CREATED_DATE

Created date. The date the record was created. Date will be in the form DDMON-YYYY. 


\section{CREATED_IN_INSTANCE}

Created in instance. The database instance in which the record was created. Each computer system has a unique database instance code and this attribute stores that information to determine on which computer the record was created.

8. MODIFIED_BY

Modified by. The employee who modified the record. This field will be blank (null) if the data have not been modified since initial creation. This attribute is intentionally left blank in download files.

\section{MODIFIED DATE}

Modified date. The date the record was last modified. This field will be blank (null) if the data have not been modified since initial creation. Date will be in the form DD-MON-YYYY.

\section{MODIFIED_IN_INSTANCE}

Modified in instance. The database instance in which the record was modified. This field will be blank (null) if the data have not been modified since initial creation. 
DRAFT FIA Database Description and Users Manual for Phase 2, version 4.0

Chapter 3. Population Evaluation Group Table

Population Evaluation Group Table (Oracle table name is POP_EVAL_GRP)

\begin{tabular}{|c|c|c|c|}
\hline & Column name & Descriptive name & Oracle data type \\
\hline 1 & $\mathrm{CN}$ & Sequence number & VARCHAR2(34) \\
\hline 2 & EVAL_CN_FOR_EXPALL & $\begin{array}{l}\text { Evaluation sequence number for } \\
\text { expansions of all plots }\end{array}$ & VARCHAR2(34) \\
\hline 3 & EVAL_CN_FOR_EXPCURR & $\begin{array}{l}\text { Evaluation sequence number for } \\
\text { expansions of current area }\end{array}$ & VARCHAR2(34) \\
\hline 4 & EVAL_CN_FOR_EXPVOL & $\begin{array}{l}\text { Evaluation sequence number for } \\
\text { expansions of volume }\end{array}$ & VARCHAR2(34) \\
\hline 5 & EVAL_CN_FOR_EXPGROW & $\begin{array}{l}\text { Evaluation sequence number for } \\
\text { expansions of growth }\end{array}$ & VARCHAR2(34) \\
\hline 6 & EVAL_CN_FOR_EXPMORT & $\begin{array}{l}\text { Evaluation sequence number for } \\
\text { expansions of mortality }\end{array}$ & VARCHAR2(34) \\
\hline 7 & EVAL_CN_FOR_EXPREMV & $\begin{array}{l}\text { Evaluation sequence number for } \\
\text { expansions of removals }\end{array}$ & VARCHAR2(34) \\
\hline 8 & RSCD & Region or Station code & NUMBER(2) \\
\hline 9 & EVAL_GRP & Evaluation group & NUMBER(6) \\
\hline 10 & EVAL_GRP_DESCR & Evaluation group description & VARCHAR2(255) \\
\hline 11 & STATECD & State code & NUMBER(4) \\
\hline 12 & LAND_ONLY & Land only & VARCHAR2(1) \\
\hline 13 & CREATED_BY & Created by & VARCHAR2(30) \\
\hline 14 & CREATED_DATE & Created date & DATE \\
\hline 15 & CREATED_IN_INSTANCE & Created in instance & VARCHAR2(6) \\
\hline 16 & MODIFIED_BY & Modified by & VARCHAR2(30) \\
\hline 17 & MODIFIED_DATE & Modified date & DATE \\
\hline 18 & MODIFIED_IN_INSTANCE & Modified in instance & VARCHAR2(6) \\
\hline 19 & NOTES & Notes & VARCHAR2(2000) \\
\hline
\end{tabular}

\begin{tabular}{|l|l|l|l|}
\hline Type of key & Column(s) order & Tables to link & Abbreviated notation \\
\hline Primary & CN $)$ & N/A & PEG_PK \\
\hline Unique & RSCD, EVAL_GRP) & N/A & PEG_UK \\
\hline Foreign & (EVAL_CN_FOR_EXPALL) & $\begin{array}{l}\text { POP_EVAL_GRP to } \\
\text { POP_EVAL }\end{array}$ & PEG_PEV_FK \\
\hline & $\begin{array}{l}\text { POP_EVAL_GRP to } \\
\text { POP_EVAL }\end{array}$ & PEG_PEV_FK_2 \\
\hline & $\begin{array}{l}\text { POP_EVAL_GRP to } \\
\text { POP_EVAL }\end{array}$ & PEG_PEV_FK_3 \\
\hline & (EVAL_COR_EXPCURR) & $\begin{array}{l}\text { POP_EVAL_GRP to } \\
\text { POP_EVAL }\end{array}$ & PEG_PEV_FK_4 \\
\hline & $\begin{array}{l}\text { POP_EVAL_GRP to } \\
\text { POP_EVAL }\end{array}$ & PEG_PEV_FK_5 \\
\hline
\end{tabular}

1. $\mathrm{CN}$

Sequence number. A unique sequence number used to identify an evaluation group record. 


\section{EVAL CN FOR EXPALL}

Evaluation sequence number for expansions of all plots. This attribute links to the POP_EVAL.CN on the evaluation record. When this attribute is populated, it points to the evaluation used to estimate total area, including both sampled and nonsampled plots. Users must first obtain the correct sequence number in this attribute in order to run queries like those shown in chapter 4. This attribute will be dropped in version 5.0.

\section{EVAL_CN_FOR_EXPCURR}

Evaluation sequence number for expansions of current area. This attribute links to the POP_EVAL.CN on the evaluation record. When this attribute is populated, it points to the evaluation used to estimate total area, using only sampled plots. Users must first obtain the correct sequence number in this attribute in order to run queries like those shown in chapter 4 . This attribute will be dropped in version 5.0.

\section{EVAL_CN_FOR_EXPVOL}

Evaluation sequence number for expansions of volume. This attribute links to the POP_EVAL.CN of the evaluation record. When this attribute is populated, it points to the evaluation used to estimate volume, biomass or number of trees, based on the sampled plots within the population that qualify for volume estimates. Users must first obtain the correct sequence number in this attribute in order to run queries like those shown in chapter 4. This attribute will be dropped in version 5.0.

\section{EVAL_CN_FOR_EXPGROW}

Evaluation sequence number for expansions of growth. This attribute links to the POP_EVAL.CN of the evaluation record. When this attribute is populated, it points to the evaluation used to estimate net average annual growth, based on the remeasured plots within the population that qualify for growth estimates. Users must first obtain the correct sequence number in this attribute in order to run queries like those shown in chapter 4. This attribute will be dropped in version 5.0.

\section{EVAL_CN_FOR_EXPMORT}

Evaluation sequence number for expansions of mortality. This attribute links to the POP_EVAL.CN of the evaluation record. When this attribute is populated, it points to the evaluation used to estimate average annual mortality, based on the remeasured plots within the population that qualify for mortality estimates. Users must first obtain the correct sequence number in this attribute in order to run queries like those shown in chapter 4 . This attribute will be dropped in version 5.0. 


\section{EVAL CN FOR EXPREMV}

Evaluation sequence number for expansions of removals. This attribute links to the POP EVAL.CN of the evaluation record. When this attribute is populated, it points to the evaluation used to estimate annual removals, based on the remeasured plots within the population that qualify for removals estimates. Users must first obtain the correct sequence number in this attribute in order to run queries like those shown in chapter 4 . This attribute will be dropped in version 5.0.

8. RSCD

Region or Station Code. Identification number of the Forest Service National Forest System Region or Station (FIA work unit) that provided the inventory data (see appendix $\mathrm{C}$ for more information).

$\begin{array}{ll}\text { Code } & \text { Description } \\ 22 & \text { Rocky Mountain Research Station (RMRS) } \\ 23 & \text { North Central Research Station (NCRS) } \\ 24 & \text { Northeastern Research Station (NERS) } \\ 26 & \text { Pacific Northwest Research Station (PNWRS) } \\ 27 & \text { Pacific Northwest Research Station (PNWRS)-Alaska } \\ 33 & \text { Southern Research Station (SRS) }\end{array}$

9. EVAL GRP Evaluation group. An evaluation group identifies the evaluations that were used in producing a core set of tables. In some cases one evaluation will be used for area and volume and another evaluation for growth, removals and mortality. The value of this attribute is used to select the appropriate State and year of interest to produce a set of summary tables.

10. EVAL_GRP_DESCR

Evaluation group description. A description of the evaluation group that includes the State and range of years for the evaluation, for example, "Minnesota: 1004;2005;2006;2007;2008". This is useful to include in a summary report to clearly identify the source of the data.

11. STATECD State code. Bureau of the Census Federal Information Processing Standards (FIPS) two-digit code for each State. Refer to appendix C. For evaluations that do not conform to the boundaries of a single State the value of STATECD should be set to 99 .

12. LAND_ONLY Land only. A code indicating area used in stratifying evaluations. See POP_ESTN_UNIT.AREA_SOURCE for more information.

\section{Code Description \\ Y Only census land was used in the stratification process. \\ $\mathrm{N}$ Census land and water were used in the stratification process.}

13. CREATED_BY Created by. The employee who created the record. This attribute is intentionally left blank in download files. 
14. CREATED_DATE

Created date. The date the record was created. Date will be in the form DDMON-YYYY.

15. CREATED_IN_INSTANCE

Created in instance. The database instance in which the record was created. Each computer system has a unique database instance code and this attribute stores that information to determine on which computer the record was created.

16. MODIFIED_BY

Modified by. The employee who modified the record. This field will be blank (null) if the data have not been modified since initial creation. This attribute is intentionally left blank in download files.

17. MODIFIED_DATE

Modified date. The date the record was last modified. This field will be blank (null) if the data have not been modified since initial creation. Date will be in the form DD-MON-YYYY.

18. MODIFIED_IN_INSTANCE

Modified in instance. The database instance in which the record was modified. This field will be blank (null) if the data have not been modified since initial creation.

19. NOTES

Notes. An optional item where additional information about the evaluation group may be stored. 
FIA Database Description and Users Manual for Phase 2, version 4.0

Chapter 3. Population Evaluation Type Table

Population Evaluation Type Table (Oracle table name is POP_EVAL_TYP)

\begin{tabular}{|l|l|l|l|}
\hline & Column name & Descriptive name & Oracle data type \\
\hline 1 & EVAL_GRP_CN & Evaluation group sequence number & VARCHAR2(34) \\
\hline 2 & EVAL_CN & Evaluation sequence number & VARCHAR2(34) \\
\hline 3 & EVAL_TYP & Evaluation type & VARCHAR2(15) \\
\hline 4 & STATECD & State code & NUMBER(4) \\
\hline 5 & CREATED_BY & Created by & VARCHAR2(30) \\
\hline 6 & CREATED_DATE & Created date & DATE \\
\hline 7 & CREATED_IN_INSTANCE & Created in instance & VARCHAR2(6) \\
\hline 8 & MODIFIED_BY & Modified by & VARCHAR2(30) \\
\hline 9 & MODIFIED_DATE & Modified date & DATE \\
\hline 10 & MODIFIED_IN_INSTANCE & Modified in instance & VARCHAR2(34) \\
\hline 11 & CN & Sequence number &
\end{tabular}

\begin{tabular}{|l|l|l|l|}
\hline Type of key & Column(s) order & Tables to link & Abbreviated notation \\
\hline Primary & (CN) & N/A & PET_PK \\
\hline Unique & $\begin{array}{l}\text { (EVAL_GRP_CN, } \\
\text { EVAL_CN, EVAL_TYP) }\end{array}$ & N/A & PET_UK \\
\hline Foreign & (EVAL_GRP_CN) & $\begin{array}{l}\text { POP_EVAL_TYP to } \\
\text { POP_EVAL_GRP }\end{array}$ & PET_PEG_FK \\
\hline & (EVAL_CN) & POP_EVAL_TYP to POP_EVAL & PET_PEV_FK \\
\hline & (EVAL_TYP) & $\begin{array}{l}\text { POP_EVAL_TYP to } \\
\text { REF_POP_EVAL_TYP_DESCR }\end{array}$ & PET_PED_FK \\
\hline
\end{tabular}

1. EVAL_GRP_CN

Evaluation group sequence number. Foreign key linking the population evaluation type record to the population evaluation group record.

2. EVAL_CN Evaluation sequence number. Foreign key linking the population evaluation type record to the population evaluation record.

3. EVAL TYP Evaluation type. Describes the type of evaluation. Evaluation type is needed to generate summary reports for an inventory. For example, a specific evaluation is associated with the evaluation for volume (Expvol). At the present time, seven types of evaluations can be produced. See also the REF_POP_EVAL_TYP_DESCR table.

\section{Evaluation type values}

Expall

Expchng

Expcurr

Expgrow

Expmort

Expremv

Expvol 
4. STATECD State code. Bureau of the Census Federal Information Processing Standards (FIPS) two-digit code for each State. Refer to appendix C.

5. CREATED_BY Created by. The employee who created the record. This attribute is intentionally left blank in download files.

6. CREATED_DATE

Created date. The date the record was created. Date will be in the form DDMON-YYYY.

7. CREATED_IN_INSTANCE

Created in instance. The database instance in which the record was created. Each computer system has a unique database instance code and this attribute stores that information to determine on which computer the record was created.

8. MODIFIED_BY

Modified by. The employee who modified the record. This field will be blank (null) if the data have not been modified since initial creation. This attribute is intentionally left blank in download files.

9. MODIFIED_DATE

Modified date. The date the record was last modified. This field will be blank (null) if the data have not been modified since initial creation. Date will be in the form DD-MON-YYYY.

10. MODIFIED_IN_INSTANCE

Modified in instance. The database instance in which the record was modified. This field will be blank (null) if the data have not been modified since initial creation.

11. CN Sequence number. A unique sequence number used to identify a population evaluation type record 
DRAFT FIA Database Description and Users Manual for Phase 2, version 4.0

Chapter 3. Population Plot Stratum Assignment Table

\section{Population Plot Stratum Assignment Table (Oracle table name is} POP_PLOT_STRATUM_ASSGN)

\begin{tabular}{|l|l|l|l|}
\hline & Colum name & Descriptive name & Oracle data type \\
\hline 1 & CN & Sequence number & VARCHAR2(34) \\
\hline 2 & STRATUM_CN & Stratum sequence number & VARCHAR2(34) \\
\hline 3 & PLT_CN & Plot sequence number & VARCHAR2(34) \\
\hline 4 & STATECD & State code & NUMBER(4) \\
\hline 5 & INVYR & Inventory year & NUMBER(4) \\
\hline 6 & UNITCD & Survey unit code & NUMBER(2) \\
\hline 7 & COUNTYCD & County code & NUMBER(3) \\
\hline 8 & PLOT & Phase 2 plot number & NUMBER(5) \\
\hline 9 & RSCD & Region or Station code & NUMBER(2) \\
\hline 10 & EVALID & Evaluation identifier & NUMBER(6) \\
\hline 11 & ESTN_UNIT & Estimation unit & NUMBER(6) \\
\hline 12 & STRATUMCD & Stratum code & NUMBER(6) \\
\hline 13 & CREATED_BY & Created by & VARCHAR2(30) \\
\hline 14 & CREATED_DATE & Created date & DATE \\
\hline 15 & CREATED_IN_INSTANCE & Created in instance & VARCHAR2(6) \\
\hline 16 & MODIFIED_BY & Modified by & VARCHAR2(30) \\
\hline 17 & MODIFIED_DATE & Modified date & Dodified in instance \\
\hline 18 & MODIFIED_IN_INSTANCE & & VARCHAR2(6) \\
\hline
\end{tabular}

\begin{tabular}{|c|c|c|c|}
\hline Type of key & Column(s) order & Tables to link & Abbreviated notation \\
\hline Primary & $(\mathrm{CN})$ & N/A & PPSA PK \\
\hline \multirow[t]{2}{*}{ Unique } & $\begin{array}{l}\text { (PLT_CN, } \\
\text { STRATUM CN) }\end{array}$ & $\mathrm{N} / \mathrm{A}$ & PPSA_UK \\
\hline & $\begin{array}{l}\text { (STATECD, INVYR, } \\
\text { UNITCD, COUNTYCD, } \\
\text { PLOT, RSCD, EVALID, } \\
\text { ESTN_UNIT, } \\
\text { STRATUMCD) }\end{array}$ & $\mathrm{N} / \mathrm{A}$ & PPSA_UK2 \\
\hline \multirow[t]{2}{*}{ Foreign } & (PLT_CN) & $\begin{array}{l}\text { POP_PLOT_STRATUM_ASSGN } \\
\text { to PLOT }\end{array}$ & PPSA_PLT_FK \\
\hline & (STRATUM_CN) & $\begin{array}{l}\text { POP_PLOT_STRATUM_ASSGN } \\
\text { to POP_STRATUM }\end{array}$ & PPSA_PSM_FK \\
\hline
\end{tabular}

1. $\mathrm{CN}$

Sequence number. A unique sequence number used to identify a population plot stratum assignment record.

2. STRATUM_CN

Stratum sequence number. Foreign key linking the population plot stratum assignment record to the population stratum record. 
3. PLT_CN

4. STATECD

5. INVYR
Plot sequence number. Foreign key linking the population plot stratum assignment record to the plot record.

State code. Bureau of the Census Federal Information Processing Standards (FIPS) two-digit code for each State. Refer to appendix C.

Inventory year. The year that best represents when the inventory data were collected. Under the annual inventory system, a group of plots is selected each year for sampling. The selection is based on a panel system. INVYR is the year in which the majority of plots in that group were collected (plots in the group have the same panel and, if applicable, subpanel). Under periodic inventory, a reporting inventory year was selected, usually based on the year in which the majority of the plots were collected or the mid-point of the years over which the inventory spanned. For either annual or periodic inventory, INVYR is not necessarily the same as MEASYEAR.

\section{Exceptions:}

INVYR $=9999$. INVYR is set to 9999 to distinguish Phase 3 plots taken by the western FIA work units that are "off subpanel." This is due to differences in measurement intervals between Phase 3 (measurement interval $=5$ years) and Phase 2 (measurement interval $=10$ years) plots. Only users interested in performing certain Phase 3 data analyses should access plots with this anomalous value in INVYR.

INVYR $<100$. INVYR $<100$ indicates that population estimates were derived from a pre-NIMS regional processing system and the same plot either has been or may soon be re-processed in NIMS as part of a separate evaluation. The NIMS processed copy of the plot follows the standard INVYR format. This only applies to plots collected in the South $(\mathrm{RSCD}=33)$ with the national design or a similar regional design (PLOT.DESIGNCD $=1$ or 220233) that were collected when the inventory year was 1998 through 2005.

INVYR $=98$ is equivalent to 1998 but processed through regional system $\mathrm{INVYR}=99$ is equivalent to 1999 but processed through regional system INVYR $=0$ is equivalent to 2000 but processed through regional system $\mathrm{INVYR}=1$ is equivalent to 2001 but processed through regional system $\mathrm{INVYR}=2$ is equivalent to 2002 but processed through regional system INVYR $=3$ is equivalent to 2003 but processed through regional system INVYR $=4$ is equivalent to 2004 but processed through regional system $\mathrm{INVYR}=5$ is equivalent to 2005 but processed through regional system

6. UNITCD

7. COUNTYCD County code. The identification number for a county, parish, watershed, borough, or similar governmental unit in a State. FIPS codes from the Bureau of the Census are used. Refer to appendix $\mathrm{C}$ for codes. 
8. PLOT

9. RSCD

10. EVALID
Phase 2 plot number. An identifier for a plot. Along with INVYR, STATECD, UNITCD, COUNTYCD, PLOT may be used to uniquely identify a plot.

Region or Station Code. Identification number of the Forest Service National Forest System Region or Station (FIA work unit) that provided the inventory data (see appendix $\mathrm{C}$ for more information).

$\begin{array}{ll}\text { Code } & \text { Description } \\ 22 & \text { Rocky Mountain Research Station (RMRS) } \\ 23 & \text { North Central Research Station (NCRS) } \\ 24 & \text { Northeastern Research Station (NERS) } \\ 26 & \text { Pacific Northwest Research Station (PNWRS) } \\ 27 & \text { Pacific Northwest Research Station (PNWRS) - Alaska } \\ 33 & \text { Southern Research Station (SRS) }\end{array}$

Evaluation identifier. The EVALID code and the RSCD code together uniquely identify a set of field plots and associated Phase 1 summary data used to make population estimates.

11. ESTN_UNIT Estimation unit. A geographic area upon which stratification is performed. Sampling intensity is uniform within an estimation unit.

12. STRATUMCD Stratum code. The code used for a particular stratum, which is unique within an RSCD, EVALID, ESTN_UNIT.

13. CREATED_BY Created by. The employee who created the record. This attribute is intentionally left blank in download files.

14. CREATED_DATE

Created date. The date the record was created. Date will be in the form DDMON-YYYY.

\section{CREATED_IN_INSTANCE}

Created in instance. The database instance in which the record was created. Each computer system has a unique database instance code and this attribute stores that information to determine on which computer the record was created.

16. MODIFIED_BY

Modified by. The employee who modified the record. This field will be blank (null) if the data have not been modified since initial creation. This attribute is intentionally left blank in download files. 
17. MODIFIED_DATE

Modified date. The date the record was last modified. This field will be blank (null) if the data have not been modified since initial creation. Date will be in the form DD-MON-YYYY.

18. MODIFIED_IN_INSTANCE

Modified in instance. The database instance in which the record was modified. This field will be blank (null) if the data have not been modified since initial creation. 
FIA Database Description and Users Manual for Phase 2, version 4.0

Chapter 3. Population Stratum Table

\section{Population Stratum Table (Oracle table name is POP_STRATUM)}

\begin{tabular}{|l|l|l|l|}
\hline & Column name & Descriptive name & Oracle data type \\
\hline 1 & CN & Sequence number & VARCHAR2(34) \\
\hline 2 & ESTN_UNIT_CN & Estimation unit sequence number & VARCHAR2(34) \\
\hline 3 & RSCD & Region or Station code & NUMBER(2) \\
\hline 4 & EVALID & Evaluation identifier & NUMBER(6) \\
\hline 5 & ESTN_UNIT & Estimation unit & NUMBER(6) \\
\hline 6 & STRATUMCD & Stratum code & NUMBER(6) \\
\hline 7 & STRATUM_DESCR & Stratum description & VARCHAR2(255) \\
\hline 8 & STATECD & State code & NUMBER(4) \\
\hline 9 & P1POINTCNT & Phase 1 point count & NUMBER(12) \\
\hline 10 & P2POINTCNT & Phase 2 point count & NUMBER(12) \\
\hline 11 & EXPNS & Expansion factor & NUMBER \\
\hline 12 & ADJ_FACTOR_MACR & Adjustment factor for the macroplot & NUMBER(5,4) \\
\hline 13 & ADJ_FACTOR_SUBP & Adjustment factor for the subplot & NUMBER(5,4) \\
\hline 14 & ADJ_FACTOR_MICR & Adjustment factor for the microplot & NUMBER(5,4) \\
\hline 15 & CREATED_BY & Created by & VARCHAR2(30) \\
\hline 16 & CREATED_DATE & Created date & DATE \\
\hline 17 & CREATED_IN_INSTANCE & Created in instance & VARCHAR2(6) \\
\hline 18 & MODIFIED_BY & Modified by & VARCHAR2(30) \\
\hline 19 & MODIFIED_DATE & Modified date & DATE \\
\hline 20 & MODIFIED_IN_INSTANCE & Modified in instance & VARCHAR2(6) \\
\hline & & & \\
\hline
\end{tabular}

\begin{tabular}{|l|l|l|l|}
\hline Type of key & Column(s) order & Tables to link & Abbreviated notation \\
\hline Primary & (CN) & N/A & PSM_PK \\
\hline Unique & (RSCD, EVALID, ESTN_UNIT, & N/A & PSM_UK \\
\hline STRATUMCD) & $\begin{array}{l}\text { POP_STRATUM to } \\
\text { FOP_ESTN_UNIT }\end{array}$ & PSM_PEU_FK \\
\hline
\end{tabular}

1. $\mathrm{CN}$

Sequence number. A unique sequence number used to identify a stratum record.

2. ESTN_UNIT_CN

Estimation unit sequence number. Foreign key linking the stratum record to the estimation unit record.

3. RSCD

Region or Station Code. Identification number of the Forest Service National Forest System Region or Station (FIA work unit) that provided the inventory data (see appendix $\mathrm{C}$ for more information). 


$\begin{array}{ll}\text { Code } & \text { Description } \\ 22 & \text { Rocky Mountain Research Station (RMRS) } \\ 23 & \text { North Central Research Station (NCRS) } \\ 24 & \text { Northeastern Research Station (NERS) } \\ 26 & \text { Pacific Northwest Research Station (PNWRS) } \\ 27 & \text { Pacific Northwest Research Station (PNWRS)-Alaska } \\ 33 & \text { Southern Research Station (SRS) }\end{array}$

4. EVALID Evaluation identifier. The EVALID code and the RSCD code together uniquely identify a set of field plots and associated Phase 1 summary data used to make population estimates.

5. ESTN_UNIT Estimation unit. The particular geographic area for which a particular computation applies. Estimation units are determined by a combination of sampling intensity and geographical boundaries.

6. STRATUMCD Stratum code. A number used to uniquely identify a stratum within an estimation unit.

7. STRATUM_DESCR

Stratum description. Strata are usually based on land use (e.g., forest or nonforest) but may also be based on other criteria such as ownership (e.g., private/public/national forest).

8. STATECD State code. Bureau of the Census Federal Information Processing Standards (FIPS) two-digit code for each State. Refer to appendix C. For evaluations that do not conform to the boundaries of a single State the value of STATECD should be set to 99 .

9. P1POINTCNT Phase 1 point count. The number of basic units (pixels or points) in the stratum.

10. P2POINTCNT Phase 2 point count. The number of field plots that are within the stratum.

11. EXPNS Expansion factor. The area, in acres, that a stratum represents divided by the number of sampled plots in that stratum. This attribute can be used to obtain estimates of population area when summed across all the plots in the population of interest. Refer to chapter 4 for detailed examples.

12. ADJ_FACTOR_MACR

Adjustment factor for the macroplot. A value that adjusts the population estimates to account for partially nonsampled plots (access denied and hazardous portions). It is used with condition proportion (COND.CONDPROP_UNADJ) and area expansion (EXPNS) to provide area estimates, when COND.. PROP_BASIS = "MACR". ADJ_FACTOR_MACR is also used with EXPNS and trees per acre unadjusted (TREE.TPA_UNADJ, TREE.TPAMORT_UNADJ, TREE.TPAREMV_UNADJ, TREE.TPAGROW_UNADJ) to provide tree estimates for sampled land. If a 
macroplot was not installed, this attribute is left blank (null). Refer to chapter 4 for detailed examples.

\section{ADJ FACTOR SUBP}

Adjustment factor for the subplot. A value that adjusts the population estimates to account for partially nonsampled plots (access denied and hazardous portions). It is used with condition proportion (COND.CONDPROP_UNADJ) and area expansion (EXPNS) to provide area estimates, when COND.PROP_BASIS = "SUBP". ADJ_FACTOR_SUBP is also used with EXPNS and trees per acre unadjusted (TREE.TPA_UNADJ, TREE.TPAMORT_UNADJ, TREE.TPAREMV_UNADJ, TREE.TPAGROW_UNADJ) to provide tree estimates for sampled land. Refer to chapter 4 for detailed examples.

14. ADJ_FACTOR_MICR

Adjustment factor for the microplot. A value that adjusts population estimates to account for partially nonsampled plots (access denied and hazardous portions). It is used with POP_STRATUM.EXPNS and seedlings per acre unadjusted (SEEDLING.TPA_UNADJ) or saplings per acre unadjusted (TREE.TPA_UNADJ where TREE DIA <5.0) to provide tree estimates for sampled land. Refer to chapter 4 for detailed examples.

15. CREATED_BY Created by. The employee who created the record. This attribute is intentionally left blank in download files.

16. CREATED_DATE

Created date. The date the record was created. Date will be in the form DDMON-YYYY.

\section{CREATED_IN_INSTANCE}

Created in instance. The database instance in which the record was created. Each computer system has a unique database instance code and this attribute stores that information to determine on which computer the record was created.

18. MODIFIED_BY

Modified by. The employee who modified the record. This field will be blank (null) if the data have not been modified since initial creation. This attribute is intentionally left blank in download files.

19. MODIFIED_DATE

Modified date. The date the record was last modified. This field will be blank (null) if the data have not been modified since initial creation. Date will be in the form DD-MON-YYYY. 


\section{MODIFIED_IN_INSTANCE}

Modified in instance. The database instance in which the record was modified. This field will be blank (null) if the data have not been modified since initial creation. 
FIA Database Description and Users Manual for Phase 2, version 4.0

Chapter 3. Reference Population Attribute Table

\section{Reference Population Attribute Table (Oracle table name is REF_POP_ATTRIBUTE)}

\begin{tabular}{|l|l|l|l|}
\hline & Column name & Descriptive name & Oracle data type \\
\hline 1 & CN & Sequence number & VARCHAR2(34) \\
\hline 2 & ATTRIBUTE_NBR & Attribute number & NUMBER(3) \\
\hline 3 & ATTRIBUTE_DESCR & Attribute description & VARCHAR2(255) \\
\hline 4 & EXPRESSION & Expression & VARCHAR2(2000) \\
\hline 5 & WHERE_CLAUSE & Where clause & VARCHAR2(255) \\
\hline 6 & CREATED_BY & Created by & VARCHAR2(30) \\
\hline 8 & CREATED_DATE & Created date & DATE \\
\hline 9 & MODIFIED_BY & Created in instance & VARCHAR2(6) \\
\hline 10 & MODIFIED_DATE & Modified by & VARCHAR2(30) \\
\hline 11 & MODIFIED_IN_INSTANCE & Modified date & DATE \\
\hline 12 & FOOTNOTE & Footnote & VARCHAR2(6) \\
\hline & & & VARCHAR2(2000) \\
\hline
\end{tabular}

\begin{tabular}{|l|l|l|l|}
\hline Type of key & Column(s) order & Tables to link & Abbreviated notation \\
\hline Primary & (ATTRIBUTE_NBR) & N/A & PAE_PK \\
\hline
\end{tabular}

1. $\mathrm{CN}$

Sequence number. A unique sequence number used to identify a reference population attribute record.

2. ATTRIBUTE_NBR

Attribute number. A numeric code used to identify an attribute record. See codes and descriptions in chapter 4 , table 4.1 .

\section{ATTRIBUTE_DESCR}

Attribute description. Examples include "Area of forestland (acres)" or "All live biomass on forestland oven-dry (short tons)." See codes and descriptions in chapter 4 , table 4.1 .

\section{EXPRESSION}

Expression. SQL expression that identifies variables that are used to generate population estimate identified by ATTRIBUTE_DESCR (chapter 4, table 4.2).

\section{WHERE CLAUSE}

Where clause. SQL where clause that identifies the appropriate method for joining tables and screening records to generate population estimate identified by REF_POP_ATTRIBUTE.ATTRIBUTE_DESCR (chapter 4, table 4.2). 
6. CREATED_BY Created by. The employee who created the record. This attribute is intentionally left blank in download files.

7. CREATED DATE

Created date. The date the record was created. Date will be in the form DDMON-YYYY.

8. CREATED_IN_INSTANCE

Created in instance. The database instance in which the record was created. Each computer system has a unique database instance code and this attribute stores that information to determine on which computer the record was created.

9. MODIFIED_BY

Modified by. The employee who modified the record. This field will be blank (null) if the data have not been modified since initial creation. This attribute is intentionally left blank in download files.

10. MODIFIED_DATE

Modified date. The date the record was last modified. This field will be blank (null) if the data have not been modified since initial creation. Date will be in the form DD-MON-YYYY.

11. MODIFIED_IN_INSTANCE

Modified in instance. The database instance in which the record was modified. This field will be blank (null) if the data have not been modified since initial creation.

12. FOOTNOTE Footnote. Intentionally left blank. Will be populated in verion 5.0 
FIA Database Description and Users Manual for Phase 2, version 4.0

Chapter 3. Reference Population Evaluation Type Description Table

\section{Reference Population Evaluation Type Description Table (Oracle table name is REF POP EVAL TYP DESCR)}

\begin{tabular}{|l|l|l|l|}
\hline & Column name & Descriptive name & Oracle data type \\
\hline 1 & EVAL_TYP & Evaluation type & VARCHAR2(15) \\
\hline 2 & EVAL_TYP_DESCR & Evaluation type description & VARCHAR2(255) \\
\hline 3 & CREATED_BY & Created by & VARCHAR2(30) \\
\hline 4 & CREATED_DATE & Created date & DATE \\
\hline 5 & CREATED_IN_INSTANCE & Created in instance & VARCHAR2(6) \\
\hline 6 & MODIFIED_BY & Modified by & VARCHAR2(30) \\
\hline 7 & MODIFIED_DATE & Modified date & DATE \\
\hline 8 & MODIFIED_IN_INSTANCE & Modified in instance & VARCHAR2(6) \\
\hline 9 & CN & Sequence number & VARCHAR2(34) \\
\hline
\end{tabular}

\begin{tabular}{|l|l|l|l|}
\hline Type of key & Column(s) order & Tables to link & Abbreviated notation \\
\hline Primary & (CN) & N/A & PED_PK \\
\hline Unique & (EVAL_TYP) & N/A & PED_UK \\
\hline
\end{tabular}

1. EVAL_TYP Evaluation type. Evaluation types (EVAL_TYP) and the description of the evaluation types (EVAL_TYP_DESCR) are:

Evaluation type

Expall

Expchng

Expcurr

Expgrow

Expmort

Expremv

Expvol

\section{Evaluation type description}

All plots: sampled and nonsampled

Sampled plots used for area change estimates

Sampled plots used for current area estimates

Sampled plots used for tree growth estimates

Sampled plots used for tree mortality estimates

Sampled plots used for tree removal estimates

Sampled plots used for tree inventory estimates

2. EVAL_TYP_DESCR

Evaluation type description. The description for each evaluation type (EVAL_TYP). See the list of codes and descriptions in EVAL_TYP.

3. CREATED_BY Created by. The employee who created the record. This attribute is intentionally left blank in download files.

4. CREATED_DATE

Created date. The date the record was created. Date will be in the form DDMON-YYYY.

\section{CREATED IN INSTANCE}

Created in instance. The database instance in which the record was created.

Each computer system has a unique database instance code and this attribute 
stores that information to determine on which computer the record was created.

6. MODIFIED_BY

Modified by. The employee who modified the record. This field will be blank (null) if the data have not been modified since initial creation. This attribute is intentionally left blank in download files.

7. MODIFIED_DATE

Modified date. The date the record was last modified. This field will be blank (null) if the data have not been modified since initial creation. Date will be in the form DD-MON-YYYY.

8. MODIFIED_IN_INSTANCE

Modified in instance. The database instance in which the record was modified. This field will be blank (null) if the data have not been modified since initial creation.

9. $\mathrm{CN}$

Sequence number. A unique sequence number used to identify a reference population evaluation type description record. 
FIA Database Description and Users Manual for Phase 2, version 4.0

Chapter 3. Reference Forest Type Table

\section{Reference Forest Type Table (Oracle table name is REF_FOREST_TYPE)}

\begin{tabular}{|l|l|l|l|}
\hline & Column name & Descriptive name & Oracle data type \\
\hline 1 & VALUE & Value & NUMBER(3) \\
\hline 2 & MEANING & Meaning & VARCHAR2(80) \\
\hline 3 & TYPGRPCD & Forest type group code & NUMBER(3) \\
\hline 4 & MANUAL_START & Manual start & NUMBER(3,1) \\
\hline 5 & MANUAL_END & Manual end & NUMBER(3,1) \\
\hline 6 & ALLOWED_IN_FIELD & Allowed in field & VARCHAR2(1) \\
\hline 7 & CREATED_BY & Created by & VARCHAR2(30) \\
\hline 8 & CREATED_DATE & Created date & DATE \\
\hline 9 & CREATED_IN_INSTANCE & Created in instance & VARCHAR2(6) \\
\hline 10 & MODIFIED_BY & Modified by & VARCHAR2(30) \\
\hline 11 & MODIFIED_DATE & Modified date & DATE \\
\hline 12 & MODIFIED_IN_INSTANCE & Modified in instance & VARCHAR2(6) \\
\hline
\end{tabular}

\begin{tabular}{|l|l|l|l|}
\hline Type of key & Column(s) order & Tables to link & Abbreviated notation \\
\hline Primary & (VALUE) & N/A & RFT_PK \\
\hline
\end{tabular}

1. VALUE Value. A code used for the forest type (COND.FORTYPCD, COND.FLDTYPCD, COND.FORTYPCDCALC). Refer to appendix D.

2. MEANING Meaning. The descriptive name corresponding with the forest type code (VALUE). The names associated with these codes are used to label rows or columns in National standard presentation tables. Refer to appendix D.

3. TYPGRPCD Forest type group code. A code assigned to individual forest types in order to group them for reporting purposes. Refer to appendix D.

4. MANUAL_START

Manual start. The first version of the Field Guide (PLOT.MANUAL) that the forest type code (VALUE) began to be used.

5. MANUAL_END

Manual end. The last version of the Field Guide (PLOT.MANUAL) that the forest type code (VALUE) was valid. When MANUAL_END is blank (null), the code is still valid.

\section{ALLOWED_IN_FIELD}

Allowed in field. An indicator to show if a code (VALUE) is allowed to be used by the field crews. This is a Yes/No (Y/N) field. Specifically, forest type group codes are not allowed in the Field Guide nor is the code for a nonstocked forest type (VALUE $=999$ ). 
7 CREATED_BY Created by. The employee who created the record. This attribute is intentionally left blank in download files.

8. CREATED_DATE

Created date. The date the record was created. Date will be in the form DDMON-YYYY.

9. CREATED_IN_INSTANCE

Created in instance. The database instance in which the record was created. Each computer system has a unique database instance code and this attribute stores that information to determine on which computer the record was created.

10. MODIFIED_BY

Modified by. The employee who modified the record. This field will be blank (null) if the data have not been modified since initial creation. This attribute is intentionally left blank in download files.

11. MODIFIED_DATE

Modified date. The date the record was last modified. This field will be blank (null) if the data have not been modified since initial creation. Date will be in the form DD-MON-YYYY.

12. MODIFIED_IN_INSTANCE

Modified in instance. The database instance in which the record was modified. This field will be blank (null) if the data have not been modified since initial creation. 


\section{Reference Species Table (Oracle table name is REF_SPECIES)}

\begin{tabular}{|c|c|c|c|}
\hline & Column name & Descriptive name & Oracle data type \\
\hline 1 & SPCD & Species code & NUMBER \\
\hline 2 & COMMON_NAME & Common name of species & VARCHAR2(100) \\
\hline 3 & GENUS & Genus & VARCHAR2(40) \\
\hline 4 & SPECIES & Species name & VARCHAR2(50) \\
\hline 5 & VARIETY & Variety & VARCHAR2(50) \\
\hline 6 & SUBSPECIES & Subspecies name & VARCHAR2(50) \\
\hline 7 & SPECIES_SYMBOL & Species symbol & VARCHAR2(8) \\
\hline 8 & E_SPGRPCD & East species group code & NUMBER(2) \\
\hline 9 & W_SPGRPCD & West species group code & NUMBER(2) \\
\hline 10 & MAJOR_SPGRPCD & Major species group code & NUMBER(1) \\
\hline 11 & STOCKING_SPGRPCD & Stocking species group code & NUMBER(3) \\
\hline 12 & FOREST_TYPE_SPGRPCD & Forest type species group code & NUMBER(3) \\
\hline 13 & EXISTS_IN_NCRS & $\begin{array}{l}\text { Exists in the North Central Research } \\
\text { Station States }\end{array}$ & VARCHAR2(1) \\
\hline 14 & EXISTS_IN_NERS & $\begin{array}{l}\text { Exists in the Northeastern Research } \\
\text { Station States }\end{array}$ & VARCHAR2(1) \\
\hline 15 & EXISTS_IN_PNWRS & $\begin{array}{l}\text { Exists in the Pacific Northwest } \\
\text { Research Station States }\end{array}$ & VARCHAR2(1) \\
\hline 16 & EXISTS_IN_RMRS & $\begin{array}{l}\text { Exists in the Rocky Mountain } \\
\text { Research Station States }\end{array}$ & VARCHAR2(1) \\
\hline 17 & EXISTS_IN_SRS & $\begin{array}{l}\text { Exists in the Southern Research } \\
\text { Station States }\end{array}$ & VARCHAR2(1) \\
\hline 18 & SITETREE & Site tree & VARCHAR2(1) \\
\hline 19 & SFTWD_HRDWD & Softwood or hardwood & VARCHAR2(1) \\
\hline 20 & ST_EXISTS_IN_NCRS & $\begin{array}{l}\text { Site tree exists in the North Central } \\
\text { Research Station region }\end{array}$ & VARCHAR2(1) \\
\hline 21 & ST_EXISTS_IN_NERS & $\begin{array}{l}\text { Site tree exists in the Northeastern } \\
\text { Research Station region }\end{array}$ & VARCHAR2(1) \\
\hline 22 & ST_EXISTS_IN_PNWRS & $\begin{array}{l}\text { Site tree exists in the Pacific } \\
\text { Northwest Research Station region }\end{array}$ & VARCHAR2(1) \\
\hline 23 & ST_EXISTS_IN_RMRS & $\begin{array}{l}\text { Site tree exists in the Rocky } \\
\text { Mountain Research Station region }\end{array}$ & VARCHAR2(1) \\
\hline 24 & ST_EXISTS_IN_SRS & $\begin{array}{l}\text { Site tree exists in the Southern } \\
\text { Research Station region }\end{array}$ & VARCHAR2(1) \\
\hline 25 & EAST & East & VARCHAR2(1) \\
\hline 26 & WEST & West & VARCHAR2(1) \\
\hline 27 & WOODLAND & Woodland species & VARCHAR2(1) \\
\hline 28 & MANUAL_START & Manual start & $\operatorname{NUMBER}(3,1)$ \\
\hline 29 & MANUAL_END & Manual end & $\operatorname{NUMBER}(3,1)$ \\
\hline 30 & CREATED_BY & Created by & VARCHAR2(30) \\
\hline 31 & CREATED_DATE & Created date & DATE \\
\hline 32 & CREATED_IN_INSTANCE & Created in instance & VARCHAR2(6) \\
\hline
\end{tabular}




\begin{tabular}{|c|c|c|c|}
\hline & Column name & Descriptive name & Oracle data type \\
\hline 33 & MODIFIED_BY & Modified by & VARCHAR2(30) \\
\hline 34 & MODIFIED_DATE & Modified date & DATE \\
\hline 35 & MODIFIED_IN_INSTANCE & Modified in instance & VARCHAR2(6) \\
\hline 36 & CORE & Core & VARCHAR2(1) \\
\hline 37 & JENKINS_SPGRPCD & Jenkins species group code & NUMBER(8,5) \\
\hline 38 & JENKINS_TOTAL_B1 & Jenkins total B1 & NUMBER(8,5) \\
\hline 39 & JENKINS_TOTAL_B2 & Jenkins total B2 & NUMBER(8,5) \\
\hline 40 & JENKINS_STEM_WOOD_RATIO_B1 & Jenkins stem wood ratio B1 & NUMBER(8,5) \\
\hline 41 & JENKINS_STEM_WOOD_RATIO_B2 & Jenkins stem wood ratio B2 & NUMBER( $(8,5)$ \\
\hline 42 & JENKINS_STEM_BARK_RATIO_B1 & Jenkins stem bark ratio B1 & NUMBER(8,5) \\
\hline 43 & JENKINS_STEM_BARK_RATIO_B2 & Jenkins stem bark ratio B2 & NUMBER(8,5) \\
\hline 44 & JENKINS_FOLIAGE_RATIO_B1 & Jenkins foliage ratio B1 & NUMBER(8,5) \\
\hline 45 & JENKINS_FOLIAGE_RATIO_B2 & Jenkins foliage ratio B2 & NUMBER(8,5) \\
\hline 46 & JENKINS_ROOT_RATIO_B1 & Jenkins root ratio B1 & NUMBER(8,5) \\
\hline 47 & JENKINS_ROOT_RATIO_B2 & Jenkins root ratio $\mathrm{B} 2$ & NUMBER(8,5) \\
\hline 48 & JENKINS_SAPLING_ADJUSTMENT & Jenkins sapling adjustment factor & NUMBER(8,5) \\
\hline 49 & WOOD_SPGR_GREENVOL_DRYWT & $\begin{array}{l}\text { Green specific gravity wood (green } \\
\text { volume and oven-dry weight) }\end{array}$ & NUMBER( $(8,5)$ \\
\hline 50 & $\begin{array}{l}\text { WOOD_SPGR_GREENVOL_DRYWT_ } \\
\text { CIT }\end{array}$ & Green specific gravity wood citation & NUMBER(7) \\
\hline 51 & BARK_SPGR_GREENVOL_DRYWT & $\begin{array}{l}\text { Green specific gravity bark (green } \\
\text { volume and oven-dry weight) }\end{array}$ & NUMBER( $(8,5)$ \\
\hline 52 & $\begin{array}{l}\text { BARK_SPGR_GREENVOL_DRYWT_ } \\
\text { CIT }\end{array}$ & Green specific gravity bark citation & NUMBER(7) \\
\hline 53 & MC_PCT_GREEN_WOOD & $\begin{array}{l}\text { Moisture content of green wood as a } \\
\text { percent of oven-dry weight }\end{array}$ & NUMBER(8,5) \\
\hline 54 & MC_PCT_GREEN_WOOD_CIT & $\begin{array}{l}\text { Moisture content of green wood } \\
\text { citation }\end{array}$ & NUMBER(7) \\
\hline 55 & MC_PCT_GREEN_BARK & $\begin{array}{l}\text { Moisture content of green bark as a } \\
\text { percent of oven-dry weight }\end{array}$ & NUMBER( $(8,5)$ \\
\hline 56 & MC_PCT_GREEN_BARK_CIT & $\begin{array}{l}\text { Moisture content of green bark } \\
\text { citation }\end{array}$ & NUMBER(7) \\
\hline 57 & WOOD_SPGR_MC12VOL_DRYWT & $\begin{array}{l}\text { Wood specific gravity ( } 12 \text { percent } \\
\text { moisture content volume and oven- } \\
\text { dry weight) }\end{array}$ & NUMBER( $(8,5)$ \\
\hline 58 & $\begin{array}{l}\text { WOOD_SPGR_MC12VOL_DRYWT_ } \\
\text { CIT }\end{array}$ & $\begin{array}{l}\text { Wood specific gravity ( } 12 \text { percent } \\
\text { moisture content volume and oven- } \\
\text { dry weight) citation }\end{array}$ & NUMBER(7) \\
\hline 59 & BARK_VOL_PCT & $\begin{array}{l}\text { Bark volume as a percent of wood } \\
\text { volume }\end{array}$ & NUMBER(8,5) \\
\hline 60 & BARK_VOL_PCT_CIT & $\begin{array}{l}\text { Bark volume as a percent of wood } \\
\text { volume citation }\end{array}$ & NUMBER(7) \\
\hline 61 & RAILE_STUMP_DOB_B1 & $\begin{array}{l}\text { Raile stump diameter outside bark } \\
\text { equation coefficient B1 }\end{array}$ & NUMBER(8,5) \\
\hline 62 & RAILE_STUMP_DIB_B1 & $\begin{array}{l}\text { Raile stump diameter inside bark } \\
\text { equation coefficient B1 }\end{array}$ & NUMBER( $(8,5)$ \\
\hline
\end{tabular}




\begin{tabular}{|l|l|l|l|}
\hline & Column name & Descriptive name & Oracle data type \\
\hline 63 & RAILE_STUMP_DIB_B2 & $\begin{array}{l}\text { Raile stump diameter inside bark } \\
\text { equation coefficient B2 }\end{array}$ & NUMBER $(8,5)$ \\
\hline
\end{tabular}

\begin{tabular}{|l|l|l|l|}
\hline Type of key & Column(s) order & Tables to link & Abbreviated notation \\
\hline Primary & (SPCD) & N/A & SPC_PK \\
\hline Unique & (SPECIES_SYMBOL) & N/A & SPC_UK \\
\hline
\end{tabular}

Coefficients for calculating total aboveground biomass based on Jenkins and others (2003) equations are included in the REF_SPECIES table. Coefficients for calculating biomass components (stem wood, stem bark, foliage, coarse roots, stump, and sapling) are also included in the REF_SPECIES table. Biomass in branches and treetops (tops and limbs) may be found by subtracting the biomass in stem wood, stem bark, foliage, and stump from total aboveground biomass. Heath and others (2009) provides an overview of the historical use of Jenkins and others (2003) for biomass estimation for the U.S. forest greenhouse gas inventory (U.S. Environmental Protection Agency 2008) and an overview of the approach of the new biomass equations used for FIA data.

1. SPCD Species code. An FIA tree species code. Refer to appendix F for codes.

2. COMMON_NAME

Common name. Common name of the species. Refer to appendix F.

3. GENUS Genus. The genus name associated with the FIA tree species code. Refer to appendix F.

4. SPECIES Species. The species name associated with the FIA tree species code. Refer to appendix F.

5. VARIETY Variety. The variety name associated with the FIA tree species code.

6. SUBSPECIES Subspecies. The subspecies name associated with the FIA tree species code.

7. SPECIES_SYMBOL

Species symbol. The NRCS PLANTS database code associated with the FIA tree species code.

8. E SPGRPCD Eastern species group code. A code indicating the species group assignment for eastern species. Depending on the State in which a tree is tallied, either the eastern or western species group code is associated with the actual TREE, SITETREE, and SEEDLING data. Species group codes and names can be found in appendix G.

9. W_SPGRPCD Western species group code. A code indicating the FIADB species group assignment for western species. Depending on the State in which a tree is tallied, either the eastern or western species group code is associated with the 
actual TREE, SITETREE, and SEEDLING data. Species group codes and names can be found in appendix $\mathrm{G}$.

10. MAJOR_SPGRPCD

Major species group code. A code indicating the major species group, which can be used for reporting purposes.

$\begin{array}{ll}\text { Code } & \text { Description } \\ 1 & \text { Pine } \\ 2 & \text { Other conifers } \\ 3 & \text { Soft hardwood } \\ 4 & \text { Hard hardwood }\end{array}$

\section{STOCKING_SPGRPCD}

Stocking species group code. A code indicating which stocking equation a species is assigned.

\begin{tabular}{|c|c|}
\hline Code & Description \\
\hline 1 & Spruce-fir \\
\hline 2 & Western larch \\
\hline 3 & Black spruce \\
\hline 4 & Jack pine \\
\hline 5 & Lodgepole pine \\
\hline 6 & Shortleaf pine \\
\hline 7 & Slash pine \\
\hline 8 & Western white pine \\
\hline 9 & Longleaf pine \\
\hline 10 & Ponderosa pine \\
\hline 11 & Red pine \\
\hline 12 & Pond pine \\
\hline 13 & Eastern white pine \\
\hline 14 & Loblolly pine \\
\hline 15 & Douglas-fir \\
\hline 16 & Northern white cedar \\
\hline 17 & Eastern hemlock \\
\hline 18 & Western hemlock \\
\hline 19 & Redwood \\
\hline 20 & Average softwood \\
\hline 25 & Red maple \\
\hline 26 & Red alder \\
\hline 27 & Maple, beech, birch \\
\hline 28 & Paper birch \\
\hline 29 & Oaks and hickory \\
\hline 30 & Black walnut \\
\hline 31 & Sweetgum \\
\hline 32 & Aspen \\
\hline 33 & Cherry, ash, yellow poplar \\
\hline 35 & Basswood \\
\hline 36 & Elm, ash, cottonwood \\
\hline 37 & Average hardwood \\
\hline 38 & Dryland species \\
\hline
\end{tabular}




\section{FOREST TYPE SPGRPCD}

Forest type species group code. A code indicating which initial forest type group a species is assigned.

\section{EXISTS_IN_NCRS}

Exists in the North Central Research Station. Indicates which species are valid for North Central Research Station States. Trees that are applicable to North Central States are marked with an X.

14. EXISTS_IN_NERS

Exists in the Northeastern Research Station. Indicates which tree species are valid for Northeastern Research Station States. Tree species that are applicable to Northeastern States are marked with an X.

\section{EXISTS_IN_PNWRS}

Exists in the Pacific Northwest Research Station. Indicates which species are valid for Pacific Northwest Research Station States. Tree species that are applicable to Pacific Northwest States are marked with an X.

16. EXISTS_IN RMRS

Exists in the Rocky Mountain Research Station. Indicates which species are valid for Rocky Mountain Research Station States. Tree species that are applicable to the Rocky Mountain States are marked with an X.

17. EXISTS_IN_SRS

Exists in the Southern Research Station. Indicates which species are valid for Southern Research Station States. Tree species that are applicable to the Southern States are marked with an X.

18. SITETREE Sitetree. Indicates whether the tree species can be coded as a site tree. Tree species that are applicable to have site data collected are marked with an X.

19. SFTWD_HRDWD

Softwood/ hardwood. Indicates whether the species is a softwood or a hardwood. Softwoods are marked with an S and hardwoods with an $\mathrm{H}$.

\section{ST_EXISTS_IN_NCRS}

Site tree exists in the North Central Research Station. Indicates whether or not the species is valid as a site tree in North Central Research Station States. Tree species that are applicable to have site data collected are marked with an $\mathrm{X}$. 


\section{ST_EXISTS_IN_NERS}

Site tree exists in the Northeastern Research Station. Indicates whether or not the species is valid as a site tree in Northeastern Research Station States. Tree species that are applicable to have site data collected are marked with an X.

\section{ST_EXISTS_IN_PNWRS}

Site tree exists in the Pacific Northwest Research Station. Indicates whether or not the species is valid for a site tree in Pacific Northwest Research Station States. Tree species that are applicable to have site data collected are marked with an $\mathrm{X}$.

\section{ST_EXISTS_IN RMRS}

Site tree exists in the Rocky Mountain Research Station. Indicates whether or not the species is valid as a site tree in Rocky Mountain Research Station States. Tree species that are applicable to have site data collected are marked with an $\mathrm{X}$.

\section{ST_EXISTS_IN_SRS}

Site tree exists in the Southern Research Station. Indicates whether or not the species is valid for a site tree in Southern Research Station States. Tree species that are applicable to have site data collected are marked with an X.

25. EAST

East. Indicates if the species can occur in the Eastern United States. Valid eastern species are marked with an E.

26. WEST West. Indicates if the species can occur in the Western United States. Valid western species are marked with a W.

27. WOODLAND Woodland. Indicates if the species is classified as a woodland species, meaning that the diameter is measured as root collar. Woodland species are marked with an X.

28. MANUAL_START

Manual start. The first version of the Field Guide (PLOT.MANUAL) that the species code was used.

29. MANUAL_END

Manual end. The last version of the Field Guide (PLOT. MANUAL) that the species code was valid. When MANUAL_END is blank (null), the code is still valid.

30. CREATED_BY Created by. The employee who created the record. This attribute is intentionally left blank in download files. 


\section{CREATED DATE}

Created date. The date the record was created. Date will be in the form DDMON-YYYY.

\section{CREATED IN INSTANCE}

Created in instance. The database instance in which the record was created. Each computer system has a unique database instance code and this attribute stores that information to determine on which computer the record was created.

33. MODIFIED BY

Modified by. The employee who modified the record. This field will be blank (null) if the data have not been modified since initial creation. This attribute is intentionally left blank in download files.

34. MODIFIED_DATE

Modified date. The date the record was last modified. This field will be blank (null) if the data have not been modified since initial creation. Date will be in the form DD-MON-YYYY.

\section{MODIFIED_IN_INSTANCE}

Modified in instance. The database instance in which the record was modified. This field will be blank (null) if the data have not been modified since initial creation.

36. CORE Core. Indicates that the tree species must be tallied (measured) by all FIA work units. Species marked with a Y are core and core optional species are marked with an $\mathrm{N}$.

\section{JENKINS_SPGRPCD}

Jenkins species group code. A code that identifies a group of similar species, which is used to apply the correct biomass estimation equation and coefficient developed by Jenkins and others (2003). A specific set of biomass equation coefficients are assigned to each group. Additional explanation about how to estimate biomass, and when to use a certain set of coefficients, is provided in appendix $\mathrm{J}$. 


$\begin{array}{ll}\text { Code } & \text { Description } \\ 1 & \text { Cedar/larch } \\ 2 & \text { Douglas-fir } \\ 3 & \text { True fir/hemlock } \\ 4 & \text { Pine } \\ 5 & \text { Spruce } \\ 6 & \text { Aspen/alder/cottonwood/willow } \\ 7 & \text { Soft maple/birch } \\ 8 & \text { Mixed hardwood } \\ 9 & \text { Hard maple/oak/hickory/beech } \\ 10 & \text { Juniper/oak/mesquite }\end{array}$

38. JENKINS_TOTAL_B1

Jenkins total B1. Jenkins B1 coefficient used to estimate total aboveground oven-dry biomass (pounds). This is coefficient $\mathrm{B}_{0}$ from table 4 in Jenkins and others (2003). See appendix J for details on biomass equations.

Use JENKINS_TOTAL_B1 along with JENKINS_TOTAL_B2 to estimate total aboveground biomass (includes stem wood (bole), stump, bark, top, limbs, and foliage) with the equation below:

Total_agb $=\left(\operatorname{Exp}\left(J E N K I N S \_T O T A L \_B 1+\right.\right.$ JENKINS_TOTAL_B2 $*$ $\ln (\mathrm{DIA} * 2.54)) * 2.2046)$

$\begin{array}{ll}\text { JENKINS_SPGRPCD } & \text { JENKINS_TOTAL_B1 } \\ 1 & -2.03360 \\ 2 & -2.23040 \\ 3 & -2.53840 \\ 4 & -2.53560 \\ 5 & -2.07730 \\ 6 & -2.20940 \\ 7 & -1.91230 \\ 8 & -2.48000 \\ 9 & -2.01270 \\ 10 & -0.71520\end{array}$

39. JENKINS_TOTAL_B2

Jenkins total B2. Jenkins B2 coefficient used to estimate total aboveground oven-dry biomass (pounds). This is coefficient $\mathrm{B}_{1}$ from table 4 in Jenkins and others (2003). See appendix $\mathbf{J}$ for details on biomass equations.

Use JENKINS_TOTAL_B2 along with JENKINS_TOTAL_B1 to estimate total aboveground biomass (includes stem wood (bole), stump, bark, top, limbs, and foliage) with the equation below:

Total_agb $=\left(\operatorname{Exp}\left(J E N K I N S \_T O T A L \_B 1+\right.\right.$ JENKINS_TOTAL_B2 $*$ $\ln (\mathrm{DIA} * 2.54)) * 2.2046)$ 


$\begin{array}{ll}\text { JENKINS_SPGRPCD } & \text { JENKINS_TOTAL_B2 } \\ 1 & 2.25920 \\ 2 & 2.44350 \\ 3 & 2.48140 \\ 4 & 2.43490 \\ 5 & 2.33230 \\ 6 & 2.38670 \\ 7 & 2.36510 \\ 8 & 2.48350 \\ 9 & 2.43420 \\ 10 & 1.70290\end{array}$

40. JENKINS_STEM_WOOD_RATIO_B1

Jenkins stem wood ratio B1. A coefficient used in computing component ratio biomass. This is equivalent to coefficient $B_{0}$ for stem wood from table 6 in Jenkins and others (2003). The appropriate coefficient to use is based on the species category (SFTWD_HRDWD). The stem is defined as that portion of the tree from a 1-foot stump to a 4-inch DOB top (i.e., the merchantable bole.) See appendix J for details on biomass equations.

The average proportion of aboveground biomass in stem wood is calculated using this equation:

$$
\begin{aligned}
& \text { stem_ratio }=\operatorname{Exp}(\text { JENKINS_STEM_WOOD_RATIO_B1 + } \\
& \text { JENKINS_STEM_WOOD_RATIO_B2 / (DIA } * 2.54))
\end{aligned}
$$

\section{Species category}

Softwood (S)

$\operatorname{Hardwood}(\mathrm{H})$

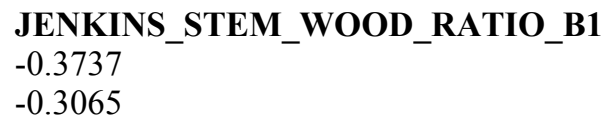

\section{JENKINS_STEM_WOOD_RATIO_B2}

Jenkins stem wood ratio B2. A coefficient used in computing component ratio biomass. This is equivalent to coefficient $B_{1}$ for stem wood from table 6 in Jenkins and others (2003). The appropriate coefficient to use is based on the species category (SFTWD_HRDWD). The stem is defined as that portion of the tree from a 1-foot stump to a 4-inch DOB top (i.e., the merchantable bole.) See appendix $\mathrm{J}$ for details on biomass equations.

The average proportion of aboveground biomass in stem wood is calculated using this equation:

$$
\begin{aligned}
& \text { stem_ratio }=\operatorname{Exp}(\text { JENKINS_STEM_WOOD_RATIO_B1 + } \\
& \text { JENKINS_STEM_WOOD_RATIO_B2 / (DIA } * 2.54))
\end{aligned}
$$

Species category

Softwood (S)

Hardwood $(\mathrm{H})$
JENKINS_STEM_WOOD_RATIO_B2

$-1.8055$

$-5.4240$ 
Jenkins stem bark ratio B1. A coefficient used in computing component ratio biomass. This is equivalent to coefficient $B_{0}$ for stem bark from table 6 in Jenkins and others (2003). The appropriate coefficient to use is based on the species category (SFTWD_HRDWD). This ratio estimates bark biomass on the stem, defined as that portion of the tree from a 1-foot stump to a 4-inch DOB top (i.e., the merchantable bole.) See appendix J for details on biomass equations.

The average proportion of aboveground biomass in stem bark is calculated using this equation:

bark_ratio $=\operatorname{Exp}\left(J E N K I N S \_S T E M \_B A R K \_R A T I O \_B 1+\right.$

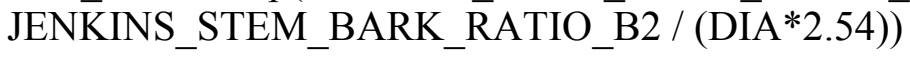

Species category JENKINS_STEM_BARK_RATIO_B1

Softwood (S) $\quad-2.0980$

Hardwood $(\mathrm{H}) \quad-2.0129$

43. JENKINS_STEM_BARK_RATIO_B2

Jenkins stem bark ratio B2. A coefficient used in computing component ratio biomass. This is equivalent to coefficient $B_{1}$ for stem bark from table 6 in Jenkins and others (2003). The appropriate coefficient to use is based on the species category (SFTWD_HRDWD). This ratio estimates bark biomass on the stem, defined as that portion of the tree from a 1-foot stump to a 4-inch DOB top (i.e., the merchantable bole.) See appendix J for details on biomass equations.

The average proportion of aboveground biomass in stem bark is calculated using this equation:

bark_ratio $=\operatorname{Exp}\left(J E N K I N S \_S T E M \_B A R K \_R A T I O \_B 1+\right.$

JENKINS_STEM_BARK_RATIO_B2 / (DIA*2.54))

$\begin{array}{ll}\text { Species category } & \text { JENKINS_STEM_BARK_RATIO_B2 } \\ \text { Softwood }(\mathrm{S}) & -1.1432 \\ \text { Hardwood }(\mathrm{H}) & -1.6805\end{array}$

44. JENKINS_FOLIAGE_RATIO_B1

Jenkins foliage ratio B1. A coefficient used in computing component ratio biomass. This is equivalent to coefficient $\mathrm{B}_{0}$ for foliage from table 6 in Jenkins and others (2003). The appropriate coefficient to use is based on the species category (SFTWD_HRDWD). See appendix J for details on biomass equations. 
The average proportion of aboveground biomass in foliage is calculated using this equation:

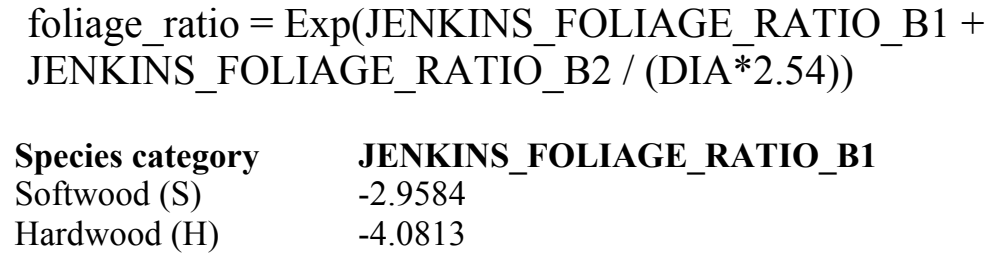

45. JENKINS_FOLIAGE_RATIO_B2

Jenkins foliage ratio $\mathrm{B} 2$. A coefficient used in computing component ratio biomass. This is equivalent to coefficient $B_{1}$ for foliage from table 6 in Jenkins and others (2003). The appropriate coefficient to use is based on the species category (SFTWD_HRDWD). See appendix J for details on biomass equations.

The average proportion of aboveground biomass in foliage is calculated using this equation:

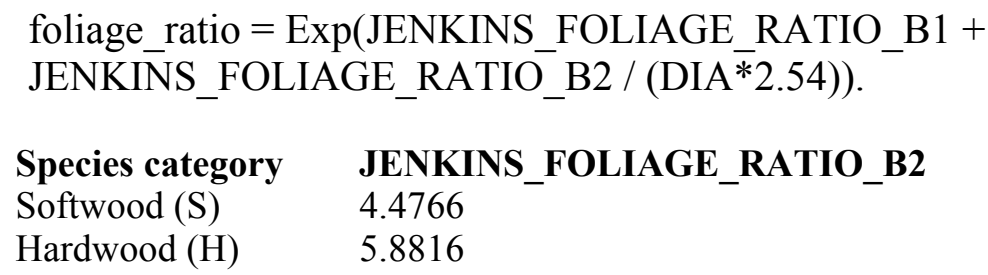

46. JENKINS_ROOT_RATIO_B1

Jenkins root ratio B1. A coefficient used in computing component ratio biomass. This is equivalent to coefficient $\mathrm{B}_{0}$ for coarse roots from table 6 in Jenkins and others (2003). The appropriate coefficient to use is based on the species category (SFTWD_HRDWD). See appendix J for details on biomass equations.

The average proportion of coarse roots to total aboveground biomass is calculated using this equation:

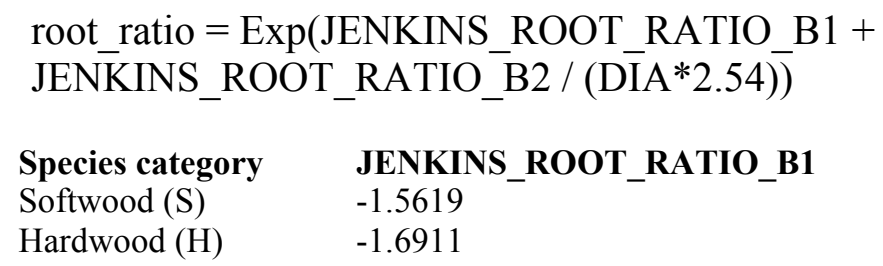

47. JENKINS_ROOT_RATIO_B2

Jenkins root ratio $\mathrm{B} 2$. A coefficient used in computing component ratio biomass. This is equivalent to coefficient $B_{1}$ for coarse roots from table 6 in Jenkins and others (2003). The appropriate coefficient to use is based on the 
species category (SFTWD_HRDWD). See appendix J for details on biomass equations.

The average proportion of coarse roots to total aboveground biomass is calculated using this equation:

root_ratio $=\operatorname{Exp}($ JENKINS_ROOT_RATIO_B $1+$

JENKINS_ROOT_RATIO_B2/(DIA*2.54))

Species category

Softwood (S)

Hardwood $(\mathrm{H})$
JENKINS_ROOT_RATIO_B2

0.6614

0.8160

\section{JENKINS_SAPLING_ADJUSTMENT}

Jenkins sapling adjustment factor. A factor used to compute the biomass of saplings. Sapling biomass is computed by multiplying diameter (DIA) by the appropriate species adjustment factor (from Jenkins and others [2003]). The sapling adjustment factor was computed as a national average ratio of the REGIONAL_DRYBIOT (total dry biomass) divided by the Jenkins total biomass for all 5.0-inch trees, which is the size at which biomass based on volume begins. Because this adjustment factor was computed at the species level, there is a specific adjustment factor for each species. Users can download the REF_SPECIES table, which includes the values of JENKINS_SAPLING_ADJUSTMENT at http://ncrs2.fs.fed.us/fiadb4downloads/datamart.html. See appendix $\mathrm{J}$ for details on biomass equations.

\section{WOOD_SPGR_GREENVOL_DRYWT}

Green specific gravity of wood (green volume and oven-dry weight). This variable is used to determine the oven-dry weight (in pounds) of live and dead trees based on volume variables in the TREE table (VOLCFSND, VOLCFGRS, VOLCFNET...). These volumes are assumed to be green wood volumes. Oven-dry biomass for the sound volume in a tree can be calculated using this equation:

$B_{\text {odw }}=$ VOLCFSND $\times$ WOOD_SPGR_GREENVOL_DRYWT $\times 62.4$

Where:

$\mathrm{B}_{\text {odw }}=$ sound oven-dry biomass of a tree in pounds

VOLCFSND $=$ sound volume of a tree in cubic feet

50. WOOD_SPGR_GREENVOL_DRYWT_CIT

Citation for WOOD_SPGR_GREENVOL_DRYWT. The value of this variable can be linked to the corresponding value in the CITATION_NBR variable in the REF_CITATION table to find the source of the WOOD_SPGR_GREENVOL_DRYWT variable. 


\section{BARK_SPGR_GREENVOL_DRYWT}

Green specific gravity of the bark (green volume and oven-dry weight).

There is some shrinkage in bark volume when a live tree is cut and dried. In FIADB, this specific gravity is used on live and dead trees to convert green volume to oven-dry weight in pounds. Oven-dry biomass for bark can be calculated using the volume of a tree using this equation:

$\mathrm{B}_{\text {odw }}=$ BARK_VOLUME $\times$ BARK_SPGR_GREENVOL_DRYWT x 62.4

Where:

$\mathrm{B}_{\mathrm{odw}}=$ oven-dry biomass of bark on a tree in pounds

BARK_VOLUME $=$ volume of the bark on a tree bole, in cubic feet. Note that bark volume is often estimated by subtracting volume of the bole inside bark from volume of the bole outside bark. Or, an estimate of bark volume can be obtained using any tree volume column along with BARK_VOL_PCT found in this table as follows:

BARK_VOLUME $=$ TREE_VOLUME $*($ BARK_VOL_PCT/100.0)

52. BARK_SPGR_GREENVOL_DRYWT_CIT

Citation for BARK_SPGR_GREENVOL_DRYWT. The value of this variable can be linked to the corresponding value in the CITATION_NBR variable in the REF_CITATION table to find the source of the BARK_SPGR_GREENVOL_DRYWT variable.

53. MC_PCT_GREEN_WOOD

Moisture content of green wood as a percent of oven-dry weight. Wood and bark are often sold based on green weight. The user is cautioned that green weights can be extremely variable geographically, seasonally, within species and across various portions of individual trees.

54. MC_PCT_GREEN_WOOD_CIT

Citation for MC_PCT_GREEN_WOOD_CIT. The value of this variable can be linked to the corresponding value in the CITATION_NBR variable in the REF_CITATION table to find the source of the MC_PT_GREEN_WOOD variable.

55. MC_PCT_GREEN_BARK

Moisture content of green bark as a percent of oven-dry weight. Wood and bark are often sold based on green weight. The user is cautioned that green weights can be extremely variable geographically, seasonally, within species and across various portions of individual trees. 
56. MC_PCT_GREEN_BARK_CIT

Citation for MC_PCT_GREEN_BARK. The value of this variable can be linked to the corresponding value in the CITATION_NBR variable in the REF_CITATION table to find the source of the MC_PCT_GREEN_BARK variable.

57. WOOD_SPGR_MC12VOL_DRYWT

Wood specific gravity (12 percent moisture content volume and oven-dry weight). Used in biomass estimation of forest products (lumber, veneer, etc.)

58. WOOD_SPGR_MC12VOL_DRYWT_CIT

Citation for WOOD_SPGR_MC12VOL_DRYWT. The value of this variable can be linked to the corresponding value in the CITATION_NBR variable in the REF_CITATION table to find the source of the WOOD_SPGR_MC12VOL_DRYWT variable.

59. BARK_VOL_PCT

Bark volume as a percent of wood volume. Bark volume expressed as a percent of wood volume. The volume of bark does not include voids due to ridges and valleys in bark.

60. BARK_VOL_PCT_CIT

Citation for BARK_VOL_PCT. The value of this variable can be linked to the corresponding value in the CITATION_NBR variable in the REF_CITATION table to find the source of the BARK_VOL_PCT variable.

61. RAILE_STUMP_DOB_B1

Raile stump diameter outside bark equation coefficient B1. This is equivalent to coefficient B from table 1 in Raile (1982). See appendix J for details on biomass equations.

This coefficient is used in an equation to estimate diameter outside bark at any point on the stump from ground to 1 foot high. From this, volume outside bark is estimated for the selected height along the stump. Volume inside bark is subtracted from volume outside bark to estimate bark volume. Both volumes are converted to biomass using either wood or bark specific gravities. (DOB and DIA are in inches, HT is in feet.)

$$
\mathrm{DOB}=\mathrm{DIA}+(\mathrm{DIA} * \text { RAILE_STUMP_DOB_B1 } *(4.5-\mathrm{HT}) /(\mathrm{HT}+1))
$$




\section{RAILE_STUMP_DIB_B1}

Raile stump diameter inside bark equation coefficient B1. This is equivalent to coefficient A from table 2 in Raile (1982). See appendix J for details on biomass equations.

This coefficient is used along with RAILE_STUMP_DIB_B2 in an equation to estimate diameter inside bark at any point on the stump from ground to 1 foot high. From this, volume inside bark is estimated for the selected height along the stump. Volume inside bark is subtracted from volume outside bark to estimate bark volume. Both volumes are converted to biomass using either wood or bark specific gravities. (DIB and DIA are in inches, HT is in feet.)

$$
\begin{aligned}
\mathrm{DIB}= & (\mathrm{DIA} * \text { RAILE_STUMP_DIB_B })+ \\
& (\text { DIA } * \text { RAILE_STUMP_DIB_B2 } *(4.5-\mathrm{HT}) /(\mathrm{HT}+1))
\end{aligned}
$$

63. RAILE_STUMP_DIB_B2

Raile stump diameter inside bark equation coefficient B2. This is equivalent to coefficient B from table 2 in Raile (1982). See appendix J for details on biomass equations.

This coefficient is used along with RAILE_STUMP_DIB_B1 in an equation to estimate diameter inside bark at any point on the stump from ground to 1 foot high. From this, volume inside bark is estimated for the selected height along the stump. Volume inside bark is subtracted from volume outside bark to estimate bark volume. Both volumes are converted to biomass using either wood or bark specific gravities. (DIB and DIA are in inches, HT is in feet.)

$$
\begin{aligned}
& \mathrm{DIB}=(\mathrm{DIA} * \text { RAILE_STUMP_DIB_B } 1)+ \\
& (\mathrm{DIA} * \text { RAILE_STUMP_DIB_B2 } *(4.5-\mathrm{HT}) /(\mathrm{HT}+1))
\end{aligned}
$$




\section{Reference Species Group Table (Oracle table name is REF_SPECIES_GROUP)}

\begin{tabular}{|l|l|l|l|}
\hline & Column name & Descriptive name & Oracle data type \\
\hline 1 & SPGRPCD & Species group code & NUMBER(2) \\
\hline 2 & NAME & Name & VARCHAR2(35) \\
\hline 3 & REGION & Region & VARCHAR2(8) \\
\hline 4 & CLASS & Class & VARCHAR2(8) \\
\hline 5 & CREATED_BY & Created by & VARCHAR2(30) \\
\hline 6 & CREATED_DATE & Created date & DATE \\
\hline 7 & CREATED_IN_INSTANCE & Created in instance & VARCHAR2(6) \\
\hline 8 & MODIFIED_BY & Modified by & VARCHAR2(30) \\
\hline 9 & MODIFIED_DATE & Modified date & DATE \\
\hline 10 & MODIFIED_IN_INSTANCE & Modified in instance & VARCHAR2(6) \\
\hline
\end{tabular}

\begin{tabular}{|l|l|l|l|}
\hline Type of key & Column(s) order & Tables to link & Abbreviated notation \\
\hline Primary & (SPGRPCD) & N/A & SGP_PK \\
\hline
\end{tabular}

1. SPGRPCD Species group code. A code assigned to each tree species in order to group them for reporting purposes on presentation tables. Codes and their associated names (NAME) are shown in appendix G. Individual tree species and corresponding species group codes are shown in appendix F.

2. NAME Name. A descriptive name for each species group code (SPGRPCD). The names associated with these codes are used to label rows or columns in national standard presentation tables.

3. REGION Region. A description of the section of the United States in which the species, and therefore species group is commonly found. Values are 'EASTERN' and 'WESTERN.'

4. CLASS Class. A descriptor for the classification of the species type with the species group. Values are 'SOFTWOOD' and 'HARDWOOD.'

5. CREATED_BY Created by. The employee who created the record. This attribute is intentionally left blank in download files.

6. CREATED_DATE

Created date. The date the record was created. Date will be in the form DDMON-YYYY.

\section{CREATED_IN_INSTANCE}

Created in instance. The database instance in which the record was created. Each computer system has a unique database instance code and this attribute stores that information to determine on which computer the record was created. 


\section{MODIFIED BY}

Modified by. The employee who modified the record. This field will be blank (null) if the data have not been modified since initial creation. This attribute is intentionally left blank in download files.

9. MODIFIED_DATE

Modified date. The date the record was last modified. This field will be blank (null) if the data have not been modified since initial creation. Date will be in the form DD-MON-YYYY.

\section{MODIFIED_IN_INSTANCE}

Modified in instance. The database instance in which the record was modified. This field will be blank (null) if the data have not been modified since initial creation. 


\section{Reference Habitat Type Description Table (Oracle table name is REF_HABTYP_DESCRIPTION)}

\begin{tabular}{|l|l|l|l|}
\hline & Column name & Descriptive name & Oracle data type \\
\hline 1 & CN & Sequence number & VARCHAR2(34) \\
\hline 2 & HABTYPCD & Habitat type code & VARCHAR2(10) \\
\hline 3 & PUB_CD & Publication code & VARCHAR2(10) \\
\hline 4 & SCIENTIFIC_NAME & Scientific name & VARCHAR2(115) \\
\hline 5 & COMMON_NAME & Common name & VARCHAR2(255) \\
\hline 6 & VALID & Valid & VARCHAR2(1) \\
\hline 7 & CREATED_BY & Created by & VARCHAR2(30) \\
\hline 8 & CREATED_DATE & Created date & DATE \\
\hline 9 & CREATED_IN_INSTANCE & Created in instance & VARCHAR2(6) \\
\hline 10 & MODIFIED_BY & Modified by & VARCHAR2(30) \\
\hline 11 & MODIFIED_DATE & Modified date & DATE \\
\hline 12 & MODIFIED_IN_INSTANCE & Modified in instance & VARCHAR2(6) \\
\hline & & & \\
\hline
\end{tabular}

\begin{tabular}{|l|l|l|l|}
\hline Type of key & Column(s) order & Tables to link & Abbreviated notation \\
\hline Primary & (CN) & N/A & RHN_PK \\
\hline Unique & (HABTYPCD, & N/A & RHN_UK \\
& PUB_CD) & $\begin{array}{l}\text { REF_HABTYP_DESCRIPTION to } \\
\text { REF_HABTYP_PUBLICATION }\end{array}$ & RHN_RPN_FK \\
\hline Foreign & (PUB_CD) & \\
\hline
\end{tabular}

1. $\mathrm{CN}$

2. HABTYPCD

3. PUB_CD
Sequence number. A unique sequence number used to identify a habitat type description record.

Habitat type code. A code representing a habitat type. Unique codes are determined by combining both habitat type code and publication code (HABTYPCD and PUB_CD).

Publication code. A code indicating the publication that lists the name associated with a particular habitat type code (HABTYPCD).

\section{SCIENTIFIC_NAME}

Scientific name. This attribute contains some type of descriptor, usually the Latin name, of the plant(s) associated with the habitat type code. It has values such as the entire scientific name or the shortened synonym of the plant(s) represented by the habitat type code or it may have an English geographic type of descriptor.

\section{COMMON_NAME}

Common name. This attribute contains some type of descriptor, usually the common name, of the plant(s) associated with the habitat type code. 
FIA Database Description and Users Manual for Phase 2, version 4.0

Chapter 3. Reference Habitat Type Description Table

6. VALID Valid. A flag to indicate if this is a valid, documented habitat type code. Values are $\mathrm{Y}$ and $\mathrm{N}$.

7. CREATED_BY Created by. The employee who created the record. This attribute is intentionally left blank in download files.

8. CREATED_DATE

Created date. The date the record was created. Date will be in the form DDMON-YYYY.

9. CREATED_IN_INSTANCE

Created in instance. The database instance in which the record was created. Each computer system has a unique database instance code and this attribute stores that information to determine on which computer the record was created.

10. MODIFIED_BY

Modified by. The employee who modified the record. This field will be blank (null) if the data have not been modified since initial creation. This attribute is intentionally left blank in download files.

11. MODIFIED_DATE

Modified date. The date the record was last modified. This field will be blank (null) if the data have not been modified since initial creation. Date will be in the form DD-MON-YYYY.

\section{MODIFIED_IN_INSTANCE}

Modified in instance. The database instance in which the record was modified. This field will be blank (null) if the data have not been modified since initial creation. 


\section{Reference Habitat Type Publication Table (Oracle table name is REF_HABTYP_PUBLICATION)}

\begin{tabular}{|l|l|l|l|}
\hline & Column name & Descriptive name & Oracle data type \\
\hline 1 & CN & Sequence number & VARCHAR2(34) \\
\hline 2 & PUB_CD & Publication code & VARCHAR2(10) \\
\hline 3 & TITLE & Title of publication & VARCHAR2(200) \\
\hline 4 & AUTHOR & Author of publication & VARCHAR2(200) \\
\hline 5 & TYPE & Type of publication & VARCHAR2(10) \\
\hline 6 & VALID & Valid & VARCHAR2(1) \\
\hline 7 & CREATED_BY & Created by & VARCHAR2(30) \\
\hline 8 & CREATED_DATE & Created date & DATE \\
\hline 9 & CREATED_IN_INSTANCE & Created in instance & VARCHAR2(6) \\
\hline 10 & MODIFIED_BY & Modified by & VARCHAR2(30) \\
\hline 11 & MODIFIED_DATE & Modified date & DATE \\
\hline 12 & MODIFIED_IN_INSTANCE & Modified in instance & VARCHAR2(6) \\
\hline
\end{tabular}

\begin{tabular}{|l|l|l|l|}
\hline Type of key & Column(s) order & Tables to link & Abbreviated notation \\
\hline Primary & (CN) & N/A & RPN_PK \\
\hline Unique & (PUB_CD) & N/A & RPN_UK \\
\hline
\end{tabular}

1. $\mathrm{CN}$

2. PUB_CD

3. TITLE

4. AUTHOR

5. TYPE

6. VALID
Sequence number. A unique sequence number used to identify a habitat type publication record.

Publication code. A code indicating the publication that lists the name associated with a particular habitat type code (REF_HABTYP_DESCRIPTION.HABTYPCD).

Title. The title of the publication defining particular habitat types.

Author. The author of the publication defining particular habitat types.

Type. An attribute describing if the habitat type publication describes potential vegetation or existing vegetation. Values are PVREF and EVREF. If it is unknown which type of habitat is being described, then TYPE $=$ ?.

Valid. A flag to indicate if this publication is valid for FIA. Values are Y and N.

7. CREATED_BY Created by. The employee who created the record. This attribute is intentionally left blank in download files.

8. CREATED_DATE

Created date. The date the record was created. Date will be in the form DDMON-YYYY. 


\section{CREATED IN INSTANCE}

Created in instance. The database instance in which the record was created. Each computer system has a unique database instance code and this attribute stores that information to determine on which computer the record was created.

10. MODIFIED_BY

Modified by. The employee who modified the record. This field will be blank (null) if the data have not been modified since initial creation. This attribute is intentionally left blank in download files.

11. MODIFIED_DATE

Modified date. The date the record was last modified. This field will be blank (null) if the data have not been modified since initial creation. Date will be in the form DD-MON-YYYY.

\section{MODIFIED_IN_INSTANCE}

Modified in instance. The database instance in which the record was modified. This field will be blank (null) if the data have not been modified since initial creation. 


Reference Citation Table (Oracle table name is REF_CITATION)
\begin{tabular}{|l|l|l|l|}
\hline & Column name & Descriptive name & Oracle data type \\
\hline 1 & CITATION_NBR & Citation number & NUMBER(7) \\
\hline 2 & CITATION & Citation & VARCHAR2(2000) \\
\hline 3 & CREATED_BY & Created by & VARCHAR2(30) \\
\hline 4 & CREATED_DATE & Created date & DATE \\
\hline 5 & CREATED_IN_INSTANCE & Created in instance & VARCHAR2(6) \\
\hline 6 & MODIFIED_BY & Modified by & VARCHAR2(30) \\
\hline 7 & MODIFIED_DATE & Modified date & DATE \\
\hline 8 & MODIFIED_IN_INSTANCE & Modified in instance & VARCHAR2(6) \\
\hline
\end{tabular}

\begin{tabular}{|l|l|l|l|}
\hline Type of key & Column(s) order & Tables to link & Abbreviated notation \\
\hline Primary & (CITATION_NBR) & N/A & CIT_PK \\
\hline
\end{tabular}

1. CITATION_NBR

Citation number. A unique number used to identify a REF_CITATION record. Citation information is currently available in the database only for information about the source of specific gravity and bark volume percent values contained in the REF_SPECIES table. REF_SPECIES variables ending in "_CIT" link back to the REF_CITATION $\bar{N}$ table through CITATION_NBR.

2. CITATION Citation. This attribute is usually a publication citation. In some cases CITATION may contain more specific information about how data were populated for a field.

3. CREATED_BY Created by. The employee who created the record. This attribute is intentionally left blank in download files.

4. CREATED_DATE

Created date. The date the record was created. Date will be in the form DDMON-YYYY.

5. CREATED_IN_INSTANCE

Created in instance. The database instance in which the record was created. Each computer system has a unique database instance code and this attribute stores that information to determine on which computer the record was created. 
6. MODIFIED_BY

Modified by. The employee who modified the record. This field will be blank (null) if the data have not been modified since initial creation. This attribute is intentionally left blank in download files.

7. MODIFIED_DATE

Modified date. The date the record was last modified. This field will be blank (null) if the data have not been modified since initial creation. Date will be in the form DD-MON-YYYY.

\section{MODIFIED_IN_INSTANCE}

Modified in instance. The database instance in which the record was modified. This field will be blank (null) if the data have not been modified since initial creation. 


\section{Reference Forest Inventory and Analysis Database Version Table (Oracle table name is REF FIADB VERSION)}

\begin{tabular}{|l|l|l|l|}
\hline & Column name & Descriptive name & Oracle data type \\
\hline 1 & VERSION & Version number & NUMBER(3,1) \\
\hline 2 & DESCR & Version description & VARCHAR2(2000) \\
\hline 3 & CREATED_BY & Created by & VARCHAR2(30) \\
\hline 4 & CREATED_DATE & Created date & DATE \\
\hline 5 & CREATED_IN_INSTANCE & Created in instance & VARCHAR2(6) \\
\hline 6 & MODIFIED_BY & Modified by & VARCHAR2(30) \\
\hline 7 & MODIFIED_DATE & Modified date & DATE \\
\hline 8 & MODIFIED_IN_INSTANCE & Modified in instance & VARCHAR2(6) \\
\hline 9 & INSTALL_TYPE & Install type & VARCHAR2(10) \\
\hline
\end{tabular}

\begin{tabular}{|l|l|l|l|}
\hline Type of key & Column(s) order & Tables to link & Abbreviated notation \\
\hline Primary & (VERSION) & N/A & RFN_PK \\
\hline
\end{tabular}

1. VERSION Version number. A unique number used to identify a

REF_FIADB_VERSION record. VERSION equals the currently available version of the FIADB.

2. DESCR Version description. A description of the FIADB version. This may include a literature citation and internet links to documentation.

3. CREATED_BY Created by. The employee who created the record. This attribute is intentionally left blank in download files.

4. CREATED_DATE

Created date. The date the record was created. Date will be in the form DDMON-YYYY.

\section{CREATED_IN_INSTANCE}

Created in instance. The database instance in which the record was created.

Each computer system has a unique database instance code and this attribute stores that information to determine on which computer the record was created.

6. MODIFIED_BY

Modified by. The employee who modified the record. This field will be blank (null) if the data have not been modified since initial creation. This attribute is intentionally left blank in download files. 


\section{MODIFIED DATE}

Modified date. The date the record was last modified. This field will be blank (null) if the data have not been modified since initial creation. Date will be in the form DD-MON-YYYY.

\section{MODIFIED_IN_INSTANCE}

Modified in instance. The database instance in which the record was modified. This field will be blank (null) if the data have not been modified since initial creation.

9. INSTALL_TYPE

Install type. Intentionally left blank. Will be populated in version 5.0. 


Reference State Elevation Table (Oracle table name is REF_STATE_ELE
\begin{tabular}{|l|l|l|l|}
\hline & Column name & Descriptive name & Oracle data type \\
\hline 1 & STATECD & State code & NUMBER(4) \\
\hline 2 & MIN_ELEV & Minimum elevation & NUMBER(5) \\
\hline 3 & MAX_ELEV & Maximum elevation & NUMBER(5) \\
\hline 4 & LOWEST_POINT & Lowest point & VARCHAR2(30) \\
\hline 5 & HIGHEST_POINT & Highest point & VARCHAR2(30) \\
\hline 6 & CREATED_BY & Created by & VARCHAR2(30) \\
\hline 7 & CREATED_DATE & Created date & DATE \\
\hline 8 & CREATED_IN_INSTANCE & Created in instance & VARCHAR26) \\
\hline 9 & MODIFIED_BY & Modified by & VARCHAR2(30) \\
\hline 10 & MODIFIED_DATE & Modified date & DATE \\
\hline 11 & MODIFIED_IN_INSTANCE & Modified in instance & VARCHAR2(6) \\
\hline
\end{tabular}

\begin{tabular}{|l|l|l|l|}
\hline Type of key & Column(s) order & Tables to link & Abbreviated notation \\
\hline Primary & (STATECD) & N/A & RSE_PK \\
\hline
\end{tabular}

1. STATECD State code. Bureau of the Census Federal Information Processing Standards (FIPS) two-digit code for each State. Refer to appendix C.

2. MIN_ELEV Minimum elevation. The minimum elevation within the State in feet.

3. MAX_ELEV Maximum elevation. The maximum elevation within the State in feet.

\section{LOWEST_POINT}

Lowest point. The name of the lowest point within the State. 'SL' refers to sea level. Negative minimum elevations are listed here.

\section{HIGHEST_POINT}

Highest point. The name of the highest point within the State. Alternative names are provided also.

6. CREATED_BY Created by. The employee who created the record. This attribute is intentionally left blank in download files.

7. CREATED_DATE

Created date. The date the record was created. Date will be in the form DDMON-YYYY. 


\section{CREATED_IN_INSTANCE}

Created in instance. The database instance in which the record was created. Each computer system has a unique database instance code and this attribute stores that information to determine on which computer the record was created.

9. MODIFIED_BY

Modified by. The employee who modified the record. This field will be blank (null) if the data have not been modified since initial creation. This attribute is intentionally left blank in download files.

10. MODIFIED_DATE

Modified date. The date the record was last modified. This field will be blank (null) if the data have not been modified since initial creation. Date will be in the form DD-MON-YYYY.

\section{MODIFIED_IN_INSTANCE}

Modified in instance. The database instance in which the record was modified. This field will be blank (null) if the data have not been modified since initial creation. 


\section{Reference Unit Table (Oracle table name is REF_UNIT)}

\begin{tabular}{|l|l|l|l|}
\hline & Column name & Descriptive name & Oracle data type \\
\hline 1 & STATECD & State code & NUMBER(4) \\
\hline 2 & VALUE & Value & NUMBER(2) \\
\hline 3 & MEANING & Meaning & VARCHAR2(80) \\
\hline 4 & CREATED_BY & Created by & VARCHAR2(30) \\
\hline 5 & CREATED_DATE & Created date & DATE \\
\hline 6 & CREATED_IN_INSTANCE & Created in instance & VARCHAR2(6) \\
\hline 7 & MODIFIED_BY & Modified by & VARCHAR2(30) \\
\hline 8 & MODIFIED_DATE & Modified date & DATE \\
\hline 9 & MODIFIED_IN_INSTANCE & Modified in instance & VARCHAR2(6) \\
\hline
\end{tabular}

\begin{tabular}{|l|l|l|l|}
\hline Type of key & Column(s) order & Tables to link & Abbreviated notation \\
\hline Primary & (STATECD, VALUE) & N/A & UNT_PK \\
\hline
\end{tabular}

1. STATECD State code. Bureau of the Census Federal Information Processing Standards (FIPS) two-digit code for each State. Refer to appendix C.

2. VALUE Value. Forest Inventory and Analysis survey unit identification number. Survey units are usually groups of counties within each State. For periodic inventories, survey units may be made up of lands of particular owners. Refer to appendix $\mathrm{C}$ for codes.

3. MEANING Meaning. The name corresponding to the survey unit code (VALUE) in the State (STATECD). Refer to appendix C.

4. CREATED_BY Created by. The employee who created the record. This attribute is intentionally left blank in download files.

5. CREATED_DATE

Created date. The date the record was created. Date will be in the form DDMON-YYYY.

6. CREATED_IN_INSTANCE

Created in instance. The database instance in which the record was created. Each computer system has a unique database instance code and this attribute stores that information to determine on which computer the record was created.

7. MODIFIED_BY

Modified by. The employee who modified the record. This field will be blank (null) if the data have not been modified since initial creation. This attribute is intentionally left blank in download files. 
FIA Database Description and Users Manual for Phase 2, version 4.0

Chapter 3. Reference Unit Table

\section{MODIFIED DATE}

Modified date. The date the record was last modified. This field will be blank (null) if the data have not been modified since initial creation. Date will be in the form DD-MON-YYYY.

\section{MODIFIED_IN_INSTANCE}

Modified in instance. The database instance in which the record was modified. This field will be blank (null) if the data have not been modified since initial creation. 


\section{Chapter 4 - Calculating Population Estimates and Their Associated Sampling Errors}

This chapter presents procedures written in Oracle ${ }^{\mathrm{TM}} \mathrm{SQL}$ script that can be used to obtain population estimates (and associated sampling errors) for standard FIA attributes from the measurement data stored in the FIADB. These estimates follow the equations presented in Bechtold and Patterson (2005, chapter 4). Population estimates for many attributes can be generated using either the web-based EVALIDator tool or the Forest Inventory Data Online (FIDO) tool, which provides interactive access to the FIADB. These tools can be found at http://fia.fs.fed.us/tools-data.

All data stored in FIADB can be downloaded from http://fia.fs.fed.us/tools-data as either comma delimited files or Microsoft (MS) Access databases. Because of size limitations, data are stored in individual State databases. The SQL scripts used with MS Access differ from Oracle ${ }^{\mathrm{TM}}$ SQL scripts described in this chapter; however a number of MS Access queries are provided in the MS Access databases. All of the FIADB 4.0 tables are included in both formats. The MS Access databases have a few additional tables that make using the data and constructing queries easier and simpler. In addition, numerous queries that produce population estimates and standard errors are provided. Users can use these queries as a starting point to create customized queries suitable for local or regional analyses.

The FIADB can be used to estimate many attributes (e.g., forest area, timberland area, number of trees, net volume, biomass) from many different samples (typically State-wide inventories for a specific year or set of years). Therefore, the number of estimates that can be made from the FIADB is very large, and continues to increase as more data are added to the FIADB. This chapter provides examples of a few estimation procedures that can be modified by the user. The resulting estimates shown as output are examples only and are not necessarily the exact numbers a user will obtain using current data.

In addition to the naming conventions used in the FIADB, reference is made to the notation and terminology used in Bechtold and Patterson (2005). To fully understand the statistical basis of the estimation, readers may find it useful to refer to that publication as they review this chapter.

Examples that estimate area of timberland, number of live trees on forest land, number of seedlings on timberland, and volume of growing-stock on timberland are presented, along with discussion of how these examples can be modified to estimate other attributes measured in Phase 2.

The basic estimation is broken down into four steps, with additional steps for users who want to go beyond the traditional population level estimates.

1. Selecting the attribute of interest (the quantity that is to be estimated).

2. Selecting an appropriate sample.

3. Linking the appropriate tables in the FIADB to produce estimates for attributes of interest for a population.

4. Producing estimates with sampling errors for attributes of interest for a population.

5. Restricting the attribute of interest to a smaller subset of the population (e.g., filtering the data to include only sawtimber stands on publicly owned timberland, versus all stands in all ownerships).

6. Changing the attribute of interest with user-defined criteria.

7. Estimating change over time on the standard 4-subplot fixed area plot. 


\section{Selecting the attribute of interest (using the REF_POP_ATTRIBUTE table)}

The most common attributes of interest in FIADB estimation are described in the REF_POP_ATTRIBUTE table, which currently contains 92 entries. Attributes are currently defined at three levels (1) condition level attributes for area estimates; (2) tree level attributes for numbers of trees, volume, growth, removals, and mortality estimates; and (3) seedling level attributes for number of seedlings estimates. Estimation of condition level attributes requires accessing data on the PLOT and COND tables. Estimation of tree level attributes requires accessing data on the PLOT, COND, and TREE tables. Estimation of seedling level attributes requires accessing data on the PLOT, COND, and SEEDLING tables. Table 4.1 lists the attributes currently defined in the REF_POP_ATTRIBUTE table.

Table 4.1. Values and Descriptions in the REF_POP_ATTRIBUTE table.

\begin{tabular}{|c|c|}
\hline $\begin{array}{l}\text { Attribute number } \\
\text { (ATTRIBUTE NBR) }\end{array}$ & $\begin{array}{l}\text { Attribute description } \\
\text { (ATTRIBUTE DESCR) }\end{array}$ \\
\hline 1 & Area sampled and denied access/hazardous (acres) \\
\hline 2 & Area of forestland (acres) \\
\hline 3 & Area of timberland (acres) \\
\hline 4 & Number of all live trees on forestland (trees) \\
\hline 5 & Number of growing-stock trees on forestland (trees) \\
\hline 6 & Number of standing dead trees 5 inches $+\mathrm{dbh}$ on forestland (trees) \\
\hline 7 & Number of all live trees on timberland (trees) \\
\hline 8 & Number of growing-stock trees on timberland (trees) \\
\hline 9 & Number of standing dead trees 5 inches $+\mathrm{dbh}$ on timberland (trees) \\
\hline 10 & All live tree and sapling aboveground biomass on forestland oven-dry (short tons) \\
\hline 11 & All live merchantable biomass on forestland oven-dry (short tons) \\
\hline 12 & All live merchantable biomass on timberland oven-dry (short tons) \\
\hline 13 & All live tree and sapling aboveground biomass on timberland oven-dry (short tons) \\
\hline 14 & Volume of all live on forestland (cuft) \\
\hline 15 & Volume of growing-stock on forestland (cuft) \\
\hline 16 & Volume of sawlog portion on forestland (cuft) \\
\hline 17 & Volume of all live on timberland (cuft) \\
\hline 18 & Volume of growing-stock on timberland (cuft) \\
\hline 19 & Volume of sawlog portion on timberland (cuft) \\
\hline 20 & Volume of sawtimber on forestland (bdft) \\
\hline 21 & Volume of sawtimber on timberland (bdft) \\
\hline 22 & All live gross sawtimber volume on forestland (bdft) \\
\hline 23 & All live gross volume on forestland (cuft) \\
\hline 24 & All live sound volume on forestland (cuft) \\
\hline 25 & Net growth of all live on forestland (cuft per year) \\
\hline 26 & Net growth of growing-stock on forestland (cuft per year) \\
\hline 27 & Net growth of sawtimber on forestland (bdft per year) \\
\hline 28 & Net growth of all live on timberland (cuft per year) \\
\hline 29 & Net growth of growing-stock on timberland (cuft per year) \\
\hline 30 & Net growth of sawtimber on timberland (bdft per year) \\
\hline 31 & Mortality of all live on forestland (cuft per year) \\
\hline 32 & Mortality of all live trees on forestland (trees per year) \\
\hline 33 & Mortality of growing-stock on forestland (cuft per year) \\
\hline 34 & Mortality of sawtimber on forestland (bdft per year) \\
\hline 35 & Mortality of all live on timberland (cuft per year) \\
\hline 36 & Mortality of all live trees on timberland (trees per year) \\
\hline 37 & Mortality of growing-stock on timberland (cuft per year) \\
\hline 38 & Mortality of sawtimber on timberland (bdft per year) \\
\hline 39 & Removals of all live on forestland (cuft per year) \\
\hline
\end{tabular}




\begin{tabular}{|c|c|}
\hline $\begin{array}{l}\text { Attribute number } \\
\text { (ATTRIBUTE_NBR) }\end{array}$ & $\begin{array}{l}\text { Attribute description } \\
\text { (ATTRIBUTE_DESCR) }\end{array}$ \\
\hline 40 & Removals of growing-stock on forestland (cuft per year) \\
\hline 41 & Removals of sawtimber on forestland (bdft per year) \\
\hline 42 & Removals of all live on timberland (cuft per year) \\
\hline 43 & Removals of growing-stock on timberland (cuft per year) \\
\hline 44 & Removals of sawtimber on timberland (bdft per year) \\
\hline 45 & Number of live seedlings on forestland (seedlings) \\
\hline 46 & Number of live seedlings on timberland (seedlings) \\
\hline 47 & Carbon in standing dead trees on forestland (short tons) \\
\hline 48 & Carbon in understory aboveground on forestland (short tons) \\
\hline 49 & Carbon in understory belowground on forestland (short tons) \\
\hline 50 & Carbon in down dead on forestland (short tons) \\
\hline 51 & Carbon in litter on forestland (short tons) \\
\hline 52 & Soil organic carbon on forestland (short tons) \\
\hline 53 & Carbon in live trees and saplings aboveground on forestland (short tons) \\
\hline 54 & Carbon in live trees and saplings belowground on forestland (short tons) \\
\hline 55 & $\begin{array}{l}\text { Carbon in live trees and saplings above and belowground on forestland (short } \\
\text { tons) }\end{array}$ \\
\hline 56 & All live top and limb biomass on forestland oven-dry (short tons) \\
\hline 57 & All live sapling biomass on forestland oven-dry (short tons) \\
\hline 58 & All live stump (ground to 12 inches) biomass on forestland oven-dry (short tons) \\
\hline 59 & $\begin{array}{l}\text { All live belowground tree and sapling and woodland species biomass on } \\
\text { forestland oven-dry (short tons) }\end{array}$ \\
\hline 60 & All live woodland species biomass on forestland oven-dry (short tons) \\
\hline 61 & Carbon in standing dead trees on timberland (short tons) \\
\hline 62 & Carbon in understory aboveground on timberland (short tons) \\
\hline 63 & Carbon in understory belowground on timberland (short tons) \\
\hline 64 & Carbon in down dead on timberland (short tons) \\
\hline 65 & Carbon in litter on timberland (short tons) \\
\hline 66 & Soil organic carbon on timberland (short tons) \\
\hline 67 & Carbon in live trees and saplings aboveground on timberland (short tons) \\
\hline 68 & Carbon in live trees belowground on timberland (short tons) \\
\hline 69 & Carbon in live trees above and belowground on timberland (short tons) \\
\hline 70 & All live top and limb biomass on timberland oven-dry (short tons) \\
\hline 71 & All live sapling biomass on timberland oven-dry (short tons) \\
\hline 72 & All live stump (ground to 12 inches) biomass on timberland oven-dry (short tons) \\
\hline 73 & $\begin{array}{l}\text { All live belowground tree and sapling and woodland species biomass on } \\
\text { timberland oven-dry (short tons) }\end{array}$ \\
\hline 74 & All live woodland species biomass on timberland oven-dry (short tons) \\
\hline 75 & $\begin{array}{l}\text { Old regional method - All live tree and sapling aboveground biomass on forestland } \\
\text { oven-dry (short tons) }\end{array}$ \\
\hline 76 & $\begin{array}{l}\text { Old regional method - All live merchantable biomass on forestland oven-dry (short } \\
\text { tons) }\end{array}$ \\
\hline 77 & $\begin{array}{l}\text { Old regional method - All live merchantable biomass on timberland oven-dry } \\
\text { (short tons) }\end{array}$ \\
\hline 78 & $\begin{array}{l}\text { Old regional method - All live tree and sapling aboveground biomass on } \\
\text { timberland oven-dry (short tons) }\end{array}$ \\
\hline 79 & Area sampled (acres) \\
\hline 80 & Harvest removals of all live on forestland (cuft per year) \\
\hline 81 & Harvest removals of growing-stock on forestland (cuft per year) \\
\hline 82 & Harvest removals of sawtimber on forestland (bdft per year) \\
\hline 83 & Harvest removals of all live on timberland (cuft per year) \\
\hline 84 & Harvest removals of growing-stock on timberland (cuft per year) \\
\hline 85 & Harvest removals of sawtimber on timberland (bdft per year) \\
\hline 86 & Other removals of all live on forestland (cuft per year) \\
\hline
\end{tabular}




\begin{tabular}{|l|l|}
\hline $\begin{array}{l}\text { Attribute number } \\
\text { (ATTRIBUTE_NBR) }\end{array}$ & $\begin{array}{l}\text { Attribute description } \\
\text { (ATTRIBUTE_DESCR) }\end{array}$ \\
\hline 87 & Other removals of growing-stock on forestland (cuft per year) \\
\hline 88 & Other removals of sawtimber on forestland (bdft per year) \\
\hline 89 & Other removals of all live on timberland (cuft per year) \\
\hline 90 & Other removals of growing-stock on timberland (cuft per year) \\
\hline 91 & Other removals of sawtimber on timberland (bdft per year) \\
\hline 92 & Volume of standing dead trees on forestland (cuft) \\
\hline
\end{tabular}

In this chapter we present examples that estimate:

- Area of timberland (REF_POP_ATTRIBUTE.ATTRIBUTE_NBR = 3).

- Number of live trees on forest land (REF_POP_ATTRIBUTE.ATTRIBUTE_NBR $=4$ ).

- Volume of growing-stock on timberland (REF_POP_ATTRIBUTE.ATTRIBUTE_NBR $=18$.

- Number of live seedlings on timberland (REF_POP_ATTRIBUTE.ATTRIBUTE_NBR = 46).

These are examples of condition, tree, and seedling level attributes that can be modified to produce other estimates of attributes at these levels. For each attribute, the REF_POP_ATTRIBUTE table contains a unique ATTRIBUTE_NBR, a description of the attribute (ATTRIBUTE_DESCR), and the variables EXPRESSION and WHERE_CLAUSE that are both portions of the SQL statements used to produce the estimates of the attribute. Table 4.2 lists these four variables for the four examples we are presenting. (Note: in EXPRESSION and WHERE_CLAUSE, 'c' stands for COND table, ' $t$ ' stands for TREE table, 's' stands for SEEDLING table, and 'pet' stands for POP_EVAL_TYP table.)

Table 4.2. REF_POP_ATTRIBUTE entries for the four examples presented in this chapter.

\begin{tabular}{|c|c|c|c|}
\hline $\begin{array}{l}\text { ATTRIBUTE } \\
\text { NBR }\end{array}$ & ATTRIBUTE DESCR & EXPRESSION a & WHERE CLAUSE \\
\hline 3 & Area of timberland (acres) & $\begin{array}{l}\text { c.condprop_unadj" } \\
\text { decode(c.prop_basis,'MACR',pop_stratum.adj_factor_macr, } \\
\text { pop_stratum.adj_factor_subp) }\end{array}$ & $\begin{array}{l}\text { and pet.eval_typ='EXPCURR' } \\
\text { and c.cond_status_cd }=1 \text { and } \\
\text { c.reservcd }=0 \text { and c.siteclcd in } \\
(1,2,3,4,5,6)\end{array}$ \\
\hline 4 & $\begin{array}{l}\text { Number of all live trees on } \\
\text { forestland (trees) }\end{array}$ & $\begin{array}{l}\text { t.tpa_unadj }{ }^{\star} \\
\text { decode(dia,null,adj_factor_subp, } \\
\text { decode(least(dia,5-0.001),dia,adj_factor_micr, } \\
\text { decode(least(dia, nvl(macro_breakpoint_dia,9999)- } \\
\text { 0.001),dia,adj_factor_subp, } \\
\text { adj_factor_macr))) }\end{array}$ & $\begin{array}{l}\text { and pet.eval_typ='EXPVOL' } \\
\text { and t.plt_cn }=c . p l t \_c n \text { and } \\
\text { t.condid }=\text { c.condid and } \\
\text { c.cond_status_cd }=1 \text { and t.statuscd }=1 \\
\text { and t.dia }>=1.0\end{array}$ \\
\hline 18 & $\begin{array}{l}\text { Volume of growing-stock on } \\
\text { timberland (cuft) }\end{array}$ & $\begin{array}{l}\text { t.tpa_unadj* t.volcfnet* } \\
\text { decode(dia,null,adj_factor_subp, } \\
\text { decode(least(dia,5-0.001),dia,adj_factor_micr, } \\
\text { decode(least(dia, nvl(macro_breakpoint_dia,9999)- } \\
\text { 0.001),dia,adj_factor_subp, } \\
\text { adj_factor_macr))) }\end{array}$ & $\begin{array}{l}\text { and pet.eval_typ='EXPVOL' } \\
\text { and t.plt_cn=c.plt_cn and } \\
\text { t.condid }=\text { c.condid and } \\
\text { c.cond_status_cd }=1 \text { and c.reservcd }=0 \\
\text { and c.siteclcd in }(1,2,3,4,5,6) \text { and } \\
\text { t.statuscd }=1 \text { and t.treeclcd }=2 \text { and } \\
\text { t.dia }>=5.0\end{array}$ \\
\hline 46 & $\begin{array}{l}\text { Number of live seedlings on } \\
\text { timberland (seedlings) }\end{array}$ & s.tpa_unadj*adj_factor_micr & $\begin{array}{l}\text { and pet.eval_typ='EXPVOL' } \\
\text { and s.plt_cn }=c . p l t \_c n \text { and } \\
\text { s.condid }=c . \text { condid and } \\
\text { c.cond_status_cd }=1 \text { and c.reservcd }=0 \\
\text { and c.siteclcd in }(1,2,3,4,5,6)\end{array}$ \\
\hline
\end{tabular}

a Note that for Microsoft Access SQL, the decode function is replaced with the IIF function 
EXPRESSION is multiplied by the expansion factor POP_STRATUM.EXPNS and summed at the condition level in the estimation procedure. In the notation used in Bechtold and Patterson (2005), this sum is $\mathrm{P}_{\text {hid }}$ for area estimation (see equation 4.1, page 47) or $\mathrm{y}_{\text {hid }}$ for the estimation of tree attributes (see equation 4.8, page 53). In all cases, EXPRESSION consists of the product of two terms, the first term (c.condprop_unadj, t.tpa_unadj, and s.tpa_unadj in our examples) is the unadjusted observation of the attribute of interest (on a per acre basis). The second term is the appropriate stratum adjustment factor. The stratum adjustment factor is the inverse of the mean proportion of the sample plot areas that were within the population. Following the notation of Bechtold and Patterson (2005) this adjustment factor is $1 / \bar{p}_{m h}$ (see equation 4.2, page 49). The decode statement simply selects the appropriate adjustment factor to be used for the specific estimate. Area estimates use either ADJ_FACTOR_MACR (in inventories where area estimates are based on the macroplot) or ADJ_FACTŌR_SUBP (in inventories where area estimates are based on the subplot) for the adjustment. The adjustment of tree- and seedling-level estimates is based on the plot on which the tree or seedling was sampled (seedlings and trees $<5$ inches diameter are sampled on the microplot, larger trees are sampled on the subplot or macroplot depending on diameter).

Common selection criteria used often with FIA data when creating queries include various classifications of land and groups of trees as shown below:

\section{Identifying land classes (COND table):}

\begin{tabular}{|l|l|}
\hline Forest land & COND_STATUS_CD $=1$ \\
\hline Timberland & COND_STATUS_CD $=1$, SITECLCD $<7, \operatorname{RESERVCD~}=0$ \\
\hline Nonforest land & COND_STATUS_CD $=2$ \\
\hline Reserved forest land & COND_STATUS_CD $=1$, RESERVCD $=1$ \\
\hline Unreserved forest land & COND_STATUS_CD $=1$, RESERVCD $=0$ \\
\hline Productive forest land & COND_STATUS_CD $=1$, SITECLCD $<7$ \\
\hline Unproductive forest land & COND_STATUS_CD $=1$, SITECLCD $=7$ \\
\hline
\end{tabular}

Identifying tree characteristics:

\begin{tabular}{|l|l|}
\hline Live trees & TREE.STATUSCD $=1$ \\
\hline Standing dead trees & TREE.STATUSCD $=2$, TREE.STANDING_DEAD_CD $=1$ \\
\hline Growing-stock trees & TREE.STATUSCD $=1$, TREE.TREECLCD $=2$ \\
\hline Growing-stock volume & TREE.STATUSCD $=1$, TREE.TREECLCD $=2$, TREE.DIA $\geq 5.0$ \\
\hline
\end{tabular}

\section{Selecting an appropriate sample (using the POP_EVAL_GRP, POP_EVAL, and POP_EVAL_TYP tables)}

In order to compute a sample-based population estimate, the appropriate sample and stratification must be identified. In FIA estimation, the sample is a set of plots that were selected for the attribute of interest that was observed. The stratification consists of an assignment of plots to strata (nonoverlapping areas of a known or estimated size) that in aggregate define the population of interest. There is an assignment of plots to every stratum, and all plots are assigned to one, and only one stratum, for each evaluation. FIA uses the term "evaluation" to reference the relationship that links a set of plots to a set of strata for estimation purposes. Thus, an evaluation is a set of plots defined 
in the FIADB that can be used to make a statistically valid sample-based estimate for a population (area of land) based on a specific stratification.

Each evaluation used by FIA is identified, named, and stored as a single entry in the POP_EVAL table. The important data items in the POP_EVAL table are listed in table 4.3 for all evaluations that are loaded into the FIADB for data collected in Minnesota through 2006. CN is the control number that uniquely identifies the entry and is used in creating links to other tables. RSCD (Region or Station Code) and EVALID (Evaluation Identifier) are the natural identifiers of a specific record. EVAL_DESCR provides a description of the evaluation. STATECD and LOCATION_NM describe the geographic extent of the population that was sampled and REPORT_YEAR_NM describes the years in which the sample was taken. For older periodic inventories, REPORT_YEAR_NM typically reflects a single reporting year (the one used in the FIA publications), even though the plots may have been measured over several years. Annual inventories (taken since 1999) list the years of data measurements used in the estimation. There are usually multiple evaluations for a specific year because not all plots observed have every attribute of interest, and/or different stratifications are used in the estimation of different attributes of interest. For example, volume estimation can be done on plots measured at only one point in time. However, growth estimates require repeat measurements. Thus, evaluations for the estimation of growth only assign those plots that are repeat measurement plots to strata, and do not include onetime measurement plots.

Table 4.3. Important POP_EVAL entries for Minnesota through 2006 from the FIADB.

\begin{tabular}{|c|c|c|c|c|c|c|c|}
\hline & \multicolumn{7}{|c|}{ Data item names } \\
\hline & CN & RSCD & EVALID & EVAL DESCR & STATECD & LOCATION NM & REPORT YEAR NM \\
\hline \multirow{21}{*}{$\begin{array}{l}\text { Data } \\
\text { item } \\
\text { values }\end{array}$} & 107106457010661 & 23 & 277701 & Minnesota, 1977: area (periodic) & 27 & Minnesota & 1977 \\
\hline & 107106458010661 & 23 & 277702 & Minnesota, 1977: volume (periodic) & 27 & Minnesota & 1977 \\
\hline & 107106459010661 & 23 & 277703 & Minnesota, 1977: growth (periodic) & 27 & Minnesota & 1977 \\
\hline & 107106460010661 & 23 & 277704 & Minnesota, 1977: mortality (periodic) & 27 & Minnesota & 1977 \\
\hline & 107106461010661 & 23 & 277705 & Minnesota, 1977: removals (periodic) & 27 & Minnesota & 1977 \\
\hline & 107106462010661 & 23 & 279001 & Minnesota, 1990: area (periodic) & 27 & Minnesota & 1990 \\
\hline & 107106463010661 & 23 & 279002 & Minnesota, 1990: volume (periodic) & 27 & Minnesota & 1990 \\
\hline & 107106464010661 & 23 & 279003 & Minnesota, 1990: growth (periodic) & 27 & Minnesota & 1990 \\
\hline & 107106465010661 & 23 & 279004 & Minnesota, 1990: mortality (periodic) & 27 & Minnesota & 1990 \\
\hline & 107106466010661 & 23 & 279005 & Minnesota, 1990: removals (periodic) & 27 & Minnesota & 1990 \\
\hline & 107106467010661 & 23 & 279006 & Minnesota, 1990: change (periodic) & 27 & Minnesota & 1990 \\
\hline & 107106444010661 & 23 & 270300 & Minnesota, 1999-2003: all land & 27 & Minnesota & $\begin{array}{l}\text { 1999;2000;2001; } \\
2002 ; 2003\end{array}$ \\
\hline & 107106445010661 & 23 & 270301 & Minnesota, 1999-2003: area/volume & 27 & Minnesota & $\begin{array}{l}\text { 1999;2000;2001; } \\
2002 ; 2003\end{array}$ \\
\hline & 107106446010661 & 23 & 270302 & Minnesota, 1990 to 1999-2003: GRM & 27 & Minnesota & $\begin{array}{l}\text { 1999;2000;2001; } \\
2002 ; 2003\end{array}$ \\
\hline & 107106448010661 & 23 & 270400 & Minnesota, 2000-2004: all land & 27 & Minnesota & $\begin{array}{l}2000 ; 2001 ; 2002 ; \\
2003 ; 2004\end{array}$ \\
\hline & 107106449010661 & 23 & 270401 & Minnesota, 2000-2004: area/volume & 27 & Minnesota & $\begin{array}{l}2000 ; 2001 ; 2002 ; \\
2003 ; 2004\end{array}$ \\
\hline & 107106450010661 & 23 & 270402 & Minnesota, 1999 to 2004: GRM & 27 & Minnesota & 2004 \\
\hline & 107106451010661 & 23 & 270500 & Minnesota, 2001-2005: all land & 27 & Minnesota & $\begin{array}{l}2001 ; 2002 ; 2003 ; \\
2004 ; 2005\end{array}$ \\
\hline & 107106452010661 & 23 & 270501 & Minnesota, 2001-2005: area/volume & 27 & Minnesota & $\begin{array}{l}2001 ; 2002 ; 2003 ; \\
2004 ; 2005\end{array}$ \\
\hline & 107106453010661 & 23 & 270502 & $\begin{array}{l}\text { Minnesota, } 1999-2000 \text { to } 2004-2005: \\
\text { GRM }\end{array}$ & 27 & Minnesota & $2004 ; 2005$ \\
\hline & 107106454010661 & 23 & 270600 & Minnesota, 2002-2006: all land & 27 & Minnesota & $\begin{array}{l}2002 ; 2003 ; 2004 ; \\
2005 ; 2006\end{array}$ \\
\hline
\end{tabular}




\begin{tabular}{|c|c|r|r|l|r|r|l|}
\hline & \multicolumn{7}{|c|}{ Data item names } \\
\hline & CN & RSCD & \multicolumn{1}{|c|}{ EVALID } & \multicolumn{1}{|c|}{ EVAL DESCR } & STATECD & LOCATION NM & REPORT YEAR NM \\
\hline \multirow{3}{*}{107106455010661} & 23 & 270601 & Minnesota, 2002-2006: area/volume & 27 & Minnesota & $\begin{array}{l}2002 ; 2003 ; 2004 ; \\
2005 ; 2006\end{array}$ \\
\cline { 2 - 9 } & 107106456010661 & 23 & 270602 & $\begin{array}{l}\text { Minnesota, 1999-2001 to 2004-2006: } \\
\text { GRM }\end{array}$ & 27 & Minnesota & $2004 ; 2005 ; 2006$ \\
\hline
\end{tabular}

An evaluation group is the set of evaluations that goes into the contents of a typical FIA report for a State. For example the evaluations that went into the report entitled "Minnesota's forests 1999-2003 (Part A.)" (Miles and others 2007) are identified by EVALIDs 270300, 270301 and 270302, and are collectively identified by a single record in the POP_EVAL_GRP table. Table 4.4 lists the important attributes for all evaluation groups that are loaded into FIADB for data collected in Minnesota through 2006.

Table 4.4. Important POP_EVAL_GRP entries for Minnesota through 2006 from the FIADB.

\begin{tabular}{|c|c|c|c|c|c|c|}
\hline Data item names & & & Data it & alues & & \\
\hline $\mathrm{CN}$ & 107114016010661 & 107114017010661 & 107114012010661 & 107114013010661 & 107114014010661 & 107114015010661 \\
\hline \begin{tabular}{|l} 
EVAL_CN_FOR_EXPALL \\
\end{tabular} & & & 107106444010661 & 107106448010661 & 107106451010661 & 107106454010661 \\
\hline EVAL_CN_FOR_EXPCURR & 107106457010661 & 107106462010661 & 107106445010661 & 107106449010661 & 107106452010661 & 107106455010661 \\
\hline EVAL_CN_FOR_EXPVOL & 107106458010661 & 107106463010661 & 107106445010661 & 107106449010661 & 107106452010661 & 107106455010661 \\
\hline EVAL_CN_FOR_EXPGROW & 107106459010661 & 107106464010661 & 107106446010661 & 107106450010661 & 107106453010661 & 107106456010661 \\
\hline EVAL_CN_FOR_EXPMORT & 107106460010661 & 107106465010661 & 107106446010661 & 107106450010661 & 107106453010661 & 107106456010661 \\
\hline EVAL_CN_FOR_EXPREMV & 107106461010661 & 107106466010661 & 107106446010661 & 107106450010661 & 107106453010661 & 107106456010661 \\
\hline RSCD & 23 & 23 & 23 & 23 & 23 & 23 \\
\hline EVAL_GRP & 271977 & 271990 & 272003 & 272004 & 272005 & 272006 \\
\hline EVAL_GRP_DESCR & Minnesota: 1977 & Minnesota: 1990 & $\begin{array}{r}\text { Minnesota: } \\
\text { 1999;2000;2001; } \\
\text { 2002;2003 }\end{array}$ & $\begin{array}{r}\text { Minnesota: } \\
\text { 2000;2001;2002; } \\
2003 ; 2004\end{array}$ & $\begin{array}{r}\text { Minnesota: } \\
2001 ; 2002 ; 2003 ; \\
2004 ; 2005\end{array}$ & $\begin{array}{r}\text { Minnesota: } \\
\text { 2002;2003;2004; } \\
\text { 2005;2006 }\end{array}$ \\
\hline
\end{tabular}

In the POP_EVAL_GRP table the data item EVAL_GRP identifies the evaluation group by its State code (first $\overline{2}$ digits) and a year (last 4 digits), which is the year commonly associated with estimates (if EVAL_GRP does not follow this format, see the EVAL_GRP_DESCR for the precise identification). In table 4.4 we see evaluation groups for two periodic inventory estimates (1977 and 1990), and four annual estimates (2003, 2004, 2005 and 2006). The EVAL_GRP_DESCR describes the groups, and indicates that all of the annual inventory estimates are based on 5 years of measurements taken over the 5-year period ending with that date. The data items EVAL_CN_FOR_EXPALL, EVAL_CN_FOR_EXPCURR, EVAL_CN_FOR_EXPVOL,

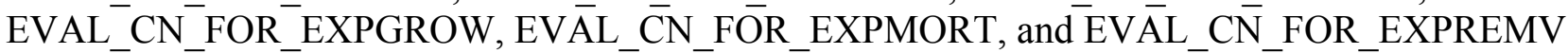
identify the evaluations in POP_EVAL that are appropriate for the estimation of various attributes of interest. EVAL_CN_FOR_EXPCURR identifies the evaluation used in the estimation of most area estimates, such as the area of forestland or the area of timberland. EVAL_CN_FOR_EXPVOL identifies the evaluation used in the estimation of tree-level attributes such as number, volume, and biomass of trees, and seedling-level estimates, such as number of seedlings.

EVAL_CN_FOR_EXPGROW, EVAL_CN_FOR_EXPMORT, and EVAL_CN_FOR_EXPREMV identify the evaluations used in the estimation of growth, mortality, and removals, respectively. The evaluation identified by EVAL_CN_FOR_EXPALL is only appropriate for area estimation where the area of hazardous and denied access are of interest. All other evaluations treat hazardous and denied access as non-measured and adjust the estimate to account for these areas. 
The POP_EVAL_TYP table was added to the FIADB in the transition from version 3.0 to 4.0 to provide a link between the evaluation groups in POP_EVAL_GRP and the evaluations in POP_EVAL. In FIADB 3.0, users could select the appropriate evaluation sequence number (EVĀL_CN_FOR_xxx) from the POP_EVAL_GRP table. This evaluation sequence number allowed them to select the appropriate plots and associated expansions. Evaluations are now also identified by the type of evaluation in the value of POP_EVAL_TYP.EVAL_TYP, which can take on values of "EXPALL," "EXPCURR," "EXPVOL," "EXPGROW," "EXPMORT," or "EXPREMV" to identify the type of attributes that can be estimated from a specific evaluation. This table allows users to perform similar queries on the appropriate evaluation by identifying only the eval_grp (STATECD*10000 + INV_YR) and evaluation type (EVAL_TYP) and allows a variety of evaluations to be added in the future. The methods used in version 3.0 will continue to work in version 4.0. The examples presented here incorporate the POP_EVAL_TYP as the link from the POP_EVAL_GRP to the POP_EVAL table. In the examples below, either of the two joins will select the appropriate evaluation for the estimation of area and volume attributes for the Minnesota 2003 annual inventory.

FIADB 4.0 example:

select pev.cn,pev.eval_descr

from pop_eval_typ pet, pop_eval pev, pop_eval_grp peg

where peg.eval_grp $=272003$ and peg.cn $=$ pet.eval_grp_cn and pev.cn $=$ pet.eval_cn and pet.eval_typ $=$ 'EXPCURR'

FIADB 3.0 example:

select pev.cn, pev.eval_descr

from pop_eval pev, pop_eval_grp peg

where peg.eval_grp $=272003$ and

pev.cn $=$ peg.eval_cn_for_expcurr

\section{Linking the appropriate tables in FIADB to produce estimates of attributes of interest for a population}

The following Oracle ${ }^{\mathrm{TM}}$ SQL script can be modified to produce an estimate of any condition-, tree-, or seedling-level attribute listed in the REF_POP_ATTRIBUTE table. In this standard script (example 4.1), the non-bold text applies to all estimates and the bold text is modified by the user, depending on the desired attribute of interest and evaluation group. The line numbers have been added for reference. On line 01, the text in the column EXPRESSION in the

REF_POP_ATTRIBUTE table associated with the desired attribute of interest should be inserted. Lines 05 or 06 include either the TREE table or SEEDLING table, and neither line should be included for condition level estimates. Line 05 should be included for tree level estimates and line 06 should be included for seedling level estimates. On line 14, the additions to the SQL where clause from the WHERE_CLAUSE column of the REF_POP_ATTRIBUTE table for the desired attribute of interest should be inserted. Finally, on line $\overline{21}$, the desired evaluation group needs to be indicated by replacing the characters SSYYYY with the desired evaluation group, whereby SS = STATECD of the desired State, and YYYY = year of the desired inventory (if EVAL_GRP does not follow this format, see the EVAL_GRP_DESCR for the precise identification). With these changes, a user can produce the standard estimates for any desired population from the REF_POP_ATTRIBUTE table. 
Estimation requires linking the attribute values (on the COND, TREE, and SEEDLING tables) to the stratification information (on the POP_PLOT_STRATUM_ASSGN, POP_STRATUM, and POP_ESTN_UNIT) for the selected evaluation that defines the sample. Those links are provided in lines 15 thru 20 of the script, and these lines do not change. Line 15 links the POP_PLOT_STRATUM_ASSGN record (which contains EXPNS, the plot expansion factor or acres assigned to the plot) to the plot record. Line 16 links the POP_PLOT_STRATUM_ASSGN record to the POP_STRATUM (which identifies each stratum in the estimation unit). Line 17 links the POP_ESTN_UNIT (which identifies each estimation unit in the evaluation) to the POP

STRATŪM record. Line 18 links the POP_EVAL, which identifies each evaluation, to the specific evaluation that is required for the estimation. Lines 19 and 20 link the appropriate evaluation to the attribute and evaluation group for which the estimate is being made. See figure 6 for a schematic of links of some of the FIADB tables.

The following table shows some common aliases or abbreviations used within a SQL script to reduce the overall length of the script and improve readability.

Common aliases for FIADB tables

\begin{tabular}{|l|l|}
\hline$p$ & PLOT \\
\hline$c$ & COND \\
\hline$t$ & TREE \\
\hline$s$ & SEEDLING \\
\hline$p p s a$ & POP_PLOT_STRATUM_ASSGN \\
\hline psm & POP_STRATUM \\
\hline peu & POP_ESTN_UNIT \\
\hline pet & POP_EVAL_TYP \\
\hline peg & POP_EVAL_GRP \\
\hline pev & POP_EVAL_C \\
\hline
\end{tabular}

Example 4.1. Standard estimation script

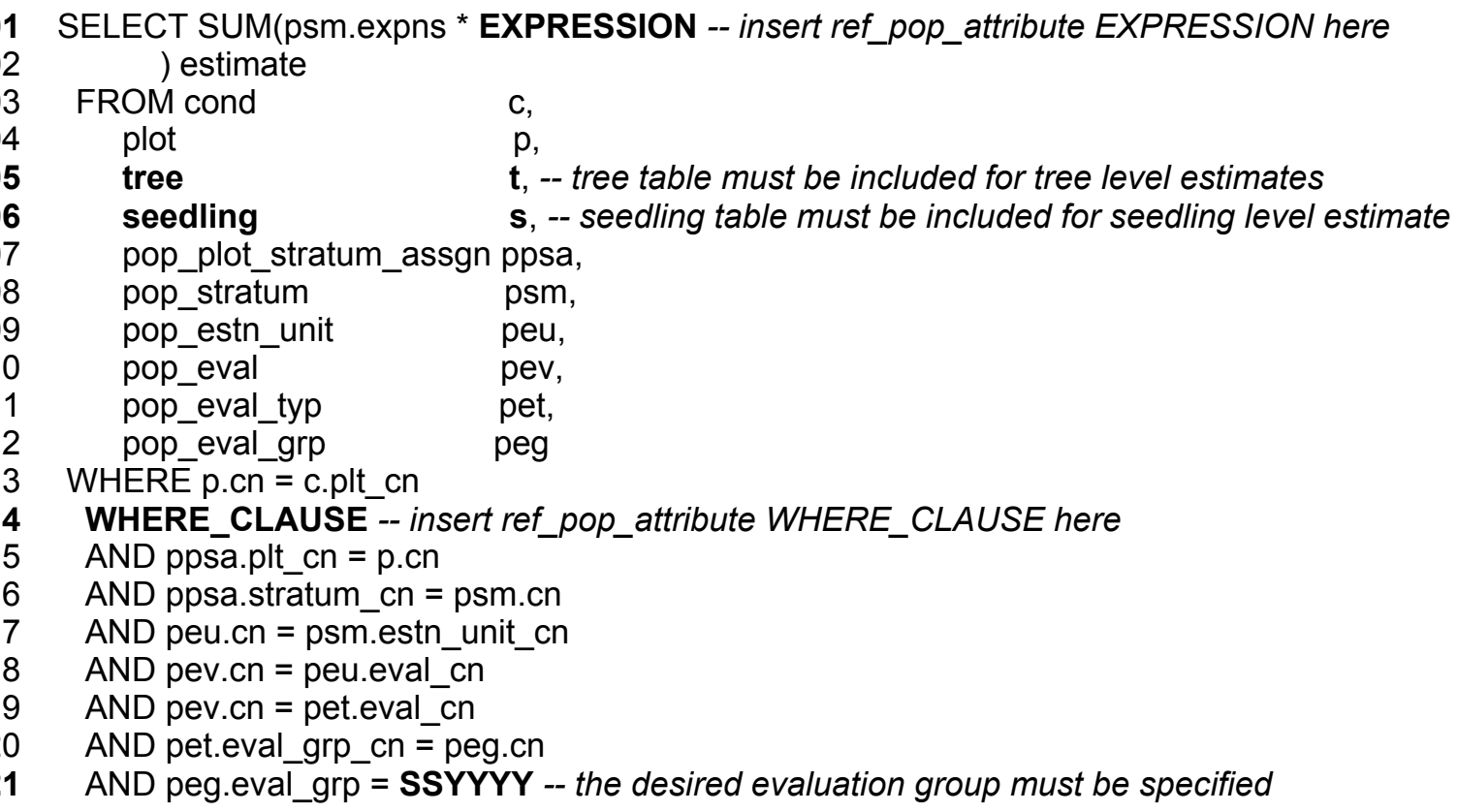




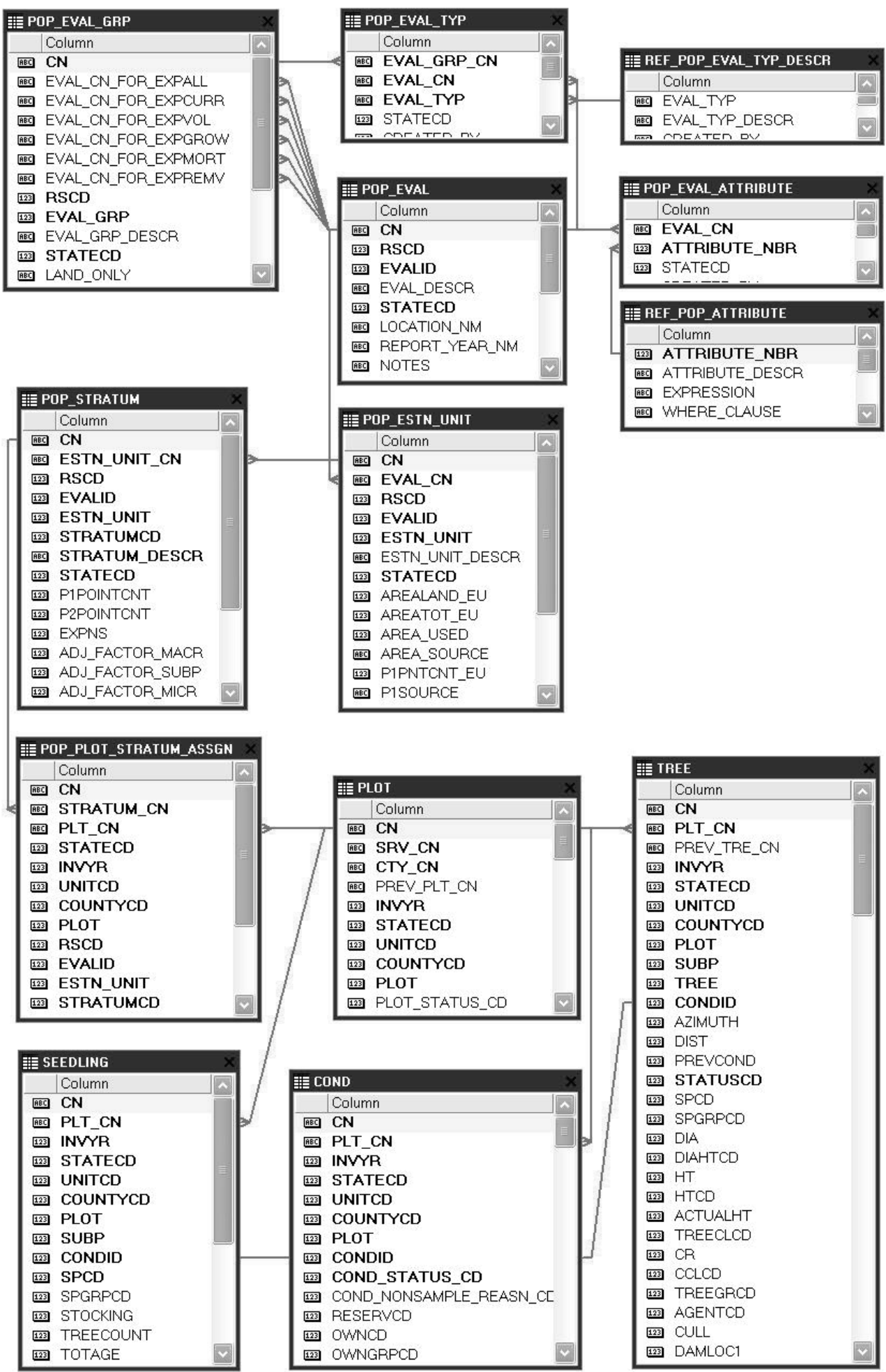

Figure 6. An abbreviated diagram of select FIADB tables. Note that there are more columns in each table than are shown. 
In the following four examples $(4.2,4.3,4.4$, and 4.5), the scripts are modified from above to produce condition, tree, and seedling level estimates for the Minnesota 2003 inventory. Here the sections in bold are the sections that changed from the standard estimation script, e.g., the REF_POP_ATTRIBUTE.EXPRESSION and REF_POP_ATTRIBUTE.WHERE_CLAUSE have been inserted, along with the chosen evaluation number.

Example 4.2 Estimate area of timberland (acres)

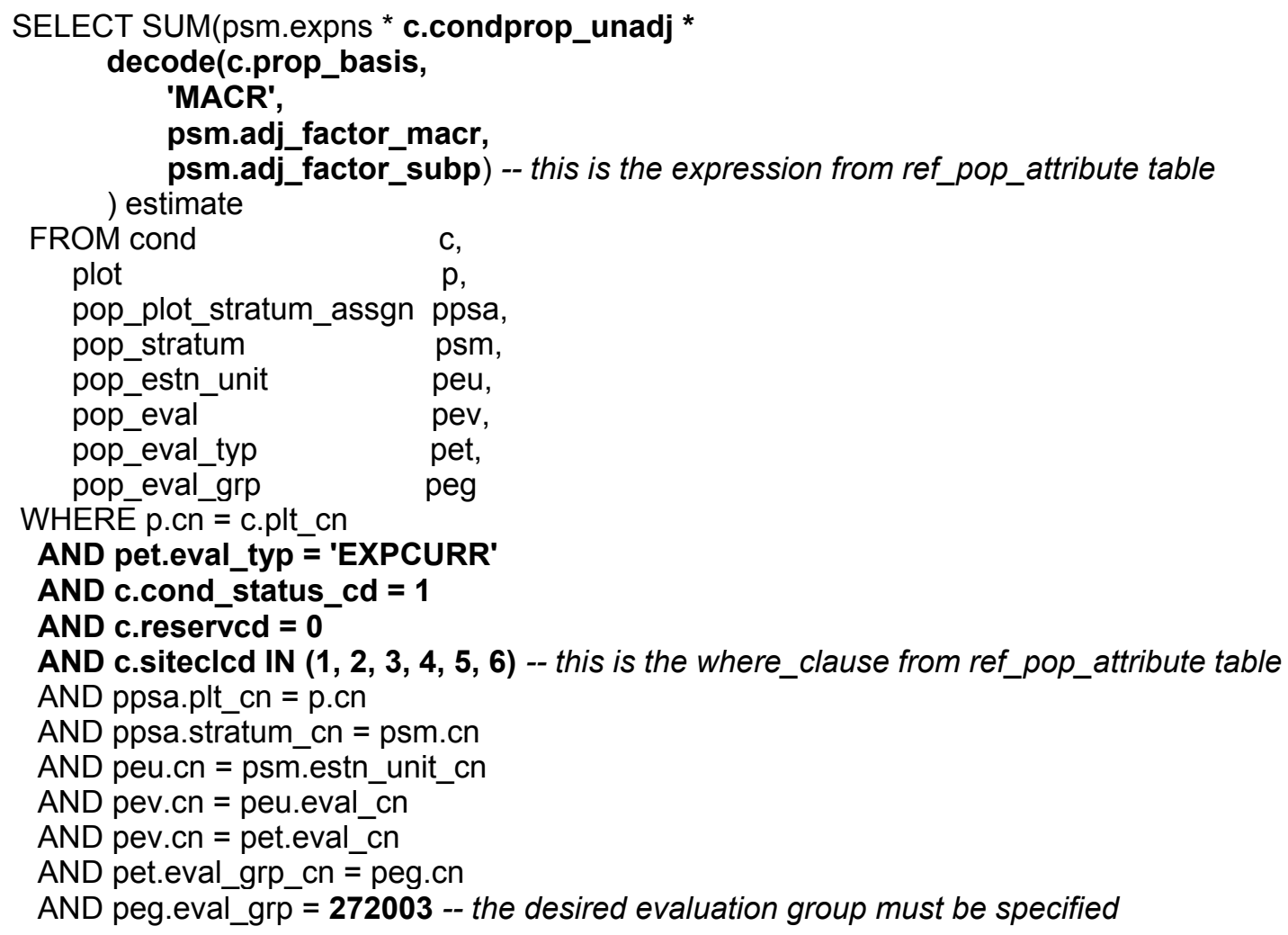

Produces the following estimate of acres of timberland: 
Example 4.3 Estimate number of live trees on forest land (trees)

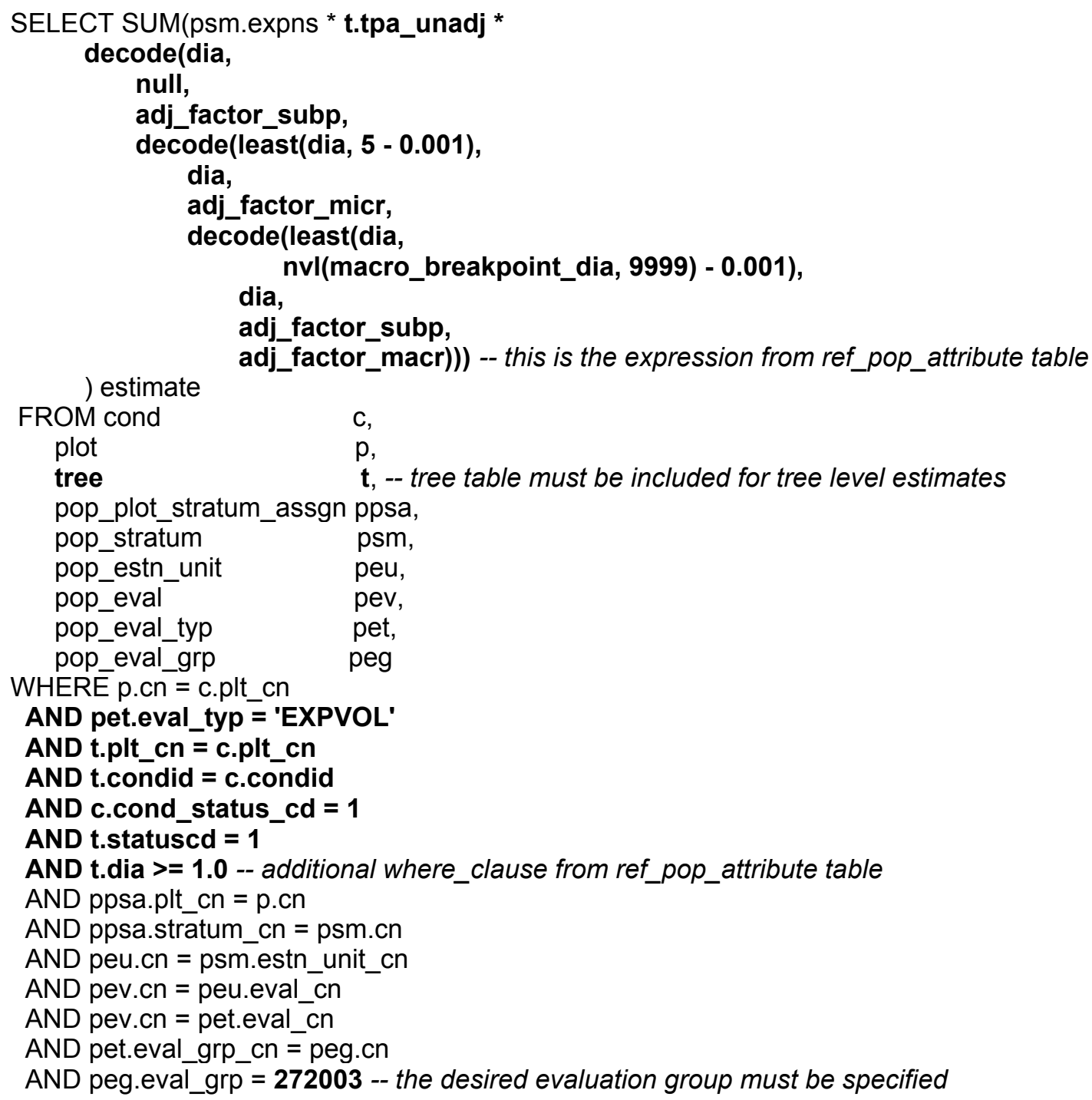

Produces the following estimate of total number of live trees on forest land:

\begin{tabular}{|l|}
\hline ESTIMATE \\
\hline $12,078,196,211$ \\
\hline
\end{tabular}


Example 4.4 Estimate number of live seedlings on timberland (seedlings)

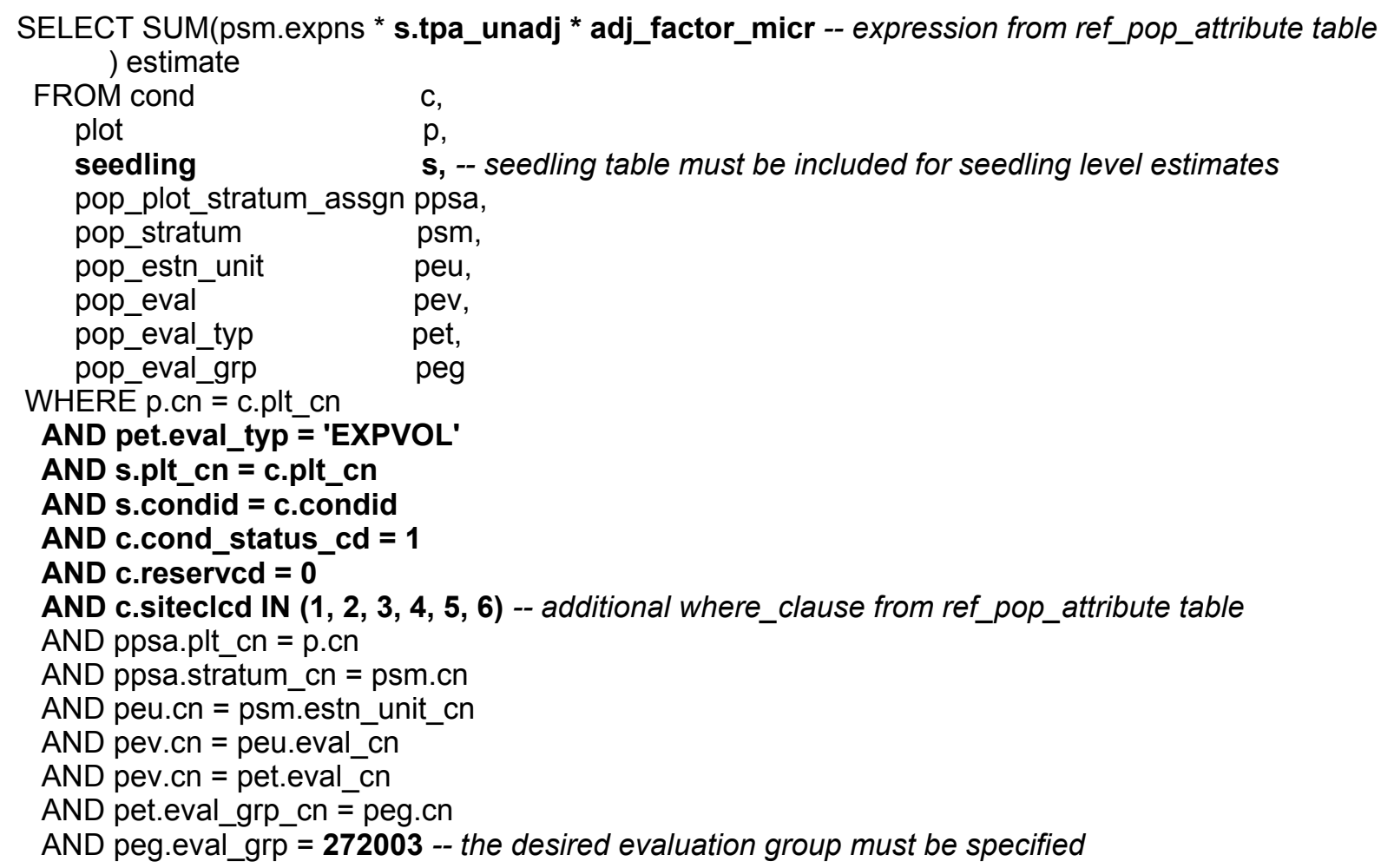

Produces the following estimate of total number of live seedlings on timberland:

\begin{tabular}{|l|}
\hline ESTIMATE \\
\hline $37,141,783,495$ \\
\hline
\end{tabular}


Example 4.5 Estimate volume of growing-stock on timberland (cubic feet)

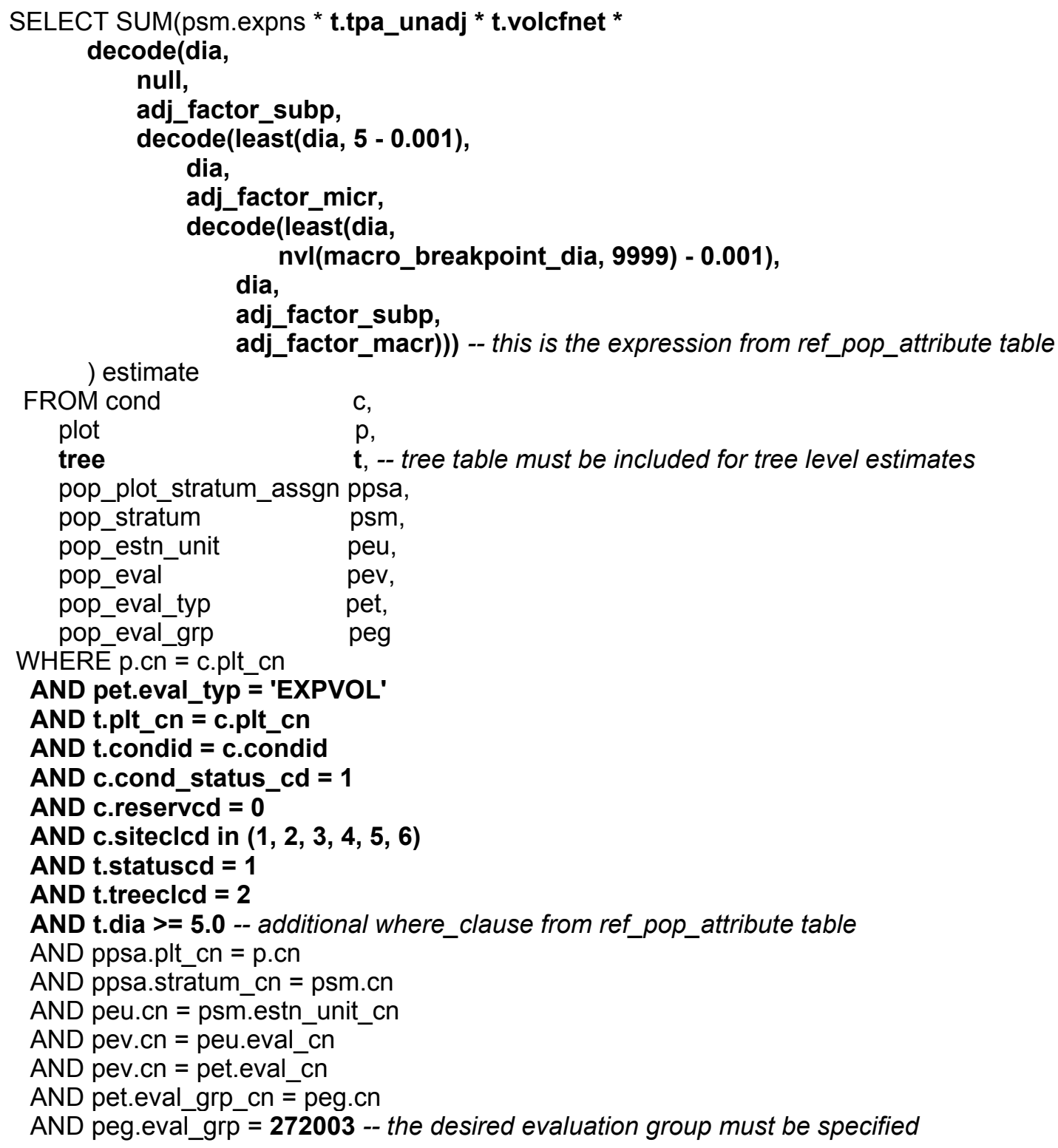

Produces the following estimate of total growing-stock volume (cubic feet) on timberland:

$$
\begin{array}{|l|}
\hline \text { ESTIMATE } \\
\hline 15,242,634,295 \\
\hline
\end{array}
$$

Users of the FIADB who wish to produce population estimates should test these four examples to be sure they are obtaining identical estimates before proceeding to more complicated estimation. Important Note: Users who access data from periodic inventories should restrict the estimation only to the standard timberland estimates. In most cases, for periodic inventories, the FIADB contains only condition level information on reserved and unproductive forest lands, and tree level information on timberland. 


\section{Producing estimates with sampling errors for attributes of interest for a population}

Producing population estimates that include error estimates (sampling error or variance of the estimate) along with the estimated total is more complicated. The following Oracle ${ }^{\mathrm{TM}}$ SQL script can be used as a template in producing estimates with sampling errors. The line numbers have been added for reference. This example follows the notation used in Bechtold and Patterson (2005, equation 4.14 on page 55). Again, the portions of the script that should be changed by the user to specify the attribute of interest and population are in bold. Besides returning the estimates and sampling errors, this script also outputs the total number of plots in the sample (TOTAL_PLOTS), the number of plots where the attribute of interest was observed to occur (NON_ZERO_PLOTS), and the total population area (TOTAL_POPULATION_ACRES). This procedure produces two intermediate tables: phase_1_summary and phase_2_summary. Phase_1_summary is a stratumlevel table that contains the stratification information necessary in the estimation within strata sample sizes $\left(\mathrm{n}_{\mathrm{h}}\right)$, stratum weights $\left(\mathrm{W}_{\mathrm{h}}\right)$, and population area $\left(\mathrm{A}_{\mathrm{T}}\right)$. Phase_2_summary is a stratumlevel table that contains a summary of the attribute of interest on per-unit-area basis $\left(\mathrm{y}_{\text {hid }}\right)$, including the sum and sum of the squared plot-level values and the number of plots where the attribute of interest was observed.

Example 4.6. Standard script for estimates with sampling errors

\begin{tabular}{|c|c|}
\hline 01 & SELECT eval_grp, \\
\hline 02 & SUM(estimate_by_estn_unit.estimate) estimate, \\
\hline 03 & CASE \\
\hline 04 & WHEN SUM(estimate_by_estn_unit.estimate) $>0$ THEN \\
\hline 05 & round(sqrt(SUM(estimate_by_estn_unit.var_of_estimate)) / \\
\hline 06 & SUM(estimate_by_estn_unit.estimate) * 100 , \\
\hline 07 & 3) \\
\hline 08 & ELSE \\
\hline 09 & 0 \\
\hline 10 & END AS se_of_estimate_pct, \\
\hline 11 & SUM(estimate_by_estn_unit.var_of_estimate) var_of_estimate, \\
\hline 12 & SUM(estimate_by_estn_unit.total_plots) total_plots, \\
\hline 13 & SUM(estimate_by_estn_unit.non_zero_plots) non_zero_plots, \\
\hline 14 & SUM(estimate_by_estn_unit.total_population_area_acres) total_population_acres \\
\hline 15 & FROM (SELECT pop_eval_grp_cn, \\
\hline 16 & eval_grp, \\
\hline 17 & estn_unit_cn, \\
\hline 18 & SUM(nvl(ysum_hd, 0) * phase_1_summary.expns) estimate, \\
\hline 19 & SUM(phase_1_summary.n_h) total_plots, \\
\hline 20 & SUM(phase_2_summary.number_plots_in_domain) domain_plots, \\
\hline 21 & SUM(phase_2_summary.non_zero_plots) non_zero_plots, \\
\hline 22 & total_area * total_area / SUM(phase_1_summary.n_h) * \\
\hline 23 & $\left((\mathrm{SUM})\left(\mathrm{w} \_\mathrm{h}\right.\right.$ * phase_1_summary. $\mathrm{n} \overline{\mathrm{h}}^{*}$ \\
\hline 24 & (((nvl(ysum_hd_sqr, 0) / phase_1_summary.n_h) - \\
\hline 25 & $((\mathrm{nvl}(\mathrm{ysum}$ hd, 0$) /$ phase_1_summary.n_h) * \\
\hline 26 & $(\mathrm{nvl}(\mathrm{ysum}$ hd, 0) / phase_1_summary.n_h))) / \\
\hline 27 & $($ phase_1_summary.n_h - 1)))) + \\
\hline 28 & 1/ SUM(phase_1_summary.n_h)* \\
\hline 29 & $\left(\operatorname{SUM}\left(\left(1-\mathrm{w} \_\mathrm{h}\right){ }^{*}\right.\right.$ phase_1_summary.n_h * \\
\hline 30 & $((($ nvl(ysum_hd_sqr, 0$) /$ phase_1_summary.n_h) - \\
\hline 31 & $(($ nvl(ysum_hd, 0)/phase_1_summary.n_h) * \\
\hline 32 & (nvl(ysum_hd, 0)/phase_1_summary.n_h)))/ \\
\hline
\end{tabular}




\begin{tabular}{|c|c|}
\hline 33 & $($ phase_1_summary.n_h - 1))))) var_of_estimate, \\
\hline 34 & total_area total_population_area_acres \\
\hline 35 & FROM (SELECT peg.eval_grp, \\
\hline 36 & peg.cn pop_eval_grp_cn, \\
\hline 37 & psm.estn_unit_cn, \\
\hline 38 & psm.expns, \\
\hline 39 & psm.cn pop_stratum_cn, \\
\hline 40 & p1pointent / \\
\hline 41 & (SELECT SUM(strs.p1pointcnt) \\
\hline 42 & FROM pop_stratum strs \\
\hline 43 & WHERE strs.estn_unit_cn = psm.estn_unit_cn) w_h, \\
\hline 44 & (SELECT SUM(strs.p1pointent) \\
\hline 45 & FROM pop_stratum strs \\
\hline 46 & WHERE strs.estn_unit_cn = psm.estn_unit_cn) n_prime, \\
\hline 47 & p1pointcnt n_prime_h, \\
\hline 48 & (SELECT SUM(eu_s.area_used) \\
\hline 49 & FROM pop_estn_unit eu_s \\
\hline 50 & WHERE eu_s.cn = psm.estn_unit_cn) total_area, \\
\hline 51 & psm.p2pointcnt n_h \\
\hline 52 & FROM pop_estn_unit peu, \\
\hline 53 & pop_stratum \\
\hline 54 & pop_eval \\
\hline 55 & pop_eval_grp peg, \\
\hline 56 & pop_eval_typ pet \\
\hline 57 & WHERE peu.cn = psm.estn_unit_cn \\
\hline 58 & and pev.cn = peu.eval_cn \\
\hline 59 & and pet.eval_cn = pev.cn \\
\hline 60 & and pet.eval_grp_cn = peg.cn \\
\hline 61 & and pet.eval_typ = 'EXPXXX' -- specify the appropriate expansion \\
\hline 62 & AND peg.eval_grp = SSYYYY -- the desired evaluation group must be specified \\
\hline 63 & phase_1_summary, \\
\hline 64 & (SELECT pop_stratum_cn, \\
\hline 65 & SUM(y_hid_adjusted) ysum_hd, \\
\hline 66 & SUM(y_hid_adjusted * y_hid_adjusted) ysum_hd_sqr, \\
\hline 67 & COUNT $\left.{ }^{*}\right)$ number_plots_in_domain, \\
\hline 68 & SUM(decode(y_hid_adjusted, 0,0, NULL, 0,1$))$ non_zero_plots \\
\hline 69 & FROM (SELECT psm.cn pop_stratum_cn, \\
\hline 70 & p.cn plt_cn, \\
\hline 71 & $\begin{array}{l}\text { SUM(EXPRESSION) y_hid_adjusted } \\
\quad-- \text { the appropriate expression from ref_pop_attribute table }\end{array}$ \\
\hline 73 & FROM cond $\mathrm{c}$, \\
\hline 74 & plot \\
\hline 75 & t, -- tree table must be included for tree level estimates \\
\hline 76 & seedling s, -- seedling table must be included for seedling level estimates \\
\hline 77 & pop_plot_stratum_assgn ppsa, \\
\hline 78 & pop_stratum \\
\hline 79 & pop_estn_unit \\
\hline 80 & pop_eval \\
\hline 81 & pop_eval_grp \\
\hline 82 & pop_eval_typ \\
\hline 83 & WHERE p.cn = c.plt_cn \\
\hline 84 & WHERE_CLAUSE -- additional where_clause from ref_pop_attribute table \\
\hline 85 & AND ppsa.plt_cn $=$ p.cn \\
\hline 86 & AND ppsa.stratum_cn = psm.cn \\
\hline 87 & AND peu.cn = psm.estn_unit_cn \\
\hline 88 & AND pev.cn = peu.eval_cn \\
\hline
\end{tabular}




\begin{tabular}{|l|c|}
\hline 89 & AND pet.eval_cn = pev.cn \\
\hline 90 & AND pet.eval_grp_cn = peg.cn \\
\hline 91 & AND peg.eval_grp = SSYYYY \\
-- the desired evaluation group must be specified \\
\hline 92 & GROUP BY psm.cn, p.cn) \\
\hline 93 & GROUP BY pop_stratum_cn) phase_2_summary \\
\hline 94 & WHERE phase_1_summary.pop_stratum_cn $=$ \\
\hline 95 & phase_2_summary.pop_stratum_cn $(+)$ \\
\hline 96 & GROUP BY pop_eval_grp_cn, \\
\hline 97 & eval_grp, \\
\hline 98 & estn_unit_cn, \\
\hline 99 & phase_1_summary.total_area) estimate_by_estn_unit \\
\hline 100 & GROUP BY pop_eval_grp_cn, eval_grp \\
\hline
\end{tabular}

In the following three examples the scripts were modified from above to produce condition, tree, and seedling level estimates for the Minnesota 2003 inventory. Here the sections in bold are the sections that changed from the standard script for estimates with sampling errors.

Example 4.7. Estimate Area of timberland (acres) with sampling error. Note the bold sections in this example match the bold sections in example 4.2, which estimates the same area without sampling errors.

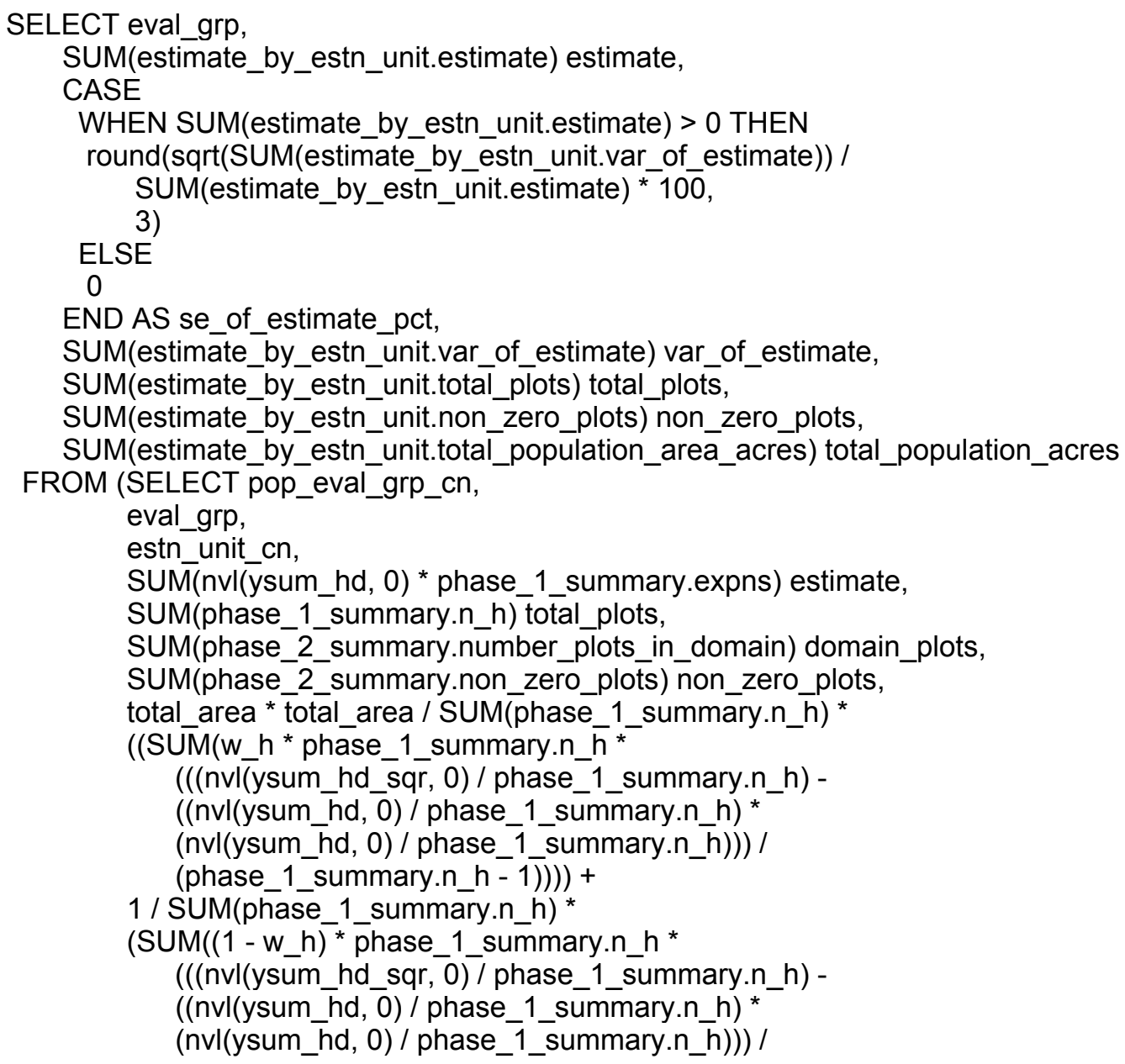


(phase_1_summary.n_h - 1))))) var_of_estimate, total_area total_population_area_acres

FROM (SELECT peg.eval_grp,

peg.cn pop_eval_grp_cn,

psm.estn_unit_cn,

psm.cn pop_stratum_cn,

psm.expns,

p1pointent /

(SELECT SUM(strs.p1pointent)

FROM pop_stratum strs

WHERE strs.estn_unit_cn = psm.estn_unit_cn) $w \_h$,

(SELECT SUM(strs.p1pointcnt)

FROM pop_stratum strs

WHERE strs.estn_unit_cn = psm.estn_unit_cn) n_prime,

p1pointcnt n_prime_h,

(SELECT SÜM(eu_s.area_used)

FROM pop_estn_unit eu_s

WHERE eu_s.cn = psm.estn_unit_cn) total_area,

psm.p2pointcnt $n \_h$

FROM pop_estn_unit peu,

pop_stratum psm,

pop_eval pev,

pop_eval_grp peg,

pop_eval_typ pet

WHERE peu.cn = psm.estn_unit_cn

AND pev.cn = peu.eval_cn

AND pet.eval_cn $=$ pev.cn

AND pet.eval_grp_cn = peg.cn

AND pet.eval_typ = 'EXPCURR' -- specify the appropriate expansion

AND peg.eval_grp = $\mathbf{2 7 2 0 0 3}$-- the desired evaluation group must be specified

) phase_1_summary,

(SELECT̄ pop_stratum_cn,

SUM(y_hid_adjusted) ysum_hd,

SUM(y_hid_adjusted * y_hid_adjusted) ysum_hd_sqr,

COUNT $\left(^{*}\right)$ number_plots_in_domain,

SUM(decode(y_hid_adjusted, 0, 0, NULL, 0,1)) non_zero_plots

FROM (SELECT psm.cn pop_stratum_cn,

$$
\text { p.cn plt_cn, }
$$

SUM(c.condprop_unadj *

decode(c.prop_basis,

'MACR',

psm.adj_factor_macr,

psm.adj_factor_subp) -- the expression from ref_pop_attribute table

$\begin{array}{ll}\text { FROM cond } & c \text {, } \\ \text { plot } & p \text {, }\end{array}$ ) y hid adjusted

pop_plot_stratum_assgn ppsa,

pop_stratum psm,

pop_estn_unit peu,

pop_eval pev,

pop_eval_grp peg,

pop_eval_typ pet

WHERE p.cn = c.plt_cn

AND pet.eval_typ = 'EXPCURR'

AND c.cond_status_cd $=1$

AND c.reservcd $=0$

AND c.siteclcd IN $(1,2,3,4,5,6)$

-- additional where_clause from ref_pop_attribute table 


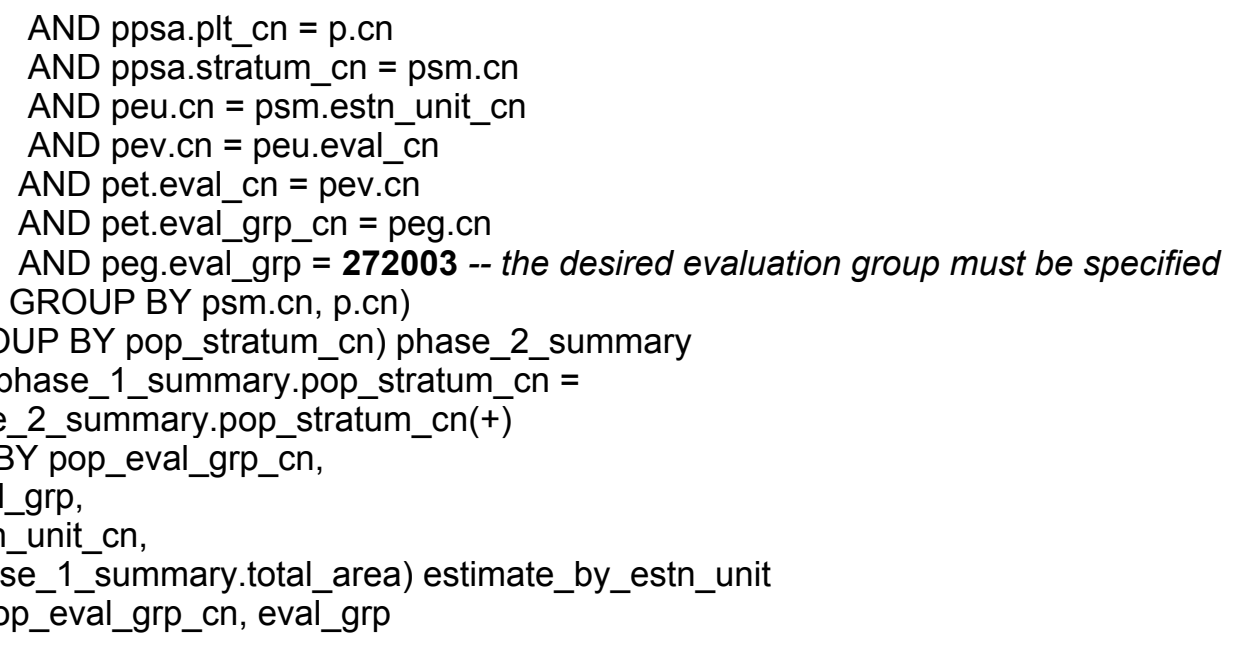

Produces the following estimate of acres of timberland with sampling error:

\begin{tabular}{|l|r|}
\hline EVAL GRP & 272003 \\
\hline ESTIMATE & $14,734,137$ \\
\hline SE OF ESTIMATE PCT & 0.7 \\
\hline VAR OF ESTIMATE & $10,998,768,175$ \\
\hline TOTAL PLOTS & 16,041 \\
\hline NON ZERO PLOTS & 4,774 \\
\hline TOTAL POPULATION ACRES & $54,002,539$ \\
\hline
\end{tabular}

Example 4.8. Estimate number of live trees on forest land (trees) with sampling error. Note the bold sections in this example match the bold sections in example 4.3, which estimates the same number of trees without sampling errors.

SELECT eval_grp,

SUM(estimate_by_estn_unit.estimate) estimate,

CASE

WHEN SUM(estimate_by_estn_unit.estimate) $>0$ THEN

round(sqrt(SUM(estimate_by_estn_unit.var_of_estimate)) /

SUM(estimate_by_estn_unit.estimate) ${ }^{*} 100$,

3)

ELSE

0

END AS se_of_estimate_pct,

SUM(estimate_by_estn_unit.var_of_estimate) var_of_estimate,

SUM(estimate_by_estn_unit.total_plots) total_plots,

SUM(estimate_by_estn_unit.non_zero_plots) non_zero_plots,

SUM(estimate_by_estn_unit.total_population_area_acres) total_population_acres

FROM (SELECT pop_eval_grp_cn,

eval_grp,

estn_unit_cn,

$\operatorname{sum}($ nvl(ysum_hd, 0) * phase_1_summary.expns) estimate,

SUM(phase_1_summary.n_h) total_plots,

SUM(phase_2_summary.number_plots_in_domain) domain_plots,

SUM(phase_2_summary.non_zero_plots) non_zero_plots,

total_area * total_area / SUM(phase_1_summary.n_h)* 


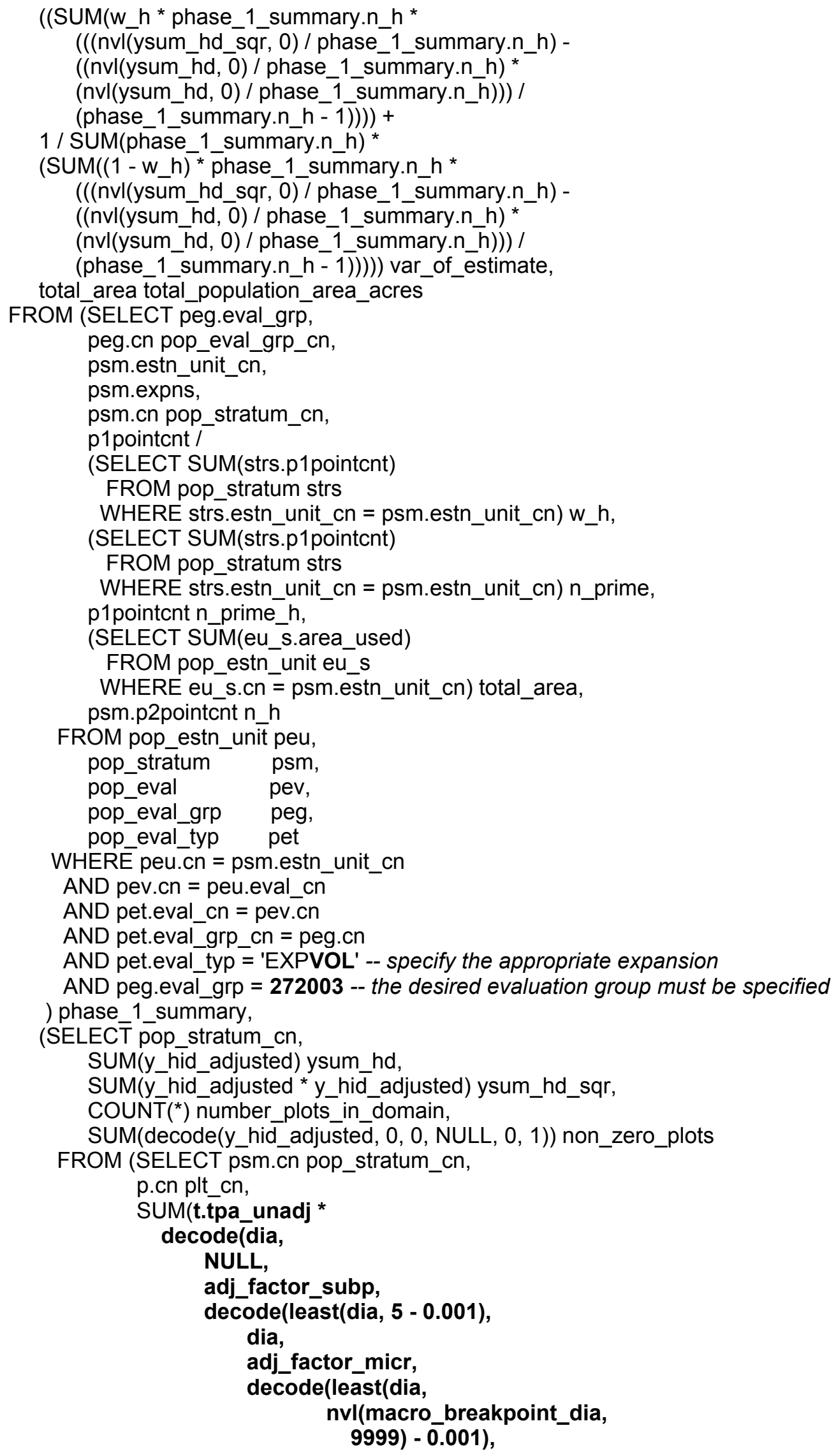




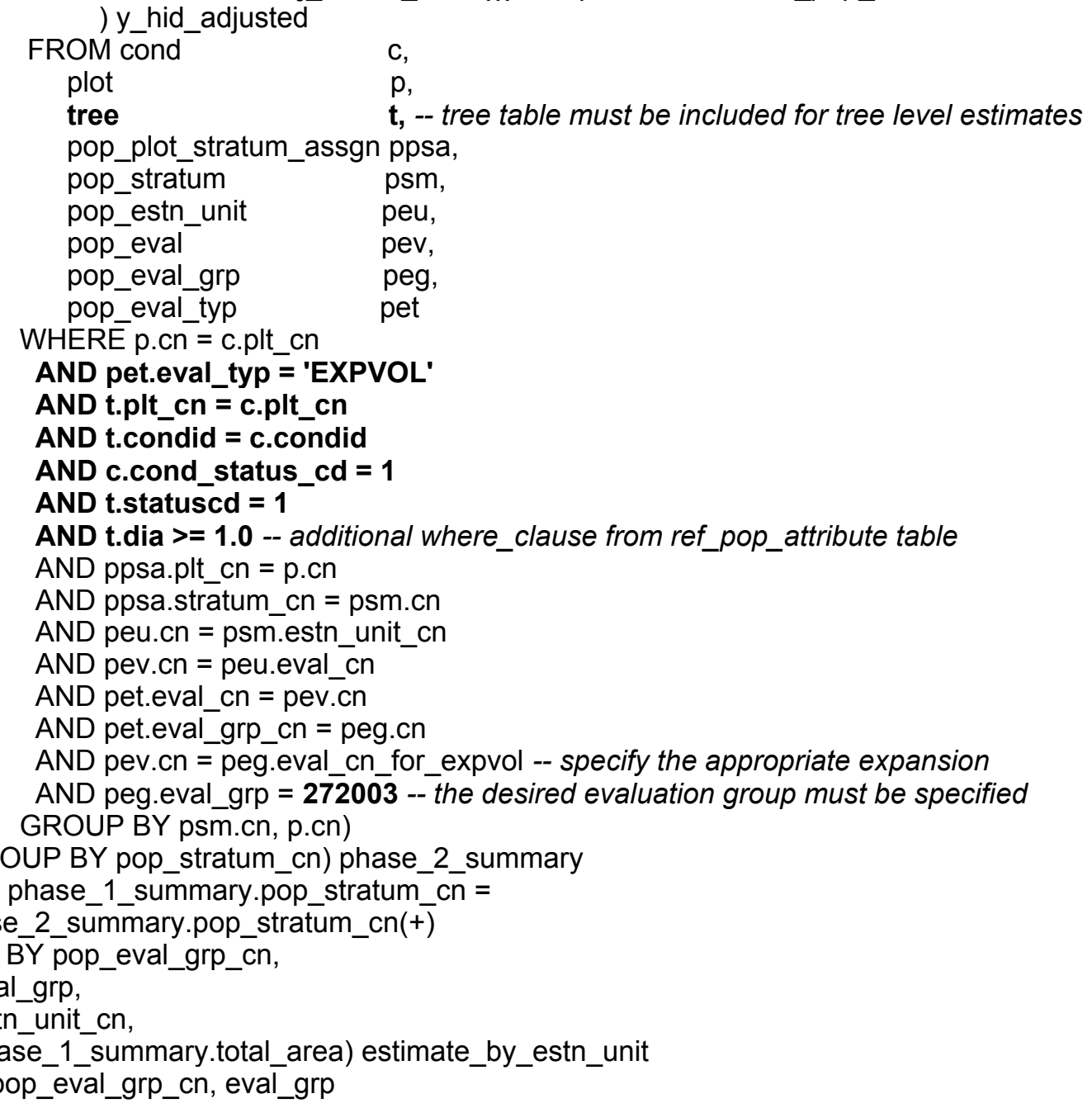

dia,

adj_factor_subp,

adj_factor_macr))) -- expression from ref_pop_attribute table

Produces the following estimate of number of live trees on forest land with sampling error:

\begin{tabular}{|l|r|}
\hline EVAL GRP & 272003 \\
\hline ESTIMATE & $12,078,196,211$ \\
\hline SE OF ESTIMATE PCT & 1.3 \\
\hline VAR OF ESTIMATE & 16,041 \\
\hline TOTAL PLOTS & 5,069 \\
\hline NON ZERO PLOTS & $54,002,539$ \\
\hline TOTAL POPULATION ACRES & \\
\hline
\end{tabular}


Example 4.9. Estimate number of seedlings on timberland (seedlings) with sampling error.

SELECT eval_grp,

SUM(estimate_by_estn_unit.estimate) estimate,

CASE

WHEN SUM(estimate_by_estn_unit.estimate) $>0$ THEN

round(sqrt(SUM(estimate_by_estn_unit.var_of_estimate)) /

SUM(estimate_by_estn_unit.estimate) ${ }^{*} 100$,

3)

ELSE

0

END AS se_of_estimate_pct,

SUM(estimate_by_estn_unit.var_of_estimate) var_of_estimate,

SUM(estimate_by_estn_unit.total_plots) total_plots,

SUM(estimate_by_estn_unit.non_zero_plots) non_zero_plots,

SUM(estimate_by_estn_unit.total_population_area_acres) total_population_acres

FROM (SELECT pop_eval_grp_cn,

eval_grp,

estn_unit_cn,

sum(nvl(ysum_hd, 0) * phase_1_summary.expns) estimate,

SUM(phase_1_summary.n_h) total_plots,

SUM(phase_2_summary.number_plots_in_domain) domain_plots,

SUM(phase_2_summary.non_zero_plots) non_zero_plots,

total_area * total_area / SUM(phase_1_summary.n_h) *

$\left((S U M)\left(w \_h\right.\right.$ * phase_1_summary.n_ $\bar{h}{ }^{*}$

(((nvl(ysum_hd_sqr, 0)/phase_1_summary.n_h) -

((nvl(ysum_hd, 0$) /$ phase_1_summary.n_h) *

$($ nvl (ysum_hd, 0) / phase_1_summary.n_h $))) /$

(phase_1_summary.n_h-1)))) +

1/ SUM(phase_1_summary.n_h) *

$\left(\operatorname{SUM}\left(\left(1-w \_h\right)^{*}\right.\right.$ phase_1_summary.n_h *

(((nvl(ysum_hd_sqr, 0$) /$ phase_1_summary.n_h) -

$\left(\left(\right.\right.$ nvl $\left(y s u m \_h d, 0\right) /$ phase_1_summary.n_h) *

(nvl(ysum_hd, 0)/ phase_1_summary.n_h))) /

(phase_1_summary.n_h-1))))) var_of_estimate,

total_area total_population_area_acres

FROM (SELECT peg.eval_grp,

peg.cn pop_eval_grp_cn,

psm.estn_unit_cn,

psm.expns,

psm.cn pop_stratum_cn,

p1pointent /

(SELECT SUM(strs.p1pointent)

FROM pop_stratum strs

WHERE strs.estn_unit_cn = psm.estn_unit_cn) w_h,

(SELECT SUM(strs.p1pointent)

FROM pop_stratum strs

WHERE strs.estn_unit_cn = psm.estn_unit_cn) n_prime,

p1pointcnt n_prime_h,

(SELECT SUMM(eu_s.area_used)

FROM pop_estn_unit eu_s

WHERE eu_s.cn = psm.estn_unit_cn) total_area,

psm.p2pointent $n \_h$

FROM pop_estn_unit peu,

pop_stratum psm,

pop_eval pev,

pop_eval_grp peg,

pop_eval_typ pet 
WHERE peu.cn = psm.estn_unit_cn

AND pev.cn = peu.eval_cn

AND pet.eval_cn $=$ pev.cn

AND pet.eval_grp_cn = peg.cn

AND pet.eval_typ = 'EXPVOL' -- specify the appropriate expansion

AND peg.eval_grp = $\mathbf{2 7 2 0 0 3}$-- the desired evaluation group must be specified

) phase_1_summary,

(SELECT̄ pop_stratum_cn,

SUM(y_hid_adjusted) ysum_hd,

SUM(y_hid_adjusted * y_hid_adjusted) ysum_hd_sqr,

COUNT ${ }^{*}$ ) number_plots_in_domain,

SUM(decode(y_hid_adjusted, 0,0 , NULL, 0, 1)) non_zero_plots

FROM (SELECT psm.cn pop_stratum_cn,

p.cn plt_cn,

SUM(s.tpa_unadj* adj_factor_micr) y_hid_adjusted

FROM cond

plot

seedling

-- expression from ref_pop_attribute table

pop_plot_stratum_assgn ppsa,

pop_stratum psm,

pop_estn_unit peu,

pop_eval pev,

pop_eval_grp peg,

pop_eval_typ pet

WHERE p.cn = c.plt_cn

AND pet.eval_typ = 'EXPVOL'

AND s.plt_cn = c.plt_cn

AND s.condid $=$ c.condid

AND c.cond_status_cd $=1$

AND c.reservcd $=0$

AND c.siteclcd IN $(1,2,3,4,5,6)$

AND ppsa.plt_cn = p.cn -- additional where_clause from ref_pop_attribute table

AND ppsa.stratum_cn = psm.cn

AND peu.cn = psm.estn_unit_cn

AND pev.cn $=$ peu.eval $\_$cn

AND pet.eval_cn $=$ pev.cn

AND pet.eval_grp_cn $=$ peg.cn

AND peg.eval_grp = 272003 -- the desired evaluation group must be specified

GROUP BY psm.cn, p.cn)

GROUP BY pop_stratum_cn) phase_2_summary

WHERE phase_1_summary.pop_stratum_cn $=$

phase_2_summary.pop_stratum_cn $(+\overline{)})$

GROUP BY pop_eval_grp_cn,

eval_grp,

estn_unit_cn,

phase_1_summary.total_area) estimate_by_estn_unit

GROUP BY pop_eval_grp_cn, eval_grp 
Produces the following estimate of number of live seedlings on timberland with sampling error:

\begin{tabular}{|l|r|}
\hline EVAL GRP & 272003 \\
\hline ESTIMATE & $37,141,783,495$ \\
\hline SE OF ESTIMATE PCT & 1.8 \\
\hline VAR OF ESTIMATE & 16,041 \\
\hline TOTAL PLOTS & 4,304 \\
\hline NONZERO PLOTS & $54,002,539$ \\
\hline TOTAL POPULATION ACRES &
\end{tabular}

\section{Restricting the attribute of interest to a smaller subset of the population}

The estimation procedures presented in examples 4.1 through 4.9 can all be modified to restrict the estimation to a subset, referred to as the domain of interest. An example of a domain would be only sawtimber stands on publicly owned timberland. In effect, the attributes identified in the REF_POP_ATTRIBUTE table are a combination of an attribute (e.g., area, number of trees, volume, number of seedlings) and a domain (e.g., forest land, timberland, ownership, growing-stock trees). The attribute of interest is defined in the REF_POP_ATTRIBUTE.EXPRESSION and the domain of interest is defined by REF_POP_ATTRIBUTE.WHERE_CLAUSE. In example 4.2, the attribute of interest is area, and the domain of interest is restricted to timberland only. In example 4.3 , the attribute of interest is number of trees, and the domain of interest is restricted to live trees on forest land with diameters 1 inch and larger. In example 4.4, the attribute of interest is number of seedlings, and the domain of interest is restricted to timberland. In example 4.5, the attribute of interest is volume of growing-stock, and the domain of interest is restricted to timberland.

A word of caution when working with periodic data - not all lands and all attributes were sampled in periodic inventories. In some States, only productive, non-reserved lands were sampled in periodic inventories. So, applying estimation of number of trees to all forest land in older periodic inventories will appear to work, but trees were only measured on timberland, so the estimates will only reflect the trees on timberland. Also, in many periodic inventories, seedlings were not tallied.

In the next example, the domain of interest in example 4.3 is further restricted to a specific species ( $\mathrm{SPCD}=129$, eastern white pine), diameter (DIA $\geq 20$, trees 20 inches and larger), and ownership $(\mathrm{OWNGRPCD}=40$, private owners only). The boxed lines have been added to the procedure. The procedure now provides an estimate of the total number of live eastern white pine, 20 inches and larger on privately owned forest land. 
Example 4.10 Estimate number of live eastern white pine trees 20 inches and larger on privately owned forest land (trees).

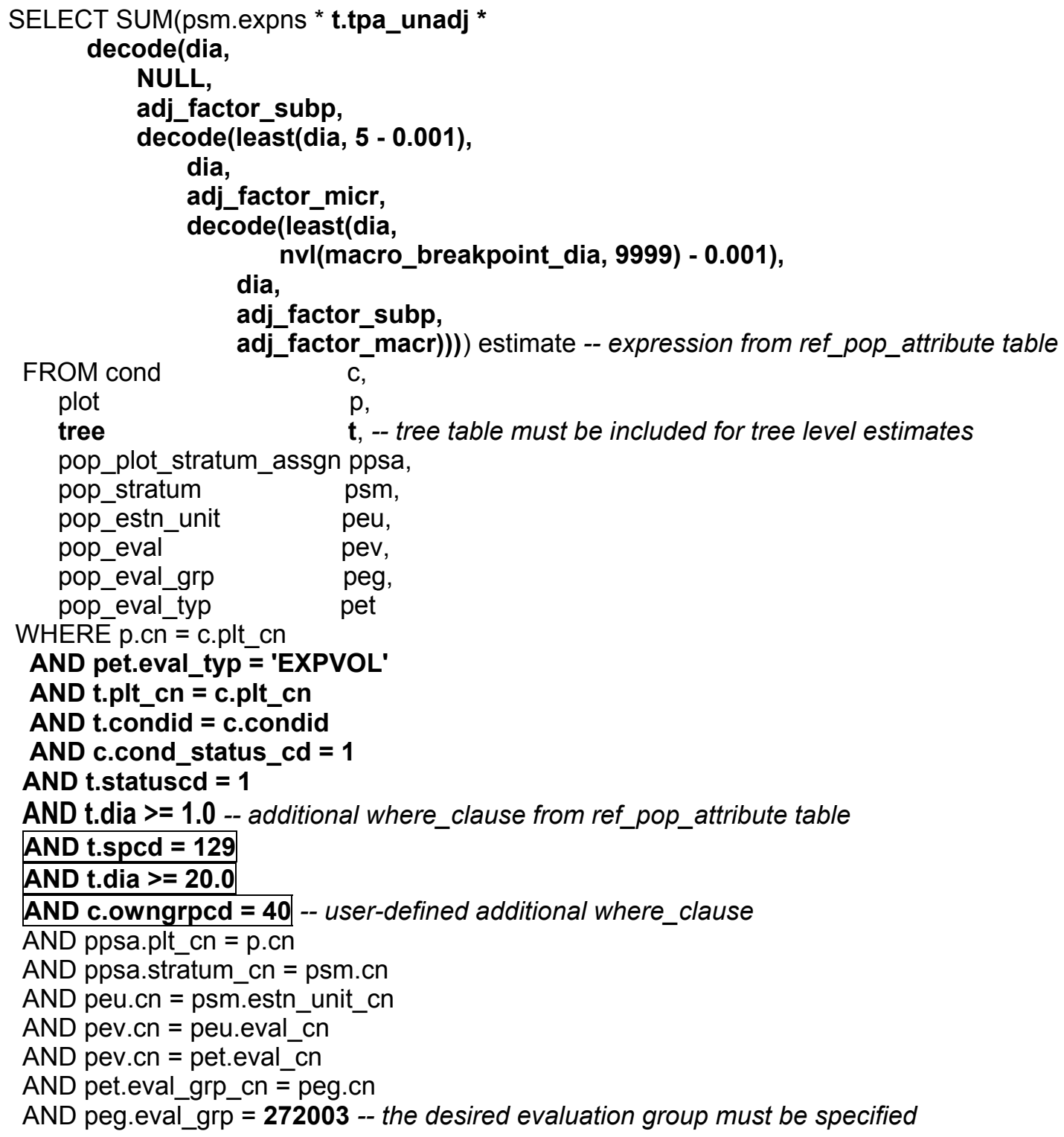

Produces the following estimate of total number of live eastern white pine, 20 inches and larger on privately owned forest land:

\begin{tabular}{|l|}
\hline ESTIMATE \\
\hline 519,317 \\
\hline
\end{tabular}


Adding the same restrictions to the where clause in example 4.8 provides the following output:

\begin{tabular}{|l|r|}
\hline EVAL GRP & 272003 \\
\hline ESTIMATE & 519,317 \\
\hline SE OF ESTIMATE PCT & 25.1 \\
\hline VAR OF ESTIMATE & $17,051,491,226$ \\
\hline TOTAL PLOTS & 16,041 \\
\hline NON ZERO PLOTS & 20 \\
\hline TOTAL POPULATION ACRES & $54,002,539$ \\
\hline
\end{tabular}

The estimated 519,317 eastern white pine trees, 20 inches and larger on privately owned forest land has a sample error of 25.1 percent. Live eastern white pine 20 inches or larger on private forest land were observed on a total of 20 plots in the State.

\section{Changing the attribute of interest with user-defined criteria}

Users can define condition level attributes of interest. The standard condition level attributes of interest are sampled land area and all land area (expressed in acres). Sampled land area (adjusted for denied access and hazardous conditions that were not sampled) is the one used for nearly all standard FIA tables that report area estimates. All land area (where denied access and hazardous are considered part of the sample) is only used in estimation that treats denied access (plots on land where field crews were unable to obtain the owner's permission to measure the plot) and hazardous (conditions that were deemed too hazardous to measure the plots) as part of the sample attribute of interest. Most of the other condition level variables that FIA observes are typically used to categorize the condition, and are most often applied as restrictions on the population in defining the domain, and do not lend themselves as an attribute of interest. For example, BALIVE (the basal area of live trees 1 inch diameter and larger) is mainly used to categorize forest land area rather than as an attribute of interest in population level estimation. Users are more interested in knowing how many acres of forest land meets some basal area requirement (say between 50 and 100 square feet per acre), rather than the total basal area of forest land in a State.

An example of a user-defined condition level attribute of interest, for which an estimate of a total might be of interest, would be total land value (see Example 4.11). Here the user would supply a function that assigns value (\$ per acre) to forest land, based on attributes in FIADB. As an example, we use a very arbitrary function of site index and basal area of live tree - value per acre $=1000+$ (site index $\times 3)+($ basal area $\times 4)$, and limit the domain of interest to only private timberland. Modifying example 1 produces the following script and estimate of total value. Since the function is a condition level value per acre, it is simply included in the expression as a multiplication factor, and the domain restriction (private timberland) is added to the where clause. The sections that have been added to example 4.2 are in boxes. The same modifications were added to example 4.7 to produce the estimates with sampling errors. 
Example 4.11 Estimated dollar value of private timberland (user defined function).

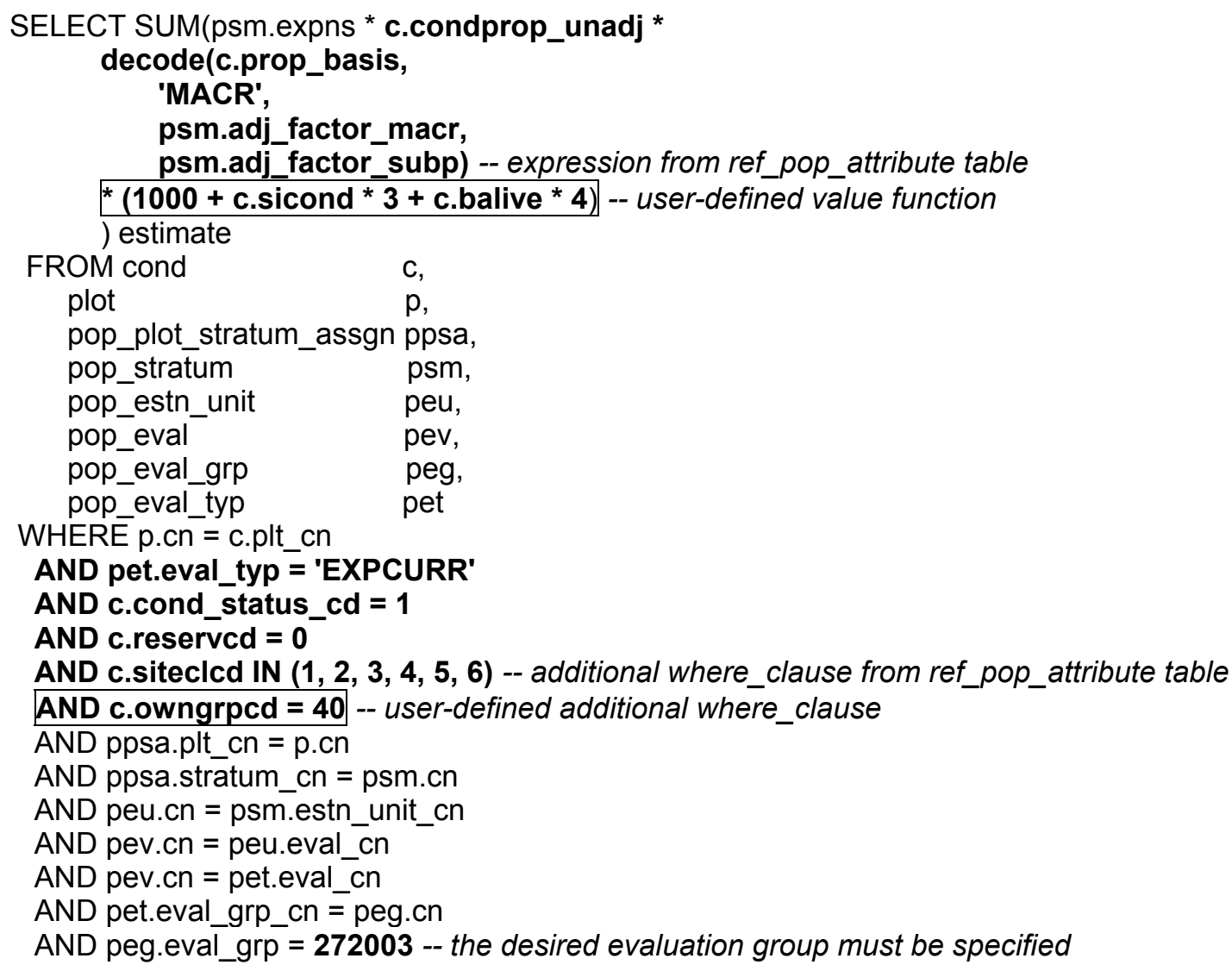

Produces the following estimate only from above example:

\begin{tabular}{|l|}
\hline ESTIMATE \\
\hline $10,156,384,067$ \\
\hline
\end{tabular}

And the same modification to example 4.7 produces the following estimate with sampling errors:

\begin{tabular}{|l|r|}
\hline EVAL GRP & 272003 \\
\hline ESTIMATE & $10,156,384,067$ \\
\hline SE OF ESTIMATE PCT & 1.4 \\
\hline VAR OF ESTIMATE & 16,041 \\
\hline TOTAL PLOTS & 2,290 \\
\hline NON ZERO PLOTS & $54,002,539$ \\
\hline TOTAL POPULATION ACRES & \\
\hline
\end{tabular}

Based on this function, the estimated total value of private timberland in the State is 10.1 billion dollars. This value function is used only as an example, any type of user defined function that assigns quantities, such as value (\$ per acre), wildlife population level (animals per acre), productivity (yield per acre), or carbon sequestration potential (tons per acre) could be used as long as it is a function of data items in the FIADB, and/or data attributes from other sources that can be linked to FIA plots. 


\section{Estimates of change over time on the standard 4-subplot fixed area plot}

A number of the attributes described in the REF_POP_ATTRIBUTE table are related to change over time and are based on computed attributes that utilize data from two points in time from the same plot. The attributes identified by values 25-44 (e.g., net growth of all live on forestland represented by 25) of REF_POP_ATTRIBUTE.ATTRIBUTE_NBR are the standard growth, removals and mortality attributes that FIA presents in its reports. The computation of these values as presented in the previous section will provide estimates of these change attributes; however, all estimation is done through the observations made and recorded at the second measurement of the plot. Users often wish (1) to obtain estimates that reflect changes in attributes over the remeasurement of the plot that go beyond these attributes, (2) to classify these standard estimates and other estimates by attributes from the previous measurement, or (3) to cross classify them by changes in various attributes over time. Examples of these types of estimations are:

- Breakdowns of change in area over time by past and current land use, forest type, or other condition attributes.

- Number of trees on forest land that changed to nonforest land.

- Removals of trees on forest land of a specific forest type that changed to a different forest type after removals.

- Mortality of trees that were in a specific diameter range in the previous measurement.

- Change in the number of seedlings per acre over time for a specific forest type.

The estimation of these and many other change attributes require properly selecting the appropriate set of plots that were measured at both points in time and linking data from these two measurements.

Prior to 1999, FIA used periodic inventories with different plot designs. Since 1999, the new annual inventory uses a national standard, 4-subplot fixed area plot design. The change estimation procedures described here are applicable to all plots measured at least twice in the annual inventory, but may not be appropriate for change estimation between periodic and annual inventories.

\subsection{Selecting an appropriate set of plots (evaluation) for change estimations}

For change estimation, select an evaluation that consists of only remeasured plots, evaluations used for growth, removals, and mortality estimation. These growth-removals-mortality (GRM) evaluations can be identified by either of the following restrictions in the where clause:

or

and pop_eval.cn = pop_eval_grp.eval_cn_for_expgrow,

and pop_eval_typ.eval_grp_cn = pop_eval_grp.cn

and pop_eval_typ.eval_typ='EXPGROW'

Either of these statements will restrict the sample plots to only those used in the estimation of growth: only the set of plots that have been measured at two points in time. In the examples we continue linking to evaluations through the POP_EVAL_TYP table (second example). 


\subsection{Linking tree level data to past condition data}

In the following examples, we demonstrate how to produce a tree-level estimate (net growth of all live trees on forest land), and then link it to conditions at two points in time (past and current) to produce a table that breaks down the estimate by condition-level attributes and the two points in time.

First we begin with the script that produces an estimate of total net growth of all live trees on forest land for the 2007 Minnesota inventory. The evaluation used in this estimate (pop_eval.evalid = 270703) consists of plots measured in 1999, 2000, 2001, and 2002 that were remeasured in 2004, 2005, 2006, and 2007, respectively.

Example 4.12 Estimate net growth of all live trees on forest land (cubic feet per year).

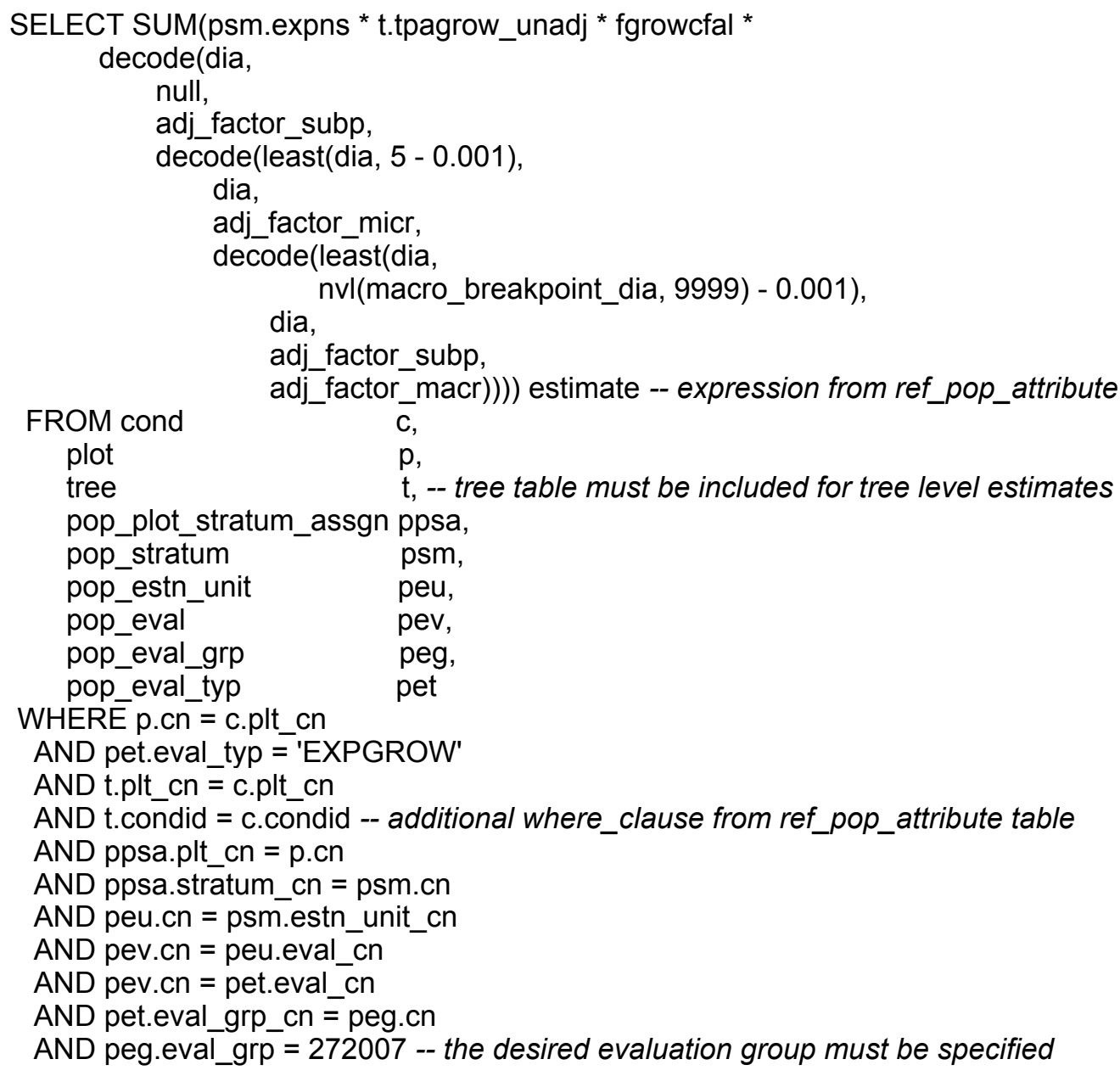

The example above produces the following estimate of total net growth of all live trees on forest land:

427,200,491 cubic feet per year

We then modified this example to link not only to the condition record at the current (second) measurement, but also to the condition record at the previous (first) measurement by using the attribute TREE.PREVCOND to link each tree record to its previous condition. We also added a 
group by clause to produce the estimates broken down by values of the condition level attributes COND_STATUS_CD (condition status code) and STDSZCD (stand-size class code) at both points in time. This procedure is shown in example 4.13, which was created by adding the bold sections to example 4.12 .

Example 4.13 Estimate net growth of all live on forest land (cubic feet per year) by condition status and stand size at two points in time.

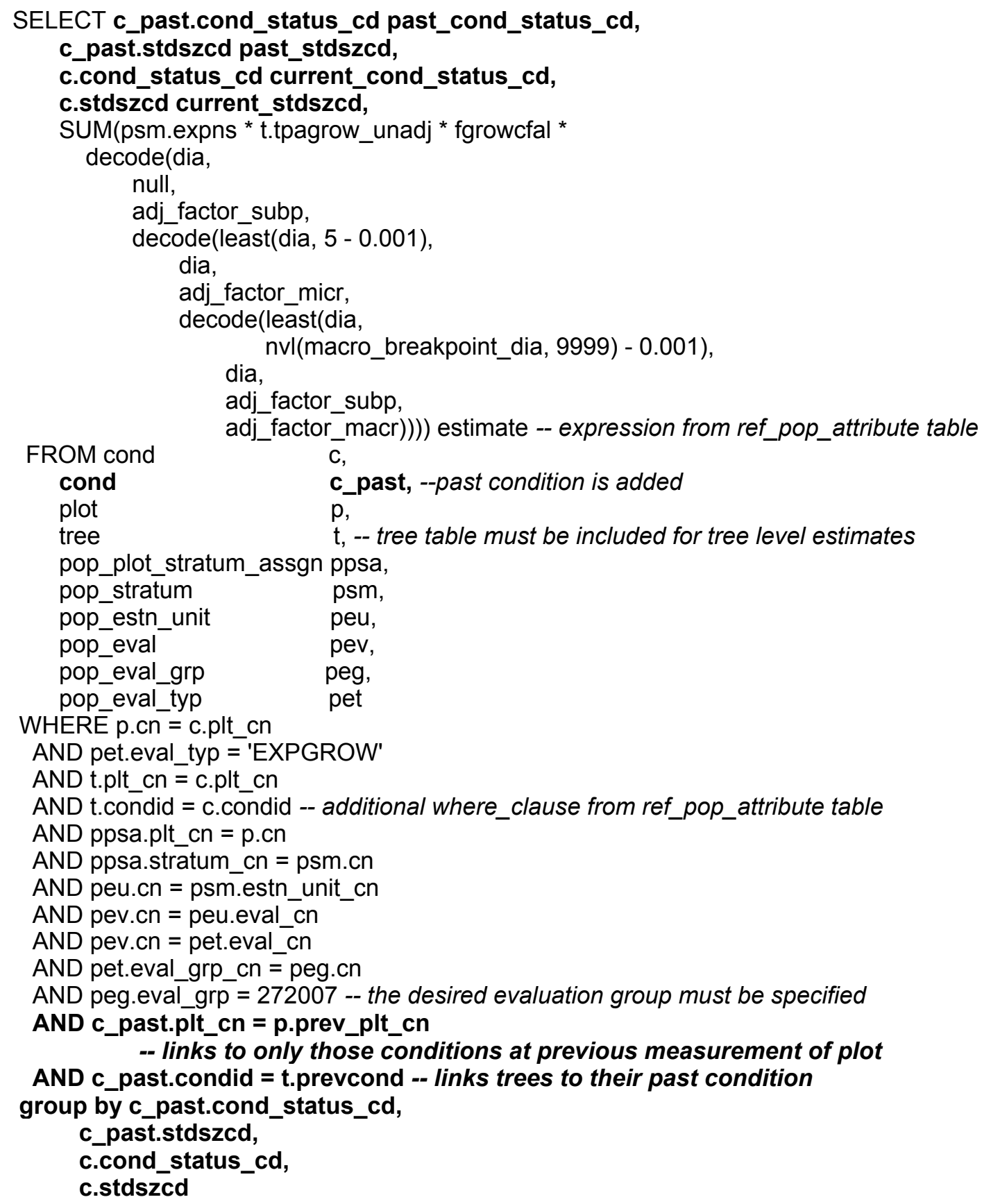


Example 4.13 produces the following estimates of total net growth of all live trees on forest land broken down by past and current COND_STATUS_CD and STDSZCD values.

\begin{tabular}{|c|c|c|c|c|}
\hline $\begin{array}{l}\text { PAST_COND_ } \\
\text { STATUS_CD }\end{array}$ & $\begin{array}{l}\text { PAST } \\
\text { STDSZ̄CD }\end{array}$ & $\begin{array}{l}\text { CURRENT_COND_ } \\
\text { STATUS_CD }\end{array}$ & $\begin{array}{l}\text { CURRENT_- } \\
\text { STDSZCD }\end{array}$ & ESTIMATE \\
\hline 1 & 年 & 1 & 1 & $81,494,163.3$ \\
\hline 1 & 1 & 1 & 2 & $-1,056,519.2$ \\
\hline 1 & 1 & 1 & 3 & $-6,077,491.9$ \\
\hline 1 & 1 & 1 & 5 & $-4,520,213.8$ \\
\hline 1 & 1 & 2 & & $708,394.8$ \\
\hline 1 & 1 & 5 & & 0.0 \\
\hline 1 & 2 & 1 & 1 & $24,639,163.2$ \\
\hline 1 & 2 & 1 & 2 & $121,373,610.5$ \\
\hline 1 & 2 & 1 & 3 & $-298,122.7$ \\
\hline 1 & 2 & 1 & 5 & $-1,358,131.3$ \\
\hline 1 & 2 & 2 & & $-720,502.7$ \\
\hline 1 & 2 & 3 & & $-41,231.9$ \\
\hline 1 & 3 & 1 & 1 & $4,596,722.9$ \\
\hline 1 & 3 & 1 & 2 & $29,398,997.6$ \\
\hline 1 & 3 & 1 & 3 & $38,089,804.3$ \\
\hline 1 & 3 & 1 & 5 & $78,764.7$ \\
\hline 1 & 3 & 2 & & $380,739.8$ \\
\hline 1 & 3 & 3 & & 0.0 \\
\hline 1 & 3 & 4 & & $-327,337.8$ \\
\hline 1 & 5 & 1 & 1 & $1,591,344.2$ \\
\hline 1 & 5 & 1 & 2 & $579,855.3$ \\
\hline 1 & 5 & 1 & 3 & $135,054.2$ \\
\hline 1 & 5 & 1 & 5 & $11,488.4$ \\
\hline 1 & 5 & 2 & & $2,210.0$ \\
\hline 1 & 5 & 5 & & 0.0 \\
\hline 2 & & 1 & 1 & $67,569,968.1$ \\
\hline 2 & & 1 & 2 & $45,417,363.4$ \\
\hline 2 & & 1 & 3 & $11,180,894.0$ \\
\hline 2 & & 1 & 5 & $557,059.5$ \\
\hline 2 & & 2 & & 0.0 \\
\hline 3 & & 1 & 1 & $4,285,796.0$ \\
\hline 3 & & 1 & 2 & $1,838,167.0$ \\
\hline 3 & & 1 & 3 & $1,187,875.3$ \\
\hline 4 & & 1 & 1 & $5,868,590.9$ \\
\hline 4 & & 1 & 2 & $212,902.8$ \\
\hline 4 & & 1 & 3 & $401,112.0$ \\
\hline 5 & & 1 & 1 & 0.0 \\
\hline
\end{tabular}


FIA Database Description and Users Manual for Phase 2, version 4.0

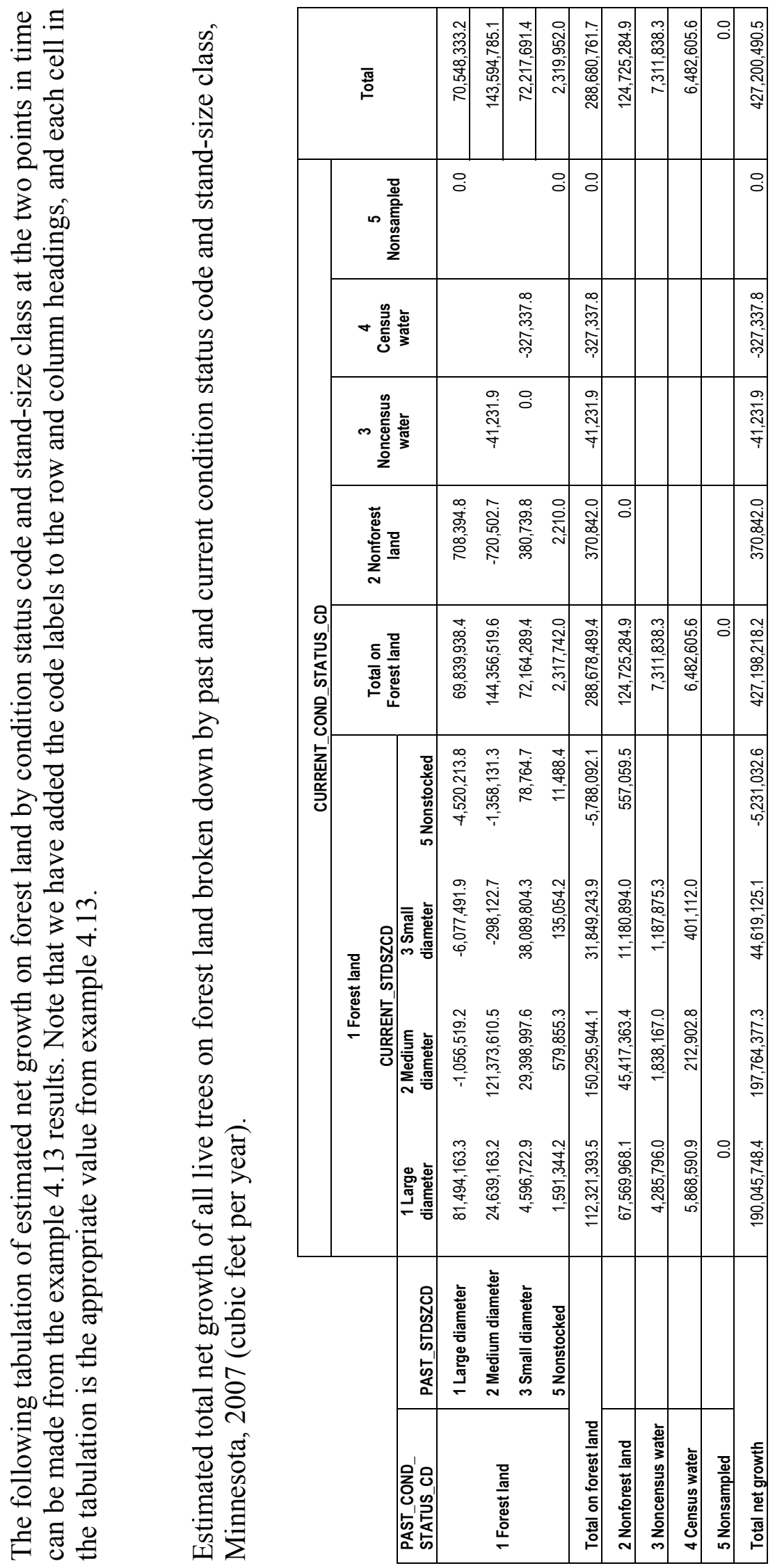




\subsection{The SUBP_COND_CHNG_MTRX (CMX) table}

The SUBP_COND_CHNG_MTRX (CMX) table was added in the FIADB version 4.0 to facilitate the tracking of area change for the annual inventory. Under this design, a plot measures area change by tracking the movement in condition boundaries within the area of the four subplots. Figure 7 shows what can happen on a plot when a condition boundary (in this case the edge of a beaver pond) moves over time. Beaver activity raised the level of the pond, increasing the pond area and converting some of the forest land to water. The same kind of changes can occur from any number of human-caused events such as timber harvesting, land clearing or road construction, or natural events such as fire, storms, or insect attacks.
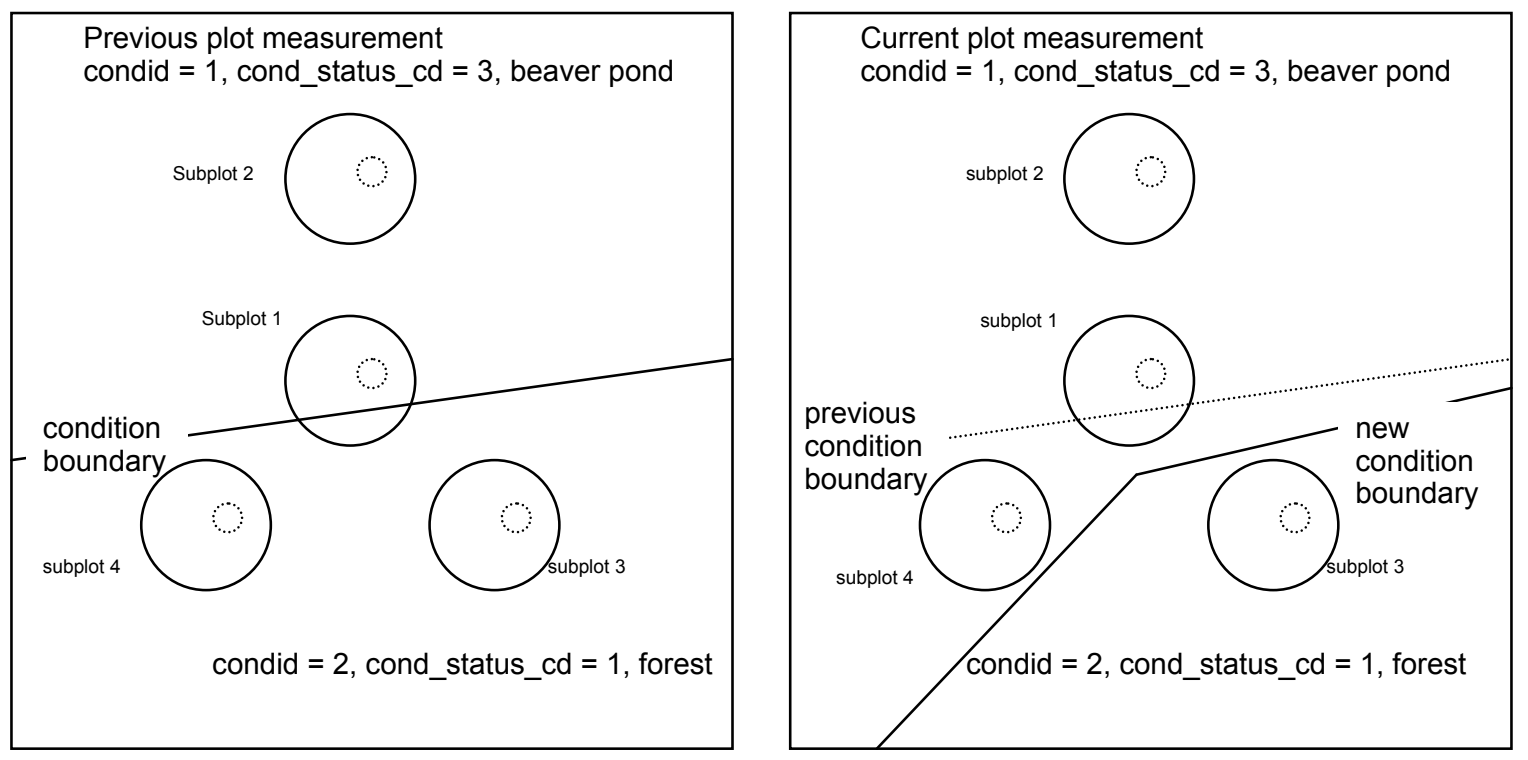

Figure 7. Example plot layout where condition boundaries changed between previous (left panel) and current plot measurements (right panel). The solid circles are the subplots and the smaller dashed circles are the microplots.

It is important to remember that condition boundaries are not just defined along changes in condition status code, but also may occur within forest land. The following tabulation shows how the area change information in figure 7 would be recorded in the CMX table

CMX table data for figure 7

\begin{tabular}{|l|l|l|l|l|}
\hline SUBP & SUBPTYP & CONDID & PREVCOND & SUBPTYP_PROP_CHNG \\
\hline 1 & 1 & 1 & 1 & .8000 \\
\hline 1 & 1 & 1 & 2 & .2000 \\
\hline 1 & 2 & 1 & 1 & 1.000 \\
\hline 2 & 1 & 1 & 1 & 1.000 \\
\hline 2 & 2 & 1 & 1 & 1.000 \\
\hline 3 & 1 & 2 & 2 & 1.000 \\
\hline 3 & 2 & 2 & 2 & 1.000 \\
\hline 4 & 1 & 1 & 2 & 1.000 \\
\hline 4 & 2 & 1 & 2 & 1.000 \\
\hline
\end{tabular}


The CMX table tracks the change in condition areas for each of the four subplots (SUBPTYP $=1$ ) and each of the four microplots (SUBPTYP =2) on this plot. In inventories where the macroplot is used there would also be entries for each macroplot (SUBPTYP = 3). The attribute PROP_BASIS in the COND table identifies how area estimation was conducted for each plot, on the basis of either the macroplot or the subplot. In this example area estimation (and thus area change estimation) is based on the subplot information, not the macroplot. Area estimation is typically based on the largest area sampled (macroplot in States where it is measured, otherwise the subplot) and not on the microplot. Area and area change estimation based on the microplot is only appropriate with another estimate solely collected on the microplot such as number of trees or biomass in trees $<5$ inches diameter at breast height. The examples of change presented here are based on the subplot, but could easily be modified to obtain estimates based on the microplots.

In the example shown in figure 7, the CMX table has two entries where SUBPTYP $=1$ and $\mathrm{SUBP}=1$. The first entry indicates that 80 percent of the subplot area was in condition 1 (water) at both measurements, and the second entry indicates 20 percent of the subplot area changed from forest to water. For the other three subplots and all four microplots, only one record exists, indicating that the entire subplot or microplot either stayed in the same condition (subplots and microplots 2 and 3) or the entire area changed from one condition to another (subplot and microplot 4). For this remeasured plot, change based on the four subplots is water to water 45 percent, forest to water 30 percent, and forest to forest 25 percent; change based on the four microplots is water to water 50 percent, forest to water 25 percent, and forest to forest 25 percent. The following section presents SQL script that produces these estimates.

\subsection{Using the CMX table to estimate area change between two measurements}

The estimation of area change over time requires linking past and current conditions through the CMX table to determine the portion of plot area that transitioned from conditions observed at time 1 to those observed at time 2 (methods applicable only between two measurements in the annual inventory). As in examples 4.12 and 4.13, select an evaluation that consists of only remeasured plots. In the examples that follow, we show how to create area change estimates that go with the net growth of all live trees on forest land as obtained from example 4.13.

We begin by modifying the script that produces the estimate of area of forest land so that it uses the net growth evaluation EXPGROW rather than the area evaluation EXPCURR that is standard for area estimations. Example 4.14 shows this modification in bold. 
Example 4.14 Estimate area of forest land (acres) based on the net growth evaluation.

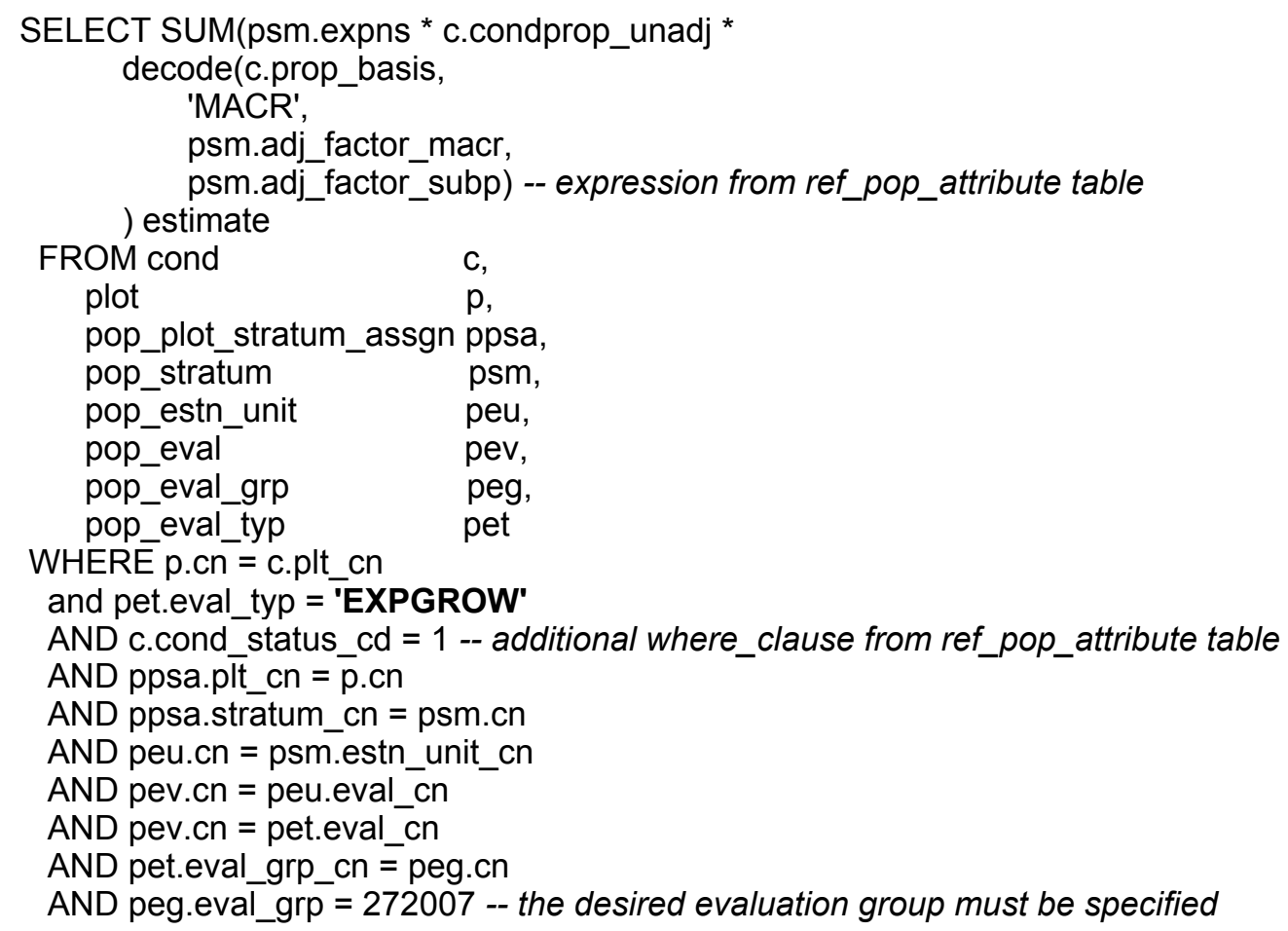

The remeasured plots (12,280 plots) associated with EXPGROW produce an area estimate of 16,962,397.2 acres of forest land versus 16,723,532.5 provided by EXCURR using all plots (17,855 plots). Both estimates of forest area are valid; however, only the one based on the remeasurement sample can be broken down into two points in time.

To estimate area change over time, the script has been further modified to link past and current condition records through the CMX table. This table has entries for every subplot on a remeasured plot and stores the proportion of the area of each subplot by the two points in time in the attribute CMX.SUBTYP_PROP_CHNG. Example 4.15 shows the script that produces the area change estimates that go with the net growth estimates produced in example 4.13. Again, changes and additions from example 4.14 are shown in bold. Line numbers are for reference purposes. 
Example 4.15 Estimate area change (acres) by condition status and stand size at two points in time, Minnesota, time 1 from 1999-2002 and time 2 from 2003-2007

\begin{tabular}{|c|c|}
\hline 1 & SELECT c_past.cond_status_cd past_cond_status_cd, \\
\hline 2 & c_past.stdszcd past_stdszcd, \\
\hline 3 & c.cond_status_cd current_cond_status_cd, \\
\hline 4 & c.stdszcd current_stdszcd, \\
\hline 5 & SUM(psm.expns * CMX.subptyp_prop_chng / 4 * \\
\hline 6 & decode(c.prop_basis, \\
\hline 7 & 'MACR', \\
\hline 8 & psm.adj_factor_macr, \\
\hline 9 & psm.adj_factor_subp) -- expression from ref_pop_attribute table \\
\hline 10 & ) estimate, \\
\hline 11 & count( $\left.{ }^{*}\right)$ COUNT, \\
\hline 12 & SUM(cmx.subptyp_prop_chng / 4) plot_area \\
\hline 13 & FROM cond \\
\hline 14 & plot \\
\hline 15 & pop_plot_stratum_assgn ppsa, \\
\hline 16 & pop_stratum \\
\hline 17 & pop_estn_unit \\
\hline 18 & pop_eval \\
\hline 19 & pop_eval_typ \\
\hline 20 & pop_eval_grp \\
\hline 21 & c_past, \\
\hline 22 & subp_cond_chng_mtrx cmx \\
\hline 23 & WHERE p.cn = c.plt_cn \\
\hline 24 & AND pet.eval_typ = 'EXPGROW' \\
\hline 25 & AND (c.cond_status_cd $=1$ or c_past.cond_status_cd = 1) \\
\hline 26 & AND ppsa.plt_cn = p.cn \\
\hline 27 & AND ppsa.stratum_cn = psm.cn \\
\hline 28 & AND peu.cn = psm.estn_unit_cn \\
\hline 29 & AND pev.cn = peu.eval_cn \\
\hline 30 & AND pev.cn = pet.eval_cn \\
\hline 31 & AND pet.eval_grp_cn = peg.cn \\
\hline 32 & AND peg.eval_grp $=272007$-- the desired evaluation group must be specified \\
\hline 33 & AND p.prev_plt_cn = c_past.plt_cn \\
\hline 34 & AND cmx.prev_plt_cn = c_past.plt_cn \\
\hline 35 & AND cmx.prevcond = c_past.condid \\
\hline 36 & AND cmx.condid = c.condid \\
\hline 37 & AND ((cmx.subptyp = 3 and c.prop_basis = 'MACR') or \\
\hline 38 & $(\mathrm{cmx}$. subptyp = 1 and c.prop_basis = 'SUBP')) \\
\hline 39 & group by c_past.cond_status_cd, \\
\hline 40 & c_past.stdszcd, \\
\hline 41 & c.cond_status_cd, \\
\hline 42 & c.stdszed \\
\hline
\end{tabular}

Example 4.15 can be used as a template to create almost any cross tabulation of past and current area estimates based on a remeasured set of plots. The following changes (bold sections) were made to example 4.14 to facilitate the estimation of area change:

- Line 21 - The table COND with the alias C_PAST was added to the list of tables to be joined. This provides the condition level attributes for the past (time 1) measurement of the plot. 
- Line 22 - The table SUBP_COND_CHG_MTRX with the alias CMX was added to the list of tables to be joined. This table provides the link between past (time 1) and current (time 2) conditions at the subplot level. Each entry in this table defines the portion (0-1) of the subplot, microplot or macroplot that was observed in a condition at time 2 and observed in a condition at time 1 . For a subplot that was entirely in a single condition at both times, there will only be one entry for the subplot, with CMX.SUBPTYP_PROP_CHNG $=1.0$. For a subplot that was mapped to be 40 percent in one condition and 60 percent in another condition at both times with no change in boundary, there will be two entries for the subplot, one with CMX.SUBPTYP_PROP_CHNG $=0.4$ and the other with CMX.SUBPTYP_PROP_ $\bar{C} H N G=0.6$. For subplots where boundaries have changed, there will be entries that account for all the pieces of the subplot area with the total value of CMX.SUBPTYP_PROP_CHNG adding to 1.0.

- Lines 1-4 and 39-42 - As in example 4.13, past and current condition status and stand-size class codes (group by c_past.cond_status_cd, c_past.stdszed, c.cond_status_cd, c.stdszcd) were grouped to obtain estimate breakdowns by these attributes.

- Line 5 - c.condprop_unadj (the total plot condition proportions that are within a specific condition) was replaced with cmx.subptyp_prop_chng / 4 (the subplot condition proportion divided by the number of subplots in the plot). The division by 4 is required because the CMX table tracks area at the subplot level (4 subplots per plot).

- Line 25 - The restrictions were changed in the where clause from AND c.cond_status_cd = 1 to AND (c.cond_status_cd $=1$ or c_past.cond_status_cd $=1$ ), to select conditions that were forest in at least one of the measurements, not just the current measurement. This query tracks the area of land that moves in and out of forest, as well as changes in stand-size class on land that remains forest.

- Lines 33-38 - These additions to the where clause provide the proper links to the C_PAST and CMX tables that were added to the table list. Line 33 (AND p.prev_plt_cn $=$ c_past.plt_cn) matches the past and current condition records to the same plot, and lines 3438 provide the other restrictions that link the appropriate conditions at the two measurements through the CMX table. Lines 37 and 38 ensure that in inventories where area estimates are based on the macroplot observations, the area change estimates are based on the macroplot observations, and in all other cases the estimates are based on the subplot observations.

- Lines 11 and 12 - count(*) COUNT and SUM(CMX.subptyp_prop_chng / 4)

PLOT_AREA provide two additional summary attributes along with the area estimates. COUNT is the total number of subplot pieces that is tracked in the estimation. PLOT_AREA is the total portion of plots that is tracked in the estimation. 
Example 4.15 produces the following estimates of total area (ESTIMATE), total number of subplots (COUNT), and total portion of plots (PLOT_AREA) broken down by past and current COND_STATUS_CD and STDSZCD values, for land that was forest at measurement time 1, measurement time 2, or both.

\begin{tabular}{|c|c|c|c|c|c|c|}
\hline $\begin{array}{l}\text { PAST_COND_ } \\
\text { STATUS_CD }\end{array}$ & $\begin{array}{l}\text { PAST } \\
\text { STDSŻCD }\end{array}$ & $\begin{array}{l}\text { CURRENT_- } \\
\text { STATUS_CD }\end{array}$ & $\begin{array}{l}\text { CURRENT_- } \\
\text { STDSZCD }\end{array}$ & ESTIMATE & COUNT & PLOT_AREA \\
\hline 1 & 1 & 1 & 1 & $3,631,160.4$ & 3208 & 767.8 \\
\hline 1 & 1 & 1 & 2 & $291,277.3$ & 274 & 63.1 \\
\hline 1 & 1 & 1 & 3 & $390,763.5$ & 360 & 83.0 \\
\hline 1 & 1 & 1 & 5 & $58,700.4$ & 53 & 12.0 \\
\hline 1 & 1 & 2 & & $70,387.0$ & 117 & 15.2 \\
\hline 1 & 1 & 3 & & $3,961.3$ & 10 & 0.8 \\
\hline 1 & 1 & 4 & & $2,892.6$ & 9 & 0.6 \\
\hline 1 & 1 & 5 & & $2,289.7$ & 2 & 0.5 \\
\hline 1 & 2 & 1 & 1 & $786,401.0$ & 709 & 167.1 \\
\hline 1 & 2 & 1 & 2 & $4,648,293.5$ & 4160 & 996.0 \\
\hline 1 & 2 & 1 & 3 & $620,036.7$ & 571 & 132.4 \\
\hline 1 & 2 & 1 & 5 & $46,356.9$ & 46 & 10.2 \\
\hline 1 & 2 & 2 & & $84,928.1$ & 133 & 18.8 \\
\hline 1 & 2 & 3 & & $1,990.6$ & 6 & 0.4 \\
\hline 1 & 2 & 4 & & 895.2 & 1 & 0.2 \\
\hline 1 & 3 & 1 & 1 & $158,110.2$ & 151 & 32.5 \\
\hline 1 & 3 & 1 & 2 & $648,108.5$ & 604 & 138.3 \\
\hline 1 & 3 & 1 & 3 & $4,243,065.9$ & 3884 & 934.6 \\
\hline 1 & 3 & 1 & 5 & $61,623.3$ & 56 & 13.1 \\
\hline 1 & 3 & 2 & & $98,616.9$ & 126 & 21.4 \\
\hline 1 & 3 & 3 & & $12,348.1$ & 11 & 2.1 \\
\hline 1 & 3 & 4 & & $4,707.5$ & 4 & 1.0 \\
\hline 1 & 5 & 1 & 1 & $16,820.1$ & 18 & 3.7 \\
\hline 1 & 5 & 1 & 2 & $18,273.1$ & 20 & 4.2 \\
\hline 1 & 5 & 1 & 3 & $95,244.4$ & 94 & 21.5 \\
\hline 1 & 5 & 1 & 5 & $61,597.5$ & 59 & 14.2 \\
\hline 1 & 5 & 2 & & $55,411.0$ & 53 & 11.9 \\
\hline 1 & 5 & 3 & & 549.8 & 1 & 0.1 \\
\hline 1 & 5 & 5 & & $2,814.4$ & 2 & 0.5 \\
\hline 2 & & 1 & 1 & $234,236.1$ & 288 & 50.7 \\
\hline 2 & & 1 & 2 & $267,173.3$ & 326 & 59.6 \\
\hline 2 & & 1 & 3 & $556,373.0$ & 564 & 126.3 \\
\hline 2 & & 1 & 5 & $48,463.7$ & 51 & 11.0 \\
\hline 3 & & 1 & 1 & $14,427.4$ & 19 & 3.1 \\
\hline 3 & & 1 & 2 & $9,767.2$ & 13 & 2.3 \\
\hline 3 & & 1 & 3 & $21,966.0$ & 21 & 4.3 \\
\hline 3 & & 1 & 5 & $1,225.5$ & 2 & 0.3 \\
\hline 4 & & 1 & 1 & $17,585.0$ & 19 & 4.0 \\
\hline 4 & & 1 & 2 & $4,149.1$ & 10 & 0.9 \\
\hline 4 & & 1 & 3 & $8,858.1$ & 9 & 2.0 \\
\hline 5 & & 1 & 1 & $2,339.8$ & 2 & 0.5 \\
\hline
\end{tabular}




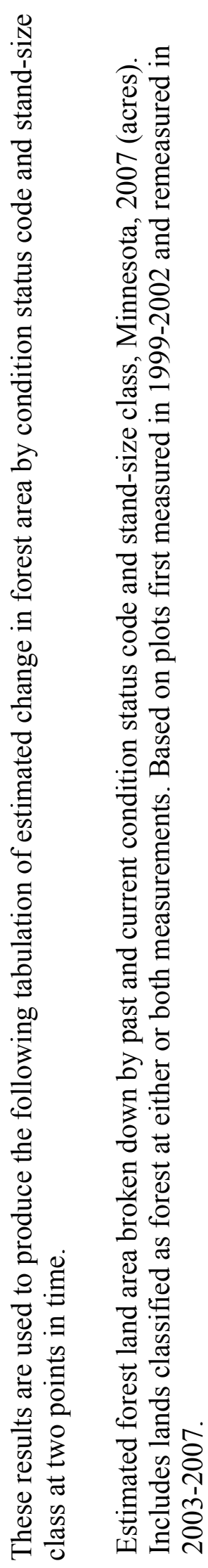

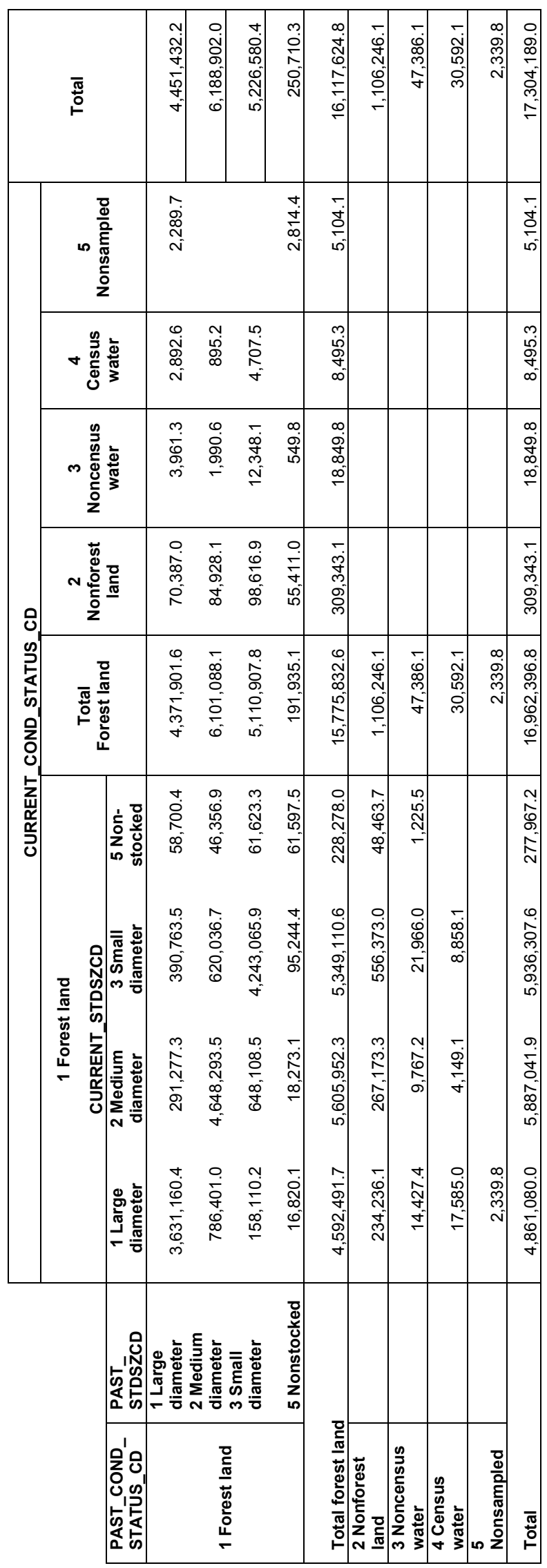

USDA Forest Service Gen. Tech. Rep. RMRS-GTR-245. 2010 
The total current forest land area in the table above (16,962,396.8 acres) matches (within 1 acre) the results we obtained in example 4.14 (16,962,397.2 acres). The difference between these two estimates is simply the rounding error introduced by storing and computing condition proportions for each of the individual subplot sections in cmx.subptyp_prop_chng versus the total condition proportion in c.condprop_unadj. The total past forest land area in the tabulation above $(16,117,624.8$ acres $)$ is based on the same remeasured plots and comes close, but does not match the 2003 estimate of forest land area (16,230,325.3 acres) one obtains when using example 4.14 and setting pet.eval_typ='EXPCURR' and pop_eval_grp.eval_grp $=272003$.

The COUNT and PLOT_AREA values provide data users with the number of measurements associated with each estimate, giving users some information about the reliability of the estimates. For example, conditions that remained as large diameter (COND.STDSZCD equals 1) from time 1 to time $2 \mathrm{had}$ an area estimate of 3,631,160.4 acres at time 2. From time 1 to time 2, 3,208 subplots or portions of subplots maintained their large diameter condition. These subplots or portions of subplots represent an area equivalent to 767.8 total plots. The estimates are based on a considerable number of observations. In contrast, if one is interested in tracking area of water (either census or noncensus water) that converts to or from forest land over time, estimates are based on far fewer observed changes. The estimated area that changed from water (COND.COND_STATUS_CD equals 3 or 4 ) to forest (COND.COND_STATUS_CD equals 1) is 77,978.2 acres, and the estimated change from forest to water is $27,345.1$ acres. The water to forest change is based on observations from 93 subplots where at least a portion of the subplot was observed to change from water to forest. The total area of this observed change is equal to 16.8 plots. The change from forest to water estimate $(27,345.1$ acres) is based on 42 subplot observations over an area equivalent to 5.2 plots.

Example 4.16 presents sampling errors for the forest to water area change estimate. This script was created from the script presented in example 4.7 with modifications similar to those made in example 4.15. The bold sections indicate where changes were made. The addition of the following code to the where clause restricts the estimation to conditions that change from forest (c_past.cond_status_cd $=1$ ) to water (c.cond_status_cd IN $(3,4)$ ):

\section{AND (c.cond_status_cd IN $(3,4)$ AND c_past.cond_status_cd = 1).}

Further modifications to this example were made to produce estimates and sampling errors for the water to forest area change and for areas that remained as large diameter conditions as discussed in the previous paragraph. The results are presented in the tabulation that follows example 4.16. Users will note that the sampling errors for the estimates of forest to water and water to forest area change are quite high (29.2 percent and 18.4 percent, respectively) and the sampling error on conditions remaining large diameter is fairly low (2.9 percent). To obtain other area change and sampling error estimates, users should modify the where clause and eval_grp.

Example 4.16. Estimate area change from forest (cond_status_cd equals 1) to water (cond_status_cd equals 3 or 4) with sampling error. Based on the Minnesota 2007 remeasurement sample. Note the bold sections in this example indicate where changes in code from example 4.7 were made.

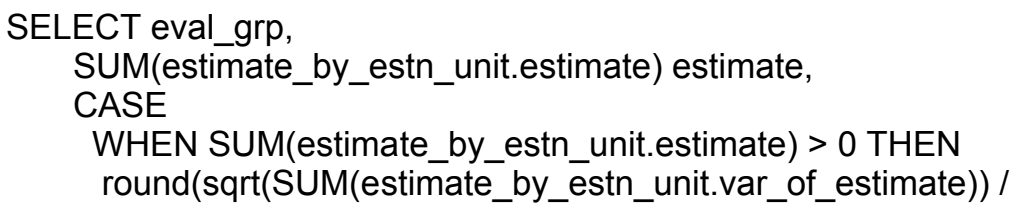


SUM(estimate_by_estn_unit.estimate) ${ }^{*}$ 100,

3)

ELSE

0

END AS se_of_estimate_pct,

SUM(estimate_by_estn_unit.var_of_estimate) var_of_estimate,

SUM(estimate_by_estn_unit.total_plots) total_plots,

SUM(estimate_by_estn_unit.non_zero_plots) non_zero_plots,

SUM(estimate_by_estn_unit.total_population_area_acres) total_population_acres

FROM (SELECT pop_eval_grp_cn,

eval_grp,

estn_unit_cn,

sum(nvl(ysum_hd, 0) * phase_1_summary.expns) estimate,

SUM(phase_1_summary.n_h) total_plots,

SUM(phase_2_summary.number_plots_in_domain) domain_plots,

SUM(phase_2_summary.non_zero_plots) non_zero_plots,

total_area * total_area / SUM(phase_1_summary.n_h) *

( $\left(S \cup M M\left(w \_h\right.\right.$ * phase_1_summary.n_ $\bar{h}$ *

(((nvl(ysum_hd_sqr, 0) / phase_1_summary.n_h) -

( (nvl(ysum_hd, 0$) /$ phase_1_summary.n_h) *

(nvl(ysum_hd, 0)/ phase_-1_summary.n_h $)$ )) /

$($ phase_1_summary.n_h-1)) )) +

$1 /$ SUM(phase_1_summary.n_h) *

$\left(\operatorname{SUM}\left(\left(1-w \_h\right){ }^{*}\right.\right.$ phase_1_summary.n_h *

(((nvl(ysum_hd_sqr, 0$) /$ phase_1_summary.n_h) -

((nvl(ysum_hd, 0)/ phase_1_summary.n_h) *

$($ nvl(ysum_hd, 0) / phase_1_summary.n_h $))) /$

(phase_1_summary.n_h-1)) ))) var_of_estimate,

total_area total_population_area_acres

FROM (SELECT peg.eval_grp,

peg.cn pop_eval_grp_cn,

psm.estn_unit_cn,

psm.cn pop_stratum_cn,

psm.expns,

p1pointent /

(SELECT SUM(strs.p1pointent)

FROM pop_stratum strs

WHERE strs.estn_unit_cn = psm.estn_unit_cn) w_h,

(SELECT SUM(strs.p1pointent)

FROM pop_stratum strs

WHERE strs.estn_unit_cn = psm.estn_unit_cn) n_prime,

p1pointcnt n_prime_h,

(SELECT SÜM(eu_s.area_used)

FROM pop_estn_unit eu_s

WHERE eu_s.cn = psm.estn_unit_cn) total_area,

psm.p2pointent n_h

FROM pop_estn_unit peu,

pop_stratum psm,

pop_eval pev,

pop_eval_grp peg,

pop_eval_typ pet

WHERE peu.cn = psm.estn_unit_cn

AND pev.cn = peu.eval_cn

AND pet.eval_cn $=$ pev.cn

AND pet.eval_grp_cn $=$ peg.cn

AND pet.eval_typ = 'EXPGROW' -- expansion factor tracking change

AND peg.eval_grp = $\mathbf{2 7 2 0 0 7}$-- desired evaluation group must be specified

) phase_1_summary, 
(SELECT pop_stratum_cn,

SUM(y_hid_adjusted) ysum_hd,

SUM(y_hid_adjusted ${ }^{*} y \_h i d \_$_adjusted) ysum_hd_sqr,

COUNT $\left(^{*}\right)$ number_plots_in_domain,

SUM(decode(y_hid_adjusted, 0,0 , NULL, 0,1$)$ ) non_zero_plots

FROM (SELECT psm.cn pop_stratum_cn,

p.cn plt_cn,

SUM(cmx.subptyp_prop_chng / 4 *

decode(c.prop_basis,

'MACR',

psm.adj_factor_macr,

psm.adj_factor_subp) -- expression for proportion of tracked plots

) y_hid_adjusted

FROM cond

plot

pop_plot_stratum_assgn ppsa,

pop_stratum psm,

pop_estn_unit peu,

pop_eval pev,

pop_eval_typ pet,

pop_eval_grp peg,

cond c_past,

subp_cond_chng_mtrx cmx

WHERE $\bar{p} . c n=\bar{c}$. plt_cn

AND pet.eval_typ = 'EXPGROW'

AND (c.cond_status_cd IN $(3,4)$ AND c_past.cond_status_cd = 1)

-- where clause tracking change

AND ppsa.plt_cn $=$ p.cn

AND ppsa.stratum_cn $=$ psm.cn

AND peu.cn $=$ psm.estn_unit_cn

AND pev.cn $=$ peu.eval_cn

AND pev.cn $=$ pet.eval_cn

AND pet.eval_grp_cn = peg.cn

AND peg.eval_grp $=\mathbf{2 7 2 0 0 7}$-- desired evaluation group must be specified

AND p.prev_plt_cn = c_past.plt_cn

AND cmx.prev_plt_cn $=$ c_past.plt_cn

AND cmx.prevcond $=$ c_past.condid

AND cmx.condid $=$ c.condid

AND ((cmx.subptyp $=3$ and c.prop_basis = 'MACR') or

(cmx.subptyp = 1 and c.prop_basis = 'SUBP'))

-- join past conditions / change matrix table

GROUP BY psm.cn, p.cn)

GROUP BY pop_stratum_cn) phase_2_summary

WHERE phase_1_summary.pop_stratum_cn =

phase_2_summary.pop_stratum_cn $(+)$

GROUP BY pop_eval_grp_cn,

eval_grp,

estn_unit_cn,

phase_1_summary.total_area) estimate_by_estn_unit

GROUP BY pop_eval_grp_cn, eval_grp 
Results of Example 4.16:

Area change estimates and sampling errors based on remeasured plots, Minnesota, 2007.

\begin{tabular}{|c|c|c|c|}
\hline & Forest to water & Water to forest & $\begin{array}{l}\text { Large diameter forest at both } \\
\text { measurements }\end{array}$ \\
\hline $\begin{array}{l}\text { Changes to where } \\
\text { clause }\end{array}$ & $\begin{array}{l}\text { AND } \\
\text { (c.cond_status_cd IN }(3,4) \\
\text { AND } \\
\text { c_past.cond_status_cd = 1) }\end{array}$ & $\begin{array}{l}\text { AND } \\
\text { (c.cond_status_cd=1 } \\
\text { AND } \\
\text { c_past.cond_status_cd IN } \\
(3,4) \text { ) }\end{array}$ & $\begin{array}{l}\text { AND } \\
\text { (c.cond_status_cd=1 } \\
\text { AND } \\
\text { c_past.cond_status_cd=1 } \\
\text { AND } \\
\text { C.STDSZCD }=1 \\
\text { AND c_past.STDSZCD = 1) }\end{array}$ \\
\hline EVAL_GRP & 272007 & 272007 & 272007 \\
\hline ESTIMATE & $27,345.1$ & $77,978.2$ & $3,631,160.4$ \\
\hline SE_OF_ESTIMATE_PCT & 29.2 & 18.4 & 2.9 \\
\hline VAR_OF_ESTIMATE & $63,796,853$ & $206,390,712$ & $11,427,498,039$ \\
\hline TOTAL_PLOTS & 12,280 & 12,280 & 12,280 \\
\hline NON_ZERO_PLOTS & 32 & 57 & 1,007 \\
\hline $\begin{array}{l}\text { TOTAL_POPULATION_ } \\
\text { ACRES }\end{array}$ & $54,008,479$ & $54,008,479$ & $54,008,479$ \\
\hline
\end{tabular}




\section{Literature Cited}

Bechtold, W.A.; Patterson, P.L., editors. 2005. The enhanced Forest Inventory and Analysis program - national sampling design and estimation procedures. Gen. Tech. Rep. SRS-80. Asheville, NC: U.S. Department of Agriculture Forest Service, Southern Research Station. $85 \mathrm{p}$.

Cleland, D.T.; Freeouf, J.A.; Keys, J.E. [and others]. 2007. Ecological subregions: sections and subsections for the conterminous United States. GTR-WO-76. Washington, DC: U.S. Department of Agriculture, Forest Service.

Gillespie, A.J.R. 1999. Rationale for a national annual forest inventory program. Journal of Forestry. 97: 16-20.

Hansen, M.H.; Frieswyk, T.; Glover, J.F.; Kelly, J.F. 1992. The eastwide forest inventory data base: users manual. Gen. Tech. Rep. NC-151. St. Paul, MN: U.S. Department of Agriculture, Forest Service, North Central Forest Experiment Station. 48 p.

Hanson, E.J.; Azuma, D.L.; Hiserote, B.A. 2002. Site index equations and mean annual increment equations for Pacific Northwest Research Station Forest Inventory and Analysis inventories, 1985-2001. Res. Note. PNW-RN-533. Portland, OR: U.S. Department of Agriculture, Forest Service. 24 p.

Hawksworth, F.G. 1979. The 6-class dwarf mistletoe rating system. Gen. Tech. Rep. RM-48. Fort Collins, CO: U.S. Department of Agriculture, Forest Service, Rocky Mountain Forest and Range Experiment Station. 7 p.

Heath, L.S.; Hansen, M. H.; Smith, J.E. [and others]. 2009. Investigation into calculating tree biomass and carbon in the FIADB using a biomass expansion factor approach. In: Forest Inventory and Analysis (FIA) Symposium 2008. RMRS-P-56CD. Fort Collins, CO: U.S. Department of Agriculture, Forest Service, Rocky Mountain Research Station. 1 CD

Jenkins, J.C.; Chojnacky, D.C.; Heath, L.S.; Birdsey, R.A. 2003. National scale biomass estimators for United States tree species. Forest Science. 49: 12-35.

Lister, A.; Scott, C.T.; King, S.L. [and others]. 2005. Strategies for preserving owner privacy in the national information management system of the USDA Forest Service's Forest Inventory and Analysis unit. In: Proceedings of the $4^{\text {th }}$ annual Forest Inventory and Analysis symposium. Gen. Tech. Rep. NC-GTR-252. St. Paul, MN: U.S. Department of Agriculture, Forest Service, North Central Research Station: 163-166.

MacLean, C.D. 1973. Estimating productivity on sites with a low stocking capacity. Res. Paper. PNW-RP-152. Portland, OR: U.S. Department of Agriculture, Forest Service, Pacific Northwest Forest and Range Experiment Station. 18 p.

MacLean C.D.; Bolsinger, C.L. 1974. Stockability equations for California forest land. Res. Note. PNW-RN-233. Portland, OR: U.S. Department of Agriculture, Forest Service. 10 p.

Miles, P.D; Smith, W.B. 2009. Specific gravity and other properties of wood and bark for 156 tree species found in North America. Res. Note. NRS-38. Newtown Square, PA: U.S. Department of Agriculture, Forest Service, Northern Research Station. 35 p.

Miles, P.D.; Brand, G.J.; Alerich, C.L. [and others]. 2001. The forest inventory and analysis database: database description and users manual version 1.0. Gen. Tech. Rep. NC-218. St. Paul, MN: U.S. Department of Agriculture, Forest Service, North Central Research Station. $130 \mathrm{p}$.

Miles, P.D.; Jacobson, K.; Brand, G.J. [and others]. 2007. Minnesota's forests 1999-2003 (Part A). Reourc. Bull. NRS-12A. Newtown Square, PA: U.S. Department of Agriculture, Forest Service, Northern Research Station. 92 p. 
National Atlas of the United States. 2007. Congressional Districts of the United States - 110th Congress. Reston, VA: National Atlas of the United States. Available online: http://nationalatlas.gov/atlasftp.html

Nowacki, G.; Brock, T. 1995. Ecoregions and subregions of Alaska, EcoMap version 2.0 (map). Juneau, AK: U.S. Department of Agriculture, Forest Service, Alaska Region. scale 1:5,000,000. (http://agdcftp1.wr.usgs.gov/pub/projects/fhm/ecomap.gif)

Raile, G.K. 1982. Estimating stump volume. Res. Paper. NC-224. St. Paul, MN: U.S. Department of Agriculture, Forest Service, North Central Forest Experiment Station. 4 p.

Scott, C.T.; Cassell, D.L.; Hazard, J.W. 1993. Sampling design of the U.S. National Forest Health Program. In: Nyyssonen, A.; Poso, S.; Rautala, J. (eds.), Ilvessalo Symposium on National Forest Inventories. Research Parpers 444. [Location unknown]: Finnish Forest Research Institute London. p. 150-157.

Smith, J.E.; Heath, L.S. 2002. A model of forest floor carbon mass for United States forest types. Res. Paper. NE-722. Newtown Square, PA: U.S. Department of Agriculture, Forest Service, Northeastern Research Station. 37 p.

Smith, J.E.; Heath, L.S. 2008. Forest sections of the land use change and forestry chapter, and Annex. In: US Environmental Protection Agency, Inventory of US Greenhouse Gas Emissions and Sinks: 1990-2006. EPA 430-R-08-005. http://www.epa.gov/climatechange/emissions/usinventoryreport.htm (17 October).

Smith, W.B. 2002. Forest inventory and analysis: a national inventory and monitoring program. Environmental Pollution. 116 (Suppl. 1): S233-S242.

U.S. Census Bureau. 1994. The geographic areas reference manual. http://www.census.gov/geo/www/garm.html [Date accessed: June 18, 2008].

U.S. Department of Agriculture, Forest Service. 2008. Accuracy standards. In: Forest Survey Handbook. FSH 4809.11, chapter 10. Washington, DC: U.S. Department of Agriculture, Forest Service. [Not paged]

U.S. Environmental Protection Agency. 2008. Inventory of U.S. greenhouse gas emissions and sinks: 1990-2006. EPA 430-R-08-005. Washington, DC: United States Environmental Protection Agency, Office of Atmospheric Programs. Available online at http://epa.gov/climatechange/emissions/.

Van Hooser, D.D.; Cost, N.D.; Lund, H.G. 1993. The history of the forest survey program in the United States. In: Proceedings of the IUFRO Centennial Meeting. [Location unknown]: Japan Society of Forest Planning Press, Tokyo University of Agriculture: 19-27.

Wilson, H. M. 1900. A Dictionary of Topographic Forms. Journal of the American Geographical Society of New York. 32: 32-41.

Woodall, C.W.; Conkling, B.L.; Amacher, M.C. [and others]. 2010. The Forest Inventory and Analysis database version 4.0: database description and users manual for phase 3. Gen. Tech. Rep. NRS - 61. Newtown Square, PA: U.S. Department of Agriculture, Forest Service, Northern Research Station. 180 p.

Woudenberg, S.W.; Farrenkopf, T.O. 1995. The Westwide forest inventory data base: user's manual. Gen. Tech. Rep. INT-GTR-317. Ogden, UT: U.S. Department of Agriculture, Forest Service, Intermountain Research Station. 67 p. 


\section{Appendix A. Index of Column Names}

The following table lists column names used in the database tables, their location within the table, and a short description.

\begin{tabular}{|c|c|c|c|}
\hline $\begin{array}{l}\text { Column name with (field guide } \\
\text { section) }\end{array}$ & Table name & $\begin{array}{l}\text { Location } \\
\text { in table }\end{array}$ & Description \\
\hline ACTUALHT (5.15) & TREE & 22 & Actual height of tree \\
\hline ADFORCD & COND & 15 & Administrative forest code \\
\hline ADJ_FACTOR_MACR & POP_STRATUM & 12 & $\begin{array}{l}\text { Adjustment factor for the } \\
\text { macroplot }\end{array}$ \\
\hline ADJ_FACTOR_MICR & POP_STRATUM & 14 & $\begin{array}{l}\text { Adjustment factor for the } \\
\text { microplot }\end{array}$ \\
\hline ADJ_FACTOR_SUBP & POP_STRATUM & 13 & Adjustment factor for the subplot \\
\hline AGEDIA (7.2.5) & SITETREE & 14 & Age at diameter height \\
\hline AGENTCD (5.21) & TREE & 27 & Cause of death (agent) code \\
\hline ALLOWED_IN_FIELD & REF_FOREST_TYPE & 6 & Allowed in field \\
\hline ALSTK & COND & 53 & All-live-tree stocking percent \\
\hline ALSTKCD & COND & 37 & All live stocking code \\
\hline ANN_INVENTORY & SURVEY & 8 & Annual inventory \\
\hline AREA_SOURCE & POP_ESTN_UNIT & 11 & $\begin{array}{l}\text { Source of area figures usually } \\
\text { Census Bureau or from pixel } \\
\text { counts }\end{array}$ \\
\hline AREA_USED & POP_ESTN_UNIT & 10 & $\begin{array}{l}\text { Area used to calculate all } \\
\text { expansion factors }\end{array}$ \\
\hline AREALAND_EU & POP_ESTN_UNIT & 8 & $\begin{array}{l}\text { Land area within the estimation } \\
\text { unit }\end{array}$ \\
\hline AREATOT_EU & POP_ESTN_UNIT & 9 & $\begin{array}{l}\text { Total area within the estimation } \\
\text { unit }\end{array}$ \\
\hline ASPECT & COND & 34 & Aspect \\
\hline ASPECT (3.7) & SUBPLOT & 17 & Subplot aspect \\
\hline ATTRIBUTE_DESCR & REF_POP_ATTRIBUTE & 3 & $\begin{array}{l}\text { Estimation attribute e.g., Area of } \\
\text { timberland }\end{array}$ \\
\hline ATTRIBUTE_NBR & POP_EVAL_ATTRIBUTE & 3 & Attribute number \\
\hline ATTRIBUTE_NBR & REF_POP_ATTRIBUTE & 2 & Arbitrary unique number \\
\hline AUTHOR & REF_HABTYP_PUBLICATION & 4 & Author of publication \\
\hline AZIMUTH (7.2.8) & SITETREE & 19 & Azimuth \\
\hline AZIMUTH (5.4) & TREE & 12 & Azimuth \\
\hline AZMCORN (4.2.6) & BOUNDARY & 13 & Corner azimuth \\
\hline AZMLEFT (4.2.5) & BOUNDARY & 12 & Left azimuth \\
\hline AZMRIGHT (4.2.8) & BOUNDARY & 15 & Right azimuth \\
\hline BALIVE & COND & 51 & Basal area of live trees \\
\hline BARK_SPGR_GREENVOL_DRYWT & REF_SPECIES & 51 & $\begin{array}{l}\text { Green specific gravity bark (green } \\
\text { volume and oven-dry weight) }\end{array}$ \\
\hline $\begin{array}{l}\text { BARK_SPGR_GREENVOL_DRYWT } \\
\text { CIT }\end{array}$ & REF_SPECIES & 52 & $\begin{array}{l}\text { Green specific gravity bark } \\
\text { citation }\end{array}$ \\
\hline$\overline{\text { BARK_VOL_PCT }}$ & REF_SPECIES & 59 & $\begin{array}{l}\text { Bark volume as a percent of wood } \\
\text { volume }\end{array}$ \\
\hline BARK_VOL_PCT_CIT & REF_SPECIES & 60 & $\begin{array}{l}\text { Bark volume as a percent of wood } \\
\text { volume citation }\end{array}$ \\
\hline BFSND & TREE & 73 & Board-foot-cull soundness \\
\hline BHAGE & TREE & 66 & Breast height age \\
\hline BNDCHG (4.2.3) & BOUNDARY & 10 & Boundary change code \\
\hline BOLEHT & TREE & 76 & Bole height \\
\hline BORED_CD_PNWRS & TREE & 125 & $\begin{array}{l}\text { Tree bored code, Pacific } \\
\text { Northwest Research Station }\end{array}$ \\
\hline $\begin{array}{l}\text { CANOPY_CVR_SAMPLE_METHOD } \\
\text { CD }\end{array}$ & COND & 97 & $\begin{array}{l}\text { Canopy cover sample method } \\
\text { code }\end{array}$ \\
\hline$\overline{\text { CARBON_AG }}$ & TREE & 121 & Carbon aboveground \\
\hline CARBON_BG & TREE & 122 & Carbon belowground \\
\hline CARBON_DOWN_DEAD & COND & 67 & Carbon in down dead \\
\hline CARBON_LITTER & COND & 68 & Carbon in litter \\
\hline
\end{tabular}




\begin{tabular}{|c|c|c|c|}
\hline $\begin{array}{l}\text { Column name with (field guide } \\
\text { section) }\end{array}$ & Table name & $\begin{array}{l}\text { Location } \\
\text { in table }\end{array}$ & Description \\
\hline CARBON_SOIL_ORG & COND & 69 & $\begin{array}{l}\text { Carbon in soil fine organic } \\
\text { material }\end{array}$ \\
\hline CARBON_STANDING_DEAD & COND & 70 & Carbon in standing dead trees \\
\hline CARBON_UNDERSTORY_AG & COND & 71 & $\begin{array}{l}\text { Carbon in the aboveground } \\
\text { portions of seedlings, shrubs, and } \\
\text { bushes }\end{array}$ \\
\hline CARBON_UNDERSTORY_BG & COND & 72 & $\begin{array}{l}\text { Carbon in the belowground } \\
\text { portion of seedlings, shrubs ,and } \\
\text { bushes }\end{array}$ \\
\hline CCLCD (5.17) & TREE & 25 & Crown class code \\
\hline CDENCD (12.9) & TREE & 61 & Crown density code \\
\hline CDIEBKCD (12.10) & TREE & 62 & Crown dieback code \\
\hline CFSND & TREE & 74 & Cubic-foot-cull soundness \\
\hline CITATION & REF_CITATION & 2 & Citation \\
\hline CITATION_NBR & REF_CITATION & 1 & Citation number \\
\hline CLASS & REF_SPECIES_GROUP & 4 & Class \\
\hline CLIGHTCD (12.6) & TREE & 59 & Crown light exposure code \\
\hline $\mathrm{CN}$ & BOUNDARY & 1 & Sequence number \\
\hline $\mathrm{CN}$ & COND & 1 & Sequence number \\
\hline $\mathrm{CN}$ & COUNTY & 5 & Sequence number \\
\hline $\mathrm{CN}$ & PLOT & 1 & Sequence number \\
\hline $\mathrm{CN}$ & POP_ESTN_UNIT & 1 & Sequence number \\
\hline $\mathrm{CN}$ & POP_EVAL & 1 & Sequence number \\
\hline $\mathrm{CN}$ & POP_EVAL_ATTRIBUTE & 1 & Sequence number \\
\hline $\mathrm{CN}$ & POP_EVAL_GRP & 1 & Sequence number \\
\hline $\mathrm{CN}$ & POP_EVAL_TYP & 11 & Sequence number \\
\hline $\mathrm{CN}$ & POP_PLOT_STRATUM_ASSGN & 1 & Sequence number \\
\hline $\mathrm{CN}$ & POP_STRATUMM & 1 & Sequence number \\
\hline $\mathrm{CN}$ & REF $^{-}$HABTYP DESCRIPTION & 1 & Sequence number \\
\hline $\mathrm{CN}$ & REF_HABTYP_PUBLICATION & 1 & Sequence number \\
\hline $\mathrm{CN}$ & REF_POP_ATTRIBUTE & 1 & Sequence number \\
\hline $\mathrm{CN}$ & REF_POP_EVAL_TYP DESCR & 9 & Sequence number \\
\hline $\mathrm{CN}$ & SEEDLING & 1 & Sequence number \\
\hline $\mathrm{CN}$ & SITETREE & 1 & Sequence number \\
\hline $\mathrm{CN}$ & SUBPLOT & 1 & Sequence number \\
\hline $\mathrm{CN}$ & SUBP_COND & 1 & Sequence number \\
\hline $\mathrm{CN}$ & SUBP_COND_CHNG_MTRX & 1 & Sequence number \\
\hline $\mathrm{CN}$ & SURVEY & 1 & Sequence number \\
\hline $\mathrm{CN}$ & TREE & 1 & Sequence number \\
\hline COMMON_NAME & REF_HABTYP_DESCRIPTION & 5 & Common name \\
\hline COMMON_NAME & REF_SPECIES & 2 & Common name of species \\
\hline CORE & REF_SPECIES & 36 & Core \\
\hline $\begin{array}{l}\text { COND_NONSAMPLE_REASN_CD } \\
(2.4 .3)\end{array}$ & COND & 10 & $\begin{array}{l}\text { Condition nonsampled reason } \\
\text { code }\end{array}$ \\
\hline COND_STATUS_CD (2.4.2) & COND & 9 & Condition status code \\
\hline CONDID $(2.4 .1)$ & COND & 8 & Condition class number \\
\hline CONDID (6.3) & SEEDLING & 9 & Condition class number \\
\hline CONDID & SITETREE & 9 & Condition class number \\
\hline CONDID & SUBP_COND & 9 & Condition class number \\
\hline CONDID & SUBP_COND_CHNG_MTRX & 6 & Condition class number \\
\hline CONDID (5.3) & TREE & 11 & Condition class number \\
\hline CONDLIST & SUBPLOT & 15 & $\begin{array}{l}\text { Subplot/macroplot plot condition } \\
\text { list }\end{array}$ \\
\hline CONDLIST & SITETREE & 24 & Condition class list \\
\hline CONDPROP_UNADJ & COND & 29 & Condition proportion unadjusted \\
\hline CONGCD & PLOT & 28 & Congressional district code \\
\hline CONTRAST (4.2.4) & BOUNDARY & 11 & Contrasting condition \\
\hline COUNTYCD & BOUNDARY & 6 & County code \\
\hline COUNTYCD & COND & 6 & County code \\
\hline COUNTYCD & COUNTY & 3 & County code \\
\hline COUNTYCD (1.2) & PLOT & 8 & County code \\
\hline
\end{tabular}


Column name with (field guide section)

COUNTYCD

COUNTYCD

COUNTYCD

COUNTYCD

COUNTYCD

COUNTYCD

COUNTYNM

CPOSCD (12.7)

CR (5.19)

CREATED BY

CREATED_BY

CREATED_BY

CREATED BY

CREATED BY

CREATED_BY

CREATED BY

CREATED BY

CREATED_BY

CREATED BY

CREATED_BY

CREATED_BY

CREATED BY

CREATED_BY

CREATED BY

CREATED BY

CREATED_BY

CREATED BY

CREATED_BY

CREATED_BY

CREATED BY

CREATED BY

CREATED BY

CREATED BY

CREATED_BY

CREATED BY

CREATED BY

CREATED_BY

CREATED BY

CREATED_BY

CREATED_DATE

CREATED_DATE

CREATED_DATE

CREATED DATE

CREATED DATE

CREATED_DATE

CREATED_DATE

CREATED DATE

CREATED_DATE

CREATED DATE

CREATED_DATE

CREATED DATE

CREATED_DATE

CREATED_DATE

CREATED DATE

CREATED DATE

CREATED_DATE

CREATED DATE

CREATED_DATE

CREATED_DATE

CREATED_DATE

CREATED_DATE

\begin{tabular}{|c|c|c|}
\hline Table name & $\begin{array}{l}\text { Location } \\
\text { in table }\end{array}$ & Description \\
\hline POP_PLOT_STRATUM_ASSGN & 7 & County code \\
\hline SEED̄LING $\bar{D}^{-}$ & 6 & County code \\
\hline SITETREE & 7 & County code \\
\hline SUBPLOT & 7 & County code \\
\hline SUBP_COND & 6 & County code \\
\hline TREE & 7 & County code \\
\hline COUNTY & 4 & County name \\
\hline TREE & 58 & Crown position code \\
\hline TREE & 24 & Compacted crown ratio \\
\hline BOUNDARY & 18 & Created by \\
\hline COND & 73 & Created by \\
\hline COUNTY & 6 & Created by \\
\hline PLOT & 33 & Created by \\
\hline POP_ESTN_UNIT & 14 & Created by \\
\hline POP_EVAL & 9 & Created by \\
\hline POP_EVAL_ATTRIBUTE & 5 & Created by \\
\hline POP_EVAL_GRP & 13 & Created by \\
\hline POP_EVAL_TYP & 5 & Created by \\
\hline POP_PLOT_STRATUM_ASSGN & 13 & Created by \\
\hline POP_STRAT̄UM & 15 & Created by \\
\hline REF_CITATION & 3 & Created by \\
\hline REF_FIADB_VERSION & 3 & Created by \\
\hline REF_FOREST_TYPE & 7 & Created by \\
\hline REF_HABTYP_DESCRIPTION & 7 & Created by \\
\hline REF_HABTYP_PUBLICATION & 7 & Created by \\
\hline REF_POP_ATTRIBUTE & 6 & Created by \\
\hline REF_POP_EVAL_TYP_DESCR & 3 & Created by \\
\hline REF_SPEC̄IES & 30 & Created by \\
\hline REF_SPECIES_GROUP & 5 & Created by \\
\hline REF_STATE_ELEEV & 6 & Created by \\
\hline REF_UNIT & 4 & Created by \\
\hline SEED̄LING & 15 & Created by \\
\hline SITETREE & 25 & Created by \\
\hline SUBPLOT & 20 & Created by \\
\hline SUBP_COND & 10 & Created by \\
\hline SUBP_COND_CHNG_MTRX & 10 & Created by \\
\hline SURVEY & 10 & Created by \\
\hline TREE & 81 & Created by \\
\hline TREE_REGIONAL_BIOMASS & 5 & Created by \\
\hline BOUNDARY & 19 & Created date \\
\hline COND & 74 & Created date \\
\hline COUNTY & 7 & Created date \\
\hline PLOT & 34 & Created date \\
\hline POP_ESTN_UNIT & 15 & Created date \\
\hline POP_EVAL & 10 & Created date \\
\hline POP_EVAL_ATTRIBUTE & 6 & Created date \\
\hline POP_EVAL_GRP & 14 & Created date \\
\hline POP_EVAL_TYP & 6 & Created date \\
\hline POP_PLOT_STRATUM_ASSGN & 14 & Created date \\
\hline POP_STRAT̄UM & 16 & Created date \\
\hline REF_CITATION & 4 & Created date \\
\hline REF_FIADB_VERSION & 4 & Created date \\
\hline REF_FOREST_TYPE & 8 & Created date \\
\hline REF_HABTYP_DESCRIPTION & 8 & Created date \\
\hline REF_HABTYP_PUBLICATION & 8 & Created date \\
\hline REF_POP_ATTRIBUTE & 7 & Created date \\
\hline REF_POP_EVAL_TYP_DESCR & 4 & Created date \\
\hline REF_SPECIES - & 31 & Created date \\
\hline REF_SPECIES_GROUP & 6 & Created date \\
\hline REF_STATE_ELEEV & 7 & Created date \\
\hline REF_UNIT & 5 & Created date \\
\hline
\end{tabular}




\begin{tabular}{|c|c|c|c|}
\hline $\begin{array}{l}\text { Column name with (field guide } \\
\text { section) }\end{array}$ & Table name & $\begin{array}{l}\text { Location } \\
\text { in table }\end{array}$ & Description \\
\hline CREATED_DATE & SEEDLING & 16 & Created date \\
\hline CREATED_DATE & SITETREE & 26 & Created date \\
\hline CREATED_DATE & SUBPLOT & 21 & Created date \\
\hline CREATED_DATE & SUBP_COND & 11 & Created date \\
\hline CREATED DATE & SUBP $^{-}$COND_CHNG MTRX & 11 & Created date \\
\hline CREATED_DATE & SURVEY & 11 & Created date \\
\hline CREATED_DATE & TREE & 82 & Created date \\
\hline CREATED_DATE & TREE_REGIONAL_BIOMASS & 6 & Created date \\
\hline CREATED_IN_INSTANCE & BOUNDARY & 20 & Created in instance \\
\hline CREATED_IN_INSTANCE & COND & 75 & Created in instance \\
\hline CREATED_IN_INSTANCE & COUNTY & 8 & Created in instance \\
\hline CREATED IN IN INSTANCE & PLOT & 35 & Created in instance \\
\hline CREATED IN INSTANCE & POP ESTN UNIT & 16 & Created in instance \\
\hline CREATED_IN_INSTANCE & POP_EVAL & 11 & Created in instance \\
\hline CREATED_IN_INSTANCE & POP_EVAL_ATTRIBUTE & 7 & Created in instance \\
\hline CREATED_IN_INSTANCE & POP_EVAL_GRP & 15 & Created in instance \\
\hline CREATED_IN_INSTANCE & POP_EVAL_TYP & 7 & Created in instance \\
\hline CREATED IN INSTANCE & POP PLOT ${ }^{-}$STRATUM ASSGN & 15 & Created in instance \\
\hline CREATED_IN_INSTANCE & POP_STRATTUM & 17 & Created in instance \\
\hline CREATED_IN_INSTANCE & REF_CITATION & 5 & Created in instance \\
\hline CREATED_IN_INSTANCE & REF_FIADB_VERSION & 5 & Created in instance \\
\hline CREATED_IN_INSTANCE & REF_FOREST_TYPE & 9 & Created in instance \\
\hline CREATED_IN_INSTANCE & REF_HABTYP_DESCRIPTION & 9 & Created in instance \\
\hline CREATED_IN_INSTANCE & REF_HABTYP_PUBLICATION & 9 & Created in instance \\
\hline CREATED_IN_INSTANCE & REF_POP_ATTRIBUTE & 8 & Created in instance \\
\hline CREATED_IN_INSTANCE & REF_POP_EVAL_TYP_DESCR & 5 & Created in instance \\
\hline CREATED_IN_INSTANCE & REF_SPECIES & 32 & Created in instance \\
\hline CREATED_IN_INSTANCE & REF_SPECIES_GROUP & 7 & Created in instance \\
\hline CREATED_IN_INSTANCE & REF_STATE_ELEV & 8 & Created in instance \\
\hline CREATED_IN_INSTANCE & REF_UNIT & 6 & Created in instance \\
\hline CREATED IN INSTANCE & SEED̄LING & 17 & Created in instance \\
\hline CREATED_IN_INSTANCE & SITETREE & 27 & Created in instance \\
\hline CREATED_IN_INSTANCE & SUBPLOT & 22 & Created in instance \\
\hline CREATED_IN_INSTANCE & SUBP_COND & 12 & Created in instance \\
\hline CREATED_IN_INSTANCE & SUBP_COND_CHNG_MTRX & 12 & Created in instance \\
\hline CREATED_IN_INSTANCE & SURVEY & 12 & Created in instance \\
\hline CREATED_IN_INSTANCE & TREE & 83 & Created in instance \\
\hline CREATED_IN_INSTANCE & TREE_REGIONAL_BIOMASS & 7 & Created in instance \\
\hline $\mathrm{CTY}_{-} \mathrm{CN}^{-}-$ & $\mathrm{PLOT}^{-}$ & 3 & County sequence number \\
\hline CULE & TREE & 28 & $\begin{array}{l}\text { Rotten and missing cull, } \\
\text { computed and includes percent } \\
\text { missing top }\end{array}$ \\
\hline CULL_FLD (5.13) & TREE & 91 & $\begin{array}{l}\text { Rotten and missing cull, field- } \\
\text { recorded }\end{array}$ \\
\hline CULLBF & TREE & 71 & Board-foot cull \\
\hline CULLCF & TREE & 72 & Cubic-foot cull \\
\hline CULLDEAD & TREE & 68 & Dead cull \\
\hline CULLFORM & TREE & 69 & Form cull \\
\hline CULLMSTOP & TREE & 70 & Missing top cull \\
\hline CVIGORCD (12.8) & TREE & 60 & Sapling vigor code \\
\hline CYCLE & BOUNDARY & 16 & Inventory cycle number \\
\hline CYCLE & COND & 79 & Inventory cycle number \\
\hline CYCLE & PLOT & 46 & Inventory cycle number \\
\hline CYCLE & SEEDLING & 23 & Inventory cycle number \\
\hline CYCLE & SITETREE & 31 & Inventory cycle number \\
\hline CYCLE & SUBPLOT & 26 & Inventory cycle number \\
\hline CYCLE & SUBP_COND & 21 & Inventory cycle number \\
\hline CYCLE & SURVEY & 16 & Inventory cycle number \\
\hline CYCLE & TREE & 123 & Inventory cycle number \\
\hline DAMLOC1 $(5.20 .1)$ & TREE & 29 & Damage location 1 code \\
\hline
\end{tabular}


FIA Database Description and Users Manual for Phase 2, version 4.0

Appendix A

\begin{tabular}{|c|c|c|c|}
\hline $\begin{array}{l}\text { Column name with (field guide } \\
\text { section) }\end{array}$ & Table name & $\begin{array}{l}\text { Location } \\
\text { in table }\end{array}$ & Description \\
\hline DAMLOC1_PNWRS & TREE & 126 & $\begin{array}{l}\text { Damage location 1, Pacific } \\
\text { Northwest Research Station }\end{array}$ \\
\hline DAMLOC2 (5.20.4) & TREE & 32 & Damage location 2 code \\
\hline DAMLOC2_PNWRS & TREE & 127 & $\begin{array}{l}\text { Damage location 2, Pacific } \\
\text { Northwest Research Station }\end{array}$ \\
\hline DAMSEV1 (5.20.3) & TREE & 31 & Damage severity 1 code \\
\hline DAMSEV2 (5.20.6) & TREE & 34 & Damage severity 2 code \\
\hline DAMTYP1 (5.20.2) & TREE & 30 & Damage type 1 code \\
\hline DAMTYP2 (5.20.5) & TREE & 33 & Damage type 2 code \\
\hline DECAYCD (5.23) & TREE & 35 & Decay class code \\
\hline DECLINATION (1.11) & PLOT & 40 & Declination \\
\hline DESCR & REF_FIADB_VERSION & 2 & Version description \\
\hline DESIGNCD & PLOT & 17 & Plot design code \\
\hline DIA (7.2.3) & SITETREE & 12 & Current diameter \\
\hline DIA (5.9.2) & TREE & 18 & Current diameter \\
\hline DIACALC & TREE & 65 & Current diameter calculated \\
\hline DIACHECK (5.12) & TREE & 54 & Diameter check code \\
\hline DIACHECK_PNWRS & TREE & 128 & $\begin{array}{l}\text { Diameter check, Pacific } \\
\text { Northwest Research Station }\end{array}$ \\
\hline DIAHTCD & TREE & 19 & Diameter height code \\
\hline DIST (7.2.9) & SITETREE & 20 & Horizontal distance \\
\hline DIST (5.5) & TREE & 13 & Horizontal distance \\
\hline DISTCORN (4.2.7) & BOUNDARY & 14 & Corner distance \\
\hline DMG_AGENT1_CD_PNWRS & TREE & 129 & $\begin{array}{l}\text { Damage agent } 1 \text {, Pacific } \\
\text { Northwest Research Station }\end{array}$ \\
\hline DMG_AGENT2_CD_PNWRS & TREE & 130 & $\begin{array}{l}\text { Damage agent 2, Pacific } \\
\text { Northwest Research Station }\end{array}$ \\
\hline DMG_AGENT3_CD_PNWRS & TREE & 131 & $\begin{array}{l}\text { Damage agent } 3 \text {, Pacific } \\
\text { Northwest Research Station }\end{array}$ \\
\hline DRYBIO_BG & TREE & 120 & Dry biomass belowground \\
\hline DRYBIO_BOLE & TREE & 115 & Dry biomass of bole \\
\hline DRYBIO_SAPLING & TREE & 118 & Dry biomass of sapling \\
\hline DRYBIO_STUMP & TREE & 117 & Dry biomass of stump \\
\hline DRYBIO_TOP & TREE & 116 & Dry biomass of top \\
\hline DRYBIO_WDLD_SPP & TREE & 119 & Dry biomass of woodland species \\
\hline DSTRBCD $1 \quad(2.5 . \overline{1} 1)$ & COND & 38 & Disturbance 1 code \\
\hline DSTRBCD2 (2.5.13) & COND & 40 & Disturbance 2 code \\
\hline DSTRBCD3 (2.5.15) & COND & 42 & Disturbance 3 code \\
\hline DSTRBYR1 (2.5.12) & COND & 39 & Year of disturbance 1 \\
\hline DSTRBYR2 (2.5.14) & COND & 41 & Year of disturbance 2 \\
\hline DSTRBYR3 (2.5.16) & COND & 43 & Year of disturbance 3 \\
\hline E_SPGRPCD & REF_SPECIES & 8 & East species group code \\
\hline EAsT & REF_SPECIES & 25 & East \\
\hline ECO_UNIT_PNW & PLOT & 48 & $\begin{array}{l}\text { Ecological unit used to identify } \\
\text { Pacific Northwest Research } \\
\text { Station stockability algorithms }\end{array}$ \\
\hline ECOSUBCD & PLOT & 27 & Ecological subsection code \\
\hline ELEV & PLOT & 22 & Elevation \\
\hline EMAP_HEX & PLOT & 41 & EMAP hexagon \\
\hline END_INVYR & POP_EVAL & 16 & End inventory year \\
\hline ESTN__UNIT & POP_ESTN_UNIT & 5 & Estimation unit \\
\hline ESTN_UNIT & POP_PLOT_STRATUM_ASSGN & 11 & Estimation unit \\
\hline ESTN_UNIT & POP_STRATUM & 5 & Estimation unit \\
\hline ESTN_UNIT_CN & POP_STRATUM & 2 & Estimation unit sequence number \\
\hline ESTN_UNIT_DESCR & POP_ESTN_UNIT & 6 & Estimation unit description \\
\hline $\mathrm{EVAL}_{-}^{-} \mathrm{CN}$ & POP_ESTN_UNIT & 2 & Evaluation sequence number \\
\hline EVAL_CN & POP_EVAL_ATTRIBUTE & 2 & Evaluation sequence number \\
\hline EVAL_CN & POP_EVAL_TYP & 2 & Evaluation sequence number \\
\hline EVAL_CN_FOR_EXPALL & POP_EVAL_GRP & 2 & $\begin{array}{l}\text { Evaluation sequence number for } \\
\text { expansions of all plots }\end{array}$ \\
\hline
\end{tabular}




\begin{tabular}{|c|c|c|c|}
\hline $\begin{array}{l}\text { Column name with (field guide } \\
\text { section) }\end{array}$ & Table name & $\begin{array}{l}\text { Location } \\
\text { in table }\end{array}$ & Description \\
\hline EVAL_CN_FOR_EXPCURR & POP_EVAL_GRP & 3 & $\begin{array}{l}\text { Evaluation sequence number for } \\
\text { expansions of current area }\end{array}$ \\
\hline EVAL_CN_FOR_EXPGROW & POP_EVAL_GRP & 5 & $\begin{array}{l}\text { Evaluation sequence number for } \\
\text { expansions of growth }\end{array}$ \\
\hline EVAL_CN_FOR_EXPMORT & POP_EVAL_GRP & 6 & $\begin{array}{l}\text { Evaluation sequence number for } \\
\text { expansions of mortality }\end{array}$ \\
\hline EVAL_CN_FOR_EXPREMV & POP_EVAL_GRP & 7 & $\begin{array}{l}\text { Evaluation sequence number for } \\
\text { expansions of removals }\end{array}$ \\
\hline EVAL_CN_FOR_EXPVOL & POP_EVAL_GRP & 4 & $\begin{array}{l}\text { Evaluation sequence number for } \\
\text { expansions of volume }\end{array}$ \\
\hline EVAL_DESCR & POP_EVAL & 4 & Evaluation description \\
\hline EVAL_GRP & POP_EVAL_GRP & 9 & $\begin{array}{l}\text { Reporting year followed by } 4 \\
\text { more digits to make the } \\
\text { statecd/eval_grp combo unique }\end{array}$ \\
\hline EVAL_GRP_CN & POP_EVAL_TYP & 1 & $\begin{array}{l}\text { Evaluation group sequence } \\
\text { number }\end{array}$ \\
\hline EVAL_GRP_DESCR & POP_EVAL_GRP & 10 & Evaluation group description \\
\hline EVAL_TYP $^{-}$ & POP_EVAL_TYP & 3 & Evaluation type \\
\hline EVAL_TYP & REF_POP_EVAL_TYP_DESCR & 1 & Evaluation type \\
\hline EVAL_TYP_DESCR & REF_POP_EVAL_TYP_DESCR & 2 & Evaluation type description \\
\hline EVALID & POP_ESTN̄_UNIT & 4 & Evaluation identifier \\
\hline EVALID & POP_EVAL & 3 & Evaluation identifier \\
\hline EVALID & POP_PLOT_STRATUM_ASSGN & 10 & Evaluation identifier \\
\hline EVALID & POP_STRAT̄UM & 4 & Evaluation identifier \\
\hline EXISTS_IN_NCRS & REF_SPECIES & 13 & $\begin{array}{l}\text { Exists in the North Central } \\
\text { Research Station States }\end{array}$ \\
\hline EXISTS_IN_NERS & REF_SPECIES & 14 & $\begin{array}{l}\text { Exists in the Northeastern } \\
\text { Research Station States }\end{array}$ \\
\hline EXISTS_IN_PNWRS & REF_SPECIES & 15 & $\begin{array}{l}\text { Exists in the Pacific Northwest } \\
\text { Research Station States }\end{array}$ \\
\hline EXISTS_IN_RMRS & REF_SPECIES & 16 & $\begin{array}{l}\text { Exists in the Rocky Mountain } \\
\text { Research Station States }\end{array}$ \\
\hline EXISTS_IN_SRS & REF_SPECIES & 17 & $\begin{array}{l}\text { Exists in the Southern Research } \\
\text { Station States }\end{array}$ \\
\hline EXPNS & POP_STRATUM & 11 & Expansion factor \\
\hline EXPRESSION & REF_POP_ATTRIBUTE & 4 & $\begin{array}{l}\text { Part of the expression used to } \\
\text { produce the estimate }\end{array}$ \\
\hline FGROWBFSL & TREE & 95 & $\begin{array}{l}\text { Net annual merchantable board- } \\
\text { foot growth of sawtimber tree on } \\
\text { forest land }\end{array}$ \\
\hline FGROWCFAL & TREE & 96 & $\begin{array}{l}\text { Net annual sound cubic-foot } \\
\text { growth of a live tree on forest } \\
\text { land }\end{array}$ \\
\hline FGROWCFGS & TREE & 94 & $\begin{array}{l}\text { Net annual merchantable cubic- } \\
\text { foot growth of growing-stock tree } \\
\text { on forest land }\end{array}$ \\
\hline FIRE_SRS & COND & 87 & Fire, Southern Research Station \\
\hline FLDĀGE & COND & 52 & Field-recorded stand age \\
\hline FLDSZCD (2.5.4) & COND & 21 & Field stand-size class code \\
\hline FLDTYPCD (2.5.3) & COND & 17 & Field forest type code \\
\hline FMORTBFSL & TREE & 98 & $\begin{array}{l}\text { Board-foot volume of a } \\
\text { sawtimber tree for mortality } \\
\text { purposes on forest land }\end{array}$ \\
\hline FMORTCFAL & TREE & 99 & $\begin{array}{l}\text { Sound cubic-foot volume of a tree } \\
\text { for mortality purposes on forest } \\
\text { land }\end{array}$ \\
\hline FMORTCFGS & TREE & 97 & $\begin{array}{l}\text { Cubic-foot volume of a growing- } \\
\text { stock tree for mortality purposes } \\
\text { on forest land. }\end{array}$ \\
\hline FOOTNOTE & REF_POP_ATTRIBUTE & 12 & Footnote \\
\hline FOREST_TYPE_SPGRPCD & REF_SPECIES & 12 & Forest type species group code \\
\hline
\end{tabular}


FIA Database Description and Users Manual for Phase 2, version 4.0

Appendix A

\begin{tabular}{|c|c|c|c|}
\hline $\begin{array}{l}\text { Column name with (field guide } \\
\text { section) }\end{array}$ & Table name & $\begin{array}{l}\text { Location } \\
\text { in table }\end{array}$ & Description \\
\hline FORINDCD (2.5.8) & COND & 14 & $\begin{array}{l}\text { Private owner industrial status } \\
\text { code }\end{array}$ \\
\hline FORMCL & TREE & 77 & Form class \\
\hline FORTYPCD & COND & 16 & Forest type code \\
\hline FORTYPCDCALC & COND & 55 & $\begin{array}{l}\text { Forest type code calculated with a } \\
\text { national algorithm }\end{array}$ \\
\hline FREMVBFSL & TREE & 101 & $\begin{array}{l}\text { Board-foot volume of a } \\
\text { sawtimber tree for removal } \\
\text { purposes on forest land }\end{array}$ \\
\hline FREMVCFAL & TREE & 102 & $\begin{array}{l}\text { Sound cubic-foot volume of the } \\
\text { tree for removal purposes on } \\
\text { forest land }\end{array}$ \\
\hline FREMVCFGS & TREE & 100 & $\begin{array}{l}\text { Cubic-foot volume of a growing- } \\
\text { stock tree for removal purposes } \\
\text { on forest land }\end{array}$ \\
\hline GENUS & REF_SPECIES & 3 & Genus \\
\hline GRAZING_SRS & COND & 88 & $\begin{array}{l}\text { Grazing, Southern Research } \\
\text { Station }\end{array}$ \\
\hline GROUND_LAND_CLASS_PNW & COND & 82 & $\begin{array}{l}\text { Present ground class code, Pacific } \\
\text { Northwest Research Station }\end{array}$ \\
\hline GROW_TYP_CD & PLOT & 23 & $\begin{array}{l}\text { Type of annual volume growth } \\
\text { code }\end{array}$ \\
\hline GROWBFSL & TREE & 46 & $\begin{array}{l}\text { Net annual merchantable board- } \\
\text { foot growth of sawtimber size tree } \\
\text { on timberland }\end{array}$ \\
\hline GROWCFAL & TREE & 47 & $\begin{array}{l}\text { Net annual sound cubic-foot } \\
\text { growth of a live tree on } \\
\text { timberland }\end{array}$ \\
\hline GROWCFGS & TREE & 45 & $\begin{array}{l}\text { Net annual merchantable cubic- } \\
\text { foot growth of growing-stock tree } \\
\text { on timberland }\end{array}$ \\
\hline GSSTK & COND & 54 & Growing-stock stocking percent \\
\hline GSSTKCD & COND & 36 & Growing-stock stocking code \\
\hline HAPTYPCD & REF_HABTYP_DESCRIPTION & 2 & Habitat type code \\
\hline HABTYPCD1 & COND & 56 & Primary condition habitat type \\
\hline HABTYPCD1_DESCR_PUB_CD & COND & 58 & $\begin{array}{l}\text { Habitat type code } 1 \text { description } \\
\text { publication code }\end{array}$ \\
\hline HABTYPCD1_PUB_CD & COND & 57 & $\begin{array}{l}\text { Habitat type code } 1 \text { publication } \\
\text { code }\end{array}$ \\
\hline HABTYPCD2 & COND & 59 & Secondary condition habitat type \\
\hline HABTYPCD2_DESCR_PUB_CD & COND & 61 & $\begin{array}{l}\text { Habitat type code } 2 \text { description } \\
\text { publication code }\end{array}$ \\
\hline HABTYPCD2_PUB_CD & COND & 60 & $\begin{array}{l}\text { Habitat type code } 2 \text { publication } \\
\text { code }\end{array}$ \\
\hline HARVEST_TYPE1_SRS & COND & 89 & $\begin{array}{l}\text { Harvest type code } 1 \text {, Southern } \\
\text { Research Station }\end{array}$ \\
\hline HARVEST_TYPE2_SRS & COND & 90 & $\begin{array}{l}\text { Harvest type code 2, Southern } \\
\text { Research Station }\end{array}$ \\
\hline HARVEST_TYPE3_SRS & COND & 91 & $\begin{array}{l}\text { Harvest type code } 3 \text {, Southern } \\
\text { Research Station }\end{array}$ \\
\hline HIGHEST_POINT & REF_STATE_ELEV & 5 & Highest point \\
\hline HRDWD_CLUMP_CD & TREE & 79 & Hardwood clump code \\
\hline HT (7.24) & SITETREE & 13 & Total height \\
\hline $\mathrm{HT}(5.14)$ & TREE & 20 & Total height \\
\hline HTCALC & TREE & 78 & Current height calculated \\
\hline HTCD (5.16) & TREE & 21 & Height method code \\
\hline HTDMP (5.24) & TREE & 88 & $\begin{array}{l}\text { Length (height) to diameter } \\
\text { measurement point }\end{array}$ \\
\hline INSTALL_TYPE & REF_FIADB_VERSION & 12 & Install type \\
\hline INTENSITYY & PLOT $\quad-$ & 45 & Intensity \\
\hline
\end{tabular}




\begin{tabular}{|c|c|c|c|}
\hline $\begin{array}{l}\text { Column name with (field guide } \\
\text { section) }\end{array}$ & Table name & $\begin{array}{l}\text { Location } \\
\text { in table }\end{array}$ & Description \\
\hline $\begin{array}{l}\text { INVASIVE_NONSAMPLE_REASON } \\
\text { CD }\end{array}$ & SUBPLOT & 34 & Invasive nonsampled reason code \\
\hline $\begin{array}{l}\text { INNVASIVE_SAMPLING_STATUS_ } \\
\text { CD }\end{array}$ & PLOT & 55 & Invasive sampling status code \\
\hline INVASIVE_SPECIMEN_RULE_CD & PLOT & 56 & Invasive specimen rule code \\
\hline INVASIVE_SUBP_STAT̄US_CD̄ & SUBPLOT & 33 & Invasive subplot status code \\
\hline INVYR & BOUNDARY & 3 & Inventory year \\
\hline INVYR & COND & 3 & Inventory year \\
\hline INVYR & PLOT & 5 & Inventory year \\
\hline INVYR & POP_PLOT_STRATUM_ASSGN & 5 & Inventory year \\
\hline INVYR & SEED̄LING ${ }^{-}$ & 3 & Inventory year \\
\hline INVYR & SITETREE & 4 & Inventory year \\
\hline INVYR & SUBPLOT & 4 & Inventory year \\
\hline INVYR & SUBP_COND & 3 & Inventory year \\
\hline INVYR & SURVEY & 2 & Inventory year \\
\hline INVYR & TREE & 4 & Inventory year \\
\hline JENKINS_FOLIAGE_RATIO_B1 & REF_SPECIES & 44 & Jenkins foliage ratio $\mathrm{B} 1$ \\
\hline JENKINS_FOLIAGE_RATIO_B2 & REF_SPECIES & 45 & Jenkins foliage ratio B2 \\
\hline JENKINS_ROOT_RATIO_B1 & REF_SPECIES & 46 & Jenkins root ratio $B 1$ \\
\hline JENKINS_ROOT_RATIO_B2 & REF_SPECIES & 47 & Jenkins root ratio $\mathrm{B} 2$ \\
\hline JENKINS_SAPLING_ADJ̄USTMENT & REF_SPECIES & 49 & Jenkins sapling adjustment factor \\
\hline JENKINS_SPGRPCD & REF_SPECIES & 37 & Jenkins species group code \\
\hline JENKINS_STEM_BARK_RATIO_B1 & REF_SPECIES & 42 & Jenkins stem bark ratio $\mathrm{B} 1$ \\
\hline JENKINS_STEM_BARK_RATIO_B2 & REF_SPECIES & 43 & Jenkins stem bark ratio B2 \\
\hline JENKINS_STEM_WOOD_RATIO_B1 & REF_SPECIES & 40 & Jenkins stem wood ratio B1 \\
\hline JENKINS_STEM_WOOD_RATIO_B2 & REF_SPECIES & 41 & Jenkins stem wood ratio B2 \\
\hline 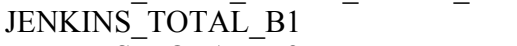 & REF_SPECIES & 38 & Jenkins coefficient B1 \\
\hline JENKINS_TOTAL_B2 & REF_SPECIES & 39 & Jenkins coefficient B2 \\
\hline $\mathrm{KINDCD}^{-}(1.7)^{-}$ & PLOT & 16 & Sample kind code \\
\hline KINDCD_NC & PLOT & 31 & Sample kind code, North Central \\
\hline LAND_ONLY & POP_EVAL_GRP & 12 & Land only \\
\hline LAND_USE_SRS & COND & 92 & $\begin{array}{l}\text { Land use, Southern Research } \\
\text { Station }\end{array}$ \\
\hline LAT (1.6.7) & PLOT & 20 & Latitude \\
\hline LIVE_CANOPY_CVR_PCT & COND & 98 & Live canopy cover percent \\
\hline $\begin{array}{l}\text { LIVE_MISSING_CANOPYY_CVR_ } \\
\text { PCT }\end{array}$ & COND & 99 & $\begin{array}{l}\text { Live plus missing canopy cover } \\
\text { percent }\end{array}$ \\
\hline LOCATION_NM & POP_EVAL & 6 & Usually State name or super State \\
\hline LON $(1.16 .8)$ & PLOT & 21 & Longitude \\
\hline LOWEST_POINT & REF_STATE_ELEV & 4 & Lowest point \\
\hline MACRCONDD & SUBPLOT & 14 & Macroplot center condition \\
\hline MACRCOND_PROP & SUBP_COND & 18 & $\begin{array}{l}\text { Proportion of this macroplot in } \\
\text { this condition }\end{array}$ \\
\hline MACRO_BREAKPOINT_DIA (1.17) & PLOT & 44 & Macroplot breakpoint diameter \\
\hline MACRPROP_UNADJ & COND & 32 & Macroplot proportion unadjusted \\
\hline MAJOR_SPGRPCD & REF_SPECIES & 10 & Major species group code \\
\hline MANUĀL (1.9) & PLOT & 29 & $\begin{array}{l}\text { Manual (field guide) version } \\
\text { number }\end{array}$ \\
\hline MANUAL_END & REF_FOREST_TYPE & 5 & Manual end \\
\hline MANUAL_END & REF_SPECIES & 29 & Manual end \\
\hline MANUAL_START & REF_FOREST_TYPE & 4 & Manual start \\
\hline MANUAL_START & REF_SPECIES & 28 & Manual start \\
\hline MAPDEN & COND & 18 & Mapping density \\
\hline MAX_ELEV & REF_STATE_ELEV & 3 & Maximum elevation \\
\hline MC_PCT_GREEN BARK & REF_SPECIES & 55 & $\begin{array}{l}\text { Moisture content of green bark as } \\
\text { a percent of oven-dry weight }\end{array}$ \\
\hline MC_PCT_GREEN_BARK_CIT & REF_SPECIES & 56 & $\begin{array}{l}\text { Moisture content of green bark } \\
\text { citation }\end{array}$ \\
\hline MC_PCT_GREEN_WOOD & REF_SPECIES & 53 & $\begin{array}{l}\text { Moisture content of green wood } \\
\text { as a percent of oven-dry weight }\end{array}$ \\
\hline
\end{tabular}


Column name with (field guide section)

MC_PCT_GREEN_WOOD_CIT

MEANING

MEANING

MEASDAY (1.10.3)

MEASMON (1.10.2)

MEASYEAR (1.10.1)

METHOD

MICRCOND (3.5)

MICRCOND_PROP

MICROPLOT_LOC

MICRPROP UNNADJ

MIN ELEV

MIST_CL_CD (5.26)

MIST CL CD PNWRS

\section{MIXEDCONFCD}

MODIFIED_BY
MODIFIED_BY
MODIFIED_BY
MODIFIED_BY
MODIFIED_BY
MODIFIED_BY
MODIFIED_BY
MODIFIED_BY
MODIFIED_BY
MODIFIED_BY
MODIFIED_BY
MODIFIED_BY
MODIFIED_BY
MODIFIED_BY
MODIFIED_BY
MODIFIED_BY
MODIFIED_BY
MODIFIED_BY
MODIFIED_BY
MODIFIED_BY
MODIFIED_BY
MODIFIED_BY
MODIFIED_BY
MODIFIED_BY
MODIFIED_BY
MODIFIED_BY
MODIFIED_BY
MODIFIED_BY
MODIFIED_BY
MODIFIED_BY
MODIFIED_DATE
MODIFIED_DATE
MODIFIED_DATE
MODIFIED_DATE
MODIFIED_DATE
MODIFIED_DATE
MODIFIED_DATE
MODIFIED_DATE
MODIFIED_DATE
MODIFIED_DATE
MODIFIED_DATE

\begin{tabular}{|c|c|c|}
\hline Table name & $\begin{array}{l}\text { Location } \\
\text { in table }\end{array}$ & Description \\
\hline REF_SPECIES & 54 & $\begin{array}{l}\text { Moisture content of green wood } \\
\text { citation }\end{array}$ \\
\hline REF_FOREST_TYPE & 2 & Meaning \\
\hline REF_UNIT & 3 & Meaning \\
\hline PLOT̄ & 14 & Measurement day \\
\hline PLOT & 13 & Measurement month \\
\hline PLOT & 12 & Measurement year \\
\hline SITETREE & 21 & Site tree method code \\
\hline SUBPLOT & 12 & Microplot center condition \\
\hline SUBP_COND & 16 & $\begin{array}{l}\text { Proportion of this microplot in } \\
\text { this condition }\end{array}$ \\
\hline PLOT & 39 & Microplot location \\
\hline COND & 30 & Microplot proportion unadjusted \\
\hline REF_STATE_ELEV & 2 & Minimum elevation \\
\hline TREE & 90 & Mistletoe class code \\
\hline TREE & 132 & $\begin{array}{l}\text { Leafy mistletoe class code, } \\
\text { Pacific Northwest Research } \\
\text { Station }\end{array}$ \\
\hline COND & 62 & $\begin{array}{l}\text { Calculated forest type for mixed } \\
\text { conifer site }\end{array}$ \\
\hline BOUNDARY & 21 & Modified by \\
\hline COND & 76 & Modified by \\
\hline COUNTY & 9 & Modified by \\
\hline PLOT & 36 & Modified by \\
\hline POP_ESTN_UNIT & 17 & Modified by \\
\hline POP_EVAL ${ }^{-}$ & 12 & Modified by \\
\hline POP_EVAL_ATTRIBUTE & 8 & Modified by \\
\hline POP_EVAL_GRP & 16 & Modified by \\
\hline POP_EVAL_TYP & 8 & Modified by \\
\hline POP_PLOT_STRATUM_ASSGN & 16 & Modified by \\
\hline POP_STRAT̄UM & 18 & Modified by \\
\hline REF_CITATION & 6 & Modified by \\
\hline REF_FIADB_VERSION & 6 & Modified by \\
\hline REF_FOREST_TYPE & 10 & Modified by \\
\hline REF_HABTYP_DESCRIPTION & 10 & Modified by \\
\hline REF_HABTYP_PUBLICATION & 10 & Modified by \\
\hline REF_POP_ATTRIBUTE & 9 & Modified by \\
\hline REF_POP_EVAL_TYP_DESCR & 6 & Modified by \\
\hline REF_SPECIES & 33 & Modified by \\
\hline REF_SPECIES_GROUP & 8 & Modified by \\
\hline REF_STATE_ĒEEV & 9 & Modified by \\
\hline REF_UNIT & 7 & Modified by \\
\hline SEED̄LING & 18 & Modified by \\
\hline SITETREE & 28 & Modified by \\
\hline SUBPLOT & 23 & Modified by \\
\hline SUBP_COND & 13 & Modified by \\
\hline SUBP_COND_CHNG_MTRX & 13 & Modified by \\
\hline SURVEY & 13 & Modified by \\
\hline TREE & 84 & Modified by \\
\hline TREE_REGIONAL_BIOMASS & 8 & Modified by \\
\hline BOUNDARY & 22 & Modified date \\
\hline COND & 77 & Modified date \\
\hline COUNTY & 10 & Modified date \\
\hline PLOT & 37 & Modified date \\
\hline POP_ESTN_UNIT & 18 & Modified date \\
\hline $\mathrm{POP}^{-} \mathrm{EVAL}^{-}$ & 13 & Modified date \\
\hline POP_EVAL_ATTRIBUTE & 9 & Modified date \\
\hline POP EVAL GRP & 17 & Modified date \\
\hline POP_EVAL_TYP & 9 & Modified date \\
\hline POP_PLOT_STRATUM_ASSGN & 17 & Modified date \\
\hline POP_STRATUMM & 19 & Modified date \\
\hline
\end{tabular}




\begin{abstract}
Column name with (field guide section)

MODIFIED_DATE

MODIFIED_DATE

MODIFIED DATE

MODIFIED_DATE

MODIFIED DATE

MODIFIED DATE

MODIFIED_DATE

MODIFIED DATE

MODIFIED_DATE

MODIFIED DATE

MODIFIED_DATE

MODIFIED_DATE

MODIFIED_DATE

MODIFIED DATE

MODIFIED_DATE

MODIFIED DATE

MODIFIED_DATE

MODIFIED_DATE

MODIFIED_DATE

MODIFIED_IN_INSTANCE MODIFIED_IN_INSTANCE

MODIFIED IN INSTANCE

MODIFIED_IN_INSTANCE

MODIFIED IN INSTANCE

MODIFIED IN INSTANCE

MODIFIED_IN_INSTANCE

MODIFIED IN INSTANCE

MODIFIED_IN_INSTANCE

MODIFIED IN_INSTANCE

MODIFIED IN INSTANCE

MODIFIED_IN_INSTANCE

MODIFIED IN INSTANCE

MODIFIED IN INSTANCE

MODIFIED_IN_INSTANCE

MODIFIED IN INSTANCE

MODIFIED IN INSTANCE

MODIFIED_IN_INSTANCE

MODIFIED IN INSTANCE

MODIFIED_IN_INSTANCE

MODIFIED_IN_INSTANCE

MODIFIED IN_INSTANCE

MODIFIED_IN_INSTANCE

MODIFIED_IN_INSTANCE

MODIFIED IN INSTANCE

MODIFIED_IN_INSTANCE

MODIFIED_IN_INSTANCE

MODIFIED IN INSTANCE

MODIFIED_IN_INSTANCE

MODIFIED IN INSTANCE

MORT_TYP_CD
\end{abstract}

MORTBFSL

MORTCD (5.7.3)

MORTCFAL

MORTCFGS

\begin{tabular}{|c|c|c|}
\hline Table name & $\begin{array}{l}\text { Location } \\
\text { in table }\end{array}$ & Description \\
\hline REF_CITATION & 7 & Modified date \\
\hline REF FIADB VERSION & 7 & Modified date \\
\hline REF_FOREST_TYPE & 11 & Modified date \\
\hline REF_HABTYP_DESCRIPTION & 11 & Modified date \\
\hline REF_HABTYP_PUBLICATION & 11 & Modified date \\
\hline REF_POP_ATTRIBUTE & 10 & Modified date \\
\hline REF_POP_EVAL_TYP_DESCR & 7 & Modified date \\
\hline REF_SPEC̄IES - & 34 & Modified date \\
\hline REF_SPECIES_GROUP & 9 & Modified date \\
\hline REF_STATE_ĒEEV & 10 & Modified date \\
\hline REF_UNIT ${ }^{-}$ & 8 & Modified date \\
\hline SEEDLING & 19 & Modified date \\
\hline SITETREE & 29 & Modified date \\
\hline SUBPLOT & 24 & Modified date \\
\hline SUBP_COND & 14 & Modified date \\
\hline SUBP_COND_CHNG_MTRX & 14 & Modified date \\
\hline SURVEY $\quad-$ & 14 & Modified date \\
\hline TREE & 85 & Modified date \\
\hline TREE_REGIONAL_BIOMASS & 9 & Modified date \\
\hline BOUNDARY & 78 & Modified in instance \\
\hline COND & 78 & Modified in instance \\
\hline COUNTY & 11 & Modified in instance \\
\hline PLOT & 38 & Modified in instance \\
\hline POP_ESTN_UNIT & 19 & Modified in instance \\
\hline POP_EVAL & 14 & Modified in instance \\
\hline POP_EVAL_ATTRIBUTE & 10 & Modified in instance \\
\hline POP_EVAL_GRP & 18 & Modified in instance \\
\hline POP_EVAL_TYP & 10 & Modified in instance \\
\hline POP_PLOT_STRATUM_ASSGN & 18 & Modified in instance \\
\hline POP_STRATUMM & 20 & Modified in instance \\
\hline REF_CITATION & 8 & Modified in instance \\
\hline REF_FIADB_VERSION & 8 & Modified in instance \\
\hline REF_FOREST_TYPE & 12 & Modified in instance \\
\hline REF_HABTYP_DESCRIPTION & 12 & Modified in instance \\
\hline REF_HABTYP_PUBLICATION & 12 & Modified in instance \\
\hline REF_POP_ATTRIBUTE & 11 & Modified in instance \\
\hline REF_POP_EVAL_TYP_DESCR & 8 & Modified in instance \\
\hline REF_SPEC̄IES & 35 & Modified in instance \\
\hline REF_SPECIES_GROUP & 10 & Modified in instance \\
\hline REF_STATE_ELEV & 11 & Modified in instance \\
\hline REF_UNIT & 9 & Modified in instance \\
\hline SEED̄LING & 20 & Modified in instance \\
\hline SITETREE & 30 & Modified in instance \\
\hline SUBPLOT & 25 & Modified in instance \\
\hline SUBP_COND & 15 & Modified in instance \\
\hline SUBP_COND_CHNG_MTRX & 15 & Modified in instance \\
\hline SURVEY & 15 & Modified in instance \\
\hline TREE & 86 & Modified in instance \\
\hline TREE_REGIONAL_BIOMASS & 10 & Modified in instance \\
\hline PLOT & 24 & $\begin{array}{l}\text { Type of annual mortality volume } \\
\text { code }\end{array}$ \\
\hline TREE & 49 & $\begin{array}{l}\text { Board-foot volume of a } \\
\text { sawtimber size tree on timberland } \\
\text { for mortality purposes }\end{array}$ \\
\hline TREE & 87 & Mortality code \\
\hline TREE & 50 & $\begin{array}{l}\text { Sound cubic-foot volume of a tree } \\
\text { on timberland for mortality } \\
\text { purposes }\end{array}$ \\
\hline TREE & 48 & $\begin{array}{l}\text { Cubic-foot volume of a growing- } \\
\text { stock tree on timberland for } \\
\text { mortality purposes }\end{array}$ \\
\hline
\end{tabular}




\begin{tabular}{|c|c|c|c|}
\hline $\begin{array}{l}\text { Column name with (field guide } \\
\text { section) }\end{array}$ & Table name & $\begin{array}{l}\text { Location } \\
\text { in table }\end{array}$ & Description \\
\hline MORTYR (5.22) & TREE & 55 & Mortality year \\
\hline NAME & REF_SPECIES_GROUP & 2 & Name \\
\hline NBR_LIVE_STEMS & COND & 100 & Number of live stems \\
\hline $\begin{array}{l}\text { NF_COND_NONSAMPLE_REASN } \\
\text { CD }\end{array}$ & COND & 96 & $\begin{array}{l}\text { Nonforest condition nonsampled } \\
\text { reason code }\end{array}$ \\
\hline NF_COND_STATUS_CD & COND & 95 & Nonforest condition status code \\
\hline $\begin{array}{l}\text { NF_PLOT_NONSAMPLE_REASN } \\
\text { CD }\end{array}$ & PLOT & 52 & $\begin{array}{l}\text { Nonforest plot nonsampled reason } \\
\text { code }\end{array}$ \\
\hline NF_PLOT_STATUS_CD & PLOT & 51 & Nonforest plot status code \\
\hline NF- SAMPLING_STĀTUS_CD & PLOT & 50 & Nonforest sampling status code \\
\hline $\begin{array}{l}\text { NF_SUBP_NONSAMPLE_REASN_ } \\
\mathrm{CD}\end{array}$ & SUBPLOT & 30 & $\begin{array}{l}\text { Nonforest subplot nonsampled } \\
\text { reason code }\end{array}$ \\
\hline NF_SUBP_STATUS_CD & SUBPLOT & 29 & Nonforest subplot status code \\
\hline NONFR_INCL_PCT_MACRO & SUBP_COND & 20 & $\begin{array}{l}\text { Nonforest inclusions percentage } \\
\text { of macroplot }\end{array}$ \\
\hline NONFR_INCL_PCT_SUBP & SUBP_COND & 19 & $\begin{array}{l}\text { Nonforest inclusions percentage } \\
\text { of subplot }\end{array}$ \\
\hline NOTES & POP_EVAL & 8 & Evaluation notes \\
\hline NOTES & POP_EVAL_GRP & 19 & Notes \\
\hline NOTES & SURVEY & 9 & Notes (about the inventory) \\
\hline OPERABILITY_SRS & COND & 93 & $\begin{array}{l}\text { Operability in Southern Research } \\
\text { Station }\end{array}$ \\
\hline OWNCD (2.5.7) & COND & 12 & Owner class code \\
\hline OWNGRPCD (2.5.2) & COND & 13 & Owner group code \\
\hline P1PNTCNT_EU & POP_ESTN_UNIT & 12 & $\begin{array}{l}\text { Phase } 1 \text { point count (total number } \\
\text { of pixels) in the estimation unit }\end{array}$ \\
\hline P1POINTCNT & POP_STRATUM & 9 & Phase 1 point count \\
\hline P1SOURCE & POP_ESTN_UNIT & 13 & Phase 1 source \\
\hline P2A_GRM_FLG & SUBPLOT & 19 & $\begin{array}{l}\text { Periodic to annual growth, } \\
\text { removal, and mortality flag }\end{array}$ \\
\hline P2A_GRM_FLG & TREE & 103 & $\begin{array}{l}\text { Periodic to annual growth, } \\
\text { removal, and mortality flag }\end{array}$ \\
\hline P2PANEL & PLOT & 25 & Phase 2 panel number \\
\hline P2POINTCNT & POP_STRATUM & 10 & Phase 2 point count \\
\hline $\begin{array}{l}\text { P2VEG_SAMPLING_LEVEL_ } \\
\text { DETAIL_CD }\end{array}$ & PLOT & 54 & $\begin{array}{l}\text { P2 vegetation sampling level } \\
\text { detail code }\end{array}$ \\
\hline P2VEG_SAMPLING_STATUS_CD & PLOT & 53 & $\begin{array}{l}\text { P2 vegetation sampling status } \\
\text { code }\end{array}$ \\
\hline $\begin{array}{l}\text { P2VEG_SUBP_NONSAMPLE_ } \\
\text { REASN_CD }\end{array}$ & SUBPLOT & 32 & $\begin{array}{l}\text { P2 vegetation nonsampled reason } \\
\text { code }\end{array}$ \\
\hline P2VEG_SUBP_STATUS_CD & SUBPLOT & 31 & P2 vegetation subplot status code \\
\hline P3 OZŌNE IND & SURVEY & 3 & Phase 3 ozone indicator plot. \\
\hline P3P̄ANEL & PLOT & 26 & Phase 3 panel number \\
\hline PHYSCLCD (2.5.23) & COND & 35 & Physiographic class code \\
\hline $\begin{array}{l}\text { PLANT_STOCKABILITY_FACTOR_ } \\
\text { PNW }\end{array}$ & COND & 83 & $\begin{array}{l}\text { Plant stockability factor, Pacific } \\
\text { Northwest Research Station }\end{array}$ \\
\hline PLOT & BOUNDARY & 7 & Phase 2 Plot number \\
\hline PLOT & COND & 7 & Phase 2 Plot number \\
\hline PLOT (1.3) & PLOT & 9 & Phase 2 Plot number \\
\hline PLOT & POP_PLOT_STRATUM_ASSGN & 8 & Phase 2 Plot number \\
\hline PLOT & SEEDLING & 7 & Phase 2 Plot number \\
\hline PLOT & SITETREE & 8 & Phase 2 Plot number \\
\hline PLOT & SUBPLOT & 8 & Phase 2 Plot number \\
\hline PLOT & SUBP_COND & 7 & Phase 2 Plot number \\
\hline PLOT & TREE & 8 & Phase 2 Plot number \\
\hline $\begin{array}{l}\text { PLOT_NONSAMPLE_REASN_CD } \\
(1.5)\end{array}$ & PLOT & 11 & Plot nonsampled reason code \\
\hline PLOT_STATUS_CD (1.4) & PLOT & 10 & Plot status code \\
\hline PLT_ $\overline{\mathrm{C} N}$ & BOUNDARY & 2 & Plot sequence number \\
\hline $\mathrm{PLT}_{-}^{-} \mathrm{CN}$ & COND & 2 & Plot sequence number \\
\hline PLT_CN & POP_PLOT_STRATUM_ASSGN & 3 & Plot sequence number \\
\hline
\end{tabular}




\begin{tabular}{|c|c|c|c|}
\hline $\begin{array}{l}\text { Column name with (field guide } \\
\text { section) }\end{array}$ & Table name & $\begin{array}{l}\text { Location } \\
\text { in table }\end{array}$ & Description \\
\hline PLT_CN & SEEDLING & 2 & Plot sequence number \\
\hline $\mathrm{PLT}_{-}^{-} \mathrm{CN}$ & SITETREE & 2 & Plot sequence number \\
\hline $\mathrm{PLT}_{-}^{-} \mathrm{CN}$ & SUBPLOT & 2 & Plot sequence number \\
\hline PLT_CN & SUBP_COND & 2 & Plot sequence number \\
\hline $\mathrm{PLT}^{-} \mathrm{CN}$ & SUBP COND_CHNG_MTRX & 5 & Plot sequence number \\
\hline PLT_CN & TREE & 2 & Plot sequence number \\
\hline $\begin{array}{l}\text { POINTT_NONSAMPLE_REASN_CD } \\
(3.3)\end{array}$ & SUBPLOT & 11 & Point nonsampled reason code \\
\hline PRESNFCD & COND & 50 & Present nonforest code \\
\hline PREV_PLT_CN & PLOT & 4 & Previous plot sequence number \\
\hline PREV_PLT_CN & SUBP_COND_CHNG_MTRX & 7 & Previous plot sequence number \\
\hline PREV_PNTN_SRS & TREE $^{-}--{ }^{-}-$ & 142 & $\begin{array}{l}\text { Previous periodic prism point, } \\
\text { tree number, Southern Research } \\
\text { Station }\end{array}$ \\
\hline PREV_SBP_CN & SUBPLOT & 3 & $\begin{array}{l}\text { Previous subplot sequence } \\
\text { number }\end{array}$ \\
\hline PREV_SIT_CN & SITETREE & 3 & $\begin{array}{l}\text { Previous site tree sequence } \\
\text { number }\end{array}$ \\
\hline PREV_STATUS_CD (5.6) & TREE & 109 & Previous tree status code \\
\hline PREV_TRE_CN & TREE & 3 & Previous tree sequence number \\
\hline PREV_WDLEDSTEM (5.10) & TREE & 110 & $\begin{array}{l}\text { Previous woodland tree species } \\
\text { stem count }\end{array}$ \\
\hline PREVCOND & SUBP_COND_CHNG_MTRX & 8 & Previous condition class number \\
\hline PREVCOND & TREE & 14 & Previous condition class number \\
\hline PREVDIA (5.9.1) & TREE & 93 & Previous diameter \\
\hline PROP_BASIS & COND & 28 & Proportion basis \\
\hline PUB_ē D & REF_HABTYP_DESCRIPTION & 3 & Publication code \\
\hline PUB_CD & REF_HABTYP_PUBLICATION & 2 & Publication code \\
\hline QA_ĒTATUS (1.14) & PLOT & 32 & Quality assurance status \\
\hline RAILEESTUMP_DIB_B1 & REF_SPECIES & 62 & $\begin{array}{l}\text { Raile stump diameter inside bark } \\
\text { equation coefficient } \mathrm{B} 1\end{array}$ \\
\hline RAILE_STUMP_DIB_B2 & REF_SPECIES & 63 & $\begin{array}{l}\text { Raile stump diameter inside bark } \\
\text { equation coefficient B2 }\end{array}$ \\
\hline RAILE_STUMP_DOB_B1 & REF_SPECIES & 61 & $\begin{array}{l}\text { Raile stump diameter outside bark } \\
\text { equation coefficient B1 }\end{array}$ \\
\hline RDDISTCD (1.12) & PLOT & 18 & $\begin{array}{l}\text { Horizontal distance to improved } \\
\text { road code }\end{array}$ \\
\hline RECONCILECD (5.7.1) & TREE & 92 & Reconcile code \\
\hline REGION & REF_SPECIES_GROUP & 3 & Region \\
\hline REGIONAL_DRYBIOM & TREE_REGION̄AL_BIOMASS & 4 & $\begin{array}{l}\text { Regional merchantable stem } \\
\text { biomass oven-dry weight }\end{array}$ \\
\hline REGIONAL_DRYBIOT & TREE_REGIONAL_BIOMASS & 3 & $\begin{array}{l}\text { Regional total live tree biomass } \\
\text { oven-dry weight }\end{array}$ \\
\hline REMPER & PLOT & 15 & Remeasurement period \\
\hline REMVBFSL & TREE & 52 & $\begin{array}{l}\text { Board-foot volume of a } \\
\text { sawtimber size tree on timberland } \\
\text { for removal purposes }\end{array}$ \\
\hline REMVCFAL & TREE & 53 & $\begin{array}{l}\text { Sound cubic-foot volume of a tree } \\
\text { on timberland for removal } \\
\text { purposes }\end{array}$ \\
\hline REMVCFGS & TREE & 51 & $\begin{array}{l}\text { Cubic-foot volume of a growing- } \\
\text { stock tree on timberland for } \\
\text { removal purposes }\end{array}$ \\
\hline REPORT_YEAR_NM & POP_EVAL & 7 & Report year name \\
\hline RESERVCD $(2.5 .1)$ & $\mathrm{COND}$ & 11 & Reserved status code \\
\hline ROOT_DIS_SEV_CD_PNWRS & SUBPLOT & 28 & $\begin{array}{l}\text { Root disease severity rating code, } \\
\text { Pacific Northwest Research } \\
\text { Station }\end{array}$ \\
\hline ROUGHCULL (5.25) & TREE & 89 & Rough cull percentage \\
\hline RSCD & POP_ESTN_UNIT & 3 & Region or Station code \\
\hline
\end{tabular}




\begin{tabular}{|c|c|c|c|}
\hline $\begin{array}{l}\text { Column name with (field guide } \\
\text { section) }\end{array}$ & Table name & $\begin{array}{l}\text { Location } \\
\text { in table }\end{array}$ & Description \\
\hline RSCD & POP_EVAL & 2 & Region or Station code \\
\hline RSCD & POP_EVAL_GRP & 8 & Region or Station code \\
\hline RSCD & POP_PLOT_STRATUM_ASSGN & 9 & Region or Station code \\
\hline RSCD & POP_STRATUMM & 3 & Region or Station code \\
\hline RSCD & SURVEY & 7 & Region or Station code \\
\hline SALVCD & TREE & 56 & Salvable dead code \\
\hline SAMP_METHOD_CD & PLOT & 42 & Sample method code \\
\hline SAWHT & TREE & 75 & Sawlog height \\
\hline SCIENTIFIC_NAME & REF_HABTYP_DESCRIPTION & 4 & Scientific name \\
\hline SEVERITY1_CD_PNWRS & TREE & 133 & $\begin{array}{l}\text { Damage severity 1, Pacific } \\
\text { Northwest Research Station, for } \\
\text { years 2001-2004 }\end{array}$ \\
\hline SEVERITY1A_CD_PNWRS & TREE & 134 & $\begin{array}{l}\text { Damage Severity 1, Pacific } \\
\text { Northwest Research Station }\end{array}$ \\
\hline SEVERITY1B_CD_PNWRS & TREE & 135 & $\begin{array}{l}\text { Damage severity B, Pacific } \\
\text { Northwest Research Station }\end{array}$ \\
\hline SEVERITY2_CD_PNWRS & TREE & 136 & $\begin{array}{l}\text { Damage severity 2, Pacific } \\
\text { Northwest Research Station, for } \\
\text { years 2001-2004 }\end{array}$ \\
\hline SEVERITY2A_CD_PNWRS & TREE & 137 & $\begin{array}{l}\text { Damage severity 2A, Pacific } \\
\text { Northwest Research Station, } \\
\text { starting in } 2005\end{array}$ \\
\hline SEVERITY2B_CD_PNWRS & TREE & 138 & $\begin{array}{l}\text { Damage severity in } 2 B \text {, Pacific } \\
\text { Northwest Research Station, } \\
\text { starting in } 2005\end{array}$ \\
\hline SEVERITY3_CD_PNWRS & TREE & 139 & $\begin{array}{l}\text { Damage severity } 3 \text {, Pacific } \\
\text { Northwest Research Station, for } \\
\text { years 2001-2004 }\end{array}$ \\
\hline SFTWD_HRDWD & REF_SPECIES & 19 & Softwood or hardwood \\
\hline SIBASE & COND & 24 & Site index base age \\
\hline SIBASE & SITETREE & 17 & Site index base age \\
\hline SICOND & COND & 23 & Site index for the condition \\
\hline SISP & COND & 25 & Site index species code \\
\hline SITECL_METHOD & COND & 66 & Site class method \\
\hline SITECLC $\bar{C}$ & COND & 22 & Site productivity class code \\
\hline SITECLCDEST & COND & 64 & $\begin{array}{l}\text { Site productivity class code } \\
\text { estimated }\end{array}$ \\
\hline SITETREE & REF_SPECIES & 18 & Site tree \\
\hline SITETREE_TREE & COND & 65 & Site tree tree number \\
\hline SITREE & SITETREE & 16 & Site index for the tree \\
\hline SITREE & TREE & 80 & Calculated site index \\
\hline SITREE_EST & SITETREE & 22 & Estimated site index for the tree \\
\hline SLOPE & COND & 33 & Slope \\
\hline SLOPE (3.6) & SUBPLOT & 16 & Subplot slope \\
\hline SOIL_ROOTING_DEPTH_PNW & COND & 81 & $\begin{array}{l}\text { Soil rooting depth code, Pacific } \\
\text { Northwest Research Station }\end{array}$ \\
\hline SPCD & REF_SPECIES & 1 & Species code \\
\hline SPCD (6.2) & SEED̄LING & 10 & Species code \\
\hline SPCD (7.2.2) & SITETREE & 11 & Species code \\
\hline SPCD (5.8) & TREE & 16 & Species code \\
\hline SPECIES & REF_SPECIES & 4 & Species name \\
\hline SPECIES_SYMBOL & REF_SPECIES & 7 & Species symbol \\
\hline SPGRPCD & REF_SPECIES_GROUP & 1 & Species group code \\
\hline SPGRPCD & SEEDLING & 11 & Species group code \\
\hline SPGRPCD & SITETREE & 15 & Species group code \\
\hline SPGRPCD & TREE & 17 & Species group code \\
\hline SRV_CN & PLOT & 2 & Survey sequence number \\
\hline ST_EXXISTS_IN_NCRS & REF_SPECIES & 20 & $\begin{array}{l}\text { Site tree exists in the North } \\
\text { Central Research Station region }\end{array}$ \\
\hline
\end{tabular}




\begin{tabular}{|c|c|c|c|}
\hline $\begin{array}{l}\text { Column name with (field guide } \\
\text { section) }\end{array}$ & Table name & $\begin{array}{l}\text { Location } \\
\text { in table }\end{array}$ & Description \\
\hline ST_EXISTS_IN_NERS & REF_SPECIES & 21 & $\begin{array}{l}\text { Site tree exists in the Northeastern } \\
\text { Research Station region }\end{array}$ \\
\hline ST_EXISTS_IN_PNWRS & REF_SPECIES & 22 & $\begin{array}{l}\text { Site tree exists in the Pacific } \\
\text { Northwest Research Station } \\
\text { region }\end{array}$ \\
\hline ST_EXISTS_IN_RMRS & REF_SPECIES & 23 & $\begin{array}{l}\text { Site tree exists in the Rocky } \\
\text { Mountain Research Station region }\end{array}$ \\
\hline ST_EXISTS_IN_SRS & REF_SPECIES & 24 & $\begin{array}{l}\text { Site tree exists in the Southern } \\
\text { Research Station region }\end{array}$ \\
\hline STAND_STRUCTURE_SRS & COND & 94 & $\begin{array}{l}\text { Stand structure, Southern } \\
\text { Research Station }\end{array}$ \\
\hline STANDING_DEAD_CD (5.7.2) & TREE & 108 & Standing dead code \\
\hline START_INVYR & POP_EVAL & 15 & Start inventory year \\
\hline STATEĀB & SURVEY & 5 & State abbreviation \\
\hline STATECD & BOUNDARY & 4 & State code \\
\hline STATECD & COND & 4 & State code \\
\hline STATECD & COUNTY & 1 & State code \\
\hline STATECD (1.1) & PLOT & 6 & State code \\
\hline STATECD & POP_ESTN_UNIT & 7 & State code \\
\hline STATECD & POP_EVAL ${ }^{-}$ & 5 & State code \\
\hline STATECD & POP_EVAL_ATTRIBUTE & 4 & State code \\
\hline STATECD & POP_EVAL_GRP & 11 & State code \\
\hline STATECD & POP_EVAL_TYP & 4 & State code \\
\hline STATECD & POP_PLOT_STRATUM_ASSGN & 4 & State code \\
\hline STATECD & POP_STRATUM & 8 & State code \\
\hline STATECD & REF_STATE_ELEV & 1 & State code \\
\hline STATECD & REF_UNIT & 1 & State code \\
\hline STATECD & SEED̄LING & 4 & State code \\
\hline STATECD & SITETREE & 5 & State code \\
\hline STATECD & SUBPLOT & 5 & State code \\
\hline STATECD & SUBP_COND & 4 & State code \\
\hline STATECD & SUBP_COND_CHNG_MTRX & 2 & State code \\
\hline STATECD & SURVEY & 4 & State code \\
\hline STATECD & TREE & 5 & State code \\
\hline STATECD & TREE_REGIONAL_BIOMASS & 2 & State code \\
\hline STATENM & SURVEY & 6 & State name \\
\hline STATUSCD & TREE & 15 & Status code \\
\hline STDAGE $(2.5 .10)$ & COND & 19 & Stand age \\
\hline STDORGCD & COND & 26 & Stand origin code \\
\hline STDORGSP & COND & 27 & Stand origin species code \\
\hline STDSZCD & COND & 20 & $\begin{array}{l}\text { Stand-size class code derived by } \\
\text { algorithm }\end{array}$ \\
\hline STND_COND_CD_PNWRS & COND & 84 & $\begin{array}{l}\text { Stand condition code, Pacific } \\
\text { Northwest Research Station }\end{array}$ \\
\hline STND_STRUC_CD_PNWRS & COND & 85 & $\begin{array}{l}\text { Stand structure code, Pacific } \\
\text { Northwest Research Station }\end{array}$ \\
\hline STOCKING & SEEDLING & 12 & Tree stocking \\
\hline STOCKING & TREE & 36 & Tree stocking \\
\hline STOCKING_SPGRPCD & REF_SPECIES & 11 & Stocking species group code \\
\hline STRATUM_CN & POP_PLOT_STRATUM_ASSGN & 2 & Stratum sequence number \\
\hline STRATUM_DESCR & POP_STRATUMM & 7 & Stratum description \\
\hline STRATUMCD & POP_PLOT_STRATUM_ASSGN & 12 & Stratum code \\
\hline STRATUMCD & POP_STRAT̄UM & 6 & Stratum code \\
\hline STUMP_CD_PNWRS & COND & 86 & $\begin{array}{l}\text { Stump code, Pacific Northwest } \\
\text { Research Station }\end{array}$ \\
\hline SUBCYCLE & BOUNDARY & 17 & Inventory subcycle number \\
\hline SUBCYCLE & COND & 80 & Inventory subcycle number \\
\hline SUBCYCLE & PLOT & 47 & Inventory subcycle number \\
\hline SUBCYCLE & SEEDLING & 24 & Inventory subcycle number \\
\hline SUBCYCLE & SITETREE & 32 & Inventory subcycle number \\
\hline SUBCYCLE & SUBPLOT & 27 & Inventory subcycle number \\
\hline
\end{tabular}




\begin{tabular}{|c|c|c|c|}
\hline $\begin{array}{l}\text { Column name with (field guide } \\
\text { section) }\end{array}$ & Table name & $\begin{array}{l}\text { Location } \\
\text { in table }\end{array}$ & Description \\
\hline SUBCYCLE & SUBP_COND & 22 & Inventory subcycle number \\
\hline SUBCYCLE & SURVEY & 17 & Inventory subcycle number \\
\hline SUBCYCLE & TREE & 124 & Inventory subcycle number \\
\hline SUBP (4.2.1) & BOUNDARY & 8 & Subplot number \\
\hline SUBP (6.1) & SEEDLING & 8 & Subplot number \\
\hline SUBP (7.2.7) & SITETREE & 18 & Subplot number \\
\hline SUBP (3.1) & SUBPLOT & 9 & Subplot number \\
\hline SUBP & SUBP_COND & 8 & Subplot number \\
\hline SUBP & SUBP_COND_CHNG_MTRX & 3 & Subplot number \\
\hline SUBP (5.1) & TREE & 9 & Subplot number \\
\hline SUBP_EXAMINE_CD (1.6) & PLOT & 43 & Subplots examined code \\
\hline SUBP_STATUS_CD (3.2) & SUBPLOT & 10 & Subplot status code \\
\hline SUBPANEL & PLOT & 30 & Subpanel \\
\hline SUBPCOND (3.4) & SUBPLOT & 13 & Subplot center condition \\
\hline SUBPCOND_PROP & SUBP_COND & 17 & $\begin{array}{l}\text { Proportion of this subplot in this } \\
\text { condition }\end{array}$ \\
\hline SUBPPROP UNADJ & COND & 31 & Subplot proportion unadjusted \\
\hline SUBPTYP $(\overline{4} .2 .2)$ & BOUNDARY & 9 & Subplot type code \\
\hline SUBPTYP & SUBP_COND_CHNG_MTRX & 4 & Subplot type code \\
\hline SUBPTYP_PROP_CHNG & SUBP_COND_CHNG_MTRX & 9 & $\begin{array}{l}\text { Percent change of subplot } \\
\text { condition between previous to } \\
\text { current inventory }\end{array}$ \\
\hline SUBSPECIES & REF SPECIES & 6 & Subspecies name \\
\hline TITLE & REF_HABTYP_PUBLICATION & 3 & Title of publication \\
\hline TOPO_POSITION_PNW & PLOT & 49 & $\begin{array}{l}\text { Topographic position, Pacific } \\
\text { Northwest Research Station }\end{array}$ \\
\hline TOTAGE & SEEDLING & 14 & Total age of seedling \\
\hline TOTAGE & TREE & 67 & Total tree age \\
\hline TPA_UNADJ & SEEDLING & 22 & Trees per acre unadjusted \\
\hline TPA_UNADJ & TREE & 111 & Trees per acre unadjusted \\
\hline TPAḠGOW_UNADJ & TREE & 114 & $\begin{array}{l}\text { Growth trees per acre unadjusted } \\
\text { for denied access, hazardous, out } \\
\text { of sample conditions }\end{array}$ \\
\hline TPAMORT_UNADJ & TREE & 112 & $\begin{array}{l}\text { Mortality trees per acre per year } \\
\text { unadjusted for denied access, } \\
\text { hazardous, out of sample } \\
\text { conditions }\end{array}$ \\
\hline TPAREMV_UNADJ & TREE & 113 & $\begin{array}{l}\text { Removal trees per acre per year } \\
\text { unadjusted for denied access, } \\
\text { hazardous, out of sample } \\
\text { conditions }\end{array}$ \\
\hline TRANSCD (12.11) & TREE & 63 & Foliage transparency code \\
\hline TRE_CN & TREE_REGIONAL_BIOMASS & 1 & Tree sequence number \\
\hline TREE & SITETREE & 10 & Tree number \\
\hline TREE (5.2) & TREE & 10 & Tree record number \\
\hline TREECLCD & TREE & 23 & Tree class code \\
\hline TREECLCD_NCRS & TREE & 106 & $\begin{array}{l}\text { Tree class code, North Central } \\
\text { Research Station }\end{array}$ \\
\hline TREECLCD_NERS & TREE & 104 & $\begin{array}{l}\text { Tree class code, Northeastern } \\
\text { Research Station }\end{array}$ \\
\hline TREECLCD_RMRS & TREE & 107 & $\begin{array}{l}\text { Tree class code, Rocky Mountain } \\
\text { Research Station }\end{array}$ \\
\hline TREECLCD_SRS & TREE & 105 & $\begin{array}{l}\text { Tree class code, Southern } \\
\text { Research Station }\end{array}$ \\
\hline TREECOUNT (6.4) & SEEDLING & 13 & Tree count for seedlings \\
\hline TREECOUNT_CALC & SEEDLING & 21 & Tree count used in calculations \\
\hline TREEGRCD & TREE & 26 & Tree grade code \\
\hline TREEHISTCD & TREE & 64 & Tree history code \\
\hline TRTCD1 (2.5.17) & COND & 44 & Stand Treatment 1 code \\
\hline TRTCD2 (2.5.19) & COND & 46 & Stand treatment 2 code \\
\hline TRTCD3 (2.5.21) & COND & 48 & Stand Treatment 3 code \\
\hline
\end{tabular}




\begin{tabular}{|c|c|c|c|}
\hline $\begin{array}{l}\text { Column name with (field guide } \\
\text { section) }\end{array}$ & Table name & $\begin{array}{l}\text { Location } \\
\text { in table }\end{array}$ & Description \\
\hline TRTYR1 (2.5.18) & COND & 45 & Treatment year 1 \\
\hline TRTYR2 (2.5.20) & COND & 47 & Treatment year 2 \\
\hline TRTYR3 2.5.22) & COND & 49 & Treatment year 3 \\
\hline TYPE & REF_HABTYP_PUBLICATION & 5 & Type of publication \\
\hline TYPGRPCD & REF_FOREST_TYPE & 3 & Forest type group code \\
\hline UNCRCD $(5.18,12.5)$ & TRE $\bar{E}$ & 57 & Uncompacted live crown ratio \\
\hline UNITCD & BOUNDARY & 5 & Survey unit code \\
\hline UNITCD & COND & 5 & Survey unit code \\
\hline UNITCD & COUNTY & 2 & Survey unit code \\
\hline UNITCD & PLOT & 7 & Survey unit code \\
\hline UNITCD & POP_PLOT_STRATUM_ASSGN & 6 & Survey unit code \\
\hline UNITCD & SEEDLEING & 5 & Survey unit code \\
\hline UNITCD & SITETREE & 6 & Survey unit code \\
\hline UNITCD & SUBPLOT & 6 & Survey unit code \\
\hline UNITCD & SUBP_COND & 5 & Survey unit code \\
\hline UNITCD & TREE $^{-}$ & 6 & Survey unit code \\
\hline UNKNOWN_DAMTYP1_PNWRS & TREE & 140 & $\begin{array}{l}\text { Unknown damage type 1, Pacific } \\
\text { Northwest Research Station }\end{array}$ \\
\hline UNKNOWN_DAMTYP2_PNWRS & TREE & 141 & $\begin{array}{l}\text { Unknown damage type 2, Pacific } \\
\text { Northwest Research Station }\end{array}$ \\
\hline VALID & REF HABTYP DESCRIPTION & 6 & Valid \\
\hline VALID & REF_HABTYP_PUBLICATION & 6 & Valid \\
\hline VALIDCD & SITETREE & 23 & Validity code \\
\hline VALUE & REF_FOREST_TYPE & 1 & Value \\
\hline VALUE & REF_UNIT & 2 & Value \\
\hline VARIETY & REF_SPECIES & 5 & Variety \\
\hline VERSION & REF_FIADB_VERSION & 1 & Version number \\
\hline VOL_LOC_GRP & COND & 63 & Volume location group \\
\hline VOLBFGR $\overline{\mathrm{B}}$ & TREE & 43 & $\begin{array}{l}\text { Gross board-foot volume in the } \\
\text { sawlog portion }\end{array}$ \\
\hline VOLBFNET & TREE & 42 & $\begin{array}{l}\text { Net board-foot volume in the } \\
\text { sawlog portion }\end{array}$ \\
\hline VOLCFGRS & TREE & 39 & Gross cubic-foot volume \\
\hline VOLCFNET & TREE & 38 & Net cubic-foot volume \\
\hline VOLCFSND & TREE & 44 & Sound cubic-foot volume \\
\hline VOLCSGRS & TREE & 41 & $\begin{array}{l}\text { Gross cubic-foot volume in the } \\
\text { sawlog portion }\end{array}$ \\
\hline VOLCSNET & TREE & 40 & $\begin{array}{l}\text { Net cubic-foot volume in the } \\
\text { sawlog portion }\end{array}$ \\
\hline W_SPGRPCD & REF_SPECIES & 9 & West species group code \\
\hline WĀTERCD (1.13) & PLOT & 19 & Water on plot code \\
\hline WATERDEP (3.8) & SUBPLOT & 18 & Water or snow depth \\
\hline WDLDSTEM (5.11) & TREE & 37 & $\begin{array}{l}\text { Woodland tree species current } \\
\text { stem count }\end{array}$ \\
\hline WEST & REF_SPECIES & 26 & West \\
\hline WHERE_CLAUSE & REF_POP_ATTRIBUTE & 5 & Part of the where clause \\
\hline $\begin{array}{l}\text { WOOD_SPGR_GREENVOL_ } \\
\text { DRYWT }\end{array}$ & REF_SPEC̄IES & 49 & $\begin{array}{l}\text { Green specific gravity wood } \\
\text { (green volume and oven-dry } \\
\text { weight) }\end{array}$ \\
\hline $\begin{array}{l}\text { WOOD_SPGR_GREENVOL_ } \\
\text { DRYWT_CIT }\end{array}$ & REF_SPECIES & 50 & $\begin{array}{l}\text { Green specific gravity wood } \\
\text { citation }\end{array}$ \\
\hline WOOD_SPGR_MC12VOL_DRYWT & REF_SPECIES & 57 & $\begin{array}{l}\text { Wood specific gravity ( } 12 \text { percen } \\
\text { moisture content volume and } \\
\text { oven-dry weight) }\end{array}$ \\
\hline $\begin{array}{l}\text { WOOD_SPGR_MC12VOL_DRYWT_ } \\
\text { CIT }\end{array}$ & REF_SPECIES & 58 & $\begin{array}{l}\text { Wood specific gravity ( } 12 \text { percen } \\
\text { moisture content volume and } \\
\text { oven-dry weight) citation }\end{array}$ \\
\hline WOODLAND & REF_SPECIES & 27 & Woodland species \\
\hline
\end{tabular}




\section{Appendix B. Forest Inventory and Analysis (FIA) Plot Design Codes and Definitions by FIA Work Unit}

\begin{tabular}{|c|c|c|}
\hline $\begin{array}{l}\text { FIA work } \\
\text { unit }\end{array}$ & $\begin{array}{l}\text { Plot design } \\
\text { code } \\
\text { (DESIGNCD) }\end{array}$ & Definition \\
\hline $\begin{array}{l}{ }^{\mathrm{a}} \mathrm{NRS}-\mathrm{NE}, \\
{ }^{\mathrm{b}} \mathrm{NRS}-\mathrm{NC}, \\
{ }^{\mathrm{c}} \mathrm{SRS}, \\
{ }^{\mathrm{d}} \mathrm{RMRS}, \\
{ }^{\mathrm{e}} \mathrm{PNWRS}\end{array}$ & 1 & $\begin{array}{l}\text { National plot design consists of four } 24 \text {-foot fixed-radius subplots for } \\
\text { trees } \geq 5 \text { inches DBH, and four } 6.8 \text {-foot fixed-radius microplots for seedlings } \\
\text { and trees } \geq 1 \text { and }<5 \text { inches DBH. Subplot } 1 \text { is the center plot, and subplots } 2,3 \text {, } \\
\text { and } 4 \text { are located } 120.0 \text { feet, horizontal, at azimuths of } 360,120 \text {, and } 240 \text {, } \\
\text { respectively. The microplot center is } 12 \text { feet east of the subplot center. Four } \\
58.9 \text {-foot fixed-radius macroplots are optional. A plot may sample more than } \\
\text { one condition. When multiple conditions are encountered, condition boundaries } \\
\text { are delineated (mapped). }\end{array}$ \\
\hline \multirow[t]{8}{*}{${ }^{\mathrm{a}} \mathrm{NRS}-\mathrm{NE}$} & 101 & $\begin{array}{l}\text { Various plot designs. Converted from Eastwide Database format, some fields } \\
\text { may be null. }\end{array}$ \\
\hline & 111 & $\begin{array}{l}\text { Four-subplot design similar to DESIGNCD } 1 \text {, except the microplot for seedlings } \\
\text { is } 1 / 1000 \text { acre }(3.7 \text {-foot radius). If the plot is used for growth estimates, it is } \\
\text { overlaid on a } 5 \text { subplot design, where remeasurement of trees ( } \geq 5 \text { inches) is on } \\
\text { subplot } 1 \text { only. Poletimber-sized trees remeasured on a } 24 \text {-foot radius plot, } \\
\text { sawtimber-sized trees remeasured on a } 49 \text {-foot radius plot. If the plot is not used } \\
\text { for growth estimates, it is an initial plot establishment. }\end{array}$ \\
\hline & 112 & $\begin{array}{l}\text { DESIGNCD 111, except that if the plot is used for growth estimates, the } \\
\text { remeasurement of trees ( } \geq 5 \text { inches) is on the } 24 \text {-foot-radius subplot } 1 \text { only, } \\
\text { regardless of tree size or previous plot size or type (varied). }\end{array}$ \\
\hline & 113 & $\begin{array}{l}\text { DESIGNCD 111, except that if the plot is used for growth estimates, the } \\
\text { remeasurement of trees ( } \geq 5 \text { inches) is on the } 24 \text {-foot-radius subplot } 1 \text { only, } \\
\text { regardless of tree size or previous plot size or type (single subplot } 1 / 5 \text { acre). }\end{array}$ \\
\hline & 115 & $\begin{array}{l}\text { DESIGNCD 1. Overlaid on a FHM 4-subplot plot design. These plots are not } \\
\text { used in change estimates. }\end{array}$ \\
\hline & 116 & $\begin{array}{l}\text { DESIGNCD 1. Overlaid on } 1 / 5 \text { acre plot for all trees } \geq 5 \text { inches DBH ( } 1 / 5 \text { acre } \\
\text { plot was an initial measurement). Remeasurement of subplot } 1 \text { is only on the } \\
24 \text {-foot-radius plot for all trees ( } \geq 5 \text { inches), regardless of tree size or previous } \\
\text { plot size. }\end{array}$ \\
\hline & 117 & $\begin{array}{l}\text { DESIGNCD } 1 \text {. Overlaid on } 1 / 5 \text { acre plot for all trees } \geq 5 \text { inches DBH }(1 / 5 \text { acre } \\
\text { plot was remeasurement). Remeasurement of subplot } 1 \text { is only on the } 24 \text {-foot- } \\
\text { radius plot for all trees ( } \geq 5 \text { inches), regardless of tree size or previous plot size. }\end{array}$ \\
\hline & 118 & $\begin{array}{l}\text { DESIGNCD 1. Overlaid on } 10 \text {-subplot, variable-radius design. Remeasurement } \\
\text { of trees ( } \geq 5 \text { inches) on } 5 \text { of the } 10 \text { subplots; ingrowth based on trees ( } \geq 5 \text { inches) } \\
\text { that grew onto five } 6.8 \text {-foot radius subplots. }\end{array}$ \\
\hline \multirow[t]{8}{*}{${ }^{b} \mathrm{NRS}-\mathrm{NC}$} & 301 & $\begin{array}{l}\text { Various plot designs. Converted from Eastwide Database format, some fields } \\
\text { may be null. }\end{array}$ \\
\hline & 311 & $\begin{array}{l}\text { Four-subplot design similar to DESIGNCD } 1 \text {, except the } 1 / 24 \text { acre and } 1 / 300 \\
\text { acre plots have common centers. Conditions are mapped and boundaries may be } \\
\text { within the plots. }\end{array}$ \\
\hline & 312 & DESIGNCD 1. Initial plot establishment. \\
\hline & 313 & DESIGNCD 311. Overlaid on previous plots, no remeasurements. \\
\hline & 314 & DESIGNCD 1. Overlaid on previous plots, no remeasurements. \\
\hline & 315 & $\begin{array}{l}\text { DESIGNCD 311. Overlaid on same design. Only trees } \geq 5 \text { inches DBH are } \\
\text { remeasured. }\end{array}$ \\
\hline & 316 & $\begin{array}{l}\text { DESIGNCD 1. Overlaid on DESIGNCD } 311 \text { Only trees } \geq 5 \text { inches DBH are } \\
\text { remeasured. }\end{array}$ \\
\hline & 317 & $\begin{array}{l}\text { DESIGNCD 1. Overlaid on DESIGNCD } 326 \text {. Only the first } 5 \text { points } \\
\text { (trees } \geq 5 \text { inches DBH) and first } 3,1 / 300 \text { acre plots (trees } \geq 1 \text { and }<5 \text { inches } \\
\text { DBH) are remeasured, but conditions were not re-mapped. }\end{array}$ \\
\hline
\end{tabular}




\begin{tabular}{|c|c|c|}
\hline \multirow[t]{11}{*}{$\begin{array}{l}\text { FIA work } \\
\text { unit }\end{array}$} & $\begin{array}{l}\text { Plot design } \\
\text { code } \\
\text { (DESIGNCD) }\end{array}$ & Definition \\
\hline & 318 & $\begin{array}{l}\text { DESIGNCD } 311 \text {. Overlaid on DESIGNCD } 325 \text {. Only the first } 5 \text { points } \\
\text { (trees } \geq 5 \text { inches DBH) and first } 3,1 / 300 \text { acre plots (trees } \geq 1 \text { and }<5 \text { inches } \\
\text { DBH) are remeasured. }\end{array}$ \\
\hline & 319 & $\begin{array}{l}\text { DESIGNCD } 1 \text {. Overlaid on DESIGNCD } 325 \text {. Only the first } 5 \text { points } \\
\text { (trees } \geq 5 \text { inches DBH) and first } 3,1 / 300 \text { acre plots (trees } \geq 1 \text { and }<5 \text { inches } \\
\text { DBH) are remeasured. }\end{array}$ \\
\hline & 320 & $\begin{array}{l}\text { DESIGNCD } 311 \text {. Overlaid on modified DESIGNCD } 325 \text {. Only the first } 5 \\
\text { points (trees } \geq 5 \text { inches DBH) and first } 31 / 300 \text { acre plots (trees } \geq 1 \text { and } \\
<5 \text { inches DBH) are remeasured. }\end{array}$ \\
\hline & 321 & $\begin{array}{l}\text { DESIGNCD 1. Overlaid on modified DESIGNCD 325. Only the first } 5 \text { points } \\
\text { (trees } \geq 5 \text { inches DBH) and first } 31 / 300 \text { acre plots (trees } \geq 1 \text { and }<5 \text { inches } \\
\text { DBH) are remeasured. }\end{array}$ \\
\hline & 322 & $\begin{array}{l}\text { DESIGNCD } 311 \text {. Overlaid on DESIGNCD } 327 \text {. Only the first } 5 \text { points } \\
\text { (trees } \geq 5 \text { inches DBH) and first } 3,1 / 300 \text { acre plots (trees } \geq 1 \text { and }<5 \text { inches } \\
\text { DBH) are remeasured. }\end{array}$ \\
\hline & 323 & $\begin{array}{l}\text { DESIGNCD 1. Overlaid on DESIGNCD } 327 \text {. Only the first } 5 \text { points } \\
\text { (trees } \geq 5 \text { inches DBH) and first } 31 / 300 \text { acre plots (trees } \geq 1 \text { and }<5 \text { inches } \\
\text { DBH) are remeasured. }\end{array}$ \\
\hline & 325 & $\begin{array}{l}\text { Ten variable-radius, } 37.5 \text { BAF points, } 70 \text { feet apart, for trees } \geq 5 \text { inches DBH } \\
\text { and } 10,1 / 300 \text { acre plots for seedlings and trees } \geq 1 \text { and }<5 \text { inches DBH. Point } \\
\text { and plot center were coincident. Conditions were not mapped. Instead, points } \\
\text { were rotated into forest or nonforest based on the condition at point center. }\end{array}$ \\
\hline & 326 & $\begin{array}{l}\text { Ten variable-radius, } 37.5 \text { BAF points, } 70 \text { feet apart, for trees } \geq 5 \text { and } \\
<17.0 \text { inches DBH, } 101 / 24 \text { acre plots for trees } \geq 17.0 \text { inches DBH, and } 10 \text {, } \\
1 / 300 \text { acre plots for seedlings and trees } \geq 1 \text { and }<5 \text { inches DBH. Point and plot } \\
\text { center were coincident. Conditions were mapped. }\end{array}$ \\
\hline & 327 & $\begin{array}{l}\text { Ten variable-radius, } 37.5 \text { BAF points, } 70 \text { feet apart, for trees } \geq 5 \text { inches DBH } \\
\text { and } 10,1 / 300 \text { acre plots for seedlings and trees } \geq 1 \text { and }<5 \text { inches DBH. Point } \\
\text { and plot center were coincident. Conditions were not mapped. Instead, points } \\
\text { were rotated into forest or nonforest based on the condition at point center. } \\
\text { Diameters were estimated with a model, but all dead and cut trees were } \\
\text { recorded. }\end{array}$ \\
\hline & 328 & $\begin{array}{l}\text { DESIGNCD 1. Overlaid on DESIGNCD 311. All trees and saplings are } \\
\text { remeasured. }\end{array}$ \\
\hline \multirow[t]{10}{*}{${ }^{\mathrm{c}} \mathrm{SRS}$} & 210 & $\begin{array}{l}\text { Other plot design installed by previous research stations within the 13-State } \\
\text { Southern area not described by DESIGNCD 211-219. }\end{array}$ \\
\hline & 211 & $\begin{array}{l}\text { Ten variable-radius, } 37.5 \mathrm{BAF} \text { points, } 70 \text { feet apart. Remeasure first } 3 \text { points of } \\
\text { same design or new/replacement plot. }\end{array}$ \\
\hline & 212 & $\begin{array}{l}\text { Five variable-radius, } 37.5 \text { BAF points, } 70 \text { feet apart. Remeasure first } 5 \text { points of } \\
\text { DESIGNCD } 211 \text { or new/replacement plot. }\end{array}$ \\
\hline & 213 & $\begin{array}{l}\text { Five variable-radius, } 37.5 \text { BAF points, } 70 \text { feet apart. Remeasure DESIGNCD } \\
212 \text {. }\end{array}$ \\
\hline & 214 & $\begin{array}{l}\text { Ten variable-radius, } 37.5 \text { BAF points, } 66 \text { feet apart. Remeasure same design or } \\
\text { new/replacement plot. }\end{array}$ \\
\hline & 215 & $\begin{array}{l}\text { Five variable-radius, } 37.5 \text { BAF points, } 66 \text { feet apart. Remeasure first } 5 \text { points of } \\
\text { DESIGNCD } 214 \text { or new/replacement plot. }\end{array}$ \\
\hline & 216 & $\begin{array}{l}\text { Ten variable-radius, } 37.5 \text { BAF points, } 66 \text { feet apart. Remeasure DESIGNCD } \\
215 \text {. }\end{array}$ \\
\hline & 217 & $\begin{array}{l}\text { Five point cluster plot, point } 1 \text { is } 1 / 5 \text { th acre sawtimber plot and } 1 / 10 \text { th acre } \\
\text { poletimber plot, points } 2-5 \text { are } 37.5 \text { BAF prism points. No remeasurement. }\end{array}$ \\
\hline & 218 & $\begin{array}{l}\text { Remeasurement of DESIGNCD 217, point } 1 \text { only. Used only for change } \\
\text { estimates. }\end{array}$ \\
\hline & 219 & $\begin{array}{l}\text { Three point, } 2.5 \text { BAF metric prism plot, points } 25 \text { meters apart. Remeasure } \\
\text { same design or new/replacement plot. }\end{array}$ \\
\hline
\end{tabular}




\begin{tabular}{|c|c|c|}
\hline $\begin{array}{l}\text { FIA work } \\
\text { unit }\end{array}$ & $\begin{array}{l}\text { Plot design } \\
\text { code } \\
\text { (DESIGNCD) }\end{array}$ & Definition \\
\hline & 220 & $\begin{array}{l}\text { Four } 1 / 24 \text { acre plots for trees } \geq 5 \text { inches DBH and } 4,1 / 300 \text { acre plots for } \\
\text { seedlings and trees } \geq 1 \text { and }<5 \text { inches DBH. The } 1 / 24 \text { acre and } 1 / 300 \text { acre plots } \\
\text { have common centers. Conditions are mapped and boundaries may be within the } \\
\text { plots. Remeasurement plot not described by } 221-229 \text {. }\end{array}$ \\
\hline & 221 & DESIGNCD 220. Remeasure same design or new/replacement plot. \\
\hline & 222 & DESIGNCD 220. Overlaid on and remeasurement of DESIGNCD 212 or 213. \\
\hline & 223 & $\begin{array}{l}\text { DESIGNCD } 220 . \text { Overlaid on and remeasurement of first } 5 \text { points of } \\
\text { DESIGNCD } 214 \text { or } 216 .\end{array}$ \\
\hline & 230 & DESIGNCD 1. Remeasurement plot not described by DESIGNCD 231-239. \\
\hline & 231 & $\begin{array}{l}\text { DESIGNCD 1. Overlaid on and remeasurement of DESIGNCD } 212 \text { or } \\
\text { DESIGNCD } 213 .\end{array}$ \\
\hline & 232 & $\begin{array}{l}\text { DESIGNCD 1. Overlaid on and remeasurement of first } 5 \text { points of DESIGNCD } \\
214 \text { or } 216 \text {. }\end{array}$ \\
\hline & 233 & $\begin{array}{l}\text { DESIGNCD 1. Overlaid on and remeasurement of DESIGNCD 220, 221, 222, } \\
\text { or } 223\end{array}$ \\
\hline & 240 & $\begin{array}{l}\text { DESIGNCD 1. Collected in metric and converted to English in the database. } \\
\text { Remeasurement not described by } 241-249 \text {. }\end{array}$ \\
\hline & 241 & $\begin{array}{l}\text { DESIGNCD 1. Collected in metric and converted to English in the database. } \\
\text { Remeasure same design or new/replacement plot. }\end{array}$ \\
\hline & 242 & $\begin{array}{l}\text { DESIGNCD 1. Overlaid on and remeasurement of DESIGNCD 219. Collected } \\
\text { in metric and converted to English in the database. }\end{array}$ \\
\hline & 299 & Other plot design not described in DESIGNCD 200-298. \\
\hline \multirow[t]{10}{*}{${ }^{\mathrm{d}} \mathrm{RMRS}$} & 403 & $\begin{array}{l}\text { One } 1 / 10^{\text {th }} \text { acre fixed-radius plot divided into } 4 \text { quadrants and four } 1 / 300^{\text {th }} \text { acre } \\
\text { fixed-radius microplots. Timber and woodland tree species }<5.0 \text { inches DRC } \\
\text { tallied on microplot. }\end{array}$ \\
\hline & 404 & $\begin{array}{l}\text { One } 1 / 20 \text { th acre fixed-radius plot divided into } 4 \text { quadrants and four } 1 / 300^{\text {th }} \text { acre } \\
\text { fixed-radius microplots. Timber and woodland tree species }<5.0 \text { inches DRC } \\
\text { tallied on microplot. }\end{array}$ \\
\hline & 405 & $\begin{array}{l}\text { One } 1 / 5 \text { th acre fixed-radius plot divided into } 4 \text { quadrants and four } 1 / 300^{\text {th }} \text { acre } \\
\text { fixed-radius microplots. Timber and woodland tree species }<5.0 \text { inches DRC } \\
\text { tallied on microplot. }\end{array}$ \\
\hline & 410 & $\begin{array}{l}40 \mathrm{BAF} \text { variable-radius plots and } 1 / 300^{\text {th }} \text { acre fixed-radius microplots; number } \\
\text { of microplots = number of points installed. Timber tree species }<5.0 \text { inches } \\
\text { DBH; woodland tree species }<3.0 \text { inches DRC measured on microplot. }\end{array}$ \\
\hline & 411 & $\begin{array}{l}40 \text { BAF variable-radius plots and } 1 / 300^{\text {th }} \text { acre fixed-radius microplots; } 3 \\
\text { microplots installed on points } 1,2 \text {, and } 3 \text {. Timber tree species }<5.0 \text { inches DBH; } \\
\text { woodland tree species }<3.0 \text { inches DRC measured on microplot. }\end{array}$ \\
\hline & 412 & $\begin{array}{l}40 \text { BAF variable-radius plots and } 1 / 300^{\text {th }} \text { acre fixed-radius microplots; } 3 \\
\text { microplots installed on points } 1,2 \text {, and } 5 \text {. Timber tree species }<5.0 \text { inches DBH; } \\
\text { woodland tree species }<3.0 \text { inches DRC measured on microplot. }\end{array}$ \\
\hline & 413 & $\begin{array}{l}20 \text { BAF variable-radius plots and } 1 / 300^{\text {th }} \text { acre fixed-radius microplots; number } \\
\text { of microplots = number of points installed. Timber tree species }<5.0 \text { inches } \\
\text { DBH; woodland tree species }<3.0 \text { inches DRC measured on microplot. }\end{array}$ \\
\hline & 414 & $\begin{array}{l}20 \text { BAF variable-radius plots and } 1 / 300 \text { th acre fixed-radius microplots; } 3 \\
\text { microplots installed on points } 1,2 \text {, and 3. Timber tree species }<5.0 \text { inches DBH; } \\
\text { woodland tree species }<3.0 \text { inches DRC measured on microplot. }\end{array}$ \\
\hline & 415 & $\begin{array}{l}20 \text { BAF variable-radius plots and } 1 / 300 \text { th acre fixed-radius microplots; } 3 \\
\text { microplots installed on points } 1,2 \text {, and } 5 \text {. Timber tree species }<5.0 \text { inches DBH; } \\
\text { woodland tree species }<3.0 \text { inches DRC measured on microplot. }\end{array}$ \\
\hline & 420 & $\begin{array}{l}\text { One } 1 / 10^{\text {th }} \text { acre fixed-radius plot and one centered } 1 / 100^{\text {th }} \text { acre microplot. } \\
\text { Timber tree species }<5.0 \text { inches DBH; woodland tree species }<3.0 \text { inches DRC } \\
\text { measured on microplot. }\end{array}$ \\
\hline
\end{tabular}




\begin{tabular}{|c|c|c|}
\hline $\begin{array}{l}\text { FIA work } \\
\text { unit }\end{array}$ & $\begin{array}{l}\text { Plot design } \\
\text { code } \\
\text { (DESIGNCD) }\end{array}$ & Definition \\
\hline & 421 & $\begin{array}{l}\text { One } 1 / 20 \text { th acre fixed-radius plot and one centered } 1 / 100^{\text {th }} \text { acre microplot. } \\
\text { Timber tree species }<5.0 \text { inches DBH; woodland tree species }<3.0 \text { inches DRC } \\
\text { measured on microplot. }\end{array}$ \\
\hline & 422 & $\begin{array}{l}\text { One } 1 / 5 \text { th acre fixed-radius plot and one centered } 1 / 100^{\text {th }} \text { acre microplot. } \\
\text { Timber tree species }<5.0 \text { inches DBH; woodland tree species }<3.0 \text { inches DRC } \\
\text { measured on microplot. }\end{array}$ \\
\hline & 423 & $\begin{array}{l}\text { One } 1 / 10 \text { th acre fixed-radius plot divided into } 4 \text { quadrants and four } 1 / 300^{\text {th }} \text { acre } \\
\text { fixed-radius microplots. Timber tree species }<5.0 \text { inches DBH; woodland tree } \\
\text { species }<3.0 \text { inches DRC measured on microplot. }\end{array}$ \\
\hline & 424 & $\begin{array}{l}\text { One } 1 / 20 \text { th acre fixed-radius plot divided into } 4 \text { quadrants and four } 1 / 300^{\text {th }} \text { acre } \\
\text { fixed-radius microplots. Timber tree species }<5.0 \text { inches DBH; woodland tree } \\
\text { species }<3.0 \text { inches DRC measured on microplot. }\end{array}$ \\
\hline & 425 & $\begin{array}{l}\text { One } 1 / 5 \text { th acre fixed-radius plot divided into } 4 \text { quadrants and four } 1 / 300^{\text {th }} \text { acre } \\
\text { fixed-radius microplots. Timber tree species }<5.0 \text { inches DBH; woodland tree } \\
\text { species }<3.0 \text { inches DRC measured on microplot. }\end{array}$ \\
\hline \multirow[t]{13}{*}{${ }^{{ }^{e} \mathrm{PNWRS}}$} & 501 & $\begin{array}{l}\text { DESIGNCD } 1 \text { with optional macroplot. Trees } \geq 24 \text { inches DBH are tallied on } \\
\text { macroplot. }\end{array}$ \\
\hline & 502 & $\begin{array}{l}\text { DESIGNCD } 1 \text { with optional macroplot. Trees } \geq 30 \text { inches DBH are tallied on } \\
\text { macroplot. }\end{array}$ \\
\hline & 503 & $\begin{array}{l}\text { DESIGNCD } 1 \text { with optional macroplot. Trees } \geq 4 \text { inches DBH are tallied on } \\
\text { macroplot. Trees } \geq 32 \text { inches DBH are tallied on one 1-hectare plot. }\end{array}$ \\
\hline & 504 & $\begin{array}{l}\text { DESIGNCD } 1 \text { with optional macroplot. Trees } \geq 24 \text { inches DBH are tallied on } \\
\text { macroplot. Trees } \geq 48 \text { inches DBH are tallied on one } 1 \text {-hectare plot. }\end{array}$ \\
\hline & 505 & $\begin{array}{l}\text { DESIGNCD } 1 \text { with optional macroplot. Trees } \geq 30 \text { inches DBH are tallied on } \\
\text { macroplot. Trees } \geq 48 \text { inches DBH are tallied on one } 1 \text {-hectare plot. }\end{array}$ \\
\hline & 550 & $\begin{array}{l}\text { Five } 30.5 \text { BAF points for trees } \geq 5 \text { inches and }<35.4 \text { inches DBH; five } 55.8 \text { foot } \\
\text { fixed-radius plots for trees } \geq 35.4 \text { inches DBH; and five } 7.7 \text {-foot fixed-radius } \\
\text { plots for seedlings and saplings }<5 \text { inches DBH. Point and plot centers are } \\
\text { coincident. Conditions are mapped. }\end{array}$ \\
\hline & 551 & $\begin{array}{l}\text { Five } 20 \text { BAF points for trees } \geq 5 \text { inches and }<35.4 \text { inches DBH; five } 55.6 \text { foot } \\
\text { fixed-radius plots for trees } \geq 35.4 \text { inches DBH; and five } 9.7 \text {-foot fixed-radius } \\
\text { plots for seedlings and saplings }<5 \text { inches DBH. Point and plot centers are } \\
\text { coincident. Conditions are mapped. }\end{array}$ \\
\hline & 552 & $\begin{array}{l}\text { Five } 30 \text { BAF points for trees } \geq 5 \text { inches and }<35.4 \text { inches DBH; five } 55.6 \text {-foot } \\
\text { fixed-radius plots for trees } \geq 35.4 \text { inches } \mathrm{DBH} \text {; and five } 7.9 \text {-foot fixed-radius } \\
\text { plots for seedlings and saplings }<5 \text { inches DBH. Point and plot centers are } \\
\text { coincident. Conditions are mapped. }\end{array}$ \\
\hline & 553 & $\begin{array}{l}\text { Four } 1 / 24 \text { acre plots for live trees and four } 58.9 \text {-foot fixed-radius plots for trees } \\
\geq 11.8 \text { inches DBH. Plot centers are coincident. Conditions are mapped. }\end{array}$ \\
\hline & 554 & $\begin{array}{l}\text { Four } 1 / 24 \text { acre plots for live trees and four } 58.9 \text {-foot fixed-radius plots for trees } \\
\geq 19.7 \text { inches DBH. Plot centers are coincident. Conditions are mapped. }\end{array}$ \\
\hline & 555 & $\begin{array}{l}\text { Five } 30.5 \text { BAF points for trees } \geq 6.9 \text { inches and }<35.4 \text { inches DBH; five } \\
55.8 \text {-foot fixed-radius plots for trees } \geq 35.4 \text { inches DBH; and five } 10.8 \text {-foot } \\
\text { fixed-radius plots for seedlings and saplings }<6.9 \text { inches DBH. Point and plot } \\
\text { centers are coincident. Conditions are mapped. }\end{array}$ \\
\hline & 556 & $\begin{array}{l}\text { Five } 30.5 \text { BAF points for trees } \geq 6.9 \text { inches and }<35.4 \text { inches DBH; five } \\
55.8 \text {-foot fixed-radius plots for trees } \geq 35.4 \text { inches DBH; five } 10.8 \text {-foot fixed- } \\
\text { radius plots for saplings } \geq 5 \text { inches and }<6.9 \text { inches DBH; and the northeast } \\
\text { quadrant of each of the five } 10.8 \text {-foot fixed-radius plots for trees }<5 \text { inches } \\
\text { DBH. Point and plot centers are coincident. Conditions are not mapped. }\end{array}$ \\
\hline & 557 & $\begin{array}{l}\text { Five } 40 \text { BAF points for trees } \geq 5 \text { inches DBH; and five } 6.9 \text {-foot fixed-radius } \\
\text { plots for saplings } \geq 1 \text { and }<5 \text { inches DBH. Point and plot centers are coincident. } \\
\text { Conditions are not mapped. }\end{array}$ \\
\hline
\end{tabular}




\begin{tabular}{|c|c|c|}
\hline $\begin{array}{l}\text { FIA work } \\
\text { unit }\end{array}$ & $\begin{array}{l}\text { Plot design } \\
\text { code } \\
\text { (DESIGNCD) }\end{array}$ & Definition \\
\hline & 558 & $\begin{array}{l}\text { Three } 30.5 \text { BAF points for trees } \geq 6.9 \text { inches and }<35.4 \text { inches DBH; three } \\
55.8 \text {-foot fixed-radius plots for trees } \geq 35.4 \text { inches DBH; three } 10.8 \text {-foot fixed- } \\
\text { radius plots for saplings } \geq 5 \text { inches and }<6.9 \text { inches DBH; and the northeast } \\
\text { quadrant of each of the three } 10.8 \text {-foot fixed-radius plots for trees }<5 \text { inches } \\
\text { DBH. Point and plot centers are coincident. Conditions are mapped, only } \\
\text { condition class } 1 \text { measured. Overlaid on and remeasurement of same design. }\end{array}$ \\
\hline & 559 & $\begin{array}{l}\text { Four } 40 \text { BAF points for trees } \geq 5 \text { inches DBH; and four } 6.9 \text {-foot fixed-radius } \\
\text { plots for saplings } \geq 1 \text { and }<5 \text { inches DBH. Point and plot centers are coincident. } \\
\text { Conditions are mapped, only condition class } 1 \text { measured. Overlaid on and } \\
\text { remeasurement of same design. }\end{array}$ \\
\hline $\begin{array}{l}{ }^{2} \text { NRS-NE, } \\
{ }^{\text {b} N R S-N C, ~} \\
\text { cSRS, } \\
{ }^{\text {d } R M R S,} \\
{ }^{\text {e}} \text { PNWRS }\end{array}$ & 999 & $\begin{array}{l}\text { A plot record created to represent reserved or other nonsampled or } \\
\text { undersampled areas where there were no ground plots; the plot has no design } \\
\text { type; rather, it is a placeholder for area estimates. In all cases where } \\
\text { DESIGNCD } 999 \text { plots are present, they are only used for estimates of area; they } \\
\text { are not used in estimates of numbers of trees, volume or change (i.e., tree level } \\
\text { estimates). }\end{array}$ \\
\hline
\end{tabular}

${ }^{a}$ Northern Research Station - previously Northeastern

${ }^{\mathrm{b}}$ Northern Research Station - previously North Central

${ }^{\mathrm{c}}$ Southern Research Station

${ }^{\mathrm{d}}$ Rocky Mountain Research Station

${ }^{\mathrm{e}}$ Pacific Northwest Research Station

Other acronyms and definitions:

$\mathrm{BAF}$ - basal area factor

$\mathrm{DRC}$ - diameter at root collar

Sawtimber-sized trees - softwoods $\geq 9$ inches DBH, hardwoods $\geq 11$ inches DBH.

Poletimber-sized trees - softwoods $\geq 5$ inches and $<9$ inches DBH, hardwoods $\geq 5$ inches and $<11$ inches DBH 


\section{Appendix C. State, Survey Unit, and County Codes}

\begin{tabular}{|c|c|c|c|c|}
\hline State Code: 1 & State Name: & Alabama & State Abbreviation: $\mathrm{AL}$ & Region/Station Code: 33 \\
\hline Survey Unit Code: & Survey & y Unit Name: & Southwest-South & \\
\hline \multicolumn{5}{|c|}{ County code and county name } \\
\hline Baldwin & 53 & Escambia & Washington & \\
\hline Covington & 97 & Mobile & & \\
\hline
\end{tabular}

Survey Unit Code: 2 Survey Unit Name: Southwest-North

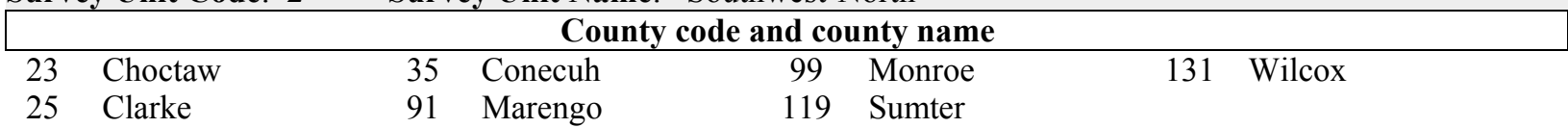

Survey Unit Code: 3 Survey Unit Name: Southeast

\begin{tabular}{|clrlrlrl|}
\hline \multicolumn{8}{|c|}{ County code and county name } \\
\hline 1 & Autauga & 31 & Coffee & 67 & Henry & 109 & Pike \\
5 & Barbour & 41 & Crenshaw & 69 & Houston & 113 & Russell \\
11 & Bullock & 45 & Dale & 81 & Lee & 123 & Tallapoosa \\
13 & Butler & 47 & Dallas & 85 & Lowndes & & \\
17 & Chambers & 51 & Elmore & 87 & Macon & & \\
21 & Chilton & 61 & Geneva & 101 & Montgomery & &
\end{tabular}

Survey Unit Code: 4 Survey Unit Name: West Central

\begin{tabular}{|clllll|}
\hline & & \multicolumn{4}{c|}{ County code and county name } \\
\hline 7 & Bibb & 65 & Hale & 105 & Perry \\
57 & Fayette & 75 & Lamar & 107 & Pickens \\
63 & Greene & 93 & Marion & 125 & Tuscaloosa \\
\hline
\end{tabular}

Survey Unit Code: 5 Survey Unit Name: North Central

\begin{tabular}{|clllrlll|}
\hline \multicolumn{7}{c|}{ County code and county name } \\
\hline 9 & Blount & 29 & Cleburne & 73 & Jefferson & 121 & Talladega \\
15 & Calhoun & 37 & Coosa & 111 & Randolph & 127 & Walker \\
19 & Cheroke & 43 & Cullman & 115 & St. Clair & 133 & Winston \\
27 & Clay & 55 & Etowah & 117 & Shelby & &
\end{tabular}

Survey Unit Code: 6 Survey Unit Name: North

\begin{tabular}{|llllllll|}
\hline \multicolumn{7}{|c|}{ County code and county name } \\
\hline 33 & Colbert & 71 & Jackson & 83 & Limestone & 103 & Morgan \\
49 & DeKalb & 77 & Lauderdale & 89 & Madison & & \\
59 & Franklin & 79 & Lawrence & 95 & Marshall & & \\
\end{tabular}




\begin{tabular}{|c|c|c|c|}
\hline State & State Name: $\mathrm{Al}$ & \multicolumn{2}{|c|}{ State Abbreviation: $\mathrm{AK} \quad$ Region/Station Code: 27} \\
\hline \multicolumn{2}{|c|}{ Survey Unit Code: 1} & e: Alaska & \\
\hline \multicolumn{4}{|c|}{ County code and county name } \\
\hline 13 & Aleutians East Borough & 170 & Matanuska-Susitna Borough \\
\hline 16 & Aleutians West Census Area & 180 & Nome Census Area \\
\hline 20 & Anchorage Borough & 185 & North Slope Borough \\
\hline 50 & Bethel Census Area & 188 & Northwest Arctic Borough \\
\hline 60 & Bristol Bay Borough & 201 & Prince of Wales-Outer Ketchikan Census Area \\
\hline 68 & Denali Borough & 220 & Sitka Borough \\
\hline 70 & Dillingham Census Area & 232 & Skagway-Hoonah-Angoon Census Area \\
\hline 90 & Fairbanks North Star Borough & 240 & Southeast Fairbanks Census Area \\
\hline 100 & Haines Borough & 261 & Valdez-Cordova Census Area \\
\hline 110 & Juneau Borough & 270 & Wade Hampton Census Area \\
\hline 122 & Kenai Peninsula Borough & 280 & Wrangell-Petersburg Census Area \\
\hline 130 & Ketchikan Gateway Borough & 282 & Yakutat Borough \\
\hline 150 & Kodiak Island Borough & 290 & Yukon-Koyukuk Census Area \\
\hline 164 & Lake and Peninsula Borough & & \\
\hline
\end{tabular}

\begin{tabular}{|c|c|c|c|}
\hline State Code: 4 & State Name: Arizona & State Abbreviation: $\mathrm{AZ}$ & Region/Station Code: 22 \\
\hline Survey Unit Code: 1 & Survey Unit Name: & Southern & \\
\hline \multicolumn{4}{|c|}{ County code and county name } \\
\hline Cochise & $12 \mathrm{La} \mathrm{Paz}$ & Pinal & \\
\hline 9 Graham & 13 Maricopa & Santa Cruz & \\
\hline 11 Greenlee & 19 Pima & Yuma & \\
\hline
\end{tabular}

Survey Unit Code: 2 Survey Unit Name: Northern

County code and county name

$\begin{array}{llclcl}1 & \text { Apache } & 7 & \text { Gila } & 17 & \text { Navajo } \\ 5 & \text { Coconino } & 15 & \text { Mohave } & 25 & \text { Yavapai }\end{array}$




\begin{tabular}{|c|c|c|c|}
\hline State Code: 5 & State Name: Arkansas & State Abbreviation: $\mathrm{AR}$ & Region/Station Code: 33 \\
\hline Survey Unit Code: & Survey Unit Name: & South Delta & \\
\hline \multicolumn{4}{|c|}{ County code and county name } \\
\hline Arkansas & 69 Jefferson & 85 Lonoke & 117 Prairie \\
\hline 17 Chicot & 77 Lee & 95 Monroe & \\
\hline 41 Desha & 79 Lincoln & 107 Phillips & \\
\hline
\end{tabular}

Survey Unit Code: 2 Survey Unit Name: North Delta

\begin{tabular}{|c|c|c|c|c|}
\hline \multicolumn{5}{|c|}{ County code and county name } \\
\hline 21 Clay & 37 Cross & 75 & Lawrence & 123 St. Francis \\
\hline 31 Craighead & 55 Greene & 93 & Mississippi & 147 Woodruff \\
\hline 35 Crittenden & 67 Jackson & 111 & Poinsett & \\
\hline
\end{tabular}

Survey Unit Code: 3 Survey Unit Name: Southwest

\begin{tabular}{|clllrlll|}
\hline \multicolumn{7}{|c|}{ County code and county name } \\
\hline 3 & Ashley & 27 & Columbia & 59 & Hot Spring & 99 & Nevada \\
11 & Bradley & 39 & Dallas & 61 & Howard & 103 Ouachita \\
13 & Calhoun & 43 & Drew & 73 & Lafayette & 109 Pike \\
19 & Clark & 53 & Grant & 81 & Little River & 133 & Sevier \\
25 & Cleveland & 57 & Hempstead & 91 & Miller & 139 & Union \\
\hline
\end{tabular}

Survey Unit Code: 4 Survey Unit Name: Ouachita

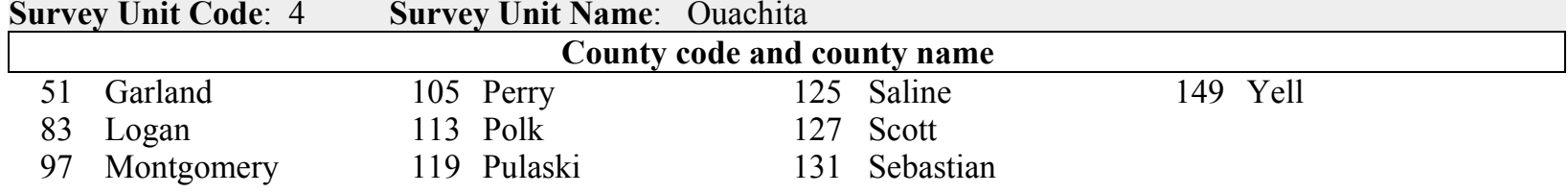

\begin{tabular}{|c|c|c|c|}
\hline \multirow[t]{2}{*}{ Survey Unit Code: 5} & \multicolumn{3}{|c|}{ Survey Unit Name: Ozark } \\
\hline & County & code and county name & \\
\hline 5 Baxter & 33 Crawford & 71 Johnson & 129 Searcy \\
\hline 7 Benton & 45 Faulkner & 87 Madison & 135 Sharp \\
\hline 9 Boone & 47 Franklin & 89 Marion & 137 Stone \\
\hline 15 Carroll & 49 Fulton & 101 Newton & 141 Van Buren \\
\hline 23 Cleburne & 63 Independence & 115 Pope & 143 Washington \\
\hline 29 Conway & 65 Izard & 121 Randolph & 145 White \\
\hline
\end{tabular}


State Code: 6 State Name: California State Abbreviation: CA Region/Station Code: 26

Survey Unit Code: 1 Survey Unit Name: North Coast

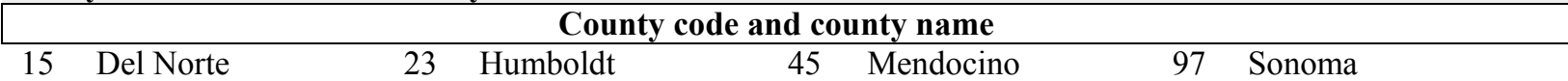

Survey Unit Code: 2 Survey Unit Name: North Interior

\begin{tabular}{|llllcl|}
\hline & & \multicolumn{4}{c|}{ County code and county name } \\
\hline 35 & Lassen & 89 & Shasta & 105 & Trinity \\
49 & Modoc & 93 & Siskiyou & &
\end{tabular}

Survey Unit Code: 3 Survey Unit Name: Sacramento

\begin{tabular}{|clclclll|}
\hline \multicolumn{7}{c|}{ County code and county name } \\
\hline 7 & Butte & 33 & Lake & 63 & Plumas & 103 & Tehama \\
11 & Colusa & 55 & Napa & 67 & Sacramento & 113 & Yolo \\
17 & El Dorado & 57 & Nevada & 91 & Sierra & 115 & Yuba \\
21 & Glenn & 61 & Placer & 101 & Sutter & &
\end{tabular}

Survey Unit Code: 4 Survey Unit Name: Central Coast

\begin{tabular}{|c|c|c|c|c|c|c|c|}
\hline \multicolumn{8}{|c|}{ County code and county name } \\
\hline 1 & Alameda & 69 & San Benito & 83 & Santa Barbara & 111 & Ventura \\
\hline 13 & Contra Costa & 75 & San Francisco & 85 & Santa Clara & & \\
\hline 41 & Marin & 79 & San Luis Obispo & 87 & Santa Cruz & & \\
\hline 53 & Monterey & 81 & San Mateo & 95 & Solano & & \\
\hline
\end{tabular}

Survey Unit Code: 5 Survey Unit Name: San Joaquin

\begin{tabular}{|clllllll|}
\hline \multicolumn{7}{|c|}{ County code and county name } \\
\hline 3 & Alpine & 29 & Kern & 47 & Merced & 107 & Tulare \\
5 & Amador & 31 & Kings & 51 & Mono & 109 & Tuolumne \\
9 & Calaveras & 39 & Madera & 77 & San Joaquin & & \\
19 & Fresno & 43 & Mariposa & 99 & Stanislaus & &
\end{tabular}

Survey Unit Code: 6 Survey Unit Name: Southern

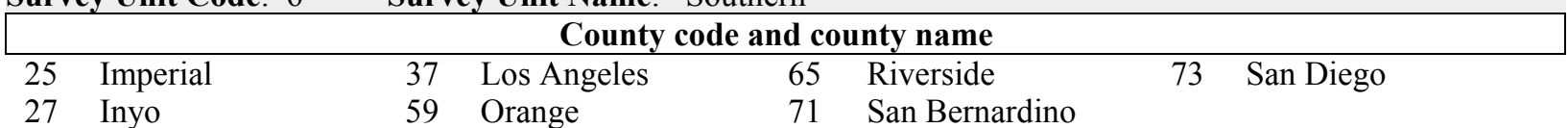




\begin{tabular}{|c|c|c|c|c|}
\hline State Code: 8 & State Name: & Colorado & State Abbreviation: $\mathrm{CO}$ & Region/Station Code: 22 \\
\hline Survey Unit Code: & Surve & y Unit Name: & Northern Front Range & \\
\hline \multicolumn{5}{|c|}{ County code and county name } \\
\hline Boulder & 39 & Elbert & Jefferson & Park \\
\hline Clear Creek & 41 & El Paso & Lake & 119 Teller \\
\hline Douglas & 47 & Gilpin & Larimer & \\
\hline
\end{tabular}

Survey Unit Code: 2 Survey Unit Name: Southern Front Range

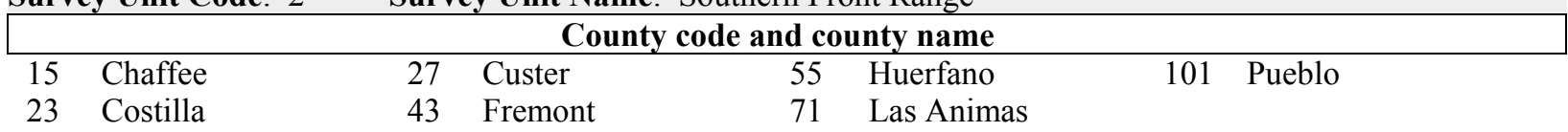

Survey Unit Code: 3 Survey Unit Name: West Central

\begin{tabular}{|clllclll|}
\hline \multicolumn{7}{c|}{ County code and county name } \\
\hline 3 & Alamosa & 51 & Gunnison & 97 & Pitkin & 111 & San Juan \\
21 & Conejos & 53 & Hinsdale & 105 & Rio Grande & 117 & Summit \\
37 & Eagle & 57 & Jackson & 107 & Routt & & \\
49 & Grand & 79 & Mineral & 109 & Saguache & &
\end{tabular}

Survey Unit Code: 4 Survey Unit Name: Western

\begin{tabular}{|clllclcl|}
\hline \multicolumn{7}{c|}{ County code and county name } \\
\hline 7 & Archuleta & 45 & Garfield & 81 & Moffat & 91 & Ouray \\
29 & Delta & 67 & La Plata & 83 & Montezuma & 103 & Rio Blanco \\
33 & Dolores & 77 & Mesa & 85 & Montrose & 113 & San Miguel \\
\hline
\end{tabular}

Survey Unit Code: 5 Survey Unit Name: Eastern

\begin{tabular}{|clrlrlrl|}
\hline \multicolumn{7}{c|}{ County code and county name } \\
\hline 1 & Adams & 25 & Crowley & 75 & Logan & 115 & Sedgwick \\
5 & Arapahoe & 31 & Denver & 87 & Morgan & 121 & Washington \\
9 & Baca & 61 & Kiowa & 89 & Otero & 123 & Weld \\
11 & Bent & 63 & Kit Carson & 95 & Phillips & 125 & Yuma \\
17 & Cheyenne & 73 & Lincoln & 99 & Prowers & &
\end{tabular}

\begin{tabular}{|c|c|c|c|c|}
\hline State Code: 9 & State Name: & Connecticut & State Abbreviation: CT & Region/Station Code: 24 \\
\hline Survey Unit Code: & Surve & y Unit Name: & Connecticut & \\
\hline \multicolumn{5}{|c|}{ County code and county name } \\
\hline Fairfield & 5 & Litchfield & New Haven & Tolland \\
\hline Hartford & 7 & Middlesex & New London & Windham \\
\hline
\end{tabular}

\begin{tabular}{|c|c|c|c|}
\hline State Code: 10 & State Name: Delaware & State Abbreviation: DE & Region/Station Code: 24 \\
\hline Survey Unit Code: & Survey Unit Name: & Delaware & \\
\hline
\end{tabular}

1 Kent $\quad 3$ New Castle $\quad 5$ Sussex

State Code: $11 \quad$ State Name: District of Columbia $\quad$ State Abbrev.: $\quad$ DC $\quad$ Region/Station Code: 24 
State Code: 12 State Name: Florida State Abbreviation: FL Region/Station Code: 33

Survey Unit Code: 1 Survey Unit Name: Northeastern

\begin{tabular}{|clclclll|}
\hline \multicolumn{7}{c|}{ County code and county name } \\
\hline 1 & Alachua & 31 & Duval & 79 & Madison & 123 & Taylor \\
3 & Baker & 35 & Flagler & 83 & Marion & 125 & Union \\
7 & Bradford & 41 & Gilchrist & 89 & Nassau & 127 & Volusia \\
19 & Clay & 47 & Hamilton & 107 & Putnam & & \\
23 & Columbia & 67 & Lafayette & 109 & St. Johns & & \\
29 & Dixie & 75 & Levy & 121 & Suwannee & &
\end{tabular}

Survey Unit Code: 2 Survey Unit Name: Northwestern

\begin{tabular}{|clllllll|}
\hline \multicolumn{70}{c|}{ County code and county name } \\
\hline 5 & Bay & 39 & Gadsden & 65 & Jefferson & 113 & Santa Rosa \\
13 & Calhoun & 45 & Gulf & 73 & Leon & 129 & Wakulla \\
33 & Escambia & 59 & Holmes & 77 & Liberty & 131 & Walton \\
37 & Franklin & 63 & Jackson & 91 & Okaloosa & 133 & Washington
\end{tabular}

Survey Unit Code: 3 Survey Unit Name: Central

\begin{tabular}{|c|c|c|c|c|c|c|c|}
\hline \multicolumn{8}{|c|}{ County code and county name } \\
\hline 9 & Brevard & 55 & Highlands & 93 & Okeechobee & 105 & Polk \\
\hline 17 & Citrus & 57 & Hillsborough & 95 & Orange & 111 & St. Lucie \\
\hline 27 & DeSoto & 61 & Indian River & 97 & Osceola & 115 & Sarasota \\
\hline 49 & Hardee & 69 & Lake & 101 & Pasco & 117 & Seminole \\
\hline 53 & Hernando & 81 & Manatee & 103 & Pinellas & 119 & Sumter \\
\hline \multicolumn{2}{|c|}{ Survey Unit Code: 4} & \multicolumn{6}{|c|}{ Survey Unit Name: Southern } \\
\hline \multicolumn{8}{|c|}{ County code and county name } \\
\hline 11 & Broward & 25 & Dade & 71 & Lee & 99 & Palm Beach \\
\hline 15 & Charlotte & 43 & Glades & 85 & Martin & & \\
\hline 21 & Collier & 51 & Hendry & 87 & Monroe & & \\
\hline
\end{tabular}




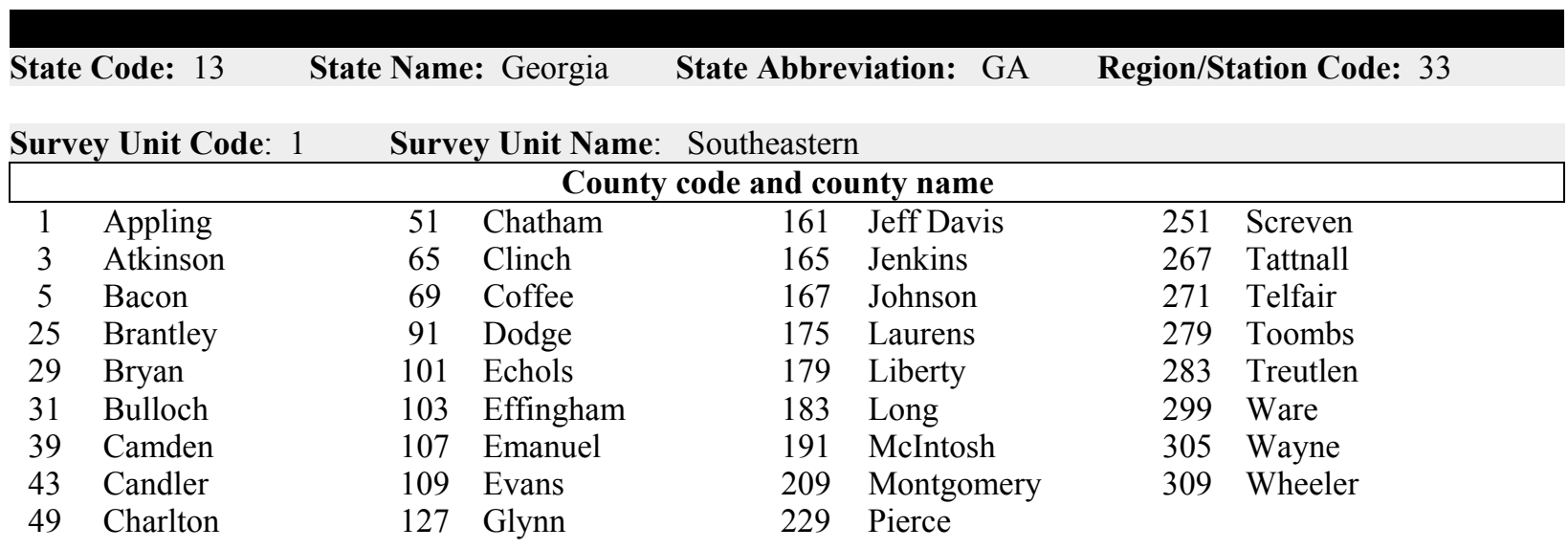

Survey Unit Code: 2 Survey Unit Name: Southwestern

\begin{tabular}{|clclllll|}
\hline \multicolumn{7}{|c|}{ County code and county name } \\
\hline 7 & Baker & 81 & Crisp & 173 & Lanier & 277 & Tift \\
17 & Ben Hill & 87 & Decatur & 185 & Lowndes & 287 & Turner \\
19 & Berrien & 93 & Dooly & 201 & Miller & 315 & Wilcox \\
27 & Brooks & 99 & Early & 205 & Mitchell & 321 & Worth \\
71 & Colquitt & 131 & Grady & 253 & Seminole & & \\
75 & Cook & 155 & Irwin & 275 & Thomas & &
\end{tabular}

Survey Unit Code: 3 Survey Unit Name: Central

\begin{tabular}{|c|c|c|c|c|c|c|c|}
\hline \multicolumn{8}{|c|}{ County code and county name } \\
\hline 9 & Baldwin & 141 & Hancock & 211 & Morgan & 265 & Taliaferro \\
\hline 21 & $\mathrm{Bibb}$ & 145 & Harris & 215 & Muscogee & 269 & Taylor \\
\hline 23 & Bleckley & 153 & Houston & 225 & Peach & 273 & Terrell \\
\hline 33 & Burke & 159 & Jasper & 231 & Pike & 289 & Twiggs \\
\hline 35 & Butts & 163 & Jefferson & 235 & Pulaski & 293 & Upson \\
\hline 37 & Calhoun & 169 & Jones & 237 & Putnam & 301 & Warren \\
\hline 53 & Chattahoochee & 171 & Lamar & 239 & Quitman & 303 & Washington \\
\hline 61 & Clay & 177 & Lee & 243 & Randolph & 307 & Webster \\
\hline 73 & Columbia & 181 & Lincoln & 245 & Richmond & 317 & Wilkes \\
\hline 79 & Crawford & 189 & McDuffie & 249 & Schley & 319 & Wilkinson \\
\hline 95 & Dougherty & 193 & Macon & 259 & Stewart & & \\
\hline 125 & Glascock & 197 & Marion & 261 & Sumter & & \\
\hline 133 & Greene & 207 & Monroe & 263 & Talbot & & \\
\hline
\end{tabular}

Survey Unit Code: 4 Survey Unit Name: North Central

\begin{tabular}{|c|c|c|c|c|c|c|c|}
\hline \multicolumn{8}{|c|}{ County code and county name } \\
\hline 11 & Banks & 97 & Douglas & 143 & Haralson & 219 & Oconee \\
\hline 13 & Barrow & 105 & Elbert & 147 & Hart & 221 & Oglethorpe \\
\hline 45 & Carroll & 113 & Fayette & 149 & Heard & 223 & Paulding \\
\hline 59 & Clarke & 117 & Forsyth & 151 & Henry & 233 & Polk \\
\hline 63 & Clayton & 119 & Franklin & 157 & Jackson & 247 & Rockdale \\
\hline 67 & Cobb & 121 & Fulton & 195 & Madison & 255 & Spalding \\
\hline 77 & Coweta & 135 & Gwinnett & 199 & Meriwether & 285 & Troup \\
\hline 89 & DeKalb & 139 & Hall & 217 & Newton & 297 & Walton \\
\hline
\end{tabular}

Georgia cont. 
Georgia cont.

\begin{tabular}{|c|c|c|c|c|c|c|c|}
\hline Surv & y Unit Code: 5 & Surv & y Unit Nam & Northern & & & \\
\hline & & & Coun & code and co & nty nams & & \\
\hline 15 & Bartow & 111 & Fannin & 213 & Murray & 295 & Walker \\
\hline 47 & Catoosa & 115 & Floyd & 227 & Pickens & 311 & White \\
\hline 55 & Chattooga & 123 & Gilmer & 241 & Rabun & 313 & Whitfield \\
\hline 57 & Cherokee & 129 & Gordon & 257 & Stephens & & \\
\hline 83 & Dade & 137 & Habersham & 281 & Towns & & \\
\hline 85 & Dawson & 187 & Lumpkin & 291 & Union & & \\
\hline
\end{tabular}

\section{State Code: 15 State Name: Hawaii State Abbreviation: HI Region/Station Code: 26}

\begin{tabular}{|llllcc|}
\hline & & \multicolumn{4}{c|}{ County code and county name } \\
\hline 1 & Hawaii & 5 & Kalawao & 9 & Maui \\
3 & Honolulu & 7 & Kauai & & \\
\hline
\end{tabular}

\begin{tabular}{|c|c|c|c|}
\hline State Code: 16 & State Name: Idaho & tate Abbreviation: ID & Region/Station Code: 22 \\
\hline Survey Unit Code: 1 & Survey Unit Name: & : Northern & \\
\hline \multicolumn{4}{|c|}{ County code and county name } \\
\hline Benewah & Clearwater & Latah & Shoshone \\
\hline 17 Bonner & Idaho & Lewis & \\
\hline 21 Boundary & Kootenai & Nez Perce & \\
\hline
\end{tabular}

Survey Unit Code: 2 Survey Unit Name: Southwestern

\begin{tabular}{|clllrlll|}
\hline \multicolumn{7}{|c|}{ County code and county name } \\
\hline 1 & Ada & 27 & Canyon & 73 & Owyhee & 87 & Washington \\
15 & Adams & Boise & 39 & Elmore & 75 & Payette & \\
\end{tabular}

Survey Unit Code: 3 Survey Unit Name: Southeastern

\begin{tabular}{|c|c|c|c|c|c|c|c|}
\hline \multicolumn{8}{|c|}{ County code and county name } \\
\hline 5 & Bannock & 25 & Camas & 43 & Fremont & 65 & Madison \\
\hline 7 & Bear Lake & 29 & Caribou & 47 & Gooding & 67 & Minidoka \\
\hline 11 & Bingham & 31 & Cassia & 51 & Jefferson & 71 & Oneida \\
\hline 13 & Blaine & 33 & Clark & 53 & Jerome & 77 & Power \\
\hline 19 & Bonneville & 37 & Custer & 59 & Lemhi & 81 & Teton \\
\hline 23 & Butte & 41 & Franklin & 63 & Lincoln & 83 & Twin Falls \\
\hline
\end{tabular}


State Code: 17

State Name: Illinois

State Abbreviation: IL

Region/Station Code: 23

Survey Unit Code: 1 Survey Unit Name: Southern

\begin{tabular}{|clclclll}
\hline \multicolumn{7}{c|}{ County code and county name } \\
\hline 3 & Alexander & 69 & Hardin & 145 & Perry & 165 & Saline \\
55 & Franklin & 77 & Jackson & 151 & Pope & 181 & Union \\
59 & Gallatin & 87 & Johnson & 153 & Pulaski & 193 & White \\
65 & Hamilton & 127 & Massac & 157 & Randolph & 199 & Williamson
\end{tabular}

Survey Unit Code: 2 Survey Unit Name: Claypan

\begin{tabular}{|c|c|c|c|c|c|c|c|}
\hline \multicolumn{8}{|c|}{ County code and county name } \\
\hline 5 & Bond & 47 & Edwards & 101 & Lawrence & 163 & St. Clair \\
\hline 13 & Calhoun & 49 & Effingham & 117 & Macoupin & 173 & Shelby \\
\hline 23 & Clark & 51 & Fayette & 119 & Madison & 185 & Wabash \\
\hline 25 & Clay & 61 & Greene & 121 & Marion & 189 & Washington \\
\hline 27 & Clinton & 79 & Jasper & 133 & Monroe & 191 & Wayne \\
\hline 33 & Crawford & 81 & Jefferson & 135 & Montgomery & & \\
\hline 35 & Cumberland & 83 & Jersey & 159 & Richland & & \\
\hline
\end{tabular}

Survey Unit Code: 3 Survey Unit Name: Prairie

\begin{tabular}{|clllllll|}
\hline \multicolumn{7}{c|}{ County code and county name } \\
\hline 1 & Adams & 53 & Ford & 105 & Livingston & 149 & Pike \\
7 & Boone & 57 & Fulton & 107 & Logan & 155 & Putnam \\
9 & Brown & 63 & Grundy & 109 & McDonough & 161 & Rock Island \\
11 & Bureau & 67 & Hancock & 111 & McHenry & 167 & Sangamon \\
15 & Carroll & 71 & Henderson & 113 & McLean & 169 & Schuyler \\
17 & Cass & 73 & Henry & 115 & Macon & 171 & Scott \\
19 & Champaign & 75 & Iroquois & 123 & Marshall & 175 & Stark \\
21 & Christian & 85 & Jo Daviess & 125 & Mason & 177 & Stephenson \\
29 & Coles & 89 & Kane & 129 & Menard & 179 & Tazewell \\
31 & Cook & 91 & Kankakee & 131 & Mercer & 183 & Vermilion \\
37 & DeKalb & 93 & Kendall & 137 & Morgan & 187 & Warren \\
39 & De Witt & 95 & Knox & 139 & Moultrie & 195 & Whiteside \\
41 & Douglas & 97 & Lake & 141 & Ogle & 197 & Will \\
43 & DuPage & 99 & La Salle & 143 & Peoria & 201 & Winnebago \\
45 & Edgar & 103 & Lee & 147 & Piatt & 203 & Woodford
\end{tabular}


State Code: 18 State Name: Indiana State Abbreviation: IN Region/Station Code: 23

Survey Unit Code: 1 Survey Unit Name: Lower Wabash

\begin{tabular}{|llclrlll|}
\hline \multicolumn{7}{c|}{ County code and county name } \\
\hline 21 & Clay & 83 & Knox & 129 & Posey & 165 & Vermillion \\
27 & Daviess & 101 & Martin & 133 & Putnam & 167 & Vigo \\
51 & Gibson & 121 & Parke & 153 & Sullivan & & \\
55 & Greene & 125 & Pike & 163 & Vanderburgh & &
\end{tabular}

Survey Unit Code: 2 Survey Unit Name: Knobs

\begin{tabular}{|llclllll|}
\hline \multicolumn{7}{|c|}{ County code and county name } \\
\hline 13 & Brown & 61 & Harrison & 117 & Orange & 173 & Warrick \\
19 & Clark & 71 & Jackson & 119 & Owen & 175 & Washington \\
25 & Crawford & 93 & Lawrence & 123 & Perry & & \\
37 & Dubois & 105 & Monroe & 143 & Scott & & \\
43 & Floyd & 109 & Morgan & 147 & Spencer & &
\end{tabular}

Survey Unit Code: 3 Survey Unit Name: Upland Flats

\begin{tabular}{|llllll|}
\hline & & \multicolumn{4}{c|}{ County code and county name } \\
\hline 29 & Dearborn & 77 & Jefferson & 137 & Ripley \\
41 & Fayette & 79 & Jennings & 155 & Switzerland \\
47 & Franklin & 115 & Ohio & 161 & Union
\end{tabular}

Survey Unit Code: 4 Survey Unit Name: Northern

\begin{tabular}{|c|c|c|c|c|c|c|c|}
\hline \multicolumn{8}{|c|}{ County code and county name } \\
\hline 1 & Adams & 45 & Fountain & 87 & Lagrange & 139 & Rush \\
\hline 3 & Allen & 49 & Fulton & 89 & Lake & 141 & St. Joseph \\
\hline 5 & Bartholomew & 53 & Grant & 91 & La Porte & 145 & Shelby \\
\hline 7 & Benton & 57 & Hamilton & 95 & Madison & 149 & Starke \\
\hline 9 & Blackford & 59 & Hancock & 97 & Marion & 151 & Steuben \\
\hline 11 & Boone & 63 & Hendricks & 99 & Marshall & 157 & Tippecanoe \\
\hline 15 & Carroll & 65 & Henry & 103 & Miami & 159 & Tipton \\
\hline 17 & Cass & 67 & Howard & 107 & Montgomery & 169 & Wabash \\
\hline 23 & Clinton & 69 & Huntington & 111 & Newton & 171 & Warren \\
\hline 31 & Decatur & 73 & Jasper & 113 & Noble & 177 & Wayne \\
\hline 33 & De Kalb & 75 & Jay & 127 & Porter & 179 & Wells \\
\hline 35 & Delaware & 81 & Johnson & 131 & Pulaski & 181 & White \\
\hline 39 & Elkhart & 85 & Kosciusko & 135 & Randolph & 183 & Whitley \\
\hline
\end{tabular}




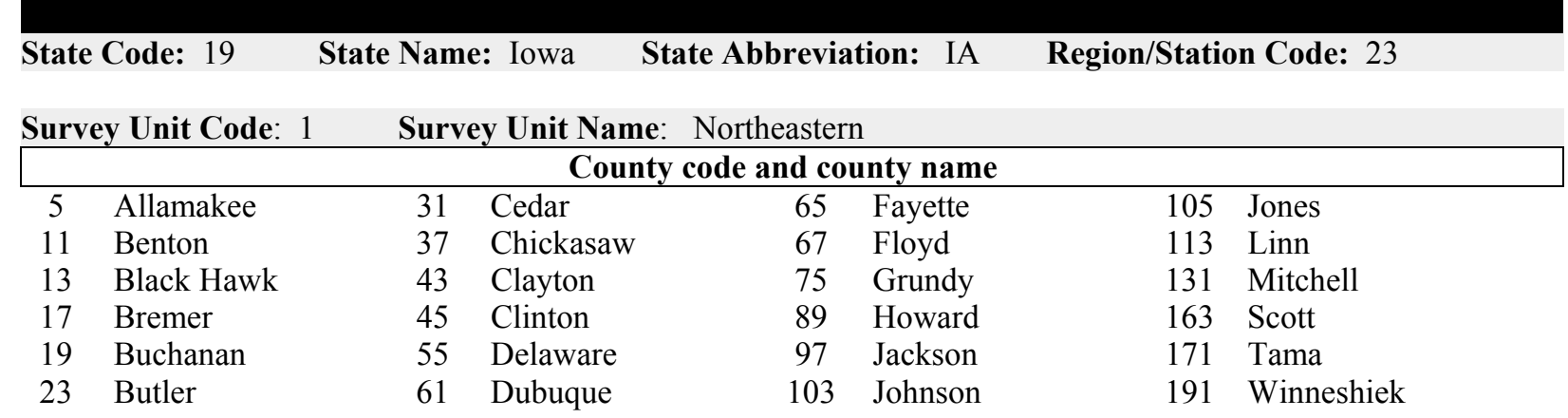

Survey Unit Code: 2 Survey Unit Name: Southeastern

\begin{tabular}{clllllll|}
\hline \multicolumn{7}{c}{ County code and county name } \\
15 & Appanoose & 83 & Hardin & 121 & Madison & 177 & Van Buren \\
39 & Clarke & 87 & Henry & 123 & Mahaska & 179 & Wapello \\
49 & Dallas & 95 & Iowa & 125 & Marion & 181 & Warren \\
51 & Davis & 99 & Jasper & 127 & Marshall & 183 & Washington \\
53 & Decatur & 101 & Jefferson & 135 & Monroe & 185 & Wayne \\
57 & Des Moines & 107 & Keokuk & 139 & Muscatine & 187 & Webster \\
77 & Guthrie & 111 & Lee & 153 & Polk & & \\
79 & Hamilton & 115 & Louisa & 157 & Poweshiek & &
\end{tabular}

Survey Unit Code: 3 Survey Unit Name: Southwestern

\begin{tabular}{|clrlrlrl|}
\hline \multicolumn{7}{|c|}{ County code and county name } \\
\hline 1 & Adair & 47 & Crawford & 133 & Monona & 165 & Shelby \\
3 & Adams & 71 & Fremont & 137 & Montgomery & 173 & Taylor \\
9 & Audubon & 73 & Greene & 145 & Page & 175 & Union \\
27 & Carroll & 85 & Harrison & 155 & Pottawattamie & 193 & Woodbury \\
29 & Cass & 129 & Mills & 159 & Ringgold & &
\end{tabular}

Survey Unit Code: 4 Survey Unit Name: Northwestern

\begin{tabular}{|c|c|c|c|c|c|c|c|}
\hline \multicolumn{8}{|c|}{ County code and county name } \\
\hline 21 & Buena Vista & 63 & Emmet & 119 & Lyon & 161 & Sac \\
\hline 25 & Calhoun & 69 & Franklin & 141 & O'Brien & 167 & Sioux \\
\hline 33 & Cerro Gordo & 81 & Hancock & 143 & Osceola & 189 & Winnebago \\
\hline 35 & Cherokee & 91 & Humboldt & 147 & Palo Alto & 195 & Worth \\
\hline 41 & Clay & 93 & Ida & 149 & Plymouth & 197 & Wright \\
\hline 59 & Dickinson & 109 & Kossuth & 151 & Pocahontas & & \\
\hline
\end{tabular}


State Code: $20 \quad$ State Name: Kansas $\quad$ State Abbreviation: KS Region/Station Code: 23

Survey Unit Code: 1 Survey Unit Name: Northeastern

\begin{tabular}{|clrlrlll}
\hline \multicolumn{7}{c}{ County code and county name } \\
\hline 5 & Atchison & 59 & Franklin & 117 & Marshall & 177 & Shawnee \\
13 & Brown & 61 & Geary & 121 & Miami & 197 & Wabaunsee \\
27 & Clay & 85 & Jackson & 131 & Nemaha & 201 & Washington \\
41 & Dickinson & 87 & Jefferson & 139 & Osage & 209 & Wyandotte \\
43 & Doniphan & 91 & Johnson & 149 & Pottawatomie & & \\
45 & Douglas & 103 & Leavenworth & 161 & Riley &
\end{tabular}

Survey Unit Code: 2 Survey Unit Name: Southeastern

\begin{tabular}{|c|c|c|c|c|c|c|c|}
\hline \multicolumn{8}{|c|}{ County code and county name } \\
\hline 1 & Allen & 21 & Cherokee & 99 & Labette & 133 & Neosho \\
\hline 3 & Anderson & 31 & Coffey & 107 & Linn & 205 & Wilson \\
\hline 11 & Bourbon & 35 & Cowley & 111 & Lyon & 207 & Woodson \\
\hline 15 & Butler & 37 & Crawford & 115 & Marion & & \\
\hline 17 & Chase & 49 & Elk & 125 & Montgomery & & \\
\hline 19 & Chautauqua & 73 & Greenwood & 127 & Morris & & \\
\hline
\end{tabular}

Survey Unit Code: 3 Survey Unit Name: Western

\begin{tabular}{|clllllll|}
\hline \multicolumn{7}{|c|}{ County code and county name } \\
9 & Barber & 71 & Greeley & 129 & Morton & 171 & Scott \\
23 & Barton & 75 & Hamilton & 135 & Ness & 173 & Sedgwick \\
25 & Clark & 77 & Harper & 137 & Norton & 175 & Seward \\
29 & Cloud & 79 & Harvey & 141 & Osborne & 179 & Sheridan \\
33 & Comanche & 81 & Haskell & 143 & Ottawa & 181 & Sherman \\
39 & Decatur & 83 & Hodgeman & 145 & Pawnee & 183 & Smith \\
47 & Edwards & 89 & Jewell & 147 & Phillips & 185 & Stafford \\
51 & Ellis & 93 & Kearny & 151 & Pratt & 187 & Stanton \\
53 & Ellsworth & 95 & Kingman & 153 & Rawlins & 189 & Stevens \\
55 & Finney & 97 & Kiowa & 155 & Reno & 191 & Sumner \\
57 & Ford & 101 & Lane & 157 & Republic & 193 & Thomas \\
63 & Gove & 105 & Lincoln & 159 & Rice & 195 & Trego \\
65 & Graham & 109 & Logan & 163 & Rooks & 199 & Wallace \\
67 & Grant & 113 & McPherson & 165 & Rush & 203 & Wichita \\
69 & Gray & 119 & Meade & 167 & Russell & &
\end{tabular}


State Code: 21

State Name: Kentucky

State Abbreviation: KY

Region/Station Code: 33

Survey Unit Code: 1 Survey Unit Name: Eastern

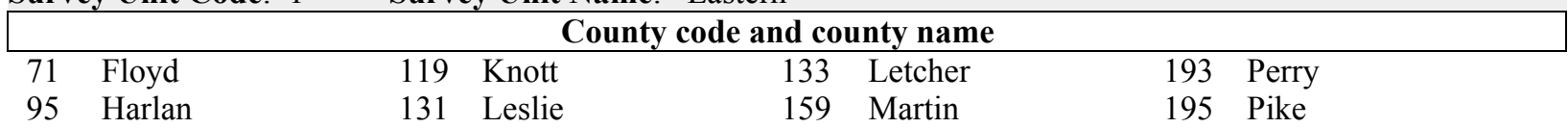

Survey Unit Code: 2 Survey Unit Name: Northern Cumberland

\begin{tabular}{|c|c|c|c|c|c|c|c|}
\hline \multicolumn{8}{|c|}{ County code and county name } \\
\hline 19 & Boyd & 115 & Johnson & 165 & Menifee & 237 & Wolfe \\
\hline 43 & Carter & 127 & Lawrence & 175 & Morgan & & \\
\hline 63 & Elliott & 135 & Lewis & 197 & Powell & & \\
\hline 89 & Greenup & 153 & Magoffin & 205 & Rowan & & \\
\hline
\end{tabular}

Survey Unit Code: 3 Survey Unit Name: Southern Cumberland

\begin{tabular}{|llclllll|}
\hline \multicolumn{7}{c|}{ County code and county name } \\
\hline 13 & Bell & 65 & Estill & 125 & Laurel & 189 & Owsley \\
25 & Breathitt & 109 & Jackson & 129 & Lee & 203 & Rockcastle \\
51 & Clay & 121 & Knox & 147 & McCreary & 235 & Whitley
\end{tabular}

Survey Unit Code: 4 Survey Unit Name: Bluegrass

\begin{tabular}{|clllllll|}
\hline & & \multicolumn{9}{c|}{ County code and county name } \\
11 & Anderson & 67 & Fayette & 113 & Jessamine & 187 & Owen \\
15 & Boone & 69 & Fleming & 117 & Kenton & 191 & Pendleton \\
17 & Bourbon & 73 & Franklin & 137 & Lincoln & 201 & Robertson \\
21 & Boyle & 77 & Gallatin & 151 & Madison & 209 & Scott \\
23 & Bracken & 79 & Garrard & 161 & Mason & 211 & Shelby \\
37 & Campbell & 81 & Grant & 167 & Mercer & 215 & Spencer \\
41 & Carroll & 97 & Harrison & 173 & Montgomery & 223 & Trimble \\
49 & Clark & 103 & Henry & 181 & Nicholas & 229 & Washington
\end{tabular}

Survey Unit Code: 5 Survey Unit Name: Pennyroyal

\begin{tabular}{|c|c|c|c|c|c|c|c|}
\hline \multicolumn{8}{|c|}{ County code and county name } \\
\hline 1 & Adair & 57 & Cumberland & 99 & Hart & 179 & Nelson \\
\hline 27 & Breckinridge & 85 & Grayson & 123 & Larue & 199 & Pulaski \\
\hline 29 & Bullitt & 87 & Green & 155 & Marion & 207 & Russell \\
\hline 45 & Casey & 91 & Hancock & 163 & Meade & 217 & Taylor \\
\hline 53 & Clinton & 93 & Hardin & 169 & Metcalfe & 231 & Wayne \\
\hline
\end{tabular}

Survey Unit Code: 6 Survey Unit Name: Western Coalfield

\begin{tabular}{|c|c|c|c|c|c|c|c|}
\hline \multicolumn{8}{|c|}{ County code and county name } \\
\hline 3 & Allen & 55 & Crittenden & 141 & Logan & 213 & Simpson \\
\hline 9 & Barren & 59 & Daviess & 149 & McLean & 219 & Todd \\
\hline 31 & Butler & 61 & Edmonson & 171 & Monroe & 225 & Union \\
\hline 33 & Caldwell & 101 & Henderson & 177 & Muhlenberg & 227 & Warren \\
\hline 47 & Christian & 107 & Hopkins & 183 & Ohio & 233 & Webster \\
\hline
\end{tabular}

Survey Unit Code: 7 Survey Unit Name: Western

\begin{tabular}{|c|c|c|c|c|c|c|c|}
\hline \multicolumn{8}{|c|}{ County code and county name } \\
\hline 7 & Ballard & 75 & Fulton & 139 & Livingston & 157 & Marshall \\
\hline 35 & Calloway & 83 & Graves & 143 & Lyon & 221 & Trigg \\
\hline 39 & Carlisle & 105 & Hickman & 145 & McCracken & & \\
\hline
\end{tabular}


State Code: 22 State Name: Louisiana State Abbreviation: LA Region/Station Code: 33

Survey Unit Code: 1 Survey Unit Name: North Delta

\begin{tabular}{|llllcl|}
\hline & & \multicolumn{4}{c|}{ County code and county name } \\
\hline 25 & Catahoula & 41 & Franklin & 83 & Richland \\
29 & Concordia & 65 & Madison & 107 & Tensas \\
35 & East Carroll & 67 & Morehouse & 123 & West Carroll
\end{tabular}

\begin{tabular}{|c|c|c|c|c|c|c|c|}
\hline \multicolumn{2}{|c|}{ Survey Unit Code: 2} & \multicolumn{6}{|c|}{ Survey Unit Name: South Delta } \\
\hline \multicolumn{8}{|c|}{ County code and county name } \\
\hline 1 & Acadia & 47 & Iberville & 77 & Pointe Coupee & 99 & St. Martin \\
\hline 5 & Ascension & 51 & Jefferson & 87 & St. Bernard & 101 & St. Mary \\
\hline 7 & Assumption & 55 & Lafayette & 89 & St. Charles & 109 & Terrebonne \\
\hline 9 & Avoyelles & 57 & Lafourche & 93 & St. James & 113 & Vermilion \\
\hline 23 & Cameron & 71 & Orleans & 95 & St. John the Baptist & 121 & West Baton Rouge \\
\hline 45 & Iberia & 75 & Plaquemines & 97 & St. Landry & 125 & West Feliciana \\
\hline
\end{tabular}

Survey Unit Code: 3 Survey Unit Name: Southwest

\begin{tabular}{|c|c|c|c|c|c|c|c|}
\hline \multicolumn{8}{|c|}{ County code and county name } \\
\hline 3 & Allen & 39 & Evangeline & 59 & La Salle & 85 & Sabine \\
\hline 11 & Beauregard & 43 & Grant & 69 & Natchitoches & 115 & Vernon \\
\hline 19 & Calcasieu & 53 & Jefferson Davis & 79 & Rapides & & \\
\hline
\end{tabular}

Survey Unit Code: 4 Survey Unit Name: Southeast

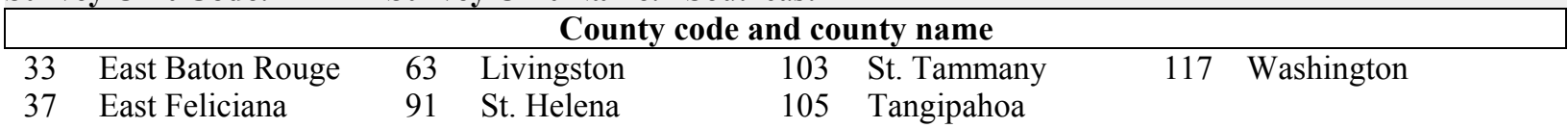

Survey Unit Code: 5 Survey Unit Name: Northwest

\begin{tabular}{|llllclll|}
\hline \multicolumn{7}{|c|}{ County code and county name } \\
\hline 13 & Bienville & 27 & Claiborne & 73 & Ouachita & 127 & Winn \\
15 & Bossier & 31 & De Soto & 81 & Red River & & \\
17 & Caddo & 49 & Jackson & 111 & Union & & \\
21 & Caldwell & 61 & Lincoln & 119 & Webster & &
\end{tabular}




State Code: $23 \quad$ State Name: Maine $\quad$ State Abbreviation: ME
\begin{tabular}{|cc|}
\hline Survey Unit Code: 1 & Survey Unit Name: Washington \\
\hline \multicolumn{2}{|c|}{ County code and county name } \\
\hline 29 & Washington \\
Survey Unit Code: 2 & Survey Unit Name: Aroostook \\
\hline & County code and county name \\
\hline
\end{tabular}

3 Aroostook

Survey Unit Code: 3 Survey Unit Name: Penobscot

\begin{tabular}{|ll|}
\hline & County code and county name \\
\hline
\end{tabular}

Survey Unit Code: 4 Survey Unit Name: Hancock

9 Hancock County code and county name

Survey Unit Code: 5 Survey Unit Name: Piscataquis

\begin{tabular}{|ll|}
\hline & County code and county name \\
\hline
\end{tabular}

Survey Unit Code: $6 \quad$ Survey Unit Name: Capitol Region

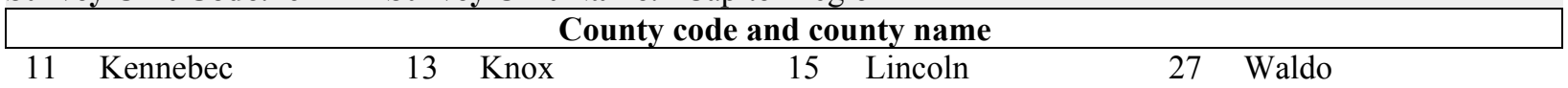

Survey Unit Code: 7 Survey Unit Name: Somerset

County code and county name

25 Somerset

Survey Unit Code: 8 Survey Unit Name: Casco Bay

County code and county name

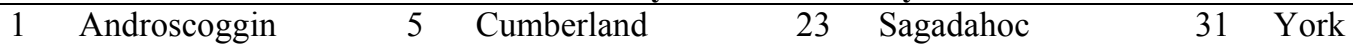

Survey Unit Code: 9 Survey Unit Name: Western Maine

County code and county name

$7 \quad$ Franklin $\quad 17$ Oxford 


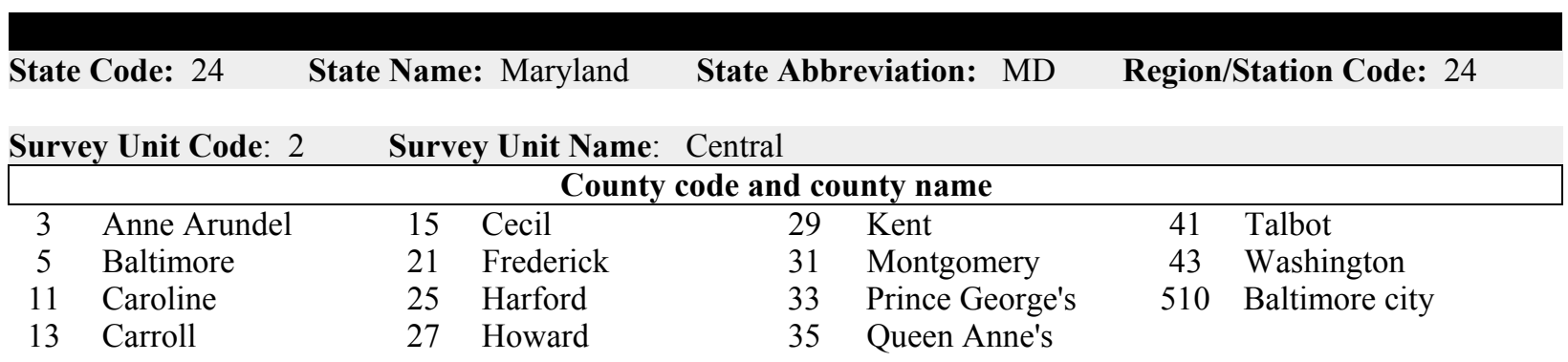

Survey Unit Code: 3 Survey Unit Name: Southern

\begin{tabular}{|llllll|}
\hline & & \multicolumn{4}{c|}{ County code and county name } \\
\hline 09 & Calvert & 17 & Charles & 37 & St. Mary's
\end{tabular}

Survey Unit Code: 4 Survey Unit Name: Lower Eastern Shore

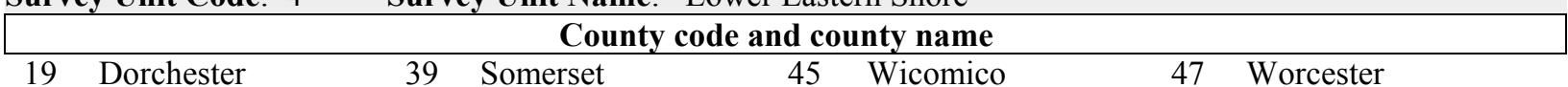

Survey Unit Code: 5 Survey Unit Name: Western

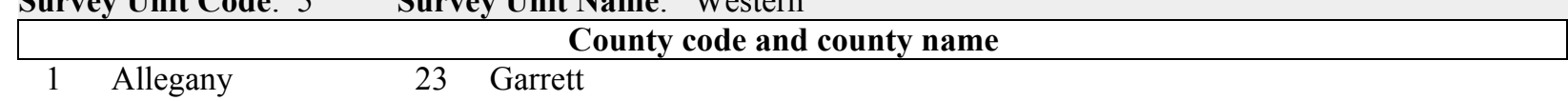

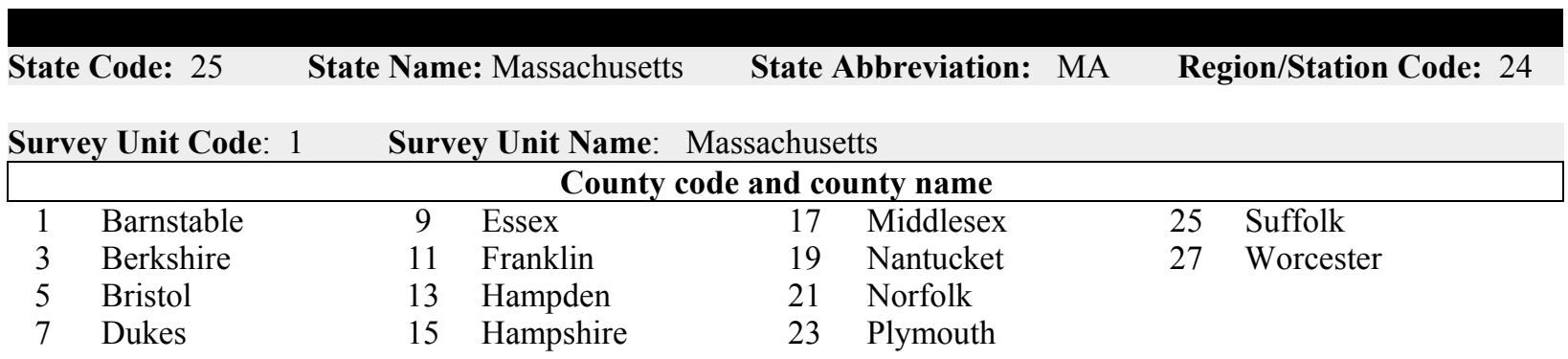


State Code: 26

State Name: Michigan

State Abbreviation: MI

Region/Station Code: 23

Survey Unit Code: 1 Survey Unit Name: Eastern Upper Peninsula

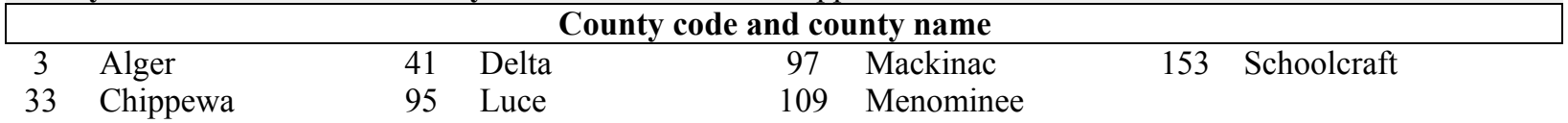

Survey Unit Code: 2 Survey Unit Name: Western Upper Peninsula

\begin{tabular}{|llllllll|}
\hline \multicolumn{7}{|c|}{ County code and county name } \\
\hline 13 & Baraga & 53 & Gogebic & 71 & Iron & 103 & Marquette \\
43 & Dickinson & 61 & Houghton & 83 & Keweenaw & 131 & Ontonagon
\end{tabular}

Survey Unit Code: 3 Survey Unit Name: Northern Lower Peninsula

\begin{tabular}{|clllllll|}
\hline \multicolumn{7}{|c|}{ County code and county name } \\
\hline 1 & Alcona & 39 & Crawford & 101 & Manistee & 133 & Osceola \\
9 & Alpena & 47 & Emmet & 105 & Mason & 135 & Oscoda \\
11 & Arenac & 51 & Gladwin & 107 & Mecosta & 137 & Otsego \\
17 & Bay & 55 & Grand Traverse & 111 & Midland & 141 & Presque Isle \\
19 & Benzie & 69 & Iosco & 113 & Missaukee & 143 & Roscommon \\
29 & Charlevoix & 73 & Isabella & 119 & Montmorency & 165 & Wexford \\
31 & Cheboygan & 79 & Kalkaska & 123 & Newaygo & & \\
35 & Clare & 85 & Lake & 127 & Oceana & &
\end{tabular}

Survey Unit Code: 4 Survey Unit Name: Southern Lower Peninsula

\begin{tabular}{|c|c|c|c|c|c|c|c|}
\hline \multicolumn{8}{|c|}{ County code and county name } \\
\hline 5 & Allegan & 57 & Gratiot & 91 & Lenawee & 147 & St. Clair \\
\hline 15 & Barry & 59 & Hillsdale & 93 & Livingston & 149 & St. Joseph \\
\hline 21 & Berrien & 63 & Huron & 99 & Macomb & 151 & Sanilac \\
\hline 23 & Branch & 65 & Ingham & 115 & Monroe & 155 & Shiawassee \\
\hline 25 & Calhoun & 67 & Ionia & 117 & Montcalm & 157 & Tuscola \\
\hline 27 & Cass & 75 & Jackson & 121 & Muskegon & 159 & Van Buren \\
\hline 37 & Clinton & 77 & Kalamazoo & 125 & Oakland & 161 & Washtenaw \\
\hline 45 & Eaton & 81 & Kent & 139 & Ottawa & 163 & Wayne \\
\hline 49 & Genesee & 87 & Lapeer & 145 & Saginaw & & \\
\hline
\end{tabular}




\begin{tabular}{|c|c|c|c|}
\hline State Code: 27 & State Name: Minnesota & State Abbreviation: $\mathrm{MN}$ & Region/Station Code: 23 \\
\hline Survey Unit Code: 1 & Survey Unit Name: & Aspen-Birch & \\
\hline \multicolumn{4}{|c|}{ County code and county name } \\
\hline Carlton & Koochiching & 137 St. Louis & \\
\hline Cook & Lake & & \\
\hline
\end{tabular}

Survey Unit Code: 2 Survey Unit Name: Northern Pine

\begin{tabular}{|llllllll|}
\hline \multicolumn{7}{c|}{ County code and county name } \\
\hline 1 & Aitkin & 21 & Cass & 57 & Hubbard & 87 & Mahnomen \\
5 & Becker & 29 & Clearwater & 61 & Itasca & 135 & Roseau \\
7 & Beltrami & 35 & Crow Wing & 77 & Lake of the Woods & 159 & Wadena
\end{tabular}

Survey Unit Code: 3 Survey Unit Name: Central Hardwood

\begin{tabular}{|clclclll}
\hline \multicolumn{7}{|c|}{ County code and county name } \\
\hline 3 & Anoka & 49 & Goodhue & 97 & Morrison & 141 & Sherburne \\
9 & Benton & 53 & Hennepin & 109 & Olmsted & 145 & Stearns \\
19 & Carver & 55 & Houston & 111 & Otter Tail & 153 & Todd \\
25 & Chisago & 59 & Isanti & 115 & Pine & 157 & Wabasha \\
37 & Dakota & 65 & Kanabec & 123 & Ramsey & 163 & Washington \\
41 & Douglas & 79 & Le Sueur & 131 & Rice & 169 & Winona \\
45 & Fillmore & 95 & Mille Lacs & 139 & Scott & 171 & Wright
\end{tabular}

Survey Unit Code: 4 Survey Unit Name: Prairie

\begin{tabular}{|c|c|c|c|c|c|c|c|}
\hline \multicolumn{8}{|c|}{ County code and county name } \\
\hline 11 & Big Stone & 67 & Kandiyohi & 103 & Nicollet & 143 & Sibley \\
\hline 13 & Blue Earth & 69 & Kittson & 105 & Nobles & 147 & Steele \\
\hline 15 & Brown & 73 & Lac qui Parle & 107 & Norman & 149 & Stevens \\
\hline 23 & Chippewa & 81 & Lincoln & 113 & Pennington & 151 & Swift \\
\hline 27 & Clay & 83 & Lyon & 117 & Pipestone & 155 & Traverse \\
\hline 33 & Cottonwood & 85 & McLeod & 119 & Polk & 161 & Waseca \\
\hline 39 & Dodge & 89 & Marshall & 121 & Pope & 165 & Watonwan \\
\hline 43 & Faribault & 91 & Martin & 125 & Red Lake & 167 & Wilkin \\
\hline 47 & Freeborn & 93 & Meeker & 127 & Redwood & 173 & Yellow Medicine \\
\hline 51 & Grant & 99 & Mower & 129 & Renville & & \\
\hline 63 & Jackson & 101 & Murray & 133 & Rock & & \\
\hline
\end{tabular}




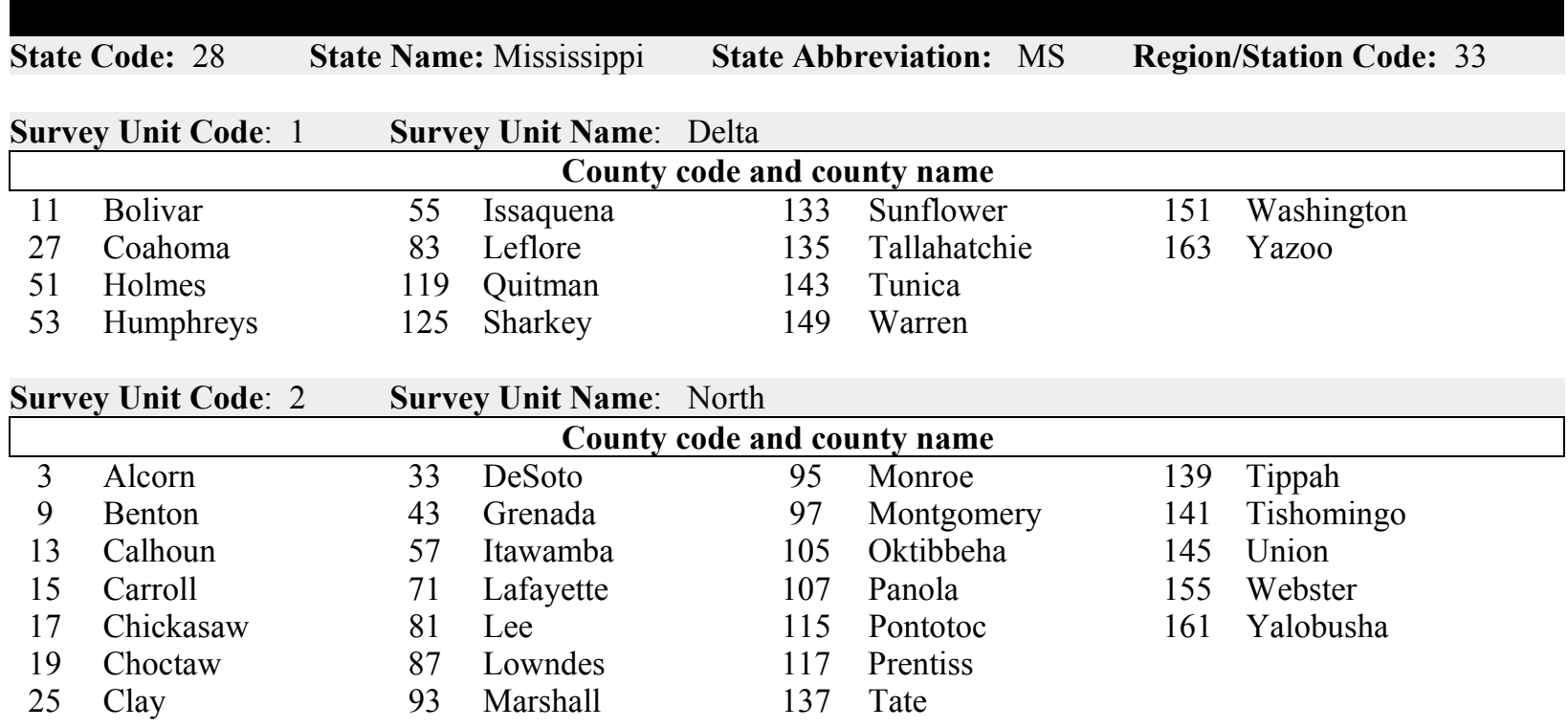

Survey Unit Code: 3 Survey Unit Name: Central

\begin{tabular}{|clclclll}
\hline \multicolumn{7}{|c|}{ County code and county name } \\
\hline 7 & Attala & 75 & Lauderdale & 103 & Noxubee & 129 & Smith \\
61 & Clarke & 79 & Leake & 121 & Rankin & 159 & Winston \\
69 & Kemper & 99 & Neshoba & 123 & Scott & & \\
\end{tabular}

Survey Unit Code: 4 Survey Unit Name: South

\begin{tabular}{|llllclll|}
\hline \multicolumn{7}{|c|}{ County code and county name } \\
\hline 31 & Covington & 47 & Harrison & 77 & Lawrence & 147 & Walthall \\
35 & Forrest & 59 & Jackson & 91 & Marion & 153 & Wayne \\
39 & George & 65 & Jefferson Davis & 109 & Pearl River & & \\
41 & Greene & 67 & Jones & 111 & Perry & & \\
45 & Hancock & 73 & Lamar & 131 & Stone & &
\end{tabular}

Survey Unit Code: 5 Survey Unit Name: Southwest

\begin{tabular}{|clllllll|}
\hline \multicolumn{7}{|c|}{ County code and county name } \\
\hline 1 & Adams & 29 & Copiah & 63 & Jefferson & 113 & Pike \\
5 & Amite & 37 & Franklin & 85 & Lincoln & 157 & Wilkinson \\
21 & Claiborne & 49 & Hinds & 89 & Madison & &
\end{tabular}


State Code: $29 \quad$ State Name: Missouri $\quad$ State Abbreviation: $\mathrm{MO}$ Region/Station Code: 23

Survey Unit Code: 1 Survey Unit Name: Eastern Ozarks

\begin{tabular}{|llclclll|}
\hline \multicolumn{7}{|c|}{ County code and county name } \\
\hline 17 & Bollinger & 65 & Dent & 179 & Reynolds & 221 & Washington \\
23 & Butler & 93 & Iron & 181 & Ripley & 223 & Wayne \\
35 & Carter & 123 & Madison & 187 & St. Francois & & \\
55 & Crawford & 149 & Oregon & 203 & Shannon & &
\end{tabular}

Survey Unit Code: 2 Survey Unit Name: Southwestern Ozarks

\begin{tabular}{|clclllll}
\hline \multicolumn{7}{c|}{ County code and county name } \\
\hline 9 & Barry & 91 & Howell & 153 & Ozark & 215 & Texas \\
43 & Christian & 119 & McDonald & 209 & Stone & 225 & Webster \\
67 & Douglas & 145 & Newton & 213 & Taney & 229 & Wright
\end{tabular}

Survey Unit Code: 3 Survey Unit Name: Northwestern Ozarks

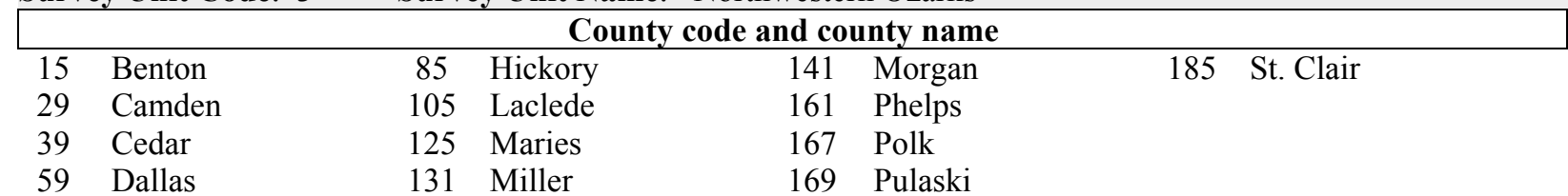

Survey Unit Code: 4 Survey Unit Name: Prairie

\begin{tabular}{|c|c|c|c|c|c|c|c|}
\hline \multicolumn{8}{|c|}{ County code and county name } \\
\hline 1 & Adair & 53 & Cooper & 107 & Lafayette & 171 & Putnam \\
\hline 3 & Andrew & 57 & Dade & 109 & Lawrence & 173 & Ralls \\
\hline 5 & Atchison & 61 & Daviess & 111 & Lewis & 175 & Randolph \\
\hline 7 & Audrain & 63 & DeKalb & 113 & Lincoln & 177 & Ray \\
\hline 11 & Barton & 75 & Gentry & 115 & Linn & 195 & Saline \\
\hline 13 & Bates & 77 & Greene & 117 & Livingston & 197 & Schuyler \\
\hline 21 & Buchanan & 79 & Grundy & 121 & Macon & 199 & Scotland \\
\hline 25 & Caldwell & 81 & Harrison & 127 & Marion & 205 & Shelby \\
\hline 33 & Carroll & 83 & Henry & 129 & Mercer & 211 & Sullivan \\
\hline 37 & Cass & 87 & Holt & 137 & Monroe & 217 & Vernon \\
\hline 41 & Chariton & 95 & Jackson & 147 & Nodaway & 227 & Worth \\
\hline 45 & Clark & 97 & Jasper & 159 & Pettis & & \\
\hline 47 & Clay & 101 & Johnson & 163 & Pike & & \\
\hline 49 & Clinton & 103 & Knox & 165 & Platte & & \\
\hline
\end{tabular}

Survey Unit Code: 5 Survey Unit Name: Riverborder

\begin{tabular}{|c|c|c|c|c|c|c|c|}
\hline \multicolumn{8}{|c|}{ County code and county name } \\
\hline 19 & Boone & 73 & Gasconade & 143 & New Madrid & 189 & St. Louis \\
\hline 27 & Callaway & 89 & Howard & 151 & Osage & 201 & Scott \\
\hline 31 & Cape Girardeau & 99 & Jefferson & 155 & Pemiscot & 207 & Stoddard \\
\hline 51 & Cole & 133 & Mississippi & 157 & Perry & 219 & Warren \\
\hline 69 & Dunklin & 135 & Moniteau & 183 & St. Charles & 510 & St. Louis city \\
\hline 71 & Franklin & 139 & Montgomery & 186 & Ste. Genevieve & & \\
\hline
\end{tabular}




\begin{tabular}{|c|c|c|c|c|c|c|c|}
\hline \multicolumn{2}{|c|}{ State Code: 30} & \multicolumn{2}{|c|}{ State Name: Montana } & \multicolumn{2}{|c|}{ State Abbreviation: $\mathrm{MT}$} & \multicolumn{2}{|c|}{ Region/Station Code: 22} \\
\hline \multicolumn{2}{|c|}{ Survey Unit Code: 1} & \multicolumn{4}{|c|}{ Survey Unit Name: Northwestern } & & \\
\hline \multicolumn{8}{|c|}{ County code and county name } \\
\hline 29 & Flathead & 47 & Lake & 53 & Lincoln & 89 & Sanders \\
\hline \multicolumn{2}{|c|}{ Survey Unit Code: 2} & \multicolumn{4}{|c|}{ Survey Unit Name: Eastern } & & \\
\hline \multicolumn{8}{|c|}{ County code and county name } \\
\hline 3 & Big Horn & 27 & Fergus & 71 & Phillips & 95 & Stillwater \\
\hline 5 & Blaine & 33 & Garfield & 73 & Pondera & 97 & Sweet Grass \\
\hline 9 & Carbon & 35 & Glacier & 75 & Powder River & 99 & Teton \\
\hline 11 & Carter & 37 & Golden Valley & 79 & Prairie & 101 & Toole \\
\hline 15 & Chouteau & 41 & Hill & 83 & Richland & 103 & Treasure \\
\hline 17 & Custer & 51 & Liberty & 85 & Roosevelt & 105 & Valley \\
\hline 19 & Daniels & 55 & McCone & 87 & Rosebud & 109 & Wibaux \\
\hline 21 & Dawson & 65 & Musselshell & 91 & Sheridan & 111 & Yellowstone \\
\hline 25 & Fallon & 69 & Petroleum & & & & \\
\hline
\end{tabular}

Survey Unit Code: 3 Survey Unit Name: Western

\begin{tabular}{|llllllll}
\hline \multicolumn{7}{|c|}{ County code and county name } \\
\hline 39 & Granite & 61 & Mineral & 63 & Missoula & 81 & Ravalli
\end{tabular}

Survey Unit Code: 4 Survey Unit Name: West Central

\begin{tabular}{|clllllll|}
\hline \multicolumn{7}{|c|}{ County code and county name } \\
\hline 7 & Broadwater & 43 & Jefferson & 49 & Lewis and Clark & 77 & Powell \\
13 & Cascade & 45 & Judith Basin & 59 & Meagher & 107 & Wheatland
\end{tabular}

Survey Unit Code: 5 Survey Unit Name: Southwestern

\begin{tabular}{|cccccc|}
\hline & & \multicolumn{4}{c|}{ County code and county name } \\
\hline 1 & Beaverhead & 31 & Gallatin & 67 & Park \\
23 & Deer Lodge & 57 & Madison & 93 & Silver Bow \\
\hline
\end{tabular}


State Code: $31 \quad$ State Name: Nebraska $\quad$ State Abbreviation: NE $\quad$ Region/Station Code: 23

Survey Unit Code: 1 Survey Unit Name: Eastern

\begin{tabular}{|c|c|c|c|c|c|c|c|}
\hline \multicolumn{8}{|c|}{ County code and county name } \\
\hline 1 & Adams & 55 & Douglas & 99 & Kearney & 151 & Saline \\
\hline 11 & Boone & 59 & Fillmore & 109 & Lancaster & 153 & Sarpy \\
\hline 19 & Buffalo & 61 & Franklin & 119 & Madison & 155 & Saunders \\
\hline 21 & Burt & 63 & Frontier & 121 & Merrick & 159 & Seward \\
\hline 23 & Butler & 65 & Furnas & 125 & Nance & 163 & Sherman \\
\hline 25 & Cass & 67 & Gage & 127 & Nemaha & 167 & Stanton \\
\hline 27 & Cedar & 73 & Gosper & 129 & Nuckolls & 169 & Thayer \\
\hline 35 & Clay & 77 & Greeley & 131 & Otoe & 173 & Thurston \\
\hline 37 & Colfax & 79 & Hall & 133 & Pawnee & 175 & Valley \\
\hline 39 & Cuming & 81 & Hamilton & 137 & Phelps & 177 & Washington \\
\hline 41 & Custer & 83 & Harlan & 139 & Pierce & 179 & Wayne \\
\hline 43 & Dakota & 87 & Hitchcock & 141 & Platte & 181 & Webster \\
\hline 47 & Dawson & 93 & Howard & 143 & Polk & 185 & York \\
\hline 51 & Dixon & 95 & Jefferson & 145 & Red Willow & & \\
\hline 53 & Dodge & 97 & Johnson & 147 & Richardson & & \\
\hline
\end{tabular}

Survey Unit Code: 2 Survey Unit Name: Western

\begin{tabular}{|clllclll|}
\hline \multicolumn{7}{|c|}{ County code and county name } \\
\hline 3 & Antelope & 33 & Cheyenne & 91 & Hooker & 123 & Morrill \\
7 & Arthur & 45 & Dawes & 101 & Keith & 135 & Perkins \\
9 & Banner & 49 & Deuel & 103 & Keya Paha & 149 & Rock \\
13 & Box Butte & 57 & Dundy & 105 & Kimball & 157 & Scotts Bluff \\
15 & Boyd & 69 & Garden & 107 & Knox & 161 & Sheridan \\
17 & Brown & 71 & Garfield & 111 & Lincoln & 165 & Sioux \\
29 & Chase & 75 & Grant & 113 & Logan & 171 & Thomas \\
31 & Cherry & 85 & Hayes & 115 & Loup & 183 & Wheeler
\end{tabular}




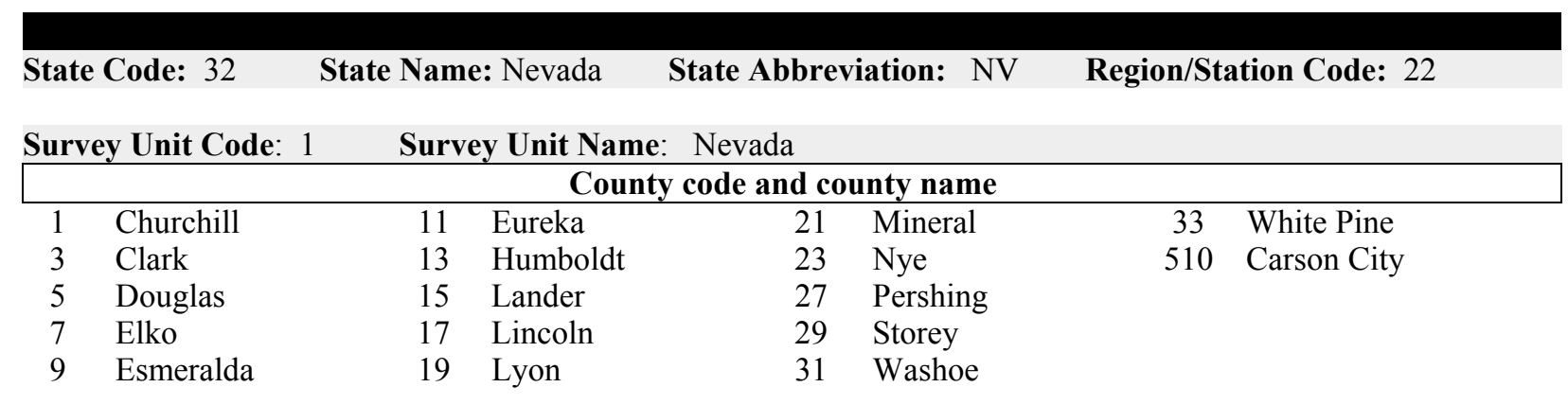

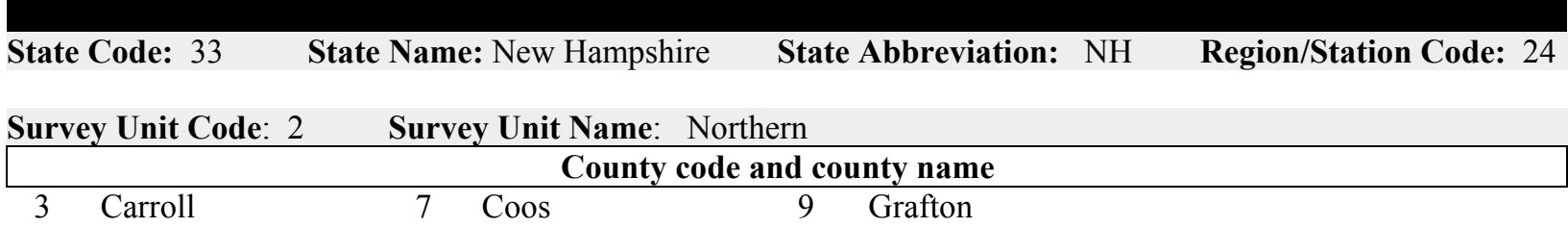

Survey Unit Code: 3 Survey Unit Name: Southern

\begin{tabular}{|llllllll|}
\hline \multicolumn{7}{|c|}{ County code and county name } \\
\hline 1 & Belknap & 11 & Hillsborough & 15 & Rockingham & 19 & Sullivan \\
5 & Cheshire & 13 & Merrimack & 17 & Strafford & &
\end{tabular}




\begin{tabular}{|c|c|c|c|c|c|c|c|}
\hline Stat & Code: 34 & State Nan & : New Jersey & State Ab & eviation: $\mathrm{NJ}$ & Regior & tation Code: 24 \\
\hline Sur & y Unit Code: & Sur & y Unit Name: & New Jersey & & & \\
\hline & & & County & code and co & nty name & & \\
\hline 1 & Atlantic & 13 & Essex & 25 & Monmouth & 37 & Sussex \\
\hline 3 & Bergen & 15 & Gloucester & 27 & Morris & 39 & Union \\
\hline 5 & Burlington & 17 & Hudson & 29 & Ocean & 41 & Warren \\
\hline 7 & Camden & 19 & Hunterdon & 31 & Passaic & & \\
\hline 9 & Cape May & 21 & Mercer & 33 & Salem & & \\
\hline 11 & Cumberland & 23 & Middlesex & 35 & Somerset & & \\
\hline
\end{tabular}

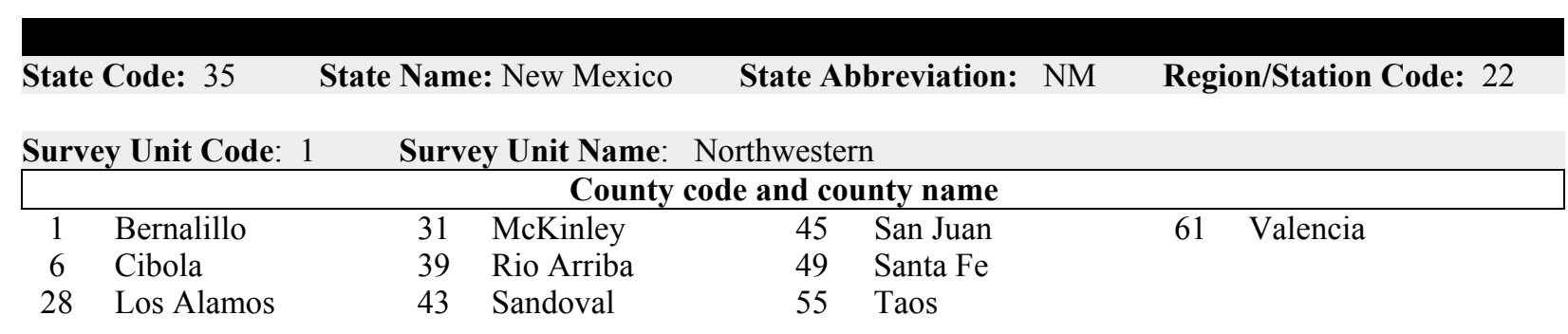

Survey Unit Code: 2 Survey Unit Name: Northeastern

\begin{tabular}{|cllllllll}
\hline \multicolumn{10}{|c|}{ County code and county name } \\
\hline 7 & Colfax & 21 & Harding & 37 & Quay & 57 & Torrance \\
19 & Guadalupe & 33 & Mora & 47 & San Miguel & 59 & Union
\end{tabular}

Survey Unit Code: 3 Survey Unit Name: Southwestern

\begin{tabular}{|clllllll|}
\hline \multicolumn{7}{|c|}{ County code and county name } \\
\hline 3 & Catron & 17 & Grant & 29 & Luna & 53 & Socorro \\
13 & Dona Ana & 23 & Hidalgo & 51 & Sierra & &
\end{tabular}

Survey Unit Code: 4 Survey Unit Name: Southeastern

\begin{tabular}{|lllllllll}
\hline \multicolumn{7}{c|}{ County code and county name } \\
\hline 5 & Chaves & 11 & De Baca & 25 & Lea & 35 & Otero \\
9 & Curry & 15 & Eddy & 27 & Lincoln & 41 & Roosevelt
\end{tabular}


State Code: 36

State Name: New York

State Abbreviation: NY

Region/Station Code: 24

Survey Unit Code: 1 Survey Unit Name: Adirondack

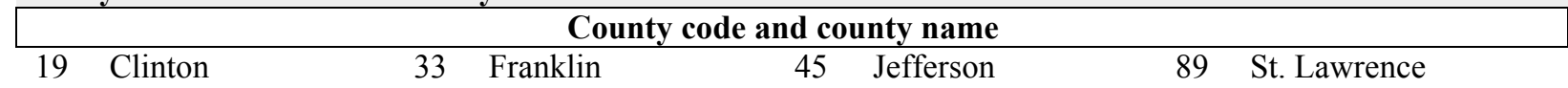

Survey Unit Code: 2 Survey Unit Name: Lake Plain

\begin{tabular}{|llllllll|}
\hline \multicolumn{7}{c|}{ County code and county name } \\
\hline 11 & Cayuga & 53 & Madison & 69 & Ontario & 117 & Wayne \\
29 & Erie & 55 & Monroe & 73 & Orleans & 121 & Wyoming \\
37 & Genesee & 63 & Niagara & 75 & Oswego & 123 & Yates \\
51 & Livingston & 67 & Onondaga & 99 & Seneca & &
\end{tabular}

Survey Unit Code: 3 Survey Unit Name: Western Adirondack

\begin{tabular}{|llllllll|}
\hline \multicolumn{7}{|c|}{ County code and county name } \\
\hline 35 & Fulton & 43 & Herkimer & 49 & Lewis & 65 & Oneida
\end{tabular}

Survey Unit Code: 4 Survey Unit Name: Eastern Adirondack

\begin{tabular}{|lllll|}
\hline & & \multicolumn{3}{c|}{ County code and county name } \\
\hline 31 & Essex & 41 & Hamilton & 113 Warren
\end{tabular}

Survey Unit Code: 5 Survey Unit Name: Southwest Highlands

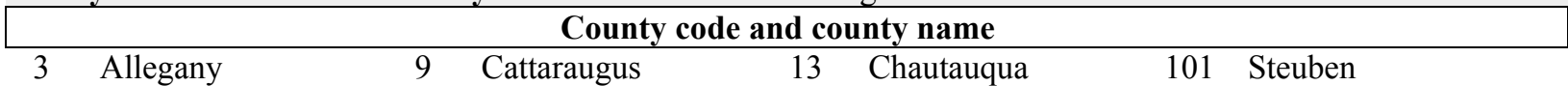

Survey Unit Code: 6 Survey Unit Name: South-Central Highlands

\begin{tabular}{|clclcl|}
\hline & & \multicolumn{4}{c|}{ County code and county name } \\
\hline 7 & Broome & 23 & Cortland & 97 & Schuyler \\
15 & Chemung & 25 & Delaware & 107 & Tioga \\
17 & Chenango & 77 & Otsego & 109 & Tompkins
\end{tabular}

Survey Unit Code: 7 Survey Unit Name: Capitol District

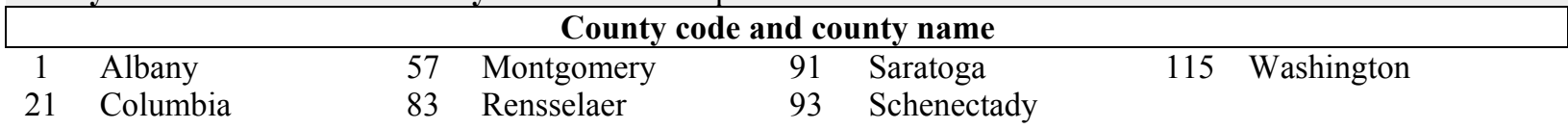

Survey Unit Code: 8 Survey Unit Name: Catskill-Lower Hudson

\begin{tabular}{|clllllll|}
\hline \multicolumn{7}{c|}{ County code and county name } \\
\hline 5 & Bronx & 59 & Nassau & 81 & Queens & 103 & Suffolk \\
27 & Dutchess & 61 & New York & 85 & Richmond & 105 & Sullivan \\
39 & Greene & 71 & Orange & 87 & Rockland & 111 & Ulster \\
47 & Kings & 79 & Putnam & 95 & Schoharie & 119 & Westchester
\end{tabular}


State Code: 37 State Name: North Carolina $\quad$ State Abbreviation: $\quad$ NC $\quad$ Region/Station Code: 33

Survey Unit Code: 1 Survey Unit Name: Southern Coastal Plain

\begin{tabular}{|c|c|c|c|c|c|c|c|}
\hline \multicolumn{8}{|c|}{ County code and county name } \\
\hline 17 & Bladen & 85 & Harnett & 125 & Moore & 163 & Sampson \\
\hline 19 & Brunswick & 93 & Hoke & 129 & New Hanover & 165 & Scotland \\
\hline 47 & Columbus & 101 & Johnston & 133 & Onslow & 191 & Wayne \\
\hline 51 & Cumberland & 103 & Jones & 141 & Pender & & \\
\hline 61 & Duplin & 105 & Lee & 153 & Richmond & & \\
\hline 79 & Greene & 107 & Lenoir & 155 & Robeson & & \\
\hline
\end{tabular}

Survey Unit Code: 2 Survey Unit Name: Northern Coastal Plain

\begin{tabular}{|llllclll|}
\hline \multicolumn{7}{c|}{ County code and county name } \\
\hline 13 & Beaufort & 53 & Currituck & 95 & Hyde & 143 & Perquimans \\
15 & Bertie & 55 & Dare & 117 & Martin & 147 & Pitt \\
29 & Camden & 65 & Edgecombe & 127 & Nash & 177 & Tyrrell \\
31 & Carteret & 73 & Gates & 131 & Northampton & 187 & Washington \\
41 & Chowan & 83 & Halifax & 137 & Pamlico & 195 & Wilson \\
49 & Craven & 91 & Hertford & 139 & Pasquotank & &
\end{tabular}

Survey Unit Code: 3 Survey Unit Name: Piedmont

\begin{tabular}{|clllllll|}
\hline \multicolumn{7}{|c|}{ County code and county name } \\
\hline 1 & Alamance & 59 & Davie & 119 & Mecklenburg & 167 & Stanly \\
3 & Alexander & 63 & Durham & 123 & Montgomery & 169 & Stokes \\
7 & Anson & 67 & Forsyth & 135 & Orange & 171 & Surry \\
25 & Cabarrus & 69 & Franklin & 145 & Person & 179 & Union \\
33 & Caswell & 71 & Gaston & 149 & Polk & 181 & Vance \\
35 & Catawba & 77 & Granville & 151 & Randolph & 183 & Wake \\
37 & Chatham & 81 & Guilford & 157 & Rockingham & 185 & Warren \\
45 & Cleveland & 97 & Iredell & 159 & Rowan & 197 & Yadkin \\
57 & Davidson & 109 & Lincoln & 161 & Rutherford & &
\end{tabular}

Survey Unit Code: 4 Survey Unit Name: Mountains

\begin{tabular}{|c|c|c|c|c|c|c|c|}
\hline \multicolumn{8}{|c|}{ County code and county name } \\
\hline 5 & Alleghany & 39 & Cherokee & 111 & McDowell & 189 & Watauga \\
\hline 9 & Ashe & 43 & Clay & 113 & Macon & 193 & Wilkes \\
\hline 11 & Avery & 75 & Graham & 115 & Madison & 199 & Yancey \\
\hline 21 & Buncombe & 87 & Haywood & 121 & Mitchell & & \\
\hline 23 & Burke & 89 & Henderson & 173 & Swain & & \\
\hline 27 & Caldwell & 99 & Jackson & 175 & Transylvania & & \\
\hline
\end{tabular}




\begin{tabular}{|c|c|c|c|c|c|c|c|}
\hline \multirow{2}{*}{\multicolumn{2}{|c|}{$\begin{array}{l}\text { State Code: } 38 \\
\text { Survey Unit Code: } 1\end{array}$}} & \multicolumn{2}{|c|}{ State Name: North Dakota } & \multicolumn{2}{|c|}{ State Abbreviation: ND } & \multicolumn{2}{|c|}{ Region/Station Code: 23} \\
\hline & & Surv & y Unit Name: & Eastern & & & \\
\hline \multicolumn{8}{|c|}{ County code and county name } \\
\hline 1 & Adams & 29 & Emmons & 57 & Mercer & 85 & Sioux \\
\hline 3 & Barnes & 31 & Foster & 59 & Morton & 87 & Slope \\
\hline 5 & Benson & 33 & Golden Valley & 61 & Mountrail & 89 & Stark \\
\hline 7 & Billings & 35 & Grand Forks & 63 & Nelson & 91 & Steele \\
\hline 9 & Bottineau & 37 & Grant & 65 & Oliver & 93 & Stutsman \\
\hline 11 & Bowman & 39 & Griggs & 67 & Pembina & 95 & Towner \\
\hline 13 & Burke & 41 & Hettinger & 69 & Pierce & 97 & Traill \\
\hline 15 & Burleigh & 43 & Kidder & 71 & Ramsey & 99 & Walsh \\
\hline 17 & Cass & 45 & LaMoure & 73 & Ransom & 101 & Ward \\
\hline 19 & Cavalier & 47 & Logan & 75 & Renville & 103 & Wells \\
\hline 21 & Dickey & 49 & McHenry & 77 & Richland & 105 & Williams \\
\hline 23 & Divide & 51 & McIntosh & 79 & Rolette & & \\
\hline 25 & Dunn & 53 & McKenzie & 81 & Sargent & & \\
\hline 27 & Eddy & 55 & McLean & 83 & Sheridan & & \\
\hline
\end{tabular}


State Code: $39 \quad$ State Name: Ohio State Abbreviation: $\mathrm{OH}$ Region/Station Code: 24

Survey Unit Code: 1 Survey Unit Name: South-Central

\begin{tabular}{|clclclll|}
\hline \multicolumn{7}{c|}{ County code and county name } \\
\hline 1 & Adams & 53 & Gallia & 87 & Lawrence & 145 & Scioto \\
25 & Brown & Clermont & 71 & Highland & 131 & Pike & \\
\end{tabular}

Survey Unit Code: 2 Survey Unit Name: Southeastern

\begin{tabular}{|clllllll|}
\hline \multicolumn{7}{|c|}{ County code and county name } \\
\hline 9 & Athens & 105 & Meigs & 127 & Perry & 167 & Washington \\
73 & Hocking & 115 & Morgan & 163 & Vinton & &
\end{tabular}

Survey Unit Code: 3 Survey Unit Name: East-Central

\begin{tabular}{|llllclll|}
\hline \multicolumn{7}{|c|}{ County code and county name } \\
\hline 13 & Belmont & 59 & Guernsey & 81 & Jefferson & 121 & Noble \\
19 & Carroll & 67 & Harrison & 111 & Monroe & 157 & Tuscarawas \\
31 & Coshocton & 75 & Holmes & 119 & Muskingum & &
\end{tabular}

Survey Unit Code: 4 Survey Unit Name: Northeastern

\begin{tabular}{|clllllll|}
\hline \multicolumn{7}{c|}{ County code and county name } \\
\hline 5 & Ashland & 55 & Geauga & 103 & Medina & 155 & Trumbull \\
7 & Ashtabula & 77 & Huron & 133 & Portage & 169 & Wayne \\
29 & Columbiana & 85 & Lake & 139 & Richland & & \\
35 & Cuyahoga & 93 & Lorain & 151 & Stark & & \\
43 & Erie & 99 & Mahoning & 153 & Summit & &
\end{tabular}

Survey Unit Code: 5 Survey Unit Name: Southwestern

\begin{tabular}{|llllllll|}
\hline \multicolumn{7}{|c|}{ County code and county name } \\
\hline 17 & Butler & 45 & Fairfield & 61 & Hamilton & 113 & Montgomery \\
23 & Clark & 47 & Fayette & 89 & Licking & 129 & Pickaway \\
27 & Clinton & 49 & Franklin & 97 & Madison & 135 & Preble \\
37 & Darke & 57 & Greene & 109 & Miami & 165 & Warren
\end{tabular}

Survey Unit Code: 6 Survey Unit Name: Northwestern

\begin{tabular}{|c|c|c|c|c|c|c|c|}
\hline \multicolumn{8}{|c|}{ County code and county name } \\
\hline 3 & Allen & 63 & Hancock & 107 & Mercer & 149 & Shelby \\
\hline 11 & Auglaize & 65 & Hardin & 117 & Morrow & 159 & Union \\
\hline 21 & Champaign & 69 & Henry & 123 & Ottawa & 161 & Van Wert \\
\hline 33 & Crawford & 83 & Knox & 125 & Paulding & 171 & Williams \\
\hline 39 & Defiance & 91 & Logan & 137 & Putnam & 173 & Wood \\
\hline 41 & Delaware & 95 & Lucas & 143 & Sandusky & 175 & Wyandot \\
\hline 51 & Fulton & 101 & Marion & 147 & Seneca & & \\
\hline
\end{tabular}


State Code: 40

State Name: Oklahoma

State Abbreviation: $\mathrm{OK}$

Region/Station Code: 33

Survey Unit Code: 1 Survey Unit Name: Southeast

\begin{tabular}{|clclclcc|}
\hline \multicolumn{7}{c|}{ County code and county name } \\
\hline 5 & Atoka & 29 & Coal & 79 & Le Flore & 127 & Pushmataha \\
13 & Bryan & 61 & Haskell & 89 & McCurtain & & \\
23 & Choctaw & 77 & Latimer & 121 & Pittsburg & &
\end{tabular}

Survey Unit Code: 2 Survey Unit Name: Northeast

\begin{tabular}{|clllclll|}
\hline \multicolumn{7}{|c|}{ County code and county name } \\
\hline 1 & Adair & 41 & Delaware & 97 & Mayes & 115 & Ottawa \\
& Cherokee & 91 & McIntosh & 101 & Muskogee & 135 & Sequoyah
\end{tabular}

Survey Unit Code: 3 Survey Unit Name: Northcentral

\begin{tabular}{|clllllll}
\hline \multicolumn{7}{c|}{ County code and county name } \\
\hline 35 & Craig & 113 & Osage & 131 & Rogers & 145 & Wagoner \\
37 & Creek & 117 & Pawnee & 143 & Tulsa & 147 & Washington \\
105 & Nowata & 119 & Payne & & & &
\end{tabular}

Survey Unit Code: 4 Survey Unit Name: Southcentral

\begin{tabular}{|c|c|c|c|c|c|c|c|}
\hline \multicolumn{8}{|c|}{ County code and county name } \\
\hline 19 & Carter & 81 & Lincoln & 95 & Marshall & 111 & Okmulgee \\
\hline 27 & Cleveland & 83 & Logan & 99 & Murray & 123 & Pontotoc \\
\hline 49 & Garvin & 85 & Love & 107 & Okfuskee & 125 & Pottawatomie \\
\hline 63 & Hughes & 87 & McClain & 109 & Oklahoma & 133 & Seminole \\
\hline 69 & Johnston & & & & & & \\
\hline
\end{tabular}

Survey Unit Code: 5 Survey Unit Name: Southwest

\begin{tabular}{|clllllll|}
\hline \multicolumn{7}{c|}{ County code and county name } \\
\hline 9 & Beckham & 33 & Cotton & 57 & Harmon & 129 & Roger Mills \\
11 & Blaine & 39 & Custer & 65 & Jackson & 137 & Stephens \\
15 & Caddo & 43 & Dewey & 67 & Jefferson & 141 Tillman \\
17 & Canadian & 51 & Grady & 73 & Kingfisher & 149 Washita \\
31 & Comanche & 55 & Greer & 75 & Kiowa & &
\end{tabular}

Survey Unit Code: 6 Survey Unit Name: High Plains

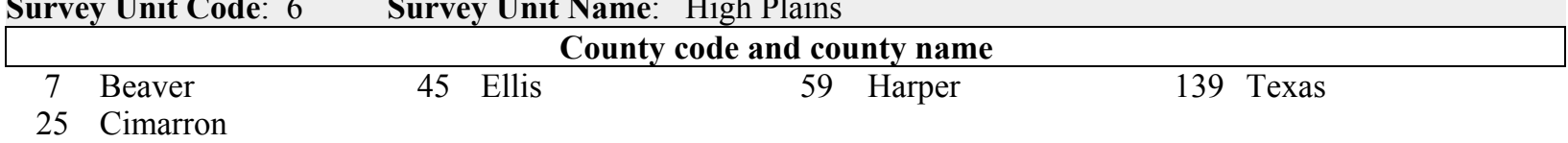

Survey Unit Code: 7 Survey Unit Name: Great Plains

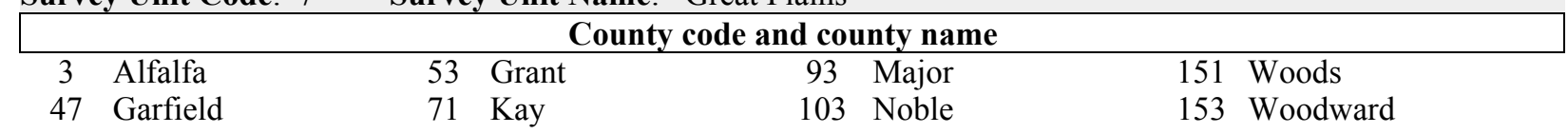




\begin{tabular}{|c|c|c|c|}
\hline State Code: 41 & State Name: Oregon & State Abbreviation: OR & Region/Station Code: 26 \\
\hline Survey Unit Code: ( & Survey Unit Name: & : Northwest & \\
\hline \multicolumn{4}{|c|}{ County code and county name } \\
\hline Clackamas & Hood River & Polk & Yamhill \\
\hline Clatsop & Marion & Tillamook & \\
\hline Columbia & Multnomah & Washington & \\
\hline
\end{tabular}

Survey Unit Code: 1 Survey Unit Name: West Central

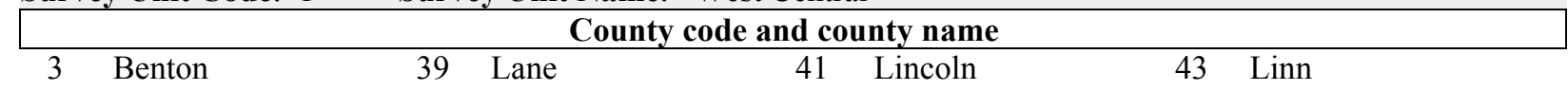

Survey Unit Code: 2 Survey Unit Name: Southwest

\begin{tabular}{|llllll|}
\hline & & \multicolumn{4}{c|}{ County code and county name } \\
\hline 11 & Coos & 19 & Douglas & 33 & Josephine \\
15 & Curry & 29 & Jackson & & \\
\hline
\end{tabular}

Survey Unit Code: 3 Survey Unit Name: Central

\begin{tabular}{|llllll|}
\hline & & \multicolumn{4}{c|}{ County code and county name } \\
\hline 13 & Crook & 31 & Jefferson & 55 & Sherman \\
17 & Deschutes & 35 & Klamath & 65 & Wasco \\
21 & Gilliam & 37 & Lake & 69 & Wheeler
\end{tabular}

Survey Unit Code: 4 Survey Unit Name: Blue Mountains

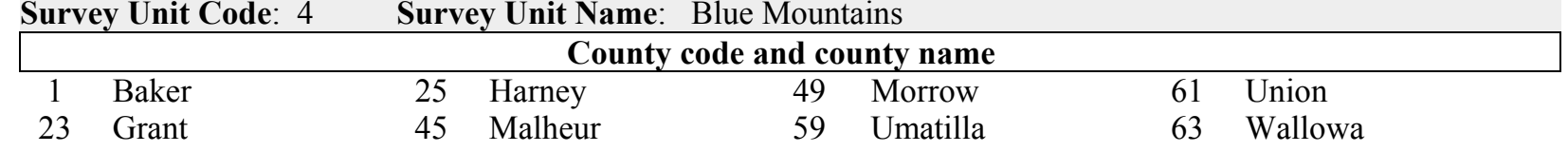




\begin{tabular}{llllll|}
\hline State Code: 42 & \multicolumn{1}{c|}{ State Name: Pennsylvania } & State Abbreviation: PA & Region/Station Code: 24 \\
Survey Unit Code: & 0 & Survey Unit Name: & South Central \\
\hline \multicolumn{7}{|c}{ County code and county name } \\
\hline 43 & Dauphin & 61 & Huntingdon & 99 & Perry \\
55 & Franklin & 67 & Juniata & 109 & Snyder \\
57 & Fulton & 87 & Mifflin & 119 & Union
\end{tabular}

Survey Unit Code: 5 Survey Unit Name: Western

\begin{tabular}{|llllllll|}
\hline \multicolumn{7}{c|}{ County code and county name } \\
\hline 3 & Allegheny & 19 & Butler & 59 & Greene & 85 & Mercer \\
5 & Armstrong & 39 & Crawford & 63 & Indiana & 125 & Washington \\
7 & Beaver & 49 & Erie & 73 & Lawrence & 129 & Westmoreland
\end{tabular}

Survey Unit Code: 6 Survey Unit Name: North Central/Allegheny

\begin{tabular}{|llllllll}
\hline \multicolumn{7}{c|}{ County code and county name } \\
\hline 23 & Cameron & 35 & Clinton & 81 & Lycoming & 117 & Tioga \\
27 & Centre & 47 & Elk & 83 & McKean & 121 & Venango \\
31 & Clarion & 53 & Forest & 105 & Potter & 123 & Warren \\
33 & Clearfield & 65 & Jefferson & 113 & Sullivan & &
\end{tabular}

Survey Unit Code: 7 Survey Unit Name: Southwestern

\begin{tabular}{|clllcl|}
\hline & & & \multicolumn{2}{c|}{ County code and county name } \\
\hline 9 & Bedford & 21 & Cambria & 111 & Somerset \\
13 & Blair & 51 & Fayette & & \\
\hline
\end{tabular}

Survey Unit Code: 8 Survey Unit Name: Northeastern/Pocono

\begin{tabular}{|c|c|c|c|c|c|c|c|}
\hline \multicolumn{8}{|c|}{ County code and county name } \\
\hline 15 & Bradford & 79 & Luzerne & 103 & Pike & 131 & Wyoming \\
\hline 25 & Carbon & 89 & Monroe & 107 & Schuylkill & & \\
\hline 37 & Columbia & 93 & Montour & 115 & Susquehanna & & \\
\hline 69 & Lackawanna & 97 & Northumberland & 127 & Wayne & & \\
\hline
\end{tabular}

Survey Unit Code: 9 Survey Unit Name: Southeastern

\begin{tabular}{|c|c|c|c|c|c|c|c|}
\hline \multicolumn{8}{|c|}{ County code and county name } \\
\hline 1 & Adams & 41 & Cumberland & 77 & Lehigh & 133 & York \\
\hline 11 & Berks & 45 & Delaware & 91 & Montgomery & & \\
\hline 17 & Bucks & 71 & Lancaster & 95 & Northampton & & \\
\hline 29 & Chester & 75 & Lebanon & 101 & Philadelphia & & \\
\hline
\end{tabular}

\begin{tabular}{l} 
State Code: $44 \quad$ State Name: Rhode Island $\quad$ State Abbreviation: RI $\quad$ Region/Station Code: 24 \\
Survey Unit Code: $1 \quad$ Survey Unit Name: Rhode Island \\
\hline \multicolumn{4}{|c|}{ County code and county name } \\
\hline
\end{tabular}

$\begin{array}{llllcr}1 & \text { Bristol } & 5 & \text { Newport } & 9 & \text { Washington } \\ 3 & \text { Kent } & 7 & \text { Providence } & & \end{array}$


State Code: $45 \quad$ State Name: South Carolina $\quad$ State Abbreviation: $\mathrm{SC}$ Region/Station Code: 33

Survey Unit Code: 1 Survey Unit Name: Southern Coastal Plain

\begin{tabular}{|llllllll|}
\hline \multicolumn{7}{c|}{ County code and county name } \\
\hline 3 & Aiken & 11 & Barnwell & 29 & Colleton & 53 & Jasper \\
5 & Allendale & 13 & Beaufort & 35 & Dorchester & 63 & Lexington \\
9 & Bamberg & 17 & Calhoun & 49 & Hampton & 75 & Orangeburg
\end{tabular}

Survey Unit Code: 2 Survey Unit Name: Northern Coastal Plain

\begin{tabular}{|c|c|c|c|c|c|c|c|}
\hline \multicolumn{8}{|c|}{ County code and county name } \\
\hline 15 & Berkeley & 31 & Darlington & 51 & Horry & 69 & Marlboro \\
\hline 19 & Charleston & 33 & Dillon & 55 & Kershaw & 79 & Richland \\
\hline 25 & Chesterfield & 41 & Florence & 61 & Lee & 85 & Sumter \\
\hline 27 & Clarendon & 43 & Georgetown & 67 & Marion & 89 & Williamsburg \\
\hline
\end{tabular}

Survey Unit Code: 3 Survey Unit Name: Piedmont

\begin{tabular}{|clllllll|}
\hline & & \multicolumn{9}{c|}{ County code and county name } \\
\hline 1 & Abbeville & 39 & Fairfield & 65 & McCormick & 83 & Spartanburg \\
21 & Anderson & 45 & Greenville & 71 & Newberry & 87 & Union \\
23 & Cherokee & 47 & Greenwood & 73 & Oconee & 91 & York \\
37 & Edgefield & 57 & Lancaster & 77 & Pickens & & \\
\end{tabular}

State Code: 46 State Name: South Dakota State Abbreviation: SD Region/Station Code: 23

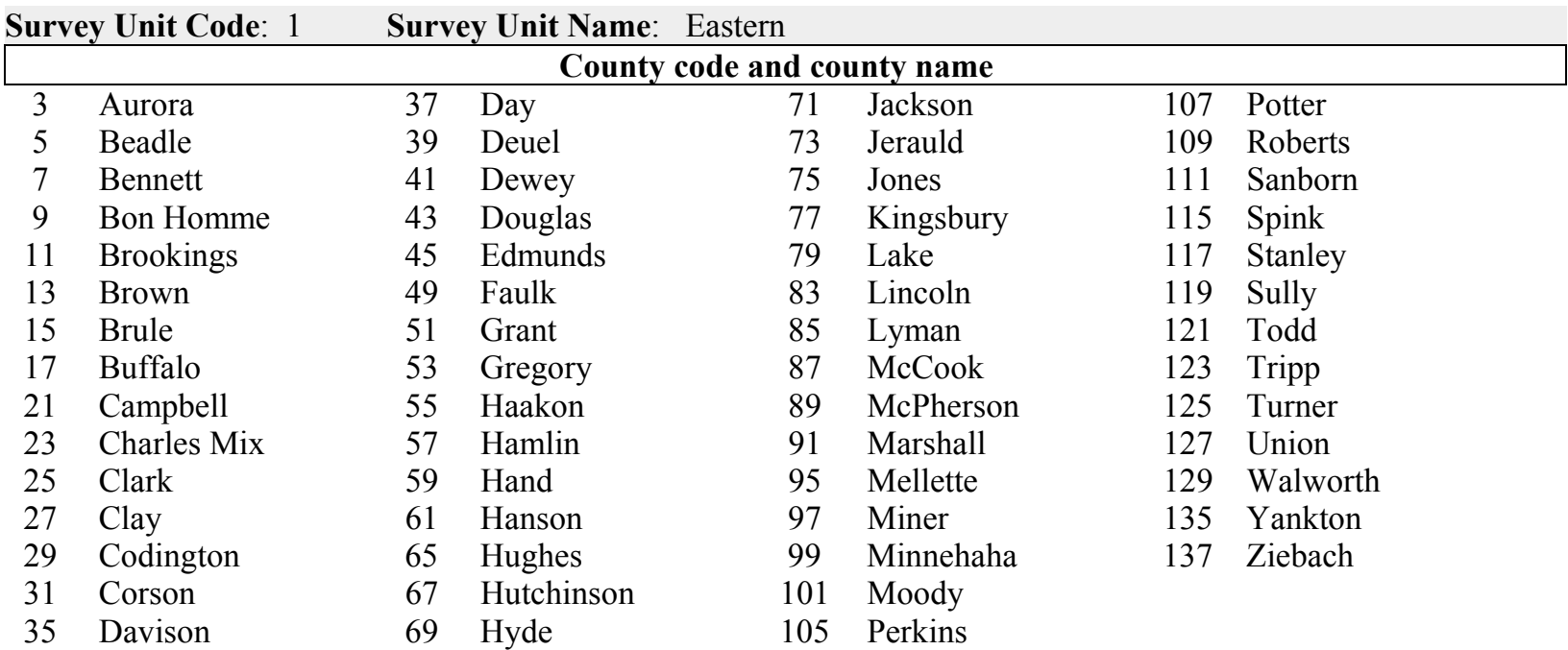

Survey Unit Code: 2 Survey Unit Name: Western

\begin{tabular}{|llllllll|}
\hline \multicolumn{10}{c|}{ County code and county name } \\
\hline 19 & Butte & 47 & Fall River & 81 & Lawrence & 103 & Pennington \\
33 & Custer & 63 & Harding & 93 & Meade & 113 & Shannon
\end{tabular}


State Code: 47

State Name: Tennessee

State Abbreviation: TN

Region/Station Code: 33

Survey Unit Code: 1 Survey Unit Name: West

\begin{tabular}{|llllclll|}
\hline \multicolumn{10}{c|}{ County code and county name } \\
\hline 17 & Carroll & 53 & Gibson & 95 & Lake & 157 & Shelby \\
23 & Chester & 69 & Hardeman & 97 & Lauderdale & 167 & Tipton \\
33 & Crockett & 75 & Haywood & 109 & McNairy & 183 & Weakley \\
45 & Dyer & 77 & Henderson & 113 & Madison & & \\
47 & Fayette & 79 & Henry & 131 & Obion & &
\end{tabular}

Survey Unit Code: 2 Survey Unit Name: West Central

\begin{tabular}{|clclclll|}
\hline \multicolumn{7}{c|}{ County code and county name } \\
\hline 5 & Benton & 81 & Hickman & 99 & Lawrence & 161 & Stewart \\
79 & Decatur & 83 & Houston & 101 & Lewis & 181 & Wayne \\
& Hardin & 85 & Humphreys & 135 & Perry & &
\end{tabular}

Survey Unit Code: 3 Survey Unit Name: Central

\begin{tabular}{|clclclll|}
\hline \multicolumn{7}{c|}{ County code and county name } \\
\hline 3 & Bedford & 41 & DeKalb & 117 & Marshall & 159 & Smith \\
15 & Cannon & 43 & Dickson & 119 & Maury & 165 & Sumner \\
21 & Cheatham & 55 & Giles & 125 & Montgomery & 169 & Trousdale \\
27 & Clay & 87 & Jackson & 127 & Moore & 187 & Williamson \\
31 & Coffee & 103 & Lincoln & 147 & Robertson & 189 & Wilson \\
37 & Davidson & 111 & Macon & 149 & Rutherford & &
\end{tabular}

Survey Unit Code: 4 Survey Unit Name: Plateau

\begin{tabular}{|c|c|c|c|c|c|c|c|}
\hline \multicolumn{8}{|c|}{ County code and county name } \\
\hline 7 & Bledsoe & 51 & Franklin & 133 & Overton & 153 & Sequatchie \\
\hline 13 & Campbell & 61 & Grundy & 137 & Pickett & 175 & Van Buren \\
\hline 35 & Cumberland & 115 & Marion & 141 & Putnam & 177 & Warren \\
\hline 49 & Fentress & 129 & Morgan & 151 & Scott & 185 & White \\
\hline
\end{tabular}

Survey Unit Code: 5 Survey Unit Name: $\quad$ East

\begin{tabular}{|clllclll|}
\hline \multicolumn{7}{|c|}{ County code and county name } \\
\hline 1 & Anderson & 59 & Greene & 93 & Knox & 145 & Roane \\
9 & Blount & 63 & Hamblen & 105 & Loudon & 155 & Sevier \\
11 & Bradley & 65 & Hamilton & 107 & McMinn & 163 & Sullivan \\
19 & Carter & 67 & Hancock & 121 & Meigs & 171 & Unicoi \\
25 & Claiborne & 73 & Hawkins & 123 & Monroe & 173 & Union \\
29 & Cocke & 89 & Jefferson & 139 & Polk & 179 & Washington \\
57 & Grainger & 91 & Johnson & 143 & Rhea & &
\end{tabular}


State Code: $48 \quad$ State Name: Texas $\quad$ State Abbreviation: $\mathrm{TX}$ Region/Station Code: 33

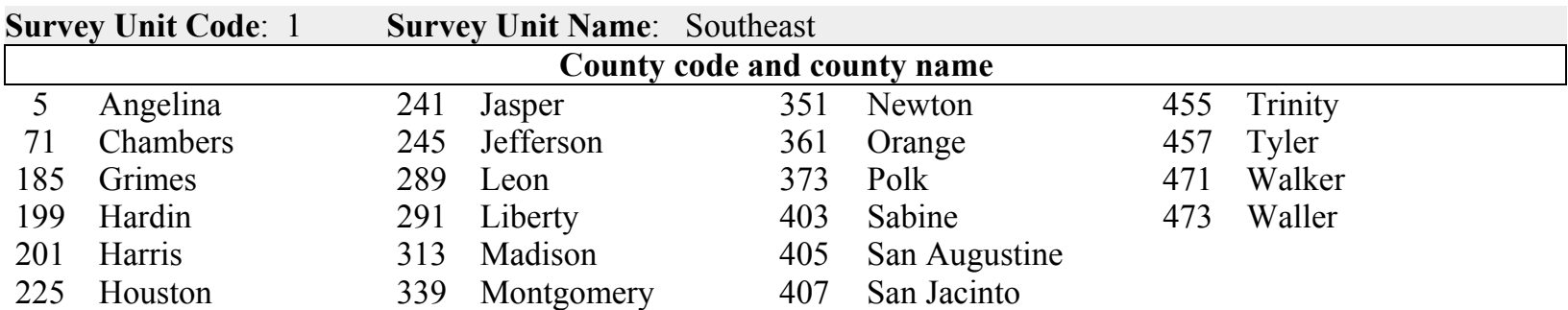

Survey Unit Code: 2 Survey Unit Name: Northeast

\begin{tabular}{|clllllll|}
\hline \multicolumn{7}{c|}{ County code and county name } \\
37 & Anderson & 183 & Gregg & 365 & Panola & 459 & Upshur \\
63 & Camp & 203 & Harrison & 387 & Red River & 467 & Van Zandt \\
67 & Cass & 213 & Henderson & 401 & Rusk & 499 & Wood \\
73 & Cherokee & 315 & Marion & 419 & Shelby & & \\
159 & Franklin & 343 & Morris & 423 & Smith & & \\
\end{tabular}

Survey Unit Code: 3 Survey Unit Name: Northcentral

\begin{tabular}{|llllll|}
\hline \multicolumn{7}{c|}{ County code and county name } \\
\hline 15 & Austin & 121 Denton & 217 Hill & 337 Montague \\
21 & Bastrop & 123 De Witt & 223 Hopkins & 349 Navarro \\
41 & Brazos & 139 Ellis & 231 Hunt & 367 Parker \\
51 & Burleson & 145 Falls & 237 Jack & 379 Rains \\
55 & Caldwell & 147 Fannin & 251 Johnson & 395 Robertson \\
77 & Clay & 149 Fayette & 257 Kaufman & 397 Rockwall \\
85 & Collin & 161 Freestone & 277 Lamar & 439 Tarrant \\
89 & Colorado & 175 Goliad & 285 Lavaca & 477 Washington \\
97 & Cooke & 177 Gonzales & 287 Lee & 497 Wise \\
113 & Dallas & 181 Grayson & 293 Limestone & 503 Young \\
119 & Delta & 187 Guadalupe & 331 Milam &
\end{tabular}

Survey Unit Code: 4 Survey Unit Name: South

\begin{tabular}{|c|c|c|c|c|c|c|c|}
\hline \multicolumn{8}{|c|}{ County code and county name } \\
\hline 7 & Aransas & 157 & Fort Bend & 273 & Kleberg & 427 & Starr \\
\hline 13 & Atascosa & 163 & Frio & 283 & La Salle & 469 & Victoria \\
\hline 25 & Bee & 167 & Galveston & 297 & Live Oak & 479 & Webb \\
\hline 39 & Brazoria & 215 & Hidalgo & 311 & McMullen & 481 & Wharton \\
\hline 47 & Brooks & 239 & Jackson & 321 & Matagorda & 489 & Willacy \\
\hline 57 & Calhoun & 247 & Jim Hogg & 323 & Maverick & 493 & Wilson \\
\hline 61 & Cameron & 249 & Jim Wells & 355 & Nueces & 505 & Zapata \\
\hline 127 & Dimmit & 255 & Karnes & 391 & Refugio & 507 & Zavala \\
\hline 131 & Duval & 261 & Kenedy & 409 & San Patricio & & \\
\hline
\end{tabular}

Texas cont. 
Texas cont.

\begin{tabular}{|llclll|} 
Survey Unit Code: 5 & \multicolumn{1}{c|}{ Survey Unit Name: Westcentral } \\
\hline \multicolumn{7}{|c}{ County code and county name } \\
\hline 19 & Bandera & 99 & Coryell & 267 Kimble & 385 Real \\
27 & Bell & 105 Crockett & 271 Kinney & 399 Runnels \\
31 & Bexar & 133 Eastland & 281 Lampasas & 411 San Saba \\
35 & Bosque & 137 Edwards & 299 Llano & 413 Schleicher \\
49 & Brown & 143 Erath & 307 McCulloch & 425 Somervell \\
53 & Burnet & 171 Gillespie & 309 McLennan & 429 Stephens \\
59 & Callahan & 193 Hamilton & 319 Mason & 435 Sutton \\
83 & Coleman & 209 Hays & 325 Medina & 453 Travis \\
91 & Comal & 221 Hood & 327 Menard & 463 Uvalde \\
93 & Comanche & 259 Kendall & 333 Mills & 465 Val Verde \\
95 & Concho & 265 Kerr & 363 Palo Pinto & 491 Williamson
\end{tabular}

\begin{tabular}{|ccccc|} 
Survey Unit Code: 6 & Survey Unit Name: & Northwest \\
\hline \multicolumn{7}{|c|}{ County code and county name } \\
\hline 3 & Andrews & 129 Donley & 235 Irion & 375 Potter \\
9 & Archer & 151 Fisher & 253 Jones & 381 Randall \\
11 & Armstrong & 153 Floyd & 263 Kent & 383 Reagan \\
17 & Bailey & 155 Foard & 269 King & 393 Roberts \\
23 & Baylor & 165 Gaines & 275 Knox & 415 Scurry \\
33 & Borden & 169 Garza & 279 Lamb & 417 Shackelford \\
45 & Briscoe & 173 Glasscock & 295 Lipscomb & 421 Sherman \\
65 & Carson & 179 Gray & 303 Lubbock & 431 Sterling \\
69 & Castro & 189 Hale & 305 Lynn & 433 Stonewall \\
75 & Childress & 191 Hall & 317 Martin & 437 Swisher \\
79 & Cochran & 195 Hansford & 329 Midland & 441 Taylor \\
81 & Coke & 197 Hardeman & 335 Mitchell & 445 Terry \\
87 & Collingsworth & 205 Hartley & 341 Moore & 447 Throckmorton \\
101 & Cottle & 207 Haskell & 345 Motley & 451 Tom Green \\
107 & Crosby & 211 Hemphill & 353 Nolan & 483 Wheeler \\
111 & Dallam & 219 Hockley & 357 Ochiltree & 485 Wichita \\
115 & Dawson & 227 Howard & 359 Oldham & 487 Wilbarger \\
117 & Deaf Smith & 233 Hutchinson & 369 Parmer & 501 Yoakum \\
125 & Dickens & & &
\end{tabular}

Survey Unit Code: 7 Survey Unit Name: West

\begin{tabular}{|c|c|c|c|c|c|c|}
\hline \multicolumn{7}{|c|}{ County code and county name } \\
\hline 43 & Brewster & 141 El Paso & 371 & Pecos & 461 & Upton \\
\hline 103 & Crane & 229 Hudsbeth & 377 & Presidio & 475 & Ward \\
\hline 109 & Culberson & 243 Jeff Davis & 389 & Reeves & 495 & Winkler \\
\hline 135 & Ector & 301 Loving & 443 & Terrell & & \\
\hline
\end{tabular}




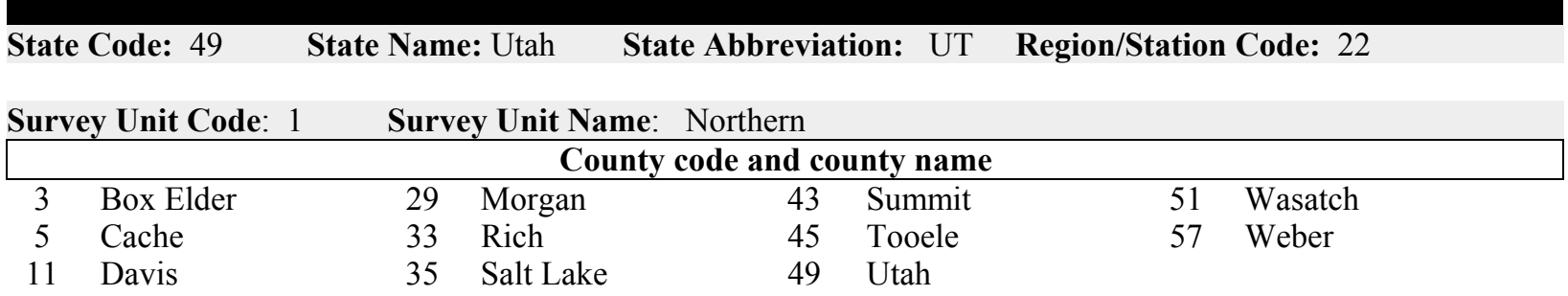

Survey Unit Code: 2 Survey Unit Name: Uinta

\begin{tabular}{|lllll|}
\hline & & \multicolumn{3}{c|}{ County code and county name } \\
\hline 9 & Daggett & 13 & Duchesne & 47 Uintah
\end{tabular}

Survey Unit Code: 3 Survey Unit Name: Central

\begin{tabular}{|llllll|}
\hline & & \multicolumn{4}{c|}{ County code and county name } \\
\hline 23 & Juab & 31 & Piute & 41 & Sevier \\
27 & Millard & 39 & Sanpete & 55 & Wayne
\end{tabular}

Survey Unit Code: 4 Survey Unit Name: Eastern

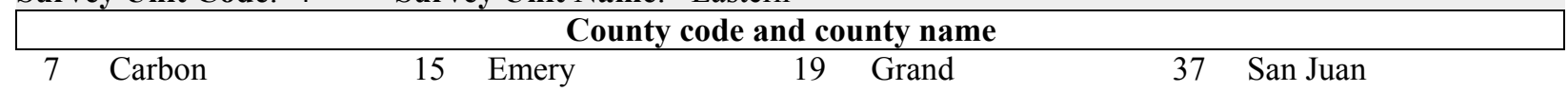

Survey Unit Code: 5 Survey Unit Name: Southwestern

\begin{tabular}{|clllcc|}
\hline & & \multicolumn{3}{c|}{ County code and county name } \\
\hline 1 & Beaver & 21 & Iron & 53 & Washington \\
17 & Garfield & 25 & Kane & & \\
\hline
\end{tabular}

\begin{tabular}{llllllll|}
\hline State Code: 50 & State Name: Vermont & State Abbreviation: & VT & Region/Station Code: 24 \\
Survey Unit Code: & 2 & Survey Unit Name: & Northern \\
\hline \multicolumn{78}{|c}{ County code and county name } \\
\hline 5 & Caledonia & 11 & Franklin & 15 & Lamoille & 19 & Orleans \\
9 & Essex & 13 & Grand Isle & 17 & Orange & 23 & Washington
\end{tabular}

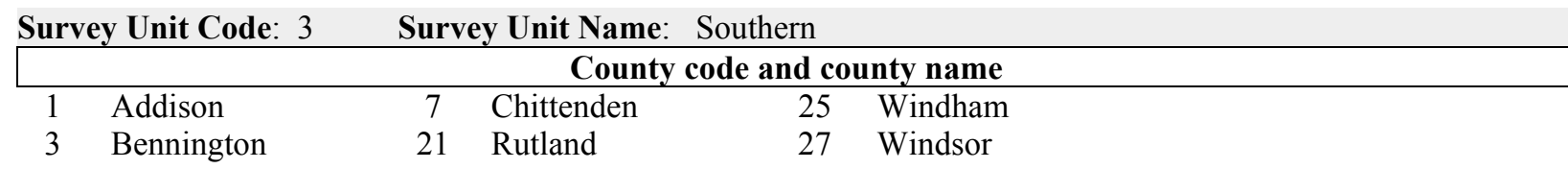




\begin{tabular}{|c|c|c|c|c|c|c|c|}
\hline Stat & Code: 51 & State Nam & : Virginia & Abb & iation: VA & $3 /$ & ion Code: 33 \\
\hline Surv & y Unit Code: 1 & Surv & y Unit Name: $\mathrm{C}$ & al Pla & & & \\
\hline & & & County coc & ind co & nty name & & \\
\hline 1 & Accomack & 85 & Hanover & 119 & Middlesex & 193 & Westmoreland \\
\hline 25 & Brunswick & 87 & Henrico & 127 & New Kent & 199 & York \\
\hline 33 & Caroline & 93 & Isle Of Wight & 131 & Northampton & 550 & Chesapeake city \\
\hline 36 & Charles City & 95 & James City & 133 & Northumberland & 650 & Hampton city \\
\hline 41 & Chesterfield & 97 & King And Queen & 149 & Prince George & 700 & Newport News city \\
\hline 53 & Dinwiddie & 99 & King George & 159 & Richmond & 800 & Suffolk city \\
\hline 57 & Essex & 101 & King William & 175 & Southampton & 810 & Virginia Beach city \\
\hline 73 & Gloucester & 103 & Lancaster & 181 & Surry & & \\
\hline 81 & Greensville & 115 & Mathews & 183 & Sussex & & \\
\hline
\end{tabular}

Survey Unit Code: 2 Survey Unit Name: Southern Piedmont

\begin{tabular}{|clllllll|}
\hline \multicolumn{7}{c|}{ County code and county name } \\
\hline 7 & Amelia & 37 & Charlotte & 111 & Lunenburg & 145 & Powhatan \\
11 & Appomattox & 49 & Cumberland & 117 & Mecklenburg & 147 & Prince Edward \\
19 & Bedford & 67 & Franklin & 135 & Nottoway & & \\
29 & Buckingham & 83 & Halifax & 141 & Patrick & & \\
31 & Campbell & 89 & Henry & 143 & Pittsylvania & &
\end{tabular}

Survey Unit Code: 3 Survey Unit Name: Northern Piedmont

\begin{tabular}{|c|c|c|c|c|c|c|c|}
\hline \multicolumn{8}{|c|}{ County code and county name } \\
\hline 3 & Albemarle & 61 & Fauquier & 109 & Louisa & 157 & Rappahannock \\
\hline 9 & Amherst & 65 & Fluvanna & 113 & Madison & 177 & Spotsylvania \\
\hline 13 & Arlington & 75 & Goochland & 125 & Nelson & 179 & Stafford \\
\hline 47 & Culpeper & 79 & Greene & 137 & Orange & & \\
\hline 59 & Fairfax & 107 & Loudoun & 153 & Prince $\mathrm{W}$ & & \\
\hline
\end{tabular}

Survey Unit Code: 4 Survey Unit Name: Northern Mountains

\begin{tabular}{|clrlrlll|}
\hline \multicolumn{7}{|c|}{ County code and county name } \\
\hline 5 & Alleghany & 43 & Clarke & 139 & Page & 171 & Shenandoah \\
15 & Augusta & 45 & Craig & 161 & Roanoke & 187 & Warren \\
17 & Bath & 69 & Frederick & 163 & Rockbridge & & \\
23 & Botetourt & 91 & Highland & 165 & Rockingham & &
\end{tabular}

Survey Unit Code: 5 Survey Unit Name: Southern Mountains

\begin{tabular}{|c|c|c|c|c|c|c|c|}
\hline \multicolumn{8}{|c|}{ County code and county name } \\
\hline 21 & Bland & 71 & Giles & 167 & Russell & 195 & Wise \\
\hline 27 & Buchanan & 77 & Grayson & 169 & Scott & 197 & Wythe \\
\hline 35 & Carroll & 105 & Lee & 173 & Smyth & & \\
\hline 51 & Dickenson & 121 & Montgomery & 185 & Tazewell & & \\
\hline 63 & Floyd & 155 & Pulaski & 191 & Washington & & \\
\hline
\end{tabular}

Virginia cont. 
Virginia cont.

Cities aggregated into other counties

\begin{tabular}{|c|c|c|c|c|}
\hline City code and city name & $\begin{array}{l}\text { Associated county code } \\
\text { and county name }\end{array}$ & City code and city name & \multicolumn{2}{|c|}{$\begin{array}{c}\text { Associated county code and } \\
\text { county name }\end{array}$} \\
\hline 510 Alexandria city & 59 Fairfax & 683 Manassas city & 153 & Prince William \\
\hline 515 Bedford city & 19 Bedford & 685 Manassas Park city & 153 & Prince William \\
\hline 520 Bristol city & 191 Washington & 690 Martinsville city & 89 & Henry \\
\hline 530 Buena Vista city & 163 Rockbridge & 710 Norfolk city & 550 & Chesapeake City \\
\hline 540 Charlottesville city & Albemarle & 720 Norton city & 195 & Wise \\
\hline 560 Clifton Forge city & Allegheny & 730 Petersburg city & 53 & Dinwiddie \\
\hline 570 Colonial Heights city & 41 Chesterfield & 730 Petersburg city & 149 & Prince George \\
\hline 580 Covington city & Allegheny & 735 Poquoson city & 199 & York \\
\hline 590 Danville city & 143 Pittsylvania & 740 Portsmouth city & 550 & Chesapeake City \\
\hline 595 Emporia city & 81 Greensville & 750 Radford city & 121 & Montgomery \\
\hline 600 Fairfax city & 59 Fairfax & 760 Richmond city & 41 & Chesterfield \\
\hline 610 Falls Church city & 59 Fairfax & 760 Richmond city & 87 & Henrico \\
\hline 620 Franklin city & 175 Southampton & 770 Roanoke city & 161 & Roanoke \\
\hline 630 Fredericksburg city & 177 Spotsylvania & 775 Salem city & 161 & Roanoke \\
\hline 640 Galax city & 35 Carroll & 780 South Boston city & 83 & Halifax \\
\hline 640 Galax city & 77 Grayson & 790 Staunton city & 15 & Augusta \\
\hline 660 Harrisonburg city & 165 Rockingham & 820 Waynesboro city & 15 & Augusta \\
\hline 670 Hopewell city & 149 Prince George & 830 Williamsburg city & 95 & County of James City \\
\hline 678 Lexington city & 163 Rockbridge & 840 Winchester city & 69 & Frederick \\
\hline 680 Lynchburg city & 31 Campbell & & & \\
\hline
\end{tabular}




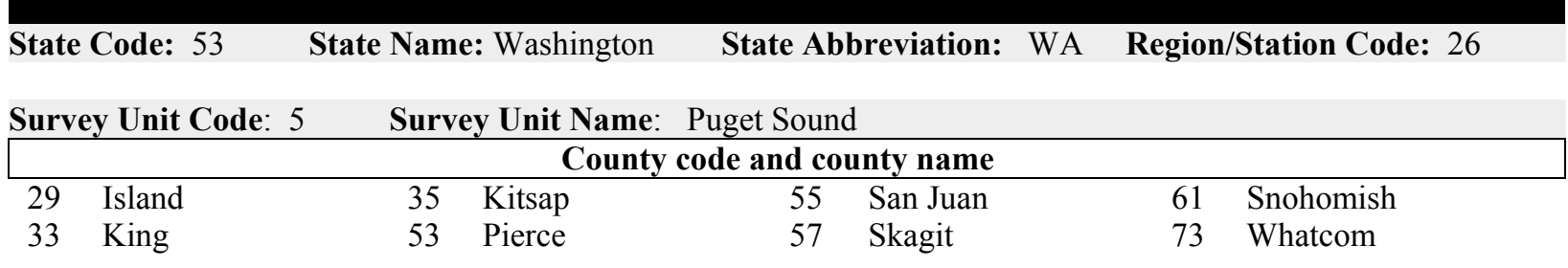

Survey Unit Code: 6 Survey Unit Name: Olympic Peninsula

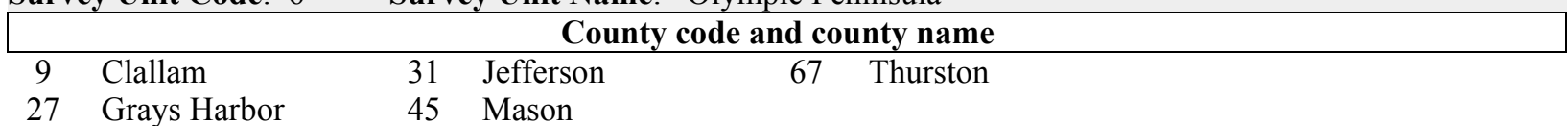

Survey Unit Code: 7 Survey Unit Name: Southwest

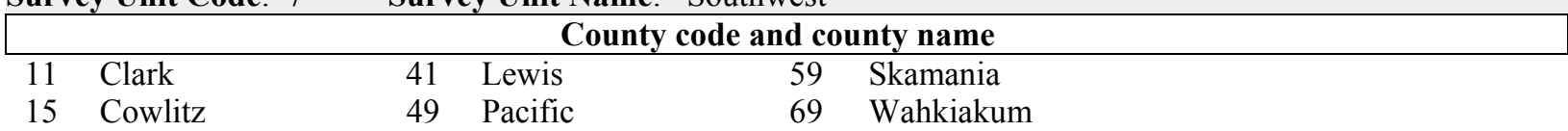

Survey Unit Code: 8 Survey Unit Name: Central

\begin{tabular}{|clllcl|}
\hline & & \multicolumn{4}{c|}{ County code and county name } \\
\hline 7 & Chelan & 37 & Kittitas & 47 & Okanogan \\
17 & Douglas & 39 & Klickitat & 77 & Yakima \\
\hline
\end{tabular}

Survey Unit Code: 9 Survey Unit Name: Inland Empire

\begin{tabular}{|clllllll|}
\hline \multicolumn{7}{c|}{ County code and county name } \\
\hline 1 & Adams & 19 & Ferry & 43 & Lincoln & 71 & Walla Walla \\
3 & Asotin & 21 & Franklin & 51 & Pend Oreille & 75 & Whitman \\
5 & Benton & 23 & Garfield & 63 & Spokane & & \\
13 & Columbia & 25 & Grant & 65 & Stevens & & \\
\end{tabular}


State Code: $54 \quad$ State Name: West Virginia $\quad$ State Abbreviation: $W V \quad$ Region/Station Code: 24

Survey Unit Code: 2 Survey Unit Name: Northeastern

\begin{tabular}{|clllllll|}
\hline \multicolumn{7}{c}{ County code and county name } \\
\hline 1 & Barbour & 31 & Hardy & 65 & Morgan & 91 & Taylor \\
3 & Berkeley & 33 & Harrison & 71 & Pendleton & 93 & Tucker \\
7 & Braxton & 37 & Jefferson & 75 & Pocahontas & 97 & Upshur \\
23 & Grant & 41 & Lewis & 77 & Preston & 101 & Webster \\
27 & Hampshire & 57 & Mineral & 83 & Randolph & &
\end{tabular}

Survey Unit Code: 3 Survey Unit Name: Southern

\begin{tabular}{|clllllll|}
\hline \multicolumn{10}{c|}{ County code and county name } \\
\hline 5 & Boone & 39 & Kanawha & 59 & Mingo & 89 & Summers \\
15 & Clay & 45 & Logan & 63 & Monroe & 109 & Wyoming \\
19 & Fayette & 47 & McDowell & 67 & Nicholas & & \\
25 & Greenbrier & 55 & Mercer & 81 & Raleigh & &
\end{tabular}

Survey Unit Code: 4 Survey Unit Name: Northwestern

\begin{tabular}{|clllllll|}
\hline \multicolumn{7}{c|}{ County code and county name } \\
11 & Brooke & 35 & Jackson & 69 & Ohio & 99 & Wayne \\
13 & Calhoun & 43 & Lincoln & 73 & Pleasants & 103 & Wetzel \\
17 & Doddridge & 49 & Marion & 79 & Putnam & 105 & Wirt \\
21 & Gilmer & 51 & Marshall & 85 & Ritchie & 107 & Wood \\
29 & Hancock & 53 & Mason & 87 & Roane & & \\
& & 61 & Monongalia & 95 & Tyler & &
\end{tabular}


State Code: 55

Survey Unit Code: 1 Survey Unit Name: Northeastern

\begin{tabular}{|c|c|c|c|c|c|c|c|}
\hline \multicolumn{8}{|c|}{ County code and county name } \\
\hline 37 & Florence & 69 & Lincoln & 83 & Oconto & 125 & Vilas \\
\hline 41 & Forest & 75 & Marinette & 85 & Oneida & & \\
\hline 67 & Langlade & 78 & Menominee & 115 & Shawano & & \\
\hline
\end{tabular}

Survey Unit Code: 2 Survey Unit Name: Northwestern

\begin{tabular}{|llllclll|}
\hline \multicolumn{7}{c|}{ County code and county name } \\
\hline 3 & Ashland & 13 & Burnett & 95 & Polk & 113 & Sawyer \\
5 & Barron & 31 & Douglas & 99 & Price & 119 & Taylor \\
7 & Bayfield & 51 & Iron & 107 & Rusk & 129 & Washburn
\end{tabular}

Survey Unit Code: 3 Survey Unit Name: Central

\begin{tabular}{|c|c|c|c|c|c|c|}
\hline \multicolumn{7}{|c|}{ County code and county name } \\
\hline 1 & Adams & 53 & Jackson & 81 & Monroe & 141 Wood \\
\hline 17 & Chippewa & 57 & Juneau & 97 & Portage & \\
\hline 19 & Clark & 73 & Marathon & 135 & Waupaca & \\
\hline 35 & Eau Claire & 77 & Marquette & 137 & Waushara & \\
\hline
\end{tabular}

Survey Unit Code: 4 Survey Unit Name: Southwestern

\begin{tabular}{|llllclll|}
\hline \multicolumn{7}{|c|}{ County code and county name } \\
\hline 11 & Buffalo & 49 & Iowa & 93 & Pierce & 121 & Trempealeau \\
23 & Crawford & 63 & La Crosse & 103 & Richland & 123 & Vernon \\
33 & Dunn & 65 & Lafayette & 109 & St. Croix & & \\
43 & Grant & 91 & Pepin & 111 & Sauk & &
\end{tabular}

Survey Unit Code: 5 Survey Unit Name: Southeastern

\begin{tabular}{|c|c|c|c|c|c|c|c|}
\hline \multicolumn{8}{|c|}{ County code and county name } \\
\hline 9 & Brown & 39 & Fond du Lac & 71 & Manitowoc & 117 & Sheboygan \\
\hline 15 & Calumet & 45 & Green & 79 & Milwaukee & 127 & Walworth \\
\hline 21 & Columbia & 47 & Green Lake & 87 & Outagamie & 131 & Washington \\
\hline 25 & Dane & 55 & Jefferson & 89 & Ozaukee & 133 & Waukesha \\
\hline 27 & Dodge & 59 & Kenosha & 101 & Racine & 139 & Winnebago \\
\hline 29 & Door & 61 & Kewaunee & 105 & Rock & & \\
\hline
\end{tabular}




\begin{tabular}{|c|c|c|c|}
\hline State Code: 56 & State Name: Wyoming & State Abbreviation: WY & Region/Station Code: 22 \\
\hline Survey Unit Code: 1 & Survey Unit Name: & Western & \\
\hline \multicolumn{4}{|c|}{ County code and county name } \\
\hline Fremont & Lincoln & Sublette & Teton \\
\hline Hot Springs & Park & Sweetwater & Uinta \\
\hline
\end{tabular}

Survey Unit Code: 2 Survey Unit Name: Central and Southeastern

\begin{tabular}{|llcllllll}
\hline \multicolumn{7}{|c|}{ County code and county name } \\
\hline 1 & Albany & 9 & Converse & 21 & Laramie & 31 & Platte \\
3 & Big Horn & 15 & Goshen & 25 & Natrona & 33 & Sheridan \\
7 & Carbon & 19 & Johnson & 27 & Niobrara & 43 & Washakie
\end{tabular}

Survey Unit Code: 3 Survey Unit Name: Northeastern

\begin{tabular}{|lllll|}
\hline & & \multicolumn{3}{c|}{ County code and county name } \\
\hline 5 & Campbell & 11 & Crook & Weston
\end{tabular}

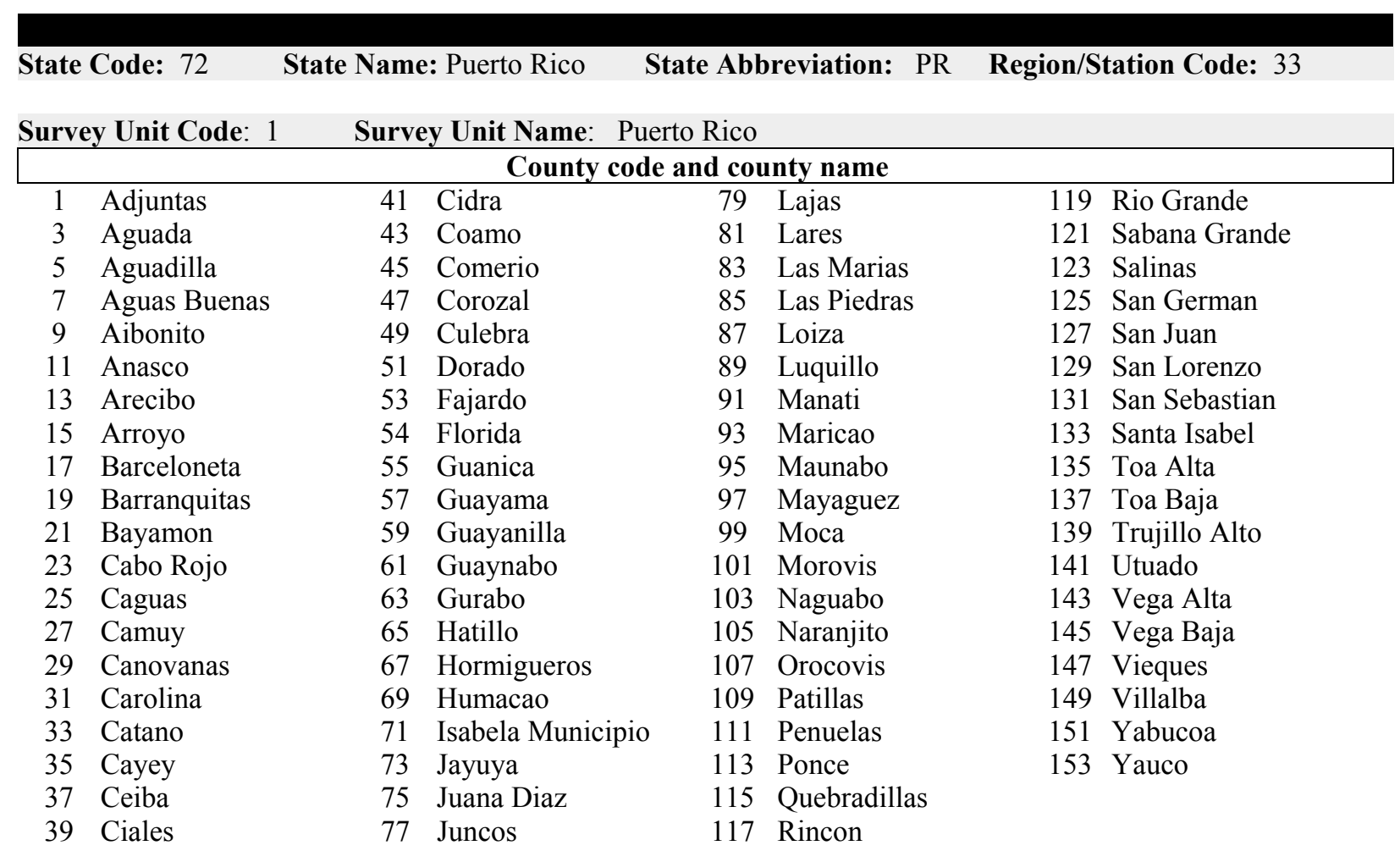

State Code: $78 \quad$ State Name: U.S. Virgin Islands $\quad$ State Abbreviation: VI Region/Station Code: 33

Survey Unit Code: 1 Survey Unit Name: Virgin Islands

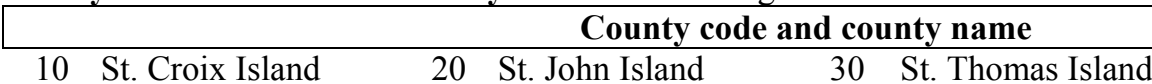




\section{Appendix D. Forest Type Codes and Names}

Note: The forest type names used by FIA do not come from a single published reference. The current list of forest type names has been developed over time using sources such as historical FIA lists, lists from the Society of American Foresters, and FIA analysts who developed names to meet current analysis and reporting needs.

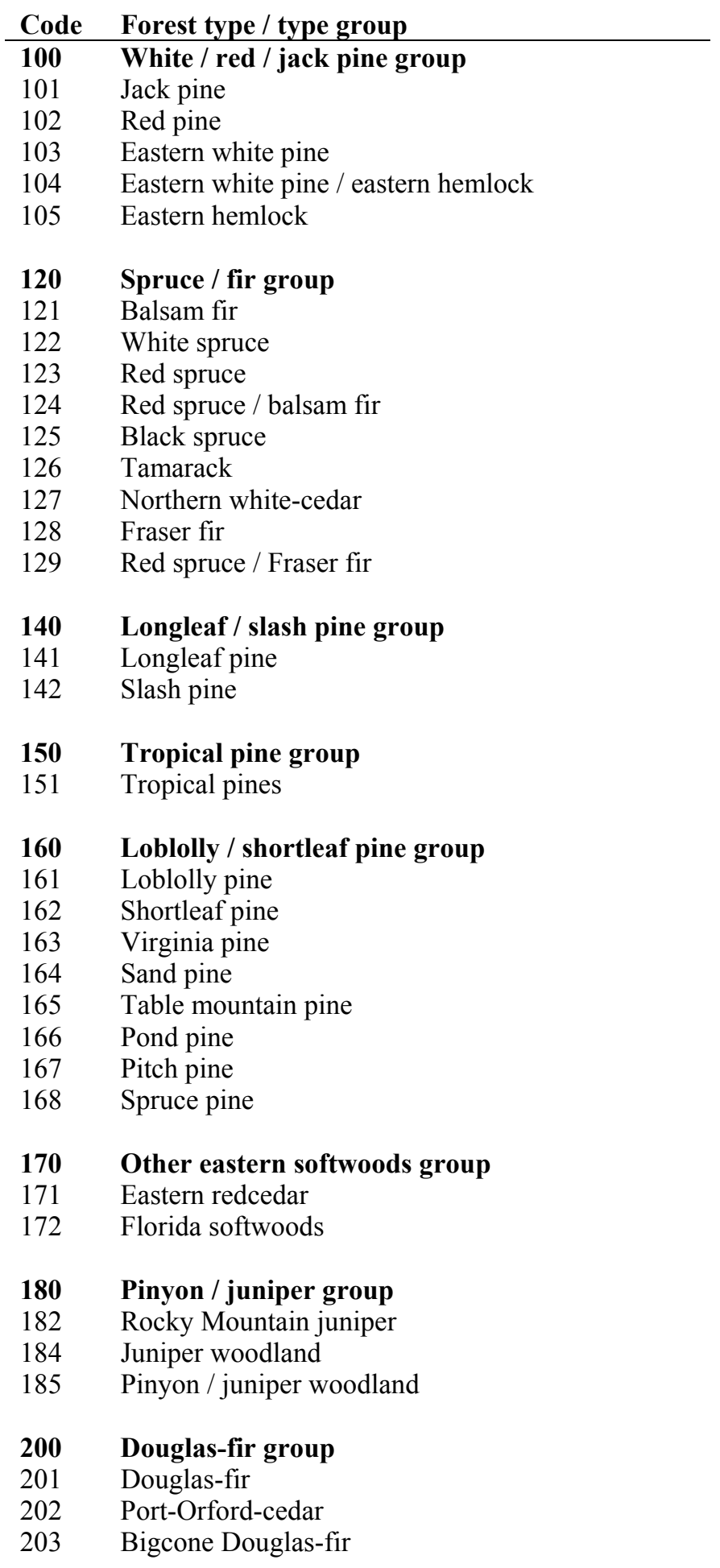


FIA Database Description and Users Manual for Phase 2, version 4.0

Appendix D

\begin{tabular}{ll} 
Code & Forest type / type group \\
\hline $\mathbf{2 2 0}$ & Ponderosa pine group \\
221 & Ponderosa pine \\
222 & Incense-cedar \\
224 & Sugar pine \\
225 & Jeffrey pine \\
226 & Coulter pine
\end{tabular}

240 Western white pine group

241 Western white pine

260 Fir / spruce / mountain hemlock group

261 White fir

262 Red fir

263 Noble fir

264 Pacific silver fir

265 Engelmann spruce

266 Engelmann spruce / subalpine fir

267 Grand fir

268 Subalpine fir

269 Blue spruce

270 Mountain hemlock

271 Alaska-yellow-cedar

280 Lodgepole pine group

281 Lodgepole pine

300 Hemlock / Sitka spruce group

$301 \quad$ Western hemlock

304 Western redcedar

305 Sitka spruce

320 Western larch group

$321 \quad$ Western larch

$340 \quad$ Redwood group

341 Redwood

342 Giant sequoia

360 Other western softwoods group

361 Knobcone pine

362 Southwestern white pine

363 Bishop pine

364 Monterey pine

365 Foxtail pine / bristlecone pine

366 Limber pine

367 Whitebark pine

368 Miscellaneous western softwoods

369 Western juniper

370 California mixed conifer group

371 California mixed conifer

$380 \quad$ Exotic softwoods group

381 Scotch pine

383 Other exotic softwoods

384 Norway spruce

385 Introduced larch 
Code Forest type / type group

$390 \quad$ Other softwoods group

391 Other softwoods

$400 \quad$ Oak / pine group

401 Eastern white pine / northern red oak / white ash

402 Eastern redcedar / hardwood

403 Longleaf pine / oak

404 Shortleaf pine / oak

405 Virginia pine / southern red oak

406 Loblolly pine / hardwood

407 Slash pine / hardwood

409 Other pine / hardwood

Oak / hickory group

Post oak / blackjack oak

Chestnut oak

White oak / red oak / hickory

White oak

Northern red oak

Yellow-poplar / white oak / northern red oak

Sassafras / persimmon

Sweetgum / yellow-poplar

Bur oak

Scarlet oak

Yellow-poplar

Black walnut

Black locust

Southern scrub oak

Chestnut oak / black oak / scarlet oak

Cherry / white ash / yellow-poplar

Elm / ash / black locust

Red maple / oak

Mixed upland hardwoods

Oak / gum / cypress group

Swamp chestnut oak / cherrybark oak

Sweetgum / Nuttall oak / willow oak

Overcup oak / water hickory

Atlantic white-cedar

Baldcypress / water tupelo

Sweetbay / swamp tupelo / red maple

Baldcypress / pondcypress

EIm / ash / cottonwood group

701 Black ash / American elm / red maple

River birch / sycamore

Cottonwood

Willow

Sycamore / pecan / American elm

Sugarberry / hackberry / elm / green ash

Silver maple / American elm

Red maple / lowland

Cottonwood / willow

800 Maple / beech / birch group

801 Sugar maple / beech / yellow birch 


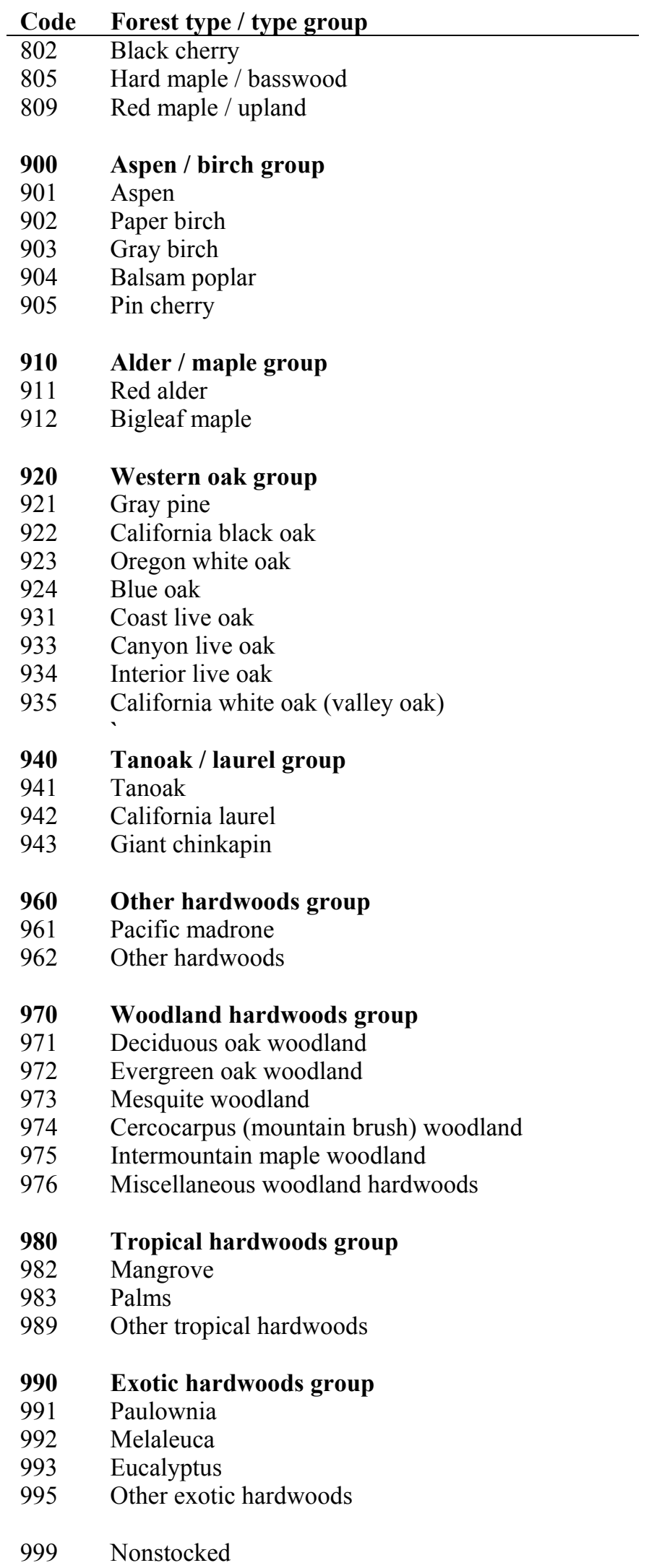




\section{Appendix E. Administrative National Forest Codes and Names}

\begin{tabular}{lll} 
Region & Code & National Forest/Grassland/Area \\
\hline Region 1 & 102 & Beaverhead \\
102 & Beaverhead-Deerlodge [now combined] \\
103 & Bitterroot \\
104 & Idaho Panhandle \\
105 & Clearwater \\
108 & Custer \\
109 & Deerlodge \\
110 & Flathead \\
111 & Gallatin \\
112 & Helena \\
114 & Kootenai \\
115 & Lewis and Clark \\
116 & Lolo \\
117 & Nez Perce \\
120 & Cedar River NGL (National Grassland) \\
121 & Little Missouri NGL \\
122 & Sheyenne NGL \\
124 & Grand River NGL \\
199 & Other NFS Areas
\end{tabular}

\begin{tabular}{|c|c|c|}
\hline Region 2 & $\begin{array}{l}202 \\
203 \\
204 \\
206 \\
206 \\
207 \\
209 \\
210 \\
211 \\
212 \\
213 \\
214 \\
215 \\
216 \\
217 \\
218 \\
219 \\
220 \\
221 \\
222 \\
223 \\
299\end{array}$ & $\begin{array}{l}\text { Bighorn } \\
\text { Black Hills } \\
\text { Grand Mesa-Uncom } \\
\text { Medicine Bow } \\
\text { Medicine Bow-Rout } \\
\text { Nebraska } \\
\text { Rio Grande } \\
\text { Arapaho-Roosevelt } \\
\text { Routt } \\
\text { Pike and San Isabel } \\
\text { San Juan } \\
\text { Shoshone } \\
\text { White River } \\
\text { Samuel R Mckelvie } \\
\text { Cimarron NGL } \\
\text { Commanche NGL } \\
\text { Pawnee NGL } \\
\text { Oglala NGL } \\
\text { Buffalo Gap NGL } \\
\text { Fort Pierre NGL } \\
\text { Thunder Basin NGL } \\
\text { Other NFS Areas }\end{array}$ \\
\hline Region 3 & $\begin{array}{l}301 \\
302 \\
303 \\
304 \\
305 \\
306 \\
307 \\
308 \\
309 \\
310 \\
312 \\
399\end{array}$ & $\begin{array}{l}\text { Apache-Sitgreaves } \\
\text { Carson } \\
\text { Cibola } \\
\text { Coconino } \\
\text { Coronado } \\
\text { Gila } \\
\text { Kaibab } \\
\text { Lincoln } \\
\text { Prescott } \\
\text { Santa Fe } \\
\text { Tonto } \\
\text { Other NFS Areas }\end{array}$ \\
\hline Region 4 & $\begin{array}{l}401 \\
402 \\
403\end{array}$ & $\begin{array}{l}\text { Ashley } \\
\text { Boise } \\
\text { Bridger-Teton }\end{array}$ \\
\hline
\end{tabular}


FIA Database Description and Users Manual for Phase 2, version 4.0

Appendix $\mathrm{E}$

\begin{tabular}{|c|c|c|}
\hline Region & Code & National Forest/Grassland/Area \\
\hline & 405 & Caribou \\
\hline & 406 & Challis \\
\hline & 407 & Dixie \\
\hline & 408 & Fishlake \\
\hline & 409 & Humboldt \\
\hline & 410 & Manti-La Sal \\
\hline & 412 & Payette \\
\hline & 413 & Salmon \\
\hline & 413 & Salmon-Challis [now combined] \\
\hline & 414 & Sawtooth \\
\hline & 415 & Targhee \\
\hline & 415 & Caribou-Targhee [now combined] \\
\hline & 417 & Toiyabe \\
\hline & 417 & Humboldt-Toiyabe [now combined] \\
\hline & 418 & Uinta \\
\hline & 419 & Wasatch-Cache \\
\hline & 420 & Desert Range Experiment Station \\
\hline & 499 & Other NFS Areas \\
\hline \multirow[t]{19}{*}{ Region 5} & 501 & Angeles \\
\hline & 502 & Cleveland \\
\hline & 503 & Eldorado \\
\hline & 504 & Inyo \\
\hline & 505 & Klamath \\
\hline & 506 & Lassen \\
\hline & 507 & Los Padres \\
\hline & 508 & Mendocino \\
\hline & 509 & Modoc \\
\hline & 510 & Six Rivers \\
\hline & 511 & Plumas \\
\hline & 512 & San Bernardino \\
\hline & 513 & Sequoia \\
\hline & 514 & Shasta-Trinity \\
\hline & 515 & Sierra \\
\hline & 516 & Stanislaus \\
\hline & 517 & Tahoe \\
\hline & 519 & Lake Tahoe Basin \\
\hline & 599 & Other NFS Areas \\
\hline \multirow[t]{22}{*}{ Region 6} & 601 & Deschutes \\
\hline & 602 & Fremont \\
\hline & 603 & Gifford Pinchot \\
\hline & 604 & Malheur \\
\hline & 605 & Mt. Baker-Snoqualmie \\
\hline & 606 & Mt. Hood \\
\hline & 607 & Ochoco \\
\hline & 608 & Okanogan \\
\hline & 609 & Olympic \\
\hline & 610 & Rogue River \\
\hline & 611 & Siskiyou \\
\hline & 612 & Siuslaw \\
\hline & 614 & Umatilla \\
\hline & 615 & Umpqua \\
\hline & 616 & Wallowa-Whitman \\
\hline & 617 & Wenatchee \\
\hline & 618 & Willamette \\
\hline & 620 & Winema \\
\hline & 621 & Colville \\
\hline & 622 & Columbia River Gorge NSA \\
\hline & 650 & Crooked River National Grassland \\
\hline & 699 & Other NFS Areas \\
\hline
\end{tabular}




\begin{tabular}{|c|c|c|}
\hline Region & Code & National Forest/Grassland/Area \\
\hline \multirow[t]{16}{*}{ Region 8} & 801 & NFS in Alabama \\
\hline & 802 & Daniel Boone \\
\hline & 803 & Chattahoochee-Oconee \\
\hline & 804 & Cherokee \\
\hline & 805 & NFS in Florida \\
\hline & 806 & Kisatchie \\
\hline & 807 & NFS in Mississippi \\
\hline & 808 & George Washington \\
\hline & 809 & Ouachita \\
\hline & 810 & Ozark and St. Francis \\
\hline & 811 & NFS in North Carolina \\
\hline & 812 & Francis Marion-Sumter \\
\hline & 813 & NFS in Texas \\
\hline & 814 & Jefferson \\
\hline & 816 & El Yunque \\
\hline & 899 & Other NFS areas \\
\hline \multirow[t]{17}{*}{ Region 9} & 902 & Chequamagon \\
\hline & 903 & Chippewa \\
\hline & 904 & Huron-Manistee \\
\hline & 905 & Mark Twain \\
\hline & 906 & Nicolet \\
\hline & 907 & Ottawa \\
\hline & 908 & Shawnee \\
\hline & 909 & Superior \\
\hline & 910 & Hiawatha \\
\hline & 912 & Hoosier \\
\hline & 915 & Midewin Tallgrass Prairie \\
\hline & 918 & Wayne \\
\hline & 919 & Allegheny \\
\hline & 920 & Green Mountain \\
\hline & 921 & Monongahela \\
\hline & 922 & White Mountain \\
\hline & 999 & Other NFS areas \\
\hline \multirow[t]{3}{*}{ Region 10} & 1004 & Chugach \\
\hline & 1005 & Tongass \\
\hline & 1099 & Other NFS Areas \\
\hline
\end{tabular}




\section{Appendix F. Tree Species Codes, Names, and Occurrences}

Major groups (MAJGRP) are (1) pines, (2) other softwoods, (3) soft hardwoods, and (4) hard hardwoods. The 48 species groups (SPGRPCD) can be found in appendix G. The FIA work units listed are NC - (former) North Central, NE - (former) Northeastern, PNW - Pacific Northwest, RM - Rocky Mountain, and SO - Southern.

\begin{tabular}{|c|c|c|c|c|c|c|c|c|c|}
\hline \multirow[b]{2}{*}{ SPCD } & \multirow[b]{2}{*}{ COMMON NAME } & \multirow[b]{2}{*}{ SCIENTIFIC NAME } & \multirow[b]{2}{*}{ SPGRPCD } & \multirow[b]{2}{*}{ MAJGRP } & \multicolumn{5}{|c|}{ Occurrence by FIA work unit } \\
\hline & & & & & NC & NE & PNW & $\mathbf{R M}$ & SO \\
\hline 0010 & fir spp. & Abies spp. & 6 & 2 & $\mathrm{X}$ & $\mathrm{X}$ & & & $\mathrm{X}$ \\
\hline 0011 & Pacific silver fir & Abies amabilis & 12 & 2 & & & $\mathrm{X}$ & & \\
\hline 0012 & balsam fir & Abies balsamea & 6 & 2 & $\mathrm{X}$ & $\mathrm{X}$ & & & $\mathrm{X}$ \\
\hline 0014 & $\begin{array}{l}\text { Santa Lucia fir or } \\
\text { bristlecone fir }\end{array}$ & Abies bracteata & 12 & 2 & & & $\mathrm{X}$ & & \\
\hline 0015 & white fir & Abies concolor & 12 & 2 & $\mathrm{X}$ & & $\mathrm{X}$ & $\mathrm{X}$ & \\
\hline 0016 & Fraser fir & Abies fraseri & 9 & 2 & $\mathrm{X}$ & $\mathrm{X}$ & & & $\mathrm{X}$ \\
\hline 0017 & grand fir & Abies grandis & 12 & 2 & & & $\mathrm{X}$ & $\mathrm{X}$ & \\
\hline 0018 & corkbark fir & Abies lasiocarpa var. arizonica & 12 & 2 & & & & $\mathrm{X}$ & \\
\hline 0019 & subalpine fir & Abies lasiocarpa & 12 & 2 & & & $\mathrm{X}$ & $\mathrm{X}$ & \\
\hline 0020 & California red fir & Abies magnifica & 12 & 2 & & & $\mathrm{X}$ & $\mathrm{X}$ & \\
\hline 0021 & Shasta red fir & Abies shastensis & 12 & 2 & & & $\mathrm{X}$ & $\mathrm{X}$ & \\
\hline 0022 & noble fir & Abies procera & 12 & 2 & & & $\mathrm{X}$ & $\mathrm{X}$ & \\
\hline 0040 & white-cedar spp. & Chamaecyparis spp. & $9 \mathrm{E}, 24 \mathrm{~W}$ & 2 & & $\mathrm{X}$ & $\mathrm{X}$ & & \\
\hline 0041 & Port-Orford-cedar & Chamaecyparis lawsoniana & 24 & 2 & & & $\mathrm{X}$ & & \\
\hline 0042 & Alaska-yellow-cedar & Chamaecyparis nootkatensis & 24 & 2 & & & $\mathrm{X}$ & & \\
\hline 0043 & Atlantic white-cedar & Chamaecyparis thyoides & 9 & 2 & & $\mathrm{X}$ & & & $\mathrm{X}$ \\
\hline 0050 & cypress & Cupressus spp. & 24 & 2 & & & $\mathrm{X}$ & & \\
\hline 0051 & Arizona cypress & Cupressus arizonica & 24 & 2 & & & $\mathrm{X}$ & $\mathrm{X}$ & $\mathrm{X}$ \\
\hline 0052 & Baker or Modoc cypress & Cupressus bakeri & 24 & 2 & & & $\mathrm{X}$ & & \\
\hline 0053 & Tecate cypress & Cupressus forbesii & 24 & 2 & & & $\mathrm{X}$ & & \\
\hline 0054 & Monterey cypress & Cupressus macrocarpa & 24 & 2 & & & $\mathrm{X}$ & & \\
\hline 0055 & Sargent's cypress & Cupressus sargentii & 24 & 2 & & & $\mathrm{X}$ & & \\
\hline 0056 & MacNab's cypress & Cupressus macnabiana & $9 \mathrm{E}, 24 \mathrm{~W}$ & 2 & & & $\mathrm{X}$ & & \\
\hline 0057 & redcedar / juniper spp. & Juniperus spp. & $9 \mathrm{E}, 23 \mathrm{~W}$ & 2 & $\mathrm{X}$ & $\mathrm{X}$ & & & $\mathrm{X}$ \\
\hline 0058 & Pinchot juniper & Juniperus pinchotii & 23 & 2 & & & & $\mathrm{X}$ & \\
\hline 0059 & redberry juniper & Juniperus coahuilensis & 23 & 2 & & & & $\mathrm{X}$ & $\mathrm{X}$ \\
\hline 0060 & Drooping juniper & Juniperus flaccida & 23 & 2 & & & & & $\mathrm{X}$ \\
\hline 0061 & Ashe juniper & Juniperus ashei & 23 & 2 & $\mathrm{X}$ & & & & $\mathrm{X}$ \\
\hline 0062 & California juniper & Juniperus californica & 23 & 2 & & & $\mathrm{X}$ & $\mathrm{X}$ & \\
\hline 0063 & alligator juniper & Juniperus deppeana & 23 & 2 & & & & $\mathrm{X}$ & $\mathrm{X}$ \\
\hline 0064 & western juniper & Juniperus occidentalis & 24 & 2 & & & $\mathrm{X}$ & $\mathrm{X}$ & \\
\hline 0065 & Utah juniper & Juniperus osteosperma & 23 & 2 & & & $\mathrm{X}$ & $\mathrm{X}$ & \\
\hline 0066 & Rocky Mountain juniper & Juniperus scopulorum & $9 \mathrm{E}, 23 \mathrm{~W}$ & 2 & $\mathrm{X}$ & & $\mathrm{X}$ & $\mathrm{X}$ & $\mathrm{X}$ \\
\hline 0067 & southern redcedar & $\begin{array}{l}\text { Juniperus virginiana var. } \\
\text { silicicola }\end{array}$ & 9 & 2 & & & & & $\mathrm{X}$ \\
\hline 0068 & eastern redcedar & Juniperus virginiana & $9 \mathrm{E}, 24 \mathrm{~W}$ & 2 & $\mathrm{X}$ & $\mathrm{X}$ & & $\mathrm{X}$ & $\mathrm{X}$ \\
\hline 0069 & oneseed juniper & Juniperus monosperma & 23 & 2 & & & & $\mathrm{X}$ & $\mathrm{X}$ \\
\hline 0070 & larch spp. & Larix spp. & 9 & 2 & $\mathrm{X}$ & $\mathrm{X}$ & & & \\
\hline 0071 & tamarack (native) & Larix laricina & $9 \mathrm{E}, 24 \mathrm{~W}$ & 2 & $\mathrm{X}$ & $\mathrm{X}$ & $\mathrm{X}$ & & \\
\hline 0072 & subalpine larch & Larix lyallii & 24 & 2 & & & $\mathrm{X}$ & $\mathrm{X}$ & \\
\hline 0073 & western larch & Larix occidentalis & 19 & 2 & & & $\mathrm{X}$ & $\mathrm{X}$ & \\
\hline 0081 & incense-cedar & Calocedrus decurrens & 20 & 2 & & & $\mathrm{X}$ & $\mathrm{X}$ & \\
\hline 0090 & spruce spp. & Picea spp. & 6 & 2 & $\mathrm{X}$ & $\mathrm{X}$ & & & $\mathrm{X}$ \\
\hline 0091 & Norway spruce & Picea abies & 9 & 2 & $\mathrm{X}$ & $\mathrm{X}$ & & & $\mathrm{X}$ \\
\hline 0092 & Brewer spruce & Picea breweriana & 18 & 2 & & & $\mathrm{X}$ & & \\
\hline 0093 & Engelmann spruce & Picea engelmannii & $9 \mathrm{E}, 18 \mathrm{~W}$ & 2 & $\mathrm{X}$ & & $\mathrm{X}$ & $\mathrm{X}$ & \\
\hline 0094 & white spruce & Picea glauca & $6 \mathrm{E}, 18 \mathrm{~W}$ & 2 & $\mathrm{X}$ & $\mathrm{X}$ & $\mathrm{X}$ & $\mathrm{X}$ & $\mathrm{X}$ \\
\hline 0095 & black spruce & Picea mariana & $6 \mathrm{E}, 18 \mathrm{~W}$ & 2 & $\mathrm{X}$ & $\mathrm{X}$ & $\mathrm{X}$ & & $\mathrm{X}$ \\
\hline 0096 & blue spruce & Picea pungens & $9 \mathrm{E}, 18 \mathrm{~W}$ & 2 & $\mathrm{X}$ & $\mathrm{X}$ & & $\mathrm{X}$ & $\mathrm{X}$ \\
\hline 0097 & red spruce & Picea rubens & 6 & 2 & & $\mathrm{X}$ & & & $\mathrm{X}$ \\
\hline 0098 & Sitka spruce & Picea sitchensis & 17 & 2 & & & $\mathrm{X}$ & & \\
\hline 0100 & pine spp. & Pinus spp. & $9 \mathrm{E}, 24 \mathrm{~W}$ & 1 & $\mathrm{X}$ & $\mathrm{X}$ & $\mathrm{X}$ & & \\
\hline
\end{tabular}




\begin{tabular}{|c|c|c|c|c|c|c|c|c|c|}
\hline \multirow[b]{2}{*}{ SPCD } & \multirow[b]{2}{*}{ COMMON NAME } & \multirow[b]{2}{*}{ SCIENTIFIC NAME } & \multirow[b]{2}{*}{ SPGRPCD } & \multirow[b]{2}{*}{ MAJGRP } & \multicolumn{5}{|c|}{ Occurrence by FIA work unit } \\
\hline & & & & & NC & NE & PNW & $\mathbf{R M}$ & SO \\
\hline 0101 & whitebark pine & Pinus albicaulis & 24 & 1 & & & $\mathrm{X}$ & $\mathrm{X}$ & \\
\hline 0102 & $\begin{array}{l}\text { Rocky Mountain } \\
\text { bristlecone pine }\end{array}$ & Pinus aristata & 24 & 1 & & & & $\mathrm{X}$ & \\
\hline 0103 & knobcone pine & Pinus attenuata & 24 & 1 & & & $\mathrm{X}$ & & \\
\hline 0104 & foxtail pine & Pinus balfouriana & 24 & 1 & & & $\mathrm{X}$ & $\mathrm{X}$ & \\
\hline 0105 & jack pine & Pinus banksiana & 5 & 1 & $\mathrm{X}$ & $\mathrm{X}$ & & & \\
\hline 0106 & $\begin{array}{l}\text { common or two-needle } \\
\text { pinyon }\end{array}$ & Pinus edulis & 23 & 1 & & & $X$ & $X$ & $\mathrm{X}$ \\
\hline 0107 & sand pine & Pinus clausa & 3 & 1 & & & & & $\mathrm{X}$ \\
\hline 0108 & lodgepole pine & Pinus contorta & 21 & 1 & $\mathrm{X}$ & & $\mathrm{X}$ & $\mathrm{X}$ & \\
\hline 0109 & Coulter pine & Pinus coulteri & 24 & 1 & & & $\mathrm{X}$ & & \\
\hline 0110 & shortleaf pine & Pinus echinata & 2 & 1 & $\mathrm{X}$ & $\mathrm{X}$ & & & $\mathrm{X}$ \\
\hline 0111 & slash pine & Pinus elliottii & 1 & 1 & & & & & $\mathrm{X}$ \\
\hline 0112 & Apache pine & Pinus engelmannii & 24 & 1 & & & & $\mathrm{X}$ & \\
\hline 0113 & limber pine & Pinus flexilis & 24 & 1 & $\mathrm{X}$ & & $\mathrm{X}$ & $\mathrm{X}$ & $\mathrm{X}$ \\
\hline 0114 & southwestern white pine & Pinus strobiformis & 24 & 1 & & & & $\mathrm{X}$ & \\
\hline 0115 & spruce pine & Pinus glabra & 3 & 1 & & & & & $\mathrm{X}$ \\
\hline 0116 & Jeffrey pine & Pinus jeffreyi & 11 & 1 & & & $\mathrm{X}$ & $\mathrm{X}$ & \\
\hline 0117 & sugar pine & Pinus lambertiana & 14 & 1 & & & $\mathrm{X}$ & $\mathrm{X}$ & \\
\hline 0118 & Chihuahua pine & Pinus leiophylla & 24 & 1 & & & & $\mathrm{X}$ & \\
\hline 0119 & western white pine & Pinus monticola & 15 & 1 & & & $\mathrm{X}$ & $\mathrm{X}$ & \\
\hline 0120 & bishop pine & Pinus muricata & 24 & 1 & & & $\mathrm{X}$ & & \\
\hline 0121 & longleaf pine & Pinus palustris & 1 & 1 & & & & & $\mathrm{X}$ \\
\hline 0122 & ponderosa pine & Pinus ponderosa & $9 \mathrm{E}, 11 \mathrm{~W}$ & 1 & $\mathrm{X}$ & & $\mathrm{X}$ & $\mathrm{X}$ & $\mathrm{X}$ \\
\hline 0123 & Table mountain pine & Pinus pungens & 3 & 1 & & $\mathrm{X}$ & & & $\mathrm{X}$ \\
\hline 0124 & Monterey pine & Pinus radiata & 24 & 1 & & & $\mathrm{X}$ & & \\
\hline 0125 & red pine & Pinus resinosa & 4 & 1 & $\mathrm{X}$ & $\mathrm{X}$ & & & $\mathrm{X}$ \\
\hline 0126 & pitch pine & Pinus rigida & 3 & 1 & & $\mathrm{X}$ & & & $\mathrm{X}$ \\
\hline 0127 & $\begin{array}{l}\text { gray pine or California } \\
\text { foothill pine }\end{array}$ & Pinus sabiniana & 24 & 1 & & & $\mathrm{X}$ & & \\
\hline 0128 & pond pine & Pinus serotina & 3 & 1 & & $\mathrm{X}$ & & & $\mathrm{X}$ \\
\hline 0129 & eastern white pine & Pinus strobus & 4 & 1 & $\mathrm{X}$ & $\mathrm{X}$ & & & $\mathrm{X}$ \\
\hline 0130 & Scotch pine & Pinus sylvestris & $3 \mathrm{E}, 24 \mathrm{~W}$ & 1 & $\mathrm{X}$ & $\mathrm{X}$ & $\mathrm{X}$ & $\mathrm{X}$ & $\mathrm{X}$ \\
\hline 0131 & loblolly pine & Pinus taeda & 2 & 1 & $\mathrm{X}$ & $\mathrm{X}$ & & & $\mathrm{X}$ \\
\hline 0132 & Virginia pine & Pinus virginiana & 3 & 1 & $\mathrm{X}$ & $\mathrm{X}$ & & & $\mathrm{X}$ \\
\hline 0133 & singleleaf pinyon & Pinus monophylla & 23 & 1 & & & $X$ & $\mathrm{X}$ & \\
\hline 0134 & border pinyon & Pinus discolor & 23 & 1 & & & & $X$ & \\
\hline 0135 & Arizona pine & Pinus arizonica & 11 & 1 & & & & $\mathrm{X}$ & \\
\hline 0136 & Austrian pine & Pinus nigra & $9 \mathrm{E}, 24 \mathrm{~W}$ & 1 & $\mathrm{X}$ & $\mathrm{X}$ & & $\mathrm{X}$ & $\mathrm{X}$ \\
\hline 0137 & Washoe pine & Pinus washoensis & 24 & 1 & & & $\mathrm{X}$ & $\mathrm{X}$ & \\
\hline 0138 & $\begin{array}{l}\text { four-leaf pine or Parry } \\
\text { pinyon pine }\end{array}$ & Pinus quadrifolia & 24 & 1 & & & $\mathrm{X}$ & & \\
\hline 0139 & Torrey pine & Pinus torreyana & 24 & 1 & & & $\mathrm{X}$ & & \\
\hline 0140 & Mexican pinyon pine & Pinus cembroides & 23 & 1 & & & & $\mathrm{X}$ & $\mathrm{X}$ \\
\hline 0141 & papershell pinyon pine & Pinus remota & 23 & 1 & & & & & $\mathrm{X}$ \\
\hline 0142 & $\begin{array}{l}\text { Great Basin bristlecone } \\
\text { pine }\end{array}$ & Pinus longaeva & 24 & 1 & & & $\mathrm{X}$ & $\mathrm{X}$ & \\
\hline 0143 & Arizona pinyon pine & Pinus monophylla var. fallax & 23 & 1 & & & & $\mathrm{X}$ & \\
\hline 0144 & Honduras pine & Pinus elliottii var. elliottii & $9 \mathrm{E}, 24 \mathrm{~W}$ & 1 & & & & & $\mathrm{X}$ \\
\hline 0200 & Douglas-fir spp. & Pseudotsuga spp. & $9 \mathrm{E}, 10 \mathrm{~W}$ & 2 & $\mathrm{X}$ & & $\mathrm{X}$ & & \\
\hline 0201 & bigcone Douglas-fir & Pseudotsuga macrocarpa & 10 & 2 & & & $\mathrm{X}$ & & \\
\hline 0202 & Douglas-fir & Pseudotsuga menziesii & $9 \mathrm{E}, 10 \mathrm{~W}$ & 2 & $\mathrm{X}$ & $\mathrm{X}$ & $\mathrm{X}$ & $\mathrm{X}$ & \\
\hline 0211 & redwood & Sequoia sempervirens & 16 & 2 & & & $\mathrm{X}$ & & \\
\hline 0212 & giant sequoia & Sequoiadendron giganteum & 24 & 2 & & & $\mathrm{X}$ & & \\
\hline 0220 & baldcypress spp. & Taxodium spp. & $9 \mathrm{E}, 24 \mathrm{~W}$ & 2 & $\mathrm{X}$ & $\mathrm{X}$ & & & $\mathrm{X}$ \\
\hline 0221 & baldcypress & Taxodium distichum & 8 & 2 & $\mathrm{X}$ & $\mathrm{X}$ & & & $\mathrm{X}$ \\
\hline 0222 & pondcypress & Taxodium ascendens & 8 & 2 & & & & & $\mathrm{X}$ \\
\hline 0223 & Montezuma baldcypress & Taxodium mucronatum & 8 & 2 & & & & & $\mathrm{X}$ \\
\hline 0230 & yew spp. & Taxus spp. & $9 \mathrm{E}, 24 \mathrm{~W}$ & 2 & $\mathrm{X}$ & & $\mathrm{X}$ & & \\
\hline 0231 & Pacific yew & Taxus brevifolia & 24 & 2 & & & $\mathrm{X}$ & $\mathrm{X}$ & \\
\hline 0232 & Florida yew & Taxus floridana & $9 \mathrm{E}, 24 \mathrm{~W}$ & 2 & & & & & $\mathrm{X}$ \\
\hline
\end{tabular}




\begin{tabular}{|c|c|c|c|c|c|c|c|c|c|}
\hline \multirow[b]{2}{*}{ SPCD } & \multirow[b]{2}{*}{ COMMON NAME } & \multirow[b]{2}{*}{ SCIENTIFIC NAME } & \multirow[b]{2}{*}{ SPGRPCD } & \multirow[b]{2}{*}{ MAJGRP } & \multicolumn{5}{|c|}{ Occurrence by FIA work unit } \\
\hline & & & & & $\mathrm{NC}$ & NE & PNW & RM & SO \\
\hline 0240 & Thuja spp. & Thuja spp. & $9 \mathrm{E}, 24 \mathrm{~W}$ & 2 & $X$ & & $\mathrm{X}$ & & \\
\hline 0241 & northern white-cedar & Thuja occidentalis & 9 & 2 & $\mathrm{X}$ & $\mathrm{X}$ & & & $\mathrm{X}$ \\
\hline 0242 & western redcedar & Thuja plicata & 22 & 2 & & & $\mathrm{X}$ & $\mathrm{X}$ & \\
\hline 0250 & Torreya (nutmeg) spp. & Torreya spp. & $9 \mathrm{E}, 24 \mathrm{~W}$ & 2 & & & $\mathrm{X}$ & & \\
\hline 0251 & $\begin{array}{l}\text { California torreya } \\
\text { (nutmeg) }\end{array}$ & Torreya californica & 24 & 2 & & & $\mathrm{X}$ & & \\
\hline 0252 & Florida torreya (nutmeg) & Torreya taxifolia & 9 & 2 & & & & & $\mathrm{X}$ \\
\hline 0260 & hemlock spp. & Tsuga spp. & 7 & 2 & $\mathrm{X}$ & & & & $\mathrm{X}$ \\
\hline 0261 & eastern hemlock & Tsuga canadensis & 7 & 2 & $\mathrm{X}$ & $\mathrm{X}$ & & & $\mathrm{X}$ \\
\hline 0262 & Carolina hemlock & Tsuga caroliniana & 7 & 2 & & & & & $\mathrm{X}$ \\
\hline 0263 & western hemlock & Tsuga heterophylla & 13 & 2 & & & $\mathrm{X}$ & $\mathrm{X}$ & \\
\hline 0264 & mountain hemlock & Tsuga mertensiana & 24 & 2 & & & $\mathrm{X}$ & $\mathrm{X}$ & \\
\hline 0299 & Unknown dead conifer & Tree evergreen & $9 \mathrm{E}, 24 \mathrm{~W}$ & 2 & $\mathrm{X}$ & $\mathrm{X}$ & $\mathrm{X}$ & $\mathrm{X}$ & $\mathrm{X}$ \\
\hline 0300 & acacia spp. & Acacia spp. & $41 \mathrm{E}, 48 \mathrm{~W}$ & 3 & & & $\mathrm{X}$ & & \\
\hline 0303 & sweet acacia & Acacia farnesiana & $43 \mathrm{E}, 48 \mathrm{~W}$ & 3 & & & & $\mathrm{X}$ & $\mathrm{X}$ \\
\hline 0304 & catclaw acacia & Acacia greggii & $43 \mathrm{E}, 48 \mathrm{~W}$ & 3 & & & $\mathrm{X}$ & $\mathrm{X}$ & $\mathrm{X}$ \\
\hline 0310 & maple spp. & Acer spp. & 31 & 4 & $\mathrm{X}$ & $\mathrm{X}$ & & & $\mathrm{X}$ \\
\hline 0311 & Florida maple & Acer barbatum & 31 & 4 & & & & & $\mathrm{X}$ \\
\hline 0312 & bigleaf maple & Acer macrophyllum & 47 & 3 & & & $\mathrm{X}$ & & $\mathrm{X}$ \\
\hline 0313 & boxelder & Acer negundo & $41 \mathrm{E}, 47 \mathrm{~W}$ & 3 & $\mathrm{X}$ & $\mathrm{X}$ & $\mathrm{X}$ & $\mathrm{X}$ & $\mathrm{X}$ \\
\hline 0314 & black maple & Acer nigrum & 31 & 4 & $\mathrm{X}$ & $\mathrm{X}$ & & & $\mathrm{X}$ \\
\hline 0315 & striped maple & Acer pensylvanicum & 43 & 3 & $\mathrm{X}$ & $\mathrm{X}$ & & & $\mathrm{X}$ \\
\hline 0316 & red maple & Acer rubrum & 32 & 3 & $\mathrm{X}$ & $\mathrm{X}$ & & & $\mathrm{X}$ \\
\hline 0317 & silver maple & Acer saccharinum & 32 & 3 & $\mathrm{X}$ & $\mathrm{X}$ & & & $\mathrm{X}$ \\
\hline 0318 & sugar maple & Acer saccharum & 31 & 4 & $\mathrm{X}$ & $\mathrm{X}$ & & & $\mathrm{X}$ \\
\hline 0319 & mountain maple & Acer spicatum & 43 & 4 & $\mathrm{X}$ & $\mathrm{X}$ & & & $\mathrm{X}$ \\
\hline 0320 & Norway maple & Acer platanoides & $31 \mathrm{E}, 47 \mathrm{~W}$ & 4 & $\mathrm{X}$ & $\mathrm{X}$ & & & $\mathrm{X}$ \\
\hline 0321 & Rocky Mountain maple & Acer glabrum & $43 \mathrm{E}, 48 \mathrm{~W}$ & 4 & $\mathrm{X}$ & & $\mathrm{X}$ & & \\
\hline 0322 & bigtooth maple & Acer grandidentatum & 48 & 4 & & & $\mathrm{X}$ & $\mathrm{X}$ & \\
\hline 0323 & chalk maple & Acer leucoderme & 31 & 4 & & & & & $\mathrm{X}$ \\
\hline 0330 & $\begin{array}{l}\text { buckeye, horsechestnut } \\
\text { spp. }\end{array}$ & Aesculus spp. & $41 \mathrm{E}, 47 \mathrm{~W}$ & 3 & $\mathrm{X}$ & $\mathrm{X}$ & & & $\mathrm{X}$ \\
\hline 0331 & Ohio buckeye & Aesculus glabra & $41 \mathrm{E}, 47 \mathrm{~W}$ & 3 & $\mathrm{X}$ & $\mathrm{X}$ & & & $\mathrm{X}$ \\
\hline 0332 & yellow buckeye & Aesculus flava & 43 & 3 & $\mathrm{X}$ & $\mathrm{X}$ & & & $\mathrm{X}$ \\
\hline 0333 & California buckeye & Aesculus californica & $41 \mathrm{E}, 47 \mathrm{~W}$ & 3 & & & $\mathrm{X}$ & & \\
\hline 0334 & Texas buckeye & Aesculus glabra var. arguta & 41 & 3 & $\mathrm{X}$ & & & & $\mathrm{X}$ \\
\hline 0336 & red buckeye & Aesculus pavia & $43 \mathrm{E}, 47 \mathrm{~W}$ & 3 & $\mathrm{X}$ & $\mathrm{X}$ & & & $\mathrm{X}$ \\
\hline 0337 & painted buckeye & Aesculus sylvatica & $41 \mathrm{E}, 47 \mathrm{~W}$ & 3 & & $\mathrm{X}$ & & & $\mathrm{X}$ \\
\hline 0341 & ailanthus & Ailanthus altissima & $43 \mathrm{E}, 47 \mathrm{~W}$ & 4 & $\mathrm{X}$ & $\mathrm{X}$ & $\mathrm{X}$ & & $\mathrm{X}$ \\
\hline 0345 & mimosa, silktree & Albizia julibrissin & 43 & 3 & $\mathrm{X}$ & & & & $\mathrm{X}$ \\
\hline 0350 & alder spp. & Alnus spp. & $41 \mathrm{E}, 47 \mathrm{~W}$ & 3 & $\mathrm{X}$ & & $\mathrm{X}$ & & \\
\hline 0351 & red alder & Alnus rubra & 45 & 3 & & & $\mathrm{X}$ & $\mathrm{X}$ & $\mathrm{X}$ \\
\hline 0352 & white alder & Alnus rhombifolia & 47 & 3 & & & $\mathrm{X}$ & $\mathrm{X}$ & \\
\hline 0353 & Arizona alder & Alnus oblongifolia & $43 \mathrm{E}, 47 \mathrm{~W}$ & 3 & & $\mathrm{X}$ & & & \\
\hline 0355 & European alder & Alnus glutinosa & $41 \mathrm{E}, 47 \mathrm{~W}$ & 3 & $\mathrm{X}$ & & & & $\mathrm{X}$ \\
\hline 0356 & serviceberry spp. & Amelanchier spp. & $43 \mathrm{E}, 48 \mathrm{~W}$ & 4 & $\mathrm{X}$ & $\mathrm{X}$ & & & $\mathrm{X}$ \\
\hline 0357 & common serviceberry & Amelanchier arborea & $43 \mathrm{E}, 48 \mathrm{~W}$ & 4 & $\mathrm{X}$ & & & & \\
\hline 0358 & roundleaf serviceberry & Amelanchier sanguinea & $43 \mathrm{E}, 48 \mathrm{~W}$ & 4 & $\mathrm{X}$ & & & & \\
\hline 0360 & Madrone spp. & Arbutus spp. & $43 \mathrm{E}, 47 \mathrm{~W}$ & 4 & & & $\mathrm{X}$ & & \\
\hline 0361 & Pacific madrone & Arbutus menziesii & 47 & 4 & & & $\mathrm{X}$ & $\mathrm{X}$ & \\
\hline 0362 & Arizona madrone & Arbutus arizonica & $43 \mathrm{E}, 47 \mathrm{~W}$ & 4 & & & $\mathrm{X}$ & & \\
\hline 0363 & Texas madrone & Arbutus xalapensis & 48 & 4 & & & & & $\mathrm{X}$ \\
\hline 0367 & pawpaw & Asimina triloba & 43 & 3 & $\mathrm{X}$ & $\mathrm{X}$ & & & $\mathrm{X}$ \\
\hline 0370 & birch spp. & Betula spp. & 41 & 4 & $\mathrm{X}$ & $\mathrm{X}$ & & & $\mathrm{X}$ \\
\hline 0371 & yellow birch & Betula alleghaniensis & 30 & 4 & $\mathrm{X}$ & $\mathrm{X}$ & & & $\mathrm{X}$ \\
\hline 0372 & sweet birch & Betula lenta & 42 & 4 & $\mathrm{X}$ & $\mathrm{X}$ & & & $\mathrm{X}$ \\
\hline 0373 & river birch & Betula nigra & 41 & 3 & $\mathrm{X}$ & $\mathrm{X}$ & & & $\mathrm{X}$ \\
\hline 0374 & water birch & Betula occidentalis & $41 \mathrm{E}, 47 \mathrm{~W}$ & 3 & $\mathrm{X}$ & & $\mathrm{X}$ & & $\mathrm{X}$ \\
\hline 0375 & paper birch & Betula papyrifera & $41 \mathrm{E}, 47 \mathrm{~W}$ & 3 & $\mathrm{X}$ & $\mathrm{X}$ & $\mathrm{X}$ & $\mathrm{X}$ & \\
\hline 0377 & Virginia roundleaf birch & Betula uber & $41 \mathrm{E}, 47 \mathrm{~W}$ & 3 & & & & & $\mathrm{X}$ \\
\hline
\end{tabular}




\begin{tabular}{|c|c|c|c|c|c|c|c|c|c|}
\hline \multirow[b]{2}{*}{ SPCD } & \multirow[b]{2}{*}{ COMMON NAME } & \multirow[b]{2}{*}{ SCIENTIFIC NAME } & \multirow[b]{2}{*}{ SPGRPCD } & \multirow[b]{2}{*}{ MAJGRP } & \multicolumn{5}{|c|}{ Occurrence by FIA work unit } \\
\hline & & & & & NC & NE & PNW & $\mathbf{R M}$ & SO \\
\hline 0378 & northwestern paper birch & Betula $\times$ utahensis & 47 & 3 & & & $\mathrm{X}$ & & \\
\hline 0379 & gray birch & Betula populifolia & 41 & 3 & $\mathrm{X}$ & $\mathrm{X}$ & & & $\mathrm{X}$ \\
\hline 0381 & chittamwood,gum bumelia & $\begin{array}{l}\text { Sideroxylon lanuginosum ssp. } \\
\text { lanuginosum }\end{array}$ & 43 & 4 & $\mathrm{X}$ & & & & $\mathrm{X}$ \\
\hline 0391 & $\begin{array}{l}\text { American hornbeam, } \\
\text { musclewood }\end{array}$ & Carpinus caroliniana & 43 & 4 & $\mathrm{X}$ & $\mathrm{X}$ & & & $\mathrm{X}$ \\
\hline 0400 & hickory spp. & Carya spp. & 29 & 4 & $\mathrm{X}$ & $\mathrm{X}$ & & & $\mathrm{X}$ \\
\hline 0401 & water hickory & Carya aquatica & 29 & 4 & $\mathrm{X}$ & & & & $\mathrm{X}$ \\
\hline 0402 & bitternut hickory & Carya cordiformis & 29 & 4 & $\mathrm{X}$ & $\mathrm{X}$ & & & $\mathrm{X}$ \\
\hline 0403 & pignut hickory & Carya glabra & 29 & 4 & $\mathrm{X}$ & $\mathrm{X}$ & & & $\mathrm{X}$ \\
\hline 0404 & pecan & Carya illinoinensis & $29 \mathrm{E}, 47 \mathrm{~W}$ & 4 & $\mathrm{X}$ & $\mathrm{X}$ & & $\mathrm{X}$ & $\mathrm{X}$ \\
\hline 0405 & shellbark hickory & Carya laciniosa & 29 & 4 & $\mathrm{X}$ & $\mathrm{X}$ & & & $\mathrm{X}$ \\
\hline 0406 & nutmeg hickory & Carya myristiciformis & 29 & 4 & & & & & $\mathrm{X}$ \\
\hline 0407 & shagbark hickory & Carya ovata & 29 & 4 & $\mathrm{X}$ & $\mathrm{X}$ & & & $\mathrm{X}$ \\
\hline 0408 & black hickory & Carya texana & 29 & 4 & $\mathrm{X}$ & & & & $\mathrm{X}$ \\
\hline 0409 & mockernut hickory & Carya alba & 29 & 4 & $\mathrm{X}$ & $\mathrm{X}$ & & & $\mathrm{X}$ \\
\hline 0410 & sand hickory & Carya pallida & 29 & 4 & $\mathrm{X}$ & $\mathrm{X}$ & & & $\mathrm{X}$ \\
\hline 0411 & scrub hickory & Carya floridana & $29 \mathrm{E}, 47 \mathrm{~W}$ & 4 & & & & & $\mathrm{X}$ \\
\hline 0412 & red hickory & Carya ovalis & $29 \mathrm{E}, 47 \mathrm{~W}$ & 4 & $\mathrm{X}$ & $\mathrm{X}$ & & & $\mathrm{X}$ \\
\hline 0413 & southern shagbark hickory & Carya carolinae-septentrionalis & $29 \mathrm{E}, 47 \mathrm{~W}$ & 4 & & & & & $\mathrm{X}$ \\
\hline 0420 & chestnut spp. & Castanea spp. & $43 \mathrm{E}, 47 \mathrm{~W}$ & 3 & $\mathrm{X}$ & $\mathrm{X}$ & & & $\mathrm{X}$ \\
\hline 0421 & American chestnut & Castanea dentata & 43 & 3 & $\mathrm{X}$ & $\mathrm{X}$ & & & $\mathrm{X}$ \\
\hline 0422 & Allegheny chinkapin & Castanea pumila & 43 & 3 & $\mathrm{X}$ & $\mathrm{X}$ & & & $\mathrm{X}$ \\
\hline 0423 & Ozark chinkapin & Castanea pumila var. ozarkensis & 43 & 3 & $\mathrm{X}$ & & & & $\mathrm{X}$ \\
\hline 0424 & Chinese chestnut & Castanea mollissima & $43 \mathrm{E}, 47 \mathrm{~W}$ & 3 & $\mathrm{X}$ & $\mathrm{X}$ & & & $X$ \\
\hline 0431 & $\begin{array}{l}\text { giant chinkapin,golden } \\
\text { chinkapin }\end{array}$ & $\begin{array}{l}\text { Chrysolepis chrysophylla var. } \\
\text { chrysophylla }\end{array}$ & 47 & 3 & & & $\mathrm{X}$ & & \\
\hline 0450 & catalpa spp. & Catalpa spp. & 42 & 4 & $\mathrm{X}$ & $\mathrm{X}$ & & & $\mathrm{X}$ \\
\hline 0451 & southern catalpa & Catalpa bignonioides & 43 & 4 & $\mathrm{X}$ & & & & $\mathrm{X}$ \\
\hline 0452 & northern catalpa & Catalpa speciosa & 41 & 3 & $\mathrm{X}$ & $\mathrm{X}$ & & & $\mathrm{X}$ \\
\hline 0460 & hackberry spp. & Celtis & 41 & 3 & $X$ & $\mathrm{X}$ & & & $\mathrm{X}$ \\
\hline 0461 & sugarberry & Celtis laevigata & $41 \mathrm{E}, 47 \mathrm{~W}$ & 3 & $\mathrm{X}$ & $\mathrm{X}$ & & & $\mathrm{X}$ \\
\hline 0462 & hackberry & Celtis occidentalis & $41 \mathrm{E}, 47 \mathrm{~W}$ & 3 & $\mathrm{X}$ & $\mathrm{X}$ & & & $\mathrm{X}$ \\
\hline 0463 & netleaf hackberry & Celtis laevigata var. reticulata & 41 & 3 & $\mathrm{X}$ & & & & $\mathrm{X}$ \\
\hline 0471 & eastern redbud & Cercis canadensis & 43 & 3 & $\mathrm{X}$ & $\mathrm{X}$ & & & $\mathrm{X}$ \\
\hline 0475 & $\begin{array}{l}\text { curlleaf mountain- } \\
\text { mahogany }\end{array}$ & Cercocarpus ledifolius & 48 & 4 & & & $\mathrm{X}$ & $\mathrm{X}$ & \\
\hline 0481 & yellowwood & Cladrastis kentukea & 43 & 4 & $\mathrm{X}$ & $\mathrm{X}$ & & & $\mathrm{X}$ \\
\hline 0490 & dogwood spp. & Cornus spp. & $43 \mathrm{E}, 47 \mathrm{~W}$ & 4 & $\mathrm{X}$ & $\mathrm{X}$ & $\mathrm{X}$ & & \\
\hline 0491 & flowering dogwood & Cornus florida & 42 & 4 & $\mathrm{X}$ & $\mathrm{X}$ & & & $\mathrm{X}$ \\
\hline 0492 & Pacific dogwood & Cornus nuttallii & 47 & 4 & & & $\mathrm{X}$ & $\mathrm{X}$ & \\
\hline 0500 & hawthorn spp. & Crataegus spp. & $43 \mathrm{E}, 47 \mathrm{~W}$ & 4 & $\mathrm{X}$ & $\mathrm{X}$ & & & $\mathrm{X}$ \\
\hline 0501 & cockspur hawthorn & Crataegus crus-galli & 43 & 4 & $\mathrm{X}$ & $\mathrm{X}$ & & & $\mathrm{X}$ \\
\hline 0502 & downy hawthorn & Crataegus mollis & 43 & 4 & $\mathrm{X}$ & $\mathrm{X}$ & & & $\mathrm{X}$ \\
\hline 0503 & Brainerd's hawthorn & Crataegus brainerdii & $43 \mathrm{E}, 47 \mathrm{~W}$ & 4 & $\mathrm{X}$ & $\mathrm{X}$ & & & $\mathrm{X}$ \\
\hline 0504 & pear hawthorn & Crataegus calpodendron & $43 \mathrm{E}, 47 \mathrm{~W}$ & 4 & $\mathrm{X}$ & $\mathrm{X}$ & & & $\mathrm{X}$ \\
\hline 0505 & fireberry hawthorn & Crataegus chrysocarpa & $43 \mathrm{E}, 47 \mathrm{~W}$ & 4 & $\mathrm{X}$ & $\mathrm{X}$ & & & $\mathrm{X}$ \\
\hline 0506 & broadleaf hawthorn & Crataegus dilatata & $43 \mathrm{E}, 47 \mathrm{~W}$ & 4 & $\mathrm{X}$ & $\mathrm{X}$ & & & $\mathrm{X}$ \\
\hline 0507 & fanleaf hawthorn & Crataegus flabellata & $43 \mathrm{E}, 47 \mathrm{~W}$ & 4 & $\mathrm{X}$ & $\mathrm{X}$ & & & $\mathrm{X}$ \\
\hline 0508 & oneseed hawthorn & Crataegus monogyna & $43 \mathrm{E}, 47 \mathrm{~W}$ & 4 & $\mathrm{X}$ & $\mathrm{X}$ & & & $\mathrm{X}$ \\
\hline 0509 & scarlet hawthorn & Crataegus pedicellata & $43 \mathrm{E}, 47 \mathrm{~W}$ & 4 & $\mathrm{X}$ & $\mathrm{X}$ & & & $\mathrm{X}$ \\
\hline 5091 & Washington hawthorn & Crataegus phaenopyrum & $43 \mathrm{E}, 47 \mathrm{~W}$ & 4 & $\mathrm{X}$ & $\mathrm{X}$ & & & $\mathrm{X}$ \\
\hline 5092 & fleshy hawthorn & Crataegus succulenta & $43 \mathrm{E}, 47 \mathrm{~W}$ & 4 & $\mathrm{X}$ & $\mathrm{X}$ & & & $\mathrm{X}$ \\
\hline 5093 & dwarf hawthorn & Crataegus uniflora & $43 \mathrm{E}, 47 \mathrm{~W}$ & 4 & $X$ & $\mathrm{X}$ & & & $\mathrm{X}$ \\
\hline 0510 & eucalyptus spp. & Eucalyptus spp. & $42 \mathrm{E}, 47 \mathrm{~W}$ & 4 & & & $\mathrm{X}$ & $\mathrm{X}$ & $\mathrm{X}$ \\
\hline 0511 & Tasmanian bluegum & Eucalyptus globulus & $43 \mathrm{E}, 47 \mathrm{~W}$ & 4 & & & $\mathrm{X}$ & & \\
\hline 0512 & river redgum & Eucalyptus camaldulensis & $43 \mathrm{E}, 47 \mathrm{~W}$ & 4 & & & $\mathrm{X}$ & & \\
\hline 0513 & grand eucalyptus & Eucalyptus grandis & $43 \mathrm{E}, 47 \mathrm{~W}$ & 4 & & & $\mathrm{X}$ & & $\mathrm{X}$ \\
\hline 0514 & swampmahogany & Eucalyptus robusta & $43 \mathrm{E}, 47 \mathrm{~W}$ & 4 & & & & & $\mathrm{X}$ \\
\hline 0520 & persimmon spp. & Diospyros spp. & $43 \mathrm{E}, 47 \mathrm{~W}$ & 4 & $\mathrm{X}$ & $\mathrm{X}$ & & & $\mathrm{X}$ \\
\hline 0521 & common persimmon & Diospyros virginiana & 42 & 4 & $\mathrm{X}$ & $\mathrm{X}$ & & & $\mathrm{X}$ \\
\hline
\end{tabular}




\begin{tabular}{|c|c|c|c|c|c|c|c|c|c|}
\hline \multirow[b]{2}{*}{ SPCD } & \multirow[b]{2}{*}{ COMMON NAME } & \multirow[b]{2}{*}{ SCIENTIFIC NAME } & \multirow[b]{2}{*}{ SPGRPCD } & \multirow[b]{2}{*}{ MAJGRP } & \multicolumn{5}{|c|}{ Occurrence by FIA work unit } \\
\hline & & & & & NC & NE & PNW & $\mathbf{R M}$ & SO \\
\hline 0522 & Texas persimmon & Diospyros texana & $43 \mathrm{E}, 47 \mathrm{~W}$ & 4 & & & & & $\mathrm{X}$ \\
\hline 0523 & Anacua knockaway & Ehretia anacua & 48 & 3 & & & & & $\mathrm{X}$ \\
\hline 0531 & American beech & Fagus grandifolia & 33 & 4 & $\mathrm{X}$ & $\mathrm{X}$ & & & $\mathrm{X}$ \\
\hline 0540 & ash spp. & Fraxinus spp. & $36 \mathrm{E}, 47 \mathrm{~W}$ & 3 & $\mathrm{X}$ & $\mathrm{X}$ & $\mathrm{X}$ & & $\mathrm{X}$ \\
\hline 0541 & white ash & Fraxinus americana & 36 & 4 & $\mathrm{X}$ & $\mathrm{X}$ & & & $\mathrm{X}$ \\
\hline 0542 & Oregon ash & Fraxinus latifolia & 47 & 4 & & & $\mathrm{X}$ & & \\
\hline 0543 & black ash & Fraxinus nigra & 36 & 3 & $\mathrm{X}$ & $\mathrm{X}$ & & & $\mathrm{X}$ \\
\hline 0544 & green ash & Fraxinus pennsylvanica & $36 \mathrm{E}, 47 \mathrm{~W}$ & 4 & $\mathrm{X}$ & $\mathrm{X}$ & & $\mathrm{X}$ & $\mathrm{X}$ \\
\hline 0545 & pumpkin ash & Fraxinus profunda & 36 & 3 & $\mathrm{X}$ & $\mathrm{X}$ & & & $\mathrm{X}$ \\
\hline 0546 & blue ash & Fraxinus quadrangulata & 36 & 4 & $\mathrm{X}$ & $\mathrm{X}$ & & & $\mathrm{X}$ \\
\hline 0547 & velvet ash & Fraxinus velutina & 47 & 4 & & & & $\mathrm{X}$ & $\mathrm{X}$ \\
\hline 0548 & Carolina ash & Fraxinus caroliniana & 36 & 4 & & & & & $\mathrm{X}$ \\
\hline 0549 & Texas ash & Fraxinus texensis & $36 \mathrm{E}, 47 \mathrm{~W}$ & 3 & & & & & $\mathrm{X}$ \\
\hline 5491 & Berlandier ash & Fraxinus berlandieriana & 36 & 3 & & & & & $\mathrm{X}$ \\
\hline 0550 & honeylocust spp. & Gleditsia spp. & $42 \mathrm{E}, 47 \mathrm{~W}$ & 4 & $\mathrm{X}$ & $\mathrm{X}$ & $\mathrm{X}$ & & \\
\hline 0551 & waterlocust & Gleditsia aquatica & 42 & 4 & $\mathrm{X}$ & & & & $\mathrm{X}$ \\
\hline 0552 & honeylocust & Gleditsia triacanthos & $42 \mathrm{E}, 47 \mathrm{~W}$ & 4 & $\mathrm{X}$ & $\mathrm{X}$ & & $\mathrm{X}$ & $\mathrm{X}$ \\
\hline 0555 & loblolly-bay & Gordonia lasianthus & 41 & 3 & & & & & $\mathrm{X}$ \\
\hline 0561 & Ginkgo, maidenhair tree & Ginkgo biloba & $43 \mathrm{E}, 47 \mathrm{~W}$ & 3 & $\mathrm{X}$ & $\mathrm{X}$ & $\mathrm{X}$ & & \\
\hline 0571 & Kentucky coffeetree & Gymnocladus dioicus & 42 & 4 & $\mathrm{X}$ & $\mathrm{X}$ & & & $\mathrm{X}$ \\
\hline 0580 & silverbell spp. & Halesia spp. & 43 & 3 & $\mathrm{X}$ & $\mathrm{X}$ & & & $\mathrm{X}$ \\
\hline 0581 & Carolina silverbell & Halesia carolina & $41 \mathrm{E}, 47 \mathrm{~W}$ & 3 & & & & & $\mathrm{X}$ \\
\hline 0582 & two-wing silverbell & Halesia diptera & $41 \mathrm{E}, 47 \mathrm{~W}$ & 3 & & & & & $\mathrm{X}$ \\
\hline 0583 & little silverbell & Halesia parviflora & $41 \mathrm{E}, 47 \mathrm{~W}$ & 3 & & & & & $\mathrm{X}$ \\
\hline 0591 & American holly & Ilex opaca & $42 \mathrm{E}, 47 \mathrm{~W}$ & 4 & $\mathrm{X}$ & $\mathrm{X}$ & $\mathrm{X}$ & & $\mathrm{X}$ \\
\hline 0600 & walnut spp. & Juglans spp. & $41 \mathrm{E}, 47 \mathrm{~W}$ & 4 & $\mathrm{X}$ & $\mathrm{X}$ & $\mathrm{X}$ & $\mathrm{X}$ & $\mathrm{X}$ \\
\hline 0601 & butternut & Juglans cinerea & 41 & 3 & $\mathrm{X}$ & $\mathrm{X}$ & & & $\mathrm{X}$ \\
\hline 0602 & black walnut & Juglans nigra & $40 \mathrm{E}, 47 \mathrm{~W}$ & 4 & $\mathrm{X}$ & $\mathrm{X}$ & $\mathrm{X}$ & $\mathrm{X}$ & $\mathrm{X}$ \\
\hline 0603 & $\begin{array}{l}\text { northern California black } \\
\text { walnut }\end{array}$ & Juglans hindsii & 47 & 4 & & & $\mathrm{X}$ & & \\
\hline 0604 & $\begin{array}{l}\text { southern California black } \\
\text { walnut }\end{array}$ & Juglans californica & 47 & 4 & & & $\mathrm{X}$ & & \\
\hline 0605 & Texas walnut & Juglans microcarpa & $41 \mathrm{E}, 47 \mathrm{~W}$ & 4 & $\mathrm{X}$ & & & & $\mathrm{X}$ \\
\hline 0606 & Arizona walnut & Juglans major & $43 \mathrm{E}, 47 \mathrm{~W}$ & 4 & & & $\mathrm{X}$ & & \\
\hline 0611 & sweetgum & Liquidambar styraciflua & $34 \mathrm{E}, 47 \mathrm{~W}$ & 3 & $\mathrm{X}$ & $\mathrm{X}$ & & & $\mathrm{X}$ \\
\hline 0621 & yellow-poplar & Liriodendron tulipifera & 39 & 3 & $\mathrm{X}$ & $\mathrm{X}$ & & & $\mathrm{X}$ \\
\hline 0631 & tanoak & Lithocarpus densiflorus & 47 & 4 & & & $\mathrm{X}$ & & \\
\hline 0641 & Osage-orange & Maclura pomifera & 43 & 4 & $\mathrm{X}$ & $\mathrm{X}$ & & & $\mathrm{X}$ \\
\hline 0650 & magnolia spp. & Magnolia spp. & 41 & 3 & $\mathrm{X}$ & $\mathrm{X}$ & & & $\mathrm{X}$ \\
\hline 0651 & cucumbertree & Magnolia acuminata & 41 & 3 & $\mathrm{X}$ & $\mathrm{X}$ & & & $\mathrm{X}$ \\
\hline 0652 & southern magnolia & Magnolia grandiflora & 41 & 3 & & $\mathrm{X}$ & & & $\mathrm{X}$ \\
\hline 0653 & sweetbay & Magnolia virginiana & 43 & 3 & & $\mathrm{X}$ & & & $\mathrm{X}$ \\
\hline 0654 & bigleaf magnolia & Magnolia macrophylla & 43 & 4 & & $\mathrm{X}$ & & & $\mathrm{X}$ \\
\hline 0655 & $\begin{array}{l}\text { mountain or Fraser } \\
\text { magnolia }\end{array}$ & Magnolia fraseri & 41 & 3 & & $\mathrm{X}$ & & & $\mathrm{X}$ \\
\hline 0657 & pyramid magnolia & Magnolia pyramidata & $41 \mathrm{E}, 47 \mathrm{~W}$ & 3 & & & & & $\mathrm{X}$ \\
\hline 0658 & umbrella magnolia & Magnolia tripetala & $41 \mathrm{E}, 47 \mathrm{~W}$ & 3 & & $\mathrm{X}$ & $\mathrm{X}$ & & $\mathrm{X}$ \\
\hline 0660 & apple spp. & Malus spp. & $43 \mathrm{E}, 47 \mathrm{~W}$ & 4 & $\mathrm{X}$ & $\mathrm{X}$ & $\mathrm{X}$ & $\mathrm{X}$ & $\mathrm{X}$ \\
\hline 0661 & Oregon crab apple & Malus fusca & 47 & 4 & & & $\mathrm{X}$ & & \\
\hline 0662 & southern crabapple & Malus angustifolia & $43 \mathrm{E}, 47 \mathrm{~W}$ & 4 & $\mathrm{X}$ & $\mathrm{X}$ & & & $\mathrm{X}$ \\
\hline 0663 & sweet crabapple & Malus coronaria & $43 \mathrm{E}, 47 \mathrm{~W}$ & 4 & $\mathrm{X}$ & $\mathrm{X}$ & & & $\mathrm{X}$ \\
\hline 0664 & prairie crabapple & Malus ioensis & $43 \mathrm{E}, 47 \mathrm{~W}$ & 4 & $\mathrm{X}$ & & & & \\
\hline 0680 & mulberry spp. & Morus spp. & 42 & 4 & $\mathrm{X}$ & $\mathrm{X}$ & & $\mathrm{X}$ & $\mathrm{X}$ \\
\hline 0681 & white mulberry & Morus alba & 42 & 4 & $\mathrm{X}$ & $\mathrm{X}$ & & & $\mathrm{X}$ \\
\hline 0682 & red mulberry & Morus rubra & 42 & 4 & $\mathrm{X}$ & $\mathrm{X}$ & & & $\mathrm{X}$ \\
\hline 0683 & Texas mulberry & Morus microphylla & $42 \mathrm{E}, 47 \mathrm{~W}$ & 4 & & & & & $\mathrm{X}$ \\
\hline 0684 & black mulberry & Morus nigra & $43 \mathrm{E}, 47 \mathrm{~W}$ & 4 & & $\mathrm{X}$ & & & $\mathrm{X}$ \\
\hline 0690 & tupelo spp. & Nyssa spp. & $35 \mathrm{E}, 47 \mathrm{~W}$ & 3 & $\mathrm{X}$ & $\mathrm{X}$ & & & $\mathrm{X}$ \\
\hline 0691 & water tupelo & Nyssa aquatica & 35 & 3 & $\mathrm{X}$ & & & & $\mathrm{X}$ \\
\hline 0692 & Ogeechee tupelo & Nyssa ogeche & 43 & 4 & & & & & $\mathrm{X}$ \\
\hline
\end{tabular}




\begin{tabular}{|c|c|c|c|c|c|c|c|c|c|}
\hline \multirow[b]{2}{*}{ SPCD } & \multirow[b]{2}{*}{ COMMON NAME } & \multirow[b]{2}{*}{ SCIENTIFIC NAME } & \multirow[b]{2}{*}{ SPGRPCD } & \multirow[b]{2}{*}{ MAJGRP } & \multicolumn{5}{|c|}{ Occurrence by FIA work unit } \\
\hline & & & & & NC & NE & PNW & $\mathbf{R M}$ & SO \\
\hline 0693 & blackgum & Nyssa sylvatica & 35 & 3 & $\mathrm{X}$ & $\mathrm{X}$ & & & $\mathrm{X}$ \\
\hline 0694 & swamp tupelo & Nyssa biflora & 35 & 3 & $\mathrm{X}$ & $\mathrm{X}$ & & & $\mathrm{X}$ \\
\hline 0701 & eastern hophornbeam & Ostrya virginiana & 43 & 4 & $\mathrm{X}$ & $\mathrm{X}$ & & & $\mathrm{X}$ \\
\hline 0711 & sourwood & Oxydendrum arboreum & 43 & 4 & $\mathrm{X}$ & $\mathrm{X}$ & & & $\mathrm{X}$ \\
\hline 0712 & paulownia, empress-tree & Paulownia tomentosa & 41 & 3 & $\mathrm{X}$ & $\mathrm{X}$ & & & $\mathrm{X}$ \\
\hline 0720 & bay spp. & Persea spp. & $43 \mathrm{E}, 47 \mathrm{~W}$ & 3 & & $\mathrm{X}$ & & & $\mathrm{X}$ \\
\hline 0721 & redbay & Persea borbonia & 41 & 3 & & & & & $\mathrm{X}$ \\
\hline 7211 & avocado & Persea americana & $43 \mathrm{E}, 47 \mathrm{~W}$ & 3 & & & & & $\mathrm{X}$ \\
\hline 0722 & water-elm, planertree & Planera aquatica & 43 & 3 & $X$ & & & & $\mathrm{X}$ \\
\hline 0729 & Sycamore spp. & Platanus spp. & $41 \mathrm{E}, 47 \mathrm{~W}$ & 3 & $X$ & $X$ & $X$ & & \\
\hline 0730 & California sycamore & Platanus racemosa & 47 & 3 & & & $X$ & & \\
\hline 0731 & American sycamore & Platanus occidentalis & $41 \mathrm{E}, 47 \mathrm{~W}$ & 3 & $\mathrm{X}$ & $\mathrm{X}$ & $X$ & $X$ & $\mathrm{X}$ \\
\hline 0732 & Arizona sycamore & Platanus wrightii & $41 \mathrm{E}, 47 \mathrm{~W}$ & 3 & & & $\mathrm{X}$ & & \\
\hline 0741 & balsam poplar & Populus balsamifera & $37 \mathrm{E}, 44 \mathrm{~W}$ & 3 & $\mathrm{X}$ & $\mathrm{X}$ & & $\mathrm{X}$ & $\mathrm{X}$ \\
\hline 0742 & eastern cottonwood & Populus deltoides & $37 \mathrm{E}, 44 \mathrm{~W}$ & 3 & $\mathrm{X}$ & $\mathrm{X}$ & & $\mathrm{X}$ & $\mathrm{X}$ \\
\hline 0743 & bigtooth aspen & Populus grandidentata & 37 & 3 & $\mathrm{X}$ & $\mathrm{X}$ & & & $\mathrm{X}$ \\
\hline 0744 & swamp cottonwood & Populus heterophylla & 37 & 3 & $\mathrm{X}$ & $\mathrm{X}$ & & & $\mathrm{X}$ \\
\hline 0745 & plains cottonwood & $\begin{array}{l}\text { Populus deltoides ssp. } \\
\text { monilifera }\end{array}$ & $37 \mathrm{E}, 44 \mathrm{~W}$ & 3 & $\mathrm{X}$ & & & $\mathrm{X}$ & \\
\hline 0746 & quaking aspen & Populus tremuloides & $37 \mathrm{E}, 44 \mathrm{~W}$ & 3 & $\mathrm{X}$ & $\mathrm{X}$ & $\mathrm{X}$ & $\mathrm{X}$ & $\mathrm{X}$ \\
\hline 0747 & black cottonwood & $\begin{array}{l}\text { Populus balsamifera ssp. } \\
\text { trichocarpa }\end{array}$ & $37 \mathrm{E}, 44 \mathrm{~W}$ & 4 & $\mathrm{X}$ & & $\mathrm{X}$ & $\mathrm{X}$ & \\
\hline 0748 & Fremont cottonwood & Populus fremontii & $37 \mathrm{E}, 44 \mathrm{~W}$ & 4 & & & $X$ & $X$ & $\mathrm{X}$ \\
\hline 0749 & narrowleaf cottonwood & Populus angustifolia & $37 \mathrm{E}, 44 \mathrm{~W}$ & 3 & $\mathrm{X}$ & & & $X$ & $\mathrm{X}$ \\
\hline 0752 & silver poplar & Populus alba & 37 & 3 & $X$ & & & & $\mathrm{X}$ \\
\hline 0753 & Lombardy poplar & Populus nigra & $37 \mathrm{E}, 44 \mathrm{~W}$ & 3 & $X$ & $\mathrm{X}$ & $X$ & & \\
\hline 0755 & mesquite spp. & Prosopis spp. & 48 & 4 & & & & & $\mathrm{X}$ \\
\hline 0757 & velvet mesquite & Prosopis velutina & 48 & 4 & & & $\mathrm{X}$ & $X$ & $\mathrm{X}$ \\
\hline 0758 & screwbean mesquite & Prosopis pubescens & 48 & 4 & & & $\mathrm{X}$ & $X$ & $\mathrm{X}$ \\
\hline 0760 & cherry and plum spp. & Prunus spp. & $43 \mathrm{E}, 47 \mathrm{~W}$ & 4 & $\mathrm{X}$ & $\mathrm{X}$ & $\mathrm{X}$ & & $\mathrm{X}$ \\
\hline 0761 & pin cherry & Prunus pensylvanica & 43 & 3 & $\mathrm{X}$ & $\mathrm{X}$ & & & $\mathrm{X}$ \\
\hline 0762 & black cherry & Prunus serotina & 41 & 3 & $\mathrm{X}$ & $\mathrm{X}$ & & & $\mathrm{X}$ \\
\hline 0763 & chokecherry & Prunus virginiana & $43 \mathrm{E}, 47 \mathrm{~W}$ & 4 & $\mathrm{X}$ & $\mathrm{X}$ & $\mathrm{X}$ & & $\mathrm{X}$ \\
\hline 0764 & peach & Prunus persica & $43 \mathrm{E}, 47 \mathrm{~W}$ & 3 & $\mathrm{X}$ & $\mathrm{X}$ & & & $\mathrm{X}$ \\
\hline 0765 & Canada plum & Prunus nigra & 43 & 4 & $\mathrm{X}$ & & & & \\
\hline 0766 & American plum & Prunus americana & 43 & 4 & $\mathrm{X}$ & $\mathrm{X}$ & & & $\mathrm{X}$ \\
\hline 0768 & bitter cherry & Prunus emarginata & 47 & 4 & & & $\mathrm{X}$ & & \\
\hline 0769 & Allegheny plum & Prunus alleghaniensis & $43 \mathrm{E}, 47 \mathrm{~W}$ & 3 & $\mathrm{X}$ & $\mathrm{X}$ & & & $\mathrm{X}$ \\
\hline 0770 & Chickasaw plum & Prunus angustifolia & $43 \mathrm{E}, 47 \mathrm{~W}$ & 3 & $X$ & $X$ & & & $\mathrm{X}$ \\
\hline 0771 & sweet cherry, domesticated & Prunus avium & $43 \mathrm{E}, 47 \mathrm{~W}$ & 3 & $\mathrm{X}$ & $\mathrm{X}$ & $\mathrm{X}$ & & \\
\hline 0772 & sour cherry, domesticated & Prunus cerasus & $43 \mathrm{E}, 47 \mathrm{~W}$ & 3 & $\mathrm{X}$ & $\mathrm{X}$ & $\mathrm{X}$ & & \\
\hline 0773 & $\begin{array}{l}\text { European plum, } \\
\text { domesticated }\end{array}$ & Prunus domestica & $43 \mathrm{E}, 47 \mathrm{~W}$ & 3 & $\mathrm{X}$ & $\mathrm{X}$ & $\mathrm{X}$ & & \\
\hline 0774 & $\begin{array}{l}\text { Mahaleb cherry, } \\
\text { domesticated }\end{array}$ & Prunus mahaleb & $43 \mathrm{E}, 47 \mathrm{~W}$ & 3 & $\mathrm{X}$ & $\mathrm{X}$ & $\mathrm{X}$ & & \\
\hline 0800 & oak spp & Quercus spp. & $42 \mathrm{E}, 48 \mathrm{~W}$ & 4 & $\mathrm{X}$ & $\mathrm{X}$ & $\mathrm{X}$ & & $\mathrm{X}$ \\
\hline 0801 & California live oak & Quercus agrifolia & 46 & 4 & & & $\mathrm{X}$ & & \\
\hline 0802 & white oak & Quercus alba & 25 & 4 & $\mathrm{X}$ & $\mathrm{X}$ & & & $\mathrm{X}$ \\
\hline 0803 & Arizona white oak & Quercus arizonica & 48 & 4 & & & & $\mathrm{X}$ & $\mathrm{X}$ \\
\hline 0804 & swamp white oak & Quercus bicolor & 25 & 4 & $\mathrm{X}$ & $\mathrm{X}$ & & & $\mathrm{X}$ \\
\hline 0805 & canyon live oak & Quercus chrysolepis & 46 & 4 & & & $\mathrm{X}$ & & \\
\hline 0806 & scarlet oak & Quercus coccinea & 28 & 4 & $X$ & $\mathrm{X}$ & & & $\mathrm{X}$ \\
\hline 0807 & blue oak & Quercus douglasii & 46 & 4 & & & $X$ & & \\
\hline 0808 & Durand oak & Quercus sinuata var. sinuata & 25 & 4 & & & & & $\mathrm{X}$ \\
\hline 0809 & northern pin oak & Quercus ellipsoidalis & 28 & 4 & $X$ & $\mathrm{X}$ & & & $\mathrm{X}$ \\
\hline 0810 & Emory oak & Quercus emoryi & 48 & 4 & & & & $X$ & $\mathrm{X}$ \\
\hline
\end{tabular}




\begin{tabular}{|c|c|c|c|c|c|c|c|c|c|}
\hline \multirow[b]{2}{*}{ SPCD } & \multirow[b]{2}{*}{ COMMON NAME } & \multirow[b]{2}{*}{ SCIENTIFIC NAME } & \multirow[b]{2}{*}{ SPGRPCD } & \multirow[b]{2}{*}{ MAJGRP } & \multicolumn{5}{|c|}{ Occurrence by FIA work unit } \\
\hline & & & & & NC & NE & PNW & RM & SO \\
\hline 0813 & cherrybark oak & Quercus pagoda & 26 & 4 & $\mathrm{X}$ & $\mathrm{X}$ & & & $\mathrm{X}$ \\
\hline 0814 & Gambel oak & Quercus gambelii & 48 & 4 & & & & $\mathrm{X}$ & $\mathrm{X}$ \\
\hline 0815 & Oregon white oak & Quercus garryana & 46 & 4 & & & $\mathrm{X}$ & & \\
\hline 0816 & scrub oak & Quercus ilicifolia & 43 & 4 & & $\mathrm{X}$ & & & $\mathrm{X}$ \\
\hline 0817 & shingle oak & Quercus imbricaria & 28 & 4 & $\mathrm{X}$ & $\mathrm{X}$ & & & $\mathrm{X}$ \\
\hline 0818 & California black oak & Quercus kelloggii & 46 & 4 & & & $\mathrm{X}$ & & \\
\hline 0819 & turkey oak & Quercus laevis & 43 & 4 & & & & & $\mathrm{X}$ \\
\hline 0820 & laurel oak & Quercus laurifolia & 28 & 4 & & $\mathrm{X}$ & & & $\mathrm{X}$ \\
\hline 0821 & California white oak & Quercus lobata & 46 & 4 & & & $\mathrm{X}$ & & \\
\hline 0822 & overcup oak & Quercus lyrata & 27 & 4 & $\mathrm{X}$ & $\mathrm{X}$ & & & $\mathrm{X}$ \\
\hline 0823 & bur oak & Quercus macrocarpa & $25 \mathrm{E}, 47 \mathrm{~W}$ & 4 & $\mathrm{X}$ & $\mathrm{X}$ & & $\mathrm{X}$ & $\mathrm{X}$ \\
\hline 0824 & blackjack oak & Quercus marilandica & 28 & 4 & $\mathrm{X}$ & $\mathrm{X}$ & & & $\mathrm{X}$ \\
\hline 0825 & swamp chestnut oak & Quercus michauxii & 25 & 4 & $\mathrm{X}$ & $\mathrm{X}$ & & & $\mathrm{X}$ \\
\hline 0826 & chinkapin oak & Quercus muehlenbergii & $25 \mathrm{E}, 47 \mathrm{~W}$ & 4 & $\mathrm{X}$ & $\mathrm{X}$ & & $\mathrm{X}$ & $\mathrm{X}$ \\
\hline 0827 & water oak & Quercus nigra & 28 & 4 & $\mathrm{X}$ & $\mathrm{X}$ & & & $\mathrm{X}$ \\
\hline 0828 & Texas red oak & Quercus texana & 28 & 4 & $\mathrm{X}$ & & & & $\mathrm{X}$ \\
\hline 0829 & Mexican blue oak & Quercus oblongifolia & 48 & 4 & & & & $\mathrm{X}$ & \\
\hline 0830 & pin oak & Quercus palustris & 28 & 4 & $\mathrm{X}$ & $\mathrm{X}$ & & & $\mathrm{X}$ \\
\hline 0831 & willow oak & Quercus phellos & 28 & 4 & $\mathrm{X}$ & $\mathrm{X}$ & & & $\mathrm{X}$ \\
\hline 0832 & chestnut oak & Quercus prinus & 27 & 4 & $\mathrm{X}$ & $\mathrm{X}$ & & & $\mathrm{X}$ \\
\hline 0833 & northern red oak & Quercus rubra & 26 & 4 & $\mathrm{X}$ & $\mathrm{X}$ & & & $\mathrm{X}$ \\
\hline 0834 & Shumard oak & Quercus shumardii & 26 & 4 & $\mathrm{X}$ & $\mathrm{X}$ & & & $\mathrm{X}$ \\
\hline 0835 & post oak & Quercus stellata & 27 & 4 & $\mathrm{X}$ & $\mathrm{X}$ & & & $\mathrm{X}$ \\
\hline 0836 & Delta post oak & Quercus similis & 27 & 4 & & & & & $\mathrm{X}$ \\
\hline 0837 & black oak & Quercus velutina & 28 & 4 & $\mathrm{X}$ & $\mathrm{X}$ & & & $\mathrm{X}$ \\
\hline 0838 & live oak & Quercus virginiana & 27 & 4 & & & & & $\mathrm{X}$ \\
\hline 0839 & interior live oak & Quercus wislizeni & 46 & 4 & & & $\mathrm{X}$ & & \\
\hline 0840 & dwarf post oak & Quercus margarettiae & 27 & 4 & $\mathrm{X}$ & & & & $\mathrm{X}$ \\
\hline 0841 & dwarf live oak & Quercus minima & 27 & 4 & & & & & $\mathrm{X}$ \\
\hline 0842 & bluejack oak & Quercus incana & 43 & 4 & & & & & $\mathrm{X}$ \\
\hline 0843 & silverleaf oak & Quercus hypoleucoides & 48 & 4 & & & & $\mathrm{X}$ & $\mathrm{X}$ \\
\hline 0844 & Oglethorpe oak & Quercus oglethorpensis & 27 & 4 & & & & & $\mathrm{X}$ \\
\hline 0845 & dwarf chinkapin oak & Quercus prinoides & 43 & 4 & $\mathrm{X}$ & & & & $\mathrm{X}$ \\
\hline 0846 & gray oak & Quercus grisea & 48 & 4 & & & & $\mathrm{X}$ & $\mathrm{X}$ \\
\hline 0847 & netleaf oak & Quercus rugosa & $43 \mathrm{E}, 48 \mathrm{~W}$ & 4 & & & & $\mathrm{X}$ & \\
\hline 0851 & Chisos oak & Quercus gracilliformis & 26 & 4 & & & & & $\mathrm{X}$ \\
\hline 8511 & Graves oak & Quercus gravesii & 26 & 4 & & & & & $\mathrm{X}$ \\
\hline 8512 & Mexican white oak & Quercus polymorpha & 26 & 4 & & & & & $\mathrm{X}$ \\
\hline 8513 & Buckley oak & Quercus buckleyi & 26 & 4 & & & & & $\mathrm{X}$ \\
\hline 8514 & Lacey oak & Quercus laceyi & 26 & 4 & & & & & $\mathrm{X}$ \\
\hline 0852 & sea torchwood & Amyris elemifera & $43 \mathrm{E}, 47 \mathrm{~W}$ & 3 & & & & & $\mathrm{X}$ \\
\hline 0853 & pond-apple & Annona glabra & $43 \mathrm{E}, 47 \mathrm{~W}$ & 3 & & & & & $\mathrm{X}$ \\
\hline 0854 & gumbo limbo & Bursera simaruba & $43 \mathrm{E}, 47 \mathrm{~W}$ & 3 & & & & & $\mathrm{X}$ \\
\hline 0855 & sheoak spp. & Casuarina spp. & $43 \mathrm{E}, 47 \mathrm{~W}$ & 3 & & & & & $\mathrm{X}$ \\
\hline 0856 & gray sheoak & Casuarina glauca & $43 \mathrm{E}, 47 \mathrm{~W}$ & 3 & & & & & $\mathrm{X}$ \\
\hline 0857 & belah & Casuarina lepidophloia & $43 \mathrm{E}, 47 \mathrm{~W}$ & 3 & & & & & $\mathrm{X}$ \\
\hline 0858 & camphortree & Cinnamomum camphora & $43 \mathrm{E}, 47 \mathrm{~W}$ & 3 & & & & & $\mathrm{X}$ \\
\hline 0859 & Florida fiddlewood & Citharexylum fruticosum & $43 \mathrm{E}, 47 \mathrm{~W}$ & 3 & & & & & $\mathrm{X}$ \\
\hline 0860 & citrus spp. & Citrus spp. & $43 \mathrm{E}, 47 \mathrm{~W}$ & 3 & & & & & $\mathrm{X}$ \\
\hline 0863 & tietongue, pigeon-plum & Coccoloba diversifolia & $43 \mathrm{E}, 47 \mathrm{~W}$ & 3 & & & & & $\mathrm{X}$ \\
\hline 0864 & soldierwood & Colubrina elliptica & $43 \mathrm{E}, 47 \mathrm{~W}$ & 3 & & & & & $\mathrm{X}$ \\
\hline 0865 & longleaf geigertree & Cordia sebestena & $43 \mathrm{E}, 47 \mathrm{~W}$ & 3 & & & & & $\mathrm{X}$ \\
\hline 8651 & Anacahuita Texas Olive & Cordia boissieri & 27 & 4 & & & & & $\mathrm{X}$ \\
\hline 0866 & carrotwood & Cupaniopsis anacardioides & $43 \mathrm{E}, 47 \mathrm{~W}$ & 3 & & & & & $\mathrm{X}$ \\
\hline 0867 & bluewood & Condalia hookeri & 48 & 4 & & & & & $\mathrm{X}$ \\
\hline 0868 & blackbead ebony & Ebenopsis ebano & $42 \mathrm{E}, 47 \mathrm{~W}$ & 4 & & & & & $\mathrm{X}$ \\
\hline 0869 & great leadtree & Leucaena pulverulenta & 43 & 3 & & & & & $\mathrm{X}$ \\
\hline 0870 & Texas sophora & Sophora affinis & $42 \mathrm{E}$ & 4 & & & & & $\mathrm{X}$ \\
\hline 0873 & red stopper & Eugenia rhombea & $43 \mathrm{E}, 47 \mathrm{~W}$ & 3 & & & & & $\mathrm{X}$ \\
\hline 0874 & butterbough, inkwood & Exothea paniculata & $43 \mathrm{E}, 47 \mathrm{~W}$ & 3 & & & & & $\mathrm{X}$ \\
\hline
\end{tabular}




\begin{tabular}{|c|c|c|c|c|c|c|c|c|c|}
\hline \multirow[b]{2}{*}{ SPCD } & \multirow[b]{2}{*}{ COMMON NAME } & \multirow[b]{2}{*}{ SCIENTIFIC NAME } & \multirow[b]{2}{*}{ SPGRPCD } & \multirow[b]{2}{*}{ MAJGRP } & \multicolumn{5}{|c|}{ Occurrence by FIA work unit } \\
\hline & & & & & NC & NE & PNW & $\mathbf{R M}$ & SO \\
\hline 0876 & Florida strangler fig & Ficus aurea & $43 \mathrm{E}, 47 \mathrm{~W}$ & 3 & & & & & $\mathrm{X}$ \\
\hline 0877 & $\begin{array}{l}\text { wild banyantree, shortleaf } \\
\text { fig }\end{array}$ & Ficus citrifolia & $43 \mathrm{E}, 47 \mathrm{~W}$ & 3 & & & & & $\mathrm{X}$ \\
\hline 0882 & beeftree, longleaf blolly & Guapira discolor & $43 \mathrm{E}, 47 \mathrm{~W}$ & 3 & & & & & $\mathrm{X}$ \\
\hline 0883 & manchineel & Hippomane mancinella & $43 \mathrm{E}, 47 \mathrm{~W}$ & 3 & & & & & $\mathrm{X}$ \\
\hline 0884 & false tamarind & Lysiloma latisiliquum & $43 \mathrm{E}, 47 \mathrm{~W}$ & 3 & & & & & $\mathrm{X}$ \\
\hline 0885 & mango & Mangifera indica & $43 \mathrm{E}, 47 \mathrm{~W}$ & 3 & & & & & $\mathrm{X}$ \\
\hline 0886 & Florida poisontree & Metopium toxiferum & $43 \mathrm{E}, 47 \mathrm{~W}$ & 3 & & & & & $\mathrm{X}$ \\
\hline 0887 & fishpoison tree & Piscidia piscipula & $43 \mathrm{E}, 47 \mathrm{~W}$ & 3 & & & & & $\mathrm{X}$ \\
\hline 0888 & octopus tree, schefflera & Schefflera actinophylla & $43 \mathrm{E}, 47 \mathrm{~W}$ & 3 & & & & & $\mathrm{X}$ \\
\hline 0890 & false mastic & Sideroxylon foetidissimum & $43 \mathrm{E}, 47 \mathrm{~W}$ & 3 & & & & & $\mathrm{X}$ \\
\hline 0891 & white bully, willow bustic & Sideroxylon salicifolium & $43 \mathrm{E}, 47 \mathrm{~W}$ & 3 & & & & & $\mathrm{X}$ \\
\hline 0895 & paradisetree & Simarouba glauca & $43 \mathrm{E}, 47 \mathrm{~W}$ & 3 & & & & & $\mathrm{X}$ \\
\hline 0897 & tamarind & Tamarindus indica & $43 \mathrm{E}, 47 \mathrm{~W}$ & 3 & & & & & $\mathrm{X}$ \\
\hline 0901 & black locust & Robinia pseudoacacia & $42 \mathrm{E}, 47 \mathrm{~W}$ & 4 & $\mathrm{X}$ & $X$ & $\mathrm{X}$ & & $X$ \\
\hline 0902 & New Mexico locust & Robinia neomexicana & 48 & 4 & & & & $\mathrm{X}$ & $\mathrm{X}$ \\
\hline 0906 & $\begin{array}{l}\text { Everglades palm, paurotis- } \\
\text { palm }\end{array}$ & Acoelorraphe wrightii & $43 \mathrm{E}, 47 \mathrm{~W}$ & 3 & & & & & $\mathrm{X}$ \\
\hline 0907 & Florida silver palm & Coccothrinax argentata & $43 \mathrm{E}, 47 \mathrm{~W}$ & 3 & & & & & $\mathrm{X}$ \\
\hline 0908 & coconut palm & Cocos nucifera & $43 \mathrm{E}, 47 \mathrm{~W}$ & 3 & & & & & $\mathrm{X}$ \\
\hline 0909 & royal palm spp. & Roystonea spp. & $43 \mathrm{E}, 47 \mathrm{~W}$ & 3 & & & & & $X$ \\
\hline 0911 & Mexican palmetto & Sabal Mexicana & $41 \mathrm{E}$ & 3 & & & & & $X$ \\
\hline 0912 & cabbage palmetto & Sabal palmetto & $43 \mathrm{E}, 47 \mathrm{~W}$ & 3 & & & & & $\mathrm{X}$ \\
\hline 0913 & key thatch palm & Thrinax morrisii & $43 \mathrm{E}, 47 \mathrm{~W}$ & 3 & & & & & $\mathrm{X}$ \\
\hline 0914 & Florida thatch palm & Thrinax radiata & $43 \mathrm{E}, 47 \mathrm{~W}$ & 3 & & & & & $\mathrm{X}$ \\
\hline 0915 & other palms & $\begin{array}{l}\text { Family Arecaceae not listed } \\
\text { above }\end{array}$ & $43 \mathrm{E}, 47 \mathrm{~W}$ & 3 & & & & & $X$ \\
\hline 0919 & western soapberry & $\begin{array}{l}\text { Sapindus saponaria var. } \\
\text { drummondii }\end{array}$ & 43 & 4 & $\mathrm{X}$ & & & & $\mathrm{X}$ \\
\hline 0921 & peachleaf willow & Salix amygdaloides & 43 & 3 & $X$ & & & & $X$ \\
\hline 0922 & black willow & Salix nigra & $41 \mathrm{E}, 47 \mathrm{~W}$ & 3 & $\mathrm{X}$ & $\mathrm{X}$ & $\mathrm{X}$ & & $\mathrm{X}$ \\
\hline 0923 & Bebb willow & Salix bebbiana & $43 \mathrm{E}, 47 \mathrm{~W}$ & 3 & $\mathrm{X}$ & & & & \\
\hline 0924 & Bonpland willow & Salix bonplandiana & $41 \mathrm{E}, 47 \mathrm{~W}$ & 3 & & & & & $\mathrm{X}$ \\
\hline 0925 & coastal plain willow & Salix caroliniana & $43 \mathrm{E}, 47 \mathrm{~W}$ & 3 & $X$ & $\mathrm{X}$ & & & $\mathrm{X}$ \\
\hline 0926 & balsam willow & Salix pyrifolia & $43 \mathrm{E}, 47 \mathrm{~W}$ & 3 & $X$ & $\mathrm{X}$ & & & \\
\hline 0927 & white willow & Salix alba & 41 & 3 & $\mathrm{X}$ & $\mathrm{X}$ & & & $\mathrm{X}$ \\
\hline 0928 & Scouler's willow & Salix scouleriana & $41 \mathrm{E}, 47 \mathrm{~W}$ & 3 & $X$ & & $\mathrm{X}$ & & \\
\hline 0929 & weeping willow & Salix sepulcralis & $41 \mathrm{E}, 47 \mathrm{~W}$ & 3 & $X$ & $\mathrm{X}$ & & & $\mathrm{X}$ \\
\hline 0931 & sassafras & Sassafras albidum & 41 & 3 & $X$ & $\mathrm{X}$ & & & $\mathrm{X}$ \\
\hline 0934 & mountain-ash spp. & Sorbus spp. & $43 \mathrm{E}, 47 \mathrm{~W}$ & 4 & $\mathrm{X}$ & $\mathrm{X}$ & & & $\mathrm{X}$ \\
\hline 0935 & American mountain-ash & Sorbus americana & 43 & 4 & $\mathrm{X}$ & $\mathrm{X}$ & & & $\mathrm{X}$ \\
\hline 0936 & European mountain-ash & Sorbus aucuparia & 43 & 4 & & $\mathrm{X}$ & & & $\mathrm{X}$ \\
\hline 0937 & northern mountain-ash & Sorbus decora & $43 \mathrm{E}, 47 \mathrm{~W}$ & 4 & $\mathrm{X}$ & $\mathrm{X}$ & & & \\
\hline 0940 & West Indian mahogany & Swietenia mahagoni & $43 \mathrm{E}, 47 \mathrm{~W}$ & 4 & & & & & $\mathrm{X}$ \\
\hline 0950 & basswood spp. & Tilia spp. & 38 & 3 & $\mathrm{X}$ & $\mathrm{X}$ & & & $\mathrm{X}$ \\
\hline 0951 & American basswood & Tilia americana & 38 & 3 & $X$ & $\mathrm{X}$ & & & $\mathrm{X}$ \\
\hline 0952 & white basswood & $\begin{array}{l}\text { Tilia americana var. } \\
\text { heterophylla }\end{array}$ & 38 & 3 & $\mathrm{X}$ & $\mathrm{X}$ & & & $\mathrm{X}$ \\
\hline 0953 & Carolina basswood & Tilia americana var. caroliniana & 38 & 3 & $\mathrm{X}$ & & & & $\mathrm{X}$ \\
\hline 0970 & elm spp. & Ulmus & 41 & 3 & $X$ & $\mathrm{X}$ & & & $\mathrm{X}$ \\
\hline 0971 & winged elm & Ulmus alata & 41 & 4 & $X$ & $\mathrm{X}$ & & & $\mathrm{X}$ \\
\hline 0972 & American elm & Ulmus americana & $41 \mathrm{E}, 47 \mathrm{~W}$ & 3 & $X$ & $\mathrm{X}$ & & $\mathrm{X}$ & $\mathrm{X}$ \\
\hline 0973 & cedar elm & Ulmus crassifolia & 41 & 3 & $X$ & & & & $\mathrm{X}$ \\
\hline 0974 & Siberian elm & Ulmus pumila & $41 \mathrm{E}, 47 \mathrm{~W}$ & 3 & $X$ & & & $X$ & $X$ \\
\hline 0975 & slippery elm & Ulmus rubra & 41 & 3 & $\mathrm{X}$ & $\mathrm{X}$ & & & $\mathrm{X}$ \\
\hline 0976 & September elm & Ulmus serotina & 41 & 3 & $\mathrm{X}$ & & & & $\mathrm{X}$ \\
\hline 0977 & rock elm & Ulmus thomasii & 42 & 4 & $\mathrm{X}$ & $\mathrm{X}$ & & & $X$ \\
\hline
\end{tabular}


FIA Database Description and Users Manual for Phase 2, version 4.0

Appendix $\mathrm{F}$

\begin{tabular}{|c|c|c|c|c|c|c|c|c|c|}
\hline \multirow[b]{2}{*}{ SPCD } & \multirow[b]{2}{*}{ COMMON NAME } & \multirow[b]{2}{*}{ SCIENTIFIC NAME } & \multirow[b]{2}{*}{ SPGRPCD } & \multirow[b]{2}{*}{ MAJGRP } & \multicolumn{5}{|c|}{ Occurrence by FIA work unit } \\
\hline & & & & & NC & NE & PNW & $\mathbf{R M}$ & SO \\
\hline 0986 & black-mangrove & Avicennia germinans & $43 \mathrm{E}, 47 \mathrm{~W}$ & 4 & & & & & $\mathrm{X}$ \\
\hline 0987 & button mangrove & Conocarpus erectus & $43 \mathrm{E}, 47 \mathrm{~W}$ & 4 & & & & & \\
\hline 0988 & white-mangrove & Laguncularia racemosa & $43 \mathrm{E}, 47 \mathrm{~W}$ & 4 & & & & & $\mathrm{X}$ \\
\hline 0989 & American mangrove & Rhizophora mangle & 43 & 4 & & & & & $\mathrm{X}$ \\
\hline 0990 & desert ironwood & Olneya tesota & $43 \mathrm{E}, 48 \mathrm{~W}$ & 4 & & & $\mathrm{X}$ & & \\
\hline 0991 & saltcedar & Tamarix spp. & $43 \mathrm{E}, 47 \mathrm{~W}$ & 3 & $\mathrm{X}$ & $\mathrm{X}$ & $\mathrm{X}$ & & \\
\hline 0992 & melaleuca & Melaleuca quinquenervia & $41 \mathrm{E}, 47 \mathrm{~W}$ & 3 & & & & & $\mathrm{X}$ \\
\hline 0993 & chinaberry & Melia azedarach & 43 & 4 & $\mathrm{X}$ & $\mathrm{X}$ & & & $\mathrm{X}$ \\
\hline 0994 & Chinese tallowtree & Triadica sebifera & 43 & 4 & & & & & $\mathrm{X}$ \\
\hline 0995 & tungoil tree & Vernicia fordii & 43 & 4 & & & & & $\mathrm{X}$ \\
\hline 0996 & smoketree & Cotinus obovatus & 43 & 4 & $\mathrm{X}$ & & & & $\mathrm{X}$ \\
\hline 0997 & Russian-olive & Elaeagnus angustifolia & $43 \mathrm{E}, 47 \mathrm{~W}$ & 3 & $\mathrm{X}$ & & & & $\mathrm{X}$ \\
\hline 0998 & unknown dead hardwood & Tree broadleaf & $43 \mathrm{E}, 47 \mathrm{~W}$ & 3 & $\mathrm{X}$ & $\mathrm{X}$ & $\mathrm{X}$ & & $\mathrm{X}$ \\
\hline 0999 & other or unknown live tree & Tree unknown & $43 \mathrm{E}, 47 \mathrm{~W}$ & 3 & $\mathrm{X}$ & $\mathrm{X}$ & & & $\mathrm{X}$ \\
\hline
\end{tabular}




\section{Appendix G. Tree Species Group Codes}

Species group name

Code

Softwood species groups

Eastern softwood species groups

Longleaf and slash pines

Loblolly and shortleaf pines

Other yellow pines

Eastern white and red pines

Jack pine

Spruce and balsam fir

Eastern hemlock

Cypress

Other eastern softwoods

Western softwood species groups

Douglas-fir

Ponderosa and Jeffrey pines

True fir

Western hemlock

Sugar pine

Western white pine

Redwood

Sitka spruce

Engelmann and other spruces

Western larch

Incense-cedar

Lodgepole pine

Western redcedar

Western woodland softwoods

Other western softwoods

Hardwood species groups

Eastern hardwood species groups

Select white oaks

Select red oaks

Other white oaks

Other red oaks

Hickory

Yellow birch

Hard maple

Soft maple

Beech

Sweetgum

Tupelo and blackgum

Ash

Cottonwood and aspen

Basswood

Yellow-poplar

Black walnut

Other eastern soft hardwoods

Other eastern hard hardwoods

Eastern noncommercial hardwoods

Western hardwood species groups

Cottonwood and aspen

Red alder

Oak

Other western hardwoods

Western woodland hardwoods 


\section{Appendix H. Damage Agent codes for PNW}

Damage Agent is a 2-digit code with values 01 to 91. For Agent and Severity 1, 2 and 3: the agent and severity codes indicate the type of agents that were present on a tree and describe their severity. Several damaging agents are automatically of highest importance and should be coded before any other agents; these agents are grouped as Class I Agents. Class I insects, diseases, or physical injuries can seriously affect vegetation. Failure to account for these agents can result in large differences in predicted outcomes for tree growth, survival, vegetative composition and structure. Class II agents can be important in local situations; recording their incidence and severity provides valuable information for those situations. Class II agents are recorded when present but only after all Class I agents.

Agents and their severity ratings are grouped by broad category. Each category has a general agent and specific agents listed. The general codes should be used if there is any question as to the identity of the specific damaging agent.

\begin{tabular}{|c|c|c|c|c|}
\hline \multicolumn{5}{|l|}{ Class I Agents } \\
\hline & & Agents & & Severity \\
\hline \multirow{11}{*}{ Bark beetles: } & Code & Agent & Code & Severity \\
\hline & 01 & General /other bark beetle & 1 & Unsuccessful current attack \\
\hline & 02 & Mountain pine beetle & 2 & Successful current attack \\
\hline & 03 & Douglas-fir beetle & 3 & Last year's successful attack \\
\hline & 04 & Spruce beetle & 4 & Older dead \\
\hline & 05 & Western pine beetle & 5 & Top kill \\
\hline & 06 & Pine engraver beetle & & \\
\hline & 07 & Fir engraver beetle & & \\
\hline & 08 & Silver fir beetle & & \\
\hline & 09 & Red turpentine beetle & & \\
\hline & 26 & Jeffrey pine beetle & & \\
\hline \multirow{13}{*}{ Defoliators: } & Code & Agent & Code & Severity \\
\hline & & & 0 & No detectable defoliation \\
\hline & 10 & General/other & 1 & Up to $33 \%$ of foliage (old and new \\
\hline & 11 & Western blackheaded & & missing/affected) \\
\hline & & budworm & 2 & 34 to $66 \%$ of foliage missing/affected \\
\hline & 12 & Pine butterfly & 3 & 67 to $100 \%$ of foliage missing/affected \\
\hline & 13 & Douglas-fir tussock moth & & \\
\hline & 14 & Larch casebearer & & \\
\hline & 15 & $\begin{array}{l}\text { Western spruce or Modoc } \\
\text { budworm }\end{array}$ & & \\
\hline & 16 & Western hemlock looper & & \\
\hline & 17 & Sawflies & & \\
\hline & 18 & Needles and sheath miners & & \\
\hline & 19 & Gypsy moth & & \\
\hline
\end{tabular}




\begin{tabular}{|c|c|c|c|c|}
\hline & & Agents & & Severity \\
\hline \multirow{2}{*}{$\begin{array}{l}\text { Root } \\
\text { diseases: }\end{array}$} & Code & Agent & Code & Severity \\
\hline & $\begin{array}{l}60 \\
61 \\
62 \\
63 \\
65 \\
66\end{array}$ & $\begin{array}{l}\text { General/other } \\
\text { Annosus root disease } \\
\text { Armillaria root disease } \\
\text { Black stain root disease } \\
\text { Laminated root rot } \\
\text { Port-Orford-cedar root } \\
\text { disease }\end{array}$ & 1 & $\begin{array}{l}\text { Tree is a live tally tree within } 30 \mathrm{ft} \text { of a tree } \\
\text { or stump that has a root disease to which } \\
\text { the tally tree is susceptible } \\
\text { Live tally tree with signs or symptoms } \\
\text { diagnostic for root disease such as } \\
\text { characteristic decay, stain, ectotrophic } \\
\text { mycelia, mycelial fans, conks or excessive } \\
\text { resin flow at the root collar. No visible } \\
\text { crown deterioration. } \\
\text { Live tally tree with signs or symptoms } \\
\text { diagnostic for root disease such as } \\
\text { characteristic decay, stain, ectotrophic } \\
\text { mycelia, mycelial fans, conks, or excessive } \\
\text { resin flow at the root collar. Visible crown } \\
\text { deterioration such as thinning chlorotic } \\
\text { foliage, reduced terminal growth, and/or } \\
\text { stress cones. }\end{array}$ \\
\hline \multirow{2}{*}{$\begin{array}{l}\text { White pine } \\
\text { blister rust: }\end{array}$} & Code & Agent & Code & Severity \\
\hline & 36 & White pine blister rust & $\begin{array}{l}1 \\
2 \\
3\end{array}$ & $\begin{array}{l}\text { Branch infections located more than } \\
2.0 \text { feet from tree bole. } \\
\text { Branch infections located } 0.5 \text { to } 2.0 \text { feet } \\
\text { from bole. } \\
\text { Bole infections present, Or: branch } \\
\text { infections within } 0.5 \text { feet of bole }\end{array}$ \\
\hline \multirow{2}{*}{$\begin{array}{l}\text { Sudden oak } \\
\text { death } \\
\text { (tanoak, } \\
\text { coast live } \\
\text { oak, black } \\
\text { oak): }\end{array}$} & Code & Agent & Code & Severity \\
\hline & 31 & Sudden oak death symptoms & $\begin{array}{l}1 \\
2 \\
3\end{array}$ & $\begin{array}{l}\text { Bleeding present on bole } \\
\text { Bleeding present on bole and adjacent } \\
\text { mortality present } \\
\text { Laboratory confirmed sudden oak death }\end{array}$ \\
\hline
\end{tabular}




\section{Class II Agents}

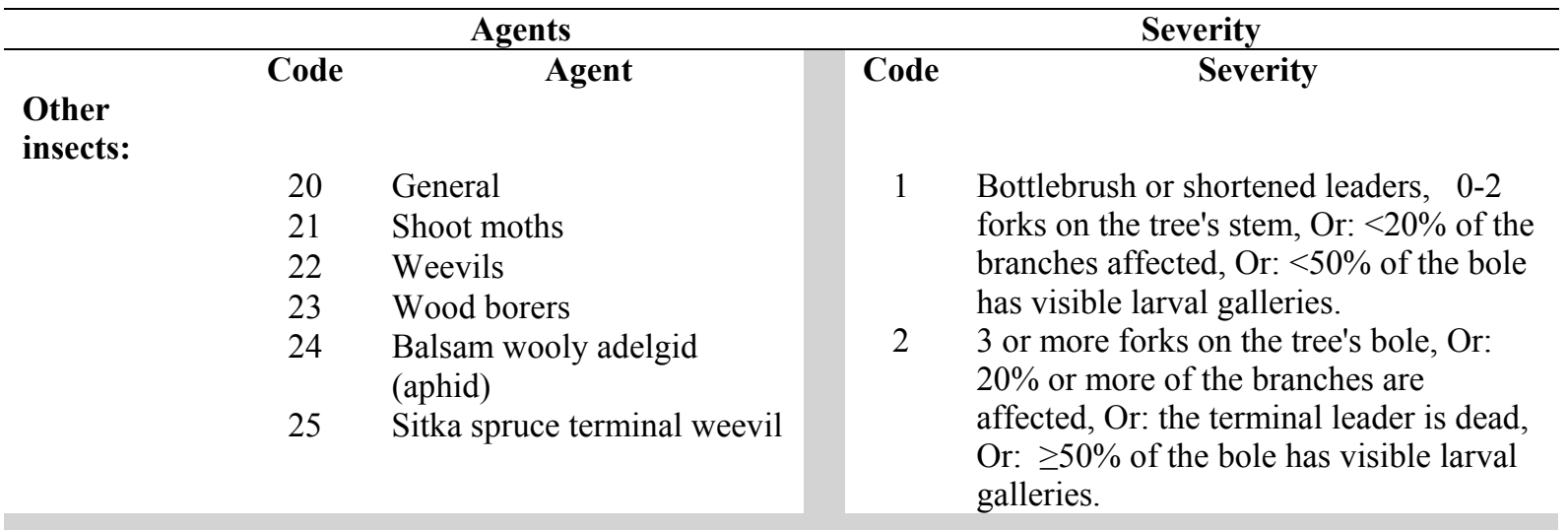

\begin{tabular}{|c|c|c|c|c|}
\hline & Code & Agent & Code & Severity \\
\hline & $\begin{array}{l}33 \\
40 \\
41 \\
42 \\
43 \\
44 \\
45\end{array}$ & $\begin{array}{l}\text { Diplodia blight } \\
\text { General/other } \\
\text { Western gall rust (Pinus } \\
\text { ponderosa, Pinus contorta) } \\
\text { Commandra blister rust } \\
\text { (Pinus ponderosa) } \\
\text { Stalactiform rust (Pinus } \\
\text { contorta) } \\
\text { Atropellis canker (Pinus } \\
\text { spp.) } \\
\text { Cytospoa or Phomopsis } \\
\text { (Pseudotsuga menziesii, } \\
\text { Abies spp.) }\end{array}$ & $\begin{array}{l}1 \\
2\end{array}$ & $\begin{array}{l}\text { Branch infections present. }<50 \% \text { of the } \\
\text { crown affected } \\
\text { Branch infections present. } \geq 50 \% \text { of the } \\
\text { crown affected, Or: any infection on the } \\
\text { bole. }\end{array}$ \\
\hline $\begin{array}{l}\text { Pitch } \\
\text { canker: }\end{array}$ & Code & $\begin{array}{l}\text { Pitch canker (CA Pinus } \\
\text { spp.) }\end{array}$ & $\begin{array}{l}1 \\
2 \\
3 \\
4\end{array}$ & $\begin{array}{l}\text { No bole canker }+<10 \text { infected branch } \\
\text { tips } \\
\text { No bole canker }+\geq 10 \text { infected branch } \\
\text { tips } \\
1 \text { or more bole cankers }+<10 \text { infected } \\
\text { branch tips } \\
1 \text { or more bole cankers }+\geq 10 \text { infected } \\
\text { branch tips }\end{array}$ \\
\hline Stem decays: & $\begin{array}{c}\text { Code } \\
46 \\
47 \\
48 \\
\\
49\end{array}$ & \begin{tabular}{l}
$\quad$ Agent \\
\multicolumn{1}{c}{ General/other } \\
Red ring rot (Phellinus pini) \\
Indian paint rot \\
(Echinodontium tinctorium) \\
Brown cubical rot \\
(Phaeolus schweinitzii)
\end{tabular} & $\begin{array}{c}\text { Code } \\
1 \\
2 \\
3 \\
4\end{array}$ & $\begin{array}{l}\text { Severity } \\
1 \text { conk on the stem or present at ground } \\
\text { level } \\
2 \text { or more conks separated by }<16 \text { feet } \\
\text { on bole } \\
2 \text { or more conks separated by } \geq 16 \text { feet } \\
\text { on bole } \\
\text { No conks. Visible decay in the interior } \\
\text { of the bole }\end{array}$ \\
\hline
\end{tabular}




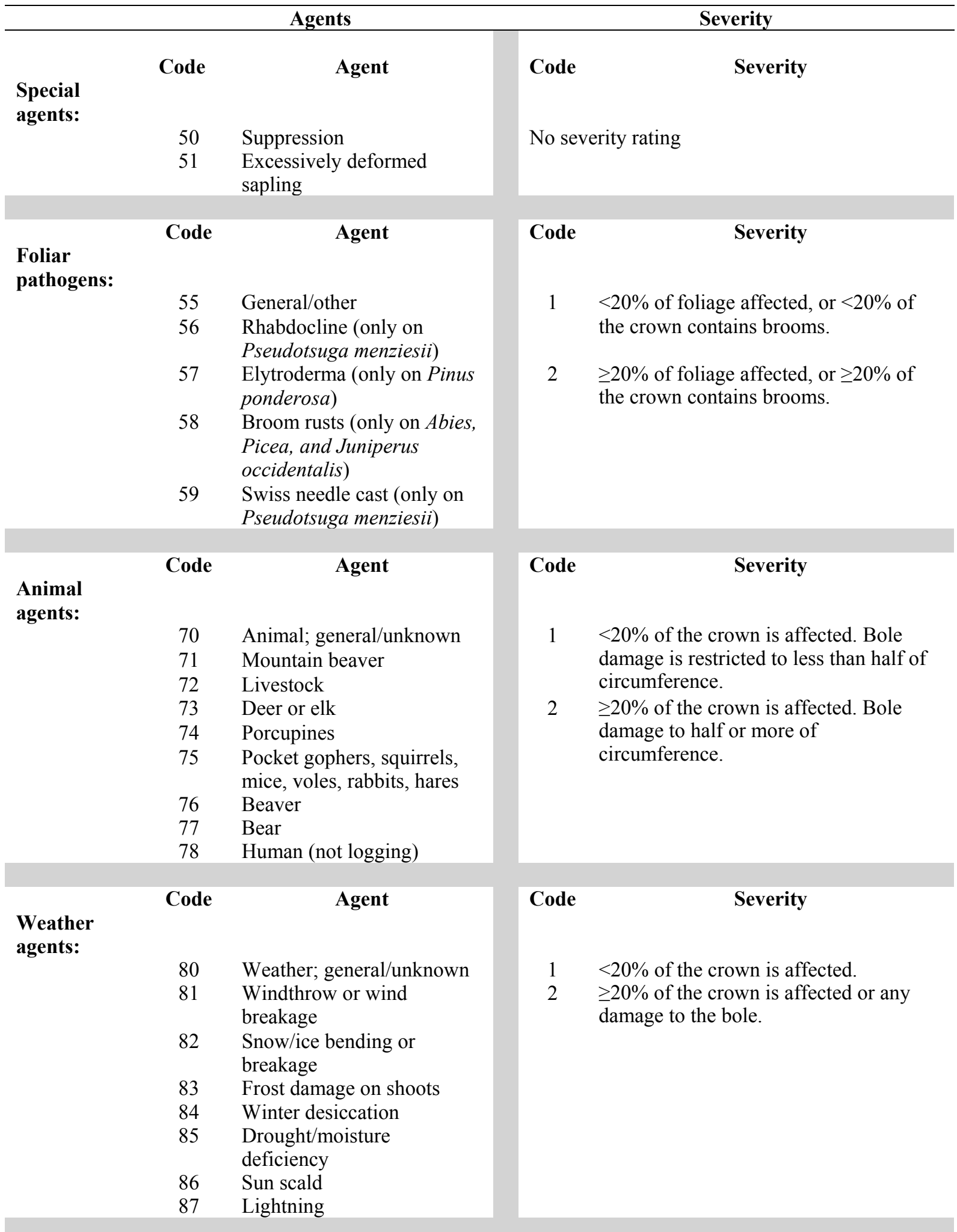




\begin{tabular}{|c|c|c|c|c|}
\hline \multicolumn{5}{|c|}{ Class II Agents } \\
\hline & & Agents & & Severity \\
\hline \multirow{2}{*}{$\begin{array}{l}\text { Physical } \\
\text { injury: }\end{array}$} & Code & Agent & Code & Severity \\
\hline & $\begin{array}{l}90 \\
91 \\
92 \\
93 \\
94\end{array}$ & $\begin{array}{l}\text { Other; general/unknown } \\
\text { Logging damage } \\
\text { Fire; basal scars or scorch } \\
\text { Improper planting } \\
\text { Air pollution or other } \\
\text { chemical damage }\end{array}$ & $\begin{array}{l}1 \\
2\end{array}$ & $\begin{array}{l}<20 \% \text { of the crown is affected. } \\
\geq 20 \% \text { of the crown is affected or any } \\
\text { damage to the bole. }\end{array}$ \\
\hline \multirow{2}{*}{$\begin{array}{l}\text { Physical } \\
\text { defect: }\end{array}$} & Code & Agent & Code & Severity \\
\hline & $\begin{array}{l}95 \\
96 \\
97 \\
98\end{array}$ & $\begin{array}{l}\text { Unspecified physical defect } \\
\text { Broken/missing top } \\
\text { Dead top } \\
\text { Forks and crooks (only if } \\
\text { caused by old top out or } \\
\text { dead top) } \\
\text { Checks/bole cracks }\end{array}$ & 0 & Severity is not rated \\
\hline
\end{tabular}




\section{Appendix I. FIA Inventories by State, Year, and Type}

\begin{tabular}{|c|c|c|c|}
\hline State code & State name & Date(s) of available periodic inventory data & Initiation of annual inventory \\
\hline 1 & Alabama & $1972,1982,1990,2000$ & 2001 \\
\hline 2 & Alaska & 1998 & 2004 \\
\hline 4 & Arizona & 1985,1999 & 2001 \\
\hline 5 & Arkansas & $1978,1988,1995$ & 2000 \\
\hline 6 & California & 1994 & 2001 \\
\hline 8 & Colorado & 1984 & 2002 \\
\hline 9 & Connecticut & 1985,1998 & 2003 \\
\hline 10 & Delaware & 1986, 1999 & 2004 \\
\hline 12 & Florida & $1970,1980,1987,1995$ & 2003 \\
\hline 13 & Georgia & $1972,1982,1989,1987$ & 1997 \\
\hline 16 & Idaho & 1991 & 2004 \\
\hline 17 & Illinois & 1985,1998 & 2001 \\
\hline 18 & Indiana & 1986, 1998 & 1999 \\
\hline 19 & Iowa & 1990 & 1999 \\
\hline 20 & Kansas & 1981, 1994 & 2001 \\
\hline 21 & Kentucky & 1988 & 1999 \\
\hline 22 & Louisiana & 1974, 1984, 1991 & 2001 \\
\hline 23 & Maine & 1995 & 1999 \\
\hline 24 & Maryland & 1986, 1999 & 2004 \\
\hline 25 & Massachusetts & 1985,1998 & 2003 \\
\hline 26 & Michigan & 1980,1993 & 2000 \\
\hline 27 & Minnesota & 1977, 1990 & 1999 \\
\hline 28 & Mississippi & 1977, 1987, 1994 & 2006 \\
\hline 29 & Missouri & 1989 & 1999 \\
\hline 30 & Montana & 1989 & 2003 \\
\hline 31 & Nebraska & 1983, 1994 & 2001 \\
\hline 32 & Nevada & 1989 & $2004^{1}$ \\
\hline 33 & New Hampshire & 1983, 1997 & 2002 \\
\hline 34 & New Jersey & 1987, 1999 & 2004 \\
\hline 35 & New Mexico & 1987, 1999 & \\
\hline 36 & New York & 1993 & 2002 \\
\hline 37 & North Carolina & $1984,1990,2002$ & 2003 \\
\hline 38 & North Dakota & 1980,1995 & 2001 \\
\hline 39 & Ohio & 1991 & 2001 \\
\hline 40 & Oklahoma & $\begin{array}{l}1989 \text { (central/west), } \\
1976,1986,1993 \text { (east) }\end{array}$ & 2008 (east) \\
\hline 41 & Oregon & 1992,1999 & 2001 \\
\hline 42 & Pennsylvania & 1989 & 2000 \\
\hline 44 & Rhode Island & 1985,1998 & 2003 \\
\hline 45 & South Carolina & 1968, 1978, 1986, 1993 & 1999 \\
\hline 46 & South Dakota & 1980,1995 & 2001 \\
\hline 47 & Tennessee & $1980,1989,1999$ & 2000 \\
\hline 48 & Texas & $1975,1986,1992$ & 2001 \\
\hline 49 & Utah & 1993 & 2000 \\
\hline
\end{tabular}


FIA Database Description and Users Manual for Phase 2, version 4.0

Appendix I

\begin{tabular}{llll}
\hline State code & State name & Date(s) of available periodic inventory data & Initiation of annual inventory \\
\hline 50 & Vermont & 1983,1997 & 2003 \\
51 & Virginia & $1977,1985,1992$ & 1998 \\
53 & Washington & 1991,2001 & 2002 \\
54 & West Virginia & 1989,2000 & 2004 \\
55 & Wisconsin & 1983,1996 & 2000 \\
56 & Wyoming & 1984,2000 & \\
72 & Puerto Rico & $2001,2002,2003,2004$ & \\
78 & US Virgin Islands & 2004 & \\
\hline
\end{tabular}

${ }^{1}$ insufficient funding to continue annual inventory after 2005 


\section{Appendix J. Biomass Estimation in the FIADB}

In previous versions of the FIADB, a variety of regional methods were used to estimate tree biomass for live and dead trees in the TREE table. In FIADB 4.0, a new nationally consistent method of estimating tree biomass has been implemented. This new approach, called the component ratio method (CRM) (Heath and others 2009), involves calculating the dry weight of individual components before estimating the total aboveground or belowground biomass. The CRM approach is based on:

- converting the sound volume of wood (VOLCFSND) in the merchantable bole to biomass using a compiled set of wood specific gravities (Miles and Smith 2009) (see REF_SPECIES table for values)

- calculating the biomass of bark on the merchantable bole using a compiled set of percent bark estimates and bark specific gravities (Miles and Smith 2009) (see REF_SPECIES table for values)

- calculating the biomass of the entire tree (total aboveground biomass), merchantable bole (including bark), and belowground biomass, using equations from Jenkins and others (2003)

- calculating the volume of the stump (wood and bark) based on equations in Raile (1982) and converting this to biomass using the same specific gravities used for the bole wood and bark

- calculating the top biomass (tree tip and all branches) by subtracting all other biomass components from the total aboveground estimate

- calculating an adjustment factor by developing a ratio between bole biomass calculated from VOLCFSND to bole biomass using equations from Jenkins and others (2003)

- applying the adjustment factor to all tree components derived from both Jenkins and Raile

The CRM approach is based on assumptions that the definition of merchantable bole in the volume prediction equations is equivalent to the bole (stem wood) in Jenkins and others (2003), and that the component ratios accurately apply.

The tables in this appendix describe the equations used in FIADB 4.0 to estimate components of tree biomass, including stem wood (bole), top and branches combined, bark, stump, and coarse roots. Most of these components are estimated through a series of ratio equations as described by Jenkins and others (2003). Stem wood biomass is calculated directly from the sound cubic-foot volume of the tree bole, percentage of bark on the bole, and specific gravities of both wood and bark.

The individual component biomass values for bole, top, and stump are not available in FIADB for sapling-size timber tree species and all woodland tree species. Because saplings (trees from 1 to 4.9 inches in diameter) have no volume in FIADB, a ratio method was developed to compute a factor that is applied to saplings based on diameter and species, and the result is stored in DRYBIO_SAPLING. For woodland species (trees where diameter is measured at the root collar $[\mathrm{DRC}]$ ), volume is calculated from the root collar to a $1 \frac{1}{2}$-inch top diameter. Because this volume accounts for a larger portion of the tree than timber species volume equations do, it was determined that the top and stump equations were not applicable to woodland species. Woodland tree volume is converted to biomass and stored in DRYBIO_WDLD_SPP, which is an estimate for total aboveground biomass, excluding foliage, the tree tip (top of the tree above $1 \frac{1}{2}$ inches in diameter), and a portion of the stump from ground to DRC. Therefore, only total aboveground and belowground biomass values are estimated for saplings and woodland species. 
Definitions of each biomass component and the equations used to estimate the oven-dry weight in pounds are shown in appendix tables $\mathrm{J}-1$ through $\mathrm{J}-4$.

- Appendix table J-1 defines the columns that are stored in the TREE table, and clarifies the set of trees (species, dimensions, live or dead, etc) that are used in each calculation.

- Appendix table J-2 defines the Jenkins component equations and explains how the equation results are used to estimate biomass. The 'Estimate name' in this table is the same name found in the coefficient definitions described in the biomass-related columns 38 to 49 of the REF_SPECIES table.

- Appendix table J-3 contains the Jenkins equations used to estimate each biomass component. The equations use the exact coefficient column names found in the REF_SPECIES table (for example, JENKINS_TOTAL_B1 in appendix table J-3 is the column name in REF_SPECIES that holds the value of the coefficient needed in the total aboveground biomass equation). The Jenkins equations use the measured tree diameter to produce an estimate.

- Appendix table J-4 contains the actual equations used in the FIADB to estimate the biomass components stored in the TREE table. These equations are a blend of Jenkins ratios, calculated bole biomass (based on calculated volume from the TREE table), and adjustment factors. The adjustment factor is an important step because it relates measurement-based bole biomass (DRYBIO_BOLE) to generalized equation-based bole biomass to improve or adjust the computed results of the Jenkins equations.

For more information please consult the publication by Heath and others (2009), titled Investigation into Calculating Tree Biomass and Carbon in the FIADB Using a Biomass Expansion Factor Approach. 
Appendix table J-1. Definition of Biomass Components stored in the TREE table.

\begin{tabular}{|c|c|c|}
\hline Component & Column name & $\begin{array}{l}\text { Biomass Component Definition } \\
\text { (all are oven-dry biomass, pounds) }\end{array}$ \\
\hline Merchantable stem (bole) & DRYBIO_BOLE & $\begin{array}{l}\text { Merchantable bole of the tree, includes stem wood and } \\
\text { bark, from a } 1 \text {-foot stump to a } 4 \text {-inch top diameter. Based } \\
\text { on VOLCFSND and specific gravity for the species. For } \\
\text { timber species with a DIA } \geq 5 \text { inches. Includes live and } \\
\text { dead trees. } \\
\text { (Note that VOLCFGRS or VOLCFNET might be used after } \\
\text { adjustment based on national averages, if VOLCFSND is } \\
\text { not available.) }\end{array}$ \\
\hline Top & DRYBIO_TOP & $\begin{array}{l}\text { Top of the tree above } 4 \text { inches diameter and all branches; } \\
\text { includes wood and bark and excludes foliage. For live and } \\
\text { dead timber species with a DIA } \geq 5 \text { inches. }\end{array}$ \\
\hline Stump & DRYBIO_STUMP & $\begin{array}{l}\text { Stump of the tree, the portion of a tree bole from ground to } \\
1 \text { foot high, includes wood and bark. For live and dead } \\
\text { timber species with a DIA } \geq 5 \text { inches. }\end{array}$ \\
\hline Belowground & DRYBIO_BG & $\begin{array}{l}\text { Coarse roots of trees and saplings with a DIA } \geq 1 \text { inch. For } \\
\text { timber and woodland species, and live and dead trees. }\end{array}$ \\
\hline Saplings & DRYBIO_SAPLING & $\begin{array}{l}\text { Total aboveground portion of live trees, excluding foliage. } \\
\text { For timber species with a DIA } \geq 1 \text { inch and }<5 \text { inches. }\end{array}$ \\
\hline Woodland tree species & DRYBIO_WDLD_SPP & $\begin{array}{l}\text { Total aboveground portion of a tree, excluding foliage, the } \\
\text { tree tip (top of the tree above } 1 \frac{1}{2} \text { inches in diameter) and a } \\
\text { portion of the stump from ground to DRC. For live and } \\
\text { dead woodland species with a DIA } \geq 1 \text { inch. Woodland } \\
\text { species can be identified by REF_SPECIES.WOODLAND } \\
=X, \text { TREE.DIAHTCD }=2 \text {, or TREE.WDLDSTEM }>0\end{array}$ \\
\hline
\end{tabular}


Appendix table J-2. Jenkins Biomass Component Equation Definitions (Refer to the REF_SPECIES table for equation coefficients and adjustment factors).

\begin{tabular}{|c|c|c|}
\hline Component & Estimate name & Definition \\
\hline Total aboveground biomass & $\begin{array}{l}\text { total_AG_biomass__ } \\
\text { Jenkins }\end{array}$ & $\begin{array}{l}\text { Total biomass (oven-dry, pounds) of the } \\
\text { aboveground portion of a tree. Includes stem wood, } \\
\text { stump, bark, top, branches, and foliage. }\end{array}$ \\
\hline Stem wood biomass ratio & stem_ratio & $\begin{array}{l}\text { A ratio that estimates biomass of the merchantable } \\
\text { bole of the tree by applying the ratio to } \\
\text { total_AG_biomass_Jenkins. Includes wood only. } \\
\text { This is the portion of the tree from a 1-foot stump } \\
\text { to a 4-inch top diameter. }\end{array}$ \\
\hline Stem bark biomass ratio & bark_ratio & $\begin{array}{l}\text { A ratio that estimates biomass of the bark on the } \\
\text { merchantable bole of the tree by applying the ratio } \\
\text { to total_AG_biomass_Jenkins. }\end{array}$ \\
\hline Foliage biomass ratio & foliage_ratio & $\begin{array}{l}\text { A ratio that estimates biomass of the foliage on the } \\
\text { entire tree by applying the ratio to } \\
\text { total_AG_biomass_Jenkins. }\end{array}$ \\
\hline Coarse root biomass ratio & root_ratio & $\begin{array}{l}\text { A ratio that estimates biomass of the belowground } \\
\text { portion of the tree by applying the ratio to } \\
\text { total_AG_biomass_Jenkins. }\end{array}$ \\
\hline Stump biomass & stump_biomass & $\begin{array}{l}\text { An estimate of the stump biomass of a tree, from } \\
\text { the ground to } 1 \text { foot high. Uses a series of equations } \\
\text { that first estimates the inside and outside bark } \\
\text { diameters, then estimates inside and outside bark } \\
\text { volumes (Raile 1982). Wood and bark volumes are } \\
\text { converted to biomass using specific gravity for the } \\
\text { species. }\end{array}$ \\
\hline Sapling biomass adjustment & $\begin{array}{l}\text { JENKINS_SAPLING } \\
\text { _ADJUSTMENT }\end{array}$ & $\begin{array}{l}\text { An adjustment factor that is used to estimate } \\
\text { sapling biomass for the tree by applying the factor } \\
\text { to the total aboveground estimate, excluding } \\
\text { foliage. The adjustment factor was computed as a } \\
\text { national average ratio of the DRYBIOT (total dry } \\
\text { biomass) divided by the Jenkins total biomass for } \\
\text { all 5.0-inch trees, which is the size at which } \\
\text { biomass, based on volume, begins. This is used on } \\
\text { timber and woodland species. }\end{array}$ \\
\hline
\end{tabular}




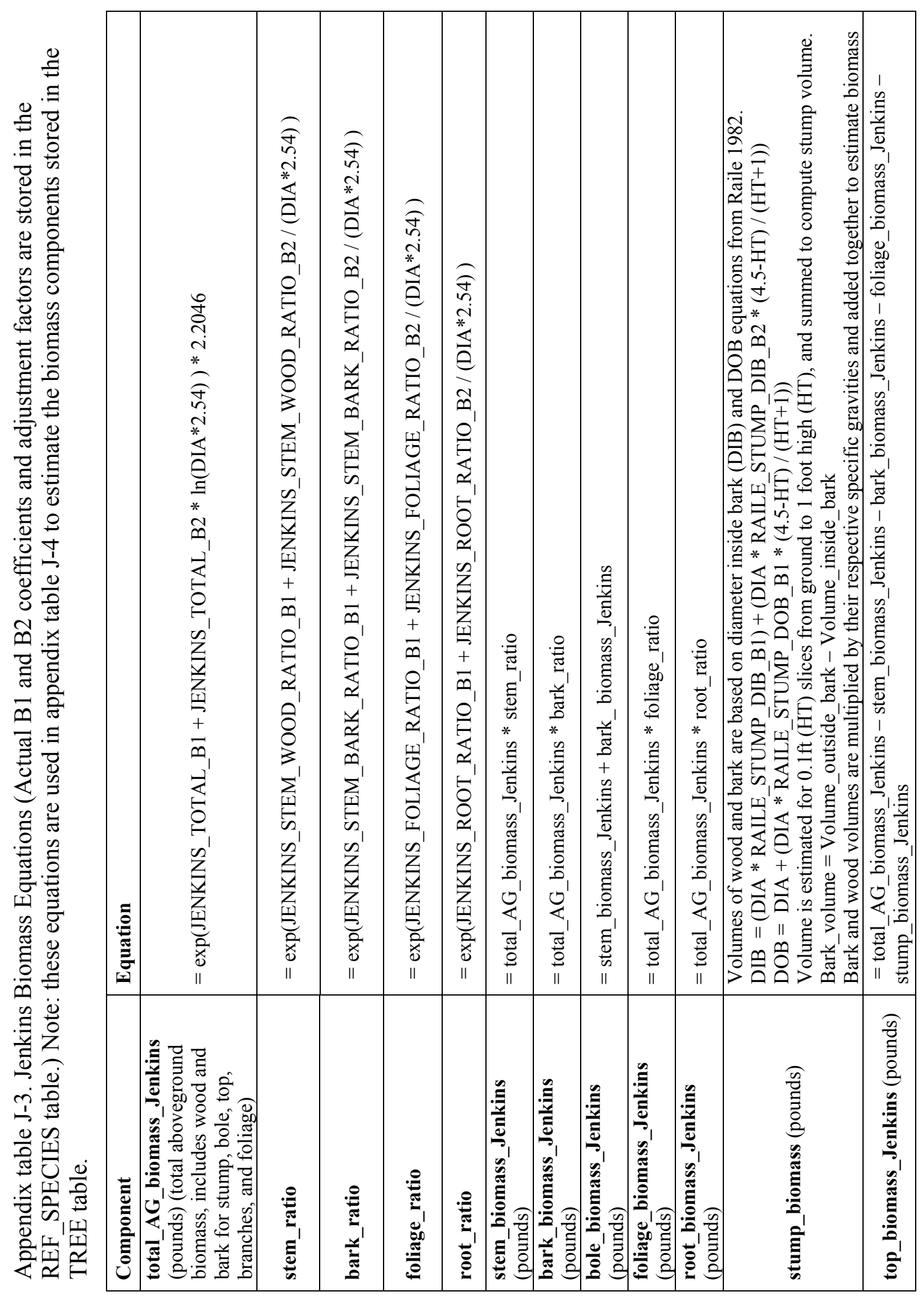




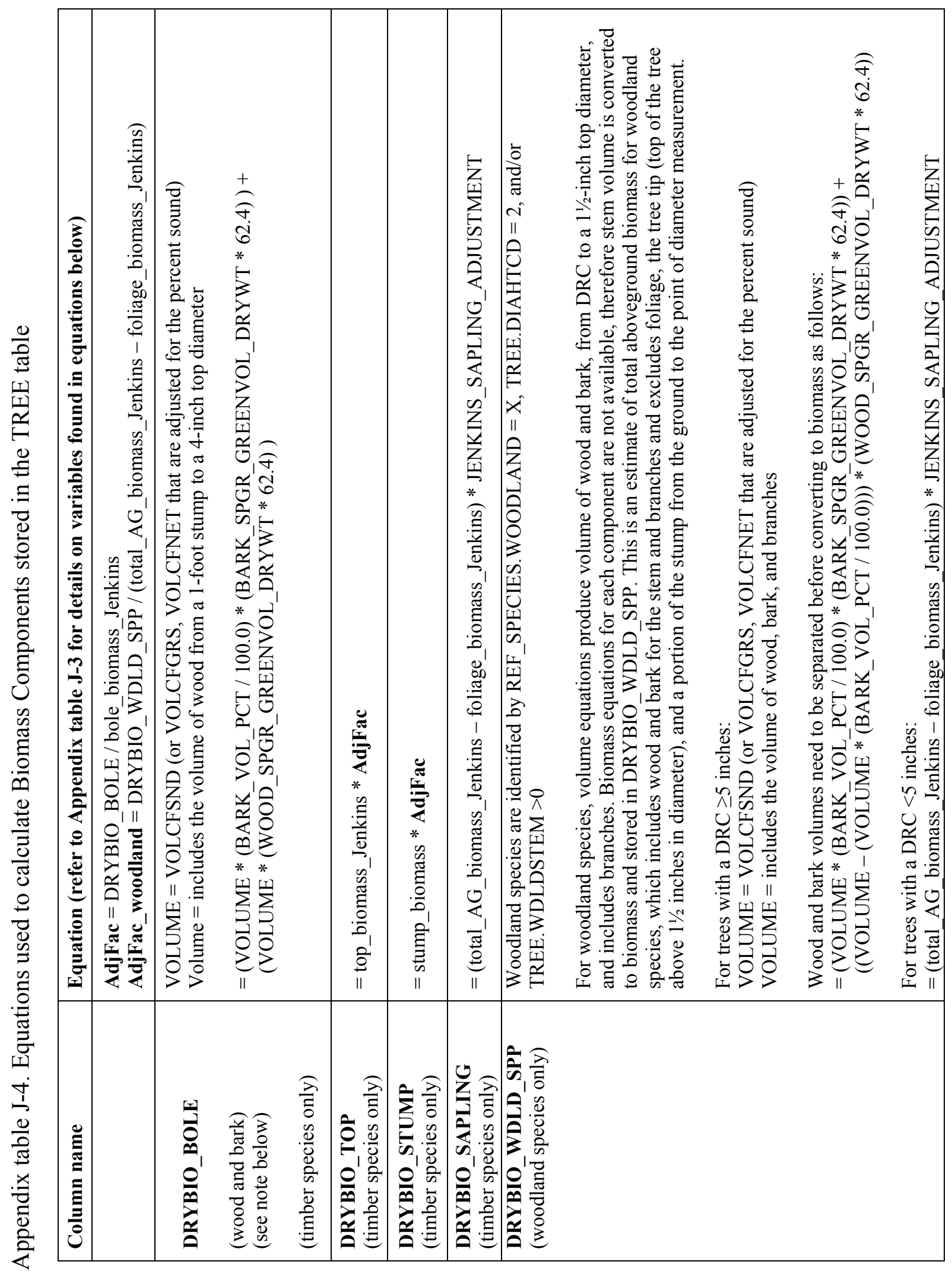




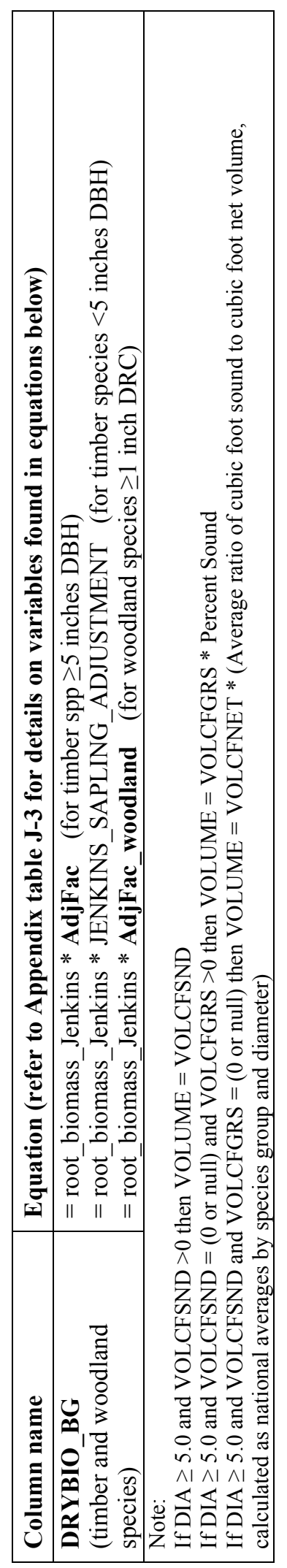





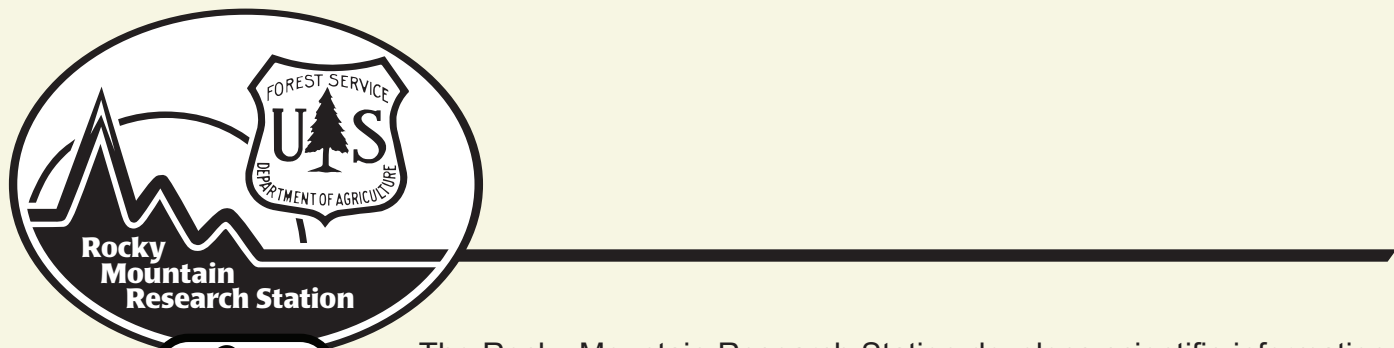

The Rocky Mountain Research Station develops scientific information and technology to improve management, protection, and use of the forests and rangelands. Research is designed to meet the needs of the National Forest managers, Federal and State agencies, public and private organizations, academic institutions, industry, and individuals. Studies accelerate solutions to problems involving ecosystems, range, forests, water, recreation, fire, resource inventory, land reclamation, community sustainability, forest engineering technology, multiple use economics, wildlife and fish habitat, and forest insects and diseases. Studies are conducted cooperatively, and applications may be found worldwide.

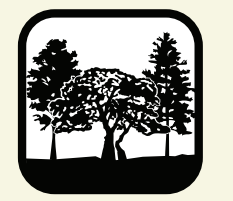

\author{
Station Headquarters \\ Rocky Mountain Research Station \\ 240 W Prospect Road \\ Fort Collins, CO 80526 \\ (970) 498-1100
}

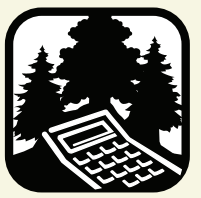

\title{
Research Locations
}

\author{
Flagstaff, Arizona \\ Fort Collins, Colorado \\ Boise, Idaho \\ Moscow, Idaho \\ Bozeman, Montana \\ Missoula, Montana
}

Reno, Nevada

Albuquerque, New Mexico

Rapid City, South Dakota

Logan, Utah

Ogden, Utah

Provo, Utah

The U.S. Department of Agriculture (USDA) prohibits discrimination in all its programs and activities on the basis of race, color, national origin, age, disability, and where applicable, sex, marital status, familial status, parental status, religion, sexual orientation, genetic information, political beliefs, reprisal, or because all or part of an individual's income is derived from any public assistance program. (Not all prohibited bases apply to all programs.) Persons with disabilities who require alternative means for communication of program information (Braille, large print, audiotape, etc.) should contact USDA's TARGET Center at (202) 720-2600 (voice and TDD). To file a complaint of discrimination, write to USDA, Director, Office of Civil Rights, 1400 Independence Avenue, S.W., Washington, DC 20250-9410, or call (800) 795-3272 (voice) or (202) 720-6382 (TDD). USDA is an equal opportunity provider and employer. 